\title{
COVID-19 NO BRASIL cenários epidemiológicos e vigilância em saúde
}

Carlos Machado de Freitas Christovam Barcellos Daniel Antunes Maciel Villela organizadores








OBSERVATÓRIO COVID-19

Covid-19 no Brasil: cenários epidemiológicos e vigilância em saúde

\author{
Carlos Machado de Freitas \\ Christovam Barcellos \\ Daniel Antunes Maciel Villela
}

(orgs.)

\title{
SciELO Books / SciELO Livros / SciELO Libros
}

FREITAS, C. M., BARCELLOS, C., and VILLELA, D. A. M., eds. Covid-19 no Brasil: cenários epidemiológicos e vigilância em saúde [online]. Rio de Janeiro: Observatório Covid-19 Fiocruz; Editora Fiocruz, 2021, 418 p. Informação para ação na Covid-19 series. ISBN: 978-65-5708-049-8. https://doi.org/10.7476/9786557081211.



All the contents of this work, except where otherwise noted, is licensed under a Creative Commons Attribution 4.0 International license.

Todo o conteúdo deste trabalho, exceto quando houver ressalva, é publicado sob a licença Creative Commons Atribição 4.0.

Todo el contenido de esta obra, excepto donde se indique lo contrario, está bajo licencia de la licencia Creative Commons Reconocimento 4.0. 


\section{COVID-19 NO BRASIL cenários epidemiológicos e vigilância em saúde}






\section{FUNDAÇÃO OSWALDO CRUZ}

Presidente

Nísia Trindade Lima

Vice-Presidente de Educação, Informação e Comunicação

Cristiani Vieira Machado

\section{EDITORA FIOCRUZ}

Diretora

Cristiani Vieira Machado

Editor Executivo

João Carlos Canossa Mendes

Editores Científicos

Carlos Machado de Freitas

Gilberto Hochman

Conselho Editorial

Bernadete Perez Coêlho

Denise Valle

José Roberto Lapa e Silva

Kenneth Rochel de Camargo Jr.

Luciana Dias de Lima

Margareth Maria Pretti Dalcolmo

Maria Cecilia de Souza Minayo

Moisés Goldbaum

Rafael Linden

Ricardo Ventura Santos

\section{OBSERVATÓRIO COVID- I 9}

Comitê Editorial

Carlos Machado de Freitas (coordenador)

Christovam Barcellos

Daniel Antunes Maciel Villela

Gustavo Corrêa Matta

Lenice Gnocchi da Costa Reis

Margareth Crisóstomo Portela 
Carlos Machado de Freitas

Christovam Barcellos

Daniel Antunes Maciel Villela

organizadores

\section{COVID-19 NO BRASIL cenários epidemiológicos e vigilância em saúde}

Série Informação para Ação na Covid-19



OBSERVATÓRIO COVID-19




Copyright (C) 2021 dos autores

Todos os direitos desta edição reservados à

FUNDAÇÃO OSWALDO CRUZ / EDITORA

Revisão

Irene Ernest Dias

Normalização de referências

Clarissa Bravo

Capa, projeto gráfico e editoração

Adriana Carvalho e Carlos Fernando Reis

Supervisão editorial

Phelipe Gasiglia

Imagens da capa

Vírus

Depositphotos, ID 391488244 - @ apid

Gráficos

Boletim Observatório Covid-19: semanas epidemiológicas 31 e 31, I a I4 ago. 2021.

Fotografia

Coleta de material para testagem de coronavírus em trabalhadores da Fiocruz realizada pelo Núcleo de Saúde do Trabalhador (Nust), 2020. Acervo Fiocruz Imagens.

Catalogação na fonte

Fundação Oswaldo Cruz

Instituto de Comunicação e Informação Científica e Tecnológica em Saúde

Biblioteca de Saúde Pública

C873c Covid-19 no Brasil: cenários epidemiológicos e vigilância em saúde / organizado por Carlos Machado de Freitas, Christovam Barcellos e Daniel Antunes Maciel Villela. - Rio de Janeiro : Observatório Covid- 19 Fiocruz, Editora Fiocruz, 2021.

4 I 8 p. : 32.274 kb; il. color. ; graf. ; tab. (Série Informação para Ação na Covid- I9)

ISBN: 978-65-5708-049-8

Inclui Bibliografia.

Site: http://books.scielo.org

I. Covid 19 - epidemiologia. 2. Infecções por Coronavírus. 3. Vigilância em Saúde Pública. 4. Vulnerabilidade Social. 5. Vulnerabilidade em Saúde. 6. Doenças Transmissíveis. 7. Mortalidade. 8. Saúde de Populações Indígenas. 9. Incêndios Florestais. 10. Sistemas de Informação. II. Gestão de Riscos. I2. Vigilância em Saúde do Trabalhador. 13. Sistema Único de Saúde. 14. Brasil. 15. Divulgação de Informações. I. Freitas, Carlos Machado de (Org). II. Barcellos, Christovam (Org.). III. Villela, Daniel Antunes Maciel (Org.). IV. Título.

CDD - 23.ed. -616.2

Glauce de Oliveira Pereira - Bibliotecária CRB 7/5642

2021

EDITORA FIOCRUZ

Av. Brasil, 4036, térreo, sala 112 - Manguinhos

2 1040-36 I - Rio de Janeiro, RJ

Editora filiada

Tels: (2 I) 3882-9039 e 3882-904 I

Telefax: (2 I) 3882-9006

e-mail:editora@fiocruz.br

www.fiocruz.br/editora



DAS EDITORAS UNIVERSITÁRIAS 


\section{Organizadores}

\section{Carlos Machado de Freitas}

Historiador, mestre em engenharia de produção, doutor em saúde pública. Pesquisador da Escola Nacional de Saúde Pública Sergio Arouca/Fiocruz.

\section{Christovam Barcellos}

Geógrafo, mestre em ciências biológicas, doutor em geociências. Pesquisador sênior do Instituto de Comunicação e Informação Científica e Tecnológica em Saúde (Icict/Fiocruz), professor da Escola Nacional de Saúde Pública Sergio Arouca/Fiocruz e pesquisador do CNPq.

\section{Daniel Antunes Maciel Villela}

Engenheiro eletrônico, doutor em engenharia elétrica. Pesquisador em saúde pública na Fundação Oswaldo Cruz, onde é coordenador do Programa de Computação Científica, coordenador adjunto do Programa de Epidemiologia em Saúde Pública da Escola Nacional de Saúde Pública Sergio Arouca e integra o Observatório Covid- 19.

\section{Autores}

\section{Aline Diniz Rodrigues Caldas}

Graduada em nutrição, doutora em epidemiologia em saúde pública e pós-doutoranda no Programa Inova-Fundação Oswaldo Cruz.

\section{Amanda Scofano de Andrade Silva}

Geógrafa, mestra em geografia e meio ambiente, com ênfase em vulnerabilidade socioambiental e geoprocessamento, doutoranda em geografia.

\section{Ana Cláudia Rorato}

Bióloga, doutora em ciência do sistema terrestre, pós-doutoranda no Projeto SinBiose Trajetórias. Colaboradora no Laboratório de investigação em Sistemas Socioambientais do Instituto Nacional de Pesquisas Espaciais.

\section{Ana Cristina Reis}

Nutricionista-sanitarista. Pesquisadora em saúde pública da Fundação Oswaldo Cruz, onde atua no Laboratório de Educação Profissional em Informações e Registros em Saúde da Escola Politécnica de Saúde Joaquim Venâncio.

\section{Ana Lúcia de Moura Pontes}

Médica, doutora em saúde pública. Pesquisadora do grupo de pesquisas Saúde, Epidemiologia e Antropologia dos Povos Indígenas da Escola Nacional de Saúde Pública Sergio Arouca/Fiocruz.

\section{Ana Paula Dal'Asta}

Geógrafa, mestra em geografia, doutora em sensoriamento remoto. Colaboradora no Instituto Nacional de Pesquisas Espaciais. 


\section{André Reynaldo Santos Périssé}

Médico infectologista, doutor em epidemiologia. Pesquisador titular em saúde pública do Departamento de Endemias Samuel Pessoa da Escola Nacional de Saúde Pública Sergio Arouca/ Fiocruz, onde integra o GT Retorno às Aulas Presenciais.

\section{Andréa da Luz Carvalho}

Psicóloga, sanitarista, analista em gestão em saúde, mestra em saúde coletiva. Coordenadora de Gestão de Pessoas da Fundação Oswaldo Cruz.

\section{Andrey Moreira Cardoso}

Médico, mestre e doutor em saúde pública, com pós-doutorado em epidemiologia. Pesquisador titular da Escola Nacional de Saúde Pública Sergio Arouca/Fiocruz.

\section{Bárbara Cunha}

Bióloga, doutora em epidemiologia em saúde pública. Pesquisadora bolsista na Escola Nacional de Saúde Pública Sergio Arouca/Fiocruz.

\section{Bernardino Cláudio de Albuquerque}

Médico, mestre em ciências/medicina (doenças infecciosas e parasitárias). Professor na Universidade Federal do Amazonas e no Instituto Leônidas \& Maria Deane - Fiocruz Amazônia.

\section{Bianca Borges da Silva Leandro}

Sanitarista. Tecnologista em saúde pública da Fundação Oswaldo Cruz, onde atua no Laboratório de Educação Profissional em Informações e Registros em Saúde da Escola Politécnica de Saúde Joaquim Venâncio.

\section{Caroline Marcelino Sixel Amorim da Silva}

Estatística, especialista em saúde pública. Analista de informação de saúde da Coordenação de Saúde do Trabalhador da Fundação Oswaldo Cruz.

\section{Cecília de Aquino Barbosa}

Psicóloga, mestra em saúde pública. Analista de gestão em saúde na Coordenação de Saúde do Trabalhador da Fundação Oswaldo Cruz.

\section{Cesar Rossas Mota Filho}

Engenheiro civil, doutor em engenharia ambiental. Professor associado do Departamento de Engenharia Sanitária e Ambiental da Universidade Federal de Minas Gerais.

\section{Chauncie Bigler}

Cientista ambiental, mestra em planejamento de desenvolvimento urbano com ênfase em sociologia urbana, justiça ambiental e geoprocessamento.

\section{Cláudia Torres Codeço}

Bióloga, doutora em biologia quantitativa. Pesquisadora em saúde pública no Programa de Computação Científica da Fundação Oswaldo Cruz.

\section{Delson Silva}

Enfermeiro especialista em enfermagem do trabalho e mestre em saúde pública. Pesquisador adjunto em saúde pública da Fundação Oswaldo Cruz e professor assistente no Departamento de Enfermagem em Saúde Pública da Faculdade de Enfermagem da Universidade do Estado do Rio de Janeiro. 


\section{Diego Ricardo Xavier}

Enfermeiro, mestre em epidemiologia e doutor em saúde pública. Pesquisador do Instituto de Comunicação e Informação Científica e Tecnológica em Saúde (Icict/Fiocruz) e membro do Projeto MonitoraCovid-19.

\section{Dirceu Bartolomeu Greco}

Professor emérito de doenças infecciosas e bioética na Faculdade de Medicina da Universidade Federal de Minas Gerais. Presidente da Sociedade Brasileira de Bioética (20I9-202I) e vice-presidente do Comitê Internacional de Bioética (Unesco Paris, 2018-202I).

\section{Eduardo Hage Carmo}

Médico sanitarista e doutor em saúde pública. Pesquisador do Centro de Integração de Dados e Conhecimentos para Saúde da Fiocruz Bahia.

\section{Elisa Maria Campos}

Jornalista e mestra em estudos globais - ciências sociais. Editora do Projeto Peaceid.

\section{Emmanuel Roux}

Doutor em automação e informática. Pesquisador do Institut de Recherche pour le Développement, (IRD), coordenador do Laboratório Misto Internacional Sentinela e pesquisador visitante no Instituto de Comunicação e Informação Científica e Tecnológica em Saúde (Icict/Fiocruz).

\section{Fabiola Naomi Eto}

Enfermeira, doutora em epidemiologia em saúde pública. Membro do comitê de produção do Boletim Epidemiológico do panorama da Covid- 19 entre trabalhadores da Fundação Oswaldo Cruz.

\section{Fatima Pivetta}

Química, doutora em saúde pública. Na Fundação Oswaldo Cruz, é tecnologista do Centro de Estudos da Saúde do Trabalhador e Ecologia Humana e pesquisadora do Laboratório Territorial de Manguinhos da Escola Nacional de Saúde Pública Sergio Arouca.

\section{Felipe Ferré}

Graduado em farmácia, especialista em informática em saúde e doutor em bioinformática com pósdoutorado em medicamentos e assistência farmacêutica. Assessor técnico do Conselho Nacional de Secretários de Saúde e membro do Programa de Pós-Graduação em Saúde Pública da Faculdade de Medicina da Universidade Federal de Minas Gerais.

\section{Felipe Gomes Naveca}

Microbiólogo e imunólogo, mestre e doutor em ciências biológicas (microbiologia).

\section{Fernanda Cristina da Silva Lopes Ferreira}

Graduada em enfermagem, especialista em saúde coletiva e mestra em saúde pública com ênfase em epidemiologia. Enfermeira na Prefeitura Municipal de Rio Acima, MG.

\section{Fernanda Martins}

Historiadora. Atua como bolsista de pesquisa no Laboratório de Educação Profissional em Informações e Registros em Saúde da Escola Politécnica de Saúde Joaquim Venâncio/Fiocruz. 


\section{Fernando Campos Avendanho}

Médico-veterinário. Assessor técnico do Conselho Nacional de Secretários de Saúde.

\section{Fernando Souza Damasco}

Geógrafo, mestre em geografia. Tecnologista do Instituto Brasileiro de Geografia e Estatística, onde é professor colaborador da Escola Nacional de Ciências Estatísticas.

\section{Fernando José Herkrath}

Odontólogo, mestre em saúde, sociedade e endemias na Amazônia, doutor em saúde coletiva (epidemiologia).

\section{Flavia Soares Lessa}

Médica, especialista em medicina do trabalho, mestra em pesquisa clínica. Tecnologista em saúde pública da Fundação Oswaldo Cruz, onde é chefe do Núcleo de Saúde do Trabalhador da Coordenação de Saúde do Trabalhador.

\section{Flávio Codeço Coelho}

Biólogo, doutor em biologia quantitativa. Professor da Escola de Matemática Aplicada da Fundação Getulio Vargas.

\section{Guilherme Loureiro Werneck}

Médico, mestre em saúde coletiva e doutor em epidemiologia e saúde coletiva. Professor do Instituto de Estudos em Saúde Coletiva da Universidade Federal do Rio de Janeiro e do Instituto de Medicina Social da Universidade do Estado do Rio de Janeiro.

\section{Guilhermo Douglass-Jaimes}

Graduado em ciências ambientais, mestre em planejamento urbano e doutor em ciências ambientais, política e gestão. Pesquisador com ênfase em determinantes sociais e espaciais da saúde, com atenção especial aos efeitos do lugar e da vizinhança na saúde, é professor assistente de análise ambiental no Pomona College.

\section{Gustavo Corrêa Matta}

Psicólogo, mestre e doutor em saúde coletiva. Coordenador da Rede Zika Ciências Sociais e do eixo Impactos Sociais do Observatório Covid- 19 da Fundação Oswaldo Cruz.

\section{Gustavo Pedroso de Lima Brusse}

Estatístico, doutor em demografia. Pesquisador colaborador do Núcleo de Estudos de População da Universidade Estadual de Campinas.

\section{Hermano Albuquerque de Castro}

Médico pneumologista, mestre em clínica médica/pneumologia e doutor em saúde pública. Na Fundação Oswaldo Cruz, é pesquisador titular da Escola Nacional de Saúde Pública Sergio Arouca e membro do GT Retorno às Aulas Presenciais.

\section{Inara do Nascimento Tavares}

Cientista social, mestra em antropologia, doutoranda no Programa de Pós-Graduação em Ciências Sociais em Desenvolvimento, Agricultura e Sociedade da Universidade Federal Rural do Rio de Janeiro. Docente do Instituto Insikiran de Formação Superior Indígena da Universidade Federal de Roraima. 


\section{Isadora Vida de Mefano e Silva}

Geógrafa, mestra em saúde pública, doutoranda no Programa de Pós-Graduação em Geografia da Universidade Federal do Rio de Janeiro. Pesquisadora colaboradora no Observatório Covid-I 9 da Fundação Oswaldo Cruz.

\section{Jacinta de Fátima Sena da Silva}

Enfermeira sanitarista, mestra e doutora em ciências da saúde. Militante em defesa do Sistema Único de Saúde. Pesquisadora colaboradora da Fiocruz Brasília e do Departamento de Saúde Coletiva da Faculdade de Ciências da Saúde da Universidade de Brasília.

\section{João Roberto Cavalcante}

Graduado em saúde coletiva, mestre em saúde pública. Sanitarista da Secretaria Municipal de Saúde do Rio de Janeiro.

\section{Jorge Mesquita Huet Machado}

Médico do trabalho e sanitarista, mestre e doutor em saúde pública com pós-doutorado em saúde coletiva. Coordenador do Programa de Promoção da Saúde, Ambiente e Trabalho da Fiocruz Brasília e pesquisador associado no Instituto de Saúde Coletiva da Universidade Federal de Mato Grosso.

\section{José Joaquín Carvajal Cortés}

Biólogo, mestre e Ph.D. em ciências (medicina tropical). Coordenador técnico no Instituto Leônidas $\varepsilon$ Maria Deane - Fiocruz Amazônia.

\section{José Mauro Pinto}

Historiador. Professor pesquisador no Laboratório de Educação Profissional em Informações e Registros em Saúde da Escola Politécnica de Saúde Joaquim Venâncio/Fiocruz.

\section{Jurandi Frutuoso Silva}

Graduado em medicina, especialista em gestão de sistemas locais de saúde, mestre em saúde coletiva. Secretário executivo do Conselho Nacional de Secretários de Saúde e membro do Núcleo de Estudos de Saúde Coletiva da Faculdade de Medicina da Universidade Federal do Ceará.

\section{Lenice Gnocchi da Costa Reis}

Médica, doutora em saúde pública. Pesquisadora titular em saúde pública da Escola Nacional de Saúde Pública Sergio Arouca/Fiocruz.

\section{Leo Heller}

Engenheiro civil, mestre em saneamento, meio ambiente e recursos hídricos, doutor em epidemiologia. Pesquisador do Instituto René Rachou - Fiocruz Minas e professor voluntário da Universidade Federal de Minas Gerais.

\section{Leonardo Soares Bastos}

Estatístico, doutor em estatística. Pesquisador em Saúde Pública no Programa de Computação Científica da Fundação Oswaldo Cruz.

\section{Lúcia Rotenberg}

Bióloga, doutora em neurociências e comportamento. Pesquisadora em saúde pública do Laboratório de Educação em Ambiente e Saúde do Instituto Oswaldo Cruz/Fiocruz. 


\section{Luiz Max Carvalho}

Bacharel em ciências biológicas modalidade microbiologia e imunologia, doutor em biologia evolutiva. Professor adjunto da Escola de Matemática Aplicada da Fundação Getulio Vargas.

\section{Marcel de Moraes Pedroso}

Graduado em história, mestre em economia e doutor em administração. Pesquisador em saúde pública do Instituto de Comunicação e Informação Científica e Tecnológica em Saúde da Fundação Oswaldo Cruz (Icict/Fiocruz).

\section{Marcelo Ferreira da Costa Gomes}

Físico, doutorado em física. Pesquisador em saúde pública no Programa de Computação Científica da Fundação Oswaldo Cruz.

\section{Marcelo Moreno dos Reis}

Engenheiro, mestre em saúde pública, doutor em ciências médicas. Tecnologista sênior em saúde pública do Centro de Estudos da Saúde do Trabalhador e Ecologia Humana da Escola Nacional de Saúde Pública Sergio Arouca/Fiocruz.

\section{Marcelo Silva Santos}

Graduado em desenho industrial. Designer da Assessoria de Comunicação da Coordenação Geral de Gestão de Pessoas da Fundação Oswaldo Cruz.

\section{Márcia Vieira Pacheco}

Médica, especialista em saúde pública e mestra em saúde coletiva. Médica do Núcleo de Saúde do Trabalhador da Fundação Oswaldo Cruz.

\section{Marcio Sacramento}

Biólogo. Pesquisador em saúde pública do Laboratório de Informação Científica e Tecnológica em Saúde do Instituto de Comunicação e Informação Científica e Tecnológica em Saúde (Icict/Fiocruz).

\section{Marcus Vinícius de Carvalho}

Graduado com MBA em marketing. Assessor técnico e gerente da Assessoria de Comunicação do Conselho Nacional de Secretários de Saúde.

\section{Margareth Crisóstomo Portela}

Engenheira elétrica, mestra em engenharia biomédica, ph.D. em política e administração de saúde. Docente da Escola Nacional de Saúde Pública Sergio Arouca/Fiocruz.

\section{Maria Angela Esteves}

Licenciada em geografia, mestra em saúde pública, doutoranda no Programa de Pós-Graduação em Informação Científica e Tecnológica em Saúde do Instituto de Comunicação e Informação Científica e Tecnológica em Saúde (Icict/Fiocruz). Analista de gestão em saúde do Icict/Fiocruz.

\section{Maria Cristina Mitsuko Peres}

Graduada em enfermagem e obstetrícia, especialista em saúde pública, mestranda em saúde pública. Pesquisadora do Centro de Estudo e Pesquisa em Emergência e Desastres em Saúde/Fiocruz. 


\section{Maria Gloria Teixeira}

Médica, mestra em doenças infecciosas e parasitárias, doutora em saúde pública/epidemiologia. Professora aposentada de epidemiologia do Instituto de Saúde Coletiva da Universidade Federal da Bahia, onde é docente do Programa de Pós-Graduação; pesquisadora do Centro de Integração de Dados e Conhecimentos para Saúde da Fiocruz Bahia.

\section{Maria Isabel Sobral Escada}

Bacharel em ecologia, mestra e doutora em sensoriamento remoto. Tecnologista do Instituto Nacional de Pesquisas Espaciais, onde atua na Divisão de Observação da Terra e Geoinformação.

\section{Mariana dos Santos Velasco}

Graduanda em enfermagem.

\section{Mariana Melo Cavalcante}

Geógrafa, pós-graduanda em ensino de geografia.

\section{Mariano Andrade da Silva}

Biólogo, especialista em gestão ambiental e em vigilância em saúde ambiental, mestre em saúde coletiva e doutor em saúde pública. Atualmente é pesquisador do Centro de Estudo e Pesquisa em Emergência e Desastres em Saúde da Fundação Oswaldo Cruz.

\section{Marília Santini de Oliveira}

Médica infectologista, mestra e doutora em pesquisa clínica em doenças infecciosas. Médica pesquisadora da Fundação Oswaldo Cruz.

\section{Marisa Augusta de Oliveira}

Enfermeira, mestra em saúde pública e doutoranda em bioética, ética aplicada e saúde coletiva. Coordenadora do Núcleo de Saúde do Trabalhador do Instituto Nacional de Infectologia Evandro Chagas (INI/Fiocruz).

\section{Martha Sharapin}

Engenheira sanitarista. Tecnologista em saúde pública da Fundação Oswaldo Cruz, onde atua no Laboratório de Educação Profissional em Informações e Registros em Saúde da Escola Politécnica de Saúde Joaquim Venâncio.

\section{Mirian Carvalho de Souza}

Estatística, mestre e doutora em epidemiologia. Epidemiologista da Divisão de Pesquisa Populacional do Instituto Nacional de Câncer do Ministério da Saúde.

\section{Mônica de Avelar Figueiredo Mafra Magalhães}

Engenheira cartógrafa, mestra em engenharia de computação, doutora em saúde. Tecnologista em saúde pública da Fundação Oswaldo Cruz, onde atua como pesquisadora no Instituto de Comunicação e Informação Científica e Tecnológica em Saúde e professora na Escola Nacional de Saúde Pública Sergio Arouca. 


\section{Natália da Cunha Cidade}

Arquiteta urbanista, mestra em urbanismo, doutoranda no Instituto de Planejamento Urbano e Regional da Universidade Federal do Rio de Janeiro.

\section{Nereu Henrique Mansano}

Graduado em medicina, especialista em pediatria, mestre em saúde coletiva com especialização em informática em saúde. Assessor técnico do Conselho Nacional de Secretários de Saúde.

\section{Núbia Cristina da Silva}

Graduada e doutorada em administração, com pós-doutorado em saúde global e especialização em visualização de dados. Pesquisadora convidada do Duke Global Health Institute/Duke University.

\section{Osvaldo Peralta Bonetti}

Enfermeiro, mestre em saúde coletiva. Tecnologista da Fiocruz Brasília.

\section{Oswaldo Gonçalves Cruz}

Biólogo, mestre em saúde pública, doutorado em engenharia biomédica. Tecnologista em saúde pública no Programa de Computação Científica da Fundação Oswaldo Cruz.

\section{Patricia Canto Ribeiro}

Mestra em epidemiologia em saúde pública, doutoranda no Programa de Pós-Graduação em Saúde Pública e Meio Ambiente da Escola Nacional de Saúde Pública Sergio Arouca/Fiocruz. Médica pneumologista da Secretaria Municipal de Saúde do Rio de Janeiro; na Fundação Oswaldo Cruz, coordenadora de Atenção à Saúde da Vice-Presidência de Ambiente, Atenção e Promoção da Saúde e do GT Retorno às Aulas Presenciais.

\section{Paulo Roberto Borges de Souza Junior}

Estatístico, mestre e doutor em saúde pública. Pesquisador do Instituto de Comunicação e Informação Científica e Tecnológica em Saúde (Icict/Fiocruz).

\section{Rachel de Almeida Menezes}

Graduada em enfermagem.

\section{Raphael de Freitas Saldanha}

Geógrafo, mestre em saúde coletiva, doutor em informação e comunicação em saúde. Atua em projetos na área de ciência de dados aplicada à saúde na Fundação Oswaldo Cruz.

\section{Raphael Mendonça Guimarães}

Enfermeiro sanitarista, mestre em população, território e estatísticas públicas, mestre e doutor em saúde coletiva, doutor em demografia. Pesquisador em saúde pública da Fundação Oswaldo Cruz, onde atua no Laboratório de Educação Profissional em Informações e Registros em Saúde da Escola Politécnica de Saúde Joaquim Venâncio.

\section{Raquel Martins Lana}

Bacharel em ciências biológicas, mestra em ecologia de biomas tropicais, doutora em epidemiologia, pós-doutoranda em epidemiologia no Programa de Computação Científica da Fundação Oswaldo Cruz. 


\section{Regina Bontorim Gomes}

Graduanda em enfermagem.

\section{Renata Gracie}

Geógrafa, mestra em saúde pública, doutora em saúde coletiva. Pesquisadora do Laboratório de Informação em Saúde do Instituto de Comunicação e Informação Científica e Tecnológica em Saúde (lcict/Fiocruz).

\section{René Mendes}

Médico, especialista em saúde pública e em medicina do trabalho, mestre e doutor em saúde pública. Livre-docente em saúde pública da Universidade de São Paulo, onde é pesquisador colaborador do Instituto de Estudos Avançados; professor da Faculdade de Ciências Médicas da Unicamp (1977-199I); professor titular (aposentado) de medicina preventiva e social da Faculdade de Medicina da Universidade Federal de Minas Gerais; associado sênior da Escola de Saúde Pública da Johns Hopkins University (1983-20l4) e presidente da Associação Brasileira de Saúde do Trabalhador e da Trabalhadora (Abrastt).

\section{Ricardo Ventura Santos}

Biólogo, mestre e doutor em antropologia. Professor titular no Departamento de Antropologia do Museu Nacional/UFRJ e pesquisador titular na Escola Nacional de Saúde Pública Sergio Arouca/Fiocruz.

\section{Rodrigo Tobias de Sousa Lima}

Odontólogo, mestre em saúde, sociedade e endemias na Amazônia, doutor em saúde pública.

\section{Rosane Harter Griep}

Enfermeira, especialista em saúde pública, mestra e doutora em epidemiologia em saúde pública. Pesquisadora do Laboratório de Educação em Ambiente e Saúde do Instituto Oswaldo Cruz/Fiocruz.

\section{Sandra de Souza Hacon}

Bióloga, mestra em ciências ambientais, doutora em geociências. Professora na Escola Nacional de Saúde Pública Sergio Arouca/Fiocruz, onde é também pesquisadora sênior do Departamento de Endemias Samuel Pessoa; pesquisadora do grupo de pesquisa Ambiente, Diversidade e Saúde.

\section{Sérgio Luiz Bessa Luz}

Biólogo, mestre em ciências veterinárias, doutor em biologia parasitária.

\section{Sergio Munck}

Estatístico. Tecnologista em saúde pública da Fundação Oswaldo Cruz, onde atua no Laboratório de Educação Profissional em Informações e Registros em Saúde da Escola Politécnica de Saúde Joaquim Venâncio.

\section{Sônia Regina da Cunha Barreto Gertner}

Psicóloga, especialista em saúde mental e psicanálise, mestra em saúde pública, doutoranda na Escola Nacional em Saúde Pública Sergio Arouca/Fiocruz. Na Fundação Oswaldo Cruz é responsável pela Coordenação da Saúde do Trabalhador e membro do Comitê Fiocruz pela Acessibilidade e Inclusão da Pessoa com Deficiência. 


\section{Tatiana de Araújo Eleutério}

Enfermeira, doutora em epidemiologia em saúde pública. Professora adjunta do Departamento de Enfermagem em Saúde Pública da Faculdade de Enfermagem da Universidade do Estado do Rio de Janeiro e enfermeira do Hospital Federal dos Servidores do Estado.

\section{Tatiane Cristina Moraes de Sousa}

Bacharel em ecologia, mestra e doutora em saúde pública.

\section{Theresa Williamson}

Bióloga-antropóloga, mestra e doutora em planejamento urbano. Fundadora e diretora executiva da Comunidades Catalisadoras (ComCat).

\section{Valcler Rangel Fernandes}

Médico, especialista em saúde do trabalhador e ecologia humana. Chefe de gabinete da Presidência da Fundação Oswaldo Cruz.

\section{Vanderlei Pascoal de Matos}

Engenheiro cartógrafo, mestre em tecnologia da informação geográfica. Atua em pesquisas sobre os temas determinantes de saúde, ciências de dados aplicadas na saúde e sistemas de informação geográfica. 


\section{Sumário}

Apresentação

Carlos Machado de Freitas, Christovam Barcellos e Daniel Antunes Maciel Villela

\section{PARTE I - CENÁRIOS}

1. Cenários Epidemiológicos no Brasil: tendências e impactos Guilherme Loureiro Werneck

2. Balanço dos Cenários Epidemiológicos nos Seis Primeiros Meses da Pandemia no Brasil

Fernanda Cristina da Silva Lopes Ferreira

3. Balanço dos Cenários Epidemiológicos da Pandemia de Covid- 19 em 2020

Carlos Machado de Freitas, Christovam Barcellos, Daniel Antunes Maciel Villela,

Gustavo Corrêa Matta, Lenice Gnocchi da Costa Reis, Margareth Crisóstomo Portela,

Raphael de Freitas Saldanha e Isadora Vida de Mefano e Silva

4. Estimativa de Risco de Espalhamento da Covid- I 9 no Brasil e Avaliação da Vulnerabilidade Socioeconômica nas Microrregiões Brasileiras

Cláudia Torres Codeço, Daniel Antunes Maciel Villela, Flávio Codeço Coelho,

Leonardo Soares Bastos, Luiz Max Carvalho, Marcelo Ferreira da Costa Gomes,

Oswaldo Gonçalves Cruz e Raquel Martins Lana

5. Pandemia de Covid- 19: o processo de interiorização e aceleração da transmissão

no país

Mônica de Avelar Figueiredo Mafra Magalhães, Christovam Barcellos,

Diego Ricardo Xavier e Raphael de Freitas Saldanha

6. Como a Aceleração dos Casos e Óbitos, Para Além da Tendência, Explica a Dinâmica da Covid- 19 no Brasil?

Raphael Mendonça Guimarães, João Roberto Cavalcante, Tatiana de Araújo Eleutério,

Mariana dos Santos Velasco, Rachel de Almeida Menezes, Regina Bontorim Gomes,

Delson Silva e Gustavo Pedroso de Lima Brusse

7. Vulnerabilidade das Populações Indígenas à Pandemia de Covid- I 9 no Brasil e os Desafios para o seu Monitoramento

Raquel Martins Lana, Cláudia Torres Codeço, Ricardo Ventura Santos, Bárbara Cunha, Flávio Codeço Coelho, Oswaldo Gonçalves Cruz, Aline Diniz Rodrigues Caldas, Mirian Carvalho de Souza, Leonardo Soares Bastos, Ana Lúcia de Moura Pontes, Marcelo Ferreira da Costa Gomes, Inara do Nascimento Tavares, Ana Paula Dal'Asta, Ana Cláudia Rorato, Maria Isabel Sobral Escada, Luiz Max Carvalho, Daniel Antunes Maciel Villela, Fernando Souza Damasco e Andrey Moreira Cardoso 
8. A Pandemia pelo Sars-CoV-2 no Estado do Amazonas José Joaquín Carvajal Cortés, Bernardino Cláudio de Albuquerque, Fernando José Herkrath, Felipe Gomes Naveca, Sérgio Luiz Bessa Luz, Rodrigo Tobias de Sousa Lima, Marcelo Ferreira da Costa Gomes, Daniel Antunes Maciel Villela, Christovam Barcellos, Carlos Machado de Freitas, Leonardo Soares Bastos, Margareth Crisóstomo Portela e Valcler Rangel Fernandes

9. Covid- 19 e Queimadas na Amazônia Legal e no Pantanal: aspectos cumulativos e vulnerabilidades

Tatiane Cristina Moraes de Sousa, Sandra de Souza Hacon e Christovam Barcellos

10. Registro de Óbitos por Covid- 9 no Município do Rio de Janeiro e a Produção de Informações pelo SUS

Bianca Borges da Silva Leandro, Ana Cristina Reis, Fernanda Martins, José Mauro Pinto,

Martha Sharapin, Marcio Sacramento, Raphael Mendonça Guimarães e Sergio Munck

11. Óbitos em Excesso, Dentro e Fora de Hospitais, e a Desassistência à Saúde no Município do Rio de Janeiro

Christovam Barcellos, Diego Ricardo Xavier, Raphael de Freitas Saldanha e Mônica de Avelar Figueiredo Mafra Magalhães

\section{PARTE II - PRODUZINDO E ORGANIZANDO INFORMAÇÃO PARA AÇÃO}

12. A Emergência de Saúde e o Acesso a Plataformas de Dados para Gestores e Sociedade Civil

Renata Gracie, Mariana Melo Cavalcante, Maria Angela Esteves, Vanderlei Pascoal de Matos, Emmanuel Roux, Diego Ricardo Xavier e Christovam Barcellos

13. O Papel Tripartite na Divulgação de Casos e Óbitos por Covid- 19 e a Atuação do Conass

Felipe Ferré, Nereu Henrique Mansano, Marcus Vinícius de Carvalho,

Fernando Campos Avendanho, Jurandi Frutuoso Silva e Núbia Cristina da Silva

14. MonitoraCovid- 19: informação e disseminação de indicadores em uma pesquisa multidisciplinar

Raphael de Freitas Saldanha, Diego Ricardo Xavier, Mônica de Avelar Figueiredo Mafra

Magalhães, Paulo Roberto Borges de Souza Junior, Marcel de Moraes Pedroso e Christovam Barcellos

15. Painel Unificador Covid- I 9 nas Favelas: metodologia para dar visibilidade a territórios periféricos

Renata Gracie, Amanda Scofano de Andrade Silva, Chauncie Bigler, Guilhermo Douglass-Jaimes, Elisa Maria Campos e Theresa Williamson

16. O Tempo dos Dados: explorando a cobertura e oportunidade dos sistemas de informação Sivep Gripe e e-SUS VE

Diego Ricardo Xavier, Raphael de Freitas Saldanha, Mônica de Avelar Figueiredo Mafra Magalhães e Christovam Barcellos 


\section{PARTE III - ESTRATÉGIAS DE ENFRENTAMENTO E VIGILÂNCIA}

17. Vigilância em Saúde: preparação, resposta às emergências de saúde pública e o enfrentamento da Covid- I 9 no Brasil

Eduardo Hage Carmo e Maria Gloria Teixeira

18. Gestão de Riscos no Primeiro Mês de Enfrentamento da Pandemia de Covid- 19 no Brasil

Isadora Vida de Mefano e Silva, Carlos Machado de Freitas, Natália da Cunha Cidade, Mariano Andrade da Silva e Maria Cristina Mitsuko Peres

19. O Panorama da Pandemia Covid- I 9 no Brasil: diferentes graus de mitigação nos estados e processo de recrudescimento

Daniel Antunes Maciel Villela

20. A Produção de Informação para Ação no Contexto da Pandemia na Interface com o Ministério Público e a Defensoria Pública

Carlos Machado de Freitas, Christovam Barcellos, Daniel Antunes Maciel Villela, Margareth Crisóstomo Portela e Valcler Rangel Fernandes

2 I. Vigilância em Saúde do Trabalhador na Pandemia

René Mendes

22. Covid- 19: situação de saúde entre trabalhadores da Fiocruz

Sônia Regina da Cunha Barreto Gertner, Andréa da Luz Carvalho, Flavia Soares Lessa,

Márcia Vieira Pacheco, Cecília de Aquino Barbosa, Caroline Marcelino Sixel Amorim da Silva, Fabiola Naomi Eto, Marcelo Moreno dos Reis, Marília Santini de Oliveira, Rosane Harter Griep, Lúcia Rotenberg, Marcelo Silva Santos e Marisa Augusta de Oliveira

23. Retorno às Atividades Escolares no Brasil em Vigência da Pandemia Covid- 19

André Reynaldo Santos Périssé, Patricia Canto Ribeiro e Hermano Albuquerque de Castro

24. Vigilância Popular em Saúde em Tempos de Pandemia: proposta de um caminho

Jorge Mesquita Huet Machado, Fatima Pivetta, Jacinta de Fátima Sena da Silva e Osvaldo Peralta Bonetti

25. Considerações sobre a Possibilidade de Transmissão Fecal-Oral da Covid-19 .. 413 Leo Heller, Cesar Rossas Mota Filho e Dirceu Bartolomeu Greco 



\title{
Apresentação
}

\author{
Carlos Machado de Freitas, Christovam Barcellos e
}

Daniel Antunes Maciel Villela

A

entrada do vírus Sars-CoV-2 em alguns países no final de 2019 e o seu espalhamento mundial no início de 2020 levaram a uma série de desafios, mas também descobertas, que nortearam as estratégias iniciais de contenção da transmissão do vírus. A emergência em Wuhan, com uma série de casos na China, seguida de vários países, inclusive com epidemias em muitas localidades da Europa e enorme número de vítimas, acendeu o alerta para a necessidade de preparação da sociedade e governos para o impacto da epidemia, envolvendo casos, óbitos e a sobrecarga dos sistemas de saúde (Li et al., 2020). Com a declaração pela Organização Mundial da Saúde (OMS) como uma pandemia, então denominada Covid-19, as políticas delineadas nas primeiras semanas de resposta deram o tom de forma influente e fundamental para as medidas de seu enfrentamento (Ferguson et al., 2020; Anderson et al., 2020).

Nas primeiras semanas da pandemia era de grande importância avaliar as experiências, algumas vezes bem-sucedidas, outras desastrosas, em outros países que vivenciavam fases mais avançadas da transmissão comunitária do vírus Sars-CoV-2 e suas consequências sobre as condições de saúde, trabalho e crises do sistema de saúde. Os modelos matemáticos baseados em dados preliminares gerados nos países inicialmente atingidos foram usados para estimar os possíveis efeitos da pandemia no Brasil (Kraemer et al., 2020; Kucharski et al., 2020; Wu, Leung E Leung, 2020; Zhang et al., 2020; Kissler et al., 2020). Uma das importantes fontes de informação foi o Imperial College London, tomado pela OMS como referência para a produção e rápida disseminação de conhecimentos, que produziu análises e estimativas sobre a situação global e de alguns países como o Brasil, classificado como um dos epicentros da pandemia no nível regional e global (Imperial College Covid- I 9 Response Team, 2020). As particularidades brasileiras, sua configuração territorial, profundas desigualdades 
sociais, estrutura do sistema de saúde e condições de vida e trabalho exigiram uma adaptação desses modelos e análises de grupos populacionais específicos que poderiam se constituir como mais vulneráveis à pandemia e, por isso, requereriam atenção especial e políticas específicas (Andrade et al., 2020; Baqui et al., 2020; Candido et al., 2020; Castro et al., 202 I; França et al., 202 I; Hawryluk et al., 2020; Martinez et al., 2020; Pontes et al., 202 I; Ranzani et al., 202 I; Souza et al., 2020).

Este terceiro volume da Série Informação para Ação na Covid-19 reúne estudos resultantes do esforço de muitos pesquisadores brasileiros em produzir e disseminar rapidamente conhecimentos que têm como base os registros de casos, hospitalizações e óbitos e com os quais se procurou subsidiar políticas e ações para o enfrentamento da pandemia no Brasil em um conjunto de iniciativas no âmbito do eixo Cenários Epidemiológicos do Observatório Covid- 19 Fiocruz. Este observatório foi constituído nos primeiros meses da pandemia no Brasil, com o objetivo de reunir informações sobre os diversos aspectos epidemiológicos, demográficos, sociais e políticos da pandemia e sua expressão em grupos sociais de maior vulnerabilidade. Tem caráter multidisciplinar, visto que a pandemia deve ser entendida como um fenômeno influenciado por diversos fatores geográficos, históricos, culturais e econômicos e afeta todas essas dimensões. Em seu âmbito, estudar, analisar e emitir alertas sobre a situação e tendências da pandemia não constitui mero exercício estatístico, pois se desdobra em uma compreensão ampla sobre a sociedade brasileira e seu sistema de saúde, com especial ênfase no Sistema único de Saúde (SUS).

Os capítulos aqui reunidos provêm da combinação dos debates e discussões em torno da pandemia e sua evolução, que resultaram em seminários, notas técnicas e relatórios produzidos até o final de 2020. Seu conteúdo não esgota a amplitude e diversidade de temas que envolvem a pandemia, em razão da opção que a comunidade científica nacional situada no âmbito da saúde pública fez por produzir e difundir o mais rápido possível dados e análises relacionados à sua dinâmica no Brasil.

Toda esta produção teve como base e estímulo a procura de respostas para os problemas que estavam se apresentando em determinado momento da pandemia, bem como o diálogo com a produção científica advinda de diversos campos de saber realizada e publicada em seu curso.

A primeira parte do volume, dedicada ao tema dos cenários, contém I I capítulos. Após os três primeiros capítulos - "Cenários epidemiológicos no Brasil: tendências e impactos", "Balanço dos cenários epidemiológicos nos seis primeiros meses da pandemia no Brasil" e "Balanço dos cenários epidemiológicos da pandemia de Covid- 19 em 
2020" -, outros três são dedicados à análise do processo de espalhamento e aceleração da pandemia no país considerando a vulnerabilidade socioeconômica ("Estimativa de risco de espalhamento da Covid- 9 no Brasil e avaliação da vulnerabilidade socioeconômica nas microrregiões brasileiras") e ao processo de interiorização e aceleração da transmissão ("Pandemia de Covid-19: o processo de interiorização e aceleração da transmissão no país" e "Como a aceleração dos casos e óbitos, para além da tendência, explica a dinâmica da Covid- 19 no Brasil?”).

Ainda neste primeiro conjunto de II capítulos, outros três são voltados para populações vulneráveis/vulnerabilizadas ("Vulnerabilidade das populações indígenas à pandemia de Covid-19 no Brasil e os desafios para o seu monitoramento") e para lugares que se tornaram vulneráveis. Com análises locais, dois capítulos exemplificam bem esses processos: "A pandemia pelo Sars-CoV-2 no estado do Amazonas", um dos epicentros da pandemia no país por falhas graves na gestão do enfrentamento, e "Covid- 19 e queimadas na Amazônia Legal e no Pantanal: aspectos cumulativos e vulnerabilidades", relacionado a dois grandes biomas do país que, em um processo crescentemente deficiente de gestão e proteção ambiental, sofreram graves queimadas que potencializaram a ampliação e o agravamento das doenças respiratórias, entre as quais a Covid- 19.

Por fim, nos dois últimos capítulos desta primeira parte dedicada aos cenários são abordados os temas relacionados aos óbitos. O primeiro, "Registro de óbitos por Covid- 19 no município do Rio de Janeiro e a produção de informações pelo SuS”, trata da importância do registro oportuno e correto de informações, entre as quais os dados sobre óbitos como fonte de informação estratégica para enfrentamento da pandemia. No segundo, "Óbitos em excesso, dentro e fora de hospitais, e a desassistência à saúde no município do Rio de Janeiro", problematiza-se o tema dos óbitos para além dos diretamente relacionados à Covid-19, considerando-se na análise não só o excesso de óbitos, mas também aqueles devidos a falhas na atenção à saúde.

A segunda parte do livro contém cinco importantes capítulos cujo foco não está exatamente na análise de dados, mas sim na constituição de painéis que disponibilizam o acesso aos dados em formatos diversos de visualização que possibilitem análises e produção de informação para a ação. O capítulo "A emergência de saúde e o acesso a plataformas de dados para gestores e sociedade civil" oferece um amplo levantamento de ferramentas para a consulta de dados, que vão desde plataformas de dados para análises globais, como as da OMS e da Universidade John Hopkins, até plataformas locais, desenvolvidas por prefeituras, instituições de pesquisa ou associações. 
O campo que envolve a produção de dados e informações envolve, ainda que nem sempre visíveis, disputas políticas, éticas e técnicas. A disponibilização dos dados em painéis e suas formas de visualização também envolvem escolhas aparentemente simples, porém condicionadas à transparência dos dados para subsidiar ações de vigilância em saúde e o livre acesso da população a tais ações. Também envolvem questões mais obscuras, que resultam em sub-registro de casos e óbitos, opacidade ou mesmo indisponibilidade de dados e informações de forma transparente e oportuna. No dia 5 de junho de 2020, o governo federal passou a restringir a divulgação do total de casos e de óbitos por Covid- 19 no Brasil, provocando imediatas reações nos meios de comunicação e entre os gestores de saúde e a comunidade científica, que criaram painéis alternativos para disponibilizar informações nacionais de evolução e distribuição da Covid- 19 no país. A coleta de dados passou a ser pulverizada e foi tornada possível pelo esforço de voluntários reunidos em projetos como o Brasil.IO (2021). Nos meios de comunicação, uma das iniciativas importantes foi a formação do Consórcio de Veículos de Imprensa, envolvendo o GI, O Globo, Extra, Estadão, Folha de S.Paulo e UOL. Outras duas iniciativas importantes estão registradas neste livro. A primeira envolve os gestores estaduais da saúde por intermédio do Conselho Nacional de Secretários de Saúde (Conass), que constituiu o Painel Conass Covid- 19 (202I) e está descrita no capítulo "O papel tripartite na divulgação de casos e óbitos de Covid-19 e a atuação do Conass". A segunda, que está descrita no capítulo "MonitoraCovid-19: informação e disseminação de indicadores em uma pesquisa multidisciplinar", envolve pesquisadores da Fundação Oswaldo Cruz (Fiocruz) e amplia as possibilidades de acesso e disponibilização de dados e informações diversas no sistema MonitoraCovid-19 (Fiocruz, 202I), que passou a reunir dados não só sobre casos e óbitos, mas também índices de positividade de testes, mobilidade da população e meios de transporte, incidência de síndromes respiratórias agudas graves (Srag) e decretos de todos os níveis de governo que passaram a regular o controle da pandemia.

A transmissão e gravidade da Covid- 19 em áreas de favela foi uma preocupação de toda a sociedade, desde o início da pandemia. No entanto, a coleta e sistematização de dados tanto populacionais quanto epidemiológicos nessas áreas requer um grande esforço, pois inexistem variáveis que identifiquem os locais de moradia, dentro ou fora de favelas, nos sistemas de informação em saúde. No capítulo "Painel Unificador Covid- I 9 nas Favelas: metodologia para dar visibilidade a territórios periféricos”, são descritos os procedimentos metodológicos para se recuperar registros de casos em áreas de favela que contam com o desenvolvimento de técnicas de geoprocessamento aliadas à participação da população, especialmente de organizações nas favelas da Rocinha e do Complexo do Alemão, ambas no município do Rio de Janeiro. 
Por fim, o último capítulo desta segunda parte, "O tempo dos dados: explorando a cobertura e oportunidade dos sistemas de informação Sivep Gripe e e-SUS VE", tem como foco a análise de dois aspectos fundamentais relacionados aos dados em situações de emergência em saúde pública e pandemias: o sub-registro de notificações e o fluxo de dados, que podem prejudicar a tomada de decisões adequadas para cada momento da pandemia.

A última parte do volume reúne nove capítulos em que se aborda uma diversidade de temas relacionados às estratégias de enfrentamento e vigilância em saúde. No primeiro, "Vigilância em saúde: preparação, resposta às emergências de saúde pública e o enfrentamento da Covid- 9 no Brasil", descreve-se o conjunto de iniciativas que ao longo dos anos contribuíram para o aperfeiçoamento das capacidades do país para a preparação e resposta às emergências de saúde pública e sua adoção no enfrentamento da pandemia por Covid- 19. O segundo, "Gestão de riscos no primeiro mês de enfrentamento da pandemia de Covid- 9 no Brasil”, tem como pano de fundo os cenários epidemiológicos da pandemia no Brasil e em diferentes países, e nele se analisa o conjunto de leis e decretos estaduais que organizaram as estratégias de enfrentamento dos diferentes estados.

O tema central dos dois capítulos seguintes é o uso da informação para a ação no contexto dos cenários epidemiológicos. Em "O panorama da pandemia Covid- 19 no Brasil: diferentes graus de mitigação nos estados e processo de recrudescimento", aborda-se o acompanhamento dos cenários epidemiológicos para o monitoramento da situação de saúde como subsídio para ações de vigilância e respostas, incluindo número adequado de leitos em enfermaria e leitos de UTI. E em "A produção de informação para ação no contexto da pandemia na interface com o Ministério Público e a Defensoria Pública" se relata como a análise de cenários epidemiológicos em diferentes momentos subsidiou a adoção de medidas de distanciamento social e restrição da circulação de pessoas, bem como de garantia de leitos de UTI para Covid- 19. Esse texto é um exemplo do uso, por esferas de governo e do Poder Judiciário, de informações reunidas, analisadas e divulgadas no âmbito do Observatório Covid- 9 como parâmetro para o controle da pandemia em diversos momentos.

Em seguida, em outros dois capítulos são abordados temas relacionados à saúde dos trabalhadores durante a pandemia. No primeiro, "Vigilância em saúde do trabalhador na pandemia”, se destaca, além da importância do trabalho na determinação social da pandemia da Covid-19 no Brasil, a necessidade do reconhecimento sanitário e médico-previdenciário da Covid- 9 relacionada ao trabalho como direito. O capítulo seguinte, "Covid- 19: situação de saúde entre trabalhadores da Fiocruz", é dedicado ao conjunto de ações realizadas para vigilância e cuidados na Fiocruz, instituição que tem 
trabalhadores em diversos setores produtivos, desde a assistência à saúde (hospitais e centros de saúde) até a produção de kits de testes e vacinas para enfrentamento da pandemia, entre outros.

No capítulo "Retorno às atividades escolares no Brasil em vigência da pandemia Covid- 19", é abordado o complexo e relevante tema que envolve crianças e adolescentes, mas também trabalhadores da educação e comunidades escolares amplas, nos diferentes cenários de transmissão da pandemia e as incertezas que giram em torno destes. Escolas são importantes e fundamentais equipamentos presentes nos territórios. E no capítulo "Vigilância popular em saúde em tempos de pandemia: proposta de um caminho" se assume, em diálogo com a perspectiva da promoção da saúde, que dois pilares são fundamentais para se apreender a complexidade do processo saúde-doença nos territórios e desenvolver ações: a intersetorialidade e a participação comunitária como estratégias de engajamento da sociedade e adequação dos sistemas de vigilância em saúde para o enfrentamento da pandemia.

O último capítulo, "Considerações sobre a possibilidade de transmissão fecal-oral da Covid-19", traz importantes contribuições para a compreensão sobre a ampliação das vias de transmissão do vírus Sars-CoV-2. Trata-se de nota produzida logo após o isolamento do vírus em amostras de esgoto coletadas em algumas cidades brasileiras, o que poderia ser um alerta para uma nova forma de transmissão, mas igualmente uma estratégia de monitoramento da intensidade de transmissão em grandes áreas. Os maiores esforços de conhecimento têm se dirigido às vias de transmissão aérea da Covid-19, mas há outras potenciais vias de transmissão da doença, como a fecal-oral, o que é importante em um país onde milhões de pessoas ainda vivem em condições precárias de saneamento e habitação.

O Brasil, contando com a estrutura, mesmo que precária e subfinanciada, do SUS, dispôs de componentes importantes para a resposta à pandemia, apesar das limitações em recursos, incapacidades e limitações da coordenação nacional e regional. Essa estrutura foi demandada não apenas no sistema hospitalar, mas também na vigilância e atenção primária à saúde e nos próprios sistemas de informação implementados pelo departamento de informática do Sistema Único de Saúde, o Datasus. O país já mantinha um sistema de vigilância para síndromes respiratórias agudas graves, o Sivep Gripe, com os registros mais graves de doenças respiratórias. Em um contexto de compreensão da demanda ao sistema de saúde, tais sistemas são essenciais e puderam ser ajustados rapidamente para incluir as infecções pelo vírus Sars-CoV-2. Ao mesmo tempo, houve uma proliferação de novos sistemas de informação, com coberturas e fluxos díspares, o que dificulta sua análise integrada. 
Ao longo do primeiro ano da pandemia, a comunidade acadêmica, nacional e internacional, também se voltou com atenção para o problema nas suas várias vertentes, de forma que a produção de conhecimento foi vertiginosa. A produção de conhecimento foi importante para nortear algumas ações, ainda que tenha havido falta de ações coordenadas. Muitas recomendações puderam ser base para ações preventivas, como o fortalecimento da vigilância em saúde e da atenção primária em saúde. A experiência, no entanto, mostrou que a tomada de decisões para essas ações muitas vezes acontece de forma tardia ou insuficiente. Alguns desses aspectos constituem elementos importantes no processo de recrudescimento que viria a acontecer no início de 2021 , ao lado do surgimento preocupante de variantes com transmissibilidade elevada e do atraso da campanha de vacinação.

A permanência de níveis altos de transmissão, o surgimento de variantes do vírus, a aplicação escalonada de vacinas, a incapacidade do sistema de saúde de atender a todos de forma equânime e ao mesmo tempo universal, entre vários outros aspectos emergentes da pandemia, vão exigir a continuidade das ações de monitoramento da pandemia no Brasil. À medida que se ampliam e diversificam as estratégias de ação de controle como campanhas de imunização, distanciamento físico e social, desenvolvimento de terapias médicas, técnicas de diagnóstico incluindo a vigilância genômica -, também é requerido o aperfeiçoamento contínuo de métodos e a busca de novas fontes de dados para o monitoramento da pandemia, que devem sempre considerar a diversidade e desigualdade estrutural da sociedade brasileira.

As lições deste momento de crise devem ser mantidas em memória, para que eventuais novas pandemias sejam tratadas como crises sanitárias de forma abrangente. A experiência com a pandemia Covid- 19 mostra que a vigilância em saúde requer sistemas de informação disponíveis, atualizados e integrados. Em um país com mais de cinco mil municípios, é importante manter equipes da vigilância e da atenção primária treinadas para atualização e monitoramento de agravos. Em caso de surtos, as recomendações serão rapidamente postas em prática, se houver disponibilidade de indicadores que permitam a tomada de decisões e equipes que saibam interpretá-los.

A busca de vacinas com tecnologias modernas e a necessidade de ampliar o uso de técnicas para vigilância genômica demonstram a urgência de investimentos e tecnologias para saúde pública. Sistemas de informação com processamento computacional e capacidade analítica são ferramentas importantes em salas de decisão de eventuais novas crises sanitárias. 
Ações preventivas devem ser o modo normal das operações em saúde pública. A experiência com decisões tardias, ou sem base em indicadores sólidos e critérios científicos, por exemplo para flexibilização de atividades e comunicação para a população, foi um dos fatores que levaram ao recrudescimento da pandemia e impuseram um número extremamente alto de óbitos, além do comprometimento da saúde de muitas pessoas, mesmo que recuperadas da Covid- 19.

As iniquidades em saúde também foram evidenciadas em diversos segmentos da sociedade, como grupos sociais e populacionais vulneráveis que sofreram com maior intensidade a crise, como mostrado em vários capítulos. A perspectiva de soluções para enfrentamento de crises sanitárias com visão interdisciplinar, que contenha elementos de análise de vulnerabilidades, também é fundamental. Pandemias em particular envolvem uma dinâmica social e populacional em que os processos e comportamentos coletivos, por exemplo em mobilidade humana e atividades econômicas e em grupos, têm implicações para toda a sociedade. Enfrentar uma pandemia envolve também compreender essas dinâmicas e processos, sendo essencial reduzir ao máximo iniquidades que estão em sua base e constituição.

Esperamos que os estudos reunidos neste livro sejam referências nesse sentido e mantenham a memória das experiências do período de 2020 da pandemia. Novas epidemias certamente poderão vir, mas se estas lições forem seriamente compreendidas e assimiladas, com melhorias implementadas, a resposta será muito mais precisa e rápida para garantir um tratamento adequado com equidade para a população.

\section{REFERÊNCIAS}

ANDERSON, R. M. et al. How will country-based mitigation measures influence the course of the Covid- I 9 epidemic? The Lancet, 395(10.228): 931-934, 2020. Disponível em: <www.thelancet.com/ journals/lancet/article/PIISO I 40-6736(20)30567-5/abstract>. Acesso em: 22 mar. 2020.

ANDRADE, C. L. T. et al. Covid- I 9 hospitalizations in Brazil's Unified Health System (SUS). PLoS One, 15(I2): e0243126, 2020. Disponível em: < https://journals.plos.org/plosone/article?id=10.1371/ journal.pone.0243126>. Acesso em: 7 jan. 2021.

BAQUI, P. et al. Ethnic and regional variations in hospital mortality from Covid- 19 in Brazil: a crosssectional observational study. The Lancet Global Health, 8(8): el.018-el.026, 2020. Disponível em: $<$ www.thelancet.com/journals/langlo/article/PIIS22 I4-I09X(20)30285-0/fulltext>. Acesso em: 7 jan. 2021.

BRASIL.IO. Especial Covid-I9 - Dados por município. Disponível em: <https://brasil.io/covidI9>. Acesso em: 4 jan. 2021.

CANDIDO, D. S. et al. Evolution and epidemic spread of Sars-CoV-2 in Brazil. Science, 369(6.508): I.255-I.260, 2020. Disponível em: <https://science.sciencemag.org/content/369/6508/I255>. Acesso em: 8 jan. 2021 . 
CASTRO, M. et al. Spatiotemporal pattern of Covid-I 9 spread in Brazil. Science, 372(6.544): 82 I826, 2021 . Disponível em: < https://science.sciencemag.org/content/372/6544/82 I >. Acesso em: 23 maio 2021.

CONSELHO NACIONAL DE SECRETÁRIOS DE SAÚDE (CONASS). Painel Conass - Covid- 19. Disponível em: <www.conass.org.br/painelconasscovid I9>. Acesso em: 5 jan. 2021.

FERGUSON, N. et al. Report 9: impact of non-pharmaceutical interventions (NPIs) to reduce Covid I 9 mortality and healthcare demand. Imperial College London, 16 Mar. 2020. Disponível em: <http:// spiral.imperial.ac.uk/handle/l 0044/1/77482 >. Acesso em: 28 mar. 2020.

FRANÇA, E. B. et al. Óbitos por Covid- 9 no Brasil: quantos e quais estamos identificando? Revista Brasileira de Epidemiologia, 23: e200053, 2020. Disponível em: <www.scielo.br/j/rbepid/a/75zrygtR M8GMdgKYhTLfmpH/?format=pdfElang=pt $>$. Acesso em: 9 jan. 2021 .

FUNDAÇÃO OSWALDO CRUZ (FIOCRUZ). MonitoraCovid-19. Disponível em: < https://bigdatacovid I 9.icict.fiocruz.br/>. Acesso em: 5 jan. 2021.

HAWRYLUK, I. et al. Inference of Covid-I9 epidemiological distributions from Brazilian hospital data. Journal of the Royal Society Interface, I7(I72): 20200596, 2020. Disponível em: <https:// royalsocietypublishing.org/doi/I0.1098/rsif.2020.0596>. Acesso em: 9 jan. 2021.

IMPERIAL COLLEGE COVID-I9 RESPONSE TEAM. Report 21: estimating Covid-19 cases and reproduction number in Brazil. Imperial College London, 8 May 2020. Disponível em: <www. imperial.ac.uk/mrc-global-infectious-disease-analysis/covid-19/report-2I-brazil/>. Acesso em: 10 maio 2020.

KISSLER, S. M. et al. Projecting the transmission dynamics of Sars-CoV-2 through the postpandemic period. Science, 368(6.493): 860-868, 2020. Disponível em: <https://science.sciencemag.org/ content/368/6493/860>. Acesso em: 12 maio 2020.

KRAEMER, M. U. G. et al. The effect of human mobility and control measures on the Covid- 19 epidemic in China. Science, 368(6.490): 493-497, 2020. Disponível em: <https://science.sciencemag.org/ content/368/6490/493 >. Acesso em: 10 maio 2020.

KUCHARSKI, A. J. et al. Early dynamics of transmission and control of Covid- 19: a mathematical modelling study. The Lancet Infectious Diseases, 20(5): 553-558, 2020. Disponível em: <www. thelancet.com/article/SI473-3099(20)30 I 44-4/fulltext>. Acesso em: 10 maio 2020.

LI, Q. et al. Early transmission dynamics in Wuhan, China, of novel coronavirus-infected pneumonia. The New England Journal of Medicine, 382: I.199-1.207, 2020. Disponível em: <https://www.nejm. org/doi/full/I 0. 1056/nejmoa200 I 316>. Acesso em: 2 dez. 2020.

MARTINEZ, R. et al. Estimativas do impacto da Covid- I 9 na mortalidade no Brasil. Abrasco, 30 mar. 2020. Disponível em: <www.abrasco.org.br/site/noticias/saude-da-populacao/estimativas-doimpacto-da-covid-19-na-mortalidade-no-brasil/46151/>. Acesso em: 10 jan. 2021.

PONTES, A. L. M. et al. Pandemia de Covid- 19 e os povos indígenas no Brasil: cenários sociopolíticos e epidemiológicos. In: MATTA, G. C. et al. (Orgs.). Os Impactos Sociais da Covid-I 9 no Brasil: populações vulnerabilizadas e respostas à pandemia. Rio de Janeiro: Observatório Covid-19, Editora Fiocruz, 2021. (Informação para Ação na Covid-19). Disponível em: < http://books.scielo.org/id/r3hc2/pdf/ matta-9786557080320.pdf>. Acesso em: 8 maio 2021. 
RANZANI, O. T. et al. Characterisation of the first 250000 hospital admissions for Covid- 19 in Brazil: a retrospective analysis of nationwide data. The Lancet Respiratory Medicine, 9(4): 407-4I8, 202I. Disponível em: <https://www.thelancet.com/journals/lanres/article/PIIS22I3-2600(20)30560-9/ fulltext>. Acesso em: 6 abr. 2021.

SOUZA, W. M. et al. Epidemiological and clinical characteristics of the Covid- 19 epidemic in Brazil. Nature Human Behaviour, 4: 856-865, 2020. Disponível em: <www.nature.com/articles/s4I562020-0928-4>. Acesso em: II jan. 2021.

WU, J. T.; LEUNG, K. \& LEUNG, G. M. Nowcasting and forecasting the potential domestic and international spread of the 20I9-nCoV outbreak originating in Wuhan, China: a modelling study. The Lancet, 395(10.225): 689-697, 2020. Disponível em: <www.thelancet.com/journals/lancet/article/ PIISOI40-6736(20)30260-9/fulltext>. Acesso em: 5 mar. 2020.

ZHANG, S. et al. Estimation of the reproductive number of novel coronavirus (Covid-19) and the probable outbreak size on the Diamond Princess cruise ship: a data-driven analysis. International Journal of Infectious Diseases, 93: 201-204, 2020. Disponível em: <www.ncbi.nlm.nih.gov/pmc/articles/ PMC7 | I 059 I/>. Acesso em: 9 maio 2020. 
PARTE I

\section{CENÁRIOS}







\section{Cenários Epidemiológicos no Brasil}

tendências e impactos

Guilherme Loureiro Werneck

\section{A INVISIBILIDADE DO PREVISÍVEL}

7 pós um período de otimismo em relação à possibilidade de controle, eliminação e mesmo erradicação das doenças infecciosas, o final do século $X X$ trouxe um novo panorama sanitário marcado pelo aparecimento ou recrudescimento de novas doenças transmissíveis em escala mundial (Jones et al., 2008). Nesse contexto, tornouse consensual entre pesquisadores e profissionais da saúde da área de epidemiologia das doenças infecciosas que o advento de uma nova pandemia originada a partir de um microrganismo desconhecido não era uma questão de "se", mas de "quando" aconteceria (Wolfe, 20II).

O século XXI desponta já marcado pelo signo epidêmico. Duas epidemias de síndromes respiratórias graves por coronavírus (Sars-CoV e Mers-CoV) não lograram alcançar o status de pandemia, mas alertaram o mundo para essa possibilidade. O Sars$\mathrm{CoV}$ (coronavírus relacionado à síndrome respiratória aguda grave), reconhecido no início de 2003, espalhou-se por mais de vinte países, ocasionando mais de 8 mil casos com letalidade de cerca de 10\% (WHO, 2003). O Mers-CoV (coronavírus da síndrome respiratória do Oriente Médio), inicialmente descrito na Arábia Saudita em 2012, causou, entre 2012 e 2020, cerca de 2.500 casos, com letalidade de 35\% (WHO, 202 I). Além do alerta mundial decorrente dessas duas epidemias, o mundo ainda experimentou uma pandemia de influenza, para a qual alguma estrutura sanitária, incluindo vacina, foi disponibilizada, uma grande epidemia de Ebola e os novos desafios no campo das arboviroses (zika e chikungunya). Em 2020, enfim, chegamos à grande pandemia do desconhecimento (Fauci, Lane E Redfield, 2020). 
Logo ficou claro para a comunidade científica que a pandemia causada pelo novo coronavírus (Sars-CoV-2) se configurava como o maior desafio sanitário de nossa geração. Não só porque imediatamente se percebeu que o novo coronavírus poderia se espalhar rapidamente em uma população altamente suscetível, causando uma doença complexa e, em muitos casos, fatal (Covid-19), mas principalmente porque não tínhamos os meios adequados (vacinas ou medicamentos) para seu enfrentamento mais específico, associado à falta substancial de conhecimento científico de sua epidemiologia, fisiopatologia, microbiologia e imunologia (Anderson et al., 2020). A escassez crítica de suprimentos necessários para lidar com a doença, como equipamentos de proteção individual (EPI) e ventiladores, foi verificada em muitas partes do mundo ainda no início da pandemia. A falta de acesso a esses suprimentos decorreu, pelo menos em parte, das restrições de exportação e viagens por alguns países produtores desses insumos, assim como de uma disputa internacional para a compra, já evidenciando as dificuldades para implementação de um esforço multilateral integrado necessário a uma resposta global efetiva à pandemia (McMahon et al., 2020).

\section{ESTRUTURA DE RESPOSTA À PANDEMIA E A ABORDAGEM BRASILEIRA}

Apesar do escasso conhecimento sobre o novo coronavírus, a estrutura básica para uma resposta adequada à pandemia não era totalmente desconhecida. Conforme já salientado, o século XXI foi fértil em desafiar a comunidade de saúde pública com grandes surtos. Muito se aprendeu sobre as respostas a pandemias nos últimos vinte anos. Os princípios-chave para esse enfrentamento estão bem estabelecidos e envolvem, entre outros: I) tratar o problema com seriedade; 2) coordenar ações no nível internacional e infranacional; 3) desenvolver estratégia ampla e efetiva de comunicação com o público e a comunidade técnico-científica; 4) estabelecer procedimentos para postergar a introdução da infecção em novos territórios; 5) buscar medidas de contenção e supressão para diminuir ou interromper a propagação geográfica da infecção, à medida que a transmissão comunitária passa a ocorrer; 6) consolidar as ações de vigilância epidemiológica de base territorial, buscando ampliar a identificação de casos e o rastreamento de contatos para interrupção das redes de transmissão; 7) ampliar a realização de testes diagnósticos; 8) priorizar as medidas para salvar vidas, incluindo estruturação da atenção à saúde em seus diversos níveis de complexidade; 9) proteger e dar segurança às populações mais vulneráveis e aos profissionais da saúde; 10) investir em pesquisa científica e II) preparar-se para lidar com o futuro pós-pandêmico, o que requer a organização da sociedade para reestruturação social e econômica do país (Nurse, 2020). 
Infelizmente, a resposta brasileira à pandemia falhou na maior parte desses princípios e em todas as fases da sua evolução. Embora a transmissão comunitária do novo coronavírus no Brasil tenha sido estabelecida apenas em março, depois de já ter se espalhado pela Ásia, Europa e Estados Unidos, oferecendo oportunidades para a preparação, a resposta inicial brasileira à pandemia foi lenta e errática. Após um início promissor nas ações de enfrentamento à pandemia (Croda et al., 2020; Oliveira, W. K. et al., 2020), em que o núcleo da equipe técnica da Secretaria de Vigilância em Saúde do Ministério da Saúde teve seu trabalho preservado e o ministro da Saúde de então abraçou as recomendações de cunho técnico-científico, o processo retrocedeu rapidamente. É certo que houve esforços, principalmente nos primeiros meses da epidemia, tanto do Ministério da Saúde brasileiro quanto dos governos regionais, para aumentar o acesso aos cuidados de saúde e aprimorá-los, com aumento do número de leitos hospitalares e de UTI, EPI, ventiladores e exames, mas estes não foram suficientes. Logo, em abril, a doença causou o colapso dos serviços de saúde em Manaus, capital do estado do Amazonas, onde houve relatos de pessoas morrendo em casa sem assistência médica e pessoas sendo enterradas em valas coletivas (Orellana et al., 2020).

A ausência de uma liderança nacional para gestão da crise sanitária pode ser sentida em diferentes atos e abordagens, salientando-se, entre outras, minimização do problema e adesão a práticas anticientíficas para o enfrentamento da epidemia; falta de coordenação com outros entes federativos; ausência de ações efetivas de comunicação social sobre a importância do distanciamento social e da proteção individual, em particular o uso de máscaras; insuficiente vigilância e controle em portos e aeroportos; ênfase na assistência hospitalar e falta de envolvimento da Atenção Primária à Saúde (APS) e da Estratégia Saúde da Família (ESF) no enfrentamento da epidemia; vigilância sindrômica ativa insatisfatória e escassa testagem para isolamento de casos e rastreamento de contatos; gestão inadequada dos dados em saúde; e estímulo à reabertura das atividades sociais e econômicas sem controle das taxas de infecção na comunidade (The Lancet, 2020; Ferigato et al., 2020). Em um contexto de ausência de uma estratégia de contenção efetiva, a infecção logo se espalhou por todo o país.

Esse fracasso na resposta à pandemia é frustrante porque poderia ter sido evitado. Afinal, o Brasil tem o Sistema Único de Saúde (SUS), com enorme capacidade instalada de unidades de saúde de atenção básica, de emergência e hospitalar. Conta com a ESF e unidades de APS com cobertura de cerca de dois terços da população e grande capilaridade territorial. Além disso, é dotado de um sistema de vigilância epidemiológica com profissionais experientes e qualificados; um sistema abrangente de informações de saúde que cobre mortes, hospitalização e doenças infecciosas; um sistema de informação 
estruturado sobre mortes e hospitalizações devido a síndromes respiratórias agudas e graves (Srag); um complexo médico-industrial preparado para a produção de testes diagnósticos, equipamentos médicos, medicamentos e vacinas, além de uma comunidade científica ativa e bem treinada. Países de diferentes matizes sociais, econômicos, culturais e de organização de serviços de saúde utilizaram estratégias de enfrentamento da pandemia de Covid- 19 mais racionais e efetivas, pelo menos até o momento (final de 2020). Dentre esses se destacam países com índice de desenvolvimento humano similar ou menor que o do Brasil, como Tailândia, Senegal, Quênia, Gana, Etiópia e Vietnã (Chang, Hong E Varley, 2020; FP, 2020; Lowy Institute, 2020).

\section{TENDÊNCIAS}

A epidemia de Covid-19 encontra a população brasileira em situação de extrema vulnerabilidade social, com altas taxas de desemprego e cortes profundos nos investimentos nas políticas sociais. O crônico subfinanciamento do SUS foi agravado nos últimos anos pela priorização de um modelo econômico restritivo e avesso ao investimento em políticas sociais. A aprovação da emenda constitucional n. 95, também conhecida como Emenda Constitucional do Teto dos Gastos Públicos, trouxe ainda mais incertezas e estrangulamentos no financiamento da saúde no país. O resultado tem sido a geração, com rapidez inédita, de uma legião de pessoas altamente vulneráveis, empobrecidas, vivendo majoritariamente na informalidade, em condições precárias de habitação e saneamento, sem acesso constante à água e em situação de aglomeração (Werneck \& Carvalho, 2020).

É nesse contexto de grande desigualdade social, econômica e demográfica e em um quadro sanitário complexo de polarização epidemiológica, no qual coexistem altas cargas de doenças infecciosas e crônico-degenerativas, acidentes e violências, que a população brasileira precisou, precisa, e ainda precisará, lidar com a pandemia. O mito da "doença infecciosa democrática", aventado no começo da epidemia no Brasil, quando casos inicialmente diagnosticados pertenciam às classes sociais mais abastadas, cuja infecção foi adquirida no exterior ou por meio de contatos sociais com viajantes, mostrou-se rapidamente uma falácia. Toda epidemia é, ao mesmo tempo, um fenômeno biológico, social e histórico, refletindo iniquidades na exposição à infecção, no risco de adoecer e no acesso ao cuidado em saúde. Hoje está evidente que a carga de morbidade e mortalidade da Covid- 19 tem recaído sobre os mais pobres, os negros, as populações indígena, quilombola e ribeirinha, enfim, os socialmente excluídos, reforçando as amplas desigualdades sociais em saúde já existentes no país (Oliveira, R. G. et al., 2020, Nassif-Pires, Carvalho \& Rawet, 2020). 
O resultado desse processo é que o Brasil se tornou um dos países mais afetados pela Covid- 19 do mundo, tendo mantido uma curva epidêmica prolongada em níveis muito elevados por vários meses, mostrando alguns sinais de diminuição apenas a partir do final de agosto e em algumas regiões do país. Essa tendência decrescente logo se mostrou não sustentada, e um recrudescimento de casos e óbitos começou a ser percebido ainda em novembro.

Assim, o país termina o ano de 2020 com a situação sanitária em franca deterioração, com mais de 7 milhões de casos, quase 200 mil óbitos e uma perspectiva nebulosa pela frente, na medida em que não há sinais de modificação substancial na abordagem para o enfrentamento da pandemia por parte das suas autoridades políticas e sanitárias. Além do mais, a disponibilidade de eventuais vacinas não se vislumbra como suficiente para atender, a curto prazo, o contingente populacional necessário para conter a propagação da infecção no território nacional, especialmente se consideradas as fragilidades e lacunas do plano de imunização apresentado em 2020 pelo Ministério da Saúde do Brasil.

Infelizmente, e contra os desejos e esperanças de (quase) todos, o ano da pandemia da Covid- 19 no Brasil não irá terminar em 31 de dezembro de 2020. O ano calendário mudará, mas as mazelas de 2020 não irão embora. As circunstâncias indicam que a Covid- 19 estará entre nós ainda por bastante tempo, causando apreensões, sofrimentos, dúvidas, medos, doença e morte.

\section{IMPACTOS NA SOCIEDADE}

O controle da transmissão na comunidade é uma etapa essencial, mas não suficiente, para o início da retomada da dinâmica social e econômica. Enganam-se os que pensam que tudo voltará rapidamente ao normal no dia em que houver controle dos níveis de transmissão. Para vislumbrar os desafios que se configuram no horizonte é preciso olhar para o processo pandêmico através de duas lentes.

A primeira lente focaliza a busca e implementação de ações efetivas que levem à interrupção da transmissão. Para que isso ocorra será necessária uma conjunção de diversas medidas sanitárias, dentre elas a vacinação e as intervenções não farmacológicas (distanciamento físico, uso de máscaras, etiqueta respiratória), com alta cobertura e adesão da população. É um desafio complexo, tendo em vista a leniência com que o enfrentamento da pandemia vem sendo tratado pelas autoridades governamentais e sanitárias do país, associada à irresponsabilidade e silenciamento de amplas parcelas da população. Mesmo assim, a interrupção da transmissão somente ocorreria a médio prazo e "se tudo der certo", isto é, se a imunidade contra Sars-CoV-2, adquirida natu- 
ralmente ou por meio de vacinação, for duradoura e efetiva; se as vacinas apresentarem alta efetividade e estiverem disponíveis para amplas parcelas da população; se as ações sanitárias forem abrangentes e se não houver variações genéticas significativas no Sars-CoV-2 que afetem sua transmissibilidade, patogenicidade, virulência e imunogenicidade. Este último aspecto tomou o centro das atenções no final de 2020, com a identificação de uma mutação significante no Sars-CoV-2 detectada no Reino Unido. A correlação com altas incidências de Covid- 19 acumuladas em curto período naquela região invoca a possibilidade de que tal variação genética represente algum tipo de vantagem evolutiva no sentido de promover maior transmissibilidade do vírus, algo que naquele momento ainda carecia de evidência científica mais robusta (Wise, 2020).

A segunda lente enfoca os impactos de longo prazo da pandemia em diferentes dimensões da vida. Os impactos econômicos, educacionais e sanitários podem ser ainda mais amplos e graves do que o efeito direto da pandemia na carga de adoecimento e morte por Covid-19. De forma bastante esquemática e simplificada, a resposta à pandemia da Covid-19 poderia ser subdivida em quatro fases: contenção, mitigação, supressão e recuperação (Werneck $E$ Carvalho, 2020). O enfrentamento dos referidos impactos é parte do que se poderia denominar de resposta à fase de recuperação da pandemia (ou fase 4). Em geral, as ações de resposta à fase 4 da pandemia começam assim que há sinais de controle da transmissão e redução significativa e sustentada de casos e óbitos. Porém, numa epidemia prolongada como a que vem sendo experimentada no Brasil, a resposta à fase 4 se mistura com as ações de contenção, mitigação e supressão. No Brasil, esses impactos ainda não foram plenamente equacionados, mas precisam ser urgentemente confrontados.

No campo econômico, o impacto da pandemia é brutal. Em 2020, a economia mundial enfrentou sua pior recessão desde a II Guerra Mundial. No Brasil, ao final de 2020, previa-se que o ano terminaria com uma diminuição de cerca de 5,4\% no produto interno bruto (PIB) (World Bank, 2020). Em uma situação econômica deteriorada, sob a égide de um programa econômico de austeridade fiscal, o país adentrou 2020 com lento crescimento do PIB, altos níveis de desemprego e crescente desigualdade social e econômica.

A crise social iminente foi atenuada pela implantação de um programa temporário de transferência de renda, o Auxílio Emergencial (AE) que consistiu no pagamento de até cinco parcelas mensais de $R \$ 600,00$ e mais quatro de $R \$ 300,00$, alcançando cerca de 67 milhões de beneficiados. A proposta inicial do governo federal era que o AE durasse três meses, com parcelas de $\mathrm{R} \$ 200,00$, mas o Congresso Nacional aprovou o valor de $\mathrm{R} \$ 600,00$. O AE foi fundamental para garantir as condições mínimas de sobrevivência da população mais vulnerável: aumentou a renda acima da queda dos salários induzida 
pela crise e a pobreza foi reduzida ao nível mais baixo já registrado, mas isso não impediu que a carga de morbimortalidade da Covid- 19 fosse fortemente influenciada pelas desigualdades estruturais do país (Nassif-Pires, Carvalho \& Rawet, 2020).

O contexto social e econômico frágil, com dificuldades financeiras para pequenas empresas, associado a amplo recrudescimento das taxas de incidência e mortalidade por Covid-19, aponta para enormes desafios. A redução do valor do $A E$ nos últimos meses de 2020 e a previsão de sua interrupção em 202 I, se concretizada, poderão aprofundar a crise social e sanitária e levá-la a patamares sem precedentes na história recente do país.

No campo da educação, a situação é também de grande apreensão. O fechamento disseminado e prolongado das escolas não tem precedente na vida recente do país. $\mathrm{Na}$ ausência de conhecimento sólido sobre o papel das crianças na transmissão do Sars-CoV-2, os fundamentos para a interrupção das atividades escolares se pautaram, principalmente, no princípio da precaução e na analogia com as pandemias de influenza, em que crianças são consideradas importantes amplificadoras da transmissão. Ocorre que a duração prolongada da epidemia tornou a manutenção das escolas fechadas uma medida de prevenção relativamente anacrônica, indesejável e com efeitos deletérios previsíveis e potencialmente duradouros.

O fechamento das escolas traz altos custos sociais e econômicos para as pessoas e comunidades, com impacto maior nas populações vulnerabilizadas (Unesco, 2020). Exacerba disparidades já existentes no sistema educacional, levando à interrupção do processo de aprendizagem e ao aumento nas taxas de evasão escolar. Além disso, tem impacto na nutrição infantil, pois muitas crianças dependem da alimentação escolar, e expõe a criança a comportamentos de risco, como uso de drogas, e à violência comunitária e sexual, na medida em que pais nem sempre podem permanecer em casa para cuidar da criança devido a suas atividades laborais. Alternativas de aprendizagem a distância, ainda que desejáveis nesse contexto, podem aprofundar as desigualdades sociais, na medida em que a viabilidade e operacionalização desse tipo de atividade varia enormemente de acordo com as condições socioeconômicas de estudantes e professores e, particularmente, entre o ensino público e o privado. No contexto de fechamento das escolas e ênfase crescente no papel do ensino remoto, surgem ainda novos desafios, como falta de infraestrutura e experiência de alunos, professores, gestores educacionais e familiares para a educação a distância e em casa; insuficiência de recursos técnicos e metodológicos para criação e manutenção do ensino a distância, assim como para sua adequação às necessidades de aprendizagem; e a necessidade de medir e validar o aprendizado. Todos esses aspectos geram impactos na saúde física e mental de pais, professores e alunos. 
As consequências do prolongado fechamento de escolas podem durar anos, com substanciais perdas econômicas de longo prazo. A interrupção do processo de aprendizagem durante a II Guerra Mundial na Áustria e Alemanha foi associada a um impacto negativo na vida econômica cerca de quarenta anos depois do fim da guerra. As gerações afetadas pela guerra apresentaram desvantagens no acesso ao mercado de trabalho e redução em cerca de $10 \%$ no salário (Ichino \& Winter-Ebmer, 2004).

O conhecimento crescente sobre a dinâmica de transmissão de Sars-CoV-2 consolidou a ideia de que crianças não desempenham um papel de amplificadores da transmissão tão importante como na influenza e de que são, também, menos susceptíveis a desenvolver formas graves de Covid-19 (Tsabouri et al., 202I). Entretanto, deve-se salientar que crianças podem transmitir a infecção e, ainda que raramente, desenvolver formas graves da doença, como a síndrome inflamatória multissistêmica da criança (Tsabouri et al., 2021. Além disso, há alguma evidência de que o fechamento de escolas poderia reduzir as taxas de transmissão comunitária (Auger et al., 2020).

Considerando todos esses aspectos, são compreensíveis, ao mesmo tempo, uma conduta mais conservadora, que recomenda a suspensão das atividades escolares, e uma proposição mais flexível de reabertura parcial da escola como espaço de vivência, aprendizagem e proteção à infância. A reabertura parcial das escolas poderia ter sido paulatinamente implementada à medida que as taxas de infecção fossem controladas na comunidade, desde que se garantissem as condições físicas, técnicas e operacionais das escolas para a implementação dos protocolos sanitários recomendados. Infelizmente, o papel da escola como equipamento para socialização, proteção, inclusão e desenvolvimento da cidadania não foi priorizado pelos gestores, que preferiram ignorar sua centralidade para a vida social, em favor de interesses econômicos.

No campo da saúde há diversos desafios imediatos. Primeiro, a pandemia levou à desassistência de vastas parcelas da população portadora de doenças crônicas, transmissíveis ou não, desde o nível primário ao terciário. Na atenção básica, muitos doentes não tiveram o acompanhamento sistemático de suas doenças crônicas, em particular diabetes e hipertensão arterial, o que pode ter levado à piora do quadro clínico. Ao mesmo tempo, doenças infecciosas de tratamento longo, como tuberculose e hanseníase, também podem ter sido afetadas, com possíveis repercussões nos níveis de transmissão comunitária. Segundo, as coberturas vacinais do Programa Nacional de Imunizações, que já vinham decrescendo ao longo dos últimos anos, chegaram a níveis críticos, avizinhando a possibilidade de novos surtos de sarampo, rubéola, coqueluche, entre outras. Terceiro, as experiências de distanciamento social e perdas de familiares e amigos têm repercussões graves na saúde mental das pessoas em geral, mas 
também de grupos específicos, como profissionais da saúde, o que exige a ampliação e aperfeiçoamento das políticas públicas de cuidado no campo da saúde mental, e não sua restrição, como parece ser o objetivo da gestão da saúde em nível federal. Por fim, há de se reconhecer que a Covid-19 é uma doença insidiosa e sistêmica, que não se esgota com a cura da infecção. Relatos de comprometimentos físicos e psicológicos de longa duração em pacientes que se curaram da infecção são crescentes, o que significa que essa população necessitará de aparato especializado multidisciplinar para atenção.

O processo de recuperação promete ser longo e exigirá grande esforço nacional. Não há muito o que esperar dos gestores que optaram por negar a crise sanitária e, ao mesmo tempo, são os maiores propagadores de notícias falsas, desacreditando medidas preventivas como uso de máscaras e vacinas. Cabe a nós, pessoas, instituições, entidades, associações e movimentos sociais, agir, agora.

\section{É PRECISO SE INDIGNAR E RESPONSABILIZAR}

Em uma passagem do livro No Castelo do Barba Azul, de 1971, George Steiner se refere ao Holocausto de uma forma bastante atual. Diz ele:

Não devemos considerar essa contingência como um fato natural da vida, uma banalidade. Devemos manter vivo em nós mesmos um senso de escândalo tão avassalador que afete todos os aspectos significativos de nossa posição na história e na sociedade. Temos, como Emily Dickinson teria dito, que manter a alma terrivelmente surpresa. (...) Não há nada de natural em nossa condição atual. Não existe qualquer dignidade em dizer que "tudo é possível" ou que "esse é o destino de todo mundo". Esse tipo de pensamento corrompe e reduz o limiar da nossa indignação. Aceitar esse horror seria a nossa maior derrota como humanos (livre adaptação).

Não há mais espaço para amenidades, é preciso se indignar com o que é indigno. São vidas que estão em jogo, são vidas dos velhos, dos pobres, dos negros, dos índios, dos doentes, dos excluídos, do povo brasileiro, o maior ativo que uma nação pode ter. Não é possível se acomodar com o absurdo da necropolítica, aceitar o inaceitável, é preciso exigir que os que hoje governam este país se engajem na defesa da vida das pessoas, do contrário deverão ser julgados e responsabilizados pelos milhares de mortes já contabilizadas e pelas que se avizinham nos próximos meses. 


\section{REFERÊNCIAS}

ANDERSON, R. M. et al. How will country-based mitigation measures influence the course of the Covid- 19 epidemic? The Lancet, 395( I 0.228): 931-934, 2020.

AUGER, K. A. et al. Association between statewide school closure and Covid- I 9 Incidence and mortality in the US. Jama, 324(9): 859-870, 2020.

CHANG, R.; HONG, J. \& VARLEY, K. The best and worst places to be in Covid: U.S. sinks in ranking. The Covid Resilience Ranking. New York: Bloomberg, 2020. Disponível em: <www.bloomberg.com/ graphics/covid-resilience-ranking/>. Acesso em: 23 dez. 2020.

CRODA, J. et al. Covid- 19 in Brazil: advantages of a socialized unified health system and preparation to contain cases. Revista da Sociedade Brasileira de Medicina Tropical, 53: e20200 I67, 2020.

FAUCI, A. S.; LANE, H. C. \& REDFIELD, R. R. Covid- I9: navigating the uncharted. The New England Journal of Medicine, 382(13): 1.268-1.269, 2020.

FERIGATO, S. et al. The Brazilian government's mistakes in responding to the Covid- 19 pandemic. The Lancet, 396(10.263): I.636, 2020.

FOREIGN POLICY (FP). Covid-19 Global Response Index, 2020. Disponível em: <https:// globalresponseindex.foreignpolicy.com/>. Acesso em: 23 dez. 2020.

ICHINO, A. \& WINTER-EBMER, T. The long-run educational cost of World War II. Journal of Labor Economics, 22(I): 57-86, 2004.

JONES, K. E. et al. Global trends in emerging infectious diseases. Nature, 45 I (7. I8I): 990-993, 2008.

LOWY INSTITUTE. Covid- I 9 response, 2020. Disponível em: < https://power.lowyinstitute.org/data/ diplomatic-influence/foreign-policy/covid-19/>.

MCMAHON, D. E. et al. Global resource shortages during Covid- 19: bad news for low-income countries. PLoS Neglected Tropical Diseases, I4(7): e00084 I 2, 2020.

NASSIF-PIRES, L.; CARVALHO, L. \& RAWET, E. Multidimensional Inequality and Covid-19 in Brazil. Blithewood: Levy Economics Institute of Bard College, 2020. (Public Policy Brief, n. 153)

NURSE, J. Pandemic emergency response to the coronavirus, Covid-19: global responsibilities and an emergency framework for countries and communities. Canada: The InterAction Council, 2020. Disponível em: <www.interactioncouncil.org/sites/default/files/Global\%20Responsibilities\%20 and\%20an\%20Emergency\%20Framework\%20for\%20web_0.pdf>. Acesso em: 23 dez. 2020.

OLIVEIRA, R. G. et al. Racial inequalities and death on the horizon: Covid- 19 and structural racism. Cadernos de Saúde Pública, 36(9): e00 I 50I20, 2020.

OLIVEIRA, W. K. et al. How Brazil can hold back Covid- 19. Epidemiologia e Serviços de Saúde, 29(2): e2020044, 2020.

ORELLANA, J. D. Y. et al. Explosion in mortality in the Amazonian epicenter of the Covid- 19 epidemic 19. Cadernos de Saúde Pública, 36(7): e00 I20020, 2020.

STEINER, G. No Castelo do Barba Azul: algumas notas para a redefinição da cultura. São Paulo: Companhia das Letras, I99I. 
THE LANCET. Covid- 19 in Brazil: “So what?”. The Lancet, 395(1 0.235): 1.46 I, 2020.

TSABOURI, S. et al. Risk factors for severity in children with coronavirus disease 20 I 9: a comprehensive literature review. Pediatrics Clinics of North America, 68(I): 321-338, 2021.

UNITED NATIONS EDUCATIONAL, SCIENTIFIC AND CULTURAL FOUNDATION (UNESCO). Adverse consequences of school closures. Disponível em: < https://en.unesco.org/covid I 9/educationresponse/ consequences >. Acesso em: 23 dez. 2020.

WERNECK, G. L. \& CARVALHO, M. S. The Covid- I 9 pandemic in Brazil: chronicle of a health crisis foretold. Cadernos de Saúde Pública, 36(5): e00068820, 2020.

WISE, J. Covid- 19: new coronavirus variant is identified in UK. BMJ, 37I: m4857, 2020.

WOLFE, N. The Viral Storm: the dawn of a new pandemic age. New York: Times Books, 201 I .

WORLD BANK. The Cost of Staying Healthy. Washington: Word Bank, 2020.

WORLD HEALTH ORGANIZATION (WHO). Summary of probable Sars cases with onset of illness from I November to 3 I July 2003, 2003. Disponível em: <www.who.int/csr/sars/country/ table2003_09_23/en>. Acesso em: 23 dez. 2020.

WORLD HEALTH ORGANIZATION (WHO). Middle East respiratory syndrome coronavirus (Mers-CoV) - Saudi Arabia, 2021. Disponível em: <www.who.int/csr/don/02-jul-2020-mers-saudi-arabia/en/>. Acesso em: 18 ago. 2021. 



\section{Balanço dos Cenários Epidemiológicos nos Seis Primeiros Meses da Pandemia no Brasil}

Fernanda Cristina da Silva Lopes Ferreira

$\mathrm{N}$ o momento em que a pandemia do novo coronavírus completa um ano desde sua declaração pela Organização Mundial da Saúde (WHO, 2020), o Brasil vive uma segunda onda de forma muito crítica e avassaladora para os serviços de saúde e para a população em geral. Ainda aos seis meses desde a identificação dos primeiros casos no país, vivenciando a primeira onda da pandemia, a Fundação Oswaldo Cruz (Fiocruz) propôs um seminário para fazer um balanço do período. Já nesse momento nos assustávamos com o alto número de registros de mortos, que contabilizavam cerca de 600 vidas perdidas por milhão de habitantes. Apesar de imersos no horror por testemunharmos o caos e o aprofundamento da desigualdade social no país, do luto mal resolvido por tantas pessoas mortas e do desgaste dos profissionais da saúde, a esperança de dias melhores não nos abandonou. A ideia mais perseguida por todas as pessoas em uma corrente de positividade e um desejo forte e obstinado era a de que "tudo isso vai passar", bastaria um pouco mais de paciência, estratégias de prevenção e responsabilidade. Certamente essa tríade poderia ter livrado o Brasil de uma tragédia possivelmente ainda pior, insistentemente anunciada pela ciência em alertas frequentes. Porém, a falta de ações coordenadas de forma unificada pela liderança central do país, somada ao cansaço da população em relação ao isolamento social, fez com que a tríade fosse fortemente comprometida. Consequentemente, nos três primeiros meses do ano de 2021 o país registrou recordes de mortes, chegando a 1.900 óbitos por Covid- 19 em um único dia (Rede Covida, 2020). Nessa conta não se somam os óbitos que ocorreram de causa indireta em virtude, principalmente, da falta de assistência decorrente da alta demanda dos serviços de saúde que se dedicam, quase que exclusivamente, à assistência aos pacientes, vítimas de tão complexa enfermidade. 
Neste capítulo apresento uma sistematização breve dos temas apresentados no seminário Cenários Epidemiológicos da Covid-19 no Brasil: tendências e impactos na sociedade, cujos propósitos eram avaliar as medidas implementadas até setembro de 2020 para o controle e prevenção da doença e discutir questões relacionadas ao momento pós-pandêmico. Diante de um cenário ainda obscuro quanto ao futuro da pandemia e às consequências que ela traria para as áreas econômica, social e de saúde, uma pausa para avaliar o que até então havia sido feito. Ao mesmo tempo, apresentar as considerações, críticas e análises sobre o momento realizadas por especialistas e pesquisadores participantes ativos da saúde pública e, o mais importante, discutir as expectativas do que ainda estaria por vir, mesmo diante de tantas incertezas.

\section{A PANDEMIA COMO FENÔMENO BIOMÉDICO, SOCIAL E AMBIENTAL}

Muito além do impacto provocado na saúde das pessoas, o novo coronavírus mostrou-se fortemente eficaz para causar uma crise mundial que comprometeu várias áreas. No Brasil, a pandemia, um fenômeno biomédico, social e ambiental, despertou a necessidade da visão integrada entre ciência e saúde apoiada especialmente em dois pilares: a junção de ciência, tecnologia e inovação e o Sistema Único de Saúde (SUS), "maior sistema universal do mundo", considerado como a grande inovação e a base para enfrentar essa crise que se classifica como sanitária e humanitária (Trindade, 2020). Nesse contexto há uma expectativa de que o legado dessa experiência seja o reforço do SUS no tocante tanto ao seu financiamento quanto à integração das ações de vigilância, ciência, tecnologia e atenção à saúde.

\section{SISTEMAS DE INFORMAÇÃO E VIGILÂNCIA}

No Brasil, vinculado ao Sistema Único de Saúde está o Sistema de Vigilância Epidemiológica, que inclui os sistemas de informação em saúde (SIS). Especificamente para a vigilância da influenza e de outros vírus respiratórios, foi implantada a chamada vigilância da síndrome gripal desde a ocorrência da pandemia de HINI em 2009. Essa vigilância ocorria somente nas unidades-sentinela', ao passo que as unidades de saúde não classificadas como sentinelas notificavam apenas a síndrome respiratória aguda grave (Srag). Dentro dos SIS está o Sistema de Informações de Agravos de Notificação (Sinan), que recebe as notificações de todas as unidades de saúde referentes às doenças de notificação compulsória (DNCs). A Srag integra a lista de doenças que

\footnotetext{
' Unidades de saúde previamente definidas de acordo com critérios que conferem maior sensibilidade no reconhecimento de sintomas gripais, permitindo caracterizar o perfil da doença e da circulação viral no país, além de observar qualquer aumento de casos.
} 
devem ser comunicadas à autoridade sanitária na suspeição ou confirmação de um caso. O pesquisador do Programa de Computação Científica da Fiocruz Daniel Villela destacou que essa vigilância das doenças respiratórias funcionou como uma sentinela a partir da observação no aumento de casos graves e com a confirmação de que cerca de $95 \%$ dos casos se deviam ao Sars-CoV-2. O que atesta o importante papel exercido pelo SUS, incluindo o Sistema Nacional de Vigilância Epidemiológica, quando se trata de, de forma oportuna, possibilitar a análise e propor ações efetivas (Villela, 2020).

$\mathrm{Na}$ vigilância das doenças respiratórias, as informações cadastradas nos SIS geram dados imprescindíveis à realização de análises e modelagens. O Sivep Gripe e o Painel Coronavírus são duas importantes bases de dados, cada um com suas vantagens, desvantagens e complexidades. Ainda assim, o pesquisador do Imperial College London Thomas Mellan considera o Sivep Gripe um exemplo de sistema de informações das doenças respiratórias em saúde, por agregar os dados de todo o país, que tem população de mais 200 milhões de habitantes. Comparando os dados disponíveis em ambas as bases, ele observa que em um primeiro momento a análise dos dados do Sivep Gripe levou à falsa conclusão de que a situação estaria melhorando, o que não era verdade. O Painel Coronavírus, por sua vez, apresentou maior defasagem em relação ao registro de óbitos quando comparado com os dados do Sivep Gripe. Para que as análises pudessem, então, ser realizadas, foi aplicado o mesmo modelo proposto para a Covid-19 na Europa, com o propósito de avaliar o impacto das medidas tomadas para controlar a disseminação da doença. A base da modelagem está na contagem dos casos no tempo passado associando processos específicos, relacionados e traduzidos matematicamente, que ajudam a predizer como se darão no futuro (Mellan, 2020). No modelo proposto adota-se uma abordagem hierárquica bayesiana semimecanística, mediante a descrição da forma como a doença se dissemina, mas sem se preocupar com as interações microscópicas, conforme a Figura I. 
Figura I - Resumo esquemático dos componentes do modelo - Imperial College London, 2020

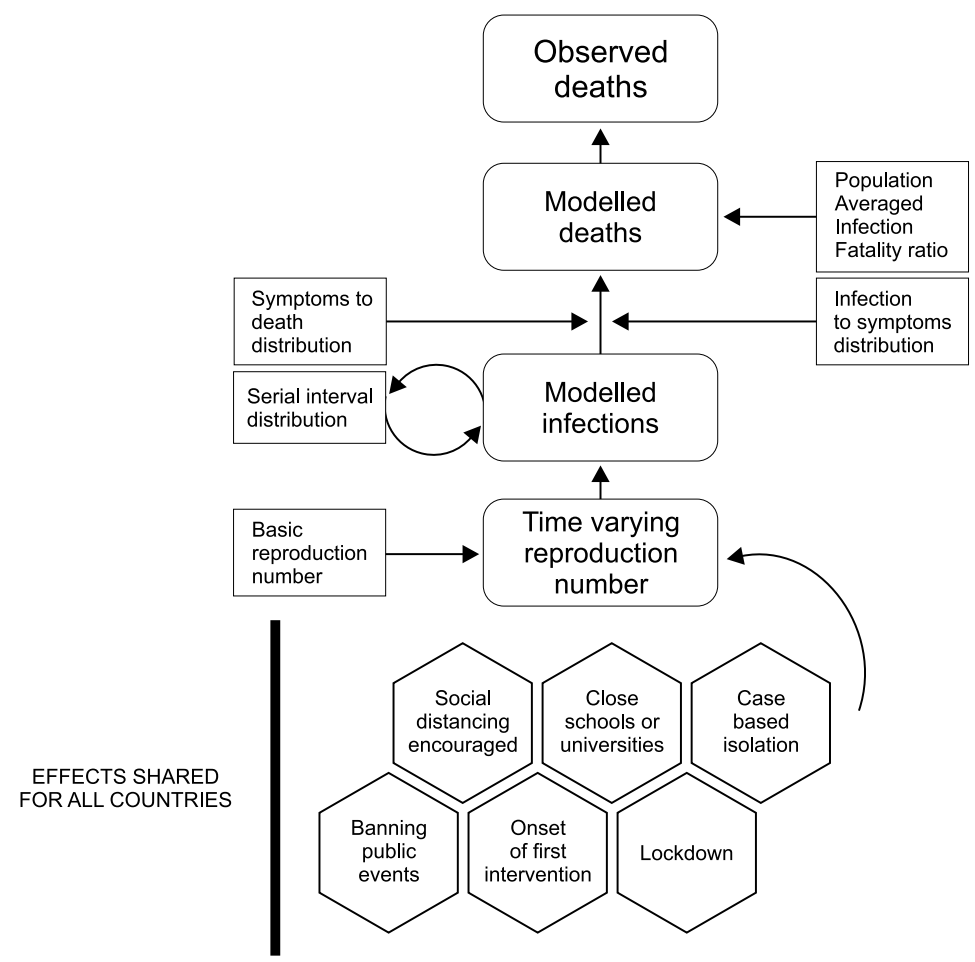

Fonte: Flaxman, 2020.

Quando se aplicou o modelo para os dados brasileiros, observou-se que as projeções foram melhores quando a modelagem foi realizada no nível dos estados, reforçando a importância das análises locais com vigilância, rastreio dos casos e ampliação da testagem com RT-PCR (reação em cadeia de polimerase da transcriptase reversa). Nessa análise o pesquisador observou que havia uma ideia não totalmente esclarecida sobre um possível recrudescimento da doença, mesmo após as intervenções implementadas, citando o exemplo da cidade de São Paulo e mencionando uma possível divergência entre lideranças governamentais (Mellan, 2020).

Num panorama geral da pandemia o pesquisador criticou a situação vivenciada no Reino Unido e no Brasil, países que chegaram a apresentar 600 óbitos por milhão de habitantes (Mellan et al., 2020). Na Europa e no Reino Unido, ao atingir o platô a curva de óbitos poderia sugerir que se havia obtido imunidade de rebanho, porém, com a flexibilização das medidas de controle observou-se um recrudescimento da 
doença. Acredita-se que o mesmo possa acontecer no Brasil, onde a primeira onda ainda não terminou, caso não se sustentem os esforços necessários para manter o Reff ${ }^{2}$ (número de reprodução efetivo) abaixo de I. Essa ideia foi reforçada pelo pesquisador Guilherme Werneck, para quem as medidas de flexibilização das atividades com o aumento da mobilidade poderiam levar a uma propagação e prorrogação da epidemia (Werneck, 2020).

\section{ANÁLISE POR REGIÕES}

Na mesma perspectiva de análises locais, o pesquisador Daniel Villela apresentou, com base nos dados do InfoGripe, uma comparação entre as grandes regiões do Brasil observando que no Sul e Centro-Oeste, com a implantação das medidas não farmacológicas de distanciamento social e restrição de viagens, entre outras, foi possível observar mudança na curva que crescia com aumento do número de casos e se estabilizou por volta da Semana Epidemiológica 12, mas com volta do aumento de casos a posteriori. Nas regiões Norte e Nordeste não se observou essa pausa no crescimento de casos. O pesquisador chamou a atenção para a região Norte, onde houve número importante de óbitos e onde se esperaria redução mais expressiva no número de casos. Mostrou que no Sudeste a curva apresenta aspecto diferente, formando um extenso platô no momento em que as medidas foram implantadas, e afirmou acreditar que isso talvez se deva à grande densidade demográfica dos estados que compõem essa região onde as medidas têm impacto muito significativo: enquanto em alguns lugares aumenta o número de casos em outros há redução de novos casos, dando impressão de estabilidade (Villela, 2020).

\section{ANÁLISE POR ESTADO E MUNICÍPIO}

Observa-se uma situação diferenciada no estado do Rio Janeiro, onde houve crescimento de casos, chegando ao pico entre a SE 17 e a 18 , com redução de casos a partir daí, mas a partir da SE 24 percebe-se certa estabilidade da curva, porém em um nível alto. Situação que gera preocupação em virtude do risco de sobrecarga dos serviços de saúde, que, estando no limite de sua capacidade, podem sofrer impacto negativo caso haja qualquer novo aumento de casos. Por isso é importante avaliar, para além da vigilância dos casos e dos óbitos, a pressão exercida pela epidemia sobre o sistema de saúde, considerando os casos graves que requerem internação (por exemplo, casos de síndrome respiratória aguda grave, Srag) (Villela, 2020).

\footnotetext{
2 Número de reprodução efetivo é o número médio de casos secundários originados a partir de um indivíduo infeccioso em uma população não susceptível (Wallinga \& Teunis, 2004).
} 
Figura 2 - Casos notificados de SRAG - Rio de Janeiro, $2020^{3}$

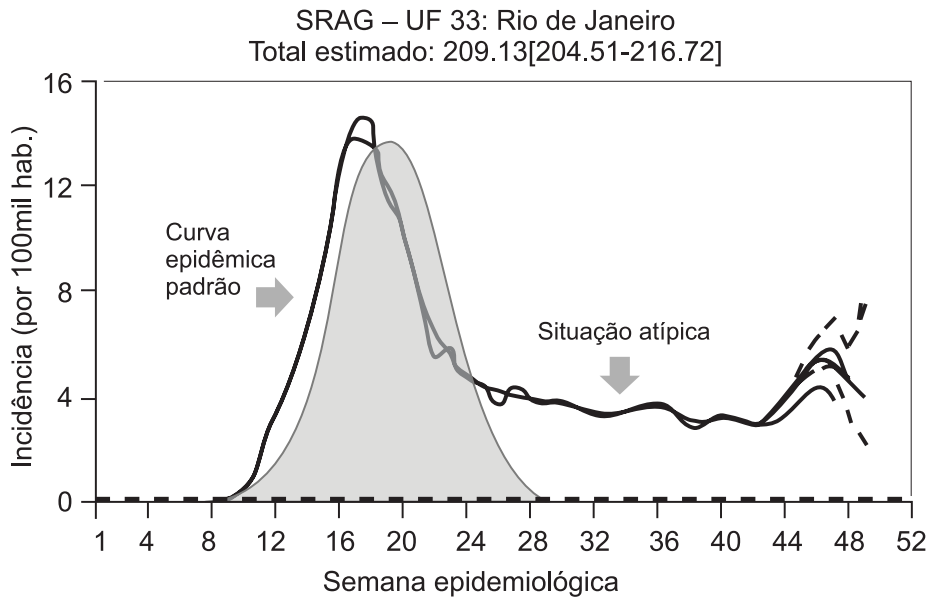

Fonte: adaptado de <https://gitlab.procc.fiocruz.br/mave/repo/-/blob/master/Boletins\%20do\%20InfoGripe/ Imagens/Territorio_33_SRAG_serietemporal.png >. Acesso em: 30 ago. 2021.

Além disso, como resultado da diferença na flexibilização das atividades a epidemia não ocorreu de forma sincronizada entre os municípios do estado, a que se soma a percepção de certa sazonalidade da doença entre estes. Sabe-se, por exemplo, que no estado do Rio de Janeiro a doença teve como entrada a sua capital, a cidade do Rio de Janeiro, confirmada pela série histórica que apresenta os primeiros casos a partir da SE 12, e ocorre de forma distinta entre os municípios do estado. Outro fato que merece atenção para uma análise cuidadosa da epidemia é a censura dos dados devida ao atraso de entrada no sistema, o que pode levar, de forma equivocada, a uma ideia de melhora da situação. A Figura 2 também apresenta um modelo de curva que representa a ocorrência de epidemias de doenças infecciosas. Nesse tipo de curva, os casos surgem, crescem normalmente de forma exponencial e após atingirem o pico iniciase o decaimento de novas ocorrências até níveis bem baixos, como mostrado na área sombreada de cinza da figura. Porém, o que tem sido observado é uma redução de novos casos até a formação de um platô em níveis altos que coincide com a reabertura das atividades, antes mais restritas, promovendo a disseminação do vírus e o surgimento de novos casos (Daniel Villela).

${ }^{3}$ O gráfico foi adaptado para demonstrar conforme marcações em cinza o que seria uma curva epidêmica padrão ou esperada de doenças infecciosas. Originalmente foi produzido pelo Grupo de Métodos Analíticos em Vigilância Epidemiológica (Mave) do Programa de Computação Científica da Fiocruz. 
Na cidade de Belo Horizonte, capital de Minas Gerais, os dados refletem uma boa condução do enfrentamento da pandemia durante a primeira onda. O número de casos e óbitos por Covid-19 na capital do estado se manteve abaixo da média nacional e promoveu uma situação menos desfavorável para o todo o estado, tendo sido destaque positivo na região Sudeste (Figura 3).

Figura 3 - Óbitos por Covid- 19 por milhão de habitantes - Estados da região Sudeste, 2020

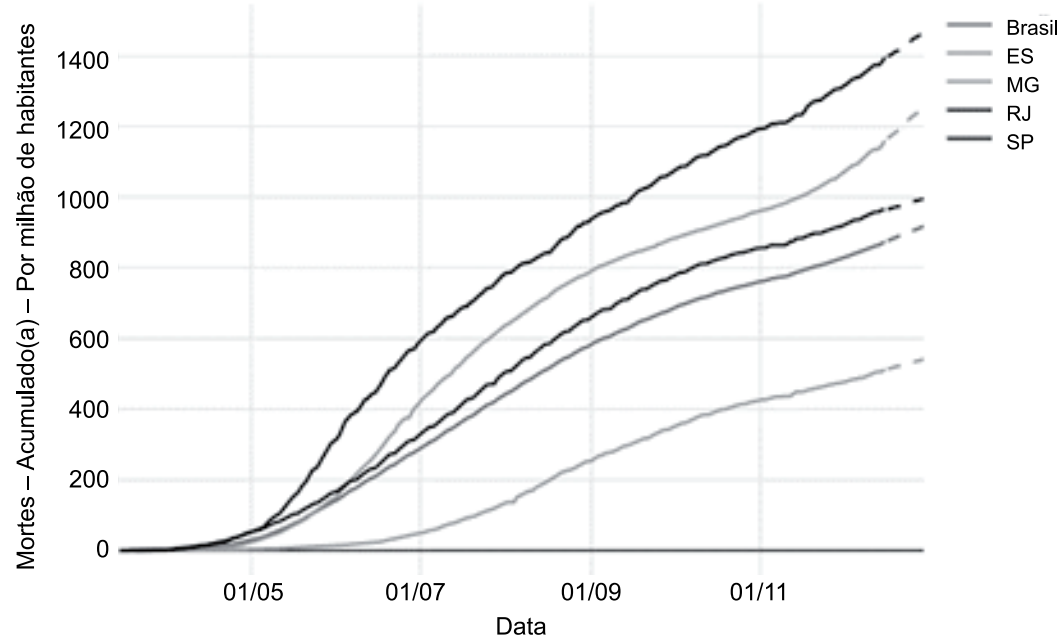

Fonte: Covid 9 Analytics, 2020.

O pesquisador Guilherme Werneck fez uma crítica aos modelos matemáticos devido às incertezas que apresentam; segundo ele, tais modelos devem ser vistos apenas como "potenciais" cenários futuros e seus resultados podem ser ainda mais comprometidos quando há baixa qualidade dos dados. O professor e pesquisador Mauricio Barreto chamou a atenção para a importância dos dados e das informações, que, quanto mais organizados, mais favorecem a elaboração e implantação de medidas cruciais como traçar modelos, analisar cenários e propor soluções mais efetivas. E como contraponto, compreende que houve avanço na área da modelagem matemática e que os modelos se modernizaram e se aperfeiçoaram, melhorando a capacidade preditiva com maior grau de certeza, quando comparados com os modelos usados no século XIX. Apesar de discordarem em alguns pontos, Werneck e Barreto afirmam que graças ao importante trabalho realizado pelas diversas instituições brasileiras foi possível garantir uma análise mais qualificada dos dados, permitindo, inclusive, concluir que algumas intervenções 
propostas têm real efeito na dinâmica da epidemia (Barreto, 2020). E que apesar do decrescimento no número de casos no Brasil, a epidemia segue, após ter alcançado seu pico, em níveis considerados ainda muito altos (Werneck, 2020).

\section{VARIABILIDADE E VULNERABILIDADE - COMPLEXIDADE}

A epidemiologia da doença na primeira onda evidenciou que homens tendem a se infectar mais e que há um gradiente forte em relação à idade - pessoas acima de 70 anos tiveram maior probabilidade de apresentar casos graves. Quanto à letalidade, observouse taxa de $1 \%$, parecida com a da gripe espanhola, considerada alta e muito pior do que a de outras gripes (Mellan, 2020). Para aprofundar a compreensão do perfil da doença e da dinâmica da disseminação do vírus no Brasil, inquéritos sorológicos foram implementados. Um deles foi realizado pela Universidade Federal de Pelotas (Ufpel) e apresentou resultados que evidenciam a alta variabilidade entre as regiões e também entre as raças branca e indígena (Villela, 2020). Werneck (2020) observou que a alta variabilidade da soroprevalência no país poderia decorrer das diferenças entre as condições de vida e da desigual distribuição dos serviços de saúde, provocando evolução da epidemia diferente em cada estado.

Além das marcadas diferenças existentes no Brasil, o fato de o governo central não assumir a coordenação da epidemia contribuiu para sua ocorrência de forma muito diversa entre os estados, se diferenciando em várias epidemias (Barreto, 2020). E apesar da estabilidade em alguns locais, evidenciada pelos dados apresentados pelos estudos de soroprevalência, a epidemia ainda não se encontrava sob controle. Ao mesmo tempo, Werneck (2020) considerou que, embora importantes, em tais estudos há dificuldade em captar o real panorama; portanto, o ideal seria o monitoramento contínuo, por exemplo, por meio da vigilância sindrômica.

Ainda sobre a variabilidade observada, o estudo da Ufpel mostrou que a raça indígena apresentava soroprevalências mais altas quando comparadas com as de pessoas da raça branca. Tais resultados confirmavam maior vulnerabilidade dessas pessoas à infecção e ao adoecimento, o que exigiria um plano de controle e prevenção específico para a raça indígena, situação que foi inclusive reportada ao Superior Tribunal Federal (STF). De forma breve, o pesquisador também mencionou o estudo sorológico realizado pelo Maranhão que apontou soroprevalência de $40 \%$ no estado, considerada muito alta em comparação com os resultados dos estudos da Ufpel (Villela, 2020). 


\section{PAPEL DA COMUNIDADE CIENTÍFICA}

A Covid- 19 pode ser considerada a grande pandemia do século XXI, e as epidemias de Sars, Mers e HIN I podem ser consideradas apenas ensaios para esta pandemia (Barreto, 2020). Sabia-se, portanto, que a ocorrência de uma pandemia era uma questão de tempo e que o mundo já deveria ter se preparado para este momento. O Brasil, por exemplo, já tinha ideia de como responder à pandemia, maior desafio de todos os tempos (Werneck, 2020). Não há dúvida do protagonismo da ciência mesmo diante de um cenário de caos do contexto que apresenta mais dúvidas do que certezas. Mas é perceptível que o país fracassou em vários aspectos. As falhas ocorreram em todas as fases de resposta à pandemia - contenção, mitigação, supressão e recuperação -, fundamentais no processo de controle de disseminação da doença e redução de impactos (Werneck, 2020).

Ainda assim, é preciso considerar que a pandemia ocorre em momento em que a ciência evoluiu consideravelmente. A comunidade de cientistas, pesquisadores, sanitaristas somou esforços para tentar interpretar a realidade, o que pode se tornar um aprendizado para as próximas pandemias (Barreto, 2020). Muita informação foi produzida mediante a análise dos dados e da realidade local: as contribuições do Observatório Covid-19, entre as quais os painéis cujo foco é a análise e acompanhamento dos dados pelo InfoGripe, pelo MonitoraCovid- 19 e pelo Painel Coronavírus - Fiocruz Bahia; a participação na definição do conjunto de critérios para a tomada de decisão quanto à reabertura das atividades, a saber, o número básico de reprodução, a taxa de ocupação de leitos hospitalares e a capacidade de testagem; a produção e divulgação de boletins epidemiológicos quinzenais com dados de Srag; e a elaboração e divulgação de tantos outros documentos sobre aspectos importantes e impactos da pandemia de Covid- 19 no país (Villela, 2020).

Apesar de todo o esforço feito pela comunidade científica, é necessário reconhecer que a academia também apresentou falhas, especialmente na comunicação tanto com o público quanto entre os próprios pesquisadores, perdendo a oportunidade de discutir temas importantes, como o uso de medicações, imunidade de grupo, incerteza das previsões, quantitativo da testagem, o papel da vigilância e da atenção básica. A elaboração e implantação de um plano para ações de contenção da doença poderia ter sido desencadeada pela comunidade científica, mas, por espera de definições governamentais, não ocorreu oportunamente. Werneck (2020), acredita que parte das dificuldades esteja relacionada a certa escassez de epidemiologistas de doenças infecciosas e pela própria perda de expertise em epidemiologia das doenças transmissíveis ocorrida ao longo do tempo, em especial pelo redirecionamento da atenção para as doenças crônicas (Werneck, 2020). O que, de qualquer forma, não comprometeu a participação 
e o engajamento da academia, que mostrou sua força e importância no envolvimento, na contribuição nas discussões e na articulação entre diferentes instituições e grupos de pesquisas, dando suporte às ações de gestão para o enfrentamento da pandemia e enfatizando assunto dos mais relevantes, a grande desigualdade existente no Brasil e agravada a partir de então (Werneck, 2020).

Diante do negacionismo e da inércia apresentados pelo governo central, a comunidade científica despontou ganhando visibilidade e (re)conquistando o respeito, a credibilidade e a admiração da população. A participação da comunidade da saúde pública e epidemiologia tornou públicos conceitos fundamentais para a vigilância, como quarentena, número básico de reprodução, ampliando a discussão entre a sociedade. Nesse contexto, sobressaíram o valor da ciência e dos sistemas universais de saúde para o enfrentamento de emergências sanitárias, que a exemplo do SUS, apesar das dificuldades como o seu "desfinanciamento", foi responsável pelos resultados menos negativos (Werneck, 2020; Trindade, 2020). E além da base científica, que inclui os testes diagnósticos e as vacinas, mostram-se imprescindíveis a articulação com amplos programas de políticas públicas, a integração e cooperação com outras instituições para organização, a transparência e a análise de dados, instrumentos de saúde pública fundamentais para o enfrentamento de crises como esta (Trindade, 2020).

\section{PARA ALÉM DAS ONDAS, O GRANDE IMPACTO SOBRE A SOCIEDADE}

A maior importância dada à política econômica do país expôs de forma muito contundente a desintegração política que vivíamos (e ainda vivemos), agravando a polarização existente na sociedade. Os gestores não se integraram, houve negação da ocorrência da pandemia, as medidas de contenção e mitigação foram insuficientes, houve baixa cobertura de testagem, falta de insumos básicos necessários, insuficiente oferta de assistência hospitalar e falha na vigilância sindrômica. Além disso, houve dificuldades para adesão às ações de distanciamento social, acentuadas, por exemplo, pela própria condição financeira e a prévia situação econômica e social vivenciada pela população (Werneck, 2020). Essas atitudes impactaram negativamente na solução tanto de um problema (pandemia) quanto do outro (economia). E o que nos resta é avaliar os impactos da pandemia, efeitos colaterais pós-infecção, e apontar soluções para os problemas a partir deste ponto. Reparando as cicatrizes da crise sanitária e ainda cicatrizando as feridas abertas ou agravadas pela pandemia, como a precariedade econômica e exacerbação da desigualdade já existente; a questão da educação, em virtude do fechamento das escolas; a questão da saúde mental, pelos diversos estressores que podem afetar a saúde da população; e a cronicidade da doença com repercussões físicas 
e mentais a longo prazo para as pessoas e para os serviços de saúde (Werneck, 2020). Para isso é necessário trabalharmos juntos, juntando informações de diversas fontes, incluindo os achados atuais de pesquisas que também abordem os aspectos sociais e econômicos. E pensar nos iminentes riscos consequentes da pandemia, como a fome, por exemplo (Barreto, 2020).

\section{AVANÇAMOS, MAS NEM TANTO}

No momento da realização do seminário aqui reportado, alguns avanços já eram perceptíveis. As medidas de isolamento social mostraram-se efetivas para a redução da contaminação. A codificação do vírus Sars-CoV-2 foi um passo fundamental para futuras conclusões e comparações. O tratamento e o manejo das pessoas com Covid tornaramse mais resolutivos com a inclusão da dexametasona, e as discussões a respeito de vacinas haviam sido iniciadas. As expectativas pelos imunobiológicos eram do tamanho do longo e caro caminho normalmente necessário para o seu desenvolvimento. E em dezembro de 2020, graças à corrida de grandes indústrias farmacêuticas, publicações sobre os resultados de eficácia e segurança surgiram sequencialmente, enchendo o mundo de esperança. A partir daí outras corridas seriam iniciadas: de um lado a produção em larga escala e a distribuição das vacinas, de outro a disputa pela aquisição de produto tão necessário para amenizar a crise mundial e promover a volta à situação de normalidade desejada. O Brasil não pareceu fazer questão de participar dessa corrida, nem de um lado nem do outro. A principal iniciativa liderada pelo governo estadual de São Paulo por intermédio do Instituto Butantã foi diversas vezes contragolpeada pelo governo federal. Por parte da Fiocruz, apesar do apoio do governo federal, um importante projeto de transferência de tecnologia para produção no país não seria suficiente para atender à necessidade de uma população como a do Brasil.

\section{E A CIÊNCIA SEGUE RETA, MESMO EM CAMINHOS TORTUOSOS}

No Brasil, mesmo com tantas forças contrárias e negativas, a comunidade científica se posicionou de forma muito oportuna. Enquanto os profissionais da saúde atuavam com as ferramentas que já conheciam e inovavam naquilo que já não era mais suficiente para a adequada assistência, a academia mostrou sua capacidade de trazer à luz percepções fundamentais para o objetivo comum de ambos os grupos: salvar vidas. Por algum momento ambos caminharam juntos sob a liderança e apoio institucional fundamental para o manejo adequado da situação. Formavam o que poderia se tornar a chave mestra para o enfrentamento de todo o desastre que estaria por vir. Mas, diante de visões tão opostas e negações tão contundentes entre as lideranças políticas institucionais, a 
condução central do enfrentamento da pandemia se desfez rapidamente, exigindo que a gestão local em cada estado e município assumisse papel individualizado à frente de um problema que era marcadamente global, sem, contudo, fornecer o devido apoio necessário para que as consequências ruins pudessem ser minimizadas.

Conclui-se, portanto, que não foi a ciência que venceu a epidemia, que as medidas foram mais bem-sucedidas nos locais onde houve afinidade entre a capacidade de interpretar a realidade e unificar o conhecimento científico e a capacidade política de conduzir todo o processo (Mauricio L. Barreto). Em breve saberemos se essa afirmativa poderá ser extrapolada para a segunda onda, pela qual passamos atualmente. No momento em que finalizo este texto contabilizamos mais de 1 I milhões de casos e 271.067 óbitos, chegando à marca 1.200 óbitos por milhão de habitantes por uma única causa (Rede Covida, 2020).


Seminário on-line, 9 de setembro de 2021

\section{COORDENADOR}

Christovam Barcellos, pesquisador do Laboratório de Informação em Saúde do Instituto de Comunicação e Informação Científica e Tecnológica em Saúde (Lis/lcict)

\section{PaLESTRANTES}

Nísia Trindade Lima, presidente da Fundação Oswaldo Cruz

Thomas Mellan, pesquisador da Faculdade de Medicina Escola de Saúde Pública do Imperial College London

Daniel Antunes Maciel Villela, pesquisador e professor do Programa de Computação Científica da Fiocruz

Guilherme Loureiro Werneck, professor do Instituto de Medicina Social da Universidade Estadual do Rio de Janeiro e Instituto de Estudos de Saúde Coletiva da Universidade Federal do Rio Janeiro

Mauricio Lima Barreto, professor no Programa de Pós-Graduação em Saúde Coletiva do Instituto de Saúde Coletiva da Universidade Federal da Bahia e pesquisador do Centro de Integração de Dados e Conhecimentos para a Saúde (Cidacs/Fiocruz) 


\section{REFERÊNCIAS}

BARRETO, M. L. Debate final seminário. In: Cenários Epidemiológicos da Covid- 9 no Brasil: tendências e impactos na sociedade, 9 set. 2020. Disponível em: <https://youtu.be/9eAhJi-XnBk>. Acesso em: I maio 202I.

BOLETIM DO INFOGRIPE. 2020. Disponível em: < https://gitlab.procc.fiocruz.br/mave/repo/-/blob/ master/Boletins\%20do\%20InfoGripe/Imagens/Territorio_33_SRAG_serietemporal.png>. Acesso em: 15 dez. 2020.

COVIDI 9 ANALYTICS. Painel interativo. Disponível em: < https://covid I 9analytics.com.br/painel-deresultados/>. Acesso em: 17 dez. 2020.

FLAXMAN, S. et al. Estimating the number of infections and the impact of non-pharmaceutical interventions on Covid-19 in European countries: technical description update. arXiv.org, 2020. Disponível em: <https://spiral.imperial.ac.uk:8443/bitstream/I0044/1/77731/10/2020-03-30COVIDI9-Report-13.pdf>. Acesso em: 4 dez. 2020.

MELLAN, T. M. Palestra Covid-infections and reproduction number in Brazil, March to September 2020. In: Cenários Epidemiológicos da Covid- 9 no Brasil: tendências e impactos na sociedade, 9 set. 2020. Disponível em: <https://youtu.be/9eAhJi-XnBk>. Acesso em: I maio 2021.

MELLAN, T. A. et al. Report 21: estimating Covid-19 cases and reproduction number in Brazil. medRxiu, 2020.

REDE COVIDA. Centro de Integração de Dados e Conhecimentos para Saúde. Testes diagnósticos da Covid-19: bases das indicações e seus usos, 2020. Disponível em: <https://painel.redecovida.org/ brasil>. Acesso em: 10 mar. 2021.

TRINDADE, N. Palestra de abertura. In: Cenários Epidemiológicos da Covid- 19 no Brasil: tendências e impactos na sociedade, 9 set. 2020. Disponível em: <https://youtu.be/9eAhJi-XnBk>. Acesso em: I maio 2021 .

VILLELA, D. A. M. Epidemiological scenarios, information for action, decision making indicators and what is next. In: Cenários Epidemiológicos da Covid- 19 no Brasil: tendências e impactos na sociedade, 9 set. 2020. Disponível em: <https://youtu.be/9eAhJi-XnBk>. Acesso em: I maio 2021.

WALLINGA, J. \& TEUNIS, P. Different epidemic curves for severe acute respiratory syndrome reveal similar impacts of control measures. American Journal of Epidemiology, 160(6): 509-516, 2004.

WERNECK, G. L. Epidemiological scenarios de Covid- 19 in Brazil: trends and impacts on society. In: Cenários Epidemiológicos da Covid- 19 no Brasil: tendências e impactos na sociedade, 9 set. 2020. Disponível em: <https://youtu.be/9eAhJi-XnBk>. Acesso em: I maio 202 I.

WORLD HEALTH ORGANIZATION (WHO). WHO Director-General's opening remarks at the media briefing on Covid-19, Mar. 2020. Disponível em: <www.who.int/director-general/speeches/detail/ who-director-general-s-opening-remarks-at-the-media-briefing-on-covid- I9--- I I-march-2020>. Acesso em: 13 mar. 2021. 



\title{
Balanço dos Cenários Epidemiológicos da Pandemia de Covid-19 em 2020
}

\author{
Carlos Machado de Freitas, Christovam Barcellos, \\ Daniel Antunes Maciel Villela, Gustavo Corrêa Matta, \\ Lenice Gnocchi da Costa Reis, Margareth Crisóstomo Portela, \\ Raphael de Freitas Saldanha e Isadora Vida de Mefano e Silva
}

No início de janeiro de 202 I, o Observatório Covid- 9 publicou um boletim com um balanço da pandemia, desde a Semana Epidemiológica (SE) em que foi registrado o primeiro caso no Brasil (SE 9, de 23 a 29/02/2020), até a última SE do ano de 2020 (SE 53 , de 27/I2/2020 a 2/0I/202 I). Nesse boletim, seguindo a abordagem que já havia sido adotada naquele que traz o balanço dos seis primeiros meses da pandemia (Freitas et al., 2020), procuramos contextualizar seu curso no Brasil, país continental, heterogêneo e também um dos que têm maiores desigualdades sociais. Esse contexto coloca alguns grupos sociais em grande desvantagem quando se trata de cumprir as medidas de higienização, distanciamento físico e social, isolamento e quarentena, bem como no acesso aos serviços de saúde, incluindo exames diagnósticos, tratamento e reabilitação.

Com os indicadores utilizados em todas as edições do Boletim do Observatório, o objetivo é oferecer um panorama geral do cenário epidemiológico para monitoramento da situação nas regiões, estados e municípios. Esses indicadores são os relacionados a incidência e mortalidade por Covid-19, incidência de síndrome respiratória aguda grave (Srag) e disponibilidade de leitos, com base em propostas internacionais de monitoramento, consignadas nas diretrizes da Organização Mundial da Saúde, OMS (WHO, 2020) e no painel covidexitstrategy.org, que hoje se encontra associado à Covid Act Now (2021).

\section{A PANDEMIA EM UM PAÍS EXTREMAMENTE DESIGUAL}

A pandemia tem revelado de modo acentuado que, embora todos possam estar expostos em algum grau ao Sars-Cov-2 e à Covid- 19, os riscos e impactos têm sido mais intensos nos grupos com maiores vulnerabilidades, como resultante das desigualdades 
sociais e iniquidades em saúde. Portanto, se por um lado é absolutamente necessário interromper a transmissão do vírus por meio da vacinação de toda a população, sob a coordenação do Programa Nacional de Imunizações (PNI), o que é dever do Estado e direito de todas e todos, por outro é necessário simultaneamente romper o ciclo vicioso e de retroalimentação das desigualdades sociais e iniquidades em saúde, pois não haverá saúde para alguns se não houver saúde para todas e todos.

Ao longo das 44 SEs de 2020 foram contabilizados 7.714 .819 casos e 195.742 óbitos que evoluíram de modo bastante heterogêneo e com grande variabilidade entre os estados e dentro deles. $\mathrm{O}$ mesmo padrão também se verificou quanto à disponibilidade de leitos de UTI Covid-19, refletindo as grandes desigualdades na distribuição de serviços de saúde mais complexos e cuidados de qualidade, o que também influenciou na alternância de períodos críticos entre estados.

No bojo das desigualdades, é relevante destacar as imensas diferenças regionais na distribuição de serviços de saúde mais complexos e cuidados de qualidade, com maior capilaridade do Sistema Único de Saúde (SUS) mas também grande concentração de serviços mais voltados para o mercado privado em áreas com percentuais elevados de beneficiários de planos de saúde. O elevado índice de mortes em casa e em serviços de saúde ambulatoriais e a mortalidade hospitalar por Covid- 19 no país expõem problemas de acesso em tempo oportuno aos recursos de tratamento necessários e desempenhos do sistema de saúde muito diferenciados entre estados brasileiros (Portela et al., 2020).

No mês de outubro de 2020, quando lançamos o boletim de balanço dos seis meses desde que a OMS declarou a Covid- 19 uma pandemia, já alertávamos para o risco de aumento de casos e óbitos caso não fossem garantidas e incentivadas as medidas de contenção (distanciamento físico e social, uso de máscaras, higienização, entre outras) e sua adequação a territórios e populações vulnerabilizadas, por meio de uma política de controle da pandemia, inclusive com ações de comunicação voltadas para os diferentes grupos da população. O que se observou foi, no entanto, a fragmentação e descontinuidade dessas políticas, bem como as desigualdades no acesso aos serviços de saúde. Como resultado desse processo, chegamos à semana 53, a última SE de 2020, com cerca de 40.000 casos diários (número próximo ao do pior período, entre junho e agosto). Em relação aos óbitos, a semana marcou o retorno de valores altos, cerca de 600 por dia, número próximo ao alcançado em meados de maio, quando se atingiu o elevado patamar de cerca de 1.000 óbitos diários, que se prolongou até o fim de agosto.

Naquele momento, como em anteriores, continuávamos a alertar que seria preciso proteger os grupos populacionais mais vulneráveis, por meio de políticas de proteção 
e prevenção coletiva, reforço das ações de atenção primária e vigilância em saúde, participação social e comunitária, garantia de acesso aos cuidados hospitalares de maior complexidade, bem como, na vacinação, priorização de grupos mais expostos e sob maior risco.

O enfrentamento da pandemia envolve confrontar as desigualdades e as questões relacionadas à equidade. E abordar a Covid-19 como uma sindemia que combina condições de vulnerabilidade social e condições de saúde e doenças preexistentes que tornam determinados indivíduos e grupos sociais mais suscetíveis e vulnerabilizados, resultando em um conjunto amplo de problemas de saúde que pode surgir e persistir por algumas semanas e meses depois. Diante disso, defendemos que a equidade em saúde deve ser um princípio norteador das políticas públicas e ações durante e após a pandemia, como abordado no Boletim Observatório Covid-19 das SEs 44 e 45 de 2020 (Boletim..., 2020).

\section{A VIGILÂNCIA DE SÍNDROMES RESPIRATÓRIAS AGUDAS GRAVES EM 2020}

As notificações de casos de síndromes respiratórias agudas graves (Srag) são registradas no Sistema de Vigilância Epidemiológica (Sivep Gripe). O sistema InfoGripe, desenvolvido e mantido no Programa de Computação Científica da Fundação Oswaldo Cruz (Procc/Fiocruz), utiliza esses dados coletados para análises de vigilância epidemiológica, com boletins semanais.

A vigilância de Srag trabalha com os registros de casos de doenças respiratórias, que no ano de 2020 foram majoritariamente decorrentes de infecção do vírus Sars-CoV-2, causador da Covid- 19.

Para ser classificado como Srag, o caso deve ser de doença respiratória com hospitalização ou óbito, neste caso independentemente de internação, e ainda apresentar os seguintes sintomas: tosse ou dor de garganta, dispneia ou saturação de oxigênio abaixo de 95\%, ou dificuldade respiratória.

A incidência de Srag no ano 2020 excedeu 640 mil casos em todo o país. Desses registros, mais de 350 mil casos tiveram alguma confirmação de vírus respiratório, seja por influenza $A$, influenza $B$, vírus sincicial respiratório ou Sars-CoV-2. O total de óbitos excedeu 150 mil em todo o país.

A grande maioria dos casos com alguma detecção de vírus revelou a predominância de infecções por Sars-CoV-2, correspondente a $97 \%$ dos casos com confirmação laboratorial. 
Os totais de casos e óbitos excederam em muito os valores registrados em anos anteriores, conforme se observa nas figuras I e 2. No final do ano, as incidências ainda eram muito altas, quando comparadas às de anos anteriores. Todo esse quadro mostra a enorme pressão imposta ao sistema de saúde em razão das Srag.

Figura I - Ocorrência de casos de síndrome respiratória aguda grave (Srag) no decorrer das semanas epidemiológicas de 9 a 52 - Brasil, 2015-2020




Figura 2 - Óbitos por síndrome respiratória aguda grave (Srag) no decorrer das semanas epidemiológicas de 9 a 52 - Brasil, 2015-2020



A evolução no número de casos por SE nos estados sugere que a epidemia aconteceu com padrões heterogêneos ao longo do território nacional. No entanto, alguns fatores devem ser destacados.

Em primeiro lugar, houve crescimento muito intenso da incidência de Srag logo na introdução do vírus Sars-CoV-2 no país. Os estados do Amazonas, Pará, Ceará e o Distrito Federal chegaram a apresentar taxas de incidência superiores a 20 casos por 100 mil habitantes no mês de abril. Por outro lado, verificou-se que em Minas Gerais, nos estados do Sul e do Centro-Oeste houve uma contenção no número de casos de Srag, provavelmente resultado de esforços para mitigar a pandemia com várias medidas destinadas a reduzir o contágio (evitar aglomerações, restrições de viagens, uso de máscaras etc.).

Mesmo que tenham sido muito importantes, essas medidas, como foram adotadas de forma descoordenada, não se mostraram suficientes para trazer a incidência a níveis baixos; mesmo após um período de redução, tal incidência esteve sempre em níveis altos em todos os estados. 
Nos últimos meses do ano, o número de casos voltou a aumentar em alguns estados como Amazonas, Amapá, Paraíba, Alagoas, Rio de Janeiro, São Paulo, Minas Gerais, estados do Sul e do Centro-Oeste. Em alguns estados, no período após a SE 40, em um processo de recrudescimento chegou-se a exceder ou se esteve próximo a 10 casos por 100 mil habitantes, como em Paraná, Santa Catarina, Rio Grande do Sul, São Paulo, Rio de Janeiro, Mato Grosso do Sul, Amapá e Amazonas.

Em relação aos óbitos, lamentavelmente também se observaram números muito expressivos no início da pandemia, quando houve uma pressão sobre o sistema de saúde, ainda sem a preparação devida. Com o tempo, houve uma melhora na atenção básica em saúde para os casos mais leves de síndrome gripal, assim como um aprendizado para o melhor manejo clínico de casos mais graves, que requerem tempo maior de hospitalização. De fato, verificou-se nos meses finais de 2020 uma diminuição da letalidade de Covid-19, apesar de sua manutenção em níveis bastante altos em alguns estados, com destaque para o Rio de Janeiro e Pernambuco.

\section{A EVOLUÇÃO DE CASOS E ÓBITOS POR COVID-19 NO BRASIL E NO MUNDO}

No Brasil, ao contrário do que ocorreu na Europa e na Ásia, observou-se um lento processo de aumento do número de casos e óbitos (figuras 3 e 4) e a formação de um prolongado patamar de transmissão desde junho, com ligeira queda em setembro e retorno de níveis epidêmicos altos ao final do ano de 2020. Nesse período, os casos nos países do Oriente eram bastante reduzidos, enquanto a Europa enfrentava um recrudescimento da pandemia, com a clara formação de uma segunda onda epidêmica.

Dos países que integram os Brics (Brasil, Rússia, Índia, China e África do Sul), Brasil e Índia foram os que acumularam maiores números de casos e óbitos. Ao se combinar taxas de incidência e de mortalidade, o Brasil, junto com o Reino Unido, Itália e Espanha se destacam dos outros países, apresentando um padrão semelhante de alta incidência e mortalidade, no entanto defasados ao longo do ano. Os Estados Unidos da América do Norte representavam um caso trágico e particular, com as maiores taxas de incidência e mortalidade e a sobreposição de três ondas epidêmicas, que não mostravam sinais de arrefecimento até o início de 2021. 
Figura 3 - Casos de Covid- 19 em alguns países selecionados entre as semanas epidemiológicas 9 e 53 - Brasil, 2020

Casos em países selecionados, totais diários e média móvel Semanas 9 a 53


Figura 4 - Óbitos por Covid- 19 em alguns países selecionados entre as semanas epidemiológicas 9 e 53 - Brasil, 2020

Óbitos em países selecionados, totais diários e média móvel Semanas 9 a 53


EUA



México







Reino Unido



Data


Observatório Covid-19 | Fiocruz 
Nas últimas semanas de 2020, o Brasil voltou a apresentar números elevados de casos e óbitos, comparáveis aos valores da pior fase da epidemia, entre junho e agosto. Naquele período, ao invés de um pico, como observado em países do Oriente e da Europa, o país registrou uma média de 40.000 casos diários e o tristemente conhecido "patamar de 1.000 mortes por dia". Em dezembro de 2020 foram notificados novamente cerca de 40.000 casos e 600 óbitos diários. As perspectivas para o verão não eram alentadoras, uma vez que o sistema hospitalar apresentava sinais de saturação e grande parte das medidas de distanciamento físico e social e uso obrigatório de máscaras vinha sendo adotada apenas parcialmente nos estados e municípios do país. Somada a isso, desde outubro se observava simultaneidade entre as tendências de alta nos estados e entre grandes e pequenas cidades, o que geraria aumento da demanda por cuidados de saúde intensivos (cf. capítulo 5 deste livro).

Examinando-se a evolução da epidemia nos estados somente até o fim de 2020, observa-se que o nível máximo de transmissão (pico) foi atingido antes em estados do Norte (Acre, Amazonas, Roraima) e alguns da região Nordeste (Maranhão e Ceará), entre maio e junho (figuras 5 e 6). Posteriormente, se verificou o pico de casos e óbitos em outros estados do Nordeste (Piauí, Pernambuco, Sergipe e Alagoas) e também em São Paulo, Goiás, Mato Grosso e no Distrito Federal. Outros estados apresentaram picos da epidemia mais próximo ao fim do ano, como Paraná, Santa Catarina, Rio Grande do Sul e Mato Grosso do Sul. Para outro grupo de estados houve uma evolução mais próxima ao que se conhece como segunda onda, com picos em meados do ano de 2020 e outro em dezembro, como Bahia, Paraíba, Espírito Santo e Rio de Janeiro. 
Figura 5 - Ocorrência de casos de Covid- 19 nos estados e Distrito Federal no decorrer das semanas epidemiológicas de 9 a 52 - Brasil, 2020



Figura 6 - Ocorrência de óbitos por Covid- 19 nos estados e Distrito Federal no decorrer das semanas epidemiológicas de 9 a 52 - Brasil, 2020



Observatório Covid-19 | Fiocruz 
As maiores taxas de incidência foram observadas nos estados de Roraima, Amapá, Tocantins, Santa Catarina e no Distrito Federal (Figura 7) e as maiores taxas de mortalidade foram registradas nos estados do Amazonas, Roraima, Pará, Ceará, Rio de Janeiro, Mato Grosso e Distrito Federal (Figura 8). A diferença entre essas classificações pode ser resultado da capacidade de cada unidade federativa em investigar, testar e notificar casos suspeitos, bem como em diagnosticar e tratar os casos mais graves, isto é, fatores fortemente associados às capacidades de vigilância e atenção do próprio sistema de saúde dos estados e municípios.

As taxas de incidência e de mortalidade nos estados envolvem uma combinação de fatores que incluem o nível de desenvolvimento socioeconômico, as condições de diagnóstico (incluindo testes) e assistência aos sintomáticos, bem como as capacidades de prevenção e controle da transmissão do vírus e da doença por meio do conjunto de medidas não farmacológicas como distanciamento físico e social e uso obrigatório de máscaras.

Figura 7 - Taxas de incidência (por 100.000 habitantes) de Covid- 19 no decorrer das semanas epidemiológicas de 9 a 53 - Estados e Distrito Federal, 2020

Casos, por 100.000 hab

Semanas 9 a 53



:



Piauí

Ceará Rio Grande do Norte

Paraíba

Figura 7 - Taxas de incidência (por 100.000 habitantes) de Covid- 19 no decorrer das semanas epidemiológicas de 9 a 53 - Estados e Distrito Federal, 2020 (continuação)

Casos, por 100.000 hab.

Semanas 9 a 53


Semana epidemiológica

Observatório Covid-19 | Fiocruz 
Figura 8 - Taxas de mortalidade (por 100.000 habitantes) por Covid- 19 no decorrer das semanas epidemiológicas de 9 a 53 - Estados e Distrito Federal, 2020

Óbitos, por 100.000 hab.

Semanas 9 a 53


$\begin{array}{lllllllllllllll}10 & 20 & 30 & 40 & 50 & 10 & 20 & 30 & 40 & 50 & 10 & 20 & 30 & 40 & 50\end{array}$

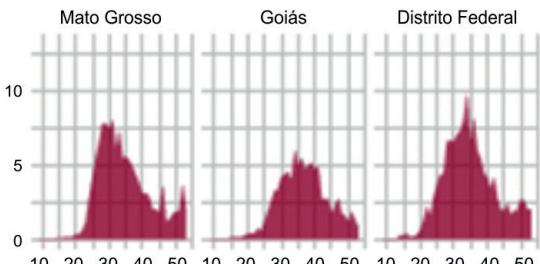

Semana epidemiológica 
A taxa de letalidade, dada pela proporção de casos que resultaram em mortes por Covid-19, caiu ao longo do ano de 2020, provavelmente devido a ações de saúde como o aumento da cobertura de testes, à melhoria e ampliação das ações da Atenção Primária em Saúde, ao aumento no número de leitos e ao aprendizado no manejo clínico de casos graves, como ocorrido em diversos países do mundo. A taxa de letalidade por Covid- 19 no Brasil se estabilizou no fim de 2020 entre $2 \%$ e 3\%. No entanto, alguns estados como o Rio de Janeiro e Pernambuco apresentaram taxas ainda elevadas: mais de 5\% (Figura 9). Os valores elevados de letalidade revelam graves falhas no sistema de atenção e vigilância em saúde nesses estados.

Figura 9 - Letalidade por Covid- 19 no decorrer das semanas epidemiológicas de 9 a 52 - Estados e Distrito Federal, 2020

Figura 9 - Letalidade por Covid- 19 no decorrer das semanas epidemiológicas de 9 a 52 - Estados e Distrito Federal, 2020 (continuação)

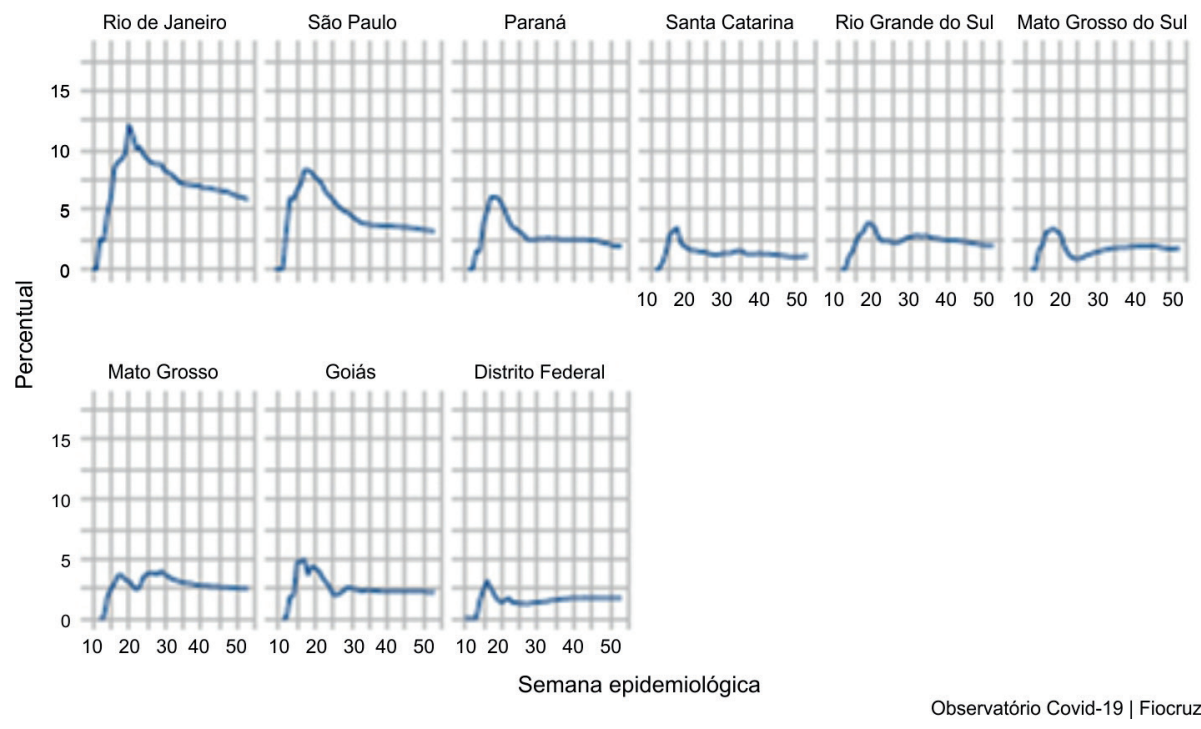

A Figura 10 situa os estados e Distrito Federal simultaneamente em relação às suas taxas de incidência e mortalidade por Covid-19, considerando dados do dia 31 de dezembro de 2020. 
Figura 10 - Distribuição dos estados e Distrito Federal segundo taxas de incidência e mortalidade por Covid-19-Brasil, 31/12/2021



\section{LEITOS DE UTI PARA COVID-19}

O Observatório Covid- 19 Fiocruz passou a monitorar as taxas de ocupação de leitos de UTI Covid- 19 do SUS para adultos em 17 de julho de 2020, não dispondo inicialmente das taxas do estado do Rio de Janeiro, representado pela sua capital. Considerando dados obtidos quinzenalmente, observa-se na Figura II a evolução do indicador nos estados e Distrito Federal, apresentando um padrão que sugere a mudança de um quadro mais desfavorável para um mais favorável no fim de agosto e nova piora a partir de novembro e, especialmente, dezembro. O início da observação se deu após a epidemia afetar mais fortemente os estados de São Paulo e Rio de Janeiro e estados da região Norte e Nordeste, fase que ficou conhecida como o "colapso do sistema de saúde". Esse indicador foi capaz de captar a fase em que a pandemia atingiu com maior intensidade a região Centro-Oeste e avançou para a região Sul. O mês de outubro se mostrou com o melhor cenário, com a maior parte dos estados com nível baixo de ocupação de leitos de UTI Covid- 19 para adultos. A partir de novembro permaneceram em alerta estados da região Norte - Amazonas, Roraima e Amapá -, bem como Pernambuco, Espírito Santo, Paraná, Santa Catarina, Mato Grosso do Sul e, no último mês, o Distrito Federal. 
Figura II - Evolução das taxas de ocupação de leitos de UTI Covid- 9 para adultos no SUS - Brasil, 17/07/2020 a 04/0 I/2021

Taxa de ocupação(\%) de leitos de UTI Covid-19 para adultos



\section{ENFRENTAR A PANDEMIA É ROMPER OS CICLOS DA TRANSMISSÃO DO VÍRUS E DAS DESIGUALDADES SIMULTANEAMENTE}

A pandemia tem revelado de modo claro que, embora todos possam estar expostos em algum grau ao vírus Sars-Cov-2 e a desenvolver a doença, os riscos e impactos têm sido desiguais não só entre os diferentes países, mas também dentro dos países, como demonstramos neste capítulo. Essas diferentes escalas espaciais são constituídas por uma multiplicidade de territórios nos quais, com seus distintos níveis de organização, as desigualdades sociais e iniquidades em saúde são materializadas, colocando alguns 
grupos em grande desvantagem no tocante à possibilidade de cumprir as medidas de higienização, distanciamento físico e social, isolamento e quarentena, bem como no acesso aos serviços de saúde, incluindo exames diagnósticos, tratamento e reabilitação.

O Brasil se encontra entre os dez países com maiores desigualdades socioeconômicas do mundo, o que constitui um desafio adicional para o enfrentamento da pandemia, principalmente para os grupos sociais que se encontram em pior posição dentro do país (Demenech et al., 2020). Os que têm condições de vida e trabalho mais precárias, maiores dificuldades no acesso aos bens e serviços essenciais, relacionadas aos fatores determinantes e condicionantes da saúde descritos na lei n. 8.080, de 19 de setembro de 1990, como a alimentação, a moradia, o saneamento básico, o meio ambiente, o trabalho, a renda, a educação, a atividade física, o transporte, o lazer e o acesso aos bens e serviços essenciais (Brasil, 1990), ou sofrem injustiças por questões de gênero, raça e etnia vivenciam de modo mais acentuado os impactos imediatos da pandemia. E também se tornam mais vulneráveis aos seus impactos de médio e longo prazos, com maior potencial de dificuldades e barreiras para a recuperação socioeconômica e da saúde durante a pandemia e no pós-pandemia (Hill E Narayan, 2020).

A relação entre esses fatores que associam a infecção pelo Sars-CoV-2, perfil epidemiológico e iniquidades socioeconômicas das populações, acrescida do baixo investimento em políticas públicas e sociais, transforma a pandemia de Covid-19 numa sindemia (Horton, 2020), em que os resultados e as repercussões de um evento sanitário se agravam em razão da associação sinérgica de fatores. Portanto, é necessário reconhecer a complexidade do problema e responder de forma coordenada e intersetorial com políticas e ações que defendam a vida e minimizem suas repercussões sobre a população e o sistema de saúde.

Além do desafio das desigualdades, vivenciamos em 2020 os desafios relacionados ao acesso às informações necessárias e oportunas para um bom enfrentamento da pandemia. Todos os indicadores disponibilizados em forma de gráficos e mapas nos boletins produzidos periodicamente pela Fiocruz dependem do suprimento permanente e seguro de dados, por meio de uma multiplicidade de sistemas de informações, como o Sivep Gripe, por exemplo. Ao longo de 2020 houve discrepâncias entre os dados reportados por estados como Mato Grosso no Sivep Gripe e no sistema do próprio estado. Houve também episódios em que o fluxo de dados foi interrompido por indisponibilidade ou mesmo receio de invasão cibernética. Em momentos críticos como uma pandemia, é importante que esses sistemas estejam com disponibilidade alta e transparência para melhor análise de cenário epidemiológico, sendo este um desafio adicional. 
O ano de 2020 terminou com a boa notícia sobre vacinas que estariam disponíveis em breve no Brasil, como as desenvolvidas pelas empresas Sinovac e AstraZeneca, envolvendo acordos de compra e transferência de tecnologias. Para que a imunidade coletiva possa ser atingida, seria necessário, além da disponibilidade das vacinas, um amplo programa de vacinação coordenado que atingisse mais de $70 \%$ da população. Se por um lado é absolutamente necessário interromper o ciclo de transmissão, por meio de vacinas aplicadas pelo SUS como um direito de todas e todos e um dever do Estado, por outro é necessário simultaneamente romper o ciclo vicioso e de retroalimentação das desigualdades sociais e iniquidades em saúde, pois não haverá saúde para alguns se não houver saúde para todos. E informações adequadas e oportunas são fundamentais para ambos os processos.

\section{REFERÊNCIAS}

BOLETIM Observatório Covid-19: semanas epidemiológicas 44 e 45: 25 a 31 de outubro e de 01 a 7 de novembro. Rio de Janeiro: Fiocruz, 2020. Disponível em: <www.arca.fiocruz.br/handle/icict/44534>. Acesso em: 18 jan. 2021.

COVID ACT NOW. Site. Disponível em: <www.covidexitstrategy.org >. e <https://covidactnow. $\mathrm{org} / \mathrm{s}=2265 \mathrm{I}$ I 88> . Acesso em: 18 jan. 2021 .

DEMENECH, L. M. et al. Desigualdade econômica e risco de infecção e morte por Covid- 19 no Brasil. Revista Brasileira de Epidemiologia, 23. Disponível em: <www.scielo.br/scielo.php?script=sci_ arttextEpid=SI 4 | 5-790X2020000 I00209Etlng=pt $>$. Acesso em: I 8 jan. 2020.

FREITAS, C. M. et al. Boletim Observatório Covid-1 9 após 6 meses de pandemia no Brasil. Rio de Janeiro: Fiocruz, 2020. Disponível em: <www.arca.fiocruz.br/handle/icict/44059>. Acesso em: 23 jan. 2020.

HILL, R. V. \& NARAYAN, A. Covid-I 9 and inequality: a review of the evidence on likely impact and policy options. Centre for Disaster Protection. Working Paper 3 December 2020. Disponível em: $<$ https://static I.squarespace.com/static/5c9d3c35ab I a625 I 5 I 24d7e9/t/5fe2 I 8df95074 I 6a29d4 9d32/I608653024I73/WP_3_22Dec.pdf>. Acesso em: I 8 jan. 2020.

HORTON, R. Offline: Covid-I9 is not a pandemic. The Lancet, 396(I0.255): 874. Disponível em: $<$ www.thelancet.com/journals/lancet/article/PIISO I 40-6736(20)32000-6/fulltext > . Acesso em: 23 jan. 2020.

PORTELA, M. C. et al. Nota Técnica. Limites e possibilidades dos municípios brasileiros para o enfrentamento dos casos graves de Covid-19. Observatório Covid-19 Fiocruz, Rio de Janeiro, 2020. Disponível em: <https://portal.fiocruz.br/sites/portal.fiocruz.br/files/documentos/nt_I_portela_ et_al_limites_e_possibilidades_dos_municipios_brasileiros_na_covid-19_1.pdf >. Acesso em: 12 jan. 2020.

WORLD HEALTH ORGANIZATION (WHO). Public health criteria to adjust public health and social measures in the context of Covid-19, 12 May 2020. Disponível em: < https://apps.who.int/iris/ bitstream/handle/I0665/332073/WHO-20 I 9-nCoV-Adjusting_PH_measures-Criteria-2020.I eng.pdf? sequence $=1$ EisAllowed $=y>$. Acesso em: 5 jan. 2021 . 


\title{
Estimativa de Risco de Espalhamento da Covid-19 no Brasil e Avaliação da Vulnerabilidade Socioeconômica nas Microrregiões Brasileiras
}

\author{
Cláudia Torres Codeço, Daniel Antunes Maciel Villela \\ Flávio Codeço Coelho, Leonardo Soares Bastos, \\ Luiz Max Carvalho, Marcelo Ferreira da Costa Gomes, \\ Oswaldo Gonçalves Cruz e Raquel Martins Lana
}

O estudo aqui apresentado foi feito no período de março a maio de 2020, durante os primeiros meses da pandemia de Covid-19. No Brasil, os primeiros casos importados tinham chegado da Europa em São Paulo e Rio de Janeiro, apenas dois meses depois do alerta feito pela China sobre a emergência do novo coronavírus. Essas grandes metrópoles foram as primeiras a declarar transmissão comunitária, quando não se é mais possível traçar a origem dos casos. Em março, toda a comunidade científica já se organizava para o enfrentamento da pandemia. Nunca antes se havia visto tão grande movimento internacional para compartilhamento de informações, dados e modelos. Vários dashboards foram rapidamente criados, como o John Hopkins nos Estados Unidos, e o Brasil.IO aqui. Modelos matemáticos eram publicados na Inglaterra e em outros países, alertando para o risco de uma pandemia com a expectativa de milhares de mortes em pouco tempo. A mídia mostrava os hospitais lotados na China e posteriormente na Itália e Espanha.

Diante desse cenário, uma força-tarefa foi organizada por pesquisadores do Programa de Computação Científica da Fundação Oswaldo Cruz (Fiocruz) e da Escola de Matemática Aplicada da Fundação Getulio Vargas (FGV). Esse grupo já tinha um histórico de colaboração havia pelo menos cinco anos em área correlata, o qual resultara no desenvolvimento de métodos analíticos para vigilância das arboviroses (InfoDengue) e de síndrome respiratória aguda grave (InfoGripe, 20 I8). O grupo de trabalho criado foi 
denominado Núcleo de Métodos Aplicados à Vigilância Epidemiológica (Grupo Mave, 202I). Em seu primeiro relatório, aqui apresentado, analisou o risco de importação de Covid- I 9 para as microrregiões brasileiras decorrente da presença de transmissão sustentada nos dois maiores centros urbanos, Rio de Janeiro e São Paulo, e os efeitos de possível ocorrência de epidemias nas microrregiões associados a faixas da população com maior risco de morbidade e letalidade, como idosos, e indicadores de capacidade no Sistema Único de Saúde (SUS), como número de leitos (Grupo Mave, 2020).

\section{VULNERABILIDADE GEOGRÁFICA}

$\mathrm{Na}$ epidemiologia, é bem conhecido que as redes de mobilidade formam os caminhos para a propagação das doenças transmissíveis, distorcendo as distâncias geográficas e tornando próximas cidades como São Paulo e Londres, Rio de Janeiro e Hong Kong (Codeço \& Coelho, 2008). Para compreender esses caminhos, é necessário conhecer as redes e fluxos de transporte e, por meio de modelos matemáticos e estatísticos, estimar a associação dos fluxos e risco de introdução dos patógenos. Quanto mais pessoas infectadas chegam, maior a probabilidade de que cadeias de transmissão se formem, gerando surtos locais e, posteriormente, epidemias. No entanto, esse não é um processo determinístico, uma vez que são as condições de receptividade e resiliência local que vão, em última análise, conformar a trajetória epidemiológica resultante.

Mediante o estabelecimento do Sars-CoV-2 nas duas maiores cidades brasileiras, naquele momento a principal questão era a velocidade e o caminho pelo qual a epidemia se disseminaria no país. Também estava em debate a eficácia de medidas de distanciamento social e redução de mobilidade de longa distância. Para avaliar a vulnerabilidade geográfica dos municípios brasileiros à introdução da Covid-19, foi calculada uma métrica de distância efetiva proposta por Gautreau, Barrat e Barthélemy (2008), que define proximidade em termos do fluxo de pessoas entre as localidades, e não da distância geográfica. Essa métrica apresenta forte correlação com o tempo até a chegada da epidemia em cada território a partir de uma origem bem definida. Isto é, quanto menor a distância efetiva, menor o tempo até a invasão. Para estimar esse tempo até a chegada e estabelecimento de epidemia, $T_{i j}$, utilizamos a medida de distância efetiva que leva em conta, além da distância efetiva, também parâmetros associados à transmissão, como a taxa de reprodução básica $R_{0}$ e o período de infecção típico y. A expressão é:

$$
T_{i j}=\frac{d_{i j}}{J\left(R_{0}-I\right)}
$$


onde o período de infecção foi definido em 8 dias, e o $R_{0}$ de 2,5, conforme estimativas da época. A distância efetiva foi calculada a partir de dados da malha aérea fornecidas pelo Official Airline Guide (OAG, 2020) referentes ao ano de 2019, agregados por ano e restritos aos fluxos nacionais. Foram utilizadas como áreas de influência imediata as microrregiões correspondentes ao município referência de cada aeroporto.

A Figura I mostra o mapa da distância efetiva entre cada município e (A) São Paulo e (B) Rio de Janeiro. Fica evidente que a primeira cidade é muito mais conectada e, consequentemente, tem maior potencial de disseminação do que a segunda.

Figura I - Distância efetiva dos municípios brasileiros em relação a $(A)$ cidade de São Paulo e (B) Rio de Janeiro. Diagramas de dispersão nos quais cada ponto corresponde a um município. A localização do município no gráfico decorre da proporção da população idosa e da distância efetiva em relação às cidades de (C) São Paulo e (D) Rio de Janeiro. Cidades indicadas são aquelas com menor distância efetiva

(A)


Percentual da populaçăo acima de 60 anos
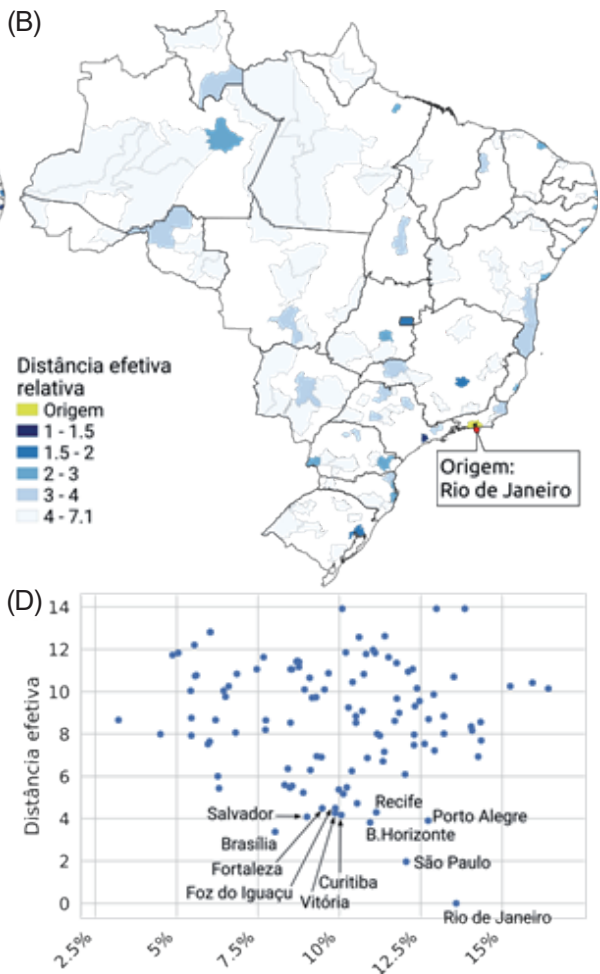

Percentual da população acima de 60 anos 


\section{CENÁRIOS DE INTERVENÇÃO}

Utilizando esse modelo, é possível construir cenários para estimar o impacto de medidas restritivas de mobilidade no tempo até a chegada do vírus em cada local. A Figura 2 ilustra esse resultado para o estado de São Paulo. Na figura de cima, observa-se que com o fluxo normal esperava-se a interiorização da Covid-19 pelo interior do estado em menos de um mês. O painel (B) da Figura 2 mostra o efeito esperado da redução de $80 \%$ na mobilidade de pessoas entre municípios associado a um distanciamento social que resultasse num número reprodutivo efetivo de 1,7 , isto é, $68 \%$ do original de 2,5 . Nesse cenário, o tempo até a epidemia chegar a alguns municípios pode alcançar dois meses e meio.

Figura 2 - Estimativa de impacto por meio de medidas restritivas de mobilidade em dois cenários de atenuação: $R_{0}$ de 2,5 e $30 \%$ de atenuação (painel superior) e $R_{0}$ de 1,7 e $80 \%$ de atenuação (painel inferior)

A partir da instalação de transmissão sustentada e alta incidência no Rio de Janeiro e em São Paulo, as microrregiões do país em que era mais provável a instalação de transmissão sustentada de Covid- 19 eram aquelas que faziam fronteira física com as cidades de São Paulo e Rio de Janeiro, bem como as capitais estaduais. Em seguida, o estabelecimento da transmissão de Covid-19 era mais provável na maioria das microrregiões do litoral, de Porto Alegre a Salvador. Outras áreas de alto risco eram as áreas vizinhas de Recife e Fortaleza, no Nordeste, áreas vizinhas de Foz do Iguaçu, Paraná, e áreas vizinhas de Cuiabá, Brasília e Goiânia, no Centro-Oeste.

Além da distância efetiva, podemos calcular a probabilidade de um surto inicial que dará início a uma epidemia em cada local. O processo de estabelecimento de uma epidemia é de natureza estocástica e depende do $R_{0}$ local e do influxo inicial de infectados (I) em uma localidade até então não exposta. Dados esses dois parâmetros, podemos calcular a probabilidade do estabelecimento da doença de forma epidêmica, ou seja, de invasão. Assumindo-se um modelo SIR estocástico de transmissão (Brauer, Van Den Driessche $\& W u, 2008)$, essa probabilidade pode ser calculada com a seguinte fórmula: $P_{e p i}=1-\left(\frac{l}{R_{0}}\right)^{l}$. Nesse cálculo as medidas de distanciamento social vão afetar o $R_{0}$ em cada microrregião e as estatísticas de mobilidade e distância efetiva.

Aliadas à prevalência da Covid- 9 nos municípios mais próximos, essas estatísticas de mobilidade nos darão o número esperado de infectados chegando por unidade de tempo (Coelho et al., 2020).

Figura 3 - Probabilidade de instalação de transmissão sustentada de Covid- 19 em microrregiões brasileiras. Estimativa feita no cenário sem redução de mobilidade






\section{ANÁLISE DE VULNERABILIDADE SOCIAL}

Como o impacto de uma epidemia não depende apenas da chegada do vírus, mas também das condições locais de transmissão e resposta, identificamos como necessário analisar também as vulnerabilidades sociais e assistenciais no país. A partir do cruzamento das áreas mais vulneráveis geograficamente e socialmente, foi possível identificar os municípios com risco iminente de desastre. A vulnerabilidade socioeconômica foi calculada por meio de um método de agrupamento de partição (K-medoid), tomando como variáveis expectativa de vida, índice Gini, componente educacional do índice de desenvolvimento humano, proporção da população vivendo abaixo do limiar de extrema pobreza, porcentagem da população urbana, porcentagem da população em domicílios com água encanada, porcentagem da população com insuficiência no abastecimento de água e tratamento de esgoto e percentual de pessoas sem acesso à eletricidade. Essas variáveis foram selecionadas de um conjunto maior, do qual foram eliminadas variáveis altamente correlacionadas (correlação de Pearson > 0.8) (Coelho et al., 2020). A vulnerabilidade da assistência hospitalar foi calculada a partir de indicadores de leitos hospitalares e leitos de UTI disponíveis no início da epidemia. O Quadro I apresenta a classificação resultante.

\section{Quadro I - Descrição das classes de vulnerabilidade social dos municípios brasileiros}

\begin{tabular}{|c|l|}
\hline Classe & \multicolumn{1}{|c|}{ Descrição } \\
\hline A & $\begin{array}{l}\text { Predominantemente urbana, com expectativa de vida acima da média, comparativamente menor } \\
\text { desigualdade, menor população vivendo em extrema pobreza, melhor acesso aos serviços de } \\
\text { abastecimento de água e esgoto, e maior escolaridade média. Nesta categoria está a maioria das } \\
\text { capitais estaduais. }\end{array}$ \\
\hline B & $\begin{array}{l}\text { Muito semelhante a A na expectativa de vida. Ainda mais urbana, mas com mais população } \\
\text { vivendo em extrema pobreza (média de 5\%). } \\
\text { Os índices de desigualdade e a infraestrutura são piores em comparação com A, mas ainda } \\
\text { acima da média. }\end{array}$ \\
\hline C & $\begin{array}{l}\text { Mistura de populações urbanas e rurais. } \\
\text { Em comparação com A e B, tem expectativa de vida significativamente menor, pobreza } \\
\text { significativamente alta e menos infraestrutura. São as áreas mais urbanizadas da região } \\
\text { Nordeste, principalmente. }\end{array}$ \\
\hline D & $\begin{array}{l}\text { Predominância de populações rurais, alta desigualdade, baixo IDH educacional (IDHedu), baixo } \\
\text { acesso a serviços de água e esgoto, mas com acesso a eletricidade. Localizada principalmente na } \\
\text { área seca do bioma Caatinga, no Nordeste e em alguns municípios do Norte. }\end{array}$ \\
\hline E & $\begin{array}{l}\text { Regiões predominantemente rurais na Amazônia. IDHedu baixo, acesso precário à água tratada, } \\
\text { disposição de esgoto e eletricidade. }\end{array}$ \\
\hline
\end{tabular}


A Figura 4C mostra o mapa de vulnerabilidade. As microrregiões das classes C, D e E são as mais vulneráveis. Elas estão localizadas principalmente nas regiões Nordeste e Norte. Como esperado, maior expectativa de vida está associada a melhores condições de vida, concentradas significativamente na parte sul do país.

Figura 4 - (A) Porcentagem da população com mais de 60 anos por microrregião;

(B) Distribuição da capacidade hospitalar medida em número de leitos hospitalares;

(C) Classificação das microrregiões em vulnerabilidade social: $A$ e B são as microrregiões com melhores índices, C, D e E têm alta vulnerabilidade social;

(D) Microrregiões com alta vulnerabilidade social e alta probabilidade de epidemia de Covid-19

(A) População acima de 60 anos

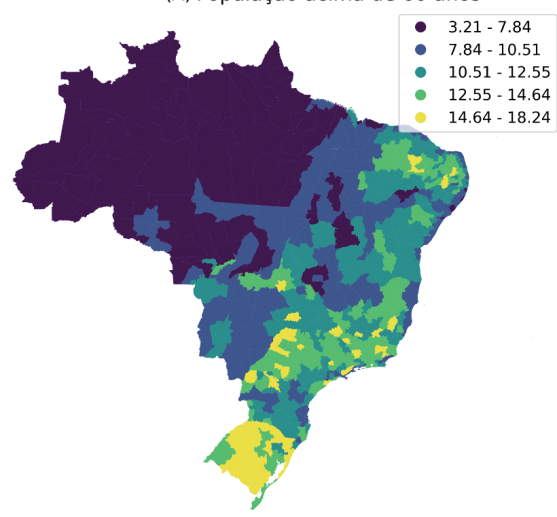

(C) Classe de vulnerabilidade socia

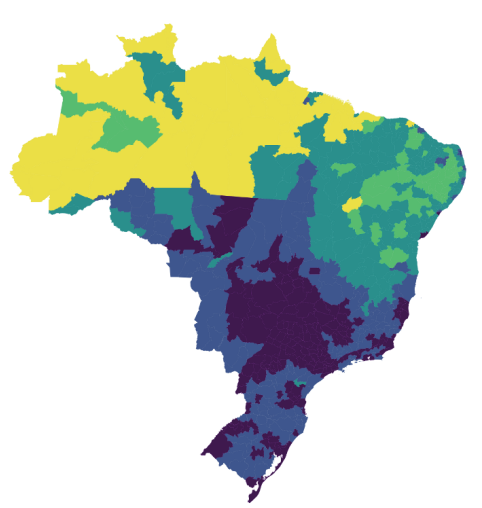

(B) Número de leitos por 10mil hab.

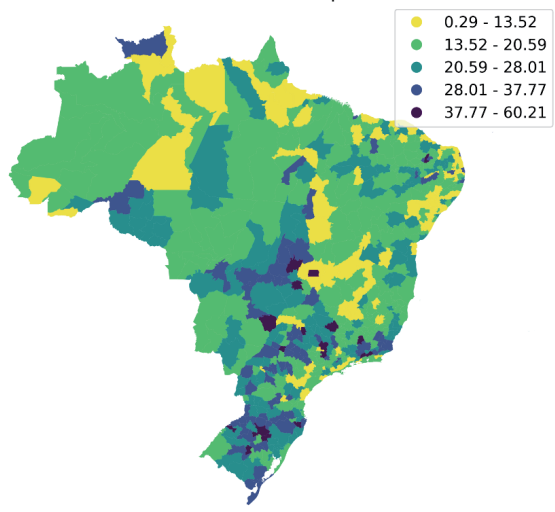

(D) Combinação de vulnerabilidade social e geográfica

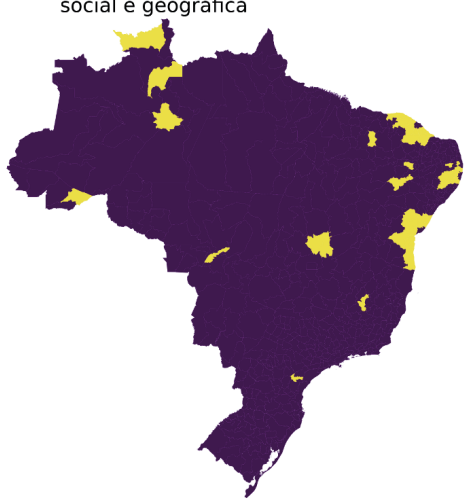




\section{PROBABILIDADE DE INVASÃO E O EFEITO DA MOBILIDADE}

A Figura 3 mostra a probabilidade de espalhamento da epidemia condicionada pelos padrões de mobilidade da população brasileira. Este mapa assume um $R_{0}$ relativamente baixo, de 1,7, se comparado aos valores inicialmente relatado para a Covid- 9 (Liu et al., 2020). Logo após o estabelecimento das barreiras sanitárias entre cidades era esperada uma redução de fluxo, que reduziria a probabilidade de invasão da epidemia em diversos municípios mais distantes dos principais centros de disseminação da primeira onda.

A Figura 2 mostra os ganhos temporais possíveis em consequência da implantação de medidas de isolamento social que reduzem o $R_{0}$.

Os painéis C e D da Figura 4 apresentam o efeito combinado da vulnerabilidade social e geográfica (dada pela probabilidade de epidemia). Essa combinação já indicava várias das regiões que apresentaram as piores epidemias do país.

Figura 5 - Distribuição do tempo ganho até a chegada da epidemia nos vários cenários de intervenção. $O$ valor do $R_{0}$ reflete a adesão dentro dos municípios ao distanciamento social. Para cada nível de distanciamento social é mostrado o efeito combinado do isolamento com redução do fluxo intermunicipal em 30,50 e $80 \%$
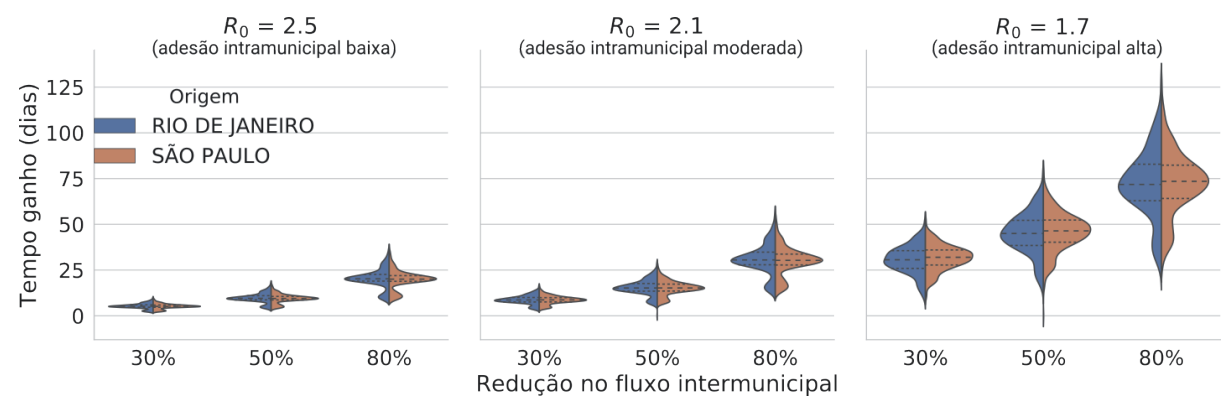

Na Figura 5 temos uma análise detalhada do efeito combinado do distanciamento social dentro dos municípios aliado a uma redução do fluxo intermunicipal de pessoas. São resultados simulados, nas microrregiões do Rio de Janeiro (em azul) e de São Paulo (em laranja).

A análise desses dados deixou claro que, na ausência de fortes restrições de mobilidade, a disseminação da Covid- 19 para as grandes áreas urbanas do país teria sido muito mais rápida do que o ocorrido. Tanto a restrição das viagens como o distanciamento social contribuíram para retardar sua transmissão. Algumas capitais estaduais das regiões Norte e Nordeste, como Manaus e Fortaleza, foram classificadas 
como prioritárias, o que se confirmou ao longo dos meses (Orellana et al., 2020; Lemos et al., 2020). Esses resultados foram publicados inicialmente na forma de relatórios (atualizados regularmente), e posteriormente em forma de artigo (Coelho et al., 2020).

Uma avaliação retrospectiva desses resultados revela que várias das epidemias mais críticas que observamos em 2020 poderiam ter sido evitadas ou atenuadas caso os resultados deste estudo tivessem dado origem a intervenções preventivas em cidades como Manaus e Fortaleza, por exemplo. Prevenções intensivas nas cidades de maior risco teriam atrasado e reduzido substancialmente o espalhamento do vírus (figuras 2 e 5 ).

Embora não se possa comparar a perda de vidas com as perdas econômicas decorrentes das restrições de movimento, estas últimas poderiam ter sido diminuídas com planos de contingência bem articulados que pudessem preservar a atividade econômica em áreas de baixo risco enquanto uma restrição mais severa de mobilidade sustentada por uma subvenção econômica do governo ficaria restrita às cidades com maior risco.

\section{LIÇÕES APRENDIDAS}

Hoje enfrentamos as consequências da gestão pouco efetiva dos riscos desta pandemia que acarretaram perdas muito maiores do que o esperado para um país com os recursos do Brasil (Lana et al., 2020). Mas as lições desta calamidade permanecem, para que futuros governos possam escolher agir preventivamente, embasados pelo conhecimento gerado pela comunidade científica brasileira.

A preparação para a vacinação é outra etapa que pode se beneficiar de forma análoga, mediante uma análise da vulnerabilidade das várias regiões de nosso país. Cumpridos os imperativos éticos de prover imunização em caráter prioritário aos grupos em maior risco e de maior exposição, restará espaço para uma estratégia que, baseada no conhecimento preliminar da vulnerabilidade social e geográfica de cada região, busque frear a segunda onda de espalhamento da Covid- 19 e minimizar as chances de reinfecção em populações já afetadas pelo vírus. A vacinação pode ser utilizada para evitar um segundo colapso dos sistemas locais de saúde, assim como para reduzir a morbidade e mortalidade nas populações locais.

Outra lição deixada por esta pandemia é a necessidade de se dispor de antemão de um mapeamento das capacidades e fragilidades do nosso sistema de saúde, público e privado, como realizado neste estudo, que seja atualizado anualmente. Somente dessa maneira podemos ter a esperança de intervir efetivamente em uma futura crise de dimensões similares. 


\section{REFERÊNCIAS}

BRAUER, F.; VAN DEN DRIESSCHE, \&WU, J. (Eds.). Mathematical Epidemiology. Springer, 2008. Disponível em: <www.amazon.com.br/Mathematical-Epidemiology- I 945-Fred-Brauer/dp/3540789 I03>. Acesso em: I fev. 2020.

CODEÇO, C. T. \& COELHO, F. C. Redes: um olhar sistêmico para a epidemiologia de doenças transmissíveis. Ciência E Saúde Coletiva, I3(6): I.767-1.774, 2008. Disponível em: <www.scielo. br/j/csc/a/qbqdmfv364nYw8gvGwWXy7f/?format=pdfElang=pt>. Acesso em: I fev. 2020.

COELHO, F. C. et al. Assessing the spread of Covid-19 in Brazil: mobility, morbidity and social vulnerability. Plos One, 15(9): e0238214, 2020. Disponível em: <https://doi.org/I0.137l/journal. pone.02382I4>. Acesso em: 18 set. 2020.

GAUTREAU, A.; BARRAT, A. \& BARTHÉLEMY, M. Global disease spread: statistics and estimation of arrival times. Journal of Theoretical Biology, 25I(3): 509-522, 2008. Disponível em: <https://doi. org/I0.10 I6/j.jtbi.2007. I2.00 I >. Acesso em: I8 set. 2020.

GRUPO MAVE. Covid-19 Grupo Mave, 2020. Disponível em: <https://covid-19.procc.fiocruz.br/ team/>. Acesso em: I jun. 2020.

GRUPO MAVE. Núcleo de Métodos Aplicados à Vigilância Epidemiológica. Disponível em: < https:// covid- I 9.procc.fiocruz.br>. Acesso em: I jun. 2021.

INFOGRIPE. Monitoramento de casos de síndrome respiratória grave (Srag) notificados no Sivep Gripe. 20 I8. Disponível em: <http://info.gripe.fiocruz.br>. Acesso em: I jun. 2021.

LANA, R. M. et al. Emergência do novo coronavírus (Sars-CoV-2) e o papel de uma vigilância nacional em saúde oportuna e efetiva”. Cadernos de Saúde Pública 36(3), 2020. Disponível em: <https://doi. org/I0.1590/0 I02-3 I Ix000 I 9620 >. Acesso em: I abr. 2021.

LEMOS, D. R. Q. et al. Health system collapse 45 days after the detection of Covid- 19 in Ceara, Northeast Brazil: a preliminary analysis. Revista da Sociedade Brasileira de Medicina Tropical, 53, 2020. Disponível em: <www.scielo.br/j/rsbmt/a/98LMbshKyrXVc7sC4nZwkSG/?lang=enEformat=pdf>. Acesso em: I jun. 2021.

LIU, Y. et al. The reproductive number of Covid- 19 is higher compared to Sars coronavirus. Journal of Travel Medicine, 27(2), 2020. Disponível em: <https://doi.org/l 0.1093/jtm/taaa02 I >. Acesso em: I abr. 2020.

OfFICIAL AIRLINE GUIDE (OAG). Site. Disponível em: <www.oag.com>. Acesso em: I abr. 2020.

ORELLANA, J. D. Y. et al. Explosão da mortalidade no epicentro amazônico da epidemia de Covid- 19. Cadernos de Saúde Pública, 36: e00 I 20020, 2020. Disponível em: < http://cadernos.ensp.fiocruz.br/ static//arquivo/I678-4464-csp-36-07-e00I20020.pdf>. Acesso em: I set. 2020. 


\title{
Pandemia de Covid-19
}

\author{
o processo de interiorização e \\ aceleração da transmissão no país
}

Mônica de Avelar Figueiredo Mafra Magalhães, Christovam Barcellos, Diego Ricardo Xavier e Raphael de Freitas Saldanha

Com a identificação de um novo coronavírus como causador da infecção do surto que se espalhava pela China e com a declaração da primeira morte ainda na primeira quinzena de janeiro e o reconhecimento, um pouco mais tarde, de que a transmissão do novo agravo se dava entre indivíduos, os olhos do mundo se voltaram para uma possível pandemia que assolaria a população mundial. Quando em 30 de janeiro de 2020 a Organização Mundial da Saúde (OMS) declarou Emergência de Saúde Pública de Importância Internacional (Espii), instituições de saúde do Brasil começaram a monitorar a evolução e disseminação da nova doença que chegou em solo nacional no dia 26 de fevereiro.

Embora o país tenha declarado Espii ainda no início de fevereiro, isso não se traduziu em iniciativas e ações públicas de contenção e preparação para o enfrentamento da Covid-19. A desarticulação entre as esferas governamentais e o discurso negacionista de muitos representantes afetaram diretamente o planejamento das ações de saúde e de restrição de mobilidade de pessoas.

Essa desarticulação afetou, entre muitas áreas de responsabilidade do Ministério da Saúde, a de organização, estruturação e disseminação de dados. Com a demanda urgente de monitoramento da Covid- 19 e, por conseguinte, a busca por dados confiáveis, surgiu a iniciativa MonitoraCovid- I9, um sistema que integra dados sobre o novo coronavírus no Brasil e no mundo, com o objetivo de oferecer um retrato em tempo real da epidemia no país, por estados e por municípios, possibilitando comparação de tendências e extração de dados para análises. Trata-se de uma plataforma de grande usabilidade que tem sido bastante utilizada por diferentes tipos de consumidores de dados de saúde pública: população em geral, pesquisadores e estudantes e gestores. 
Como parte das funções da equipe do MonitoraCovid-19, estava a divulgação da evolução da doença de maneira rápida e com uma linguagem acessível. Assim, desde março de 2020 são lançadas notas técnicas que abordam os assuntos mais emergentes no momento e ficam disponíveis no sistema para todos os usuários. Neste capítulo será abordado um dos temas que estiveram em foco durante algumas semanas no início da pandemia: a difusão do coronavírus nas cidades brasileiras desde a entrada do vírus no país até a disseminação pela quase totalidade dos municípios, em um processo que chamamos de interiorização da doença.

\section{O PAPEL DA HIERARQUIA DAS CIDADES NA DIFUSÃO DE DOENÇAS}

As doenças transmissíveis se disseminam no território de duas maneiras: a difusão hierárquica e a difusão por contágio. Na difusão hierárquica, um patógeno se espalha por uma série de cidades conforme seu tamanho relativo e a função que a cidade desempenha na região em que se localiza. Um conjunto de cidades está interligado através de uma rede que conecta as cidades chamadas centrais a núcleos urbanos que dependem dessas para realizar suas funções. Nesse mecanismo, um patógeno deve primeiro encontrar o caminho para uma cidade grande, no topo ou perto do topo, da hierarquia urbana. A partir daí, ele seguirá em cascata para cidades menores, com hierarquia mais baixa à medida que as pessoas percorrem essa rede, de cidades maiores para cidades menores.

Gould (1 993) demonstrou que a rápida disseminação do HIV/Aids nos Estados Unidos da América de 1984 a 1990 poderia ser descrita como uma difusão urbana hierárquica. Nos casos de propagação de uma doença infecciosa dentro de uma mesma cidade, o mecanismo comumente usado para explicá-la é a difusão por contágio; os indivíduos devem estar próximos uns dos outros, a fim de facilitar a transmissão do patógeno nos grupos humanos. A maioria das doenças epidêmicas depende do agrupamento dos hospedeiros humanos em densidades capazes de sustentar uma cadeia de transmissão por meio da difusão por contágio (Haggett, 2000).

Entretanto, modelos baseados inteiramente em descrições de difusão hierárquica e de contato podem ser inadequados se não considerarem a natureza altamente móvel e dinâmica das relações intra e intercidades. Inclui-se nessa interação a circulação de pessoas em busca de serviços, lazer e mercadorias, uma vez que o vírus pode ser disseminado por meio da infecção por superfícies contaminadas.

Desse modo, os modelos de disseminação devem levar em consideração as redes de transporte - aérea, rodoviária, hidroviária - com suas características, sua velocidade de conexão, sua capacidade e capilaridade. No Brasil há marcantes diferenças entre as regiões, com uma parte do território bem servida de aeroportos e rodovias bem 
pavimentadas e outras áreas onde a locomoção se dá basicamente por vias fluviais ou estradas precárias. Para avançar nessa direção, também é fundamental que a análise de disseminação seja baseada em redes que considerem o modo como a população se organiza, onde busca serviços e lazer.

\section{A DIFUSÃO E A INTERIORIZAÇÃO DO CORONAVÍRUS NAS CIDADES BRASILEIRAS}

No caso da Covid-19, que tem rápida velocidade de contágio e provoca alta letalidade entre os doentes, sobretudo em populações mais vulneráveis como idosos e pessoas que apresentam comorbidades associadas, entender a dinâmica da população e a capacidade de serviços de saúde instalados se torna mais importante. Embora sejam observados alguns padrões, a epidemia de Covid- 19 apresenta comportamento diferente daquele de outras epidemias recentes, principalmente em relação à velocidade de propagação, que é rápida e difusa.

Como na maioria dos países, o início da disseminação da doença no território nacional acompanhou os grandes hubs aeroportuários, e num segundo momento, pareceu se deslocar para municípios médios até chegar aos municípios menores. O tamanho populacional e, por consequência, o nível de centralidade do município parece responder pelo processo de propagação da Covid- 19.

\section{ENTENDENDO 0 TERRITÓRIO}

Os dados sobre casos e óbitos foram coletados no MonitoraCovid- 19 (Icict/Fiocruz, 2020). O número de habitantes dos municípios se refere às estimativas do Instituto Brasileiro de Geografia e Estatística (IBGE) para o ano de 2020 (IBGE, 2020)

O foco da análise das notas técnicas que deram origem a este capítulo foi o período de 26/02/2020 a 13/06/2020, que corresponde às semanas epidemiológicas' de 9 a 24 , o período de maior disseminação espacial no país.

Para acompanhar o fenômeno da interiorização, os municípios foram classificados segundo o número de habitantes em seis classes: até 10 mil, de 10 a 20 mil, de 20 a 50 mil, de 50 a 100 mil, de 100 a 500 mil e acima de 500 mil, conforme apresentado na Figura I.

\footnotetext{
- Semana epidemiológica é uma forma padronizada de contabilizar as semanas do calendário gregoriano. A equivalência entre semanas epidemiológicas e datas do calendário pode ser encontrada em $<$ https:// portalsinan.saude.gov.br/calendario-epidemiologico-2020>.
} 
Figura I - Municípios segundo tamanho da população - Brasil, 2020

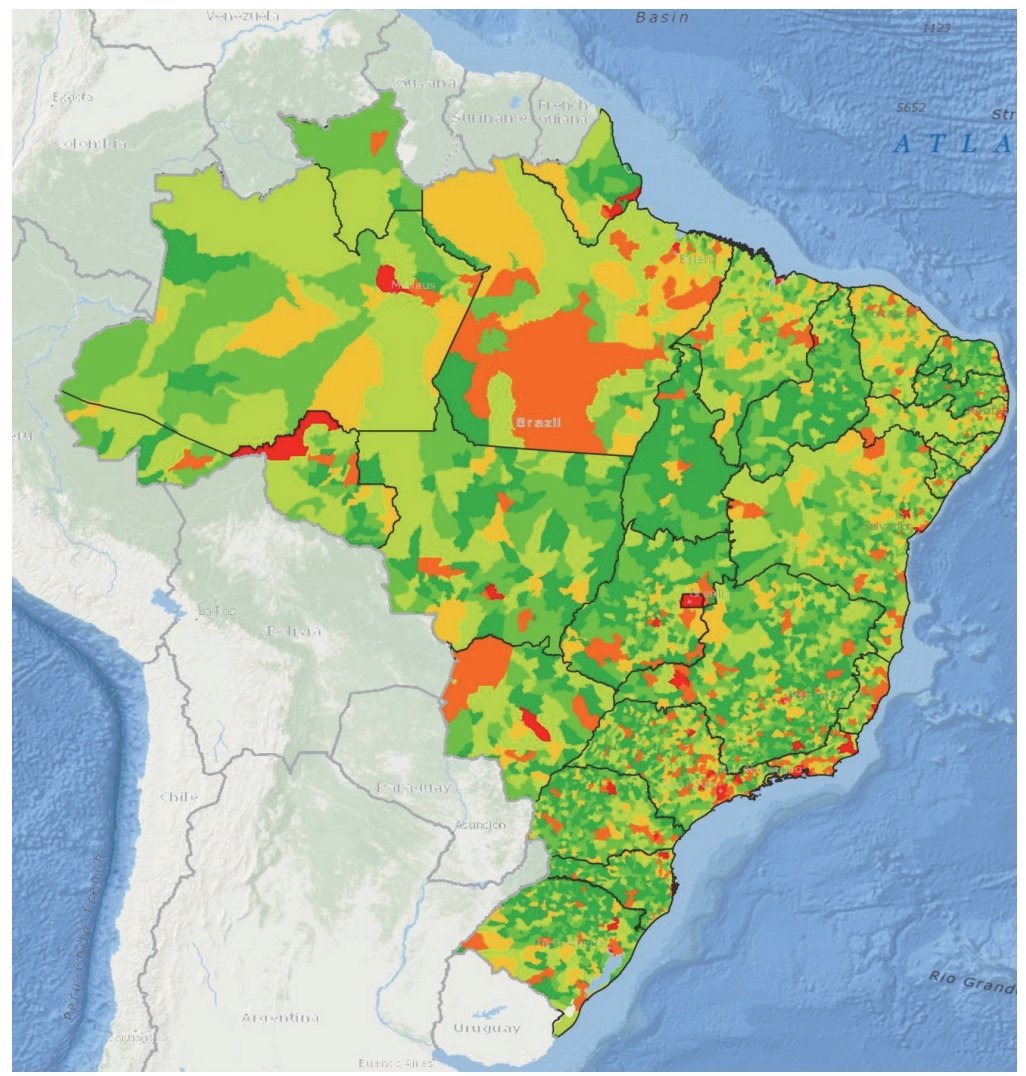

\section{Legenda}

Classes segundo tamanho da população

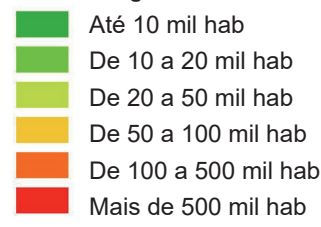

E para corroborar os resultados, foi analisada a difusão espacial utilizando-se também a classificação dos municípios definida pela pesquisa de Regiões de Influência das Cidades (Regic), produzida pelo IBGE (2008), que classifica os centros urbanos segundo a identificação de determinados equipamentos, serviços e estrutura de gestão pública e privada em hierarquias urbanas (Figura 2). Quanto mais alta a posição na hierarquia, maior o poder de atração de pessoas e a área de influência de uma cidade. Cinco grandes níveis hierárquicos foram identificados na Regic 2007: Metrópoles - principais centros 
urbanos do Brasil, que apresentam redes urbanas denominadas "redes de influência" com grande grau de extensão, algumas com influência em todo o território nacional; Capitais regionais - exercem influência no estado e em estados próximos; Centros subregionais - compreendem cidades que exercem influência preponderante sobre os demais centros próximos, por se distinguirem em termos de bens, serviços e outros aspectos de centralidade; Centros de zona - municípios ou cidades que apresentam importância regional, limitando-se às imediações/redondezas, e exercem funções elementares de gestão; e os Centros locais, representados pelos restantes dos municípios cuja importância não extrapola os limites municipais. As análises do IBGE consideram subclassificações que não serão abordadas aqui. Na edição de 2008, os quatro primeiros níveis hierárquicos eram constituídos por 802 centros urbanos, ao passo que no último nível estavam as 4.473 cidades cuja atuação é restrita apenas à área de seus municípios e seus habitantes.

\section{Figura 2 - Áreas de influência segundo hierarquia das cidades - Brasil, 2007}

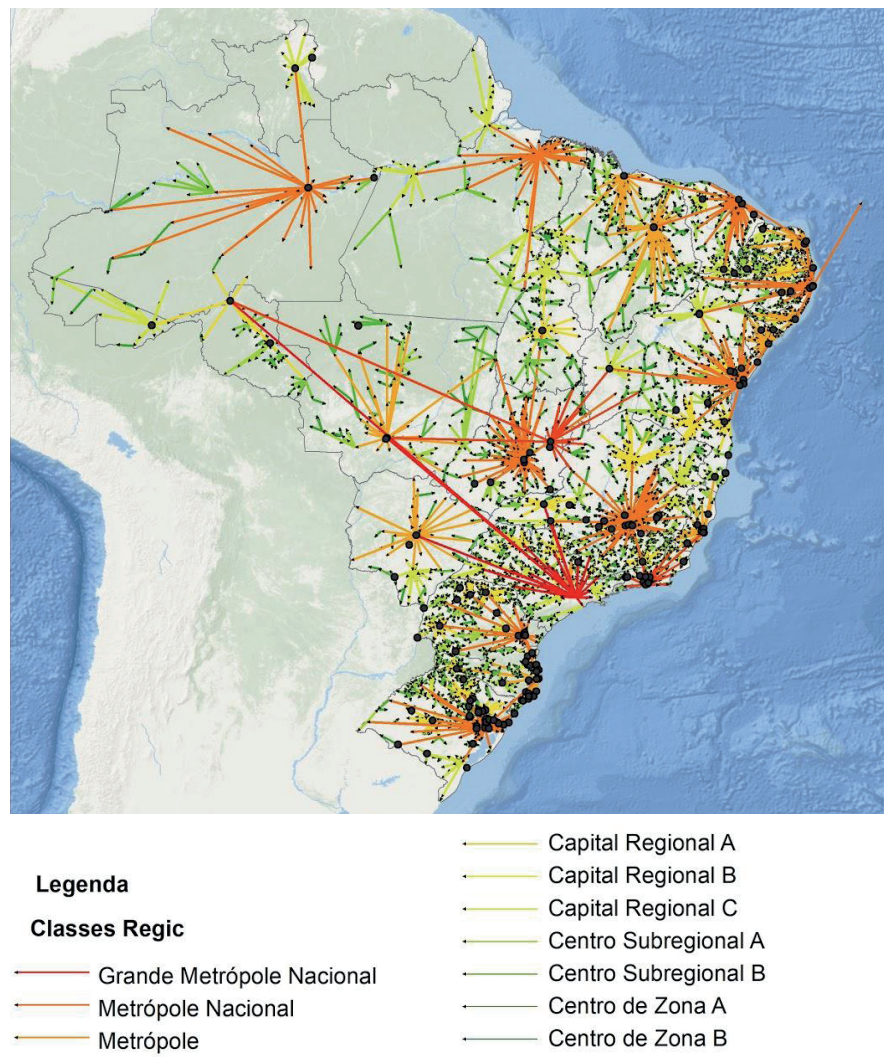

Fonte: dados da Regic 2007 (IBGE, 2008). 


\section{EXPLICITANDO 0 PROCESSO DE INTERIORIZAÇÃO DA COVID-19 NO BRASIL}

O processo de difusão da Covid- 9 no Brasil pareceu seguir a lógica observada na maioria dos países onde, a partir de grandes centros urbanos, a doença se disseminou para cidades médias e depois para as cidades pequenas, mais interioranas. A difusão em escala nacional entre os centros urbanos de nível mais alto parece ter decorrido de ligações aéreas e o espalhamento em escala regional dependeu das ligações rodoviárias e intraurbanas (no caso de grandes conurbações como as metrópoles).

Na Tabela I estão apresentados os municípios com casos positivos para Covid- I9, segundo classes de tamanho populacional. Observando-se a evolução de casos semana a semana, verifica-se um padrão de difusão hierárquica dos casos, isto é, a doença foi atingindo primeiramente as cidades mais populosas e distantes entre si e, posteriormente cidades menores e mais próximas foram se positivando (notificação de pelo menos I caso). Na semana epidemiológica 13 (22 a 28/03/2020), isto é, um mês após a entrada no Brasil, todos os municípios com mais de 500 mil habitantes já apresentavam casos da doença. Entre os municípios com população entre 100 mil e 500 mil habitantes, $42,4 \%$ dos municípios já apresentam a doença. Nos municípios com população entre 50 e 100 mil habitantes, 14,3\% têm presença de casos. Na semana epidemiológica 17 (19 a 25/04/2020), dois meses após o início da pandemia no país, os municípios com mais de 50 mil estavam quase todos positivados. Metade dos municípios com população entre 20 e 50 mil, 25,6\% dos municípios com população entre 10 a 20 mil habitantes e 10\% dos municípios com população de até 10 mil habitantes apresentavam casos de Covid-19. O Gráfico I permite observar a defasagem de tempo na chegada da doença aos grupos de municípios e como o crescimento da positividade municipal foi evoluindo ao longo das semanas. Verifica-se que as classes de municípios com maiores populações foram se positivando antes dos municípios menores. 


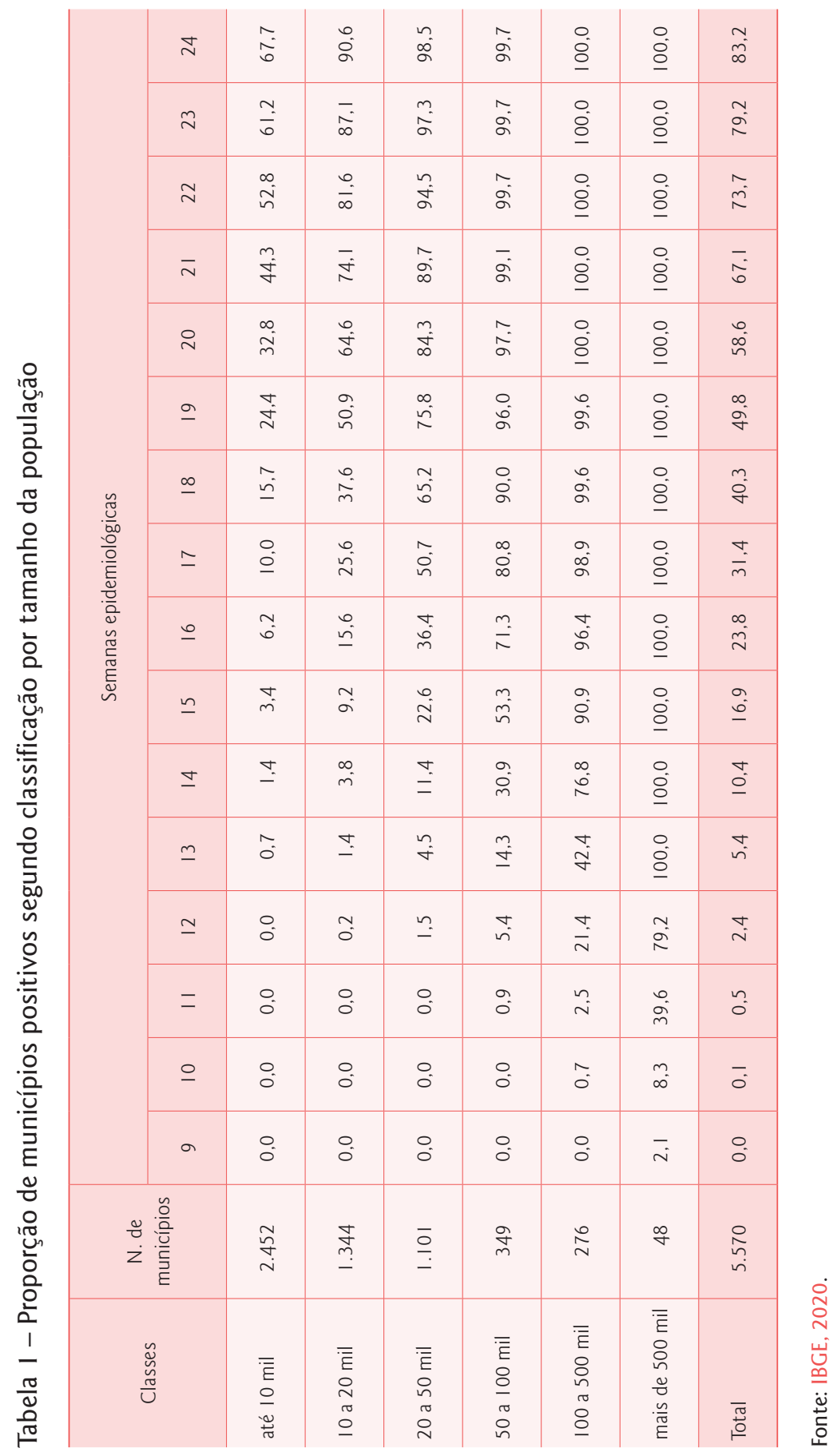


Gráfico I - Percentual de municípios com casos confirmados segundo a classe populacional por semana
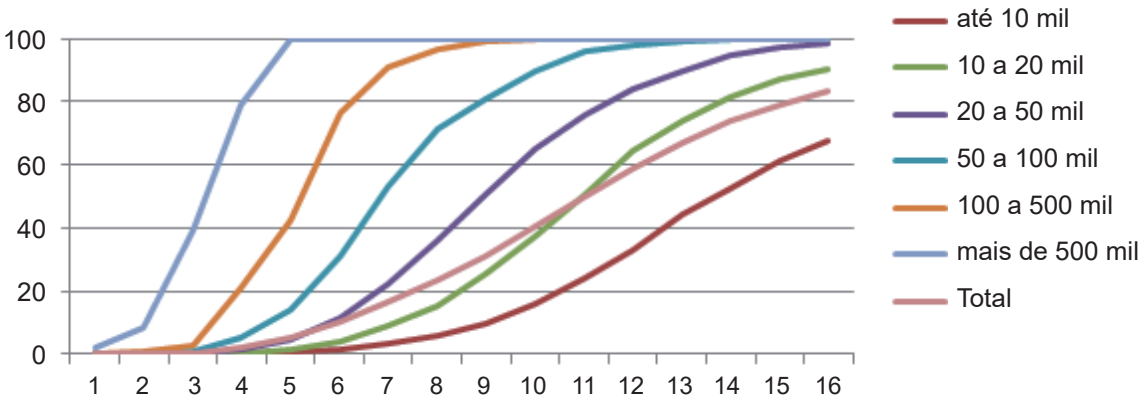

Fonte: IBGE, 2020.

A partir das informações analisadas na perspectiva da Regic 2007, é possível observar que os primeiros casos ocorreram nas duas principais metrópoles nacionais: São Paulo e Rio de Janeiro, que na hierarquia urbana brasileira vinculam o país à economia global, já que nelas estão localizados os principais aeroportos do Brasil. Em seguida, no geral, passam a ser registrados casos em Brasília e em outras metrópoles ao redor do país, com grande vinculação aérea às principais metrópoles e conectadas também a outros países. Assim, o coronavírus se espalhou por todas as regiões do país, inicialmente pelas metrópoles.

A difusão da doença continuou a ocorrer a partir das metrópoles e capitais regionais em direção a outros níveis da hierarquia urbana brasileira. Logicamente, não há uma relação linear de passagem de níveis. Centros urbanos inferiores mais próximos das capitais regionais e metrópoles registraram casos antes de centros sub-regionais mais interioranos. Uma aproximação dessa análise é exposta na Figura 3. 
Figura 3 - Municípios com casos de Covid- 19 e hierarquia urbana segundo a Regic 2007
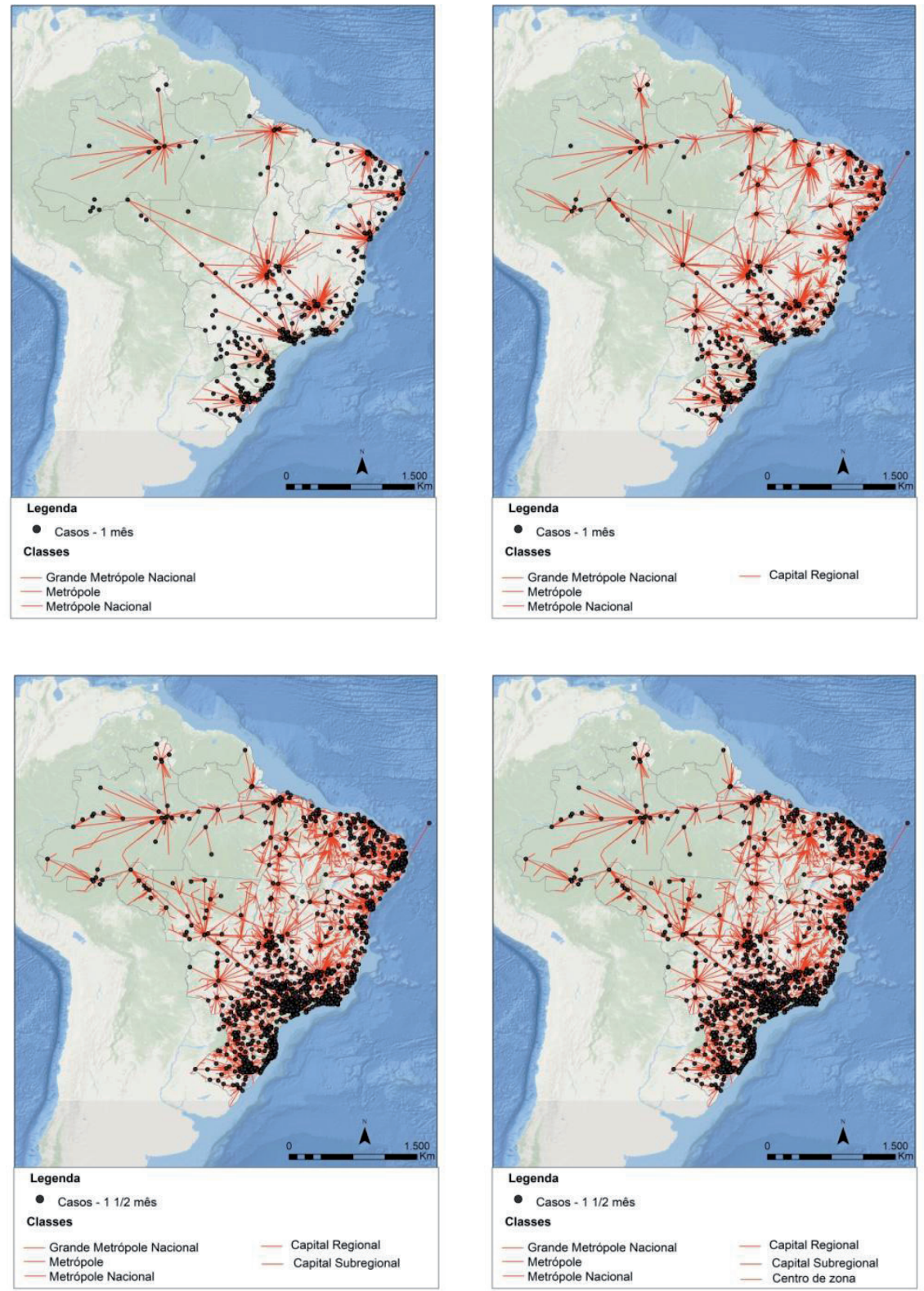

Fonte: IBGE, 2020. 
Os mapas da Figura 4 mostram a distribuição espacial dos casos de Covid- 19 por municípios desde o início, em 26 de fevereiro de 2020. Na semana epidemiológica 24 (7 a 13/06/2020) em todas as regiões e todos os estados da federação são observados casos de transmissão de forma comunitária da doença.

Figura 4 - Municípios com casos por semana epidemiológica - Brasil, 2020

$23 / 02$ a $29 / 02$

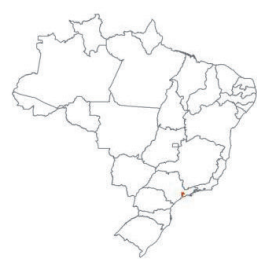

$22 / 03$ a $28 / 03$
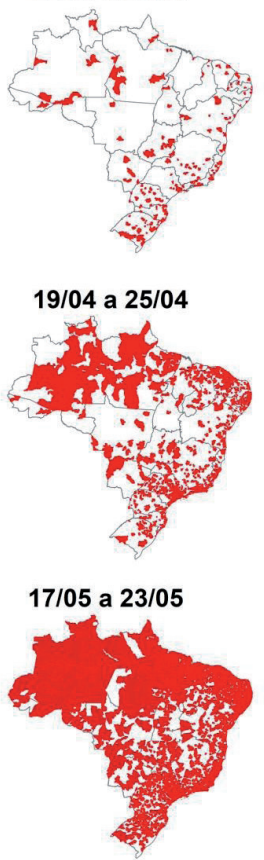

\section{Legenda}

Municípios

Caso

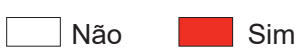

01/03 a 07/03

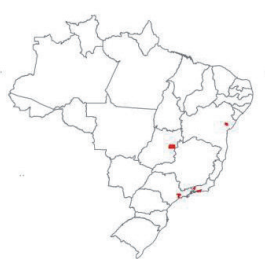

29/03 a 04/04



26/04 a 02/05

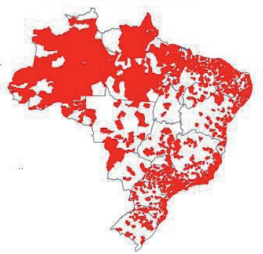

$24 / 05$ a $30 / 05$


05/04 a 11/04
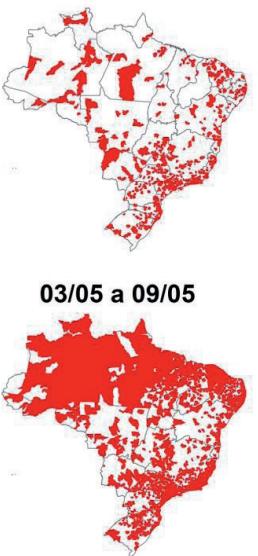

$15 / 03$ a $21 / 03$

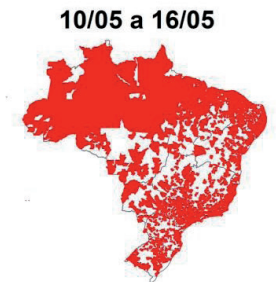

07/06 a 13/06

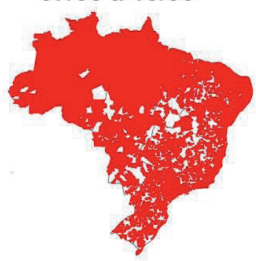

$12 / 04$ a $18 / 04$
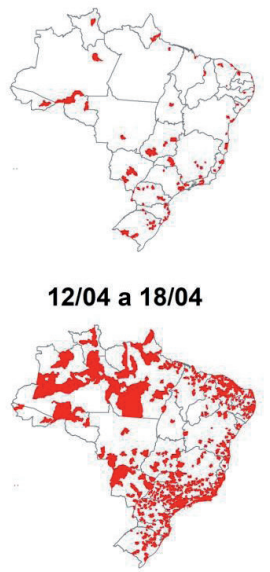
O tempo de recuperação lento associado à alta taxa de contaminação acaba por provocar o colapso em sistemas de saúde que não apresentem capacidade de prolongamento da curva epidêmica no tempo.

O avanço em direção às cidades menores revelou uma situação preocupante em razão da menor disponibilidade e capacidade dos serviços de saúde. A busca por atendimento ampliou a pressão sobre os serviços de saúde.

A disseminação da doença ocorreu das metrópoles e capitais regionais em direção aos centros de zona e centros locais. Porém, a busca por atenção à saúde ocorreu no sentido contrário, com os serviços mais complexos disponíveis nos centros de nível hierárquico mais alto, voltados para o atendimento dos casos clínicos mais problemáticos, que exigem serviços de maior complexidade, como as UTIs.

Por isso, explorar informações a respeito dos fluxos em busca da atenção à saúde registrados na Regic foi importante. A lógica de conformação das redes urbanas rompe o limite administrativo municipal e torna mais eficiente a organização do serviço, considerando que, apesar da autonomia dos municípios, muitos deles não apresentam capacidade operacional para atendimento, sobretudo de casos graves. O que pode ter influenciado o número de óbitos.

Ribeiro e colaboradores (2020) tratam esse tema dirigindo o olhar para o impacto da Covid- 9 nas cidades de acordo com seu tamanho. Segundo esses autores, cidades pequenas são proporcionalmente mais afetadas durante a propagação inicial da doença, por conta do número cumulativo de casos, e mortes per capita diminuem inicialmente com o tamanho da população. No entanto, a longo médio e prazos, as grandes cidades passam a apresentar maior incidência de casos e mortes. Provavelmente, esses padrões estão relacionados à existência, proporcionalmente, de mais infraestrutura de saúde nas grandes cidades e menor proporção de idosos nas grandes áreas urbanas. 
Figura 5 - Municípios com óbitos por semana epidemiológica - Brasil, 2020



$$
\text { 01/03 a 07/03 }
$$

$08 / 03$ a $14 / 03$

$15 / 03$ a $21 / 03$
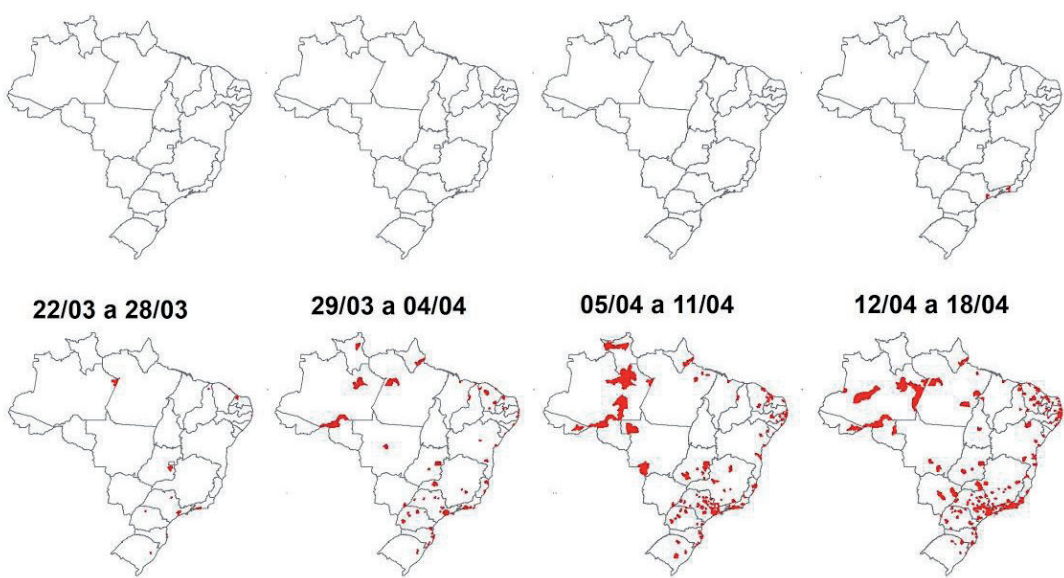

$05 / 04$ a $11 / 04$

$12 / 04$ a $18 / 04$


\section{Legenda}

Municípios

Óbitos


A Figura 5 mostra um conjunto de mapas com a distribuição espacial da ocorrência de óbitos por Covid- 19 nos municípios brasileiros por semana epidemiológica. 


\section{REFLEXÕES FINAIS}

O espalhamento da pandemia para cidades de menor porte acentua a preocupação com a organização do Sistema único de Saúde (SUS) e com o fluxo de pacientes e insumos para suprir as necessidades desses municípios cujos serviços de saúde têm, em geral, capacidade limitada.

Os primeiros dados sobre a pandemia de Covid-I9 no Brasil mostraram que as grandes cidades foram mais afetadas até a semana epidemiológica 13 e que nas semanas subsequentes a transmissão se estendeu para cidades menores. Essa difusão se deu em maior ou menor velocidade em função das medidas de restrição de mobilidade que foram sendo implementadas por estados e municípios. O transporte rodoviário teve papel importante na difusão da doença nas próximas semanas.

O comportamento espacial das pessoas foi uma das chaves para se entender a difusão espacial do Sars-CoV-2 (Meng et al., 2005). Em relação à disseminação da pandemia de Covid-19, verificou-se a importância de medidas de isolamento social e de restrições ao deslocamento de pessoas e mercadorias, limitando-o aos serviços essenciais (saúde, policiamento, entre outros) e aos artigos de primeira necessidade nesse momento.

Freitas e colaboradores (2020) oferecem ferramentas para a compreensão e apoio à decisão no caso de intervenções de mobilidade intermunicipais relacionadas à pandemia de Covid-19 e a outras epidemias: a análise das redes de mobilidade intermunicipais brasileiras com diferentes limiares de fluxo no início do surto, quando a interiorização da doença ainda não está em andamento, e a abordagem de redes complexas, considerando que a rede de mobilidade da população serve como proxy para a propagação do Sars-CoV-2.

\section{REFERÊNCIAS}

HAGGETT, P. The Geographical Structure of Epidemics. Oxford: Oxford University Press, 2000.

MENG, B. et al. Understanding the spatial diffusion process of severe acute respiratory syndrome in Beijing. Public Health, I I 9(12): I.080-1.087, 2005.

FREITAS, V. L. S. et al. The correspondence between the structure of the terrestrial mobility network and the spreading of Covid- I 9 in Brazil. Cadernos deSaúde Pública, 36(9): e00 I 84820,2020. Disponível em: <www. scielo.br/scielo.php?script $=$ sci_arttextEpid $=$ SO I 02-3 I IX202000090 5008Elng =enEnrm =iso > . Acesso em: 26 abr. 2021.

GOULD, P. The Slow Plague: a geography of the Aids pandemic. Cambridge: Blackwell, 1993. 
INSTITUTO BRASILEIRO DE GEOGRAFIA E ESTATÍSTICA (IBGE). Regiões de Influência das Cidades 2007. Rio de Janeiro: IBCE, 2008. Disponível em: <www.ibge.gov.br/geociencias/cartas-e-mapas/ redes-geograficas/I 5798-regioes-de-influencia-das-cidades.html?edicao $=16$ l $68 \varepsilon t=$ downloads $>$. Acesso em: I maio 2020.

INSTITUTO BRASILEIRO DE GEOGRAFIA E ESTATÍSTICA (IBGE). Projeção da população do Brasil por sexo e idade: 1980-2050: revisão 2008. Rio de Janeiro: IBGE, Coordenação de População e Indicadores Sociais, 2020. Disponível em: <www.ibge.gov.br/estatisticas/sociais/populacao/9l09-projecao-dapopulacao.html? =Et=downloads $>$. Acesso em: 29 abr. 2020.

INSTITUTO DE INFORMAÇÃO CIENTÍFICA E TECNOLÓGICA EM SAUDE/FUNDAÇÃO OSWALDO CRUZ (ICICT/FIOCRUZ). Monitora Covid- 19. Rio de Janeiro, 2020. Disponível em: < https://bigdatacovid I 9.icict.fiocruz.br/>. Acesso em: 30 mar. 2020.

RIBEIRO, H. V. et al. City size and the spreading of Covid- 9 in Brazil. PlosOne, I 5(9): e0239699, 2020. Disponível em: <https://doi.org/l 0.1371/journal.pone.0239699>. Acesso em: 26 abr. 2021 . 


\title{
Como a Aceleração dos Casos e Óbitos, Para Além da Tendência, Explica a Dinâmica da Covid-19 no Brasil?'
}

\author{
Raphael Mendonça Guimarães, João Roberto Cavalcante, \\ Tatiana de Araújo Eleutério, Mariana dos Santos Velasco, \\ Rachel de Almeida Menezes, Regina Bontorim Gomes, \\ Delson Silva e Gustavo Pedroso de Lima Brusse
}

O presente capítulo reportamo-nos à produção da nota técnica intitulada "Como a aceleração dos casos e óbitos, para além da tendência, explica a dinâmica da Covid- 9 no Brasil?", em meio ao contexto de novo aumento de número de casos. Cenário marcado por especulações sobre o repique de casos em decorrência das fases de flexibilização, de surgimento da segunda onda da pandemia e da discussão sobre imunidade permanente ou temporária em razão da infecção prévia. Fato é que a inspeção das curvas de casos e óbitos nos sugerem cenários, e pouco se fala sobre as principais informações que podem ser extraídas dessas curvas. Para além dos coeficientes matemáticos tradicionalmente utilizados nas análises de séries temporais, a aceleração dos casos e óbitos é importante para caracterizar e comparar as curvas epidêmicas dos distintos lugares. A incorporação desse coeficiente (aceleração) em uma análise de série temporal para a Covid-19 permite melhor compreensão da situação epidemiológica das unidades da federação brasileiras. Dito isso, procuramos aqui explorar essa possibilidade de análise.

\section{EVOLUÇÃO DA COVID-19 NO BRASIL}

A Covid-19 (do inglês Coronavirus disease 2019) é uma doença causada por um betacoronavírus nomeado Sars-CoV-2, de amplo espectro clínico, que pode gerar de infecção assintomática e síndrome gripal até casos graves, caracterizando a síndrome respiratória aguda grave (Srag) (Brasil, 2020a). No Brasil, o Ministério da Saúde decretou Emergência de Saúde Pública de Importância Internacional (Espii) no dia 30 de janeiro de 2020 e Emergência de Saúde Pública de Importância Nacional (Espin) no dia 3 de

\footnotetext{
' Apoio financeiro: Programa Inova - Edital Ideias Inovadoras - Resposta Rápida Covid- 19.
} 
fevereiro. Em I I de março de 2020, a Organização Mundial da Saúde (OMS) caracterizou a situação como pandemia em decorrência da disseminação e severidade da infecção em diversos países e continentes (WHO, 2020), e em 20 de março o Ministério da Saúde brasileiro constatou a transmissão comunitária do Sars-CoV-2 em todo o território nacional (Brasil, 2020b).

De acordo com a atualização do Painel Coronavírus do Ministério da Saúde, até o dia 3 de dezembro de 2020 o Brasil acumulou 6.487.084 casos confirmados e 175.270 óbitos, o correspondente a uma letalidade de 2,7\%. Diante da alta infectividade da doença e da indisponibilidade de medicamentos e vacinas específicas para o Sars-CoV-2, a OMS preconiza medidas não farmacológicas que incluem distanciamento social, etiqueta respiratória e lavagem das mãos como medidas eficientes de prevenção (Brasil, 2020b, 2020c).

\section{DESIGUALDADE REGIONAL E PREVISÃO DE CENÁRIOS}

O progresso de estudos aponta que não é possível prever como a pandemia irá evoluir; em cada território se observa um comportamento diferente devido a fatores como a dinâmica de propagação, distanciamento social, adesão de medidas de proteção individual, densidade demográfica, tempo de incubação viral, taxas de transmissão, fatores meteorológicos, enfim, aspectos próprios e característicos de cada território geográfico e população (Cássaro \& Pires, 2020; Pinto et al., 2020). O número médio de novas infecções geradas por uma pessoa infectada com Sars CoV-2 $\left(R_{0}\right)$ é estimado entre 2,2 e 3,6, ou seja, cada pessoa infectada seria uma fonte de infecção para 2 a 4 pessoas suscetíveis (Callejas et al., 2020).

No Brasil, em relação às questões sociais, adiciona-se a existência de um contexto de forte desigualdade social, com estratos da população vivendo em situação precária, em razão tanto da dificuldade de acesso ao saneamento básico quanto das condições de habitação e aglomeração populacional. É importante reconhecer tais características, a fim de caracterizar o território nacional, uma vez que a análise desses indicadores sociais básicos é essencial para apoiar as decisões do governo e melhorar a adesão da comunidade às medidas preventivas (Guimarães, Eleuterio $\mathcal{E}$ Monteiro-da-Silva, 2020). A caracterização das unidades da federação é importante para o reconhecimento de locais mais ou menos críticos para a intervenção imediata da vigilância em saúde e da atenção em saúde, por meio da adoção de medidas de supressão e de planos conjuntos voltados para controlar os efeitos da disseminação da Covid- I9, bem como seu potencial de gravidade (Guimarães, Eleuterio \& Monteiro-da-Silva, 2020). 
A identificação de localidades que enfrentam taxas de mortalidade mais altas e heterogêneas e maior vulnerabilidade socioeconômica é relevante, visto que uma mortalidade alta e mais heterogênea deverá impor maior complexidade ao sistema local de saúde, ao demandar uma resposta também heterogênea em termos de recursos físicos, humanos, de aporte de medicamentos e de gestão. Assim, é necessário encontrar meios para que seja possível, com esses recursos, manejar e reduzir a pressão de uma demanda por serviços de saúde alta e diferenciada. Logo, infere-se que é também imprescindível examinar a distribuição e a aceleração da incidência e da mortalidade por Covid- 9 no Brasil e em suas unidades da federação (UFs), a fim de analisar suas vulnerabilidades (Rache, Nunes \& Rocha, 2020). Nesse sentido, procuramos aqui descrever e analisar os comportamentos da distribuição de incidência e mortalidade por Covid- I 9 no Brasil, por unidades da federação, e suas respectivas acelerações, com o uso de dados públicos disponíveis nas bases de dados do Ministério da Saúde.

\section{UMA PROPOSTA DE ANÁLISE}

Para que fosse possível proceder à análise pretendida, foi realizado um estudo ecológico descritivo para avaliar a distribuição e aceleração de casos e óbitos de Covid- 19 por semana epidemiológica (SE), tomando como unidades de análise o Brasil e suas UFs até 17 de outubro de 2020, último dia da SE 42.

Em 2020, o Brasil tem uma população aproximada de 210 milhões de habitantes em 26 estados e I Distrito Federal, totalizando 27 UFs, as quais são agrupadas em cinco macrorregiões geográficas (Centro-Oeste, Nordeste, Norte, Sudeste e Sul) com características sociodemográficas, econômicas e de saúde bem distintas entre si (Brasil, 2019; IBGE, 2017).

Consideramos o período entre 26 de fevereiro, data da confirmação do primeiro caso no país, e 17 de outubro de 2020 (data de extração dos dados). A população do estudo foram casos e óbitos novos confirmados pela doença, por local de residência e agregados por país e UFs do Brasil, disponibilizados pelo Painel Coronavírus do Ministério da Saúde de modo público, agrupado e não nominal (Brasil, 2020b). Segundo a definição de caso confirmado de Covid- 19 no Brasil adotada atualmente pelo Ministério da Saúde e pelas UFs,

casos confirmados são indivíduos que possuem confirmação laboratorial para SarsCoV-2, independente de sinais e sintomas, ou por critério clínico-epidemiológico, quando o indivíduo possui histórico de contato próximo ou domiciliar, nos últimos sete dias antes do aparecimento dos sintomas com caso confirmado laboratorialmente, para o qual não foi possível realizar o teste laboratorial. (Brasil, 2020c) 
Para realizar uma inspeção visual do comportamento dos indicadores selecionados, foram elaborados gráficos de casos e óbitos novos para o Brasil e suas 27 UFs, considerando o início a partir da SE do primeiro caso ou óbito novo em cada localidade, com o intuito de descrever em que fase da epidemia o Brasil e suas UFs estão e como estão se comportando as curvas epidêmicas de cada localidade. Também foram elaborados gráficos da aceleração de casos e óbitos para o Brasil e suas 27 UFs. A aceleração foi calculada por meio da divisão da velocidade de casos e óbitos em cada semana pelo tempo. Como o tempo foi sempre o intervalo de uma semana, o valor da aceleração foi sempre igual ao valor da velocidade. A velocidade foi calculada por meio da subtração de casos e óbitos novos da SE subsequente pela SE atual.

Em todos os gráficos foram ainda obtidas curvas de ajuste para descrever mais claramente o comportamento das taxas e da aceleração no tempo.

Entre 26 de fevereiro (data do primeiro caso no Brasil) e 17 de outubro de 2020 (final da SE 42) foram registrados 5.224.362 casos e 153.675 óbitos confirmados no Brasil. As UFs com mais casos confirmados foram São Paulo ( 1.062 .634 casos), Bahia (334.697 casos), Minas Gerais (333.998 casos), Rio de Janeiro (289.569) e Ceará (264.245). Por sua vez, as UFs com mais óbitos confirmados foram São Paulo (37.992 óbitos), Rio de Janeiro (19.7 I5), Ceará (9.207), Pernambuco (8.480) e Minas Gerais (8.405).

A distribuição de casos novos de Covid-19 no Brasil cresceu a cada semana de forma vertiginosa, atingiu seu pico na SE 30 e se manteve constante até a SE 36, quando começou a declinar e apresentar queda constante até a SE 42. Os mesmos comportamentos foram observados na maioria da UFs, com explosão após as primeiras semanas de epidemia, picos a partir da SE 26 e declínios principalmente após a SE 36, com as curvas acentuadas para a direita, com exceção de Acre, Amazonas, Amapá, Pará na região Norte, e Ceará na região Nordeste, que tiveram os picos entre as SEs 21 e 26, apresentando curvas com acentuação à esquerda. Os outliers observados nas distribuições de Roraima e Rondônia na região Norte, Ceará e Rio Grande do Norte, na região Nordeste, Rio de Janeiro na região Sudeste e Santa Catarina na região Sul sugerem demora na entrega de resultados em semanas anteriores e liberação de muitos resultados em uma mesma semana (Figura I).

A aceleração de casos novos de Covid- 19 no Brasil ganhou velocidade a partir da SE 16 e somente apresentou desaceleração após a SE 27, o que gerou uma distribuição de casos novos em crescimento por mais de três meses, ameaçando o fim dos leitos disponíveis e possível colapso no sistema de saúde. A maioria das UFs apresenta também aceleração de casos novos após as primeiras SEs de registro dos respectivos 
primeiros casos de cada local, seguindo a tendência do Brasil, porém é possível observar comportamentos diferentes nas acelerações do Tocantins na região Norte, de Goiás, Mato Grosso, Mato Grosso do Sul na região Centro-Oeste, e do Rio Grande do Sul na região Sul, que apresentam as maiores oscilações de aceleração e desaceleração após a SE 27. Também foi possível observar ligeiro aumento da velocidade de casos novos após a SE 40 no Acre e no Amazonas na região Norte, na Paraíba, no Piauí e em Sergipe na região Nordeste e no Espírito Santo na região Sudeste; portanto, faz-se necessário que autoridades se mantenham atentas ao comportamento das curvas nas próximas semanas, pois essas curvas em ascensão podem indicar uma nova explosão de casos. Outliers como os de Santa Catarina na região Sul, que mostraram aceleração e desaceleração em duas semanas, sugerem que havia um acúmulo de casos que aguardavam resultado laboratorial e foram liberados todos na mesma semana (Figura 2).

A distribuição de óbitos novos de Covid- 19 no Brasil seguiu a mesma forma da distribuição de casos novos, incluindo as UFs. Como óbitos por Covid- 19 acontecem em sua maioria por pacientes que são dos grupos de risco, ou quando o sistema de saúde entra em colapso, as curvas de óbitos novos não atingiram picos, pois se comportaram com formato de monte, mantendo-se constantes por mais de dez semanas, a partir da SE 20, com curvas acentuadas à direita. Por outro lado, os estados Acre, Amazonas, Amapá e Pará na região Norte, Alagoas, Ceará, Maranhão e Pernambuco na região Nordeste e Rio de Janeiro na região Sudeste demonstraram explosão de óbitos nas primeiras semanas de epidemia, com as curvas acentuadas à esquerda, sugerindo que estavam menos preparados para lidar com a crise que os demais estados (Figura 3).

A velocidade da ocorrência de óbitos novos por Covid- 19 no Brasil se acelerou a partir da SE 12 e somente apresentou desaceleração após a SE 22; portanto, com distribuição de óbitos novos em crescimento por mais de três meses e com UFs com número de óbitos acima da capacidade hospitalar de internação que era possível na época. A maioria das UFs apresenta curva de desaceleração, com perda rápida da velocidade de óbitos novos após a SE 26, o que nos faz pensar que isto se deu quando os profissionais da saúde se adaptaram aos novos protocolos, atualizados quase que diariamente, e também na mesma época de queda abrupta de casos, fruto das medidas de isolamento impostas por governos e UFs. No entanto, foi possível observar aumento na aceleração de óbitos, que ganhou velocidade em Alagoas, Piauí, Rio Grande do Norte e Sergipe, na região Nordeste e no Espírito Santo na região Sudeste; portanto, faz-se necessária, nas próximas semanas, atenção ao comportamento das curvas, que quando em ascensão podem indicar uma nova explosão de óbitos. Outliers como os de Santa Catarina na região Sul, que já haviam sido observados na aceleração de casos, sugerem 
também um acúmulo de óbitos que aguardavam resultado laboratorial e foram liberados todos na mesma semana (Figura 4). É importante mencionar que, mesmo utilizando os dados agregados por semana epidemiológica, com o objetivo de reduzir o erro de mensuração, em alguns estados, como o Rio de Janeiro, há uma demora maior que o tempo de uma semana para se obter o resultado de exames, por sobrecarga dos Laboratórios Centrais de Saúde Pública (Lacen), o que faz com que a curva atual seja menor do que deveria ser.

Figura I - Distribuição de casos novos de Covid- 19 no Brasil e por UF e curvas de ajuste por semana epidemiológica de 2020


RO




Figura I - Distribuição de casos novos de Covid- 9 no Brasil e por UF e curvas de ajuste por semana epidemiológica de 2020 (continuação)



TO



BA


PE

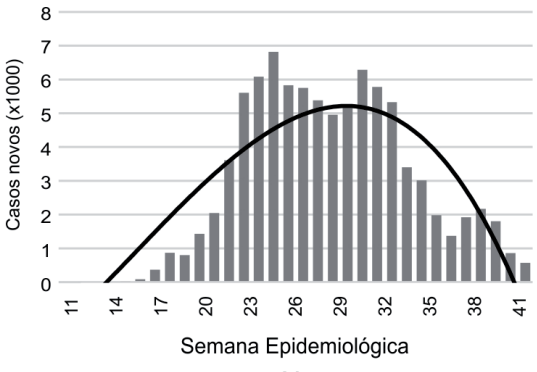

$\mathrm{AL}$


PB




Figura I - Distribuição de casos novos de Covid- 19 no Brasil e por UF e curvas de ajuste por semana epidemiológica de 2020 (continuação)



RN



12



MT



ES

Figura I - Distribuição de casos novos de Covid- 19 no Brasil e por UF e curvas de ajuste por semana epidemiológica de 2020 (continuação)


PR

RS


Fonte: elaborada pelos autores. 
Figura 2 - Aceleração de casos novos de Covid- 9 no Brasil e por UF e curvas de ajuste por semana epidemiológica de 2020



$A C$



Semana Epidemiológica

AP




Semana Epidemiológica

$\mathrm{RO}$



TO



AM



PA



RR



$\mathrm{AL}$ 
Figura 2 - Aceleração de casos novos de Covid- 19 no Brasil e por UF e curvas de ajuste por semana epidemiológica de 2020 (continuação)



BA



MA



PE



RN



CE



PB



$\mathrm{PI}$




Figura 2 - Aceleração de casos novos de Covid- 9 no Brasil e por UF e curvas de ajuste por semana epidemiológica de 2020 (continuação)


DF
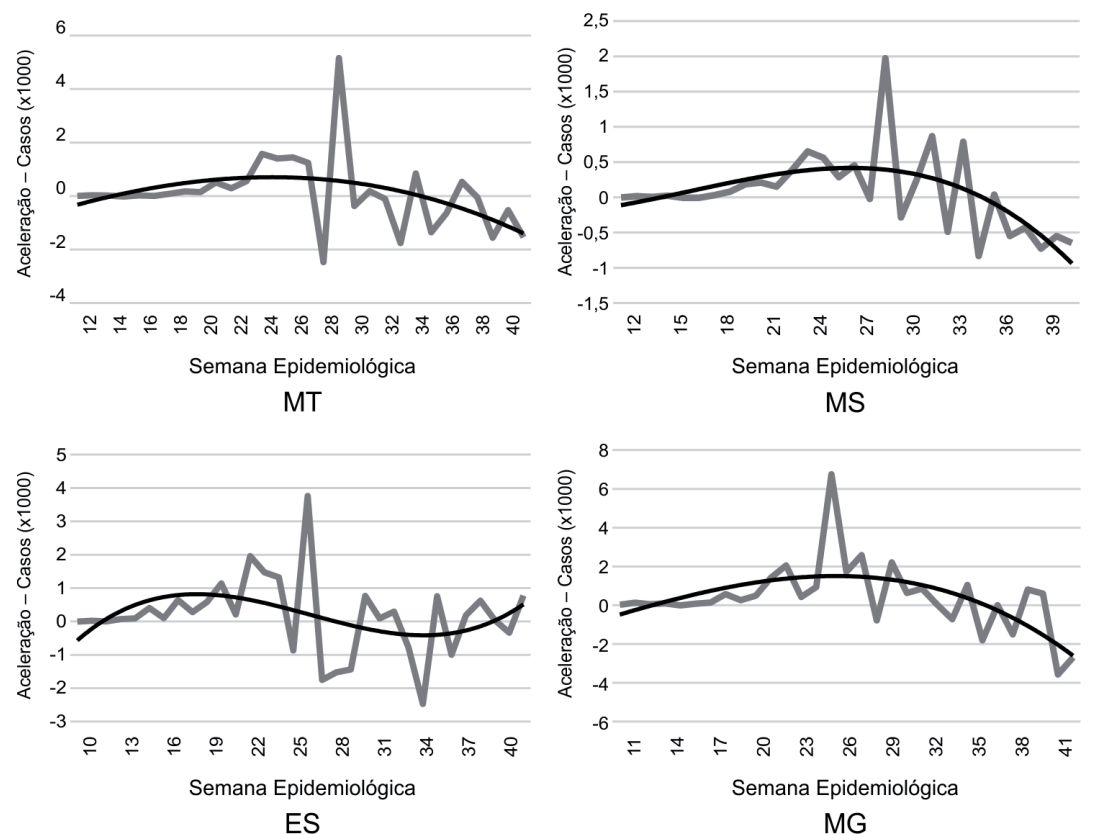

ES

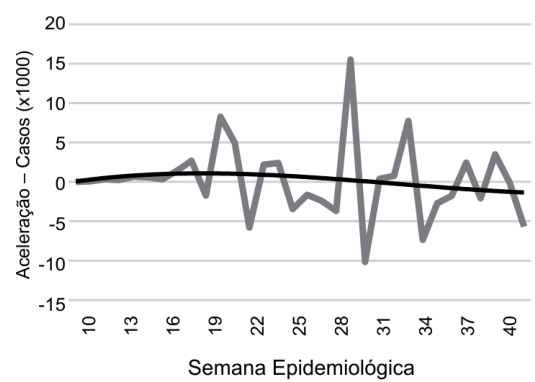

RJ




Figura 2 - Aceleração de casos novos de Covid- 19 no Brasil e por UF e curvas de ajuste por semana epidemiológica de 2020 (continuação)

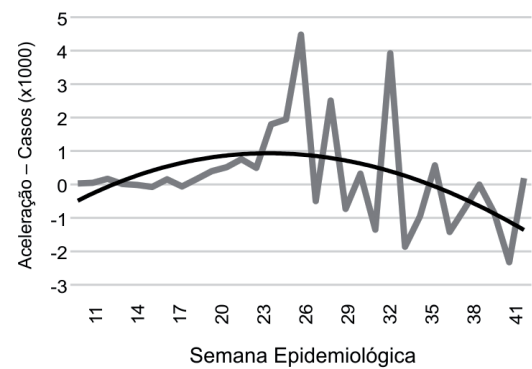

PR

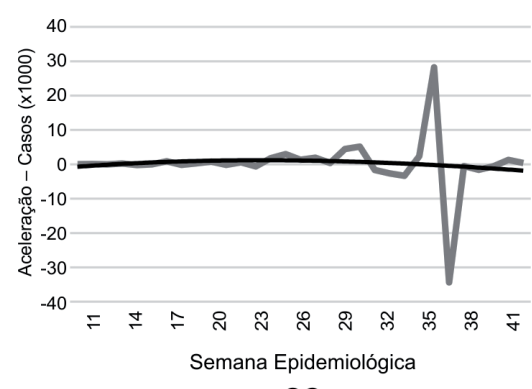

$\mathrm{SC}$

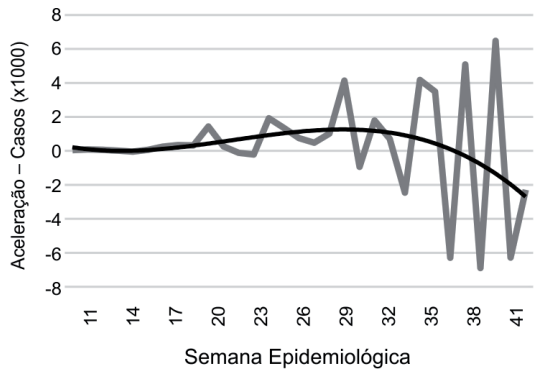

RS

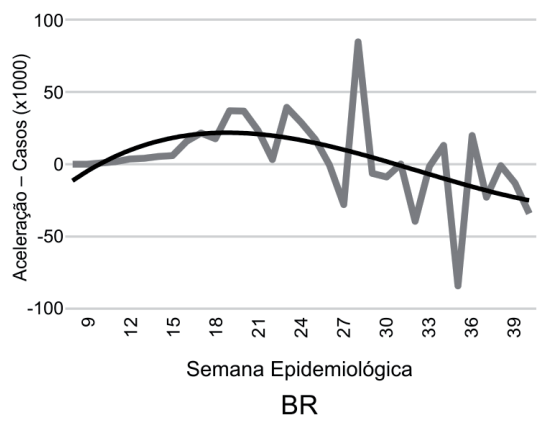

Fonte: elaborada pelos autores. 
Figura 3 - Distribuição de óbitos novos de Covid- 19 no Brasil e por UF e curvas de ajuste por semana epidemiológica de 2020

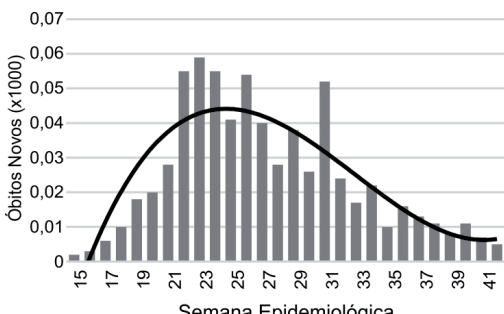

Semana Epidemiológica

$A C$

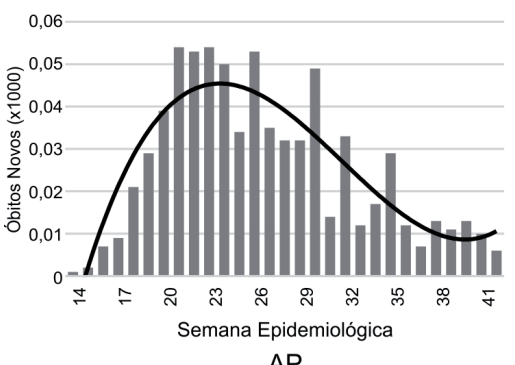

AP

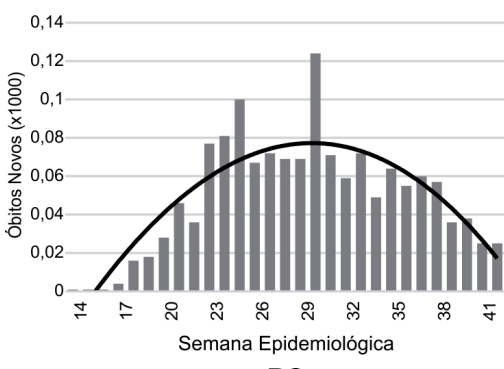

RO

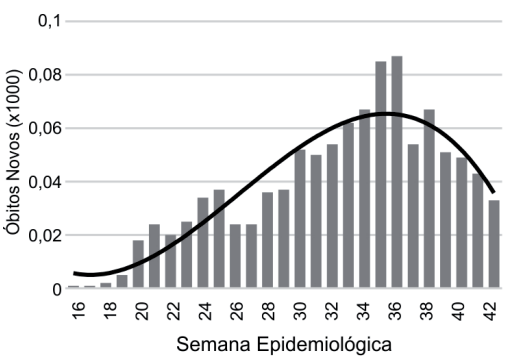

TO

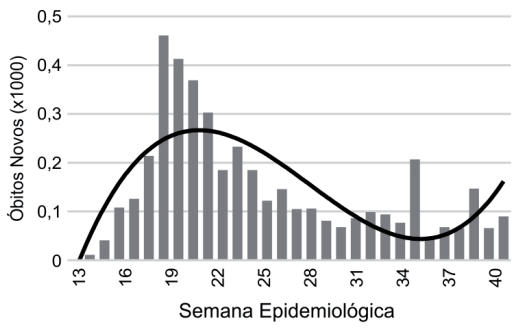

AM

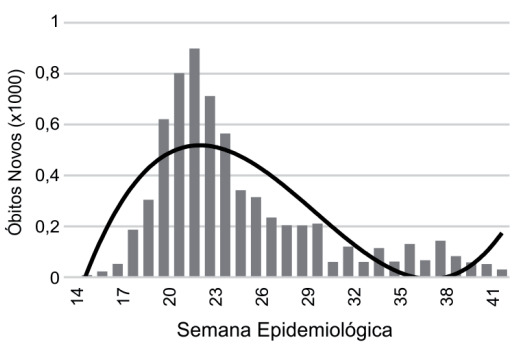

PA

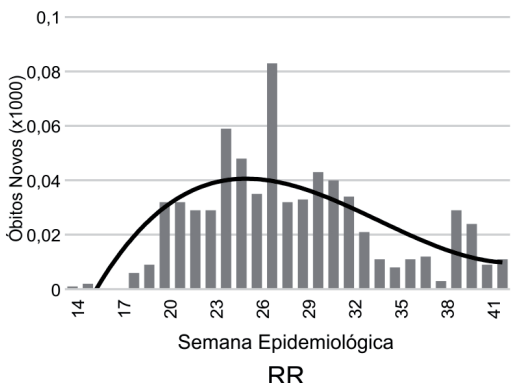

0,2

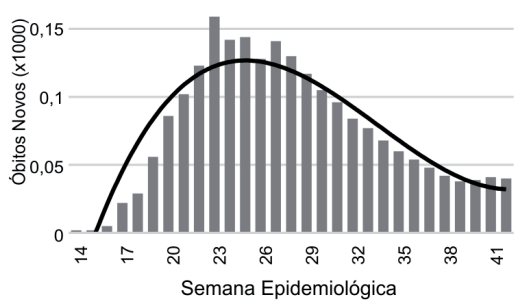

$A L$ 
Figura 3 - Distribuição de óbitos novos de Covid- 19 no Brasil e por UF e curvas de ajuste por semana epidemiológica de 2020 (continuação)

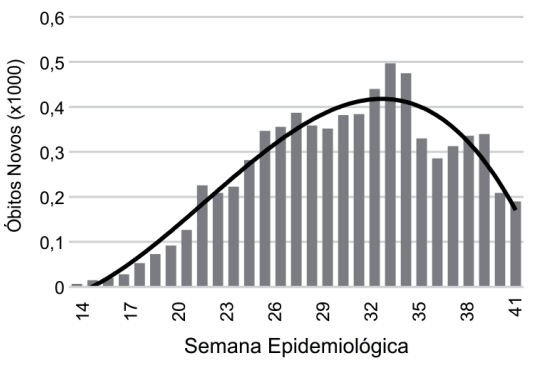

BA

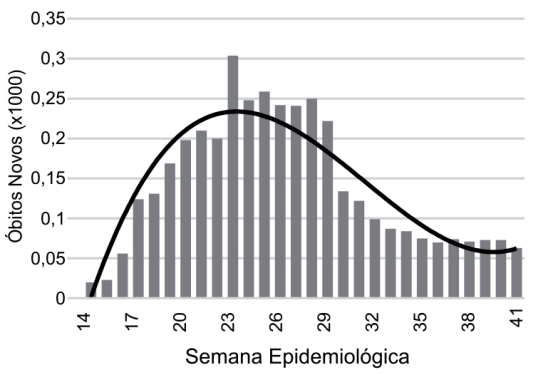

MA

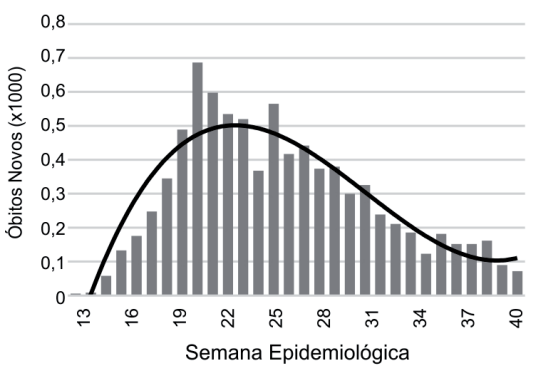

PE

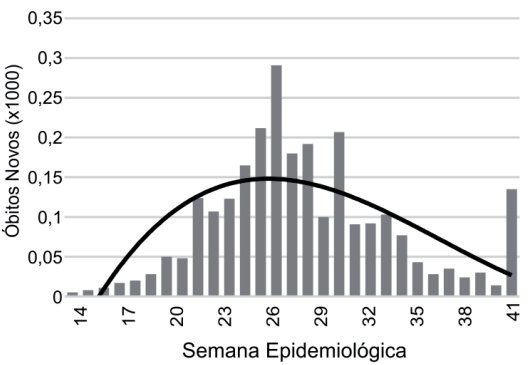

RN
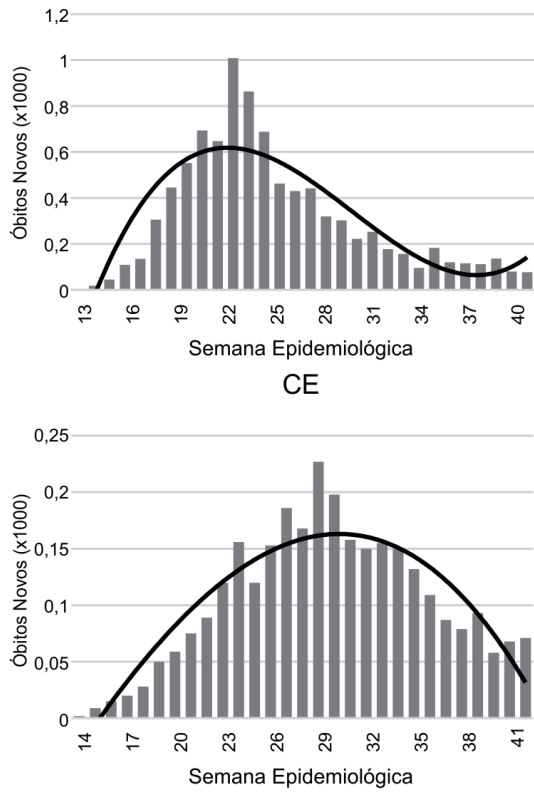

PB

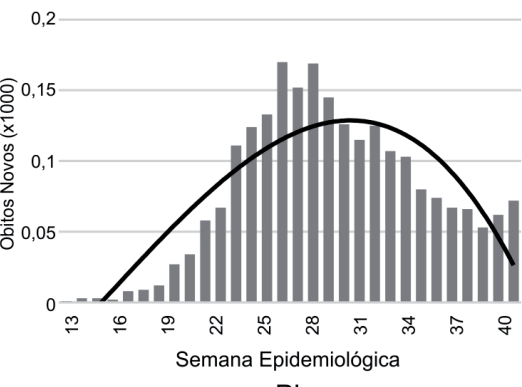

$\mathrm{PI}$

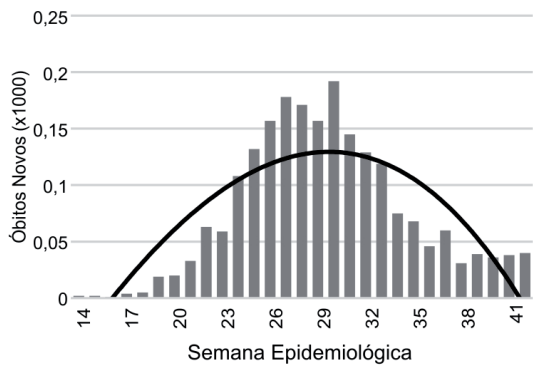

SE 
Figura 3 - Distribuição de óbitos novos de Covid- 19 no Brasil e por UF e curvas de ajuste por semana epidemiológica de 2020 (continuação)
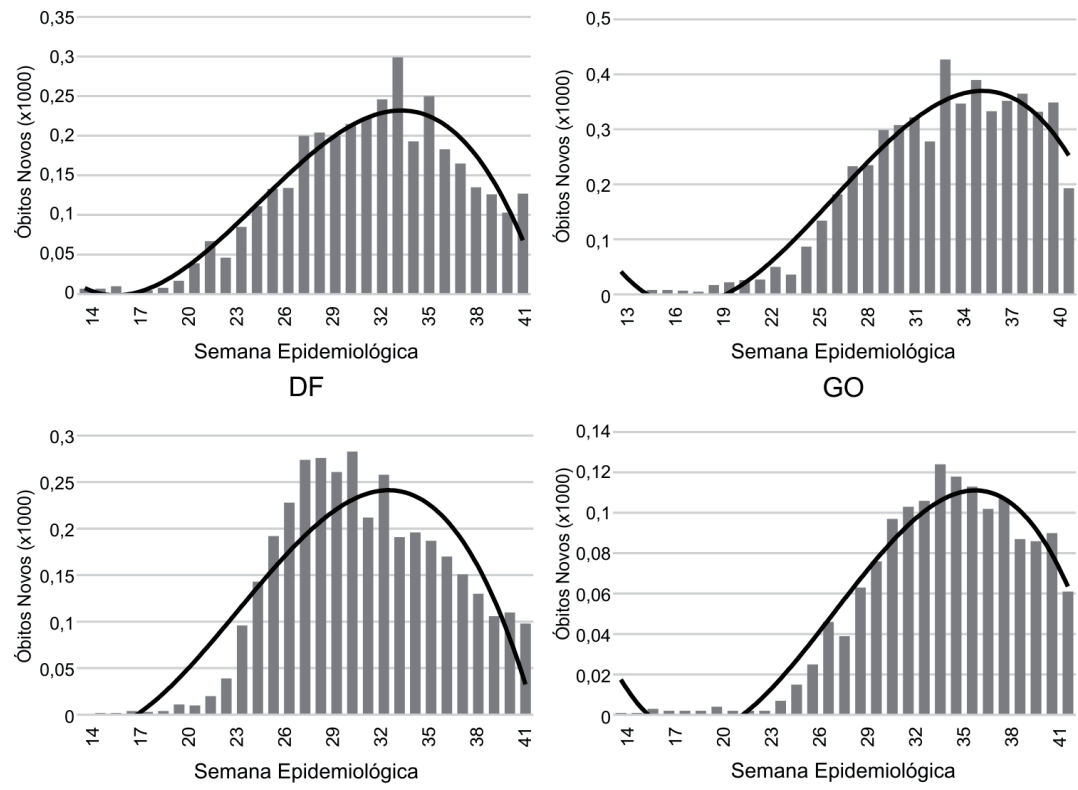

MT

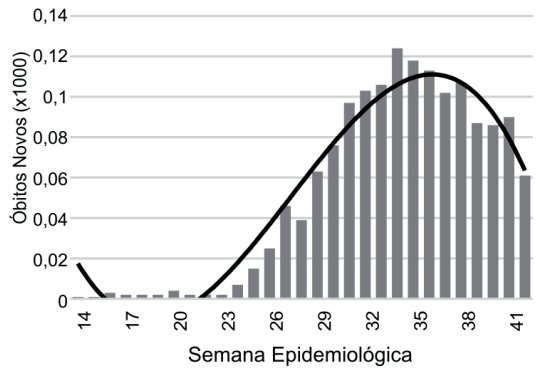

MS

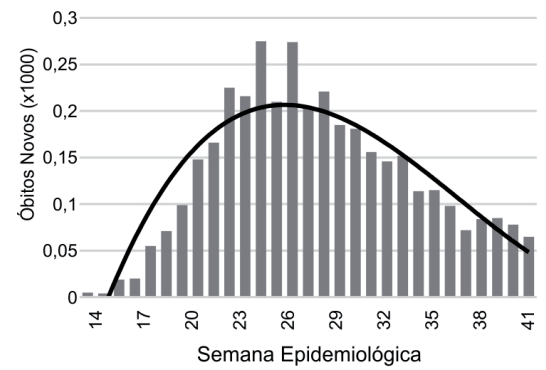

ES

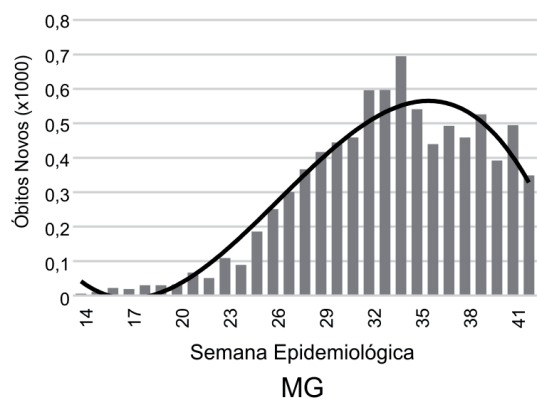



RJ

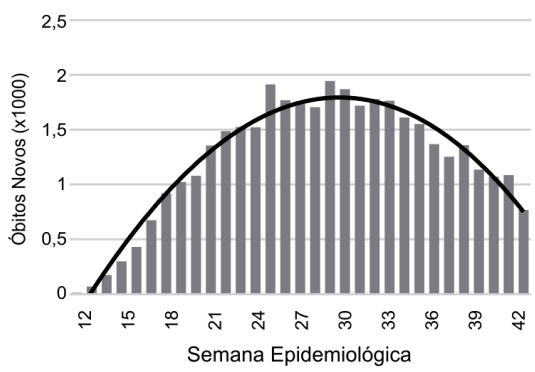

SP 
Figura 3 - Distribuição de óbitos novos de Covid- 19 no Brasil e por UF e curvas de ajuste por semana epidemiológica de 2020 (continuação)



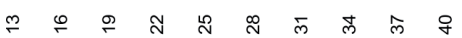
Semana Epidemiológica

PR



SC
$0,5^{-}$


Fonte: elaborada pelos autores. 
Figura 4 - Aceleração de óbitos novos de Covid- 19 no Brasil e por UF e curvas de ajuste por semana epidemiológica de 2020

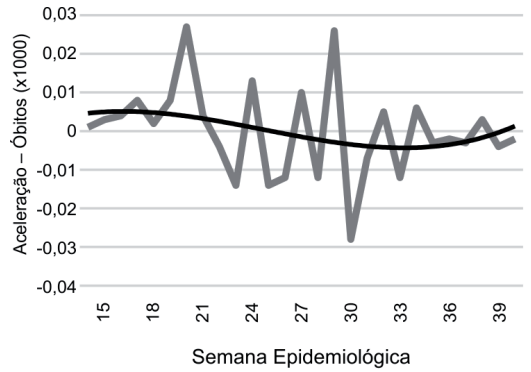

$\mathrm{AC}$

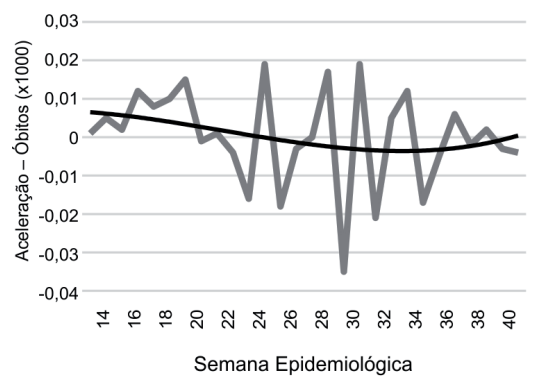

AP

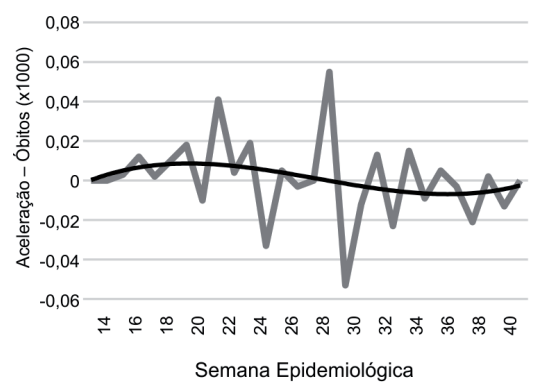

$\mathrm{RO}$



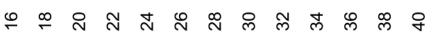

Semana Epidemiológica

TO

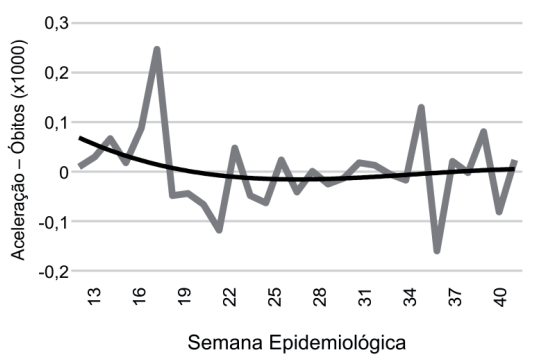

AM

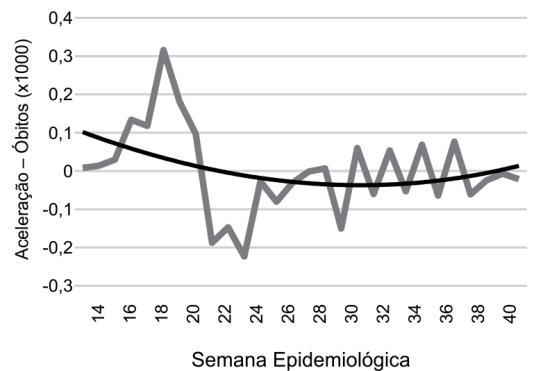

PA



Semana Epidemiológica

RR

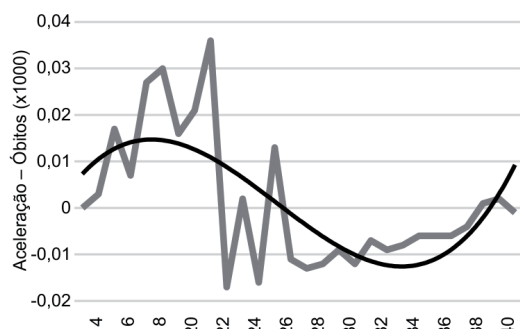

Semana Epidemiológica

$\mathrm{AL}$ 
Figura 4 - Aceleração de óbitos novos de Covid- 19 no Brasil e por UF e curvas de ajuste por semana epidemiológica de 2020 (continuação)

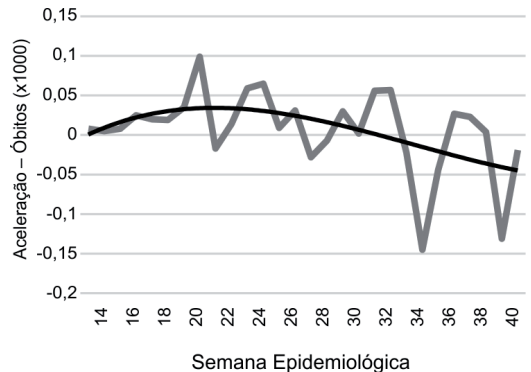

BA

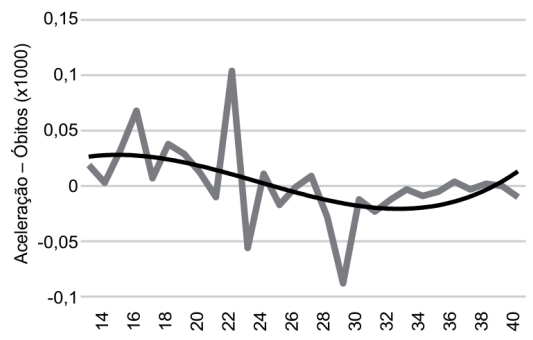

Semana Epidemiológica

MA

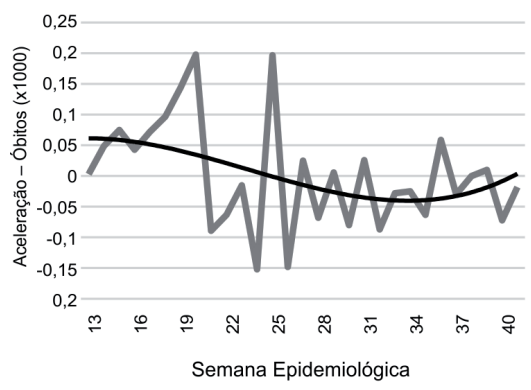

PE

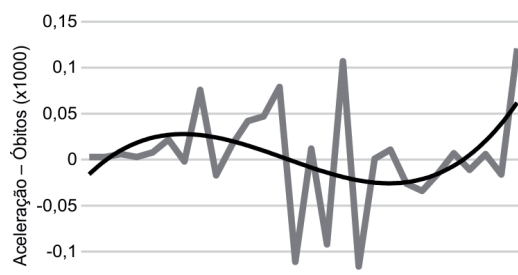

$-0,1$

ป

Semana Epidemiológica

RN

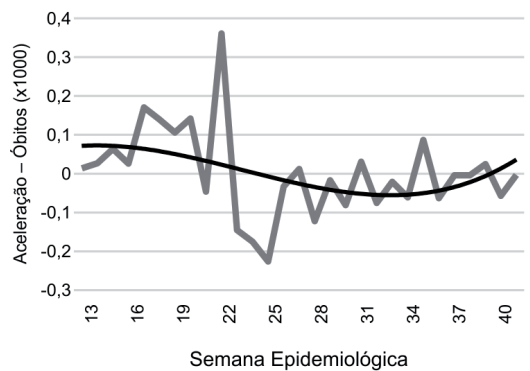

CE

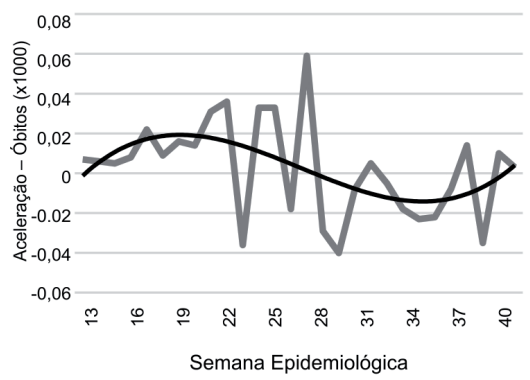

PB

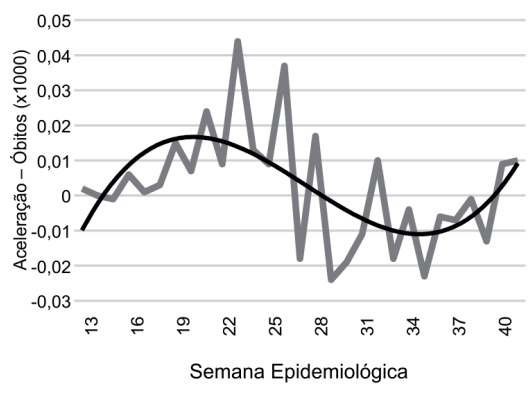

PI

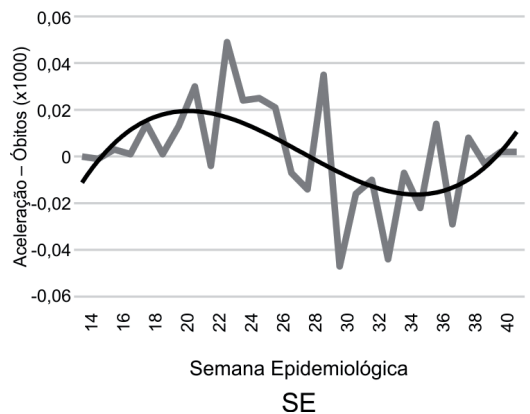


Figura 4 - Aceleração de óbitos novos de Covid- 19 no Brasil e por UF e curvas de ajuste por semana epidemiológica de 2020 (continuação)

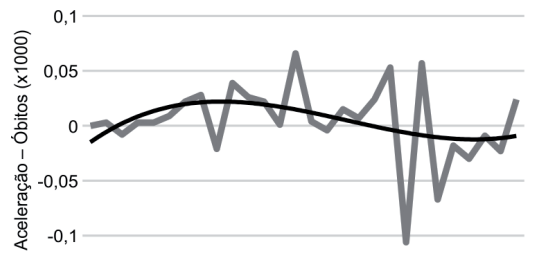

$-0,15$

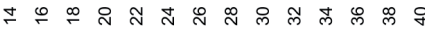
Semana Epidemiológica

DF

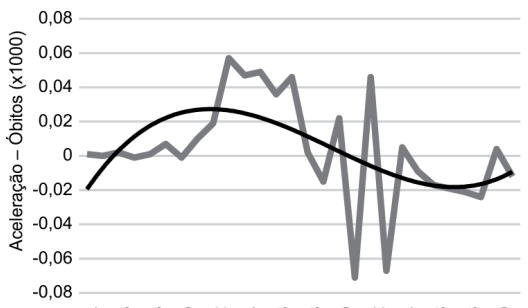

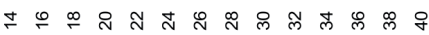
Semana Epidemiológica

MT

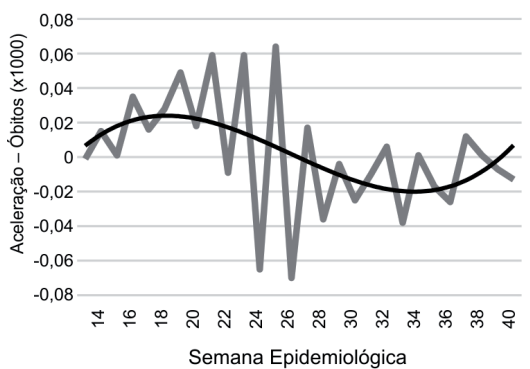

ES

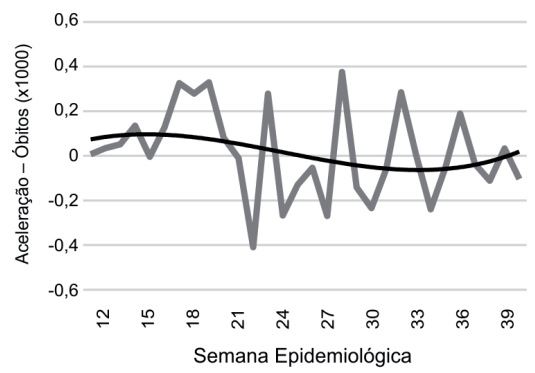

RJ

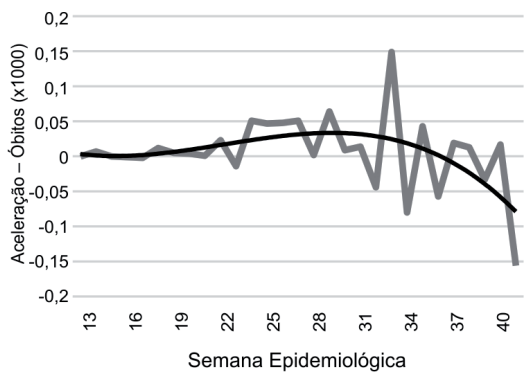

GO

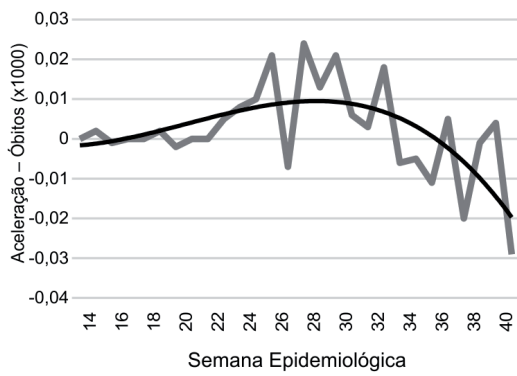

MS

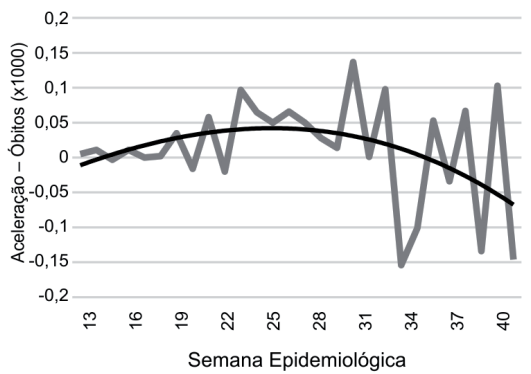

MG

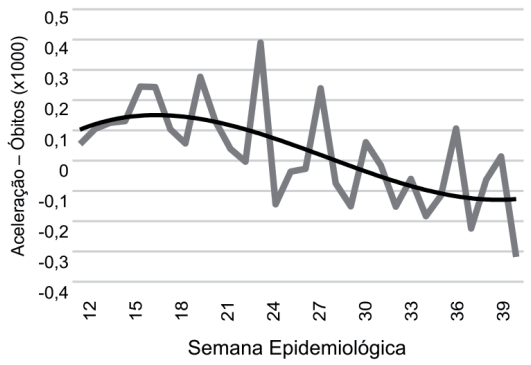

SP 
Figura 4 - Aceleração de óbitos novos de Covid- 19 no Brasil e por UF e curvas de ajuste por semana epidemiológica de 2020 (continuação)
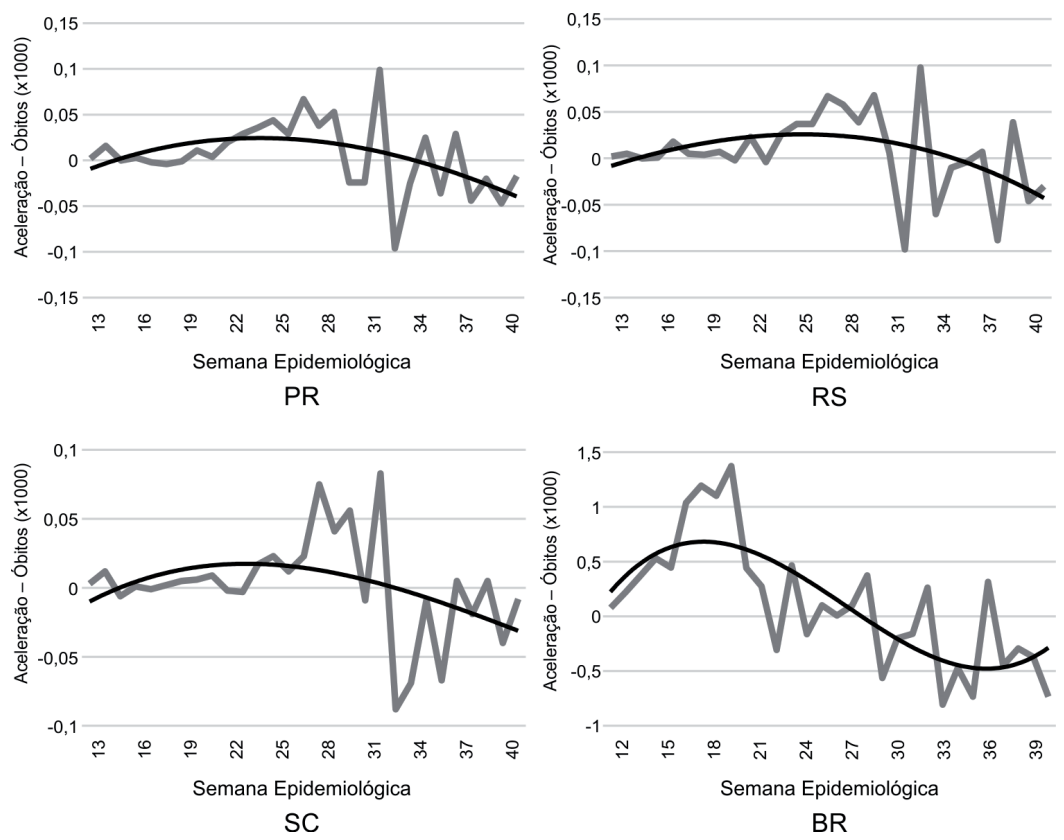

Fonte: elaborada pelos autores.

A nova epidemia causada pelo Sars-CoV-2 revelou um padrão que compreende uma fase de crescimento lenta, seguida por uma de aceleração; um curto período estacionário; um pico e, finalmente, uma fase de desaceleração. Esse comportamento foi observado para casos novos e mortes e varia por região, possivelmente devido a peculiaridades locais, como susceptibilidade genética, clima, densidade populacional e desigualdade social (Pinto et al., 2020). Segundo Pinto e colaboradores (2020), a fase de aceleração de novos casos não foi constante; se fosse, os valores teriam crescido indefinidamente e não teriam atingido um pico. Na realidade, a aceleração da Covid- 19 atinge um valor máximo e depois diminui para zero. Portanto, observa-se um primeiro estágio em que ocorre aumento de números e aceleração, e um segundo estágio, em que novos casos continuam aumentando, porém com diminuição progressiva na aceleração e chegando a zero no pico de novos casos.

Recentemente, diagnóstico e prognóstico de Covid-19 vêm sendo realizados de forma ágil e têm contribuído para tomadas de decisões médicas e de saúde pública para mitigar os danos da Covid-19. Modelos como o SIR (suscetível-infectado-recuperado), 
o modelo Richards e o modelo-D são amplamente utilizados como primeira abordagem dos dados de disseminação viral em epidemias contagiosas (Kermack \& Mckendric, 1927; Martinez, Aragon $\&$ Nunes, 2020). Utilizando esses modelos, Amaro, Dudouet e Orce (2020) mostram que, em diversos países europeus (Alemanha, Itália, França, Espanha, Reino Unido Suécia, Bélgica e Holanda), o comportamento da mortalidade por Covid- I 9 possui um padrão típico, caracterizado por um rápido aumento de casos de morte seguido por um declínio lento, assimétrico em relação ao pico pandêmico. Muitas vezes, essas tendências similares são utilizadas para o cálculo de parâmetros matemáticos tidos como universais nos modelos de predição. Entretanto, como ponderam Wynants e colaboradores (2020), muitos desses modelos têm erros de viés que sugerem que seu desempenho preditivo, quando usado na prática, é provavelmente inferior ao relatado. Como exemplo, os autores fazem uma revisão sistemática de 27 modelos, dos quais II tiveram alto risco de viés, sinalizando que os participantes inscritos nos estudos podem não ser representativos das populações-alvo dos modelos (Wynants et al., 2020).

Uma das razões para essa diferença pode residir na falta de uma perspectiva demográfica que considere a estrutura e composição dessas populações. Autores como Dowd e colaboradores (2020), Nepomuceno e colaboradores (2020) e Ined (2020) ressaltam a importância de se considerar a estrutura etária da população e os diferenciais dos diversos fatores demográficos dos países nos modelos preditivos. De acordo com os autores, além da estrutura etária, as populações mais ou menos vulneráveis pela Covid-19 podem variar segundo diversos fatores, entre os quais a densidade populacional, o tamanho e composição dos domicílios, as condições higiênicas e sanitárias, acesso a serviços de saúde, sistemas de notificação de casos, padrões de migração e deslocamento, desigualdades inter-regionais, estrutura do mercado de trabalho, disparidades econômicas, entre outras (Nepomuceno et al., 2020). Mesmo entre os países europeus, Kashnitsky e Aburto (2020) evidenciam a existência de importantes diferenças de estruturas etárias ao mostrar a proporção da população em risco de morte devido à Covid- I 9. Enquanto os países do leste europeu, como a Turquia, têm uma proporção da população em risco menor do que a média europeia devido a sua estrutura etária jovem, no oeste do continente países como Espanha, Portugal e França têm as maiores proporções de população em risco de morte devido à Covid- 19. Nas regiões rurais desses países, onde a estrutura etária é ainda mais envelhecida, a proporção da população em risco de morte é ainda maior.

Esses fatores demográficos podem ser ainda mais relevantes em regiões conhecidas pelas grandes desigualdades socioeconômicas e regionais. Segundo Lima e colaboradores (2020), na América Latina os países mais afetados pela Covid- I9, Brasil e Equador, além 
de apresentarem grandes diferenças internas em relação a estrutura etária, acesso a serviços de saúde e condições higiênicas e sanitárias, ainda sofrem com as taxas de teste mais baixas do mundo (cerca de 63 por 100.000 habitantes), problemas de qualidade dos dados, como subnotificação de óbitos e baixa cobertura de sistemas de estatísticas vitais e registro civil, e resistências à implementação de ações de distanciamento social e lockdown. Ao aplicar modelos preditivos baseados em Richards, Martinez, Aragon e Nunes (2020) mostram as limitações da previsão de longo prazo utilizando dados de dois estados brasileiros. Os autores encontraram erros de predição significantes em relação à estimação do pico de casos e do número acumulado de infectados e mostram alta a sensibilidade da estimativa dos parâmetros do modelo.

De fato, diversos estudos apontam que houve heterogeneidade na propagação da Covid- 9 no Brasil, observada por meio do número de casos por região. Atribui-se essa característica de disseminação principalmente aos fatores sociais e econômicos que contemplam, por exemplo, o quantitativo de pessoas que viajaram para o exterior, a renda familiar e a capacidade local de realização de testes. A densidade demográfica também foi destacada como fator de vulnerabilidade territorial em um estudo realizado em Nova York e Chicago (Maroko, Nash E Pavilonis, 2020) e em outro estudo realizado em Bangladesh (Sarkar, 2020). Tais fatores ressaltam que as regiões metropolitanas acabam apresentando maior vulnerabilidade quanto ao número total de casos (Ramírez $\varepsilon$ Lee, 2020). Enquanto as curvas de incidência de países europeus estavam consistentemente se achatando e diminuindo desde a implementação de intervenções não farmacológicas, a curva diária de incidência no Brasil continuava a aumentar (Souza et al., 2020).

Apesar do elevado número de casos e óbitos confirmados no Brasil até o momento, e dos esforços para diagnosticar os casos suspeitos, acredita-se que a testagem esteja aquém da necessidade, fator que pode contribuir para a subestimação da real magnitude da doença no país (Freitas et al., 2020). Ademais, não se deve assumir um crescimento exponencial dos casos e óbitos, pois essa premissa pode gerar erros e superestimação de sua frequência (Pinto et al., 2020).

Além disso, algumas variáveis socioeconômicas, como o índice de desenvolvimento humano, podem revelar a vulnerabilidade de uma população em relação ao comportamento da Covid- 9 (Maciel, Casto-Silva E Farias, 2020). O distanciamento físico é uma medida que deve ser sugerida precocemente para achatar a curva epidemiológica com o menor impacto econômico possível. Se o distanciamento físico for eficaz, limitando o acesso do público apenas aos serviços essenciais, o impacto econômico pode ser mitigado enquanto a atual epidemia de Covid- 19 é controlada (Croda et al., 2020). 
O risco de disseminação do vírus diz respeito à capacidade de transmissão local, afetada direta e indiretamente por fatores socioeconômicos. Por conseguinte, é imprescindível reconhecer a heterogeneidade de cada unidade da federação no tocante a cobertura em saúde, grau de urbanização, densidade populacional, entre outros determinantes sociais, ao considerar a análise da incidência e mortalidade por Covid- 19 (Guimarães, Eleuterio \& Monteiro-da-Silva, 2020).

A diferença por regiões e entre as cidades do Brasil são muito marcantes, e influenciadas pela heterogeneidade cultural, econômica, social e demográfica. O Epicovid I 9-BR, estudo de soroprevalência coordenado pelo Centro de Pesquisas Epidemiológicas da Universidade Federal de Pelotas, coletou dados em 133 cidades de todos os estados do Brasil. Esse estudo mostra que as 15 cidades com maiores prevalências incluem II da região Norte, 2 do Nordeste (Fortaleza e Recife) e 2 do Sudeste (Rio de Janeiro e São Paulo). Na região Sul, apenas Florianópolis apresentou prevalência superior a 0,5\%, e na região Centro-Oeste a pesquisa não encontrou nenhum caso positivo nas nove cidades estudadas, embora já haja casos e óbitos notificados. Conclui-se que as características sociodemográficas dos estados brasileiros podem afetar significativamente suas dinâmicas epidêmicas, fazendo com que sejam substancialmente diferentes (Epicovid I9-BR, 2020).

O enfrentamento de uma demanda alta e complexa por serviços de saúde é desafiador, em particular em ambientes sob vulnerabilidade socioeconômica e restrição de recursos. Embora seja necessária uma articulação mais completa de recursos e de políticas, muito possivelmente específica para cada realidade local, observamos que uma atenção primária resolutiva pode ser capaz de reduzir parte substancial da pressão em muitos municípios - inclusive naqueles onde o desafio é maior. Isso significa que uma atenção primária resolutiva pode ser instrumental para que os municípios brasileiros, principalmente os mais vulneráveis, enfrentem de modo mais efetivo e equitativo os desafios que a transição epidemiológica lhes tem trazido (Rache, Nunes $\&$ Rocha, 2020).

O rastreamento eficaz de contatos e o isolamento de casos são medidas consideradas estratégicas para o controle de uma nova onda de Covid-19, mas a probabilidade de controle diminui com longos atrasos entre a data de início dos sintomas e a implementação do isolamento, o que aumenta a probabilidade de transmissão. Na presença de surtos de Covid-19, é fundamental explicar os determinantes da dinâmica de transmissão dessa doença infecciosa para o desenho de estratégias de contenção ou redução da difusão, potencializando a política de saúde com intervenções econômicas, sociais e ambientais (Hellewell, 2020). 
O Brasil tem alguns dos piores indicadores de distanciamento social da América Latina; o governo federal vem menosprezando a magnitude da doença desde antes mesmo da confirmação do primeiro caso no país, em 25 de fevereiro de 2020. Após diversas declarações em rede nacional minimizando a gravidade da doença, governadores de todo o país informaram o declínio da adesão da população ao isolamento domiciliar, ao distanciamento social e à adoção de medidas preventivas.

Esse fato se reflete nas próprias estatísticas oficiais. Na América Latina, o Brasil é o país com maior número de casos e óbitos pela doença, seguido do Peru, que, no entanto, tem indicadores de isolamento social melhores do que os nossos. É importante ressaltar a necessidade de os governantes se basearem em evidências científicas para a tomada de decisões em relação a quando implementar, flexibilizar ou reintroduzir as medidas de distanciamento social em cada UF, assim como da colaboração da sociedade no enfrentamento dessa doença, no sentido de seguir as recomendações em níveis individual, ambiental e comunitário. Não se deve politizar nem basear em premissas ideológicas o combate à pandemia.

\section{CONSIDERAÇÕES FINAIS E RECOMENDAÇÕES}

A análise de séries temporais é bastante influenciada por cada mudança nos protocolos assistenciais e nas estratégias da vigilância epidemiológica. Dessa forma, a previsão da tendência apresenta alto grau de incerteza, e por esta razão é importante incorporar outras medidas de descrição das curvas. A aceleração dos casos e óbitos é útil nesse sentido, pois ajuda a caracterizar e comparar as curvas epidêmicas dos distintos lugares, permitindo melhor compreensão da situação epidemiológica das unidades da federação brasileiras.

Há enorme heterogeneidade no Brasil no comportamento epidêmico da Covid-19, com relação não só à tendência da incidência e mortalidade, mas também à aceleração dos casos e óbitos, demonstrando que o mecanismo de transmissibilidade e de capacidade de resposta dos sistemas locais de saúde é bastante variável de acordo com outras características que não somente a quantidade de suscetíveis. Diante da incerteza da iminência da segunda onda e do tempo de imunidade conferido pela infecção prévia, é necessário estar atento às curvas nas próximas semanas, para verificar se novamente a aceleração dos casos voltou a se comportar de forma semelhante à que se viu início da pandemia. 


\section{REFERÊNCIAS}

AMARO, J. E; DUDOUET, J. E ORCE, J. N. Global analysis of the Covid- I 9 pandemic using simple epidemiological models. arXiv.org, 2020.

BRASIL. Ministério da Saúde. Datasus: população residente - estimativas do TCU - Brasil. Brasília: Ministério da Saúde, 2019. Disponível em: <http://tabnet.datasus.gov.br/cgi/deftohtm.exe?ibge/cnv/ poptbr.def I 5>. Acesso em: 3 dez. 2020.

BRASIL. Ministério da Saúde. Sobre a doença. Brasília, 2020. Disponível em: <https://coronavirus. saude.gov.br/sobre-a-doenca>. Acesso em: 3 dez. 2020a.

BRASIL. Ministério da Saúde. Centro de Operações de Emergências em Saúde Pública. Doença pelo novo coronavírus 2019 - Covid- 19. Boletim Epidemiológico. Disponível em: < https://portalarquivos2. saude.gov.br/images/pdf/2020/fevereiro/2I/2020-02-2I-Boletim-Epidemiologico03.pdf $>$. Acesso em: 24 nov. $2020 b$.

BRASIL. Ministério da Saúde. Painel Coronavírus. Brasília, 2020. Disponível em: < https://covid.saude. gov.br>. Acesso em: 3 dez. 2020c.

CALLEJAS, D. et al. The Sars-CoV-2 pandemic in Latin America: the need for multidisciplinary approaches. Current Tropical Medicine Reports, 7: 120-125, 2020. Disponível em: <https://link.springer.com/ article/I 0.1007\%2Fs40475-020-00219-w>. Acesso em: 3 dez. 2020.

CÁSSARO, F. A. M. E PIRES, L. F. Can we predict the occurrence of Covid- 9 cases? Considerations using a simple model of growth. Science of the Total Environment, 728, 138834, 2020. Disponível em: <www.sciencedirect.com/science/article/pii/S00489697203235I 2 >. Acesso em: 3 dez. 2020.

CRODA, J. et al. Covid- 19 in Brazil: advantages of a socialized unified health system and preparation to contain cases. Revista da Sociedade Brasileira de Medicina Tropical, 53: e20200 I67, 2020. Disponível em: <www.scielo.br/scielo.php?script=sci_arttextEpid=S0037-86822020000 I $0 \mathrm{I} 000 \mathrm{EIng}=\mathrm{en} \boldsymbol{E}$ nrm=iso $>$. Acesso em: 4 dez. 2020.

DOWD, J. B. et al. Demographic science aids in understanding the spread and fatality rates of Covid- 19. Proceedings of the National Academy of Sciences of the United States of America, I I 7: 9.696-9.698, 2020.

EPICOVIDI9-BR. Covid-19 no Brasil: várias epidemias num só país. Primeira fase do EpicovidI9 reforça preocupação com a Região Norte. Pelotas, 2020. Disponível em: <www.fcm.unicamp.br/ covid/sites/default/files/2020-06/Covid_I 9\%20no\%20Brasil_varias $\% 20$ epidemias $\% 20$ num $\% 20$ s\%C3\%B3\%20pa\%C3\%ADs.pdf>. Acesso em: 2 dez. 2020.

FREITAS, A. R. R. et al. Uso do excesso de mortalidade associado à epidemia de Covid- 19 como estratégia de vigilância epidemiológica: resultados preliminares da avaliação de seis capitais brasileiras. Scielo Preprints, 2020. Disponível em: <https://preprints.scielo.org/index.php/scielo/preprint/view/442>. Acesso em: 4 dez. 2020.

GUIMARÃES, R. M.; ELEUTERIO, T. A. \& MONTEIRO-DA-SILVA, J. H. C. Estratificação de risco para predição de disseminação e gravidade da Covid- 19 no Brasil. Revista Brasileira de Estudos de População, 37: e0I22, 2020. Disponível em: <www.scielo.br/scielo.php?script=sci_arttextEpid=SOIO230982020000 l 00400 Elng $=$ ptEnrm=iso >. Acesso em: 2 dez. 2020. 
HELLEWELL, J. et al. Feasibility of controlling Covid- 19 outbreaks by isolation of cases and contacts. The Lancet Global Health, 8: e488-496, 2020. Disponível em: <www.thelancet.com/pdfs/journals/langlo/ PIIS22 I4-I09X(20)30074-7.pdf>. Acesso em: 4 dez. 2020.

INSTITUT NATIONAL D'ÉTUDES DÉMOGRAPHIQUES (INED). The contribution of demography to the Covid- 19 pandemics. Ined research group on Covid- 19 related deaths - 27 March 2020. Disponível em: <www.ined.fr/fichier/rte/39/Demo_Covid I 9_pandemics_Eng.pdf>. Acesso em: 20 nov 2020.

INSTITUTO BRASILEIRO DE GEOGRAFIA E ESTATÍSTICA (IBGE). Perfil dos Municípios Brasileiros: 2017. Rio de Janeiro: IBCE, 20I7. Disponível em: <https://agenciadenoticias.ibge.gov.br/ media/com_ mediaibge/arquivos/496bb4fbf305cca806aaal 67aa4f6dc8.pdf>. Acesso em: 3 dez. 2020.

KASHNITSKY, I. \& ABURTO, J. M. Covid- I 9 in unequally ageing European regions. World Development, 136: $105170,2020$.

KERMACK, W. O. \& MCKENDRICK, A. G. A contribution to the mathematical theory of epidemics. Proceedings of the Royal Society $A, 11$ 5(1.927): 700-721, 1927.

LIMA, E. et al. Exploring excess of deaths in the context of covid pandemic in selected countries of Latin America. Disponível em <https://ideas.repec.org/p/osf/osfxxx/xhkp4.html>. Acesso em: 26 ago. $202 \mathrm{I}$.

MACIEL, J. A. C.; CASTRO-SILVA, I. I. \& FARIAS, M. R. Análise inicial da correlação espacial entre a incidência de Covid- 19 e o desenvolvimento humano nos municípios do estado do Ceará no Brasil. Revista Brasileira de Epidemiologia, 23: p. e200057, 2020.

MAROKO, A.; NASH, D. \& PAVILONIS, B. Covid- 19 and inequity: a comparative spatial analysis of New York City and Chicago hot spots. New York, 2020. Disponível em: < https://academicworks.cuny.edu/ sph_pubs/258/>. Acesso em: 3 dez. 2020.

MARTINEZ, E. Z.; ARAGON, D. C. E NUNES, A. A. Long-term forecasts of the Covid- 19 epidemic: a dangerous idea. Revista da Sociedade Brasileira de Medicina Tropical, 53, 2020.

NEPOMUCENO, M. R. et al. Besides population age structure, health and other demographic factors can contribute to understanding the Covid- 19 burden. Proceedings of the National Academy of Sciences, I I7(25): 13.881-13.883, 2020.

PINTO, A. S. et al. Covid-I9 growth rate analysis: application of a low-complexity tool for understanding and comparing epidemic curves. Revista da Sociedade Brasileira de Medicina Tropical, 53: e2020033 I, 2020. Disponível em: <www.scielo.br/scielo.php?script=sci_arttextEpid=S0037$86822020000 \mathrm{l} 00655 \mathrm{Elng}=\mathrm{enEnrm}=\mathrm{iso}>$. Acesso em: 4 dez. 2020.

RACHE, B.; NUNES, L. \& ROCHA, R. Evolução recente e perfil atual da mortalidade no Brasil: uma análise da heterogeneidade entre municípios. Nota Técnica n. I. São Paulo: leps, 2020. Disponível em: $<$ https://ieps.org.br/wp-content/uploads/2020/03/NTI.pdf>. Acesso em: 3 dez. 2020.

RAMÍREZ, I. J. \& LEE, J. Covid- I 9 Emergence and social and health determinants in Colorado: a rapid spatial analysis. International Journal of Environmental Research and Public Health, I 7(I I): 3.856, 2020.

SARKAR, S. K. Covid-I9 susceptibility mapping using multicriteria evaluation. Disaster Medicine and Public Health Preparedness, 14(4):52 I-537, 2020. Disponível em: <www.cambridge.org/ core/journals/disaster-medicine-and-public-health-preparedness/article/covid I 9-susceptibilitymapping-using-multicriteria-evaluation/0CD338E6F2F65BC5F7587BEB28C282A9>. 
SOUZA, W. M. et al. Epidemiological and clinical characteristics of the Covid- 19 epidemic in Brazil. Nature Human Behaviour, 4: 856, 2020. Disponível em: <www.nature.com/articles/s4I562-0200928-4\#citeas >. Acesso em: 4 dez. 2020

WORLD HEALTH ORGANIZATION (WHO). WHO characterizes Covid-19 as a pandemic. 2020. Disponível em: <www.paho.org/hq/index.php?option=com_contentEview=articleEid= I5756: who-characterizes-Covid- I 9-as-a-pandemicEltemid=1926Elang=en>. Acesso em: 3 dez. 2020.

WYNANTS, L. et al. Prediction models for diagnosis and prognosis of Covid- I 9: systematic review and critical appraisal. BMJ, 369, 2020. 


\title{
Vulnerabilidade das Populações Indígenas à Pandemia de Covid-19 no Brasil e os Desafios para o seu Monitoramento
}

\author{
Raquel Martins Lana, Cláudia Torres Codeço, Ricardo Ventura Santos, \\ Bárbara Cunha, Flávio Codeço Coelho, Oswaldo Gonçalves Cruz, \\ Aline Diniz Rodrigues Caldas, Mirian Carvalho de Souza, \\ Leonardo Soares Bastos, Ana Lúcia de Moura Pontes, \\ Marcelo Ferreira da Costa Gomes, Inara do Nascimento Tavares, \\ Ana Paula Dal'Asta, Ana Cláudia Rorato, Maria Isabel Sobral Escada, \\ Luiz Max Carvalho, Daniel Antunes Maciel Villela, \\ Fernando Souza Damasco e Andrey Moreira Cardoso
}

$\mathrm{H}$ istoricamente, há inúmeros registros do expressivo e devastador impacto de doenças infecciosas e parasitárias como gripe, sarampo, varíola e malária nos povos indígenas, particularmente naqueles em isolamento ou de recente contato (Walker, Sattenspiel E Hill, 2015). Recentemente, Cardoso e colaboradores (2019) demonstraram que a introdução de vírus respiratórios em comunidades indígenas suscetíveis tem elevado potencial de disseminação, resultando em altas taxas de ataque e de internações, podendo causar óbitos, a exemplo da influenza A(HINI)pdm09 e do vírus sincicial respiratório. Mesmo em períodos não epidêmicos, essas infecções estão entre as principais causas de morbidade e mortalidade em populações indígenas (Cardoso, 2010), sendo fortemente determinadas pelas condições socioeconômicas e sanitárias precárias e pelo limitado acesso à saúde (Cardoso et al., 2015; Cardoso, Coimbra Jr. $\varepsilon$ Werneck, 20I3). Ademais, estudos atuais evidenciam que povos indígenas exibem dupla carga de morbidade, caracterizada pela alta prevalência de doenças infecciosas em paralelo à rápida emergência das doenças crônicas não transmissíveis, de modo que as comorbidades associadas às formas graves de Covid- 19 são prevalentes em indígenas (Coimbra Jr. et al., 2013).

Diante desse preocupante cenário, pesquisadores do campo da saúde dos povos indígenas da Fundação Oswaldo Cruz (Fiocruz), em parceria com o Grupo de Trabalho de Saúde Indígena da Associação Brasileira de Saúde Coletiva (Abrasco), com técnicos 
do Instituto Brasileiro de Geografia e Estatística (IBGE) e com diversas organizações indígenas e entidades da sociedade civil que apoiam a causa indígena, se mobilizaram para alertar sobre a emergência da nova pandemia em povos indígenas, monitorar a sua disseminação e apoiar o desenvolvimento de estratégias para seu enfrentamento a fim de minimizar seus impactos. Nesse sentido, entre outras iniciativas, podem ser mencionadas a elaboração de notas técnicas da Abrasco e Associação Brasileira de Antropologia (ABA) (Abrasco \& ABA, 2020a, 2020b), podcasts produzidos pela Escola Politécnica de Saúde Joaquim Venâncio da Fiocruz (EPSJV/Fiocruz, 2020), entrevistas na mídia, formação de grupos de trabalho para a organização da vigilância nos territórios indígenas, fornecimento de insumos para diagnóstico e cestas básicas, e colaboração com diversas esferas de gestão do Subsistema de Atenção à Saúde Indígena, o SasisuS.

Ainda dentro das iniciativas para atender a essa emergência em saúde pública, a Fiocruz rapidamente estruturou o Eixo de Vigilância em Saúde para acompanhar a trajetória da pandemia e colaborar de maneira intensiva no âmbito nacional e internacional para gerar evidências científicas sobre a Covid-19. Entre as iniciativas desse eixo, o Núcleo de Métodos Analíticos para Vigilância em Saúde Pública, formado pelo Programa de Computação Científica (Procc/Fiocruz) e Escola de Matemática Aplicada da Fundação Getulio Vargas (EMAp/FGV), desenvolveu análises sobre o risco de importação de Covid-19 nas microrregiões brasileiras, decorrente da presença de transmissão sustentada nos dois maiores centros urbanos do país, Rio de Janeiro e São Paulo, assim como os efeitos associados a padrões populacionais de maior risco de morbidade e letalidade em possíveis epidemias nas microrregiões brasileiras (Grupo Mave, 2020a, 2020b, 2020c).

Considerando os desafios a serem enfrentados, identificou-se a possibilidade de unir esforços com os grupos e entidades citados anteriormente, incorporando também o Instituto Nacional de Pesquisas Espaciais (Inpe), que também desenvolve pesquisas na temática indígena. Entre outros desdobramentos, a colaboração resultante permitiu a produção de relatórios (Grupo Mave, 2020d, 2020e, 2020f) cujo objetivo foi analisar a vulnerabilidade geográfica e sociodemográfica da população indígena no Brasil à Covid-19, monitorando o risco de disseminação da doença em diferentes momentos. Com a produção desse material visou-se a subsidiar a sociedade civil, incluindo as organizações indígenas, assim como o poder público com informações estratégicas para a ação. Os relatórios acompanharam temporalmente o número e a proporção da população indígena em alto risco imediato de contágio. Cabe ressaltar o significativo esforço para integrar e compatibilizar distintas fontes e bases de dados capazes de identificar segmentos populacionais indígenas em diferentes contextos de 
vulnerabilidade à Covid- 19. Dessa forma, optou-se por realizar as análises nos seguintes recortes populacionais: (I) indígenas segundo zona de residência (urbana e rural), na totalidade dos municípios brasileiros com população indígena; (2) indígenas segundo zona de residência (urbana e rural), no subconjunto de municípios abrangidos pelos Distritos Sanitários Especiais Indígenas (DSEls) do SasiSUS; e (3) indígenas residentes em Terras Indígenas (TIs) oficialmente reconhecidas.

Neste capítulo são descritos os principais achados, desafios e estratégias identificados no conjunto de relatórios e documentos produzidos ao longo dos primeiros nove meses de pandemia, com foco nas populações indígenas. No cenário de uma epidemia que se configurou como um dos maiores desafios da humanidade na era moderna, as análises aqui apresentadas contribuíram para visibilizar os contornos particulares da população indígena, que vive em um contexto de alta vulnerabilidade socioambiental, agravada por um momento político altamente desfavorável à adoção e manutenção de políticas públicas de proteção e promoção da saúde de minorias étnicas e de garantia de direitos humanos e sociais no Brasil.

\section{CONTEXTO DAS POPULAÇÕES INDÍGENAS NO BRASIL}

Diante da suscetibilidade universal ao Sars-CoV-2, coronavírus causador da Covid-19, e da inexistência de tratamento específico ou vacina no período de análise, as recomendações para a contenção da pandemia basicamente envolviam a detecção precoce dos casos, seu isolamento e o tratamento de complicações, o rastreamento de contatos e a adoção de medidas não farmacológicas de proteção individual, como distanciamento físico, uso de máscara facial, uso de álcool em gel, lavagem regular das mãos com água e sabão e não compartilhamento de utensílios de uso pessoal.

Quando se trata da população indígena, dada sua diversidade étnica, social e cultural, o contexto difere daquele observado para a maioria do país, trazendo desafios adicionais para a contenção da pandemia. Entre outras dimensões, destacam-se os seguintes pontos que exemplificam a alta vulnerabilidade dos indígenas à pandemia e justificam a ampla mobilização descrita em prol das ações a serem implementadas para proteção desses povos (Apib, 2020; Pontes et al., 2020; Santos, Pontes E Coimbra Jr., 2020):

I. No contexto de suscetibilidade universal ao novo vírus, a vulnerabilidade dos povos indígenas e de outras populações específicas se relaciona principalmente às iniquidades das condições de vida e situação de saúde, incluindo o limitado acesso a inúmeras políticas públicas capazes de reduzir essa desvantagem, como a falta de saneamento em muitas comunidades. 
2. O desafio de controlar a entrada de pessoas infectadas nos territórios indígenas, bem como de garantir o isolamento de casos suspeitos, confirmados e seus contatos. Esta dimensão envolve inclusive o estabelecimento de uma logística para monitoramento e testagem das próprias equipes multidisciplinares de Saúde Indígena (EMSIs), uma vez que a estruturação do atendimento dos DSEls envolve deslocamento constante dos profissionais entre comunidades e áreas urbanas.

3. A questão da ocupação ilegal e/ou invasão de territórios indígenas (garimpo, extração de madeira, entre outros), agravada em tempos recentes, que não tem sido enfrentada minimamente a contento pelas autoridades responsáveis.

4. No caso das populações que residem em locais remotos ou mesmo em municípios menores e distantes das capitais, independentemente da região do país, há evidente limitação no acesso oportuno e qualificado à rede de atenção à saúde. Nesses locais, a garantia de atenção integral e equânime aos povos indígenas com vistas a reduzir os impactos da pandemia pressupõe ampliação da capacidade de resposta e recursos adicionais por parte dos órgãos gestores da saúde indígena e do Sistema Único de Saúde (SUS).

\section{População indígena no Brasil e sua situação geral de saúde}

Segundo o último Censo Demográfico, realizado em 2010, havia 896 mil pessoas que se declararam ou se consideravam indígenas no país, das quais 572 mil $(63,8 \%)$ residentes em áreas rurais (IBGE, 20I2). Desse total, 517 mil (57,7\%) residiam em TIs oficialmente reconhecidas. O Censo 2010 contabilizou ainda aproximadamente 300 etnias e 270 línguas faladas (IBGE, 2012).

Análises que têm como base os dados do Censo 2010 indicam condições de desvantagem dos indígenas em comparação à população não indígena em inúmeros indicadores sociodemográficos e sanitários. Em particular nas populações residentes em Tls e aldeias se observa, por exemplo, menor proporção de escolaridade formal, menor cobertura de saneamento e elevada mortalidade precoce. Uma característica distintiva da população indígena é sua estrutura etária jovem em comparação à da população brasileira, particularmente nas TIs (Santos et al., 2019).

A vulnerabilidade sociodemográfica e sanitária da população indígena foi também evidenciada no $I^{\circ}$ Inquérito Nacional de Saúde e Nutrição dos Povos Indígenas (Coimbra Jr. et al., 2013). Os resultados dessa investigação, a mais ampla já realizada no país, indicaram níveis de desnutrição, diarreia e anemia em crianças menores de 5 anos, além 
de sobrepeso/obesidade e anemia em mulheres de 14 a 49 anos, mais pronunciados do que na população brasileira. Questões ligadas à sustentabilidade alimentar, atenção à saúde e garantia dos territórios, além de inúmeros problemas associados à invasão e contaminação ambiental por atividades garimpeiras e agropecuárias, são apontadas como centrais na determinação dos perfis de adoecimento e morte apresentados pela população indígena no Brasil.

A Política Nacional de Atenção à Saúde dos Povos Indígenas foi operacionalizada por meio do Subsistema de Atenção à Saúde Indígena (SasiSUS), implantado em 1999 como um subsistema do Sistema Único de Saúde (SUS) (Funasa, 2002). Desde 20 I 0, o SasisuS é coordenado pela Secretaria Especial de Saúde Indígena (Sesai), do Ministério da Saúde. O SasiSuS é estruturado como uma rede de serviços de atenção primária à saúde em 34 DSEls, espalhados por todo o país, onde se localizam aldeias e Tls (Figura I). Os DSEls devem atuar em articulação com os demais níveis de complexidade do SUS nas diferentes esferas, municipal, estadual e federal, para cumprir seus princípios e diretrizes, em particular universalidade, equidade, integralidade e participação comunitária. As ações de saúde são executadas no âmbito dos DSEls e das aldeias por EMSIs, com o objetivo de ampliar a cobertura, o acesso e a aceitabilidade do SUS entre essa população.

As TIs no Brasil equivalem atualmente a cerca de 15\% do território nacional, apresentando, conforme o decreto n. $1775 / 96$ (Brasil, 1996), uma complexa classificação cuja compreensão é relevante para o entendimento das análises aqui desenvolvidas (Figura I). Devido a processos históricos de ocupação, relacionados aos impactos da colonização ao longo de séculos, as Tls localizadas nas regiões de mais antiga ocupação por não indígenas (como Nordeste, parte da região Centro-Oeste, Sudeste e Sul) são comparativamente muito menores que aquelas localizadas na Amazônia Legal. Portanto, estima-se que $60 \%$ da população indígena no país residam em uma área que corresponde a $98 \%$ do total de extensão das Tls e que os demais $40 \%$ vivam em TIs que equivalem a $2 \%$ da extensão territorial total. Esse cenário evidencia que parte significativa da população indígena no Brasil vive em pequenas áreas sem condições de manutenção e reprodução dos seus modos de vida tradicionais. 
Figura I - (A) Terras Indígenas, (B) Distritos Sanitários Especiais Indígenas, (C) População indígena por município e limites de Tls em vermelho (IBGE) e (D) Limites regionais, estaduais e capitais brasileiras

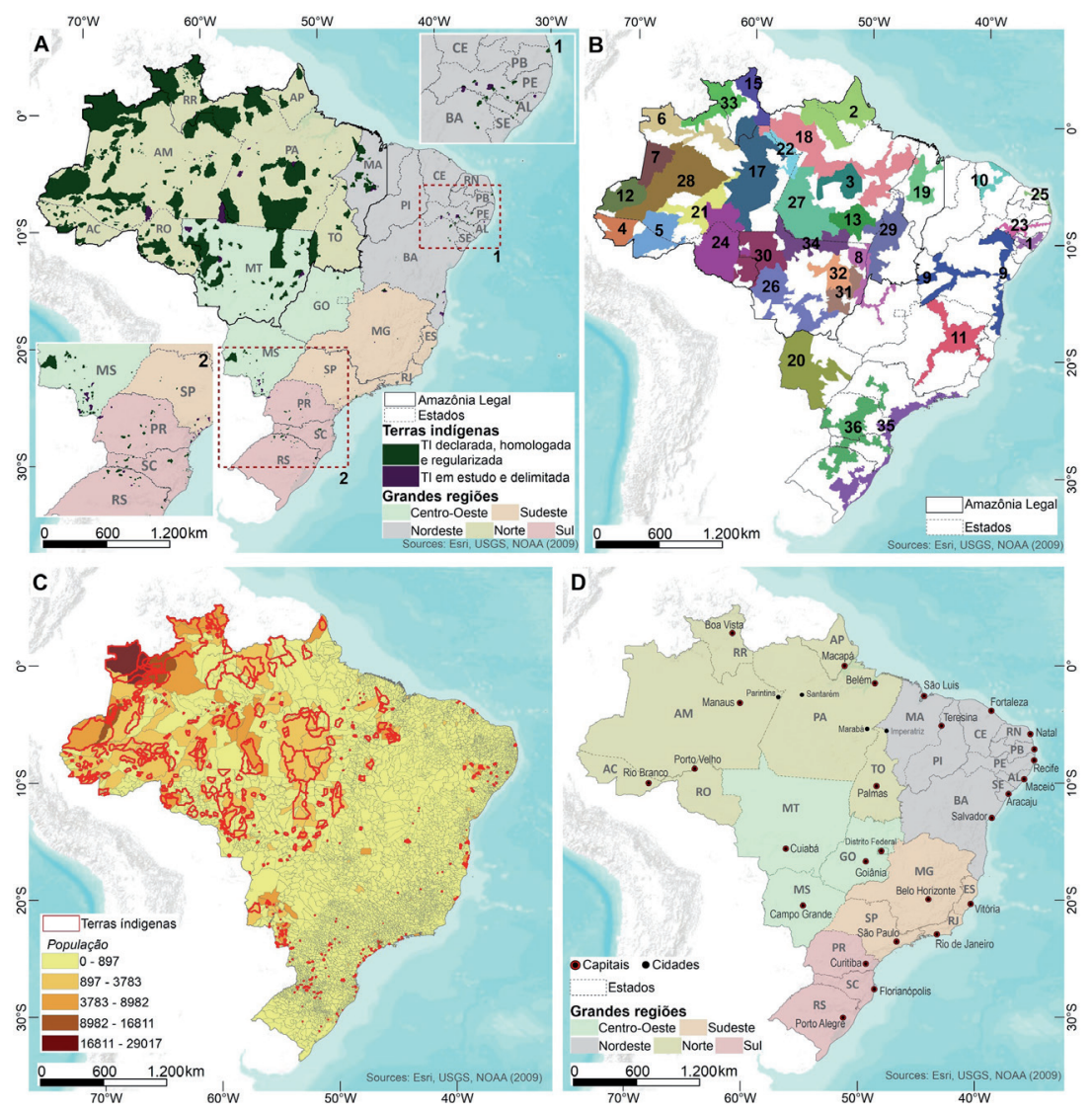

Fontes: A e B - Funai, 2020, <www.funai.gov.br/index.php/shape>; C e D - IBGE, <www.ibge.gov.br/ geociencias/downloads-geociencias.html>.

\section{TRAJETÓRIA DA PANDEMIA DE COVID-19 NAS POPULAÇÕES INDÍGENAS}

A partir das malhas territoriais de municípios brasileiros (IBGE), dos DSEls e das TIs (Funai), e dos dados coletados no Censo 20 I0, foi investigada, em escala municipal, a vulnerabilidade dos indígenas (população total, em zonas urbana e rural e em TI) à introdução imediata da epidemia de forma sustentada, classificada em três diferentes níveis de risco $(<25 \%, 25-50 \%$ e $>50 \%)$. As análises foram estratificadas em quatro 
grandes regiões, por similaridades em aspectos territoriais e ambientais: Amazônia Legal (que agrega à região Norte, o MT e parte do MA), Centro-Oeste (MS, GO e DF), Nordeste e Sul-Sudeste.

As informações de casos de Covid- I 9 foram obtidas regularmente durante o período de análise, a partir do sistema InfoGripe (Fiocruz, 2020), que monitora os dados de notificação de síndrome respiratória aguda grave (Srag) no Brasil, tendo como fonte de dados o sistema Sivep Gripe, da Secretaria de Vigilância em Saúde do Ministério da Saúde. Por meio de um modelo matemático que combina dados associados à transmissão da doença e de mobilidade humana no Brasil, calculou-se a probabilidade de a Covid- I 9 se disseminar e se estabelecer de forma sustentada em novos municípios, a curto prazo. A metodologia detalhada, assim como suas limitações, pode ser encontrada nos relatórios do Mave (Grupo Mave, 2020a).

A transmissão da Covid-19 inicialmente esteve concentrada em alguns grandes centros urbanos. Contudo, rapidamente observou-se um processo de interiorização em alguns estados, como Amazonas, Rio de Janeiro e São Paulo (Grupo Mave 2020a, 2020 b, 2020c). Principalmente na região Norte, que apresenta expressivo contingente populacional indígena, esse fenômeno teve grande impacto nos povos indígenas. A Figura 2 mostra o crescimento no número de municípios (à esquerda) e o volume da população indígena (à direita) em alto risco para Covid-19 em três momentos: 12 de abril e 4 e 17 de maio de 2020.

Por ocasião do $4^{\circ}$ Relatório do Mave, para a semana epidemiológica (SE) 15/2020 (Grupo Mave, 2020d), a população indígena em alto risco (>50\%) de introdução imediata de Covid- 19 se concentrava predominantemente em municípios que englobam grandes centros urbanos do país e seu entorno, como capitais e regiões metropolitanas do Sudeste (São Paulo e Rio de Janeiro), Nordeste (Fortaleza, Recife e Salvador), Sul (Porto Alegre e Curitiba) e Norte (Manaus, Belém e eixos Rio Branco-Porto Velho, Santarém-Parintins e Marabá-Imperatriz), além de Brasília, capital do país (Figura 2). Nesse momento, a maioria das TIs, principalmente na Amazônia Legal, estava em áreas com baixo risco de epidemia, indicando maior vulnerabilidade dos indígenas residentes fora de TIs. Nas análises subsequentes, relativas às SE I9/2020 (Grupo Mave, 2020e) e 2 1/2020 (Grupo Mave, 2020f), verifica-se rápida interiorização da pandemia no país e incremento expressivo do número de municípios e do volume de população indígena em alto risco para a epidemia, passando a atingir também as Tls. Ressalta-se o padrão de espalhamento da Covid- 19 na região Norte, que seguiu as calhas dos grandes rios, como o Amazonas, Negro, Solimões e Tapajós, atingindo inúmeras Tls e grande contingente de população indígena em toda a Amazônia Legal. Além disso, houve intensificação do 
espalhamento da epidemia em toda a região litorânea do país, a partir das capitais dos estados, e a expansão para a região Centro-Oeste (Figura 2).

Figura 2 - Probabilidade de epidemia por município e população indígena em alto risco (>50\%) imediato para epidemia em 12/04, 04/05 e 17/05 de 2020. Em vermelho, os limites das Terras Indígenas
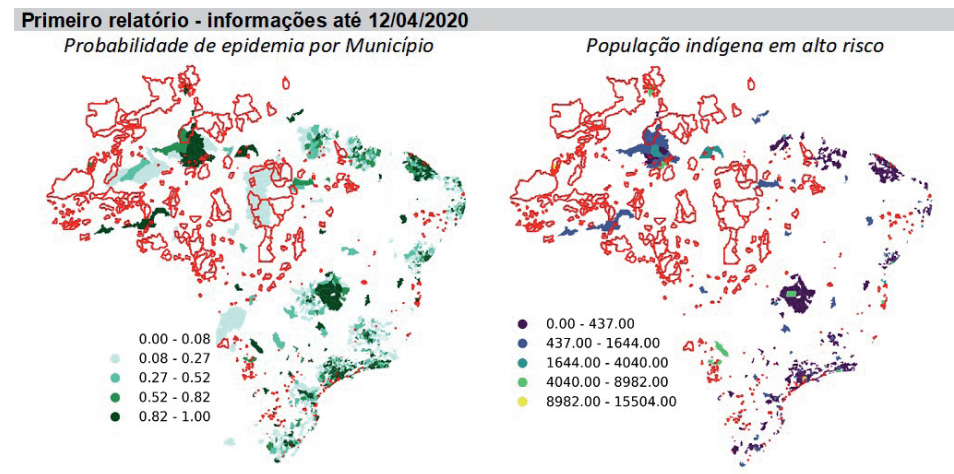

Segundo relatório - informaçōes até 04/05/2020 Probabilidade de epidemia por Municipio
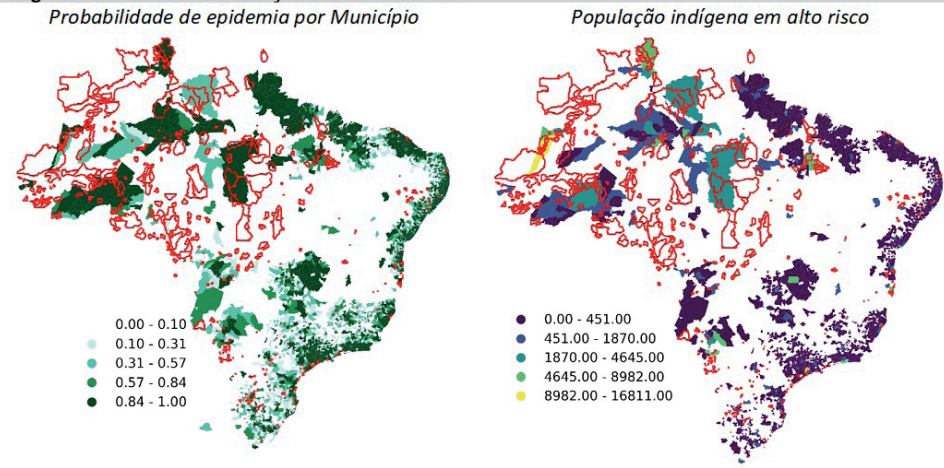

Terceiro relatório - informações até 17/05/2020 Probabilidade de epidemia por Município População indígena em alto risco
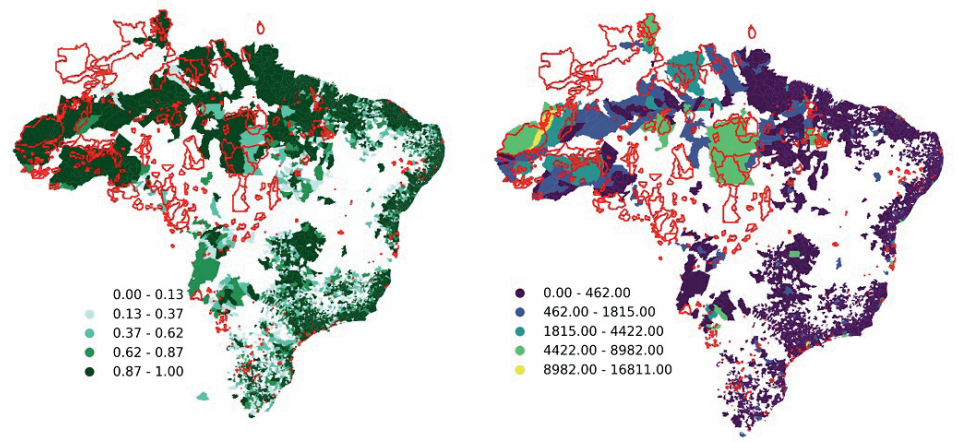
O padrão de vulnerabilidade geográfica dos povos indígenas à Covid-19, sobretudo na região da Amazônia Legal e em Tls, indica o papel preponderante dos centros regionais, que funcionam como polos de atração e circulação dessas populações em busca de acesso a produtos e serviços, atividades econômicas e interação com familiares, na disseminação e interiorização da pandemia, em grande medida, por vias fluvial e aérea. No entanto, pode-se verificar também o incremento do risco em áreas remotas fora dessas vias, em que são registradas situações de conflito e invasões de territórios, atividades de garimpo e extração madeireira, que aumentam a probabilidade de importação do Sars-CoV-2, inclusive naquelas comunidades em isolamento ou de recente contato.

Para melhor compreender os padrões e a dinâmica de disseminação da epidemia nas populações indígenas, são destacadas na Figura 3 as progressões das proporções de indígenas em alto risco imediato para a epidemia de Covid- 9 nos estratos de população indígena total, urbana e rural, na totalidade dos municípios brasileiros e somente naqueles que se sobrepõem aos territórios dos DSEIs.

Figura 3 - Evolução temporal das proporções de população indígena total, urbana e rural em alto risco (>50\%) imediato de epidemia de Covid- 19 segundo grandes regiões, no conjunto dos municípios brasileiros e nos municípios localizados em territórios de DSEIs

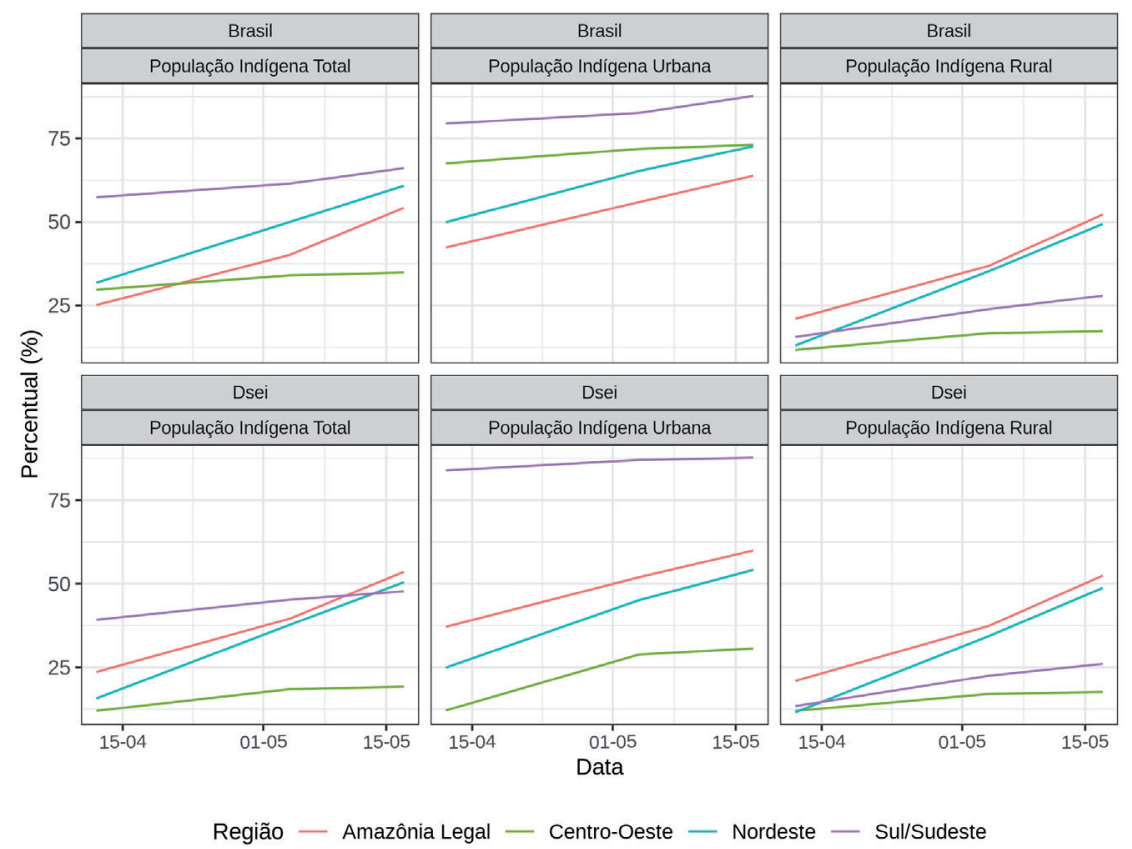


Verificou-se aumento progressivo da proporção de indígenas vivendo em municípios com alto risco imediato para Covid- 19 em todas as regiões do Brasil e nos estratos urbano ou rural (Figura 3). Quando se analisa o conjunto dos municípios brasileiros, observa-se que os indígenas residentes em áreas urbanas se encontravam em alto risco desde o primeiro momento de análise, com destaque para as regiões Sul-Sudeste e Centro-Oeste, que possuem grande contingente de população autodeclarada indígena em áreas urbanas, incluindo o Distrito Federal. As regiões da Amazônia Legal e Nordeste tiveram expressivo incremento do risco, se aproximando das demais, em particular do Centro-Oeste, o que evidencia a alta vulnerabilidade à Covid- 19 dos indígenas residentes em cidades do Norte e Nordeste nos primeiros meses da pandemia. No estrato rural, as proporções de população indígena em alto risco eram substancialmente menores que no urbano, mas as regiões da Amazônia Legal e Nordeste se destacaram, tanto por terem maior magnitude das proporções em praticamente todos os momentos de análise quanto pelo acelerado incremento dessas proporções no período.

$\mathrm{Na}$ análise restrita ao subconjunto de municípios que se sobrepõem aos DSEls, no estrato urbano se destaca a região Sul-Sudeste, com praticamente $100 \%$ da população indígena em alto risco em todo o período, ao passo que Amazônia Legal e Nordeste apresentaram risco intermediário, progressivo e acelerado, superando $50 \%$ no terceiro momento de análise. O comportamento e magnitude das proporções de população indígena em alto risco no estrato rural nos municípios em DSEls é similar ao observado no conjunto dos municípios brasileiros, indicando que a maioria da população indígena rural no Brasil reside em municípios sobrepostos aos DSEls. Verificou-se alta vulnerabilidade dos indígenas rurais da Amazônia Legal e do Nordeste (cerca de $50 \%$ no terceiro momento de análise) no período de análise. Ressalta-se que a última análise aqui apresentada foi realizada em 17/05/2020, momento em que o CentroOeste ainda não havia registrado franca interiorização da pandemia, o que veio a ser observado tardiamente, colocando os indígenas rurais dessa região entre aqueles com maior número de casos. O estrato de análise relativo aos indígenas residentes em Tls teve o mesmo comportamento do estrato rural, tanto no conjunto dos municípios brasileiros quanto no recorte de municípios sobrepostos aos DSEls (Grupo Mave, 2020d, 2020e, 2020f). 


\section{DESAFIOS E DESDOBRAMENTOS DAS INICIATIVAS DE MONITORAMENTO}

\section{A produção da informação}

A compilação e compatibilização dos dados oriundos de diferentes fontes e instituições e a geração dos relatórios e análises abordadas neste texto foram desafiadoras em um contexto de rápida expansão da pandemia. E ainda se constituem como um desafio, uma vez que a situação de pandemia ainda é realidade no país. Cabe ressaltar a limitação causada pela defasagem dos dados sociodemográficos referentes às populações indígenas, que em sua ampla maioria datam de 2010 , quando o último censo demográfico do país foi realizado. A incerteza resultante dessa defasagem em relação ao tamanho da população indígena atual, situação do domicílio e em Tls é uma questão metodológica complexa, diretamente relacionada à elaboração de estimativas mais próximas do real impacto da propagação de Covid-19 sobre essas populações. É possível que, caso fossem disponibilizadas estimativas populacionais mais recentes, a situação se mostrasse ainda mais alarmante do que aquela aqui descrita. Deve ser mencionada também a dificuldade de alinhar os diferentes níveis de agregação para os quais diferentes conjuntos de informação demográfica, sanitária e de saúde são disponibilizados, bem como dados específicos sobre mobilidade de populações indígenas e localidades específicas, que afetam as estimativas de risco. Um terceiro fator se relaciona aos problemas de preenchimento da variável cor ou raça nos formulários de notificação de casos e óbitos, incluindo a ausência da informação. Apesar da determinação de preenchimento obrigatório desde 2017 pela portaria n. 344/2017 (Brasil, 20 I7), a qualidade da informação segundo a variável cor ou raça persiste como um fator que limita as possibilidades de análise acerca de estimativas de adoecimento e morte por Covid- I 9 na população indígena, assim como em outros segmentos étnicoraciais no país.

\section{Contribuições decorrentes das análises}

Ao todo foram produzidos três relatórios, nos quais as análises basearam-se na exposição geográfica da população indígena em municípios classificados segundo níveis de probabilidade de epidemia, estimada para a população municipal, com base em metodologia previamente reportada (Mave). Adicionalmente, foram descritos fatores socioeconômicos e demográficos potencialmente relacionados à vulnerabilidade à ocorrência de Covid- 9 na população residente em TIs. Sem o intuito de listar de forma exaustiva as diversas iniciativas e potenciais impactos diretos e indiretos do trabalho colaborativo desenvolvido, podem ser mencionados: 
1. Apresentação da evolução temporal da pandemia nos povos indígenas em diversos webinars, incluindo:

a. Webinário População e Desenvolvimento em Debate, "Povos indígenas e a pandemia da Covid-19", promovido pelo Fundo de População das Nações Unidas (Unfpa) Brasil e Associação Brasileira de Estudos Populacionais (Abep). Disponível em: <https://www.youtube.com/ watch? $\mathrm{v}=\mathrm{cRV}$ dwss7BKc $>$.

b. Assembleia Nacional de Resistência Indígena, organizada pela Articulação dos Povos Indígenas do Brasil (Apib). Espaço I. Diagnósticos regionais sobre Covid- I 9 nas aldeias e o impacto sobre os povos indígenas. Disponível em: < https://www.youtube.com/watch?v=b3l l kMawCIQ>.

c. Apresentação de webinar no Programa de Videoconferências do Grupo de Interesse Especial (SIG) Saúde da Criança e do Adolescente, na Rede Universitária de Telemedicina, sobre o tema "Saúde da criança indígena".

d. Apresentação de webinar no Programa de Videoconferências do SIG Covid- I9, na Rede Universitária de Telemedicina, sobre o tema "Covid- 19 em povos indígenas no Brasil”.

2. Elaboração do documento denominado "Contribuciones para el informe del relator especial sobre los Derechos de los Pueblos Indígenas sobre el impacto de Covid- 19 en los pueblos indígenas", enviado a relator especial da Organização Mundial da Saúde (OMS), para fins de subsidiar o relator da Organização das Nações Unidas (ONU) na elaboração do documento base da Reunião da ONU.

3. Ampla referência aos resultados das análises em uma série de textos técnicos, incluindo as várias versões dos planos da União para enfrentamento da Covid- I 9 nas populações indígenas (ainda sub judice na esfera jurídica no mês de dezembro de 2020), assim como em documentos produzidos pelo grupo de especialistas da Fiocruz e da Abrasco no Âmbito da Ação de Descumprimento de Preceito Fundamental (ADPF 709/STF) movida pela Apib no Supremo Tribunal Federal (STF), relacionada às medidas governamentais de enfrentamento da Covid-19 em territórios indígenas (Pontes et al., 2020). 


\section{VULNERABILIDADE À COVID-19 E A INVISIBILIDADE DAS POPULAÇÕES INDÍGENAS: LIÇÕES DE UMA PANDEMIA NÃO DEMOCRÁTICA}

Após I I meses dos primeiros casos notificados de Covid- I 9 à OMS e da atenuação da primeira onda mundial da pandemia, verifica-se, atualmente, o recrudescimento da doença em diferentes regiões do mundo, inclusive no Brasil, onde sequer se registrou o término da primeira onda de circulação viral. A pandemia impôs uma sobrecarga aos sistemas e serviços de saúde, afetando sua capacidade de absorver as demandas de cuidados gerais e específicos da Covid- I9 na maioria dos países, e particularmente naqueles segmentos constituídos por populações mais vulnerabilizadas, como crianças, idosos, pessoas com comorbidades e minorias étnicas e sociais (WHO, 2020a). Independentemente do cenário local de transmissão atual da Covid-19, a OMS afirma que é necessário manter as medidas para reduzir a disseminação do vírus, prevenindo nova sobrecarga dos sistemas de saúde, assim como o adoecimento e a morte das pessoas com alto risco para a doença (WHO, 2020b).

Evidências geradas em dois inquéritos domiciliares nacionais sucessivos de soroprevalência de anticorpos contra o Sars-CoV-2 demonstraram prevalências crescentes no país, mas substancialmente maiores (cerca de 25\%) em I I cidades ao longo do rio Amazonas e nas áreas mais pobres e de menor acesso a serviços públicos, incluindo os de saúde (Hallal et al., 2020). Após ajuste por região de residência, número de moradores e condição socioeconômica do domicílio, constatou-se que a prevalência de anticorpos contra Sars-CoV-2 foi $87 \%$ maior em indígenas em comparação àquela entre brancos, sendo essa prevalência de $64 \%$ na análise restrita à região Norte. Infelizmente, houve descontinuidade desses inquéritos por parte do governo federal, o que inviabilizou o monitoramento da progressão e magnitude das iniquidades sociais na disseminação e ocorrência de desfechos indesejáveis e evitáveis da doença na população.

Diante dessas evidências, confirma-se a alta vulnerabilidade dos indígenas à pandemia e a influência dos determinantes sociais da saúde, que afetam de maneira desproporcional o risco de adoecimento por Covid-19 desse segmento populacional. Com base em dados dos sistemas de informação em saúde governamentais, análises apresentadas por Pontes e colaboradores (2020) indicam níveis de mortalidade e letalidade por Covid-19 mais elevados em indígenas, em particular nas faixas etárias de menores de 10 anos e a partir de 50 anos de idade, em comparação à população brasileira em geral, o que se alinha com manifestações de lideranças e organizações indígenas acerca dos drásticos impactos da pandemia (Apib, 2020). 
Considerando-se esse cenário e constatando-se os potenciais de disseminação da epidemia de Covid- 19 nos territórios indígenas e suas consequências para essas comunidades, ficou evidente a necessidade de esforços específicos voltados não somente para uma atenção qualificada e oportuna a esses povos, mas também para a sistematização e divulgação de um conjunto particular de informações em saúde. Em um cenário de marcantes iniquidades sociais e sanitárias, além da violência e fragilidade de garantia de direitos aos quais os povos indígenas estão expostos, as iniciativas de produção de informações, temporalmente oportunas, foram concebidas, e se confirmaram, como contribuições potencialmente relevantes no acompanhamento dos impactos de políticas públicas no campo da saúde indígena. Uma vez que a epidemia persiste no país, inclusive com recrudescimento, cabe destacar a necessidade de dar continuidade aos esforços no sentido de ampliar ainda mais a visibilidade à situação de saúde de populações etnicamente diferenciadas, como é o caso dos povos indígenas.

\section{REFERÊNCIAS}

ASSOCIAÇÃO BRASILEIRA DE SAÚDE COLETIVA (ABRASCO) \& ASSOCIAÇÃO BRASILEIRA DE ANTROPOLOGIA (ABA). A Covid-19 e os povos indígenas: desafios e medidas para controle do seu avanço. Nota Técnica. Rio de Janeiro, 21 mar. 2020. Disponível em: <www.abrasco.org.br/site/ outras-noticias/notas-oficiais-abrasco/a-covid-19-e-os-povos-indigenas-desafios-e-medidaspara-controle-do-seu-avanco/45866 >. Acesso em: 27 out. 2020.

ASSOCIAÇÃO BRASILEIRA DE SAÚDE COLETIVA (ABRASCO) \& ASSOCIAÇÃO BRASILEIRA DE ANTROPOLOGIA $(A B A)$. A Covid-19 e a situação alimentar entre povos indígenas: recomendações para o enfrentamento da pandemia. Nota Técnica. Rio de Janeiro, 15 abr. 2020. Disponível em: <www. abrasco.org.br/site/outras-noticias/notas-oficiais-abrasco/a-covid- 19-e-a-situacao-alimentar-entreos-povos-indigenas-recomendacoes-para-o-enfrentamento-da-pandemia/47017>. Acesso em: 27 out. 2020.

ARTICULAÇÃO DOS POVOS INDÍGENAS DO BRASIL (APIB). Comitê Nacional pela Vida e Memória Indígena. Covid-19 e Povos indígenas: nossa luta é pela vida. O enfrentamento das violências durante a pandemia. Brasília: Apib, 2020.

BRASIL. Decreto n. 1.775, de 8 jan. 1996. Dispõe sobre o procedimento administrativo de demarcação das Terras Indígenas e dá outras providências. Diário Oficial da União, Brasília, 9 jan. 1996.

BRASIL. Portaria n. 344 de I fev. 20 I 7. Dispõe sobre o preenchimento do quesito raça/cor nos formulários dos sistemas de informação em saúde. Diário Oficial da União, Brasília, 2 fev. 2017.

CARDOSO, A. M. A persistência das infecções respiratórias agudas como problema de Saúde Pública. Cadernos de Saúde Pública, 26(7): 1.270-1.271, 2010.

CARDOSO, A. M.; COIMBRA JR., C. E. A. \& WERNECK, G. L. Risk factors for hospital admission due to acute lower respiratory tract infection in Guarani indigenous children in southern Brazil: a populationbased case-control study. Tropical Medicine and International Health, 18(5): 596-607, 2013. 
CARDOSO, A. M. et al. Prevalence of pneumonia and associated factors among indigenous children in Brazil: results from the First National Survey of Indigenous People's Health and Nutrition. International Health, 7(6): 412-119, 2015.

CARDOSO, A. M. et al. Investigation of an outbreak of acute respiratory disease in an indigenous village in Brazil: contribution of influenza $A(\mathrm{HINI}) p d m 09$ and human respiratory syncytial viruses. PLoS One, 14(7): e0218925, 2019.

COIMBRA JR., C. E. A. et al. The First National Survey of Indigenous People's Health and Nutrition in Brazil: rationale, methodology, and overview of results. BMC Public Health, 13(I): 52, 2013.

ESCOLA POLITÉCNICA DE SAÚDE JOAQUIM VENÂNCIO/FUNDAÇÃO OSWALDO CRUZ (EPSJV/ FIOCRUZ). Policast. Série Covid- 19 em Povos Indígenas, março de 2020. Disponível em: <www.epsjv. fiocruz.br/noticias/radio-poli>. Acesso em: 23 out. 2020.

ESRI, USGS, NOAA. World_Terrain_Base. 2009. Disponível em: <https://server.arcgisonline.com/ ArcGIS/rest/services/World_Terrain_Base/MapServer>. Acesso em: 10 nov. 2020.

FUndAÇÃO NACIONAL DE SAúdE (FUnASA). Política Nacional de Atenção à Saúde dos Povos Indígenas. 2. ed. Brasília: Ministério da Saúde, Fundação Nacional de Saúde, 2002.

FUNDAÇÃO OSWALDO CRUZ (FIOCRUZ). InfoGripe. Monitoramento de casos de síndrome respiratória aguda grave (Srag) notificados no Sivep Gripe. Disponível em: < http://info.gripe.fiocruz.br>. Acesso em: 26 out. 2020.

GRUPO MAVE. Estimativa de risco de espalhamento da Covid- I 9 no Brasil e o impacto no sistema de saúde e população por microrregião. Relatório n. I do Grupo de Métodos Analíticos de Vigilância Epidemiológica (Mave), Procc/Fiocruz e EMAp/FGV. Rio de Janeiro, 17 mar. 2020a. Disponível em: <http://covid-1 9.procc.fiocruz.br/>. Acesso em: 26 out. 2020.

GRUPO MAVE. Estimativa de risco de espalhamento da Covid- 19 no Brasil e o impacto no sistema de saúde e população por microrregião. Relatório n. 2 do Grupo de Métodos Analíticos de Vigilância Epidemiológica (Mave), Procc/Fiocruz e EMAp/FGV. Rio de Janeiro, 25 mar. 2020b. Disponível em: $<$ http://covid-19.procc.fiocruz.br/>. Acesso em: 26 out. 2020.

GRUPO MAVE. Estimativa de risco de espalhamento da Covid- I 9 no Brasil e o impacto no sistema de saúde e população por microrregião. Relatório n. 3 do Grupo de Métodos Analíticos de Vigilância Epidemiológica (Mave), Procc/Fiocruz e EMAp/FGV. Rio de Janeiro, 2 abr. 2020c. Disponível em: < http:// covid-19.procc.fiocruz.br/>. Acesso em: 20 out. 2020.

GRUPO MAVE. Risco de espalhamento da Covid-19 em populações indígenas: considerações preliminares sobre vulnerabilidade geográfica e sociodemográfica. Relatório n. 4 do Grupo de Métodos Analíticos de Vigilância Epidemiológica (Mave), Procc/Fiocruz e EMAp/FGV. Rio de Janeiro, 18 abr. 2020d. Disponível em: <http://covid- I 9.procc.fiocruz.br/>. Acesso em: 20 out. 2020.

GRUPO MAVE. Risco de espalhamento da Covid-19 em populações indígenas: considerações preliminares sobre vulnerabilidade geográfica e sociodemográfica. 2. ed. do Relatório n. 4 do Grupo de Métodos Analíticos de Vigilância Epidemiológica (Mave), Proce/Fiocruz e EMAp/FGV. Rio de Janeiro, 5 maio 2020e. Disponível em: <http://covid- 19.procc.fiocruz.br/>. Acesso em: 20 out. 2020.

GRUPO MAVE. Risco de espalhamento da Covid- 19 em populações indígenas: considerações preliminares sobre vulnerabilidade geográfica e sociodemográfica. 3. ed. do Relatório n. 4 do Grupo de Métodos Analíticos de Vigilância Epidemiológica (Mave), PROCC/Fiocruz e EMAp/FGV. Rio de Janeiro, 17 maio 2020f. (Mimeo.) 
HALLAL, P. C. et al. Sars-CoV-2 antibody prevalence in Brazil: results from two successive nationwide serological household surveys. The Lancet Global Health, 8: el.390-1.398, 2020.

INSTITUTO BRASILEIRO DE GEOGRAFIA E ESTATÍSTICA (IBGE). Censo Demográfico 20 I0: características gerais dos indígenas - resultados do universo. Rio de Janeiro: IBGE, 2012.

PONTES et al. Pandemia de Covid-19 e os povos indígenas no Brasil: cenários sociopolíticos e epidemiológicos. In: MATTA, G. C. et al. (Orgs.). Os Impactos Sociais da Covid-I 9 no Brasil: populações vulnerabilizadas e respostas à pandemia. Rio de Janeiro: Editora Fiocruz, 202 I. (Informação para Ação na Covid- 19)

SANTOS, R. V.; PONTES, A. L. \& COIMBRA JR., C. E. A. Um "fato social total": Covid- 19 e povos indígenas no Brasil. Cadernos de Saúde Pública, 36(I 0): e00268220, 2020.

SANTOS, R. V. et al. (Orgs.). Entre Demografia e Antropologia: povos indígenas no Brasil. Rio de Janeiro: Editora Fiocruz, 2019.

WALKER, R.; SATTENSPIEL, L. \& HILL, K. Mortality from contact-related epidemics among indigenous populations in Greater Amazonia. Scientific Reports, 5(14.032), 2015.

WORLD HEALTH ORGANIZATION (WHO). Maintaining essential health services during the Covid-I 9 outbreak, I Jun. 2020a. Disponível em: <www.who.int/emergencies/diseases/novel-coronavirus-20 I 9 / related-health-issues >. Acesso em: 24 nov. 2020.

WORLD HEALTH ORGANIZATION (WHO). Critical preparedness, readiness and response actions for Covid-19: interim guidance, 4 Nov. 2020b. Disponível em: <https://apps.who.int/iris/ handle/l 0665/336373 > . Acesso em: 24 nov. 2020. 


\title{
A Pandemia pelo Sars-CoV-2 no Estado do Amazonas
}

\author{
José Joaquín Carvajal Cortés, Bernardino Cláudio de Albuquerque, \\ Fernando José Herkrath, Felipe Gomes Naveca, Sérgio Luiz Bessa Luz, \\ Rodrigo Tobias de Sousa Lima, Marcelo Ferreira da Costa Gomes, \\ Daniel Antunes Maciel Villela, Christovam Barcellos, \\ Carlos Machado de Freitas, Leonardo Soares Bastos, \\ Margareth Crisóstomo Portela e Valcler Rangel Fernandes
}

A

resposta à introdução e difusão do Sars-CoV-2 no estado do Amazonas seguiu-se à concepção dominante no país e no mundo de que esse seria mais um problema de saúde pública, visto como de impacto moderado, transitório e solucionável com a implementação de estratégias e ações de intervenção - portanto, sem grandes repercussões nas condições de vida da população. Infelizmente, o problema não foi considerado como o grande desafio sanitário que é, apesar de todos os indicadores sinalizarem nessa direção: o desconhecimento do agente e de sua dinâmica de transmissão, sua virulência, fisiopatogenia, biologia e imunologia, aliado à sua alta transmissibilidade e disseminação.

A suscetibilidade universal da população humana ao patógeno foi considerada com limitações, assim como o fato de que a proteção e preservação da vida exigiam também a produção do conhecimento sobre todas as etapas da história natural da Covid-19. Esperou-se acontecer, mesmo reconhecendo-se que poucas armas estariam disponíveis para a prevenção e quase nenhuma direcionada à preservação da vida. As perspectivas se mostraram sombrias: inexistência de tratamento específico, restrição de testes para diagnóstico, escassez de insumos laboratoriais e hospitalares, de equipamentos e de toda uma infraestrutura hospitalar necessária à assistência aos pacientes. Aliadas a todos esses fatores, ressaltam-se a reduzida experiência das equipes de saúde no manejo 
da atenção básica perante a doença e a baixa capacidade de implementar ações coletivas para restringir a velocidade de disseminação do vírus.

Não foi difícil imaginar esse cenário em um território de 1.570 .745 quilômetros quadrados, no qual as dimensões dos 62 municípios ultrapassam a área de inúmeros países. O acesso à capital por via terrestre é viável somente para 12 municípios do estado; para os demais a grande via de acesso é a malha fluvial, em que o tempo de deslocamento, em sua grande maioria, é mensurado em dias ou semanas. O sistema de saúde é configurado pelas regiões de saúde que, em termos operacionais, não desempenham satisfatoriamente esse papel, uma vez que grande parte da atenção secundária e terciária tem como única referência a capital, Manaus. Ademais, o estado do Amazonas alberga grupos populacionais extremamente vulneráveis e susceptíveis, como populações indígenas e populações ribeirinhas, ambas também ocupando áreas remotas e de difícil acesso. O estado conta com a maior população indígena em números absolutos no país: o Censo Demográfico do IBGE 2010 identificou 65 grupos indígenas no Amazonas, perfazendo um total de 168.680 indígenas, sem considerar grupos ainda não contatados, presentes em vales de grandes rios como o do rio Javari.

Nesse cenário, somente após a Organização Mundial da Saúde (OMS) ter declarado situação de Emergência de Saúde Pública de Importância Internacional (Espii), em 30 de janeiro de 2020, e o Estado brasileiro ter declarado Emergência em Saúde Pública de Importância Nacional (Espin), em 3 de fevereiro de 2020, foi criado no Amazonas o Centro de Operações de Emergência para o enfrentamento da Covid- 19 (COE-AM), no âmbito da Fundação de Vigilância em Saúde do Amazonas. Em 26 de fevereiro de 2020 foi confirmado o primeiro caso de Covid-19 no país e em 13 de março de 2020 o primeiro caso no estado do Amazonas, após o que foi decretado, em 16 de março de 2020, o Estado de Emergência em Saúde Pública no Amazonas (Manaus, 2020; Amazonas, 2020a). A partir daí o COE-AM foi reconfigurado e ampliado, com a participação de instituições representadas como possíveis interfaces no enfrentamento da situação (Amazonas, 2020b).

Nessa fase inicial, a doença teve como epicentro a capital, Manaus, com reconhecimento da transmissão comunitária em 28 de março de 2020. A difusão para os municípios foi rápida, não obedecendo à contiguidade e dispersando-se em focos para várias regiões do estado. A partir de então, o número de casos e óbitos teve crescimento exponencial, tanto na capital quanto na grande maioria dos municípios do interior. Em 30 de março o registro de casos confirmados no estado era de 229, com 205 notificados na capital. Um mês depois, em 30 de abril, o número de casos acumulados era de 5.254, 
evidenciando um acréscimo de $2.194 \%$ em relação a 30 de março; a capital demonstrou um crescimento percentual de $1.496 \%$ e o conjunto dos demais municípios, de $8.154 \%$. No dia 18 de maio, o número de casos confirmados em municípios do interior ultrapassou o registro da capital, situação que persiste até o momento. Decorridos nove meses de epidemia (20 de dezembro de 2020), o estado registrou 191.976 casos confirmados e 5.085 óbitos por Covid- 19 (FVS-RCP, 2020).

Durante esse período foram vivenciados momentos difíceis, caracterizados pelo rápido e expressivo aumento no número de casos e de óbitos na capital e em municípios do interior, com grave colapso da rede de atenção à saúde e do sistema de destinação final de corpos daqueles vitimados pela doença. Manaus passou a ocupar a mídia nacional e internacional em razão do estado de calamidade instalado, apresentando à época as maiores taxas de incidência e mortalidade por Covid- 19 dentre as capitais. Posteriormente, em função das medidas de contenção adotadas e da melhora relativa da adesão da população às medidas não farmacológicas preconizadas, associadas a uma diminuição da população suscetível, a curva de ocorrência de casos e de óbitos entrou em declínio, mantendo-se, porém, estacionada em patamares ainda preocupantes, demonstrando nos últimos meses oscilações com recrudescência.

Propomo-nos, aqui, a analisar a evolução da Covid- 19 no território amazônico, observados os aspectos da distribuição da doença na capital e de regiões de saúde do estado do Amazonas, o mapeamento de casos na região de tríplice fronteira internacional e a caracterização genética do vírus ao longo do ano de 2020. Para isso, estruturamos o capítulo em três partes: na primeira apresentamos uma análise da historicidade das doenças respiratórias de notificação compulsória, na segunda mapeamos o desenvolvimento da pandemia no interior do estado e zona de fronteira e na terceira discorremos sobre a caracterização molecular do vírus.

\section{ANÁLISE DA NOTIFICAÇÃO DA SÍNDROME RESPIRATÓRIA AGUDA GRAVE NAS REGIÕES DE SAÚDE DO ESTADO DO AMAZONAS}

Dados nacionais da vigilância de síndrome respiratória aguda grave (Srag) notificados no sistema Sivep Gripe e processados pelo InfoGripe permitem verificar padrões distintos entre os gráficos de série temporal da capital, Manaus, e aqueles das regiões de saúde do estado do Amazonas (Fiocruz, 2020a). Observam-se também diferenças na semana epidemiológica de notificação dos primeiros casos e nas incidências máximas notificadas (Figura I). Para permitir uma avaliação adequada, o município de Manaus foi analisado separadamente da sua região de saúde (Entorno de Manaus e Alto Rio Negro). 
As epidemias propagadas, ou seja, transmitidas de pessoa para pessoa, podem durar mais do que as epidemias de fonte comum e se caracterizar por várias elevações na incidência de casos por 100 mil habitantes (Torok, 2020). Quanto à magnitude da epidemia, observa-se que o município de Manaus e as regiões do Entorno de Manaus e Alto Rio Negro e Alto Solimões, que inclui a região da tríplice fronteira Brasil-ColômbiaPeru, apresentaram os picos com maiores incidências de casos notificados por 100 mil habitantes. Cavalcante e colaboradores (2020) mostraram que até a $20^{\text {a }}$ semana epidemiológica o Amazonas apresentava a maior taxa de incidência da Covid- I 9 das unidades federativas do país, bem como a maior taxa de mortalidade. Verifica-se, ainda, que algumas regiões, como Entorno de Manaus e Alto Rio Negro, mantiveram elevada notificação de casos de Srag após o período de incidência máxima.

Figura 1 - Casos notificados e estimados de síndrome respiratória aguda grave (Srag) nas regiões de saúde do Amazonas e em Manaus segundo a semana epidemiológica, por município de notificação do caso - Semanas epidemiológicas de I a 50 de 2020
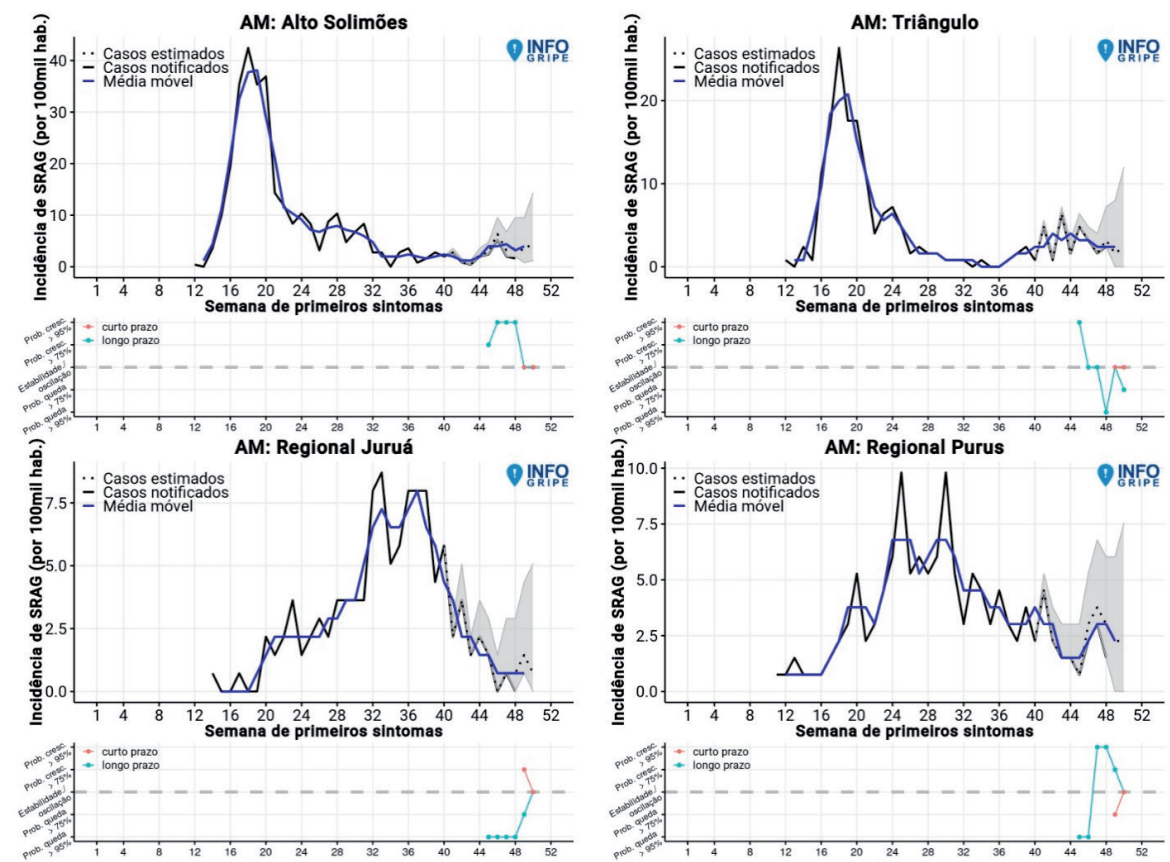
Figura I - Casos notificados e estimados de síndrome respiratória aguda grave (Srag) nas regiões de saúde do Amazonas e em Manaus segundo a semana epidemiológica, por município de notificação do caso - Semanas epidemiológicas de I a 50 de 2020 (continuação)
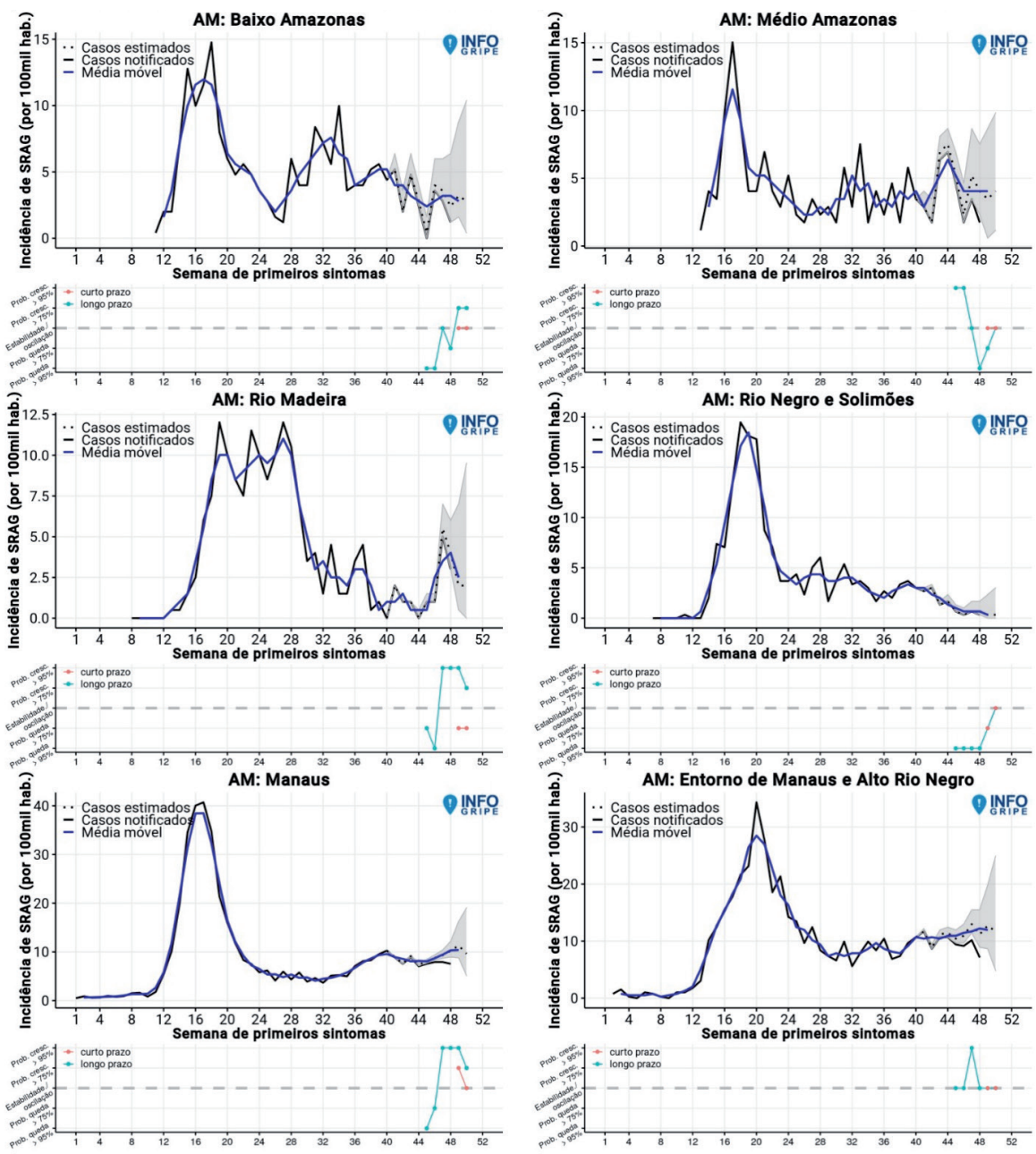

Fonte: InfoGripe - Sivep Gripe; GT Influenza (SVS/MS). 
Os gráficos também mostram que algumas regiões de saúde apresentaram notificação tardia dos primeiros casos, em especial a região do Juruá, que abrange municípios de difícil acesso. $\mathrm{Na}$ análise do comportamento das curvas epidêmicas segundo as regiões de saúde do Amazonas, identificam-se três padrões de curva principais, a saber:

I. Regiões de saúde com curva de crescimento exponencial e contínuo da taxa de incidência de casos, com posterior decréscimo em ritmos variáveis, porém mantendo uma cauda de curva em diferentes patamares de transmissão e em processo de aumento, estabilização ou queda. Esse padrão pode indicar que a epidemia seguiu seu curso natural, com baixa interferência das medidas de contenção adotadas. Representado pelo município de Manaus e regionais: Rio Negro e Solimões, Médio Amazonas, Alto Solimões, Triângulo e Entorno de Manaus e Alto Rio Negro.

2. Regiões de saúde com curva de crescimento de forma mais moderada e descontínua da taxa de incidência de casos, intercalando picos e decréscimos de seus níveis, mantendo-se em diferentes patamares de transmissão e em processo de recrudescimento, estabilização ou queda. Esse comportamento está possivelmente associado à adoção de medidas locais de contenção, com alguma efetividade, em períodos distintos, pelos municípios que as compõem. Representam esse comportamento as regiões de saúde do Rio Madeira e Baixo Amazonas.

3. Regiões com crescimento da taxa de incidência de casos de forma lenta, possivelmente traduzindo maiores restrições de acesso e menor mobilidade populacional, resultando em menor pressão de introdução do vírus. Esse padrão é representado pelas regiões de saúde do Rio Purus e do Rio Juruá, que compreendem alguns dos municípios de mais difícil acesso no estado. Em contrapartida, vale destacar as altas condições de receptividade à reprodução viral dessas áreas, decorrentes de precárias condições socioeconômicas, alta concentração de população indígena e outros grupos vulneráveis, dificuldades logísticas e nas condições de atenção à saúde, o que pode incluir ainda problemas para a testagem dos casos suspeitos e possíveis atrasos na notificação.

Compreender as características epidemiológicas da transmissão de Covid-19 é essencial para formular estratégias eficazes de controle. Análise das curvas de quatro países relacionadas à epidemia de Sars em 2003 mostrou a importância da implementação rápida de medidas de controle para limitar o impacto da epidemia, com redução tanto 
dos casos quanto do período de vigência de medidas mais restritivas de controle da infecção (Wallinga $\varepsilon$ Teunis, 2004). Cabe ressaltar, no entanto, que os dados de recortes territoriais amplos, como as regiões de saúde, podem dificultar a avaliação de heterogeneidades nos municípios que as compõem.

A Figura 2 mostra a taxa de incidência acumulada até a semana epidemiológica 50, calculada a partir das notificações de síndromes respiratórias por município de notificação; no entanto, é importante lembrar que os casos confirmados dependem da confirmação laboratorial, o que nem sempre está disponível no município.

Figura 2 - Taxa de incidência acumulada de casos confirmados de Covid- 19 por município de notificação do estado de Amazonas - Semanas epidemiológicas de I a 50 de 2020

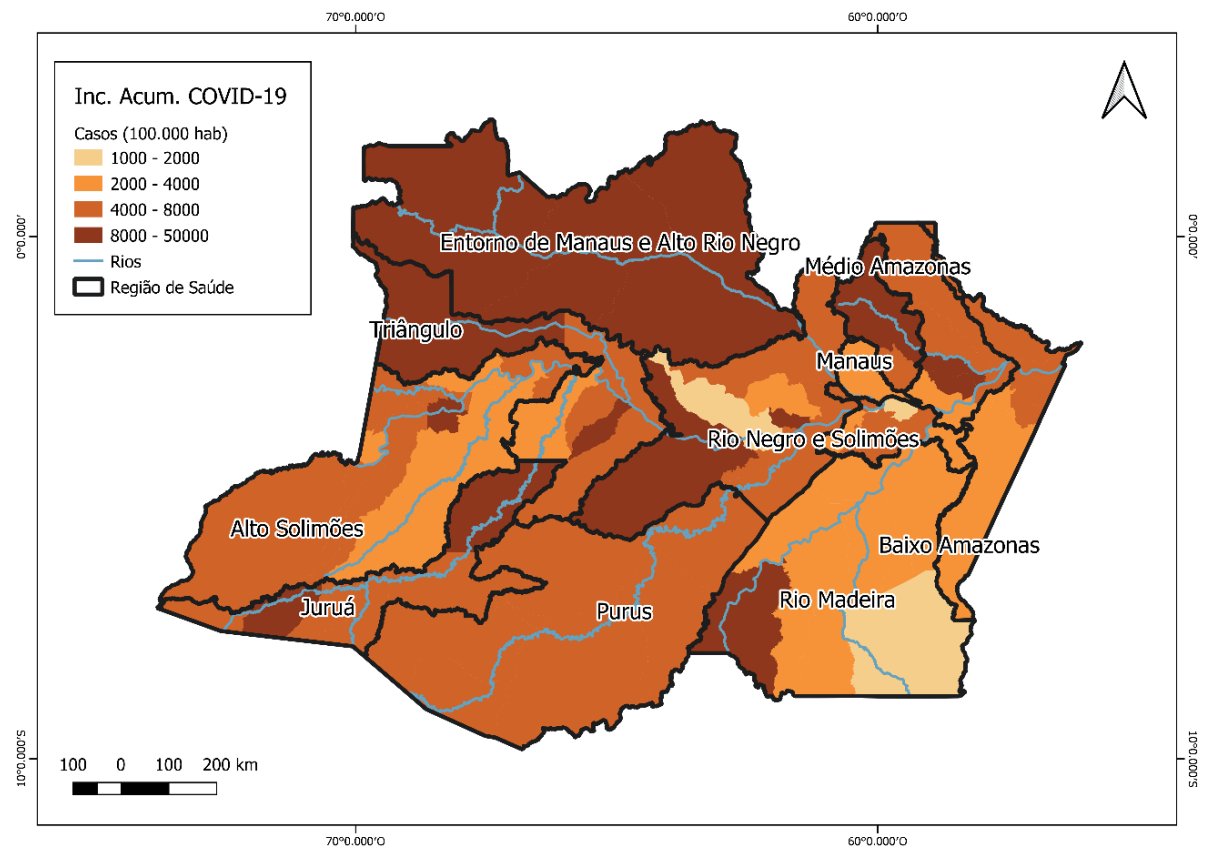

Fonte: Cievs/FVS-AM. Datum Sirgas 2000 (EPSG: 4674). Elaborada por José Joaquín Carvajal Cortés (ILMD/Fiocruz Amazônia) em 17 dez. 2020.

Quanto à sua distribuição espacial, podem-se observar alguns clusters de maior incidência de casos, nas regionais de Entorno de Manaus e Alto Rio Negro, Baixo Amazonas, Médio Amazonas, Triângulo e Juruá, destacando-se com maior incidência acumulada os municípios de Japurá, Itapiranga, Carauari, São Gabriel da Cachoeira, 
Barcelos, Presidente Figueiredo, Coari, Santa Isabel de Rio Negro e Amaturá, associados principalmente às hidrovias dos rios Solimões e Amazonas e seus afluentes.

É importante atentar para o comportamento heterogêneo da taxa de incidência e mortalidade acumulada nos diferentes recortes geográficos. O estado tem uma taxa de incidência de 4.507,7 casos/100 mil habitantes, sendo que na capital esta é de 3. 187/100 mil habitantes e para o conjunto dos 61 municípios do interior de 5.7 15/100 mil habitantes. Com relação à mortalidade, a taxa para o estado é atualmente de 122,2 óbitos/100 mil habitantes, para a capital, de 146,01 e para o interior, de 92,46. Com base nos indicadores por regionais de saúde, verifica-se que a regional do Juruá é a detentora da maior taxa de incidência acumulada (8.423,6 casos/1 00 mil habitantes), contrastando com a menor taxa de mortalidade (50,8/I00 mil habitantes). A menor incidência foi detectada na regional do Entorno de Manaus e Alto Rio Negro, com 3.9 I 0,3 casos/ I 00 mil habitantes, porém com elevada taxa de mortalidade, I39,3 óbitos/ / 00 mil habitantes (FVS-RCP, 2020).

\section{DINÂMICA EPIDEMIOLÓGICA DA COVID-19 NA ZONA DE FRONTEIRA ENTRE BRASIL, COLÔMBIA E PERU}

A zona de fronteira entre Brasil, Colômbia e Peru (tríplice fronteira amazônica) compreende as três faixas de fronteira de cada país: I) Faixa de fronteira brasileira - Arco Norte, sub-região III (Parima-Alto Rio Negro), IV (Alto Solimões), V (Alto Juruá) e VI (Vale do Acre - Purus) da faixa de fronteira brasileira; 2) Faixa de fronteira colombiana - Departamentos do Amazonas, Guainía, Putumayo e Vaupés e; 3) Faixa de fronteira peruana - Departamentos de Loreto, Madre de Dios e Ucayali (Pêgo et al., 2017). Para a elaboração desta seção, os dados de vigilância de casos confirmados e óbitos pela Covid- 19 foram analisados por município, distrito ou corregimento dos estados e departamentos fronteiriços de cada país,' publicados pelas instituições oficiais, em colaboração com a Rede Transfronteiriça para o Enfrentamento da Covid- 9 na Tríplice Fronteira entre Brasil, Colômbia e Peru (Fiocruz, 2020b), no período entre 13 de março e 17 de dezembro de 2020.

Na Amazônia, região transfronteiriça, a disseminação do Sars-CoV-2 até dezembro de 2020 foi acelerada desde o primeiro caso confirmado no município de Manaus, AM (Brasil), no dia 13 de março. Nove meses depois, a doença se disseminou em 94,7\%

I Colômbia: Vigilancia em Salud Pública/Secretaría de Salud Departamental del Amazonas (VSP Amazonas); Peru: Dirección Regional de Salud del Departamento de Loreto (Diresa Loreto); Brasil: Centro de Informações Estratégicas de Vigilância em Saúde (Cievs/FVS-AM). 
( 16 I/I 70) dos municípios da região de fronteira entre Brasil (BR), Colômbia (CO) e Peru (PE): em 100\% (62/62) dos municípios do estado do Amazonas-BR, I00\% (53/53) dos distritos de Loreto-PE e 83,6\% (46/55) dos municípios dos departamentos amazônicos da Colômbia. Quanto à evolução da disseminação do vírus, mais da metade dos municípios no estado do Amazonas no Brasil já havia confirmado casos de Covid- 19 em abril, seguidos de Peru em maio e Colômbia em julho (Carvajal-Cortés et al., 2020). A elevada mobilidade transfronteiriça nessa região, aliada às barreiras impostas pelo limite internacional, pode dificultar o registro de eventos de saúde de importância regional, o que acaba por prejudicar o trabalho da vigilância e o planejamento das ações em saúde. Aliás, a falta de conhecimento preciso sobre a magnitude das populações que vivem e circulam na fronteira, a acessibilidade a seus territórios, a conectividade fluvial e aérea, a capacidade instalada para à atenção em saúde e a capacidade de diagnóstico, entre outros, fragmenta a percepção da dinâmica espacial dos processos socioespaciais transfronteiriços.

Os municípios localizados na linha de fronteira internacional apresentaram maior número de casos confirmados acumulados, destacando-se São Gabriel da Cachoeira-BR (4.974), Lábrea-BR (3.527), Letícia-CO (2.925), Barcelos-BR (2.9 I 8), Ipixuna-BR (2.625), Santa Isabel do Rio Negro-BR (2.356), São Paulo de Olivença-BR (2.109), Tabatinga-BR (2.0I I), Boca do Acre-BR (1.948), e Benjamin Constant-BR (1.779). Além disso, esses municípios apresentaram maior incidência acumulada por 100 mil habitantes (Figura 3), destacando-se Putumayo-PE (40.67 I), Rosa Panduro-PE (38.462), Japurá-BR (21.488), Yaquerana-PE (15.022), Yaguas-PE (14.879), Teniente Manuel Clavero-PE (14.243), São Gabriel da Cachoeira-BR ( 10.917$)$, Barcelos-BR ( 0.610$)$, Santa Isabel do Rio Negro-BR (9.366) e Amaturá-BR (8.955). 
Figura 3 - Taxa de incidência e taxa de mortalidade acumulada de Covid- 19 por município de notificação, na região de fronteira entre Brasil, Colômbia e Peru

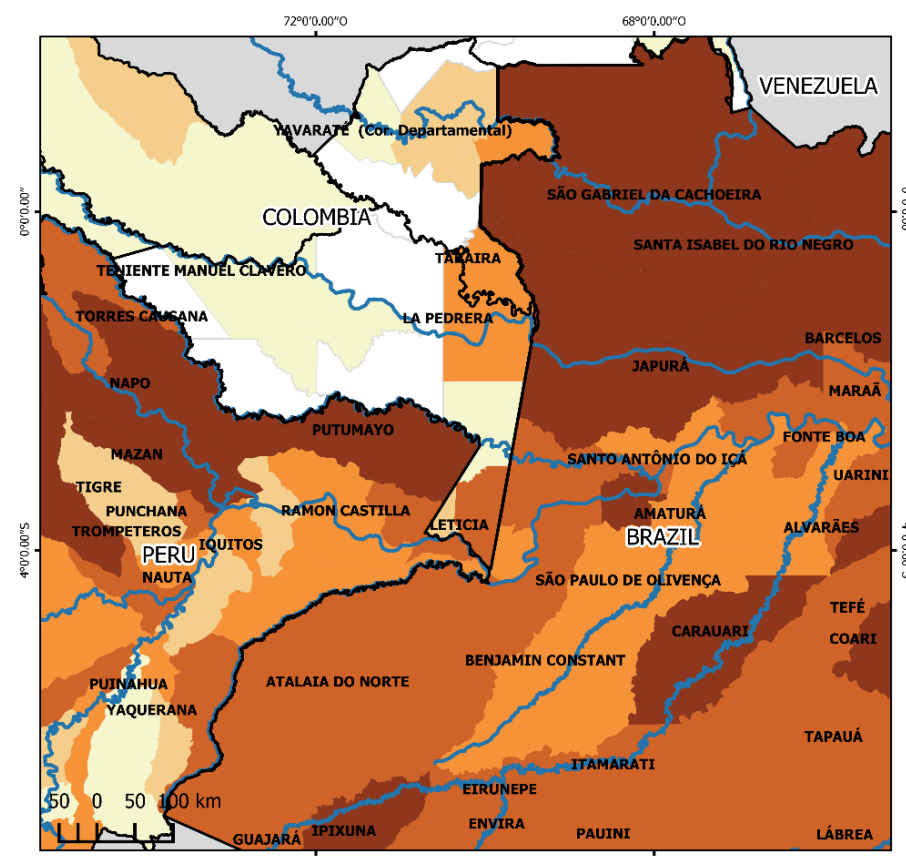

CENÁRIO

EPIDEMIOLÓGICO DE

COVID-19 NA TRIPLICE

FRONTEIRA ENTRE BRASIL, COLOOMBIA E PERU

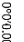
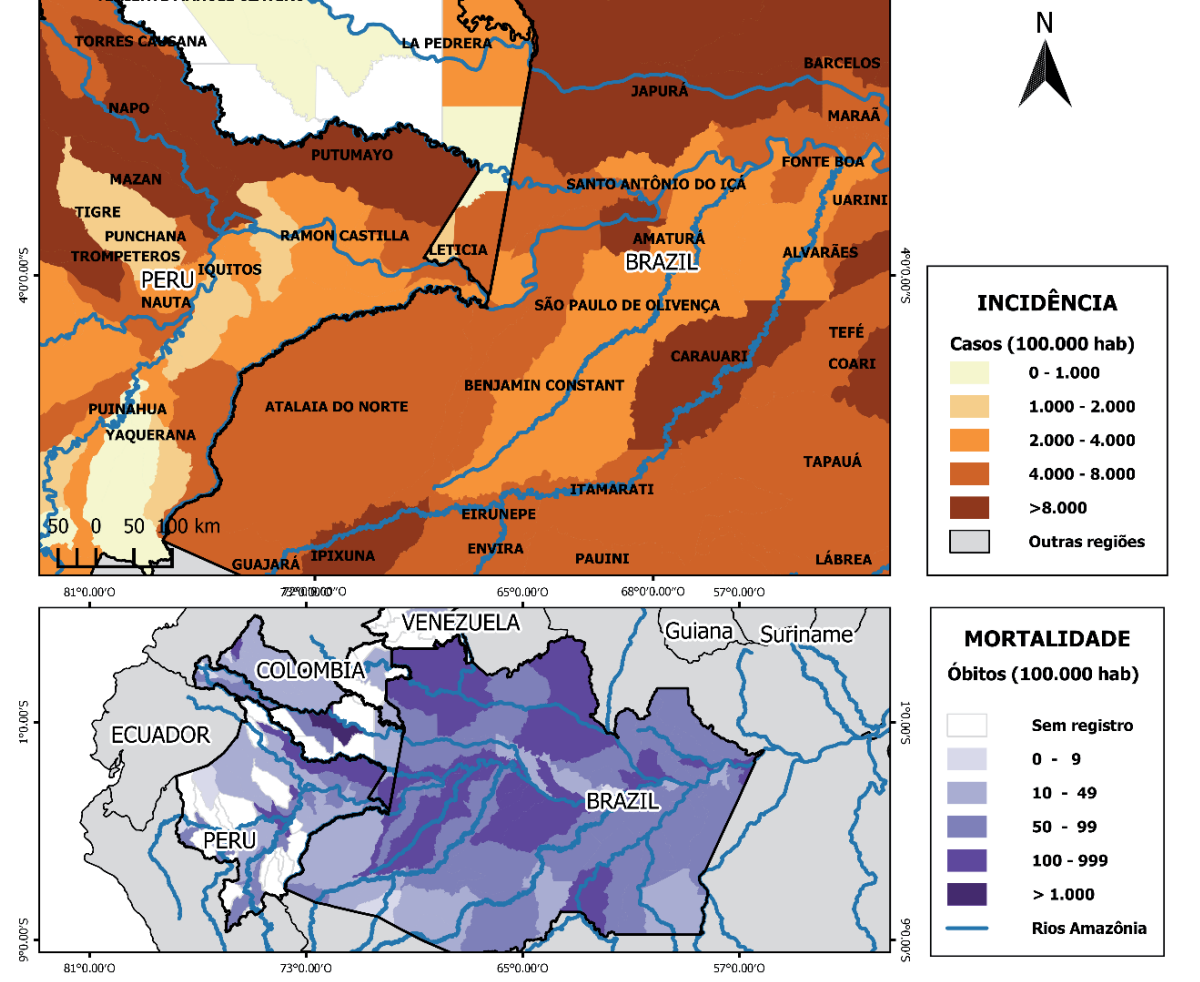

Fontes: Colômbia: VSP Amazonas; Peru: Diresa Loreto; Brasil: Cievs/FVS-AM. Datum Sirgas 2000 (EPSG: 4674). Elaborada por José Joaquín Carvajal Cortés (ILMD/Fiocruz Amazônia) em I 7 dez. 2020.

Quanto à mortalidade, os municípios localizados na faixa de fronteira tiveram maior número de óbitos confirmados acumulado, destacando-se Letícia-CO (I I3), TabatingaBR (87), Puerto Asís-CO (69), São Gabriel da Cachoeira-BR (58), Benjamin Constant-BR (46), Lábrea-BR (44), Mocoa-CO (44), Orito-CO (35), Barcelos-BR (28) e Santo Antônio do Içá-BR (28). Da mesma forma, esses municípios apresentaram maior mortalidade acumulada por 100 mil habitantes, destacando-se Letícia-CO (227), Putumayo-PE 
(136), Tabatinga-BR (132), Santo Antônio do lçá-BR (I 30), São Gabriel da Cachoeira-BR (127), Jutaí-BR (I I 2), Benjamin Constant-BR (107), Jenaro Herrera (106), Puerto AsísCO (103) e Barcelos-BR ( 102) (Figura 3).

A expansão da epidemia para áreas rurais mais afastadas através dos principais rios, tendo como epicentros inicialmente áreas urbanas maiores como Manaus-BR, Letícia$\mathrm{CO}$, Tabatinga-BR, Benjamin Constant-BR e lquitos-PE, possivelmente reflete a alta mobilidade populacional desde as localidades rurais até os principais centros urbanos, e vice-versa, em busca de acesso a serviços básicos e também em razão dos intensos fluxos e intercâmbios de produtos agrícolas e industrializados. Além desses municípios, na fronteira entre Brasil e Colômbia, observaram-se outros epicentros da epidemia: I) São Gabriel da Cachoeira-BR, município com a maior população indígena do Brasil, como epicentro da região Norte na fronteira com os departamentos de Vaupés-CO e Guainia-CO, através dos rios Negro e Vaupés, 2) o município de Japurá-BR, que faz fronteira com a área não municipalizada de La Pedrera-CO, interligados pelo rio Japurá, e 3) o município de Santo Antônio de Içá-BR, interligado com Tarapacá-CO, e as demais áreas não municipalizadas da Colômbia sobre o rio Içá. Na fronteira entre Peru e Colômbia, a alta incidência nos distritos da província de Putumayo-PE, caracterizada por contínuo fluxo de pessoas pelo rio Putumayo, possivelmente levou a doença até as áreas no interior de Puerto Arica, La Chorrera, San Rafael e El Encanto, na Colômbia.

\section{CARACTERIZAÇÃO GENÉTICA DO SARS-COV-2 CIRCULANTE NO ESTADO DO AMAZONAS}

Em março de 2020, o Instituto Leônidas e Maria Deane (ILMD, Fiocruz Amazônia), em parceria com a Fundação de Vigilância em Saúde do Estado do Amazonas (FVS-AM) e o Laboratório Central de Saúde Pública do Amazonas (Lacen-AM), iniciou a caracterização genética do Sars-CoV-2 circulante no estado do Amazonas, Brasil. O primeiro caso analisado foi o de um portador assintomático que retornava de Madri, Espanha, local que vivia uma escalada dramática no número de casos de Covid-19. Por esse motivo, mesmo que se tratasse de caso assintomático, foi realizada a testagem dentro do programa permanente de vigilância de vírus emergentes/reemergentes e negligenciados do ILMD. Após a confirmação do caso foi realizado o sequenciamento do genoma completo do Sars-CoV-2. O processo entre a identificação do caso de infecção, a preparação e o sequenciamento da amostra, e a sua disponibilização para a comunidade científica mundial durou oito dias. Esse primeiro caso foi então confirmado como pertencente à linhagem A.2, com estreita relação filogenética com amostras espanholas, confirmando o vínculo epidemiológico e o nexo temporal (Nascimento et al., 2020). Após o esforço 
para liberar a informação do primeiro genoma do Sars-CoV-2 sequenciado na região Norte do país, os pesquisadores envolvidos nesse projeto se dedicaram, entre abril e maio de 2020, a compor a rede diagnóstica oficial do estado do Amazonas.

O surgimento das linhagens é um processo natural, resultado do acúmulo de mutações ao longo do tempo em que um vírus circula em uma população. Esse processo é mais rápido em vírus de genoma RNA, tal como o Sars-CoV-2, pela falta da atividade de correção da RNA polimerase, enzima responsável pela replicação do material genético, mas também pela grande quantidade de partículas virais produzidas diariamente no hospedeiro. Levando-se em consideração que em uma pandemia milhões de pessoas são infectadas em diferentes locais do mundo, é natural supor que o processo evolutivo culminará com diversas linhagens sendo geradas. Entretanto, a informação contida nos genomas virais serve como ferramenta para a epidemiologia molecular, fornecendo dados cruciais para se entender o caminho que um vírus percorreu até chegar em determinada região. Não obstante, a caracterização genética em larga escala, como vem sendo realizada com o Sars-CoV-2 de maneira sem precedentes na história da humanidade, ajuda a identificar eventuais mutações e suas possíveis consequências. Considerando a evolução do Sars-CoV-2, um grupo de pesquisadores desenvolveu um sistema de classificação em linhagens, tendo como base dois grandes ramos que receberam a denominação de A e B (Rambaut et al., 2020). Assim, à medida que foram surgindo diferenciações genéticas dentro de cada grande ramo, foram sendo designadas linhagens A. I, A.2, B. I, B. I. I, e assim sucessivamente.

Com relação aos dados do Amazonas-BR, até novembro de 2020 foram sequenciados 79 genomas, provenientes de 18 municípios: Anori, Autazes, Careiro, Iranduba, Itacoatiara, Jutaí, Lábrea, Manacapuru, Manaquiri, Manicoré, Maués, Nova Olinda do Norte, Parintins, Presidente Figueiredo, Santa Isabel do Rio Negro, Santo Antônio do Içá e Tabatinga, além da capital Manaus. No total, oito linhagens foram identificadas: A.2; B.I; B.1.1.2; B.1.1.28; B.1.1.33; B.1.1.107; B.1.1.35 e B.1.1.1 II, das quais quatro linhagens (B.I.107; B.I.I I ; B.1.1.2 e B.I.35), que circularam na Dinamarca, Colômbia, Reino Unido e País de Gales, não possuíam registro no Brasil. Com a descoberta dos pesquisadores do ILMD, ao final de novembro de 2020, subiu de 26 para 30 o número de linhagens do Sars-CoV-2 no Brasil, de acordo com os dados disponíveis na plataforma Gisaid, principal banco de dados público com informações genéticas sobre o Sars-CoV-2. 


\section{CONSIDERAÇ̃̃ES FINAIS}

A análise da evolução da epidemia da Covid-I 9 no estado do Amazonas e seus diferentes recortes espaciais permite a construção de hipóteses que venham justificar os diferentes comportamentos de curvas epidêmicas, incluindo aspectos relacionados a fatores locais como a vulnerabilidade e receptividade da área à introdução e reprodução do agente etiológico, bem como aos impactos das medidas de controle ou de contenção da transmissão. A análise dos dados tomando como base a notificação das síndromes respiratórias é uma estratégia importante para uma avaliação que visa a conferir maior sensibilidade do sistema de vigilância local, assim como proporciona a gestão de maior oportunidade na definição ou implementação de medidas para um efetivo controle. A epidemiologia molecular também fornece subsídios essenciais para a compreensão do percurso e dinâmica do vírus nos diferentes recortes geográficos.

A identificação de ao menos oito linhagens do Sars-CoV-2 menos de três meses após o primeiro caso confirmado no Amazonas, Brasil, ressalta a intensidade com que a pandemia chegou nessa região. Dados recentes sobre uma nova variante viral encontrada no Reino Unido, possivelmente mais transmissível, mostra a necessidade do contínuo monitoramento da diversidade genética viral em diferentes regiões do mundo.

O aumento exponencial do número de casos e óbitos por Covid- 19 no Amazonas representou a crise do sistema de saúde diante das desigualdades sociais e das necessidades de saúde da população. Na capital, foi observado o aumento do número de casos da população residente em bairros socioeconomicamente favorecidos, seguido da disseminação dos casos nas áreas periféricas de Manaus, o que nos permitiu sugerir que a doença foi introduzida na capital via aérea em passageiros oriundos de outros países da Europa e da China, uma vez que o polo industrial de Manaus concentra empresas multinacionais com estreita relação comercial com produtos predominantemente chineses. Um terceiro movimento foi o espalhamento do número de casos pelos rios amazônicos em direção ao interior, sem deixar de destacar outros vetores de introdução do vírus via tríplice fronteira e municípios fronteiriços com os estados do Pará, Rondônia, Roraima e Acre, simultaneamente.

A dinâmica epidemiológica da Covid- 19 nessa fronteira mostra como a expansão da Covid-19 para áreas rurais e aldeias indígenas continua sendo motivo de muita preocupação. Porém, as situações de alta vulnerabilidade socioeconômica e desigualdade que as populações amazônicas já vivenciam, intensificadas pela presença de atividades extrativistas e econômicas ilegais, potencializam os problemas de estrutura e acesso aos serviços de saúde. 
Não obstante, vimos a expansão do número de leitos de UTI ocorrer em progressão aritmética, muito aquém do aumento do número de casos confirmados. A taxa de ocupação de leitos exclusivos das redes privada e pública chegou a 90\% e 95\%, respectivamente, ainda em abril de 2020. Não houve preparo da rede assistencial de urgência e emergência de gestões locais anteriores para o enfrentamento ao desafio pandêmico; a ajuda do governo federal, que veio a passos lentos, teria representado o apoio fundamental. À medida que houve provisão oportuna de serviços assistenciais, o sistema de saúde teve capacidade de absorver perturbações e se reorganizar, mediante lições aprendidas com a doença (Fridell et al., 2020). Houve a abertura e fechamento de dois hospitais de campanha (um de gestão municipal e outro estadual), com a expansão de 170 leitos clínicos para casos moderados, 53 dos quais exclusivos para populações indígenas.

O relaxamento das medidas de contenção no processo de evolução da epidemia determinada pelo Sars-CoV-2 é condição importante para o recrudescimento dos níveis epidêmicos e, portanto, deve ser monitorado e criteriosamente planejado. Além da ampliação da vigilância laboratorial para suporte à adequação dos serviços de saúde e à atenção aos pacientes com Srag, políticas públicas que propiciem maior adesão da população às medidas de contenção, como a prática do distanciamento social, isolamento de sintomáticos, investigação e monitoramento de contatos, uso de máscaras, higienização das mãos e de possíveis fômites, devem ser fomentadas em tempo oportuno e avaliadas de maneira contínua.

Concluímos, portanto, que a epidemia no estado e suas fronteiras segue o seu curso em dezembro de 2020, mantendo-se ativa a circulação viral em um importante percentual de população suscetível. Para o ano de 2021, a perspectiva da vacina não deve ser considerada como a solução do problema e, sim como mais uma ferramenta disponível a contribuir para esse objetivo, que representa uma grande conquista civilizatória e a melhor intervenção em saúde pública. Portanto, o uso de máscaras, higienização das mãos e de superfícies críticas, o distanciamento social, isolamento de doentes e monitoramento de contatos, a vigilância transfronteiriça em saúde pública e o fortalecimento da rede de vigilância genômica são medidas ainda imprescindíveis para que se mantenha o controle da situação.

Porém, é imperioso que o Plano Nacional de Imunização do Sistema Único de Saúde (SUS) na região amazônica leve em consideração a sazonalidade do período das chuvas, a disposição populacional ao longo dos rios e lagos e a resiliência dos serviços de saúde de atenção básica e de vigilância atuando de forma integrada. Logo, sugerimos a antecipação do calendário vacinal para os estados da região Norte de abril para fevereiro 
de cada ano, levando em consideração as condições sociais, demográficas e ambientais, uma vez que os primeiros casos de Srag iniciam-se em meados de dezembro e que a informação, necessária para a produção das vacinas, sobre as cepas dominantes na região das Américas é liberada pela OMS em novembro.

\section{REFERÊNCIAS}

AMAZONAS. Decreto n. 4206I, de 16 mar. 2020. Decreta situação de emergência na saúde pública do Estado do Amazonas, em razão da disseminação do novo coronavírus (20 I 9-nCoV), e institui o Comitê Intersetorial de Enfrentamento e Combate ao Covid- I 9. Diário Oficial do Estado, Manaus, 2020a.

AMAZONAS. Portaria n. 25I, de 31 mar. 2020. Institui o Gabinete de Gerenciamento de Crise da Secretaria de Estado da Saúde no Enfrentamento a Covid- I 9 no Amazonas. Diário Oficial do Estado, Manaus, 2020b.

CARVAJAL-CORTÉS, J. J. et al. Dinâmica epidemiológica da pandemia da Covid- I9, na fronteira entre Brasil, Colômbia e Peru; Manaus-AM. Boletim n. 2. Rede Transfronteiriça para o Enfrentamento da Covid-19, 24 jun. 2020. Disponível em: <http://periodicos.uea.edu.br/index.php/ces/issue/ view/138>. Acessado em: 18 dez. 2020.

CAVALCANTE, J. R. et al. Covid- 9 no Brasil: evolução da epidemia até a semana epidemiológica 20 de 2020. Epidemiologia e Serviços de Saúde, 29(4): e2020376, 2020.

FRIDELL, M. et al. Health system resilience: what are we talking about? A scoping review mapping characteristics and keywords. International Journal of Health Policy and Management, 9(1): 6- 16, 2020.

FUNDAÇÃO DE VIGILANCIA EM SAUDE DO AMAZONAS - DRA. ROSEMARY COSTA PINTO (FVSRCP). Boletins epidemiológicos diários da Covid-19. Portal da transparência. Disponível em: <www. fvs.am.gov.br/transparenciacovid I9_dadosepidemiologicos>. Acesso em: 18 dez. 2020.

FUNDAÇÃO OSWALDO CRUZ (FIOCRUZ). InfoGripe. Monitoramento de casos de síndrome respiratória aguda grave (Srag) notificados no Sivep Gripe. Disponível em: < http://info.gripe.fiocruz.br>. Acesso em: 17 dez. 2020a.

FUNDAÇÃO OSWALDO CRUZ (FIOCRUZ). Instituto Leônidas e Maria Deane. Repositório Epidemiológico Transfronteiriço. Disponível em: <https://amazonia.fiocruz.br/?page_id=3|692>. Acesso em: 18 dez. 2020b.

GISAID INICIATIVE. Covid- 19 lineages and variants. Disponível em: <www.gisaid.org >. Acesso em: 17 dez. 2020.

MANAUS. Decreto n. 4.787, de 23 mar. 2020. Declara estado de calamidade pública no município de Manaus para enfrentamento da pandemia do Covid-19, e dá outras providências. Diário Oficial do Município, Manaus, 2020.

NASCIMENTO, V. A. D. et al. Genomic and phylogenetic characterisation of an imported case of Sars-CoV-2 in Amazonas State, Brazil. Memórias do Instituto Oswaldo Cruz, I I 5: I-6, 2020. Disponível em: <www. arca.fiocruz.br/bitstream/icict/4365 I/2/ValdineteANascimento-AndreLGuerra_etal_IOC_2020.pdf>. Acesso em: 17 dez. 2020. 
PÊGO, B. et al. (Orgs.). Fronteiras do Brasil: diagnóstico e agenda de pesquisa para política pública. v. 2. Brasília: Ipea, Ministério da Integração Nacional, 2017.

RAMBAUT, A. et al. A dynamic nomenclature proposal for Sars-CoV-2 lineages to assist genomic epidemiology. Nature Microbiology, 5(I I): I.403-1.407, 2020. Disponível em: <www.nature.com/ articles/s41564-020-0770-5>. Acesso em: 17 dez. 2020.

TOROK, M. Focus on field epidemiology. Epidemic curves ahead. The North Carolina Institute for Public Health. North Carolina Center for Public Health Preparedness, I (5), 2003. Disponível em: <https:// nciph.sph.unc.edu/focus/vol I/issue5/I-5EpiCurves_issue.pdf>. Acesso em: 18 dez. 2020.

WALLINGA, J. \& TEUNIS, P. Different epidemic curves for severe acute respiratory syndrome reveal similar impacts of control measures. American Journal of Epidemiology, I60(6): 509-5 I6, 2004. 


\section{Covid-19 e Queimadas na Amazônia Legal e no Pantanal aspectos cumulativos e vulnerabilidades}

Tatiane Cristina Moraes de Sousa, Sandra de Souza Hacon e Christovam Barcellos

$\mathrm{D}$ esde 2019 tem sido noticiado o aumento de queimadas em áreas florestadas da Amazônia Legal durante o período de seca no bioma (Silvério et al., 2020). Em 2020, além da Amazônia, têm ganhado destaque as queimadas no Pantanal, em virtude de recordes de queimadas neste bioma em 22 anos (Observatório Pantanal, 2020). Os impactos das queimadas ultrapassam esses dois biomas, visto que a fumaça gerada tem alcançado outras regiões do país, externas a esses biomas, como o estado do Paraná, distante 1,4 mil quilômetros dos principais focos de queimada (Brodbeck, 2020).

Desde sua fundação, em 2010 , o Observatório de Clima e Saúde vem acompanhando a evolução das queimadas e seus efeitos sobre a saúde das populações na Amazônia e no Cerrado. Tem-se observado forte tendência de aumento da incidência de doenças respiratórias durante o período em que coincidem a diminuição das chuvas na região, a queda dos índices de umidade, a ocorrência de queimadas e a contaminação atmosférica pelos diversos tipos de poluentes (Ribeiro E Assunção, 2002).

O aumento na intensidade das queimadas nesses dois biomas resulta em uma série de impactos, como a geração de gases de efeito estufa, perda de habitat de fauna silvestre, comprometimento da flora e fauna local, entre outros (Fearnside, 2019 ). Além desses e tantos outros impactos, as queimadas em diferentes regiões do Brasil e no mundo neste ano apresentam um cenário ainda mais grave em virtude da pandemia de Covid-19. O material particulado gerado tem grande potencial inflamatório (Arbex et al., 2012), o que pode agravar o quadro de pessoas infectadas pelo vírus Sars-CoV-2, além de ser uma porta de entrada para infecções respiratórias (Ciencewicki E Jaspers, 2007). A interação entre os impactos decorrentes das queimadas e da pandemia de Covid-I9 na Amazônia Legal e no Pantanal se dá não somente sobre os aspectos 
clínicos (Henderson, 2020), mas também sobre o aumento na demanda de serviços de saúde em áreas com diferentes populações vivendo em um cenário de vulnerabilidade. Neste estudo, pretendemos identificar as áreas de maior vulnerabilidade aos impactos cumulativos das queimadas na Amazônia Legal e no Pantanal no contexto da pandemia de Covid- 19.

\section{MÉTODOS}

Os dados utilizados neste estudo foram obtidos em escala municipal para todos os municípios localizados na Amazônia Legal e no Pantanal. Todas as bases de dados consultadas são de acesso público, mantidas pelo Ministério da Saúde, no caso das informações sobre serviços de saúde (por meio do Datasus); pelo Ministério do Meio Ambiente e Funai, para informações sobre as unidades de conservação e terras indígenas; pelo Instituto Nacional de Pesquisas Espaciais (Inpe), sobre focos de queimadas; e pela plataforma Windy no caso dos demais dados ambientais: distribuição de material particulado, concentração de monóxido de carbono (CO), aerossol e direção dos ventos.

Os dados referentes ao número de casos e óbitos por Covid- 19 foram extraídos da plataforma MonitoraCovid- 19 (Fiocruz, 2020), mantida pelo Instituto de Comunicação e Informação Científica e Tecnológica em Saúde (Icict/Fiocruz), e os dados de internação hospitalar foram obtidos por meio do Sistema de Informações Hospitalares (SIH) (Datasus, 2020b), disponibilizado pelo Datasus (Datasus, 2020a).

\section{RESULTADOS}

\section{Queimadas florestais na Amazônia Legal e no Pantanal}

A fim de ilustrar o crescimento na intensidade de queimadas nos dois biomas estudados, na Figura I apresenta-se o número de focos de queimadas em áreas florestadas da Amazônia Legal e do Pantanal entre os meses de janeiro e setembro desde 2000. Como é possível observar, no período entre $1^{\circ}$ de janeiro e 30 de setembro de 2020 o número de focos de queimadas na Amazônia Legal foi quase 80 mil, ao passo que no Pantanal foi de 18 mil no mesmo período. Destaca-se que os resultados obtidos para o Pantanal em 2020 indicam um valor três vezes superior ao do ano anterior, 2019. 
Figura I - Número de focos de queimadas na Amazônia $(A)$ e no Pantanal (B) entre os meses de janeiro e setembro no período de 2000 a 2020

A

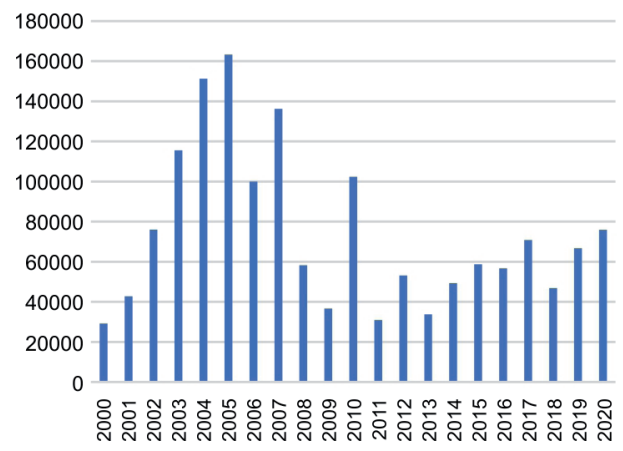

B

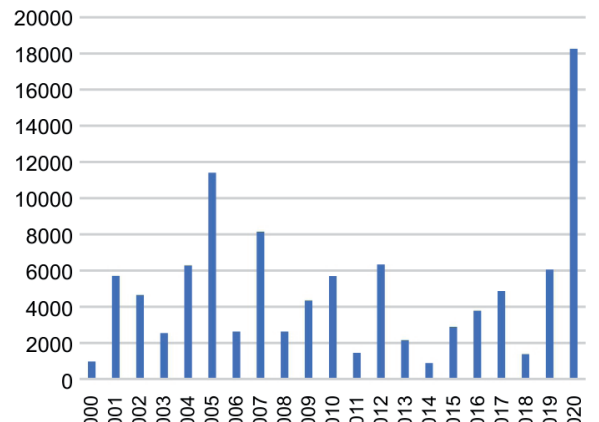

Fonte: Inpe, 2020.

As queimadas na Amazônia Legal e no Pantanal apresentam grande heterogeneidade espacial, principalmente no bioma Pantanal. Os focos de queimadas atingem grande parte dos estados do Mato Grosso, Rondônia, Maranhão, leste de Roraima e leste do Pará. Fora dessas áreas, o padrão de queimadas é bastante diverso e segue as principais estradas da região: BR-1 63 no oeste do Pará, BR-230 (Transamazônica) no Amazonas e BR-364 no Acre. Esse padrão demonstra a relação intrínseca entre as frentes de ocupação da Amazônia, o desmatamento e os incêndios florestais.

Além dos focos de queimadas, é importante observar a distribuição de outras variáveis ambientais diretamente relacionadas às queimadas na Amazônia Legal e no Pantanal, tais como: 1) material particulado $\left.\left(\mathrm{PM}_{2.5}\right), 2\right)$ concentração de monóxido de carbono (CO) e 3) direção dos ventos. A Figura 2 mostra a distribuição dessas variáveis no Brasil na primeira semana de setembro de 2020. Como pode ser observado, a maior ocorrência de material particulado $\left(\mathrm{PM}_{2.5}\right)$ e $\mathrm{CO}$ no Brasil foi registrada em áreas que correspondem aos biomas Amazônia e Pantanal. Além dessas áreas, como pode ser verificado com a direção dos ventos, as queimadas nessas regiões tendem a impactar populações residentes em outras regiões além do Norte e Centro-Oeste, chegando a ser registrado aumento de material particulado em estados das regiões Sudeste e Sul, como verificado em 2019 (Inpe, 2020). 
Figura 2 - Distribuição de material particulado $\left(\mathrm{PM}_{2.5}\right)$, monóxido de carbono (CO) e direção dos ventos no Brasil no dia 10 de setembro de 2020
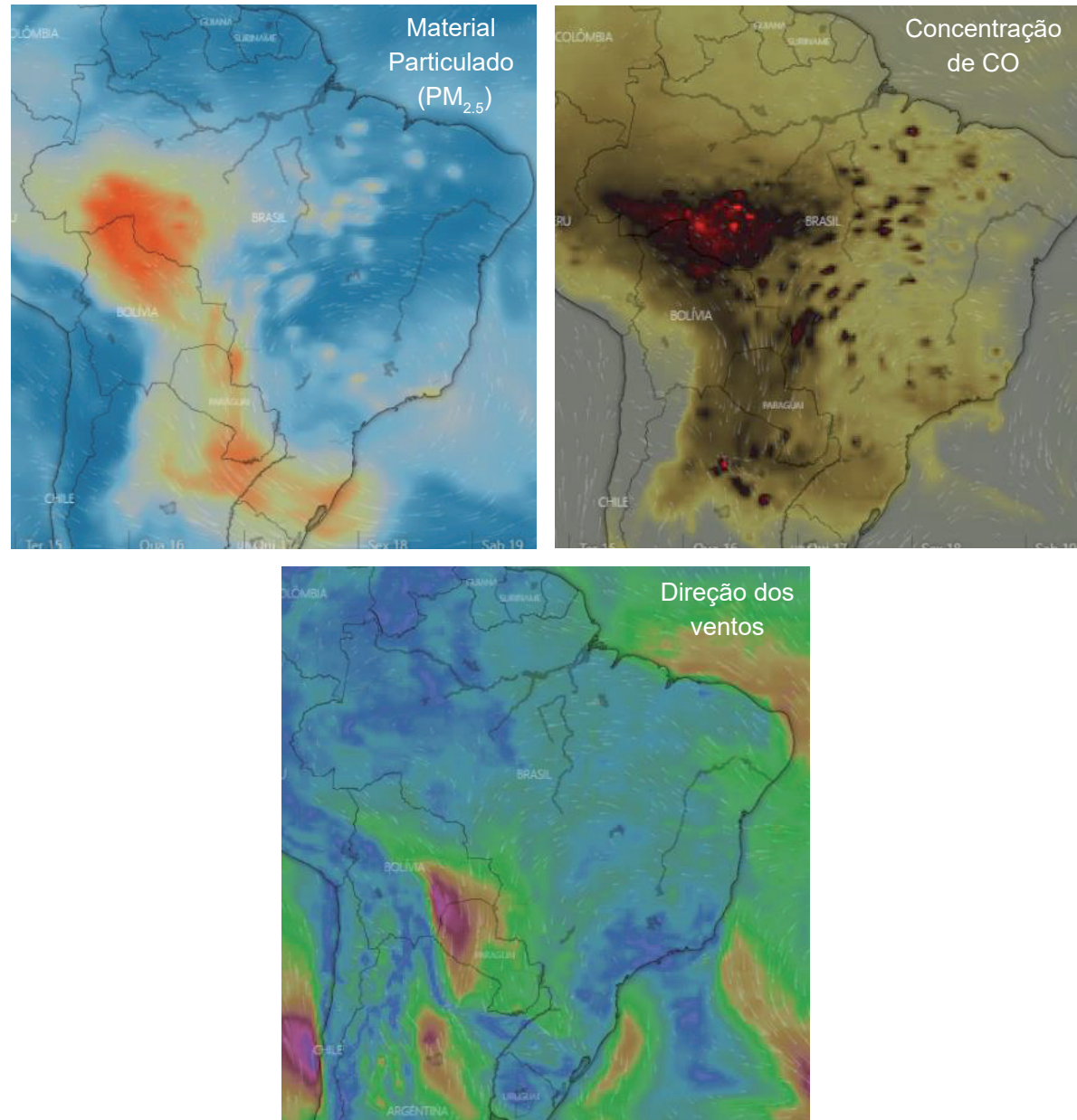

Fonte: Windy.com, 2020.

Queimadas florestais, infecções respiratórias agudas e Covid-19

Queimadas florestais podem emitir ampla gama de poluentes do ar e gases de efeito estufa, como $\mathrm{CO}_{2}$ (dióxido de carbono), $\mathrm{CH}_{4}$ (metano) e $\mathrm{N}_{2} \mathrm{O}$ (óxido nitroso). Entretanto, as queimadas são comumente relacionadas à elevada emissão e concentração de material particulado fino $\left(\mathrm{PM}_{2.5}\right)$. A associação entre $\mathrm{PM}_{2.5}$ e o surgimento ou agravamento de infecções respiratórias é clara na literatura científica (Qiu et al., 20I2), havendo 
evidências dessa associação também em cenários de queimadas de florestas brasileiras (Oliveira, Ignotti \& Hacon, 2019). Além do material particulado, são liberadas para a atmosfera grandes quantidades de compostos orgânicos voláteis (VOCs), com potencial tóxico e carcinogênico.

De modo simples, é possível afirmar que a exposição humana à poluição atmosférica, expressada por elevada emissão de material particulado, por exemplo, pode resultar em inflamações não somente no sistema respiratório, mas com potencial de causar danos sistêmicos, incluindo o aparelho circulatório (Arbex et al., 20I2).

Essas alterações se mostram mais preocupantes no cenário atual da pandemia de Covid-19. As alterações provocadas pelo $\mathrm{PM}_{2.5}$ no sistema respiratório de pessoas expostas às queimadas podem resultar no aumento da população suscetível ao vírus e da gravidade dos casos da doença (Henderson, 2020). Embora ainda não tenhamos estudos referentes ao impacto cumulativo da exposição a queimadas e infecções por Sars-CoV-2, uma metanálise realizada na China sobre a exposição ao material particulado identificou aumento de $6 \%$ nas internações por asma a cada $10 \mathrm{mg} / \mathrm{m}^{3} \mathrm{de}$ $\mathrm{PM}_{2.5}$ devido às queimadas florestais, valor superior ao esperado no caso de exposições a $\mathrm{PM}_{2.5}$ típico (Arriagada et al., 20I9). Também foi identificado aumento de 6\% no risco relativo na mortalidade por Sars em Pequim, China, em cenários com exposição durante cinco dias a $10 \mathrm{mg} / \mathrm{m}^{3}$ de $\mathrm{PM}_{10}$, que são partículas mais espessas de material particulado e, portanto, incluem o $\mathrm{PM}_{2.5}$ (Ciencewicki \& Jaspers, 2007).

Considerando a emissão de poluentes por queimadas ocorridas no ano de 2019 na Amazônia Legal, já acima dos valores obtidos anos anteriores (Figura I), Barcellos e colaboradores (2019) identificaram uma elevação de risco de 30\% na internação por doenças respiratórias de crianças moradoras de áreas próximas a queimadas, comparadas às crianças residentes em outras áreas.

Desse modo, em virtude da conhecida associação entre material particulado oriundo de queimadas e aumento na suscetibilidade e gravidade de doenças infecciosas agudas do sistema respiratório e do histórico de aumento de internações durante os períodos de queimadas na Amazônia, é possível inferir o aumento na demanda por serviços de saúde, principalmente internações, durante o período de intensas queimadas que têm ocorrido na Amazônia Legal e no Pantanal, além do potencial aumento de casos graves de Covid- 19 devido à suscetibilidade causada pela exposição prévia às fumaças.

Mesmo que não haja a infecção pelo vírus Sars-CoV-2, as pessoas afetadas pela fumaça derivada de queimadas poderão enfrentar sérios problemas de atendimento na rede de saúde, que já se encontra comprometida com a atenção aos doentes graves de Covid-19, principalmente em leitos hospitalares. 
Nos anos anteriores a 2020, foram realizadas cerca de 8.000 internações por mês na região Norte. Cerca de $9 \%$ dessas internações têm sido devidas a doenças infecciosas. As internações por doenças respiratórias, por sua vez, representavam de $8 \%$ a $13 \%$ do total de internações, com forte variação sazonal e picos no inverno, período de maior frequência de seca e queimadas. Nos últimos meses da série (a partir de abril de 2020), houve queda no número total de internações na região - parcialmente explicada pelo atraso no envio de dados do $\mathrm{SIH}$ - e aumento proporcional do número de internações por doenças infecciosas, entre as quais se destaca a Covid- 19 (código B34.2 do capítulo I da CID I0). Simultaneamente, observa-se queda no número de internações por doenças respiratórias no período em que, ao contrário, se esperaria seu aumento, como ocorrido nos anos anteriores. Esse padrão demonstra a incapacidade de atender a demandas além da epidemia de Covid- 19 devido à a sobrecarga do sistema hospitalar da região.

Figura 3 - Proporção (em \%) de internações hospitalares na região Norte devido a doenças respiratórias e doenças infecciosas

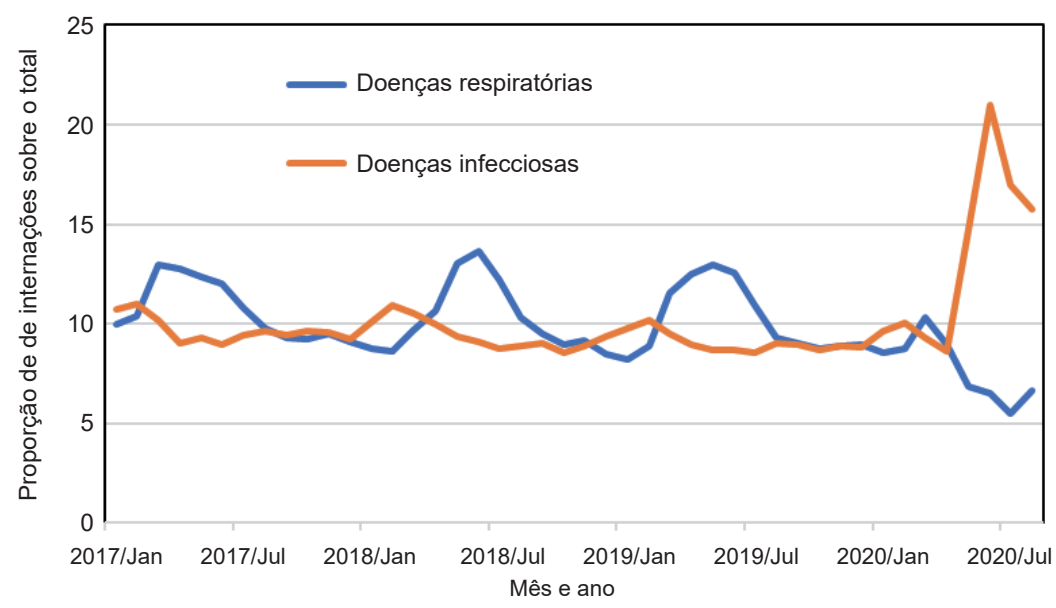

Fonte: Datasus, 2020a.

Dessa maneira, em paralelo aos fatores ambientais, é fundamental observar a extensão e intensidade da pandemia Covid- 19 na Amazônia Legal e no Pantanal desde março de 2020, quando foram registrados os primeiros casos nestes biomas. Em comparação com outros estados brasileiros, os estados que integram a Amazônia Legal (Acre, Amazônia, Amapá, Pará, Maranhão, Mato Grosso, Rondônia e Roraima) e o Pantanal (Mato Grosso e Mato Grosso do Sul), destacados em vermelho na Figura 4, apresentam elevadas taxas de casos e de óbitos por Covid-19, principalmente os estados de Roraima, Amapá, 
Mato Grosso, Amazonas, Rondônia e Acre e Pará. A fim de ilustrar a distribuição dos casos e óbitos por Covid- 19 nesses dois biomas, na Figura 4 se mostra a taxa de casos e óbitos por 100 mil habitantes nos municípios da Amazônia Legal e do Pantanal até 30 de setembro de 2020. A letalidade da doença é expressa pela proporção de óbitos em relação aos casos de Covid- 19 registrados no mesmo período. No gráfico, portanto, os estados com maior letalidade são aqueles que se afastam em direção ao extremo inferior direito da reta de interpolação (tracejada), isto é, Mato Grosso e Amazonas, dentre os estados da Amazônia Legal.

Figura 4 - Casos e óbitos (por 100 mil habitantes) de Covid- 19 nos estados brasileiros até 30 de setembro de 2020 (em vermelho os estados onde se localizam os biomas Amazônia e Pantanal)

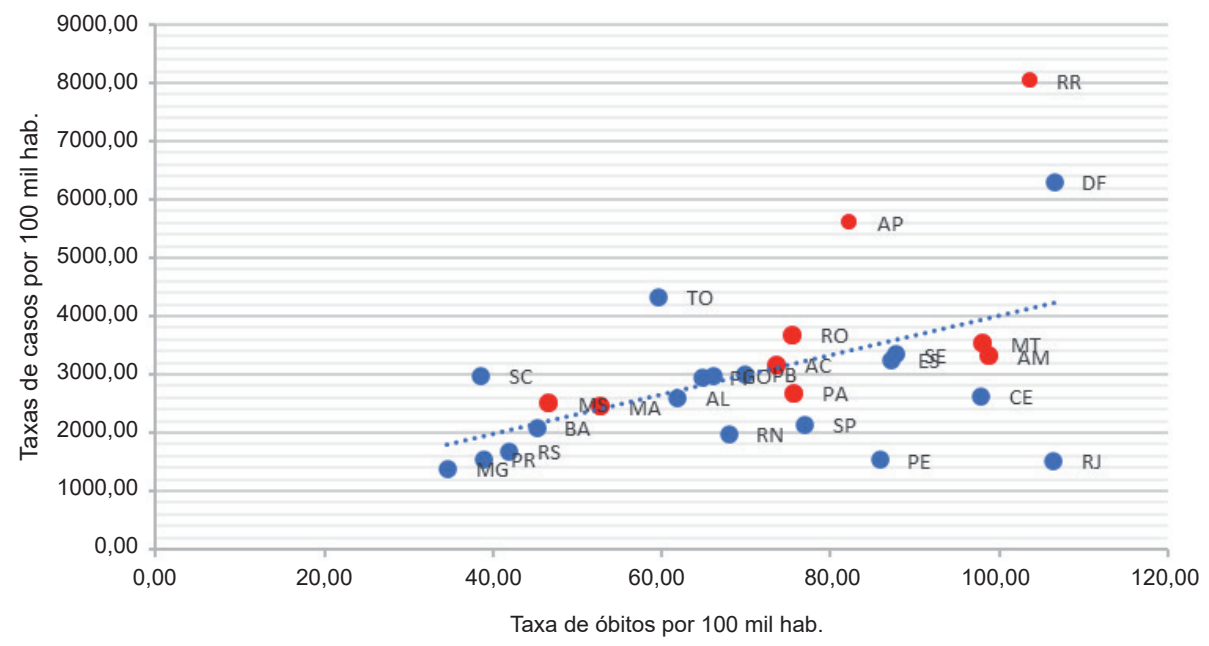

Fonte: MonitoraCovid/Icict/Fiocruz, 2020.

A Figura 5 ilustra a sobreposição de focos de queimadas em 2020 com os casos de Covid- 19 registrados até o dia 31 de agosto. A sobreposição dos focos de queimadas aos casos de Covid-19 por 100 mil habitantes registrados na Amazônia Legal e no Pantanal até 31 de agosto permite observar a ocorrência de queimadas em áreas onde têm sido registrados muitos casos de Covid- 19. 
Figura 5 - Focos de queimadas e casos de Covid- 19 por 100 mil habitantes na Amazônia Legal e no Pantanal até 31 de agosto de 2020
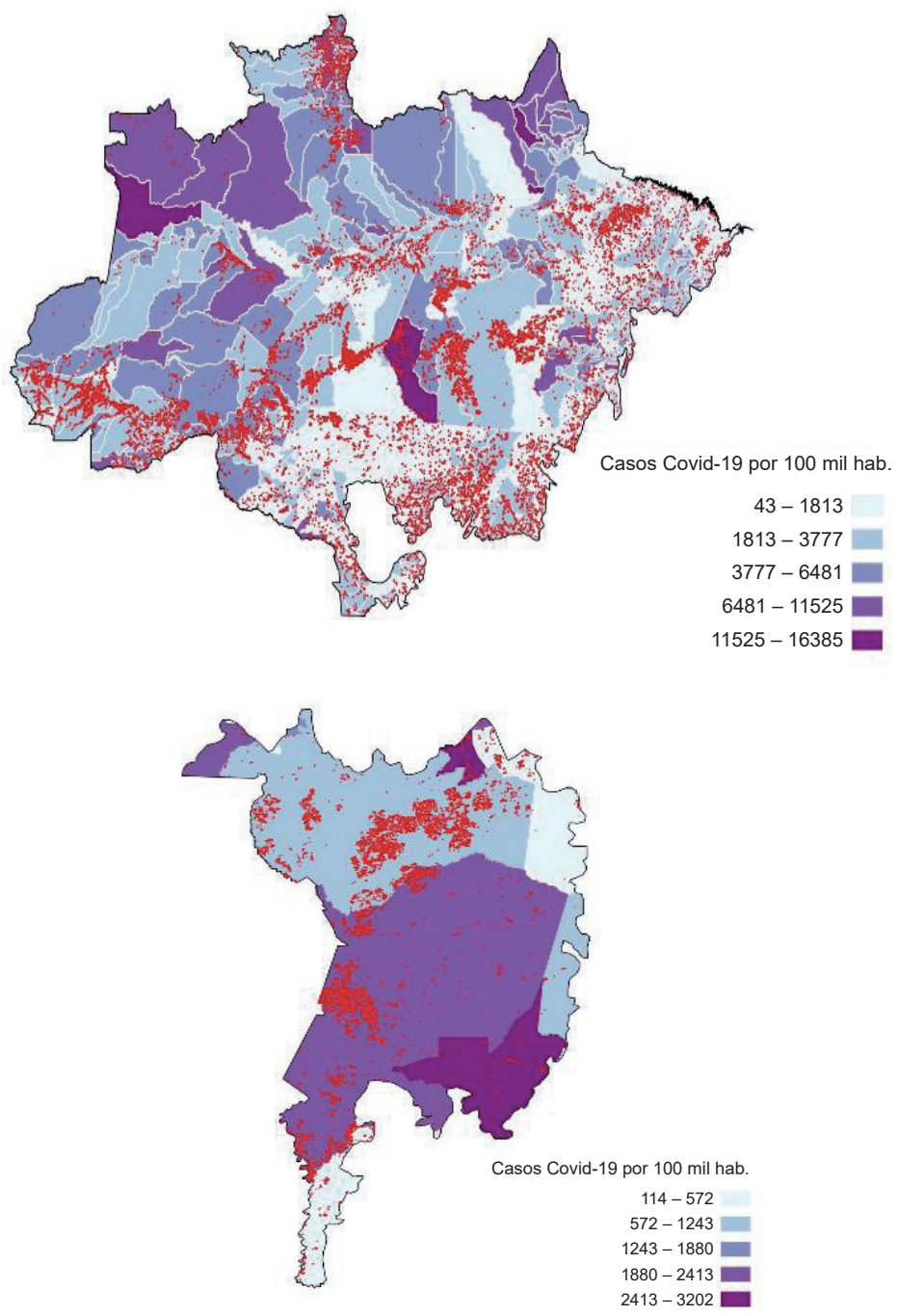

Fontes: Inpe, 2020. 


\section{Acesso a serviços de saúde na Amazônia Legal e no Pantanal}

O esperado aumento na incidência de doenças cardiovasculares e respiratórias, principalmente em grupos mais vulneráveis como crianças e idosos, em virtude das queimadas, tende a intensificar a pressão sobre os serviços de saúde dessas regiões. Entretanto, tais regiões estão entre aquelas com menores coberturas do sistema de saúde no país.

A fim de ilustrar o acesso a serviços de saúde, foi comparada a distribuição de equipes da Estratégia Saúde da Família (ESF), um dos indicadores comumente utilizados para avaliar acesso à atenção básica em saúde, e a distribuição de hospitais classificados como de alta complexidade, ou seja, capazes de habilitar unidades de tratamento intensivo (UTIs). Tanto a atenção básica como as UTIs são fundamentais no controle da epidemia, assim como no cuidado e no tratamento de pessoas infectadas pelo Sars-CoV-2. Os locais onde ocorrem as queimadas (Figura 5) apresentam menor disponibilidade de serviços de saúde de maior complexidade e, como a distribuição de equipes da ESF não ocorre de modo uniforme, menor acesso à atenção primária. À escassez de serviços de saúde de atenção primária e de alta complexidade soma-se o difícil acesso através de rodovias em grande parte da Amazônia Legal e do Pantanal. Além disso, a maior concentração de estradas encontra-se em áreas onde já estão presentes os serviços de saúde mencionados.

Outro aspecto de vulnerabilidade importante nesta avaliação se refere à presença de áreas ambientalmente protegidas, que incluem unidades de conservação e terras indígenas. A manutenção dessas áreas, além de altamente relevante na conservação desses biomas, é fundamental para assegurar a saúde ecossistêmica e, por consequência, a saúde da população indígena e ribeirinha nelas residente.

\section{CONSIDERAÇÕES FINAIS: ÁREAS DE MAIOR VULNERABILIDADE AOS IMPACTOS CUMULATIVOS DAS QUEIMADAS E DA PANDEMIA COVID-19}

Considerando todas as variáveis apresentadas anteriormente, é possível identificar três grandes áreas vulneráveis aos impactos cumulativos da epidemia de Covid- 19 e da intensificação das queimadas na Amazônia Legal e no Pantanal. Essas áreas são descritas brevemente a seguir.

Porção Ocidental da Amazônia Legal - Em virtude da elevada incidência de casos e, principalmente, de óbitos por Covid- 19 aliada à escassez de serviços de saúde e estradas. Adiciona-se a isso o registro de elevada concentração de material particulado 2.5 nesta região. Esta área corresponde ao extremo oeste do estado do Amazonas e ao estado do Acre. 


\section{Arco do Desmatamento no sudeste do Pará e norte do Mato Grosso - Em virtude do} elevado número de desmatamentos, seguido por queimadas nesta porção territorial que engloba unidades de conservação e terras indígenas, como o Parque do Xingu, que têm sido diretamente impactados pelas queimadas recentes.

Bioma Pantanal - Este bioma é composto por somente II municípios, todos com escassez de serviços de saúde e elevada taxa de casos e óbitos por Covid-19. Adicionase a esse cenário de vulnerabilidade prévia o fato do estado de o Mato Grosso do Sul, onde se localiza o bioma, ser um dos epicentros da pandemia desde junho de 2020.

\section{REFERÊNCIAS}

ARBEX, M. A. et al. A poluição do ar e o sistema respiratório. Jornal Brasileiro de Pneumologia, 38(5): 643-655, 2012.

ARRIAGADA, N. B. et al. Association between fire smoke fine particulate matter and asthma-related outcomes: systematic review and meta-analysis. Environmental Research, I79(Pt A): 108777, 2019.

BARCELLOS, C. et al. Queimadas na Amazônia e seus impactos na saúde: a incidência de doenças respiratórias no sul da Amazônia aumentou significativamente nos últimos meses. $3^{\circ}$ Informe Técnico do Observatório de Clima e Saúde. Observatório de Clima e Saúde, Rio de Janeiro, 20 I 9. Disponível em: $<$ https://climaesaude.icict.fiocruz.br/sites/climaesaude.icict.fiocruz.br/files/informe_observatorio_ queimadas.pdf $>$. Acesso em: 25 out. 2020.

BRODBECK, P. Fumaça das queimadas do Pantanal chega a Curitiba, diz Somar. GI, Rio de Janeiro, I4 set. 2020. Disponível em: <https://gl.globo.com/pr/parana/noticia/2020/09/l4/fumaca-dasqueimadas-do-pantanal-chega-a-curitiba-diz-somar.ghtml>. Acesso em: 25 out. 2020.

CIENCEWICKI, J. \& JASPERS, I. Air pollution and respiratory viral infection. Inhalation Toxicology, I9(I4): I.135-I.146, 2007.

DATASUS. Ministério da Saúde. Sistema de Informação de Hospitalizações. Datasus, 2020a. Disponível em: <https://datasus.saude.gov.br/acesso-a-informacao/morbidade-hospitalar-do-sus-sih-sus/>. Acesso em: 25 out. 2020.

DATASUS. Ministério da Saúde. Site. Disponível em: <https://datasus.saude.gov.br >. Acesso em: 25 out. 2020.

FEARNSIDE, P. M. Brazil's Amazonian Forest carbon: the key to Southern Amazonia's significance for global climate. Regional Environmental Change, 18: 47-6I, 2016. Disponível em: <doi:I0.1007/ sl0113-016-1007-2>. Acesso em: 12 jan. 2021.

FUNDAÇÃO OSWALDO CRUZ (FIOCRUZ). Instituto de Comunicação e Informação Científica e Tecnológica em Saúde. MonitoraCovid- 19. Disponível em: < https://bigdata-covid 1 9.icict.fiocruz.br/>. Acesso em: 25 out. 2020.

HENDERSON, S. B. The Covid- 19 pandemic and wildfire smoke: potentially concomitant disasters. American Journal of Public Health, I I0(8): I. I 40- I. I 42, 2020. 
INSTITUTO NACIONAL DE PESQUISAS ESPACIAIS (INPE). Programas Queimadas do Instituto Nacional de Pesquisas Espaciais, 2020. Disponível em: < http://queimadas.dgi.inpe.br/queimadas/ bdqueimadas/\#>. Acesso em: 5 out. 2020.

OBSERVATÓRIO PANTANAL. Pantanal bate recorde históricos de queimadas em 22 anos. Disponível em: $<$ https://observatoriopantanal.org/2020/07/21/pantanal-bate-recorde-historico-de-queimadasem-22-anos/>. Acesso em: 25 out. 2020.

OLIVEIRA, B. F. A.; IGNOTTI, E. \& HACON, S. A systematic review of the physical and chemical characteristics of pollutants from biomass burning and combustion of fossil fuels and health effects in Brazil. Cadernos de Saúde Pública, 27(9): 1678-1698, 2011.

QIU, H. et al. Effects of coarse particulate matter on emergency hospital admissions for respiratory diseases: a time-series analysis in Hong Kong. Environmental Health Perspectives, 120(4): 572-576, 2012.

RIBEIRO, H. \& ASSUNÇÃO, J. V. Efeitos das queimadas na saúde humana. Estudos Avançados, I6(44): 125-I48, 2002. Disponível em: <www.scielo.br/scielo.php?script=sci_arttextEpid=S0 I0340142002000 I $00008 \varepsilon I n g=e n \varepsilon n r m=i s o>$. Acesso em: 25 out. 2020.

SILVÉRIO, D. et al. Amazônia em chamas. Nota técnica do Instituto de Pesquisa Ambiental da Amazônia (Ipam). Brasília, ago. 2019. Disponível em: < https://ipam.org.br/wp-content/uploads/2019/08/NTFogo-Amazo\%CC\%82nia-2019-I_2.pdf>. Acesso em: I 2 jul. 2020.

WINDY.COM. Windy: wind map $\&$ weather forecast. Disponível em: <www.windy.com/>. Acesso em: 5 out. 2020. 



\title{
Registro de Óbitos por Covid-19 no Município do Rio de Janeiro e a Produção de Informações pelo SUS
}

\author{
Bianca Borges da Silva Leandro, Ana Cristina Reis, Fernanda Martins, \\ José Mauro Pinto, Martha Sharapin, Marcio Sacramento, \\ Raphael Mendonça Guimarães e Sergio Munck
}

Neste capítulo reportamo-nos à produção da nota técnica intitulada "Registro de óbitos por Covid-19 e a produção de informações pelo SUS", elaborada pelos profissionais do Laboratório de Educação Profissional em Informações e Registros em Saúde da Escola Politécnica de Saúde Joaquim Venâncio (EPSJV/Fiocruz) e publicizada em 30 de maio de 2020 em meio ao contexto de dificuldade de acesso aos dados sobre Covid- 19 na cidade do Rio de Janeiro, em especial à informação sobre o quantitativo de mortes. A produção desse documento foi motivada pela mudança no método de contagem dos óbitos por Covid- 19 que a Prefeitura do Rio de Janeiro implementou a partir de maio de 2020, incluindo as suas repercussões para a compreensão da evolução da Covid-19 em âmbito municipal. Não se trata de discutir apenas sobre o método de contagem de mortes, mas também sobre a relevância de se fortalecer o processo de produção de informações pelos serviços de saúde na circunstância de uma emergência sanitária.

O contexto epidemiológico que enseja esta discussão merece ser destacado. Desde o início da pandemia, o Brasil é apontado como país com baixo acesso ao teste laboratorial para a confirmação de casos por Covid-19. Pesquisadores da Universidade Federal de Pelotas (UFPel), em parceria com o Ministério da Saúde, realizaram a pesquisa "Evolução da prevalência de infecção por Covid-19 no Brasil: estudo de base populacional (Epicovid I9-BR)", na qual se estimou que para cada caso confirmado de Covid- I 9 nas estatísticas oficiais, há sete casos reais na população dos principais centros urbanos brasileiros (Boehm, 2020).

Embora o governo do estado do Rio de Janeiro tenha, em dezembro de 2020, proposto ações concretas para modificar esse cenário com uma possível testagem em massa, o acesso a esta e a confirmação do adoecimento por Covid- 19 ainda são desiguais na 
cidade do Rio de Janeiro. Desse modo, a baixa testagem e a desigualdade no acesso aos testes dentro dos municípios para o conhecimento real do processo de incidência e transmissibilidade da Covid- 19 ainda são uma realidade no país.

Alves e colaboradores (2020) indicaram que a falta de testagem em massa é um dos aspectos que influenciam a subnotificação. Esses autores elaboraram um modelo preditivo de caso. Segundo esse modelo, na data de I de dezembro de 2020 o Brasil contaria com três vezes mais casos confirmados do que as estatísticas oficiais mostram, ultrapassando 20 milhões de pessoas confirmadas com Covid-19. Esse cenário de subnotificação também se reflete na cidade do Rio de Janeiro.

Particularmente, quando o município do Rio de Janeiro alterou a forma de contagem dos óbitos, durante os meses de maio e junho de 2020, foi o momento no qual estava ocorrendo a maior concentração de óbitos, conforme se observa na Figura I. Além disso, analisando-se a taxa de mortalidade por mês observa-se que o mês de maio foi o que apresentou a maior taxa em todo o ano, 46, 18 por 100 mil habitantes, conforme a Figura 2.

Figura I - Distribuição diária dos óbitos confirmados por Covid- 19 pela data do óbito - Município do Rio de Janeiro, 23/03 a 31/12/2020

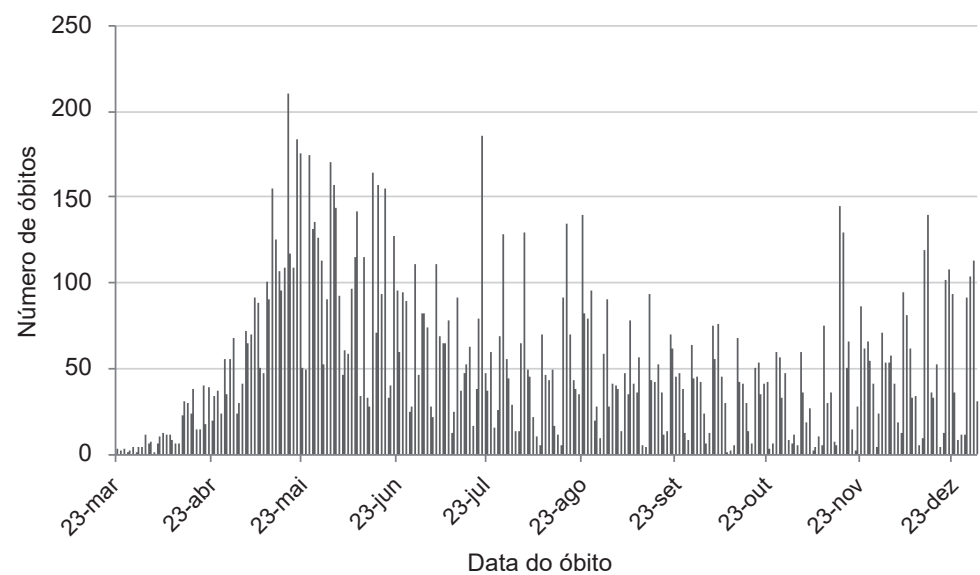

Fonte: dados extraídos no Painel Rio Covid- 19 em 22 fev. 2021. 293 óbitos com data de início de sintomas em 2020 não tinham a data do óbito registrada (Rio de Janeiro, 202l). 
Figura 2 - Total de óbitos confirmados e taxa de mortalidade por Covid- 19 por mês - Município do Rio de Janeiro, 23/03 a 31/12/2020



Fonte: dados extraídos no Painel Rio Covid- 19 em 22 fev. 202 I (Rio de Janeiro, 202 I).

Ao lado dos dados sobre o processo de adoecimento, as informações de mortalidade tornam-se relevantes para a avaliação da gravidade da doença. As estatísticas de mortalidade são, historicamente, utilizadas pela área da saúde para a compreensão do processo saúde-doença e a análise da situação de saúde. Por essa razão, causou-nos preocupação, à época, a mudança inesperada dos critérios, que poderia criar mudanças substanciais na série histórica, dificultando qualquer predição de casos e óbitos e, consequentemente, comprometendo a formulação e a eficácia de políticas públicas. Essa mudança também desconsiderava os óbitos suspeitos por Covid-19 - casos de morte por Covid- 19 ou síndrome respiratória aguda grave (Srag) em que não foi possível realizar confirmação laboratorial do vírus até o momento da emissão da Declaração de Óbito (DO) -, o que criava uma distorção nas medidas de mortalidade.

\section{DETALHANDO E REFLETINDO SOBRE A SITUAÇÃO}

Em 18 de maio de 2020, a Prefeitura Municipal da Cidade do Rio de Janeiro (PMRJ) retirou as informações sobre o número de óbitos de seu Painel de Informações oficiais sobre Covid-19 (Rio de Janeiro, 2021). Em 25 de maio, os dados voltaram a ser apresentados, porém, com uma nova metodologia, e em 28 de maio a PMRJ passou a mostrar, no referido painel, os óbitos considerando duas fontes de informação distintas. 
O novo método, apresentado, oficialmente, pela PMRJ no dia 25 de maio, considera para a contagem de óbitos somente os sepultamentos realizados no município cujas certidões de óbito apresentam como causa da morte a Covid-19. A fonte dos dados passa a ser a Coordenadoria Geral de Controle de Cemitérios e Serviços Funerários, vinculada à Secretaria Municipal de Infraestrutura, Habitação e Conservação, que coleta esses dados nos cemitérios cariocas.

Essa forma de contabilizar os óbitos diverge da que é formalmente realizada pelas demais unidades federativas em âmbito municipal e estadual, o que traz prejuízos para a comparabilidade dos dados de mortalidade no país. Assim, algumas ponderações foram feitas.

Na organização e funcionamento do Sistema Único de Saúde (SUS), já há um processo de coleta, registro e análise de informações, com um fluxo ascendente, que possibilita que a informação coletada no nível municipal chegue ao nível central (Guimarães, 2020). Nesse sistema, o acesso público às informações sobre a situação de saúde no país é previsto legalmente, o que significa dizer que a informação em saúde é um direito. O Brasil possui uma histórica experiência de construção e uso de sistemas de informações em saúde aos quais se tem recorrido de modo sistemático e contínuo no contexto da emergência sanitária (Brasil, 2009a, 2009b). A descentralização das informações em saúde é uma das inovações do SUS que precisam ser cotidianamente valorizadas.

A criação de um sistema de saúde universal, integral e equitativo, aliado a um conceito amplo de saúde foram fatores importantes que alteraram a forma como as informações e registros em saúde eram sistematizados no Brasil. Passou-se a discutir a necessidade de se organizar informações e registros que dessem visibilidade não somente à dimensão da doença ou da produção hospitalar e ambulatorial, mas também que se debruçassem sobre outros aspectos do processo saúde-doença, incluindo os determinantes sociais para uma maior compreensão das condições de vida da população. Essa discussão foi um dos frutos do avanço da Reforma Sanitária no país. (Leandro, 2020: 34)

Em todo o território brasileiro, os dados de óbitos são coletados pelo Sistema de Informação sobre Mortalidade (SIM). O SIM foi desenvolvido em I 975 e tem por objetivo fornecer informações regulares sobre o perfil de mortalidade do país (Brasil, 2009a). Durante a década de 1990, esse sistema passou por um processo de descentralização do registro dos dados no nível municipal, acompanhando o processo de municipalização dos serviços de saúde e de construção do SUS. Ao longo das últimas décadas, a base de dados do SIM tem sido utilizada como a principal fonte de informação para o cálculo de diversos indicadores de mortalidade (Brasil, 2009a; Beringuel et al., 2020; Soares Filho E Duarte, 2020; Maia, Souza E Mendes, 2020). 
Para a alimentação de informações no SIM, a coleta dos dados relacionados à mortalidade é feita com instrumento padronizado: a Declaração de Óbito. A DO, segundo o artigo 77 da lei n. 6.216 de 30 de junho de 1975, é obrigatória para que o óbito seja registrado em cartório e ocorra a emissão da certidão de óbito. Seus dados são utilizados tanto para as estatísticas vitais quanto para o registro civil, ou seja, trata-se de uma fonte de dados padronizada. Os dados de mortalidade podem ser desagregados espacialmente desde o nível estadual até o bairro, o que permite a análise da mortalidade segundo características sociodemográficas, por local de residência da pessoa falecida e pelo local de ocorrência do óbito.

A fim de compatibilizar seu uso com a nova emergência mundial de saúde pública, o Ministério da Saúde publicou um documento, em maio de 2020, com orientações para codificação das causas de morte no contexto da Covid- 19. Nele, estabelece como objetivo garantir a qualidade das informações, padronizando a codificação das causas de morte informadas na DO, visando ao processamento e à seleção da causa básica, em conformidade com o SIM (Brasil, 2020).

No município do Rio de Janeiro, a divergência na utilização de fontes para contabilizar os óbitos ficou evidente quando, no dia 25 de maio de 2020, o painel com as informações oficiais sobre Covid-19 do município registrava 1.801 óbitos confirmados, ao passo que a Secretaria Estadual de Saúde registrava para o município do Rio de Janeiro 2.978 mortes, uma diferença de 39,5\% (1.177 óbitos). (Agência O Globo, 2020)

Ao se considerar na contagem de óbitos somente os sepultamentos com causa da morte confirmada para Covid-19, cria-se uma distorção da real situação de mortalidade, pois desse modo são desconsiderados os óbitos classificados como "suspeita de Covid-19". Os óbitos suspeitos referem-se aos casos de morte por Covid-19 ou Srag em que não foi possível realizar confirmação laboratorial do vírus até o momento da emissão da DO. A recomendação do Ministério da Saúde para esses casos é que sejam investigados a fim de que seja esclarecida a causa básica da morte. Desse modo, torna-se essencial o fortalecimento dos laboratórios que realizam a confirmação laboratorial e das equipes encarregadas de realizar as investigações, permitindo a atualização, em tempo oportuno, dos dados. Fortalecer o sistema de saúde para responder à pandemia implica também garantir estrutura de insumos e pessoal para a plena realização das atividades.

É de responsabilidade das secretarias municipais de Saúde, por intermédio dos serviços de vigilância epidemiológica ou de verificação de óbito, proceder à investigação de óbitos. Após a conclusão do processo de investigação baseada na confirmação do resultado laboratorial e na análise de prontuário, se for indicada a mortalidade por 
Covid- 19 a causa suspeita é recodificada e, para efeito das estatísticas de saúde, o caso passa a ser contado como óbito confirmado por Covid-19. Quanto ao registro civil da morte, para que seja alterada a certidão de óbito, se a morte tiver sido confirmada por Covid-1 9 é necessário que a solicitação de correção seja feita pelo familiar da pessoa falecida. Vale destacar que na maioria das vezes a família não solicita a correção da certidão de óbito e os documentos dos cemitérios/sepultamentos permanecem sem a informação corrigida.

Em municípios e estados brasileiros onde há baixa cobertura de dados de mortalidade no SIM, é recomendável a utilização das informações do cemitério/sepultamento para melhorar a qualidade da informação sobre os óbitos ocorridos naquela localidade (Frias et al., 2008). Contudo, essa não é a realidade do município e do estado do Rio de Janeiro, em que o SIM tem cobertura de 97\% (Paes, 2000; Datasus, 20 I I; IBGE, 20 I8).

Outra fragilidade relacionada a essa forma de contagem de óbitos é que a partir dos dados de sepultamento não é possível estratificar as mortes por bairro (local de residência ou ocorrência), sexo ou faixa etária, contando-se somente com a informação por data e local da morte. Há consenso, atualmente, sobre a diferença e gravidade dos casos de Covid- 19 entre idosos, o que torna a informação por idade essencial para que se conheça a história natural da doença. Aliada a isso, não se pode deixar de citar a relevância dos dados de mortalidade para a análise da estratificação por grupos populacionais e distintos locais de ocorrência do óbito. Além disso, em um município de mais de 6 milhões de habitantes e com uma configuração socioespacial heterogênea, a tomada de decisões e as medidas de intervenção em saúde pública dificilmente se dão de forma uniforme no território. Portanto, é preciso reconhecer como ocorre a disseminação do vírus no espaço, de forma a identificar populações e territórios específicos de maior vulnerabilidade social e que tenham dificuldade de acesso aos serviços de saúde, informações importantes quando se discutem desigualdades sociais e saúde, uma vez que o padrão de agravamento e óbito não é homogêneo nas diferentes regiões da cidade.

Outra possibilidade importante dos dados de mortalidade obtidos no SIM é a de identificar também diferenciais de raça/cor. Em especial em relação à mortalidade por Covid- 9 na cidade do Rio de Janeiro, Angelo e colaboradores (2020) apontaram a maior taxa de mortalidade e letalidade na população negra quando comparada com a branca.

Ainda que a PMRJ tenha indicado que os dados de óbitos, informados pelo Ministério da Saúde, estavam sendo disponibilizados em outro endereço eletrônico (Saconi E Lima, 2020), dissociar esse dado do painel oficial fragiliza a compreensão da situação 
de saúde-doença. Além disso, a divulgação dos dados em outro site (Data Rio) poderia reduzir o acesso por parte da população e, consequentemente, a transparência dos dados oficiais.

Diante dessa situação, no dia 28 de maio de 2020 a PMRJ realizou nova mudança em seu painel de informações oficiais sobre Covid-19, passando a divulgar também os dados do Ministério da Saúde que têm como fonte de informação o SIM. Essa mudança foi motivada pela decisão liminar do Tribunal de Justiça, obtida pela Defensoria Pública do Rio e pelo Ministério Público Estadual, como forma de garantir a transparência das informações sobre Covid- 19 (Saconi \& Lima, 2020). Desse modo, desde a referida data estão disponibilizados no painel os totais de óbitos das duas fontes, Ministério da Saúde e sepultamentos.

Ainda assim, a divulgação simultânea das duas fontes de informação pode gerar viés (erros) e dúvidas na análise dos indicadores de taxa de mortalidade e letalidade, alterando inclusive a possibilidade de comparação com os dados anteriores e com outras realidades do país. O uso equivocado desses indicadores pode distorcer a realidade da situação de Covid- 9 no município do Rio de Janeiro e levar ao risco de flexibilização das medidas de isolamento e distanciamento social, apontadas como relevantes pela Organização Mundial da Saúde (OMS) na contenção da disseminação do vírus. A título de exemplo, tomando-se como base os dados divulgados no dia 03/12/2020 pelo Painel da PMRJ,' quando se toma como referência de cálculo os dados do Ministério da Saúde (SIM), a letalidade é de 10\%, e quando se utilizam os dados informados por sepultamentos, esse mesmo indicador passa a ter o valor de $4 \%$, ou seja, nota-se clara divergência entre os resultados.

Esse pequeno exemplo demonstra que a informação em saúde não é neutra e despolitizada. Como pontuam Moraes e Gomez (2007), a informação em saúde é permeada por visões de mundo e interesses; não se trata de uma formulação meramente técnica, pois está vinculada aos contextos histórico, político, social e econômico e pode realçar o que se deseja mostrar ou obliterar o que não se pretende evidenciar.

\section{ANÁLISE FINAL}

De todas as situações circunscritas à saúde pública, uma pandemia é a que mais exige respostas rápidas dos gestores. Para isso, é fundamental que haja sistemas de informação que disponham de dados de qualidade e confiabilidade, de forma que as

\footnotetext{
' Óbitos informados pelo Ministério da Saúde (SIM): 13.405. Óbitos informados pela fonte de sepultamentos (CGCS/PMRJ): 5.825. Total de casos confirmados: 140.864. Dados disponibilizados em 3 dez. 2020.
} 
decisões possam ser tomadas com base em evidências robustas, permitindo melhor inteligência na elaboração das ações sanitárias. Por definição, os dados de saúde devem permitir planejar ações que reduzam as possíveis desigualdades, preferencialmente de forma desagregada, para que este planejamento possa ser realizado em nível local. Para que isso se traduza no cotidiano dos serviços de saúde, é preciso avançar na governança e na gestão da informação.

As estatísticas oficiais (incluindo o registro de óbitos) precisam, portanto, ser íntegras. Há legislação pertinente sobre isso nos se chamados Princípios Fundamentais das Estatísticas Oficiais, estabelecidos pela Comissão de Estatística das Nações Unidas em 1994 e aprovados pela Assembleia Geral das Nações Unidas em 2014. Dentre esses princípios, podem ser destacados: imparcialidade, igualdade de acesso, padrões científicos de fontes e métodos de estimativa e coordenação interna nos sistemas de informação equivalentes (UN, 20I5).

Mesmo nos dados de mortalidade, há aspectos da subnotificação que precisam ser enfrentados. Muitas pessoas falecem sem terem tido acesso à realização do teste. Além disso, há municípios que têm dificuldades operacionais para realizar, de modo adequado, a investigação de óbitos em tempo oportuno. Mesmo assim, os dados de óbitos obtidos pelo SIM têm uso estratégico para os serviços de saúde e sua utilização deve ser incentivada, inclusive trazendo melhorias e qualificação para a produção da informação em saúde.

Compreender alterações na forma como os dados em saúde são organizados e disponibilizados é essencial, sobretudo em um contexto de pandemia em que há necessidade de informação constantemente atualizada. A mudança discutida neste texto data de maio de 2020, mas no início de fevereiro de 2021 uma nova mudança foi feita no painel Covid- 19 do município do Rio de Janeiro. Dessa vez, os dados de mortalidade passaram a ser disponibilizados pela data do óbito, e não mais pelo dia do registro no sistema de informação. Apesar de a data de óbito ser mais adequada para melhor compreensão no movimento da curva de mortalidade, alterações na forma de disponibilização de dados precisam ser transparentes e adequadamente publicizadas, pois implicam mudanças na série histórica que não têm nenhuma relação com mudanças do comportamento da pandemia. Atualmente, o Painel Rio Covid- 19 apresenta os dados por data de início dos sintomas ou do óbito e data de divulgação.

Leandro, Rezende e Pinto (2020) pontuam que as desigualdades no acesso à informação podem ser entendidas como um dos determinantes importantes da iniquidade em saúde. $\mathrm{O}$ acesso dificultado ou confuso aos dados de saúde prejudica não somen- 
te os indivíduos ou coletivos, mas também a formulação de políticas públicas. Desse modo, é necessário defender o acesso às informações e registros em saúde para gestores, profissionais da saúde e a população, cotidianamente, incluindo os tempos de emergência sanitária. Essa recomendação, vale mencionar, converge com o previsto no artigo $7^{\circ}$ da lei 8.080/1990, no sentido de fortalecer o SUS como um sistema público e universal e as informações em saúde como um direito de todos e todas.

Em uma conjuntura complexa de enfrentamento da pandemia por Covid-19, reforçamos a ideia descrita anteriormente sobre a necessidade de tornar a produção de informações em saúde estratégica para subsidiar, de modo qualificado, a tomada de decisão dos profissionais da saúde e gestores. Como o Brasil conta com baixa testagem para o conhecimento real do processo de incidência e transmissibilidade do novo coronavírus, as informações de mortalidade se tornam essenciais para a avaliação da gravidade da doença. Dito isso, é importante que qualquer mudança metodológica de mensuração seja discutida, justificada, validada, técnica e cientificamente, e divulgada amplamente. Adicionalmente, é importante considerar, dentro do fluxo descrito anteriormente, que as mudanças não podem ocorrer monocraticamente, mas precisam ser consideradas no conjunto das etapas de fluxo de produção da informação, a saber: local, municipal, estadual e federal.

\section{REFERÊNCIAS}

AGÊNCIA O Globo. Rio: novo método de registro exclui 1.177 mortos por Covid-19 das estatísticas. Último Segundo, 27 maio 2020. Disponível em: <https://ultimosegundo.ig.com. br/brasil/2020-05-27/rio-novo-metodo-de-registro-exclui- I I 77 -mortos-por-covid- I 9-dasestatisticas.html>. Acesso em: 28 maio 2020.

ALVES, D. et al. Estimativa de casos de Covid-19. Portal Covid-19 Brasil, São Paulo, 2020. Disponível em: <https://ciis.fmrp.usp.br/covidI9/>. Acesso em: 3 dez. 2020.

ANGELO J. R. et al. $2^{\circ}$ Boletim Socioepidemiológico Covid-19 nas favelas: análise da frequência, incidência, mortalidade e letalidade em favelas cariocas. Sala de Situação Covid-I 9 nas Favelas. Observatório Covid-19 Fiocruz, Rio de Janeiro, 2020. Disponível em: < https://portal.fiocruz.br/sites/ portal.fiocruz.br/files/documentos/boletim_final.pdf>. Acesso em: 3 dez. 2020.

BOEHM, C. Pesquisa da UFPel estima subnotificação de casos de Covid-I9 no Brasil. Agência Brasil, São Paulo, I jun. 2020. Disponível em: <https://agenciabrasil.ebc.com.br/educacao/ noticia/2020-06/pesquisa-da-ufpel-estima-subnotificacao-de-casos-de-covid- I 9-no-brasil>. Acesso em: 21 jun. 2020.

BRASIL. Ministério da Saúde. Organização Pan-Americana da Saúde. Fundação Oswaldo Cruz. A Experiência Brasileira em Sistemas de Informação em Saúde. v. I. Brasília: Ministério da Saúde, 2009a.

BRASIL. Ministério da Saúde. Organização Pan-Americana da Saúde. Fundação Oswaldo Cruz. A Experiência Brasileira em Sistemas de Informação em Saúde. v. 2. Brasília: Ministério da Saúde, 2009b. 
BRASIL. Ministério da Saúde. Secretaria de Vigilância em Saúde Departamento de Análise em Saúde e Vigilância de Doenças não Transmissíveis Coordenação-Geral de Informação e Análises Epidemiológicas. Orientações para Codificação das Causas de Morte no Contexto da Covid-19. Brasília: Ministério da Saúde, 2020. Disponível em: <https://portalarquivos.saude.gov.br/images/pdf/2020/May/I 3/orienta----espara-a-codifica----o.pdf>. Acesso em: 28 maio 2020.

BERINGUEL, B. M. et al. Mortalidade por suicídio no Estado de Pernambuco, Brasil (1 996-20 I 5). Revista Brasileira de Enfermagem, 73, supl. I: e20180270, 2020. Disponível em: <www.scielo.br/scielo. php?script $=$ sci_arttextEpid $=$ S0034-7 I 67202000 I 300 I $5 \mathrm{I} E \mathrm{Ing}=\mathrm{ptEnrm}=\mathrm{iso}>$. Acesso em: 28 maio 2020.

DEPARTAMENTO DE INFORMÁTICA DO SUS (DATASUS). Sistema de Informações sobre Mortalidade - SIM: consolidação da base de dados de 2011. Coordenação Geral de Informações e Análise Epidemiológica - CGIAE. 20II. Disponível em: <http://tabnet.datasus.gov.br/cgi/sim/Consolida_ Sim_201 I.pdf>. Acesso em: 28 maio 2020.

FRIAS, P. G. et al. Sistema de Informações sobre Mortalidade: estudo de caso em municípios com precariedade dos dados. Cadernos de Saúde Pública, 24(10): 2.257-2.266, 2008. Disponível em: $<$ www.scielo.br/scielo.php?script=sci_arttextEpid =S0 I 02-3 I I X200800 I $000007 \xi I n g=e n E n r$ $\mathrm{m}=$ iso $>$. Acesso em: 30 maio 2020

GUIMARÃES, C. No combate à epidemia, um Sistema Único, que vai muito além da assistência. Poli - Saúde, Educação e Trabalho, 2020. Disponível em: <www.epsjv.fiocruz.br/noticias/reportagem/ no-combate-a-epidemia-um-sistema-unico-que-vai-muito-alem-da-assistencia $>$. Acesso em: 28 maio 2020.

INSTITUTO BRASILEIRO DE GEOGRAFIA E ESTATÍSTICA (IBGE). Sistemas de Estatísticas Vitais no Brasil: avanços, perspectivas e desafios. Antônio Tadeu Ribeiro de Oliveira, organizador. Rio de Janeiro: IBGE, Coordenação de População e Indicadores Sociais, 2018.

LEANDRO, B. B. S. Histórico das informações e registros em saúde. In: LEANDRO, B. B. S.; REZENDE, F. A. V. S. E PINTO, J. M. C. (Orgs.). Informações e Registros em Saúde e seus Usos no SUS. Rio de Janeiro: Editora Fiocruz, 2020. (Fazer Saúde)

LEANDRO, B. B. S.; REZENDE, F. A. V. S. \& PINTO, J. M. C. (Orgs.). Informações e Registros em Saúde e seus Usos no SUS. Rio de Janeiro: Editora Fiocruz, 2020. (Fazer Saúde)

MAIA, L. T. S.; SOUZA, W. V. E MENDES, A. C. G. Determinantes individuais e contextuais associados à mortalidade infantil nas capitais brasileiras: uma abordagem multinível. Cadernos de Saúde Pública, 36(2): e00057519, 2020. Disponível em: <www.scielo.br/scielo.php?script=sci_arttextEpid=S0I023 I IX20200002050 I 2Elng=ptEnrm=iso >. Acesso em: 28 maio 2020.

MORAES, I. H. S. E GOMEZ, M. N. G. Informação e informática em saúde: caleidoscópio contemporâneo da saúde. Ciência E Saúde Coletiva, I2(3): 553-565, 2007. Disponível em: <www.scielo.br/scielo. php?script $=$ sci_arttextEpid $=$ SI 4 I3-8I232007000300002EIng $=e n E n r m=i s o>$. Acesso em: 18 dez. 2020.

PAES, N. A. Avaliação da cobertura dos registros de óbitos dos estados brasileiros em 2000. Revista de Saúde Pública, 39(6): 882-890, 2005. Disponível em: <www.scielo.br/scielo.php?script=sci_ arttextEpid=S0034-89 $102005000600003 \xi I n g=e n \varepsilon n r m=i s o>$. Acesso em: 30 maio 2020.

RIO DE JANEIRO. Secretaria Municipal de Saúde. Painel Rio Covid- I 9. Disponível em: < https://experience. arcgis.com/experience/38efc69787a346959c93 I568bd9e2cc4>. Acesso em: 22 fev. 2021. 
SACONI, J. P. E LIMA, L. Após reduzir óbitos por Covid- 19 com mudança de metodologia, prefeitura volta atrás. O Globo, Rio de Janeiro, 27 maio 2020. Disponível em: < https://oglobo.globo.com/rio/aposreduzir-obitos-por-covid-19-com-mudanca-de-metodologia-prefeitura-volta-atras-24449420>. Acesso em: 28 maio 2020.

SOARES FILHO, A. M.; DUARTE, E. C. \& MERCHAN-HAMANN, E. Tendência e distribuição da taxa de mortalidade por homicídios segundo porte populacional dos municípios do Brasil, 2000 e 2015 . Ciência E Saúde Coletiva, 25(3): I.147-I.156, 2020. Disponível em: <www.scielo.br/scielo.php?script=sci_ arttextEpid =S I 4 I 3-8 I 23202000030 I I 47EIng=enEnrm=iso >. Acesso em: 28 maio 2020.

UNITED NATIONS (UN). United Nations Fundamental Principles of Official Statistics: implementation guidelines. New York: United Nations, 2015. 



\section{Óbitos em Excesso, Dentro e Fora de Hospitais, e a Desassistência à Saúde no Município do Rio de Janeiro}

Christovam Barcellos, Diego Ricardo Xavier, Raphael de Freitas Saldanha e Mônica de Avelar Figueiredo Mafra Magalhães

O município do Rio de Janeiro apresentou ao longo da epidemia de Covid- 19 número de óbitos elevado, algumas vezes mesmo superior aos registrados na cidade de São Paulo. O número de óbitos por Covid-19 no Rio apresentava ligeira tendência de queda em outubro. No entanto, a ocorrência de picos desde agosto de 2020 mostra a vulnerabilidade da cidade a novos surtos ou mesmo a retomada dos padrões de transmissão do início do ano. A taxa de letalidade nessa cidade, dada pela proporção de casos que resultam em óbito, tem sido a mais elevada entre as capitais brasileiras, revelando falhas no sistema de saúde, desde a atenção primária e vigilância em saúde até a infraestrutura hospitalar.

O cálculo do excesso de mortalidade tem sido empregado nessa e em outras epidemias para quantificar o impacto da doença em áreas onde se dispõe de informações insuficientes (Fouillet, Pontais E Caserio-Schönemann, 2020), permitindo superar problemas de falta de diagnóstico e subnotificação (Rizzo, Forest E Montano, 2020) e identificar as principais causas de mortalidade que podem estar direta $e$ indiretamente ligadas à Covid- 19 (Vandoros, 2020).

Em alguns casos, como no município do Rio de Janeiro, os dados de mortalidade, segundo o Sistema de Informação sobre Mortalidade (SIM), podem ser liberados para o público, mesmo antes dos dados sobre Covid-19, tanto sobre casos confirmados fornecidos pelo Sistema de Informação da Vigilância Epidemiológica da Gripe (Sivep Gripe) quanto sobre internações, oriundos do Sistema de Informação de Hospitalizações (SIH). Dessa maneira, a análise de dados de mortalidade pode indicar oportunamente mudanças de tendências da epidemia, bem como as principais causas de mortalidade prevalentes na cidade. 
O estudo aqui apresentado foi originalmente publicado como nota técnica em julho e atualizado em dezembro de 2020, com a incorporação de dados até outubro. Este estudo se inscreve no esforço de compreender processos de adoecimento e morte fora das dependências dos hospitais, que vinham sendo foco da maior parte da cobertura da imprensa e das políticas de governo. Os resultados e dados avaliados nessa nota confirmam a hipótese de que grande parte dos óbitos por Covid- 19 estava ocorrendo fora de hospitais e por outros problemas de saúde que foram exacerbados com a pandemia e o colapso do sistema de saúde.

\section{METODOLOGIA}

Um dos métodos que têm sido empregados para avaliar o impacto da pandemia de Covid- 19 em todo o mundo é o cálculo do excesso de mortalidade, isto é, a diferença entre o número de óbitos observado durante a pandemia e o número esperado segundo uma série histórica. Essa metodologia envolve algumas debilidades, por não considerar a causa do óbito. Nem todos os óbitos ocorridos neste período seriam decorrentes da infecção e adoecimento pela Covid-19. Alguns desses óbitos podem ser causados pelo agravamento das condições de saúde de portadores de doenças crônicas, vítimas de acidentes ou pacientes que requerem serviços de urgência, que não encontram atendimento na rede de saúde, sobrecarregada pela própria pandemia. Outra questão não menos importante é a dificuldade de diagnóstico, tanto de Covid- 19 quanto de outras doenças, o que poderia, ao mesmo tempo, levar à subestimação do número de óbitos confirmados e à superestimação do número de casos suspeitos de Covid-19. Essas questões metodológicas têm alimentado polêmicas levantadas pela imprensa e aparecem também na forma de boatos nas mídias sociais, muitas vezes com acusações a profissionais da saúde ou gestores de manipulação da causa dos óbitos, ora escondendo, ora inflando o número de mortes por Covid- 19 (Brasil, 2020).

Os dados sobre óbitos por causa, segundo capítulos da Classificação Estatística Internacional de Doenças e Problemas Relacionados com a Saúde (CID), foram obtidos do Sistema de Informação sobre Mortalidade (SIM) disponibilizado pela Secretaria Municipal de Saúde do Rio de Janeiro (http://tabnet.rio.rj.gov.br/). Deve-se atentar para o fato de que há um atraso de semanas ou meses na digitação dos dados sobre óbitos e sua disponibilização na internet. Por essa razão, foram analisados os dados sobre mortalidade até o mês de outubro. A seleção do município do Rio de Janeiro se deveu à disponibilidade desses dados, acrescida do fato de ter sido um dos municípios mais dura e precocemente atingidos pela pandemia. 
Este estudo faz parte do esforço de monitoramento da pandemia e suas diversas manifestações epidemiológicas no Brasil realizado no âmbito do MonitoraCovid- 19. Esse sistema integra dados sobre o novo coronavírus no Brasil e no mundo com o objetivo de oferecer a autoridades da saúde, a pesquisadores e à sociedade em geral um retrato em tempo real da epidemia no país, por estados e por municípios, e em outros países.

\section{RESULTADOS}

\section{Qual foi o impacto da Covid-19 na mortalidade no Rio de Janeiro?}

A Figura I mostra o aumento no número total de óbitos no município do Rio de Janeiro em 2020, comparado com os três anos antecedentes.

Figura I - Evolução do número de óbitos no município do Rio de Janeiro, entre janeiro e outubro de 2020, em vermelho, e nos anos anteriores (2017 a 2019), em verde

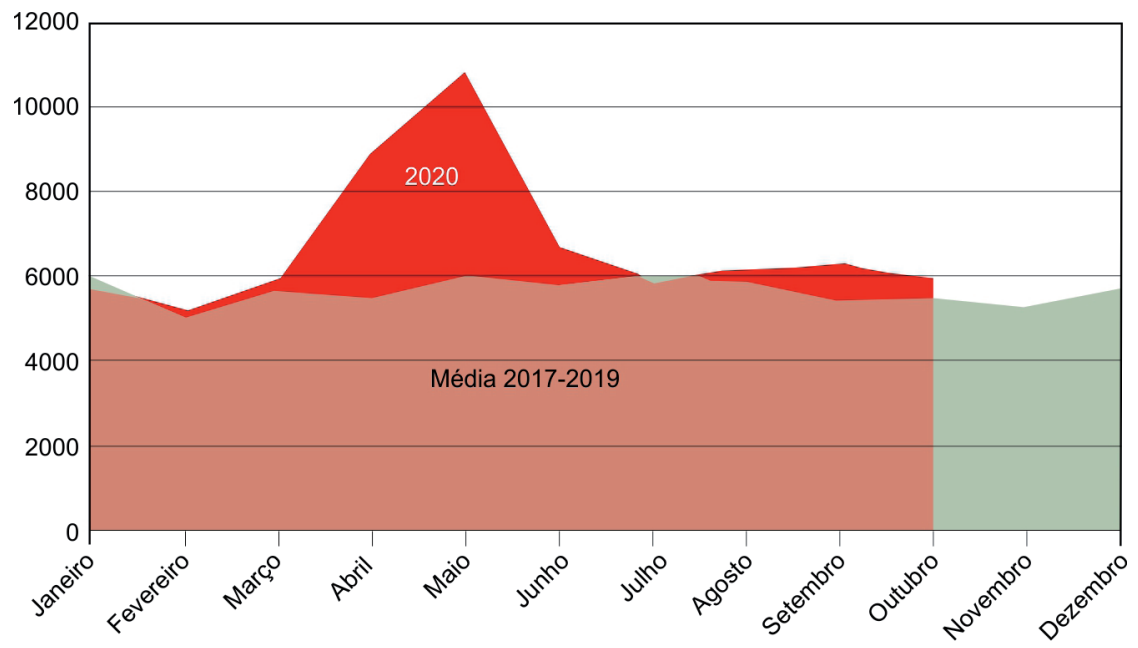

Fonte: dados da Secretaria Municipal de Saúde, Rio de Janeiro, 2020.

Observa-se na Figura I um aumento desproporcional do número de óbitos em 2020, a partir de abril. O município do Rio de Janeiro vinha mantendo a média mensal de 5.770 óbitos para os meses de abril e maio, e nos meses de abril e maio de 2020 registrou 8.692 e 10.314 óbitos, respectivamente, o que representa um excesso de aproximadamente 7.400 óbitos em abril e maio. Durante esse período, o município do Rio de Janeiro reportou um total de óbitos por Covid- 19 (confirmados) de 2.439 em abril e $3.173 \mathrm{em}$ 
maio, perfazendo um total de 5.612 óbitos. O volume de óbitos por Covid- 19 explicaria, portanto, cerca de $75 \%$ dos óbitos ocorridos em abril e maio. Outros $25 \%$ seriam decorrentes de impactos secundários da pandemia, como a exacerbação de doenças crônicas, a dificuldade de acesso a serviços de saúde para atendimento de emergências, bem como de outras manifestações clínicas da Covid- 19 não diagnosticadas como tal, como infartos e problemas respiratórios (Woolf et al., 2020).

No período de março a outubro de 2020 foi observado um excesso de mortalidade no município de cerca de 27.000 óbitos, em comparação com a média dos anos anteriores (2017 a 2019). Desse total, cerca de 13.000 foram causados diretamente pela Covid-19, segundo dados do Sivep Gripe.

Mesmo nos meses mais recentes, de setembro e outubro, se observa um excesso de mortalidade de cerca de 1.100 óbitos, acima do total esperado para o período, o que mostra que o sistema de saúde não retornou ao que seria sua "normalidade", depois da crise de abril e maio de 2020. Isso significa que os demais 14.000 do excesso de óbitos, estimados para o período entre março e setembro, podem ter sido causados indiretamente pela pandemia e pela desassistência à saúde no município. Desses, cerca de 1.800 óbitos tiveram "causas mal definidas", isto é, não tiveram diagnóstico, e muitos deles, cerca de 1.000, ocorreram nos domicílios, sem assistência médica. As diversas formas de câncer tiveram um excesso de mortalidade de 2.500 óbitos; as doenças endócrinas nutricionais e metabólicas, entre as quais se incluem as diabetes, 1.000 óbitos, e as doenças do aparelho circulatório (infartos e AVCs, principalmente) um excesso de 3.800 óbitos nesse período.

Esse excesso de óbitos é mais evidente quando consideradas somente as causas mal definidas (sem diagnóstico). A média histórica é de 220 óbitos mensais, e nos meses de abril e maio foram registrados 625 e 895 óbitos por causas mal definidas, respectivamente. Esses valores indicam um excesso de mortalidade de 1.080 óbitos com causas mal definidas, sem diagnóstico definitivo, que podem ser resultado de diversas doenças e agravos.

Nos anos anteriores, houve uma média de $30 \%$ de óbitos ocorridos fora de hospitais (em outros estabelecimentos de saúde, nos domicílios particulares ou coletivos e em logradouros públicos). Em 2020 foi observado aumento expressivo nesse índice, que chegou a $35 \%$ em abril e voltou a aumentar em agosto e outubro, o que pode demonstrar a incapacidade de diagnóstico e de internação de casos graves tanto de doenças crônicas quanto de Covid-19. Nos anos anteriores, a média de 12,7\% de óbitos ocorria nos domicílios. Esse padrão foi ultrapassado de março a maio de 2020. 
A orientação do Ministério da Saúde recomenda que os óbitos por síndrome respiratória aguda grave (Srag), independentemente de hospitalização, devam ser notificados no Sivep Gripe. Nas situações em que o óbito por Srag ocorra em municípios que não têm cadastro no Sivep Gripe, por não possuírem unidade hospitalar, orientase que o registro no sistema seja feito via Cadastro Nacional de Estabelecimentos de Saúde (CNES) de seus serviços de vigilância epidemiológica para a correta e oportuna notificação (Brasil, 202l).

Esse quadro aponta para uma condição de colapso do sistema de saúde, não somente dos hospitais, mas também da atenção primária, pois estes, caso fossem mantidas ou estendidas as ações de prevenção e tratamento oportuno de casos crônicos de doenças, poderiam evitar grande número dos óbitos.

\section{MUDANÇAS DO PERFIL DA MORTALIDADE EM 2020}

Na Tabela I está detalhado o excesso de óbitos por causa básica, segundo capítulos da CID- 10.

Tabela I - Excesso de óbitos registrados no SIM do município do Rio de Janeiro em abril e maio de 2020 em relação ao período anterior (2017 a 2019), segundo capítulos da Classificação Internacional de Doenças, versão I0 (CID-10)

\begin{tabular}{|c|c|c|c|c|c|}
\hline Causa (Capítulo da CID-10) & Hospital & $\begin{array}{c}\text { Outros } \\
\text { estabelecimentos } \\
\text { de saúde }\end{array}$ & Domicílio & $\begin{array}{l}\text { Via } \\
\text { pública }\end{array}$ & Total \\
\hline I. Algumas doenças infecciosas e parasitárias & 5.185 & 1.010 & 110 & 1 & 6.353 \\
\hline II. Neoplasias (tumores) & -526 & 0 & 165 & 0 & -371 \\
\hline $\begin{array}{l}\text { III. Doenças do sangue e dos órgãos } \\
\text { hematopoiéticos e alguns transtornos imunitários }\end{array}$ & -14 & 6 & 5 & 0 & -4 \\
\hline IV. Doenças endócrinas nutricionais e metabólicas & 16 & 65 & 112 & 1 & 208 \\
\hline V. Transtornos mentais e comportamentais & 15 & -4 & 16 & 0 & 25 \\
\hline VI. Doenças do sistema nervoso & -44 & 8 & 48 & 1 & 26 \\
\hline VII. Doenças do olho e anexos & 0 & 0 & 0 & 0 & 0 \\
\hline VIII. Doenças do ouvido e da apófise mastoide & 1 & 0 & 0 & 0 & । \\
\hline IX. Doenças do aparelho circulatório & -392 & 21 & 368 & -1 & -20 \\
\hline$X$. Doenças do aparelho respiratório & 323 & 272 & 31 & -2 & 628 \\
\hline XI. Doenças do aparelho digestivo & -110 & -5 & I & 0 & -117 \\
\hline
\end{tabular}


Tabela I - Excesso de óbitos registrados no SIM do município do Rio de Janeiro em abril e maio de 2020 em relação ao período anterior (2017 a 2019), segundo capítulos da Classificação Internacional de Doenças, versão 10 (CID-10) (continuação)

\begin{tabular}{|c|c|c|c|c|c|}
\hline Causa (Capítulo da CID-10) & Hospital & $\begin{array}{l}\text { Outros } \\
\text { estabelecimentos } \\
\text { de saúde }\end{array}$ & Domicílio & $\begin{array}{l}\text { Via } \\
\text { pública }\end{array}$ & Total \\
\hline XII. Doenças da pele e do tecido subcutâneo & -20 & -5 & 3 & 0 & -22 \\
\hline $\begin{array}{l}\text { XIII. Doenças do sistema osteomuscular e do } \\
\text { tecido conjuntivo }\end{array}$ & -7 & -2 & 6 & 0 & -2 \\
\hline XIV. Doenças do aparelho geniturinário & $-15 \mid$ & 9 & 21 & 0 & -121 \\
\hline XV. Gravidez parto e puerpério & 17 & I & -1 & 0 & 17 \\
\hline $\begin{array}{l}\text { XVI. Algumas afecções originadas no período } \\
\text { perinatal }\end{array}$ & -19 & -2 & -2 & 1 & -20 \\
\hline $\begin{array}{l}\text { XVII. Más-formações congênitas, deformidades e } \\
\text { anomalias cromossômicas }\end{array}$ & -33 & -1 & -1 & 0 & -36 \\
\hline $\begin{array}{l}\text { XVIII. Sintomas, sinais e achados anormais de } \\
\text { exames clínicos e de laboratório, não classificados } \\
\text { em outra parte }\end{array}$ & 268 & 229 & 513 & 24 & 1.066 \\
\hline XX. Causas externas de morbidade e mortalidade & -120 & । & 3 & 51 & -203 \\
\hline Total & 4.389 & 1.603 & 1.397 & 74 & 7.409 \\
\hline
\end{tabular}

Fonte de dados: Tabnet da Prefeitura (Rio de Janeiro, 2020).

Foram contabilizados cerca de 7.400 óbitos a mais que o esperado nos meses de abril e maio de 2020. Para alguns grupos de doenças, como as neoplasias, doenças do aparelho digestivo e do aparelho geniturinário, e para as causas externas, entre as quais se incluem os acidentes, homicídios e suicídios, observou-se decréscimo no número de óbitos. Por outro lado, houve grande acréscimo no número de óbitos por doenças infecciosas, doenças endócrinas nutricionais e metabólicas, doenças respiratórias e causas mal definidas. Somente no grupo de óbitos por doenças infecciosas houve um aumento de cerca de 6.300 óbitos nos meses de abril e maio de 2020, a maior parte dos quais classificados como decorrentes de "doenças infecciosas, outras e as não especificadas" (B34). 
Foi observado aumento expressivo no número de óbitos por causas mal definidas.' Esse grupo de classificações vinha mantendo uma média de 220 óbitos por mês ao longo do período estudado e aumentou para uma média de 750 nos meses de abril e maio de 2020.

Recentemente, a Organização Mundial da Saúde (OMS) estabeleceu como diretriz o uso dos códigos de emergência U07.I e U07.2 para a classificação de óbitos por Covid- 19 (WHO, 2020). No entanto, não foram encontrados registros no SIM do Rio de Janeiro até maio de 2020 com essa classificação de causa básica. Considerando os dados de óbito que têm sido divulgados, os registros de Covid- 19 foram atribuídos à CID B34.2 (Infecção por coronavírus de localização não especificada).

Observa-se que houve um excesso no número de óbitos registrados em abril e maio, tanto em hospitais (4.389) e outros estabelecimentos de saúde (1.603) quanto em domicílios (1.397). O município do Rio de Janeiro apresenta média mensal histórica de cerca de 700 pessoas que falecem nos domicílios, cerca de $12 \%$ de uma média de 5.770 óbitos mensais. Nos meses de abril e maio de 2020, foram registrados 2.864 óbitos ocorridos nos domicílios, quando seriam esperados 1.470 óbitos, o que equivale a um aumento de $95 \%$ em óbitos desassistidos.

O aumento no número de óbitos em "outros estabelecimentos de saúde", como unidades de Pronto Atendimento (UPAs) e centros e casas de Saúde, pode denotar falhas na rede de atenção, tanto pela falta de diagnóstico oportuno dos pacientes quanto pela incapacidade de encaminhar esses pacientes para serviços de saúde de maior complexidade, como as UTIs de hospitais.

Cabe destacar que os óbitos naturais (que não sejam decorrentes de violências) ocorridos sem assistência médica devem ser investigados pelo Serviço de Verificação de Óbito (SVO), que emite a Declaração de Óbito (DO). Esse procedimento foi alterado pela portaria conjunta n. I, de 30 de março de 2020, do Conselho Nacional de Justiça (CNJ) e do Ministério da Saúde, o que tem sido objeto de contestação jurídica (Grupo de Trabalho, 2020).

\footnotetext{
' O capítulo 18 da CID- 10 reúne um conjunto de sinais e sintomas inespecíficos ou não classificados, que envolvem o aparelho circulatório e respiratório (R00 a R09), aparelho digestivo e ao abdome (RI0 a RI9), tecido subcutâneo (R20 a R23), sistemas nervoso e osteomuscular (R25 a R29), aparelho urinário (R30 a R39), sintomas e sinais relativos à cognição, à percepção, ao estado emocional e ao comportamento (R40 a R46), relativos à fala e à voz (R47 a R49), sintomas e sinais gerais (R50 a R69), achados anormais de exames de sangue, sem diagnóstico (R70 a R79), de exames de urina sem diagnóstico (R80 a R82), de outros líquidos, substâncias e tecidos do corpo, sem diagnóstico (R83 a R89), exames para diagnóstico por imagem e em estudos de função, sem diagnóstico (R90 a R94) e principalmente as causas mal definidas e desconhecidas de mortalidade (R95 a R99).
} 
A Tabela 2 mostra a alteração percentual de mortalidade verificada nos meses de abril e maio de 2020 em relação aos anos anteriores (2017 a 2019), segundo causa do óbito e local de ocorrência.

Tabela 2 - Variação percentual (em \%) do número de óbitos registrados no SIM do município do Rio de Janeiro entre abril e maio de 2020 segundo local de ocorrência, em relação ao período anterior (2017 a 2019). Células em branco apresentam número insuficiente de ocorrências para a realização de análises estatísticas. As setas em vermelho indicam as principais mudanças ocorridas entre causas de mortalidade e locais de ocorrência do óbito em relação aos anos anteriores

\begin{tabular}{|c|c|c|c|c|c|}
\hline Causa (Capítulos CIDI0) & Hospital & $\begin{array}{l}\text { Outro } \\
\text { Estabelecimento } \\
\text { de Saúde }\end{array}$ & Domicílio & Via Pública & Total \\
\hline $\begin{array}{l}\text { 1. Algumas doenças } \\
\text { infecciosas e parasitárias }\end{array}$ & 1758 & 785 & 598 & & 817 \\
\hline II. Neoplasias (tumores) & -26 & & 137 & & -16 \\
\hline $\begin{array}{l}\text { IV. Doenças endócrinas } \\
\text { nutricionais e metabólicas }\end{array}$ & 4 & 63 & 109 & & 36 \\
\hline $\begin{array}{l}\text { VI. Doenças do sistema } \\
\text { nervoso }\end{array}$ & -22 & 27 & 74 & & 9 \\
\hline $\begin{array}{l}\text { IX. Doenças do aparelho } \\
\text { circulatório }\end{array}$ & -24 & 5 & 48 & & -1 \\
\hline $\begin{array}{l}\text { X. Doenças do aparelho } \\
\text { respiratório }\end{array}$ & 30 & 109 & 27 & & 43 \\
\hline $\begin{array}{l}\text { XI. Doenças do aparelho } \\
\text { digestivo }\end{array}$ & -27 & & & & -40 \\
\hline $\begin{array}{l}\text { XIV. Doenças do aparelho } \\
\text { geniturinário }\end{array}$ & -36 & 11 & 162 & & -23 \\
\hline $\begin{array}{l}\mathrm{XVIII} \text {. Sintomas e sinais } \\
\text { anormais exames clínicos e } \\
\text { laboratoriais }\end{array}$ & 157 & 248 & 382 & 456 & 235 \\
\hline $\begin{array}{l}\text { XX. Causas externas de } \\
\text { morbidade e mortalidade }\end{array}$ & -19 & & & 128 & -20 \\
\hline Total & 54 & 111 & 95 & 144 & 64 \\
\hline
\end{tabular}

Fonte de dados: Tabnet da Prefeitura, Rio de Janeiro, 2020. 
Segundo os dados organizados na tabela, percebe-se grande aumento na mortalidade por doenças infeciosas, de cerca de $800 \%$ mais que o valor histórico esperado para o período, por doenças infecciosas, nas quais se incluem as doenças diretamente relacionadas à Covid-19. Esse aumento foi registrado tanto em hospitais e outros estabelecimentos de saúde quanto nos domicílios, sem assistência médica.

Também é notável o aumento do número de óbitos com causas mal definidas (capítulo 18 da CID-10), que tiveram grande aumento nos domicílios e em vias públicas, cerca de $380 \%$ e $540 \%$ mais que o número esperado, respectivamente. Esse fato pode estar relacionado ao colapso do sistema de saúde, tanto pela lotação de hospitais quanto pela dificuldade de diagnóstico e encaminhamento de pessoas com quadros graves de Covid- 19 e outras doenças crônicas, acidentes e emergências. Chama atenção o aumento de óbitos ocorridos em outros estabelecimentos de saúde, como as UPAs e os centros de Saúde, que deveriam ter sido encaminhados para internação devido à sua gravidade mas podem ter encontrado barreiras ou resistências nos meses de abril e maio.

Por outro lado, houve sensível redução de óbitos ocorridos em hospitais devidos a neoplasias, doenças do sistema nervoso, doenças cardiovasculares, do aparelho digestivo e aparelho geniturinário. Essas mudanças recentes de padrões de mortalidade podem ser resultado de migrações de diagnóstico, como mostrado na Tabela 2.

Houve aumento no número de óbitos por doenças endócrinas, nutricionais e metabólicas e doenças respiratórias. Essa alteração de padrão pode ser consequência do agravamento de doenças crônicas, por falta de atenção adequada ou por dificuldades de obter internação e tratamento oportuno. Essas causas de mortalidade podem ter sido categorizadas dentro do capítulo de causas mal definidas, devido a dificuldades de diagnóstico e à morte sem assistência médica.

Observou-se migração de óbitos que antes ocorriam em ambiente hospitalar e durante abril e maio passaram a ser mais frequentes nos domicílios. Este é o caso dos óbitos por cânceres, doenças metabólicas (entre as quais predominam as diabetes), doenças do sistema nervoso (com grande peso da doença de Alzheimer), doenças cardiovasculares e do aparelho geniturinário (com diversos casos de insuficiência renal), que configuram um grave cenário de desassistência vivido nos meses, que pode permanecer ao longo da pandemia. A maior parte dessas doenças é crônica e o óbito delas decorrente é considerado evitável² por ações de prevenção e atenção básica de saúde. Também no

\footnotetext{
${ }^{2}$ Doenças evitáveis por ações adequadas de diagnóstico e tratamento e doenças reduzíveis por ações adequadas de promoção à saúde, vinculadas a ações adequadas de atenção à saúde, segundo Malta e colaboradores (2007).
} 
caso das violências, a redução do número de óbitos em hospitais é acompanhada pelo aumento de casos ocorridos em vias públicas, também sem assistência médica.

As análises de anomalias de mortalidade demonstram um quadro de desassistência à saúde que pode ter sido resultado das dificuldades de diagnóstico e tratamento oportuno de doenças relacionadas diretamente à Covid-19, como em óbitos por problemas respiratórios e cardiovasculares, bem como do agravamento de doenças crônicas como diabetes e doenças do sistema nervoso.

Também o aumento no número de óbitos nos domicílios e com causa mal definida revela uma situação de desassistência, vivida não somente em hospitais e serviços de alta complexidade. Toda a rede de atenção à saúde, desde as unidades básicas de saúde (UBS) até as UPAs, incluindo as atividades de vigilância em saúde e investigação epidemiológica, não foi capaz de detectar e encaminhar adequada e oportunamente os casos graves de diversas doenças, além da Covid-19, e evitar óbitos.

\section{REFERÊNCIAS}

BRASIL. Ministério da Saúde. Softwares das UPAs obrigam registro de coronavírus - É FAKE NEWS! Disponível em: <https://www.saude.gov.br/artigos/136I-fake-news/46778-software-das-upasobrigam-registro-de-coronavirus-e-fake-news >. Acesso em: 16 nov. 2020.

BRASIL. Ministério da Saúde. Secretaria de Vigilância em Saúde. Guia de Vigilância Epidemiológica: emergência de saúde pública de importância nacional pela doença pelo coronavírus 2019. Brasília: Ministério da Saúde, 202I. Disponível em: <www.conasems.org.br/wp-content/uploads/202 I/03/ guia-de-vigila\%cc\%82ncia-epidemiolo\%cc\%8 I gica-da-covid_19_15.03_2021.pdf $>$. Acesso em: 5 jan. 2020.

FOUILLET, A.; PONTAIS, I. \& CASERIO-SCHÖNEMANN, C. Excess all-cause mortality during the first wave of the Covid- 19 epidemic in France, March to May 2020. Euro Surveillance, 25(34): 200 I 485, 2020. Disponível em: <www.eurosurveillance.org/content/1 0.2807/I560-7917.ES.2020.25.34.200 I485>. Acesso em: 5 dez. 2020.

GRUPO DE TRABALHO INTERINSTITUCIONAL DE DEFESA DA CIDADANIA. Nota Técnica n. 5. Rio de Janeiro, 13 abr. 2020. Disponível em: <www.mpf.mp.br/regiao2/sala-de-imprensa/docs/nt-05_gt_ cnj_ms/at_download/file>. Acesso em: 5 dez. 2020.

MALTA, D. C. et al. Lista de causas de mortes evitáveis por intervenções do Sistema Único de Saúde do Brasil. Epidemiologia e Serviços de Saúde, 16(4): 233-244, 2007. Disponível em: <http://scielo.iec.gov. br/pdf/ess/vl 6n4/vl6n4a02.pdf>. Acesso em: 5 dez. 2020.

RIZZO, M.; FORESTI, L. \& MONTANO, N. Comparison of reported deaths from Covid- 9 and increase in total mortality in Italy. Jama International Medicine, I80(9): I.250- I 252, 2020. Disponível em: < https:// jamanetwork.com/journals/jamainternalmedicine/fullarticle/2768649>. Acesso em: 5 dez. 2020.

RIO DE JANEIRO. Secretaria Municipal de Saúde. Sistemas de Informação em Saúde. Disponível em: < http://tabnet.rio.rj.gov.br/>. Acesso em: I dez. 2020. 
VANDOROS, S. Excess mortality during the Covid- 19 pandemic: early evidence from England and Wales. Social Science E Medicine, 258: II3101, 2020. Disponível em: <www.sciencedirect.com/ science/article/abs/pii/S0277953620303208>. Acesso em: 5 dez. 2020.

WOOLF, S. H. et al. Excess deaths from Covid- 19 and other causes, March-April 2020. Jama, 324(5): 5I0-513, 2020. <https://jamanetwork.com/journals/jama/fullarticle/2768086>. Acesso em: 5 dez. 2020.

WORLD HEALTH ORGANIZATION (WHO). Emergency use ICD codes for Covid-19 disease outbreak, s. d. Disponível em: <www.who.int/classifications/icd/covidI9/en/\#: :text $=$ The $\% 20$ COVID\%2D I 9\%20disease \%20outbreak, I 9\%20confirmed\%20by\%20laboratory\%20testing > . Acesso em: 5 dez. 2020. 

PARTE ॥

\section{PRODUZINDO E ORGANIZANDO INFORMAÇÃO PARA AÇÃO}







\title{
A Emergência de Saúde e 0 Acesso a Plataformas de Dados para Gestores e Sociedade Civil
}

\author{
Renata Gracie, Mariana Melo Cavalcante, Maria Angela Esteves, \\ Vanderlei Pascoal de Matos, Emmanuel Roux, \\ Diego Ricardo Xavier e Christovam Barcellos
}

[ $\mathrm{m}$ uma pandemia que tem apresentado desafios de ação no mundo, considerada uma Crise humanitária global (Freitas et al., 2020), agir com base em informações mais próximas da realidade se torna imprescindível. Assim, diversas instituições de pesquisa e ensino nas áreas da saúde e da ciência de dados, entre outras, têm se empenhado em construir sistemas de disponibilização e análise de dados de ocorrência da Covid- 19. Esses sistemas apresentam escalas e unidades de análise diferentes, possibilitando diagnósticos integrados para as diferentes esferas de atuação: no município, no estado, na federação e em escala mundial. Alguns desses sistemas coletam dados diretamente de instituições públicas de saúde ou em repositórios de dados públicos disponibilizados em formato acessível mantidos por voluntário, como por exemplo o Brasil.IO, e servem como fonte de dados para outros sistemas, criando ambientes de troca de informação e inspiração para a inovação tecnológica e metodológica.

O Brasil tem tradição de alimentar sistemas de informação em saúde (SIS) robustos, consolidados pelo Departamento de Informática do Sistema Único de Saúde (Datasus), de âmbito nacional, e grande parte de suas informações disponíveis na internet colabora para a construção de políticas públicas e ações executadas pelo SUS e contribui para outras áreas de ação na gestão de governos (Lima et al., 2009). Contudo, uma pandemia com a magnitude e velocidade de contaminação do vírus Sars-CoV-2 inviabiliza que pesquisadores da área da saúde aguardem a consolidação dos dados, como normalmente acontece nos SIS pelo Datasus.

Na epidemia de má formação congênita causada pela infecção por zika em gestantes foi utilizado o Registro de Eventos em Saúde Pública (Resp), que apesar de algumas limitações, como um número elevado de duplicação de eventos, por exemplo, 
contribuiu muito para os SIS no Brasil e apoiou ações de políticas públicas para dar suporte aos responsáveis das crianças com má formação congênita (Lowe et al., 20 I8). A disseminação não era tão rápida e os óbitos também não. Nessa epidemia não é possível esperar a consolidação dos dados. Os trabalhos devem seguir com a informação existente, escassas, com limitações, de maneira indireta e intermitente, como tem acontecido com os dados do painel do Ministério da Saúde.

É notório que a informação é imprescindível para a tomada de decisão, mas no Brasil o poder público tem retirado investimentos de setores que a produzem, como no caso emblemático do Instituto Brasileiro de Geografia e Estatística (IBGE), que apesar de muita luta não pôde realizar o Censo 2020, transferido para 2021 .

O estabelecimento de um sistema de informação e a definição do fluxo de informação que permita coleta, organização, crítica e análise dos dados em tempo oportuno para a ação é o principal desafio hoje, com a emergência da Covid-19. Devido à necessidade de crítica e de busca ativa dos eventos de saúde, tornam-se essenciais agilidade na liberação dos dados e tempo para consolidá-los. O SIS mais dinâmico é a Autorização de Internação Hospitalar $(\mathrm{AlH})$, vinculado ao pagamento de serviços hospitalares (Jorge, Laurenti $\varepsilon$ Gotileb, 20 I0). Mesmo assim, sua defasagem é de dois meses e a qualidade do preenchimento de algumas variáveis apresenta limitações, exceto nos campos de pagamento.

Também os recursos para sistematização de dados da saúde têm escasseado. Há algum tempo o Datasus tem recebido menos investimentos em recursos humanos e alguns SIS têm se mantido com a contratação de empresas terceirizadas. Isso pode interferir na autonomia do Datasus no tocante à agilidade para atualizar os SIS. A velocidade na coleta e no armazenamento de dados para análise exigida por esta pandemia é um desafio para os SIS, que necessitam de investigação de casos e óbitos dos sistemas oficiais. Nesse contexto, destaca-se a importância do uso de dados de sistemas alternativos, que foram construídos pelo esforço das instituições de pesquisa e ensino e pela sociedade civil em todo o mundo.

Objetivamos aqui realizar um levantamento dos sistemas de informações e painéis que sistematizam dados relativos à Covid- 19 em diferentes escalas e com diferentes agregações de unidades de análise, neles identificando pontos positivos e limitações.

\section{MATERIAIS E MÉTODOS}

A partir do momento em que os casos de Covid- 19 começaram a surgir no Brasil e os dados se encontravam ainda desorganizados, diversos grupos de pesquisa começaram a tentar sistematizá-los para poderem realizar análises epidemiológicas. No Laboratório de 
Informação em Saúde do Instituto de Comunicação e Informação Científica e Tecnológica em Saúde da Fundação Oswaldo Cruz (LIS/Icict/Fiocruz) começaram a ser divulgados diferentes endereços de sistemas de informação sobre a Covid- 19; o Centro Brasileiro de Estudos de Saúde (Cebes) e os Cadernos de Saúde Pública (CSP) também começaram a listá-los. Todos os endereços listados pelo LIS, Cebes e CSP, assim como os endereços listados no interior das páginas destas organizações, foram consultados como fonte de informação. Percebemos que esses endereços não apresentavam informações por estado e as capitais dos estados e passamos a buscar sistemas que incluíssem essa variável.

Após o levantamento dos sistemas de informação sobre a Covid-19, realizamos acessos em cada um dos sistemas e identificamos os parâmetros com que os dados eram apresentados.

Posteriormente construímos um quadro com informações em escalas diferentes: as primeiras linhas se destinam aos sistemas globais, as linhas subsequentes aos nacionais, estaduais, municipais e a populações específicas como as de favelas. As colunas indicam: a Unidade de análise, Plataformas, Mapas, Modelos, Disponibilização de dados, Gráfico, Faixa etária, Sexo, Endereço do site. Pretendemos, dessa maneira, contribuir com a sociedade civil, pesquisadores e gestores para que o acesso a essas informações possibilite a tomada de decisões e a solicitação de medidas. Cabe registar que os dados podem não apresentar mais as informações exatamente da maneira como os organizamos, pois os sistemas estão em constante desenvolvimento.

\section{RESULTADOS E DISCUSSÃO}

Um dos primeiros sistemas em que se disseminaram dados sobre Covid- 19 foi criado pela norte-americana Johns Hopkins University (JHU) com base em tecnologia GIS; esse mapa, que apresenta os casos confirmados e os casos ativos agregados por 181 países no mundo (de um total de 193 países), por estados e por cidades dos Estados Unidos da América (EUA), atingiu a marca de 2,8 bilhões de visualizações únicas desde o início da pandemia até 28 de agosto de 2020. Nele também estão computados as mortes e os totais de casos recuperados, apresentados por distribuição acumulada e por taxa logarítmica.

Foram criados diversos outros sistemas, como os da Organização Mundial da Saúde (OMS) e da Organização Pan-Americana da Saúde (Opas), que utilizam plataforma paga de uma das grandes empresas de geotecnologia do mundo, a Esri. O município do Rio de Janeiro também seguiu esse caminho. 
Alguns sistemas de disponibilização de dados optaram por adotar softwares livres e abertos, o que na atual circunstância facilita muito o trabalho de cooperação; essa foi a opção do Centros de Controle e Prevenção de Doenças (CDC) europeus e dos EUA. Alguns sistemas brasileiros também estão utilizando esse tipo de solução, como é o caso do sistema liderado pelo LIS/Icict/Fiocruz, o MonitoraCovid- 19.

Outros aspectos que se deve levar em consideração além da facilidade de aquisição dos dados são a usabilidade do sistema e a interpretação dos dados visualizados para um público tão diverso. Alguns sistemas mostram os dados em tabelas, gráficos e mapas. Outros permitem visualizar os dados com todas essas possibilidades de observação dos indicadores. As tabelas apresentam dados de casos suspeitos, casos confirmados, óbitos, taxas de incidência, taxa de mortalidade, totais de pessoas recuperadas. Em geral esses dados são mais bem analisados quando estão disponíveis em gráficos e mapas, que facilitam a interpretação.

Os sistemas que disponibilizam os dados apenas em tabelas são, em geral, os sistemas que subsidiam outros sistemas. Algumas plataformas disponibilizam os dados em mapas com símbolos que variam de pontos indicando a localização dos eventos a círculos proporcionais, outras os quantificam por unidades de análise. Algumas divergências nos totais de casos e óbitos, bastante evidentes, podem atrapalhar a confiabilidade do leitor, mas por outro lado mostram o empenho das diversas equipes responsáveis por dados no mundo em acelerar o passo para subsidiar o delineamento de cenários e a organização dos gestores públicos e privados perante a crise.

Alguns municípios e estados melhoraram a divulgação dos dados com sistemas que avaliam a divulgação dos dados, como é o caso do "Índice de transparência da Covid-19", que dá nota de acordo com a visualização dos dados (facilidade da interpretação dos dados), o formato (de preferência aberto e editável como é o caso do .csv) e a série histórica (atualização dos dados).

Assim, os sites em que se apresentam modelos que apontam com clareza as estimativas do crescimento da epidemia tendem a contribuir com a população no entendimento claro do que está ocorrendo no momento e o que pode ocorrer em um futuro muito próximo e sensibilizam para, por exemplo, a importante atitude de permanecer em isolamento. Ou seja, esses cálculos permitem mostrar para a sociedade civil e para gestores de maneira geral que a situação é grave, traduzindo para a população a ideia de risco, o que pode intensificar a busca por proteção. Essa importante comunicação com a sociedade civil está prevista no pacto pela democratização e qualidade da informação e comunicação em saúde firmado na I $2^{\text {a }}$ Conferência Nacional de Saúde (Silva, Cruz \& Melo, 2007). 
Na escala global, de 33 sistemas a maioria segue o padrão da Johns Hopkins junto com o CDC, mas a OMS divulga números menores tanto de casos quanto de óbitos, por exemplo para o Brasil, e os sistemas que seguem a linha da News Google divulgam valores menores, mas não tão menores que os da OMS. Essas diferenças podem gerar incertezas em quem está buscando os dados. Assim, tomamos o cuidado de verificar que todos os estavam divulgando para o mesmo dia. Na escala nacional, somamos 29 painéis com informações de casos e óbitos divulgados por município e por estado, contendo também dados de previsão e de isolamento e informações para situação dos indígenas com relação à Covid-19. Os valores de total de casos têm algumas divergências.

$\mathrm{Na}$ escala estadual, os sistemas e painéis somaram 35 endereços cobrindo quase todas as unidades federativas; aas exceções são Mato Grosso e Tocantins. Alguns estados apresentaram mais de um sistema, como Minas Gerais e São Paulo, com três sistemas, e Rondônia, Roraima, Sergipe e Paraná, com dois sistemas. Os demais apresentam um sistema cada. A maioria divulga seus dados por município.

Na escala municipal, o somatório foi de 9 sistemas e painéis. Nessa escala, também conhecida como escala intraurbana, estão os instrumentos de levantamentos de dados diferentes dos dados de unidades político-administrativas reconhecidas; neste caso estão as áreas de favela, unidades de Saúde da Família e populações indígenas.

Foram muitas as plataformas utilizadas, com destaque para a Esri, Tableau, Stata, Google e R, e combinações entre diversas delas. Mesmo em sistemas de instituições públicas algumas plataformas utilizadas eram pagas. Sistemas globais utilizaram: 12 a Esri, 2 o R, I o Tableau, 7 o Google, I o Stata, I o HGISLab; 8 não tiveram suas plataformas identificadas.

Com relação à presença de mapas, 89 sistemas divulgaram seus dados utilizando a distribuição espacial, o que representa $79,46 \%$ dos 1 I 2 sistemas listados. A maioria apresentou o número de casos e óbitos por Covid-19, depois as taxas e, com menor frequência, a representação por áreas quentes demonstrando concentração de casos ou óbitos. Dos 1 I 2 sistemas, 30 apresentaram cálculos de modelo. A maioria calculou a estimativa.

Com relação aos sistemas que disponibilizam os dados de maneira rápida sem demandar grandes adequações - por exemplo, csu, xls, planilha web -, há na escala global 12 sistemas, na escala nacional 14 sistemas, na escala estadual I 9 sistemas e na escala local 3 sistemas. 
85 sistemas apresentaram representação de gráfico, a maioria distribuindo os casos e os óbitos. Um número menor de sistemas apresentou as informações no gráfico por faixa etária, item que tem baixa divulgação: 35 no total, a maioria dos quais as divulga por gráficos. Destaca-se que a análise de dados por Covid- 9 distribuída por faixa etária é de grande importância, pois o grupo dos idosos tem sofrido mais com a pandemia da Covid- 19 (Romero et al., 2020). Com relação à informação por sexo, um número ainda menor de sistemas a apresenta: um total de 27 , grande parte dos quais a divulga por gráfico. As populações mais específicas, como é o caso das favelas, somaram 7 sistemas, 6 no município do Rio de Janeiro.

Essas informações levantadas e sistematizadas tanto de dados de saúde quanto de dados das áreas de interesse para a saúde podem ser muito úteis para o enfrentamento da pandemia, contudo é preciso que o usuário, de posse destes dados, seja capaz de colocar a informação gerada em movimento, ou seja, tenha capacidade de capturá-los, analisá-los e comunicá-los claramente para a sociedade civil, gestores e pesquisadores. Com o intuito de comunicar aos vários usuários desses sistemas e painéis os riscos para as diferentes populações, os pesquisadores têm produzido artigos, notas técnicas, boletins, vídeos, releases e infográficos. Os diversos veículos de imprensa têm se apropriado da linguagem epidemiológica para melhor informar a população sobre os riscos da Covid-19, contudo o sistema de informações sobre a Covid- 19 divulgadas pela imprensa não está disponível em um site de maneira pública.

\section{CONSIDERAÇÕES FINAIS}

A estruturação de modelos de escala global é desafiante, pois cada país tem sua dinâmica, seus modos de vida, de transporte, de atendimento à saúde e divulgação de informações em saúde. Dentro do Brasil, muitas pesquisas atestam suas diferenças profundas; assim, modelos que levam em consideração a estimativa dos diferentes estados e municípios capacitam os pesquisadores para construir propostas que possam contribuir bastante para o debate da sociedade e dos gestores e para um diálogo mais claro sobre decisões tanto individuais quanto coletivas para o enfrentamento da pandemia.

Esta pandemia evidencia a necessidade de fortalecer a área de informação em saúde para que as decisões sejam baseadas em dados mais próximos da realidade e com um nível de detalhamento que permita que as ações em saúde de maneira geral ocorram de forma mais adequada. Segundo Santos (1993), "O espaço se globaliza, mas não é mundial como um todo senão como metáfora. Todos os lugares são mundiais, mas não há um espaço mundial. Quem se globaliza mesmo são as pessoas (p.3l)”, e a tendência das populações a aumentar o nível de interação e de seguir em direção a áreas 
mais remotas da superfície terrestre aumentam as chances de que emergências dessa magnitude sejam mais frequentes. Para soluções mais articuladas, é importante que as respostas para emergências sejam planejadas e organizadas com base em dados.

A sinergia entre a academia e os serviços de saúde pode ser muito efetiva nas respostas para a sociedade, como estamos acompanhando neste evento. Uma articulação mais dinâmica entre as diferentes esferas federal, estadual e municipal agilizaria a produção e melhoraria a qualidade dos dados publicados; no entanto, há déficit de recursos humanos e falta manutenção atualizada do conhecimento e em contato próximo com a academia para constante renovação de tecnologias. Assim, o investimento em recursos humanos na área de informação e saúde poderia ajudar no diagnóstico da situação de saúde e contribuir no enfrentamento de diversas doenças, inclusive para a Covid- 19.

Nesta pandemia, as ações de organizações não governamentais ou voluntárias têm permitido que alguns sistemas se mantenham atualizados mesmo com os intervalos sem informações consolidadas da esfera federal, como é o caso do Brasil I. O. Atualmente, no Brasil a imprensa não estava conseguindo a atualização dos dados sobre Covid- I 9 a tempo de publicá-los em seus telejornais, e por isso formou parceria para lhes dar transparência, criando o consórcio de veículos de imprensa. As informações de casos e óbitos ainda mais difíceis de capturar são as referentes a populações tradicionais, como áreas indígenas e quilombolas, e às populações que vivem em favelas.

Diversos grupos têm se organizado para reunir dados principalmente sobre as áreas de favelas, que apresentam limitações tanto para o diagnóstico quanto para o enfrentamento da Covid-19. Na saúde pública sabe-se que quanto mais informações, melhores serão as decisões tomadas pelos gestores e pela sociedade civil.

É importante ressaltar que esses esforços não substituem os dados consolidados pelos SIS, pois estes contam com investigação detalhada pela equipe de vigilância epidemiológica e com a consolidação dos dados em séries históricas para estudos futuros, mas para dar respostas mais rápidas para ações da saúde e de outras áreas da política pública o uso desses sistemas e painéis é oportuno nesta pandemia.

A disseminação de diversos painéis sobre a Covid-19 só foi possível devido à disseminação das técnicas de ciência de dados em que a aplicação do método Big Data tem aumentado a troca de dados de maneira mais ágil, com base na combinação de múltiplas tecnologias que amplia a carga de dados tão extensa e variada, vinda das mais diversas fontes (Sena E Silva, 2019). Claro que há desigualdade no acesso às diferentes tecnologias, mas a divulgação promove democratização da informação e comunicação em saúde e pode ajudar a tomar decisão mais acertadas e, portanto, 
deve ser estimulada. Em um país como o Brasil, a desigualdade de acesso à internet ocorre diferentes escalas geográficas pode explicar a ausência de alguns territórios na lista de painéis sobre Covid-19.

A disseminação de sistemas acompanhada por notas técnicas tem contribuído também para a popularização e conscientização sobre a importância da informação e comunicação em saúde para um público maior, pois estes documentos têm sido, em grande parte, acompanhados por destaques que ajudam a dialogar com as assessorias de comunicação das diferentes instituições, que por sua vez ajudam a intercomunicação com a grande mídia, e assim as populações e os gestores podem acompanhar as rápidas evoluções da disseminação e do número de óbitos por Covid-19. Em alguns municípios tais documentos foram úteis para a decretação de lockdown, mas em alguns casos, como o da cidade do Rio de Janeiro, não têm se desdobrado em ações mais efetivas; o estado do Rio de Janeiro vem, há muitos meses, se mantendo como o de maior letalidade no país, segundo o painel do Conselho Nacional de Secretários de Saúde (Conass). Também foi identificado excesso de óbitos dentro e fora de hospitais no município do Rio de Janeiro, o que pode, segundo a nota técnica n. 14 do MonitoraCovid-19, significar um atendimento inadequado pelo setor Saúde.

Mais sistemas foram estruturados após o levantamento aqui apresentado, mas ainda não foram avaliados e classificados, por isso ainda não estão registrados. O segundo levantamento soma mais de 147 sistemas com mais informações sobre populações específicas, como usuários de unidades de saúde e presidiários, e alguns de tais sistemas apresentam dados de recursos utilizados no enfrentamento da pandemia.

No Quadro I estão as plataformas encontradas no período de março a junho de 2020, iniciando pela escala global e abrangendo as escalas nacional, estadual e municipal e áreas especiais.

\section{REFERENCIAS}

FREITAS, C. M. et al. A Gestão de Riscos e Governança na Pandemia por Covid- 9 no Brasil: análise dos decretos estaduais no primeiro mês. Relatório técnico e sumário executivo. Rio de Janeiro: Cepedes, Ensp/ Fiocruz, 2020.

JORGE, M. H. P. M.; LAURENTI, R. \& GOTILEB, S. L. D. Avaliação dos sistemas de informação em saúde no Brasil. Cadernos de Saúde Coletiva, I8(1): 7-18, 2010.

LIMA, C. R. A. et al. Revisão das dimensões de qualidade dos dados e métodos aplicados na avaliação dos sistemas de informação em saúde. Cadernos de Saúde Pública, 25(I0): 2.095-2. 109 , 2009. 
LOWE, R. et al. The Zika virus epidemic in Brazil: from discovery to future implications. International Journal of Environmental Research and Public Health, 15(1): 96, 2018. Disponível em: <www.arca. fiocruz.br/handle/icict/3 I339 >. Acessado em: abril de 2019.

MONITORACOVID- 19. Óbitos em excesso, dentro e fora de hospitais, mostram quadro de desassistência à saúde no Município do Rio de Janeiro, Nota Técnica 14 - $1^{\circ}$ de dezembro de 2020. Disponível: < https://bigdata-covid I 9.icict.fiocruz.br/nota_tecnica_I4.pdf> Acessado em: novembro de 2020.

ROMERO, D. et al. O excesso de óbitos de idosos no município do Rio de Janeiro analisado segundo o local de ocorrência. Nota Técnica, Gise-LIS-Icict-Fiocruz. Rio de Janeiro, 2020. Disponível em: < https:// www.icict.fiocruz.br/sites/www.icict.fiocruz.br/files/nota_tecnica_00I_gise-icict.pdf>. Acessado em: setembro de 2020.

SANTOS, M. A aceleração contemporânea. In: SANTOS, M. et al. (Orgs.). O Novo Mapa do Mundo. São Paulo: Hucitec, 1993

SILVA, A. X.; CRUZ E. A. \& MELO, V. A importância estratégica da informação em saúde para o exercício do controle social. Ciência E Saúde Coletiva, 12(3): 683-688, 2007.

SENA, J. K. S. \& SILVA, P. H. L. Um Estudo sobre a Importância da Tecnologia Big Data e Perspectivas Futuras de sua Aplicação na Indústria, 2019. Trabalho de Conclusão de Curso, Mossoró: Universidade Federal Rural do Semiárido. Disponível em: < https://repositorio.ufersa.edu.br/handle/prefix/4624> 


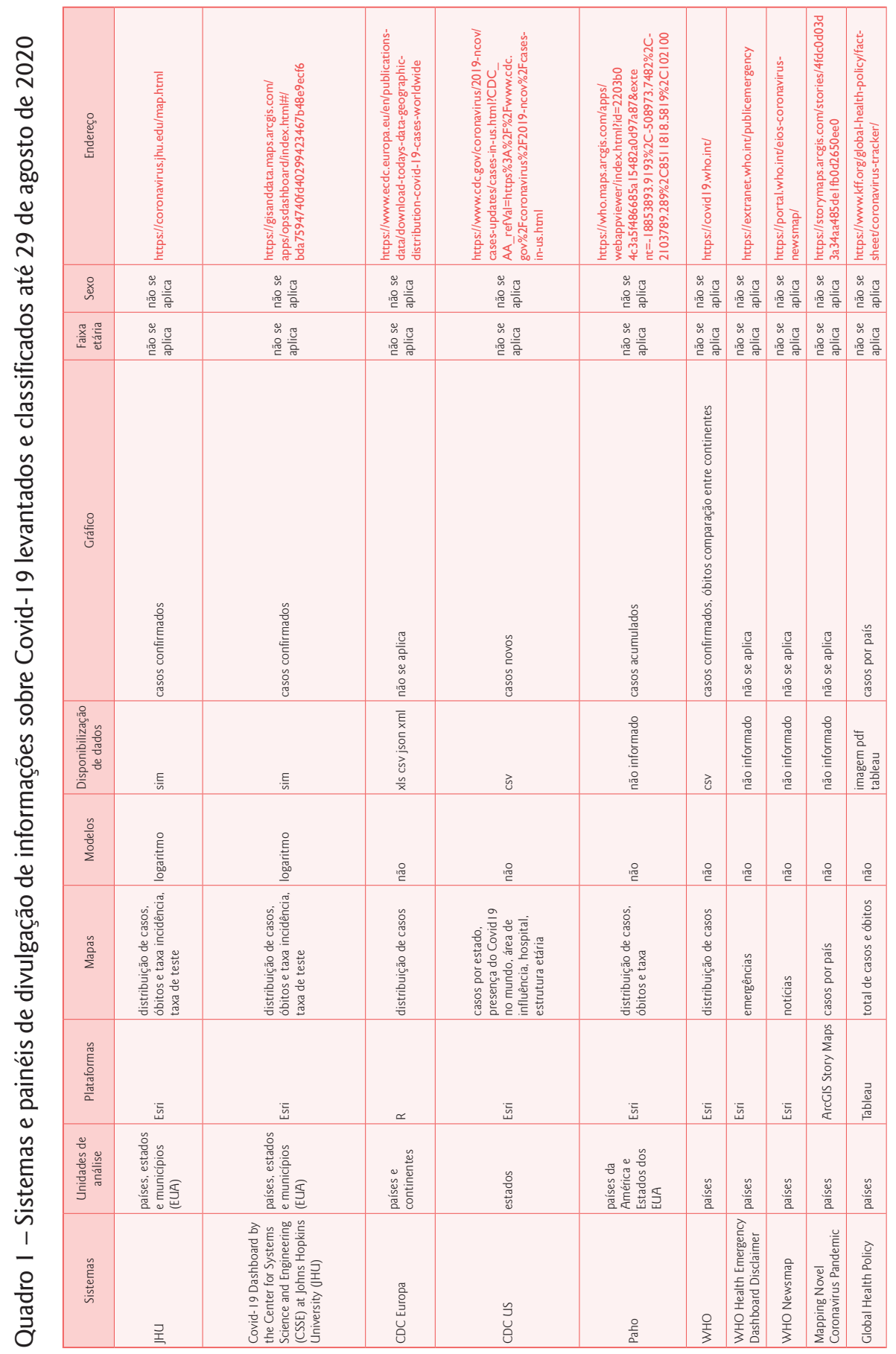




\begin{tabular}{|c|c|c|c|c|c|c|c|c|c|c|c|c|c|c|c|c|}
\hline $\begin{array}{l}\text { 巡 } \\
\text { 总 }\end{array}$ & 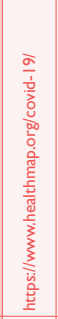 & 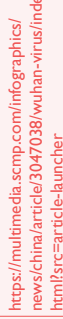 & 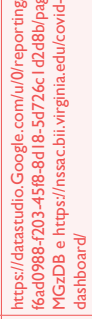 & 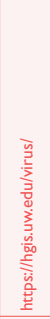 & 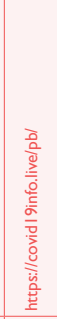 & 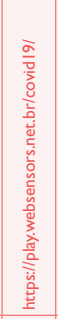 & 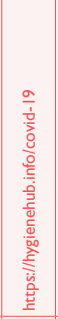 & 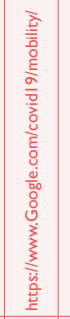 & 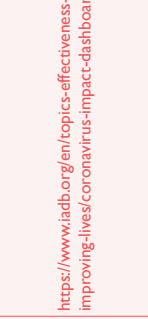 & 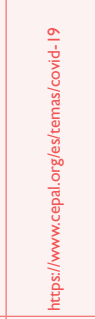 & 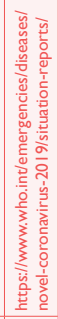 & 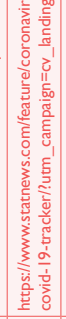 & 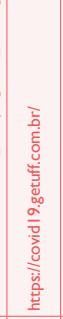 &  & 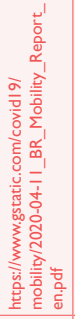 & 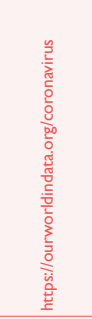 \\
\hline ஓّ̊ & 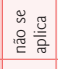 & 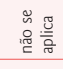 & 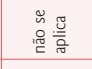 & 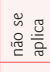 & 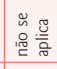 & 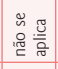 & 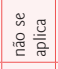 & 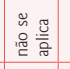 & 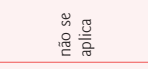 & 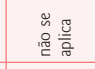 & $\frac{E}{\bar{n}}$ & 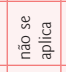 & 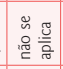 & 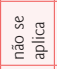 & 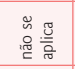 & 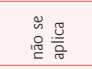 \\
\hline 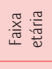 & 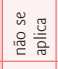 & 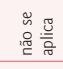 & E & 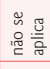 & 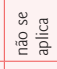 & 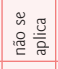 & 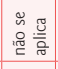 & 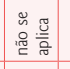 & 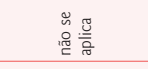 & 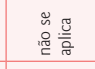 & $\frac{E}{\bar{n}}$ & 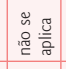 & 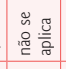 & 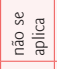 & 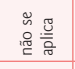 & 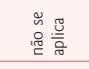 \\
\hline$\frac{8}{\frac{8}{\pi}}$ & 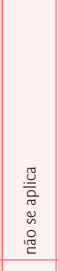 & 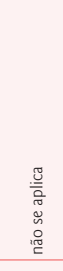 & 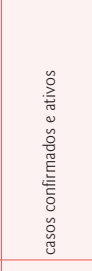 & 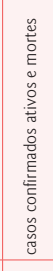 & 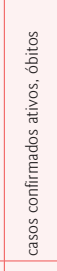 & 苍 & 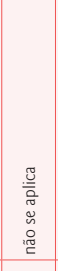 & 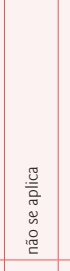 & 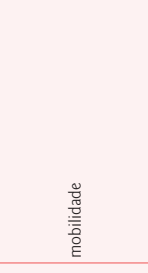 & 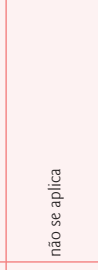 & 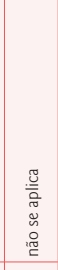 & 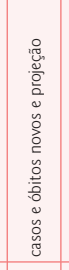 & 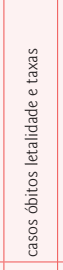 & 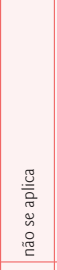 & 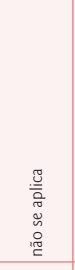 & 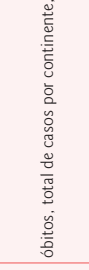 \\
\hline 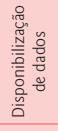 & हे & 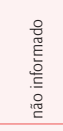 & $\begin{array}{l}\vec{े} \\
\text { 旁 }\end{array}$ & 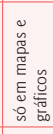 & 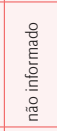 & 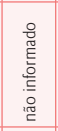 & 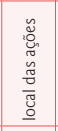 & है & 흠 & 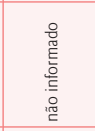 & 흠 & 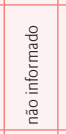 & 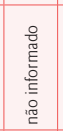 & 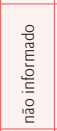 & $\begin{array}{l}\text { tे } \\
\text { o } \\
\text { है }\end{array}$ & है \\
\hline$\frac{\frac{0}{0}}{\frac{0}{2}}$ & : & 䆠 & \% & 兑 & i & 兽 & 兽 & 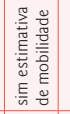 & 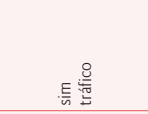 & 兽 & : & 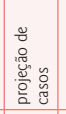 & 吕 & 兽 & 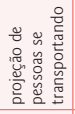 & 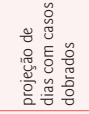 \\
\hline $\begin{array}{l}\frac{a}{00} \\
\frac{0}{20}\end{array}$ & 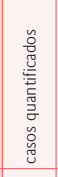 & 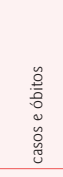 & 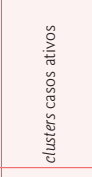 & 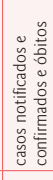 & 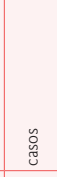 & 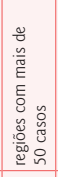 & 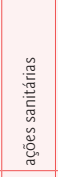 & 递 & 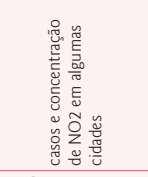 & 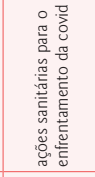 & 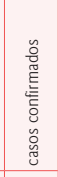 & $\begin{array}{l}\text { : } \\
\text { : } \\
0 \\
0 \\
0 \\
0 \\
0 \\
0\end{array}$ & 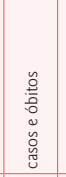 & 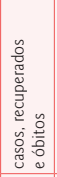 & 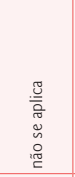 & 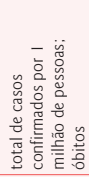 \\
\hline 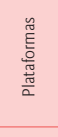 & 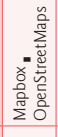 & 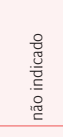 & 立 & $\begin{array}{l}\frac{0}{0} \\
\underline{\underline{0}} \\
\underline{\underline{x}}\end{array}$ & 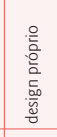 & 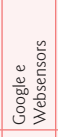 & 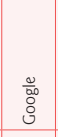 & 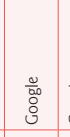 & 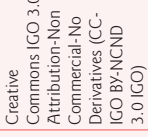 & 端 & 竭 & 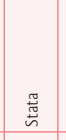 & 5 & $\begin{array}{l}\frac{0}{00} \\
8 \\
\\
\end{array}$ & $\begin{array}{l}\frac{0}{10} \\
8 \\
0\end{array}$ & $\propto$ \\
\hline 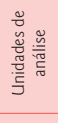 & 总 & 商 & 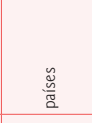 & 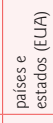 & 譬 & 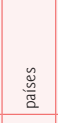 & 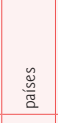 & 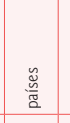 & 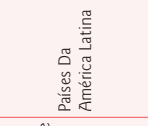 & 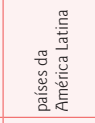 & 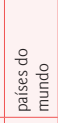 & 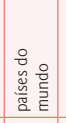 & $\begin{array}{l}\frac{\mathscr{o}}{\tilde{m}} \\
\frac{\tilde{g}}{a}\end{array}$ & 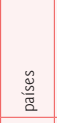 & $\begin{array}{l}\text { 訔 } \\
\frac{\tilde{a}}{a}\end{array}$ & 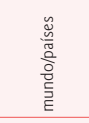 \\
\hline 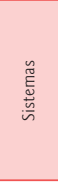 & 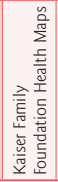 & 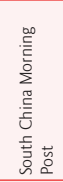 & 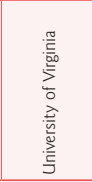 & 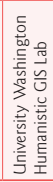 & 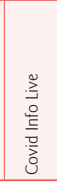 & 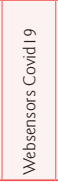 & 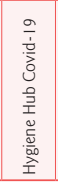 & 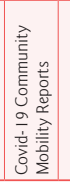 & 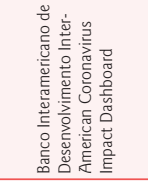 & 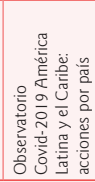 & 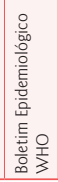 & 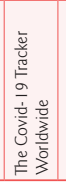 & $\begin{array}{l}\text { 岁 } \\
\text { 总 }\end{array}$ & \begin{tabular}{|c|}
$\overline{\bar{y}}$ \\
$\bar{j}$ \\
$\dot{0}$ \\
$\frac{0}{00}$ \\
0 \\
\\
\end{tabular} & 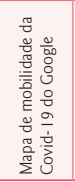 & 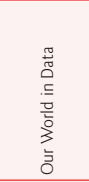 \\
\hline
\end{tabular}




\begin{tabular}{|c|c|c|c|c|c|c|c|c|c|c|c|}
\hline 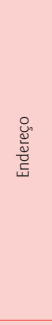 & 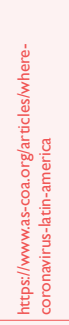 & 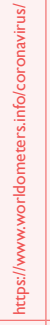 & 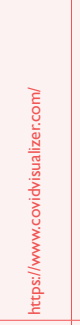 & 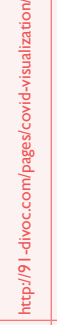 & 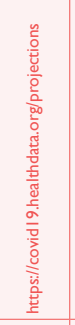 & 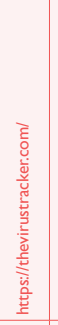 & 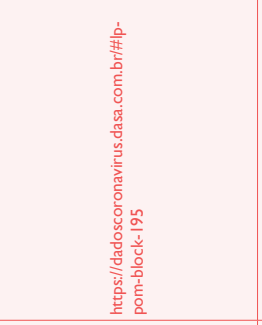 & 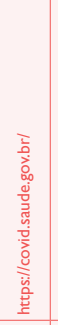 & 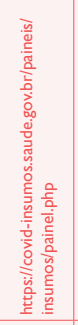 & 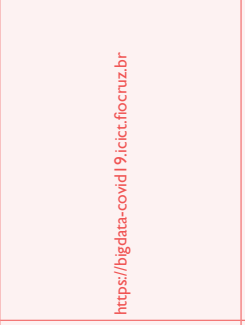 & 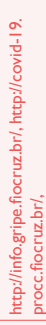 \\
\hline$\stackrel{̊}{~}$ & 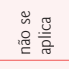 & 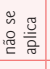 & 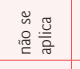 & 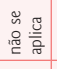 & 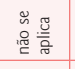 & 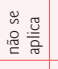 & 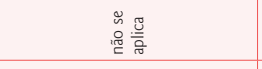 & $\frac{E}{\bar{n}}$ & 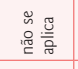 & 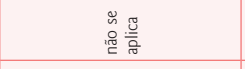 & 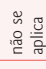 \\
\hline 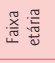 & 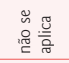 & 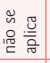 & 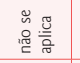 & 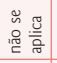 & 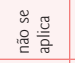 & 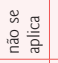 & 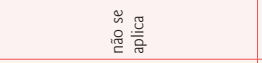 & $\frac{E}{\bar{n}}$ & $\frac{E}{\bar{n}}$ & 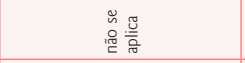 & 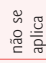 \\
\hline$\frac{8}{8}$ & 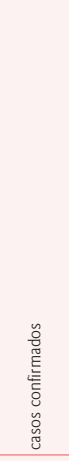 & 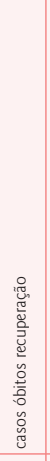 & 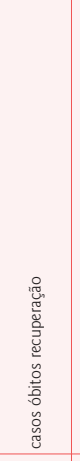 & 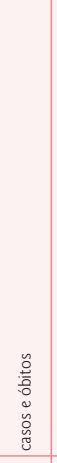 & E & 部 & 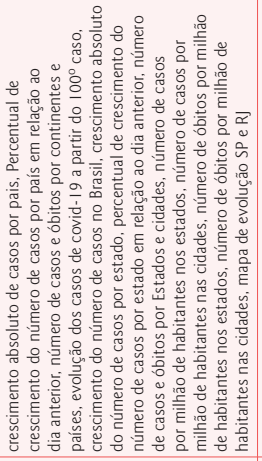 & $\frac{E}{\bar{n}}$ & 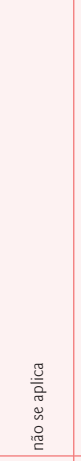 & 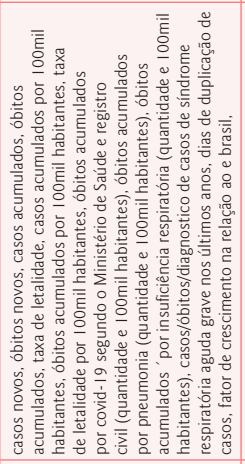 & 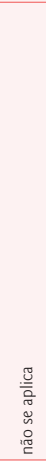 \\
\hline 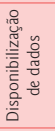 & 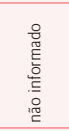 & $\frac{E}{\bar{n}}$ & 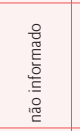 & 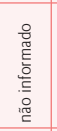 & 部 & है & 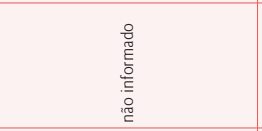 & 항 & E & 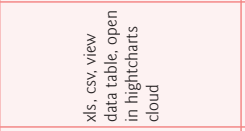 & 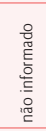 \\
\hline$\frac{\frac{u}{0}}{\frac{g}{g}}$ & 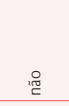 & 兽 & חृ & 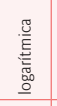 & 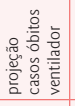 & : & 电 & 兽 & 电 & 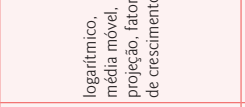 & 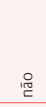 \\
\hline $\begin{array}{l}\frac{\tilde{z}}{0} \\
\frac{\pi}{2}\end{array}$ & 茶 & 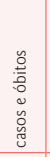 & 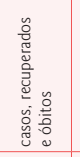 & 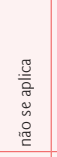 & 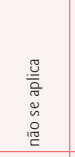 & 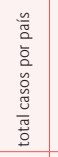 & 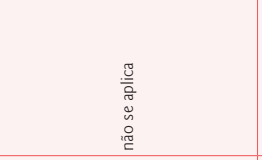 & 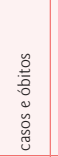 & 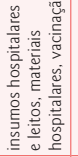 & 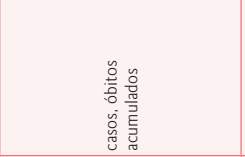 & 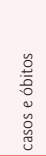 \\
\hline 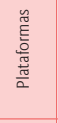 & 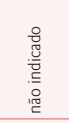 & 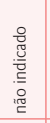 & $\begin{array}{l}\frac{\omega}{00} \\
\text { 。̊ } \\
\end{array}$ & 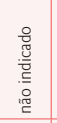 & 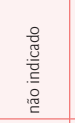 & $\propto$ & 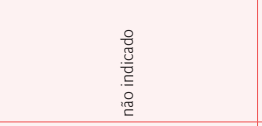 & 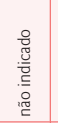 & 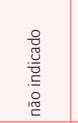 & $\simeq$ & 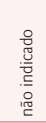 \\
\hline 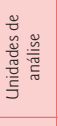 & 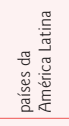 & 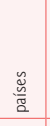 & 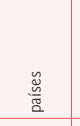 & 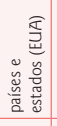 & 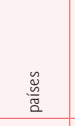 & 受 & 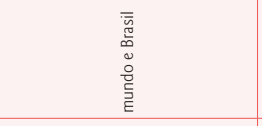 & 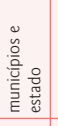 & 总 & 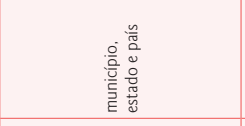 & 总 \\
\hline 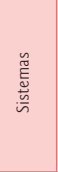 & 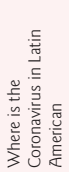 & 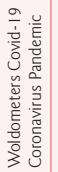 & 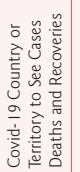 & 旁 & 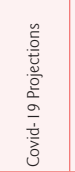 & 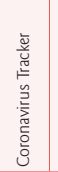 & 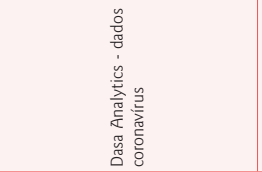 & 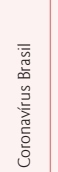 & 六 & $\underline{\underline{U}}$ & $\underline{a}$ \\
\hline
\end{tabular}




\begin{tabular}{|c|c|c|c|c|c|c|c|c|c|c|c|c|}
\hline 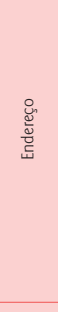 & 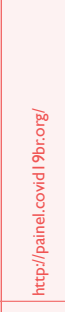 & 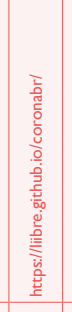 & 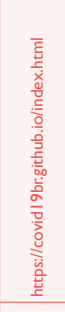 & & 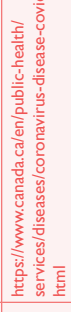 & 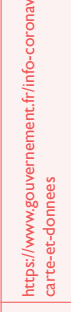 & & 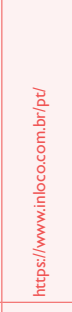 & 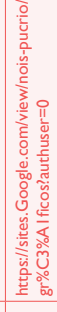 & 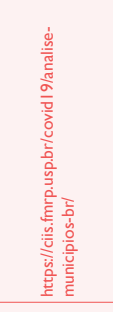 & 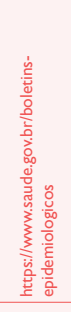 & \pm \\
\hline 宫 & 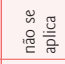 & 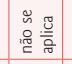 & 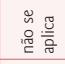 & 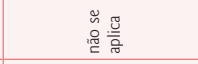 & $\frac{E}{\bar{n}}$ & 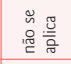 & 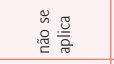 & 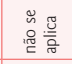 & 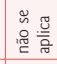 & 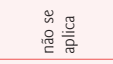 & $\frac{E}{n}$ & 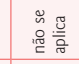 \\
\hline 證愛 & 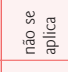 & 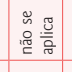 & 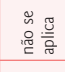 & 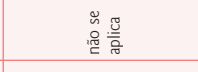 & $\frac{E}{\bar{n}}$ & 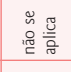 & 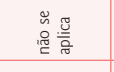 & 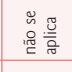 & 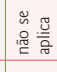 & 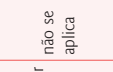 & $\frac{E}{\bar{n}}$ & 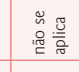 \\
\hline 圞 & 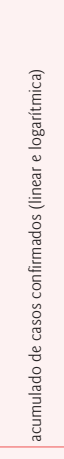 & 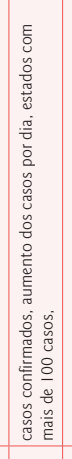 & 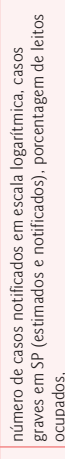 & 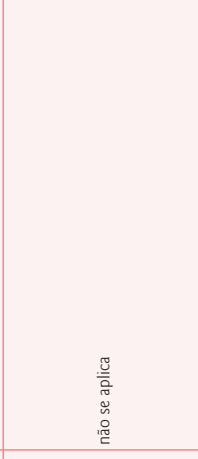 & 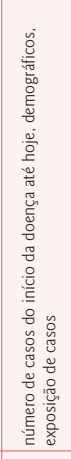 & 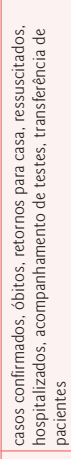 & 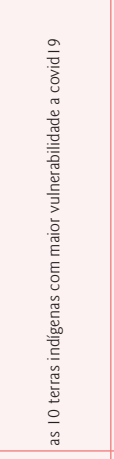 & 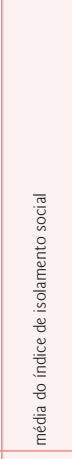 & $\frac{E}{\bar{n}}$ & 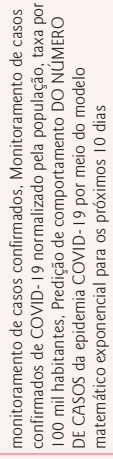 & 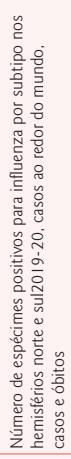 & 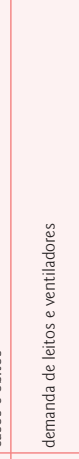 \\
\hline 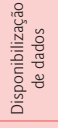 & 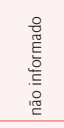 & $\frac{E}{\bar{n}}$ & 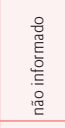 & $\frac{n}{x}$ & 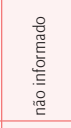 & 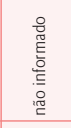 & 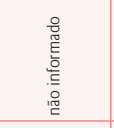 & 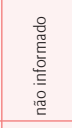 & 禺 & : & $\frac{E}{\bar{n}}$ & 兽 \\
\hline$\frac{\frac{\mathrm{o}}{\mathrm{g}}}{\frac{\mathrm{g}}{2}}$ & 咀 & 哭 & 囟 & 흘 & 兽 & 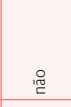 & 兽 & $\frac{E}{\bar{n}}$ & 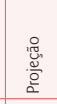 & 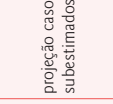 & $\frac{E}{n}$ & 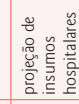 \\
\hline 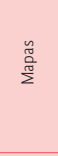 & 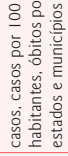 & 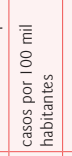 & 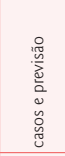 & & $\begin{array}{l}\text { 总 } \\
\text { 兽 } \\
\frac{\tilde{m}}{9} \\
\end{array}$ & 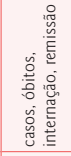 & 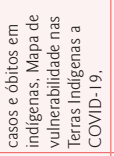 & 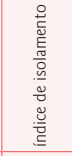 & $\stackrel{\circ}{\circ}$ & 囟 & 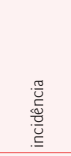 & 囟 \\
\hline 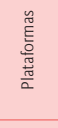 & 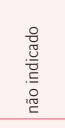 & $\propto$ & $\propto$ & 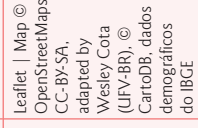 & 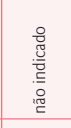 & 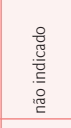 & 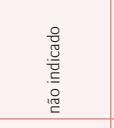 & 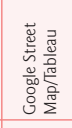 & 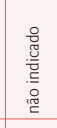 & 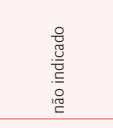 & 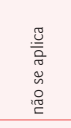 & 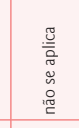 \\
\hline 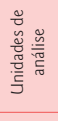 & 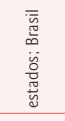 & 与 & 今 & 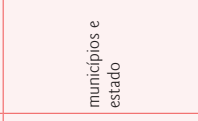 & $\frac{8}{8}$ & 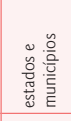 & 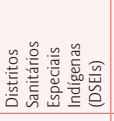 & 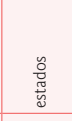 & 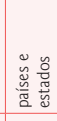 & 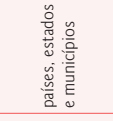 & 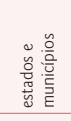 & 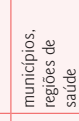 \\
\hline 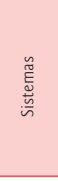 & 曽 & 产 & 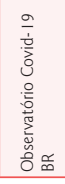 & 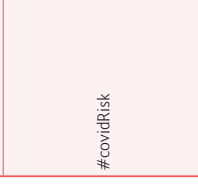 & 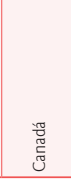 & 离 & 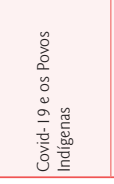 & 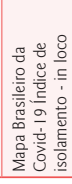 & 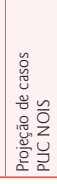 & 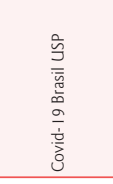 & 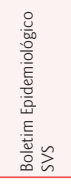 & 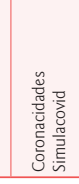 \\
\hline
\end{tabular}




\begin{tabular}{|c|c|c|c|c|c|c|c|c|c|c|c|c|c|c|c|c|}
\hline 总 & 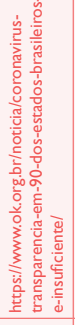 & 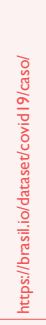 & 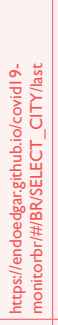 & 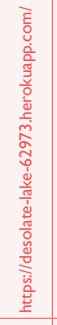 & 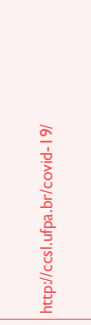 & 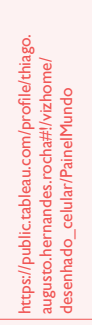 & 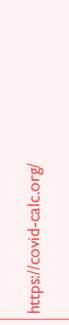 & 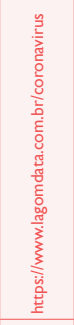 & 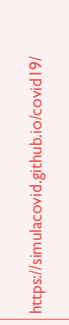 & 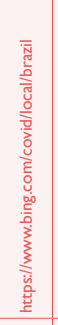 & 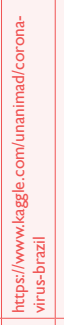 & 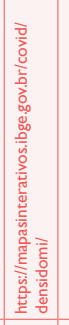 & 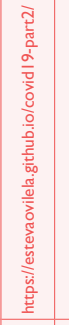 & 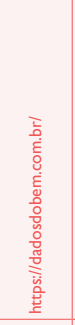 & 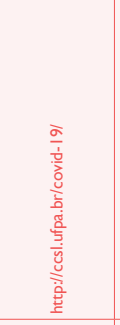 & 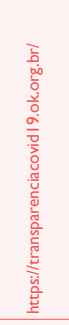 \\
\hline$\stackrel{\S}{్}$ & 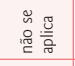 & 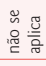 & 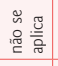 & 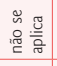 & 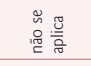 & 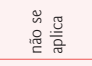 & 틈 & 틈 & 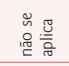 & 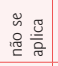 & 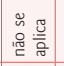 & 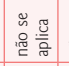 & 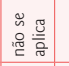 & $\frac{E}{n}$ & 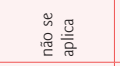 & 咅 \\
\hline 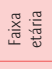 & 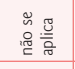 & 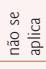 & 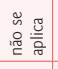 & 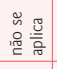 & 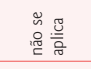 & 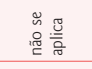 & $\frac{E}{n}$ & $\frac{E}{n}$ & 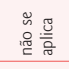 & 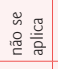 & 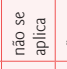 & 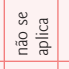 & $\frac{E}{n}$ & 틈 & 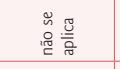 & $\frac{E}{n}$ \\
\hline 衿 & 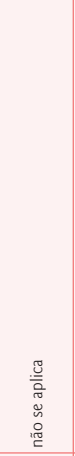 & 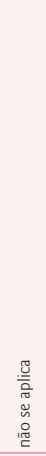 & 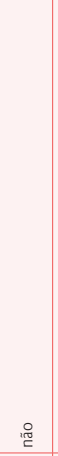 & 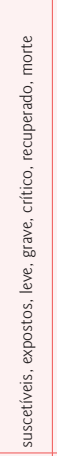 & 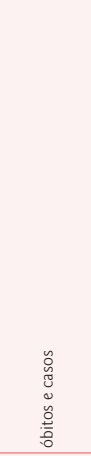 & 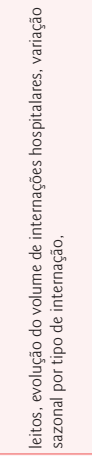 & 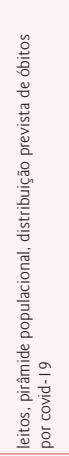 & 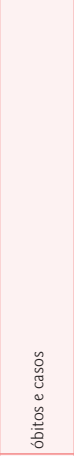 & 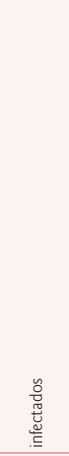 & 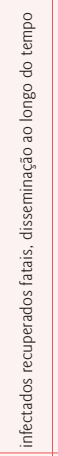 & 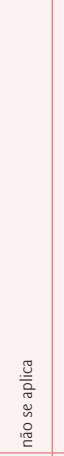 & 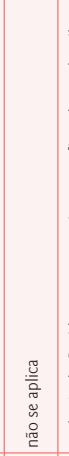 & 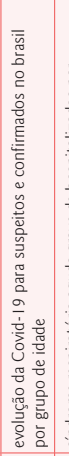 & 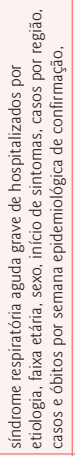 & 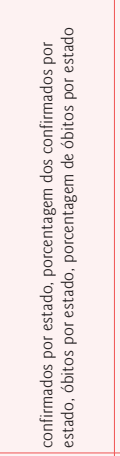 & 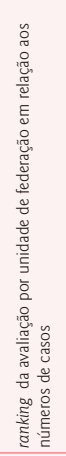 \\
\hline 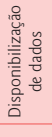 & $\frac{E}{\bar{n}}$ & $\begin{array}{l}\bar{\alpha} \\
\bar{\alpha} \\
\bar{y} \\
\end{array}$ & 电 & 囟 & I & \% & 윧 & ठे & 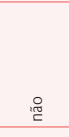 & 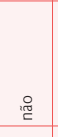 & ¿े & 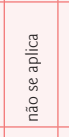 & ठे & है & : & ¿ \\
\hline $\begin{array}{l}\frac{\mathrm{g}}{\mathrm{g}} \\
\frac{\mathrm{g}}{2}\end{array}$ & 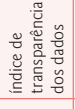 & 营 & 胥 & 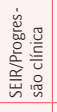 & i & \% & 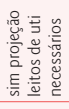 & 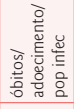 & 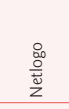 & 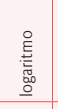 & 电 & 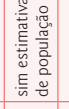 & 䄇 & I̊ & 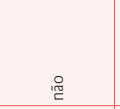 & एٓ] \\
\hline $\begin{array}{l}\frac{y}{0} \\
\frac{\pi}{20}\end{array}$ & 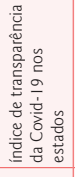 & : & 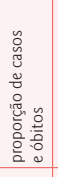 & 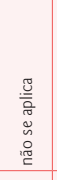 & 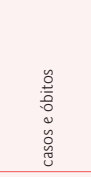 & 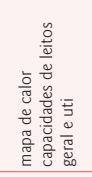 & 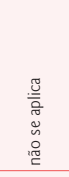 & 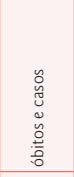 & 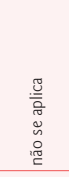 & 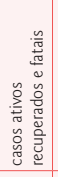 & 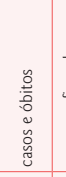 & 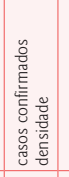 & 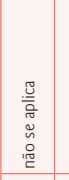 & 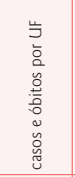 & 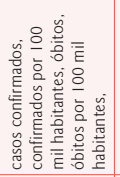 & 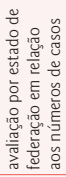 \\
\hline 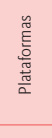 & 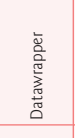 & 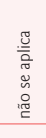 & 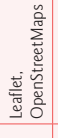 & 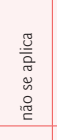 & 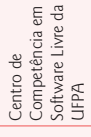 & 卷 & 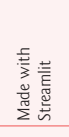 & $\propto$ & $\propto$ & 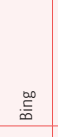 & $\propto$ & $\overline{\mathrm{s}}$ & $\propto$ & 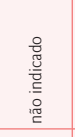 & $\frac{E}{\Sigma}$ & 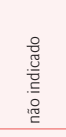 \\
\hline 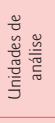 & 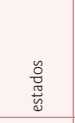 & 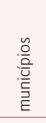 & 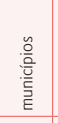 & $\begin{array}{l}\overline{\overline{\underline{m}}} \\
\bar{m}\end{array}$ & 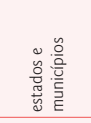 & 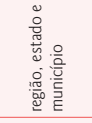 & 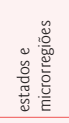 & 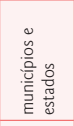 & 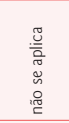 & 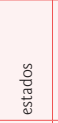 & 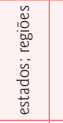 & 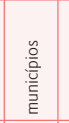 & $\overline{\overline{\bar{m}}}$ & 六 & 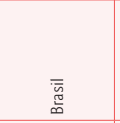 & 造 \\
\hline 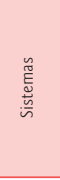 & 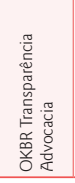 & 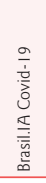 & 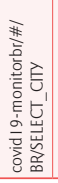 & 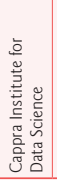 & 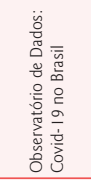 & 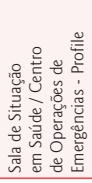 & 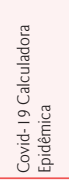 & 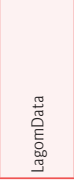 & 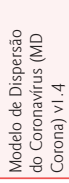 & 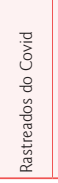 & 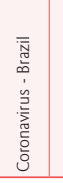 & 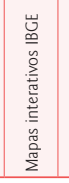 & 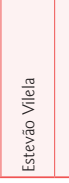 & 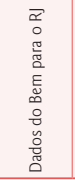 & 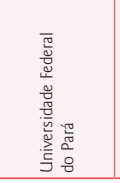 & 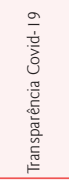 \\
\hline
\end{tabular}




\begin{tabular}{|c|c|c|c|c|c|c|c|c|c|c|c|}
\hline 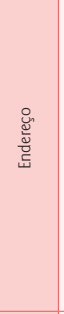 & 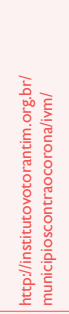 & 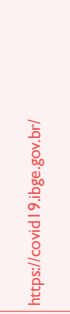 & 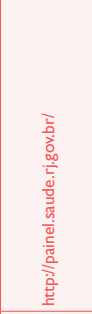 & 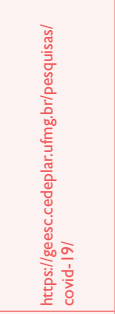 & 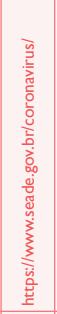 & 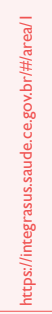 & 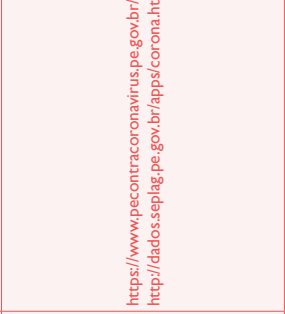 & 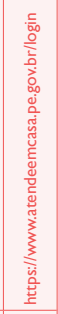 & 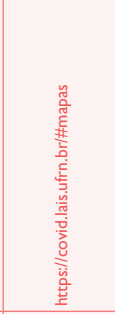 & 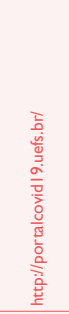 & 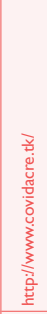 \\
\hline §్ & 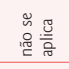 & 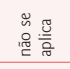 & $\frac{E}{\bar{n}}$ & 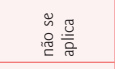 & 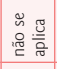 & 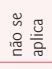 & 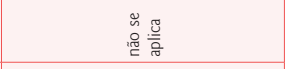 & 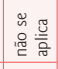 & 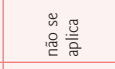 & 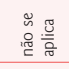 & 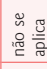 \\
\hline 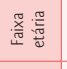 & $\frac{E}{\bar{n}}$ & 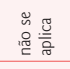 & $\frac{E}{\bar{n}}$ & 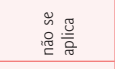 & 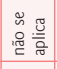 & 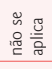 & 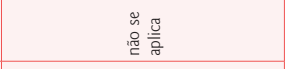 & 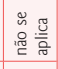 & $\frac{E}{\bar{n}}$ & 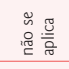 & 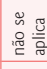 \\
\hline 恼 & 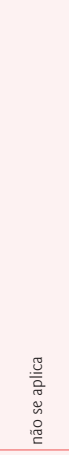 & 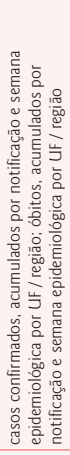 & 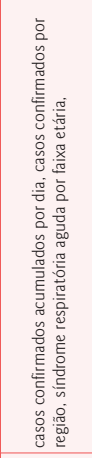 & 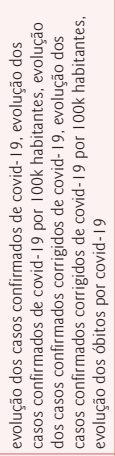 & 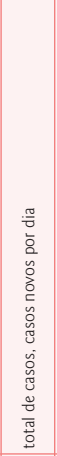 & 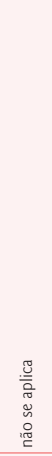 & 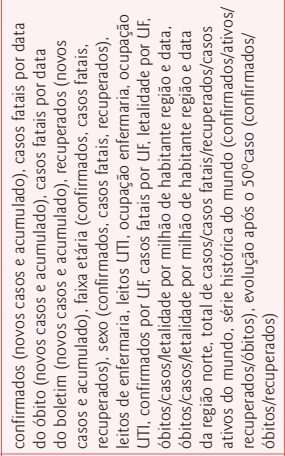 & 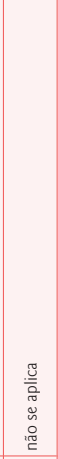 & 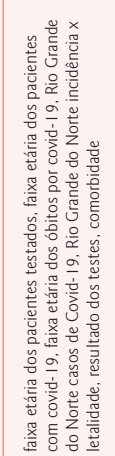 & 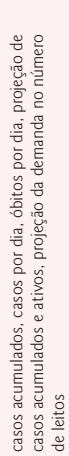 & 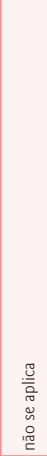 \\
\hline 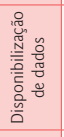 & 吕 & $\vec{b}$ & E & है & ठे & 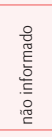 & 3 & 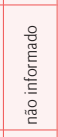 & 誉 & 兽 & 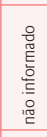 \\
\hline$\frac{\frac{0}{0}}{\frac{0}{0}}$ & 㛸 & 兽 & 兽 & io & 兽 & 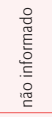 & 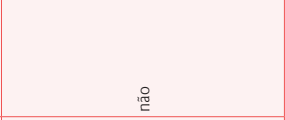 & $\stackrel{2}{\circ}$ & 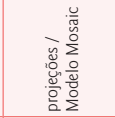 & 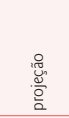 & : \% \\
\hline $\begin{array}{l}\frac{\tilde{m}}{0} \\
\frac{\pi}{2}\end{array}$ & 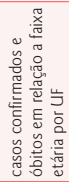 & 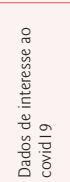 & 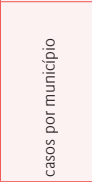 & 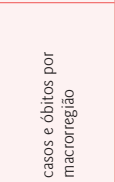 & 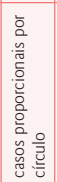 & 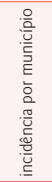 & 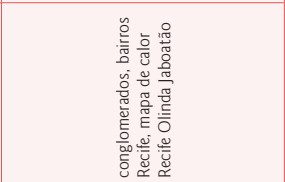 & 号 & 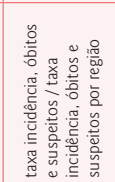 & 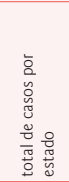 & 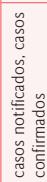 \\
\hline $\begin{array}{l}\text { 峞 } \\
\text { 产 } \\
\text { 产 } \\
\frac{\omega}{a}\end{array}$ & 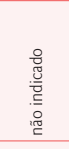 & 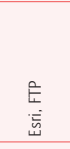 & 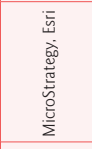 & $\overline{5}$ & 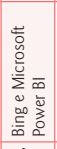 & 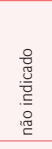 & 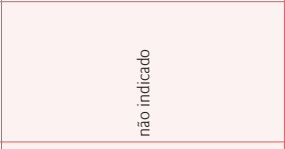 & 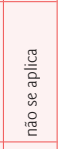 & 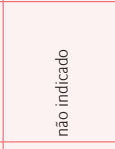 & $\begin{array}{l}\frac{x}{0} \\
\text { o. } \\
\frac{0}{2} \\
\end{array}$ & 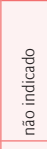 \\
\hline 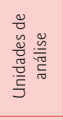 & 离 & 离 & 蒿 & 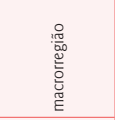 & 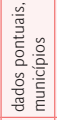 & 䓂 & 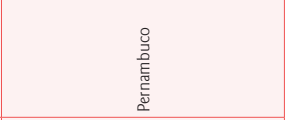 & 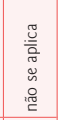 & 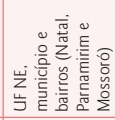 & $\begin{array}{l}\frac{0}{0} \\
\frac{\mathrm{w}}{5}\end{array}$ & 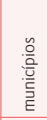 \\
\hline 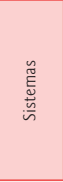 & 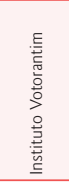 & 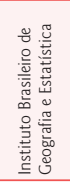 & 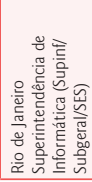 & 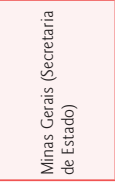 & 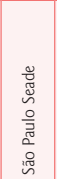 & 莺 & 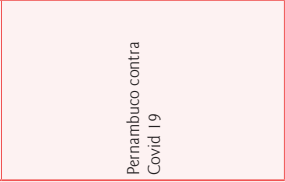 & 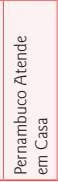 & 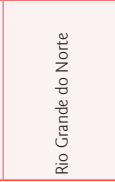 & 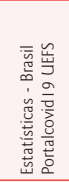 & 过 \\
\hline
\end{tabular}




\begin{tabular}{|c|c|c|c|c|c|c|c|c|c|}
\hline 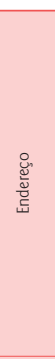 & 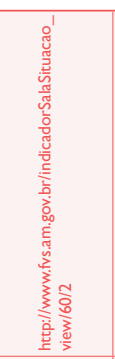 & 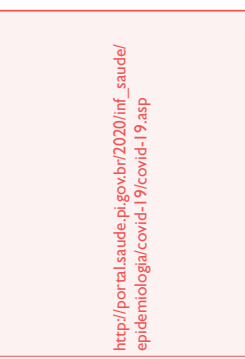 & 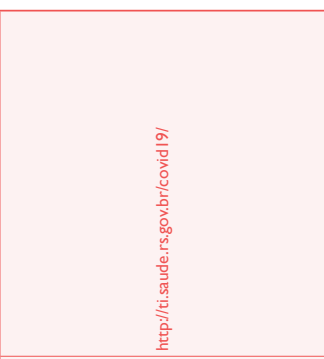 & 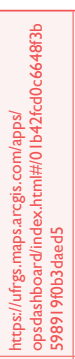 & 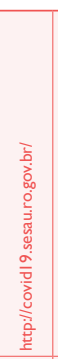 & 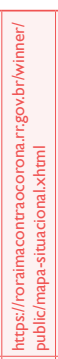 & 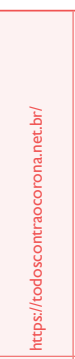 & 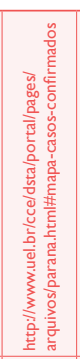 & 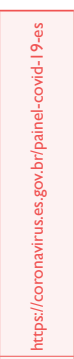 \\
\hline §̊ & 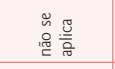 & E & 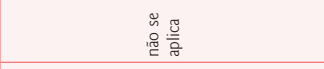 & 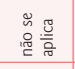 & $\frac{E}{n}$ & $\frac{E}{n}$ & $\frac{E}{n}$ & 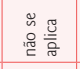 & $\frac{E}{\bar{n}}$ \\
\hline 總遥 & $\frac{E}{n}$ & $\frac{E}{n}$ & 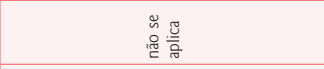 & 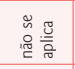 & $\frac{E}{\bar{n}}$ & $\frac{E}{n}$ & $\frac{E}{n}$ & 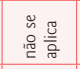 & $\frac{E}{n}$ \\
\hline$\frac{8}{\frac{8}{\pi}}$ & 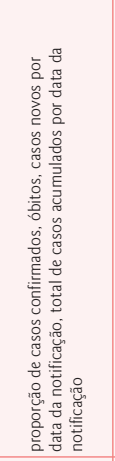 & 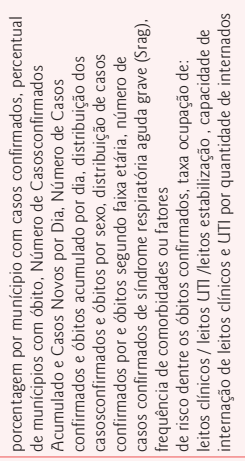 & 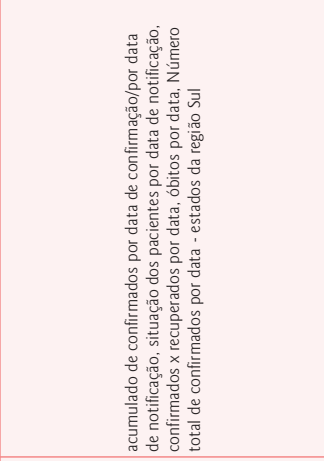 & 总 & 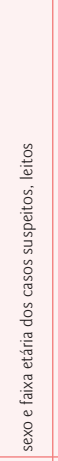 & 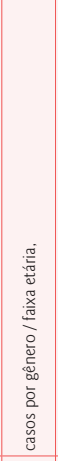 & 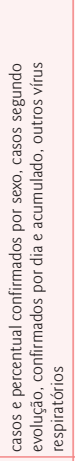 & 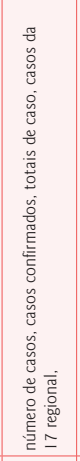 & 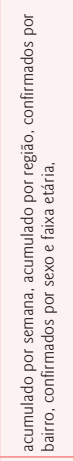 \\
\hline 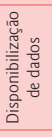 & 电 & $\stackrel{0}{\dddot{2}}$ & 욛 & 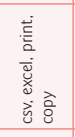 & 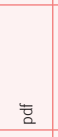 & 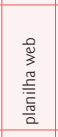 & है & 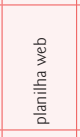 & है \\
\hline$\frac{\frac{8}{0}}{\frac{8}{2}}$ & 号 & 递 & \% & 兽 & 兽 & : 음 & 巺 & 泪 & 㣢 \\
\hline $\begin{array}{l}\frac{y}{0} \\
\frac{0}{20}\end{array}$ & 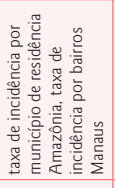 & 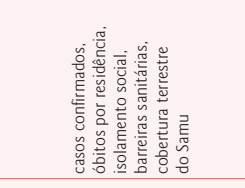 & 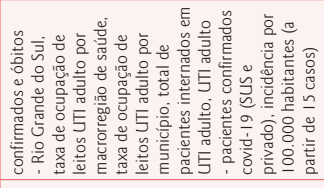 & 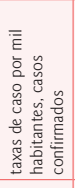 & 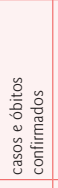 & 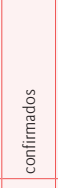 & 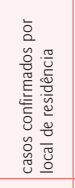 & 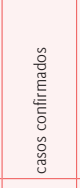 & 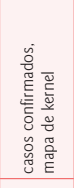 \\
\hline 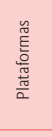 & 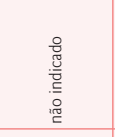 & 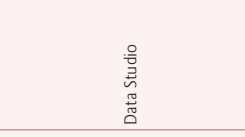 & 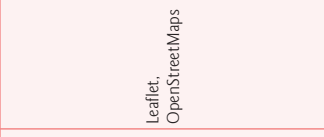 & $\overline{5}$ & 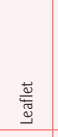 & 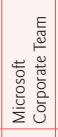 & 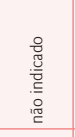 & 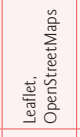 & 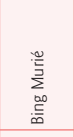 \\
\hline 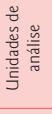 & 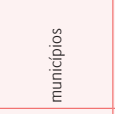 & 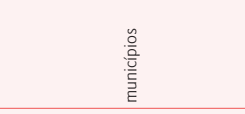 & 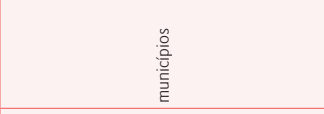 & 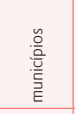 & 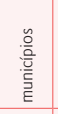 & 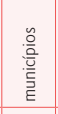 & 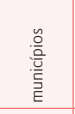 & 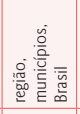 & 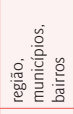 \\
\hline 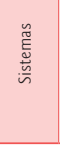 & 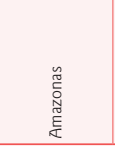 & 言 & 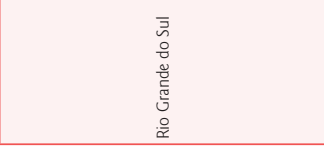 & 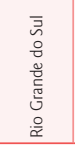 & 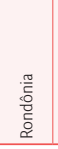 & 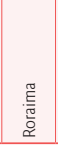 & 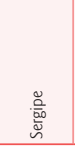 & 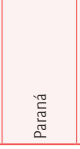 & 䓌 \\
\hline
\end{tabular}




\begin{tabular}{|c|c|c|c|c|c|c|c|c|c|c|c|c|c|c|c|}
\hline 莺 & 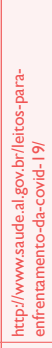 & 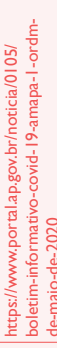 & 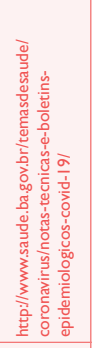 & 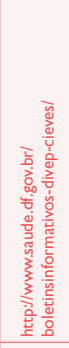 & 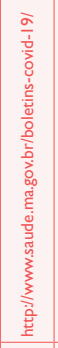 & 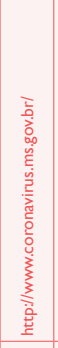 & 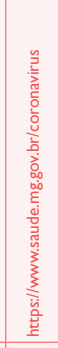 & 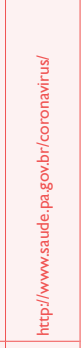 & 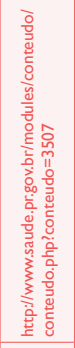 & 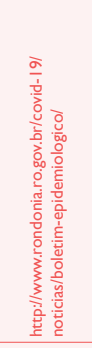 & 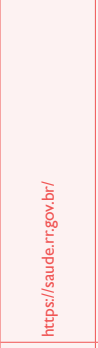 & 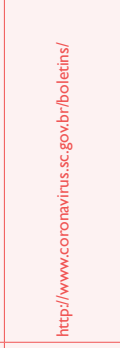 & 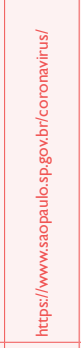 & 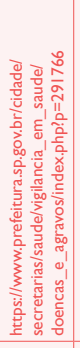 & 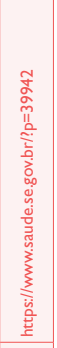 \\
\hline 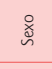 & 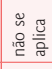 & 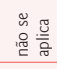 & 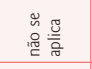 & 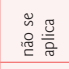 & 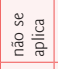 & $\frac{E}{\bar{n}}$ & 鸹 & $\frac{E}{n}$ & $\frac{E}{n}$ & $\frac{E}{n}$ & $\frac{E}{n}$ & E & 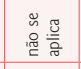 & 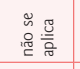 & 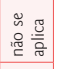 \\
\hline 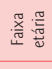 & 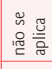 & 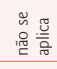 & $\frac{E}{\bar{n}}$ & 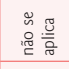 & $\underline{E}$ & हE & $\frac{E}{n}$ & $\frac{E}{n}$ & $\frac{E}{\bar{n}}$ & $\frac{E}{\bar{n}}$ & $\frac{E}{n}$ & $\frac{E}{n}$ & 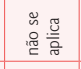 & 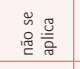 & 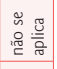 \\
\hline 初 & $\stackrel{2}{\circ}$ & 究 & 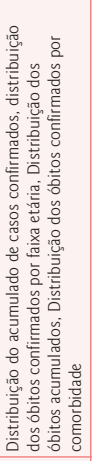 & 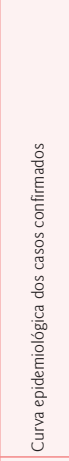 & 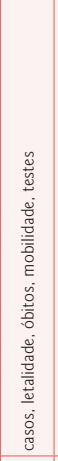 & 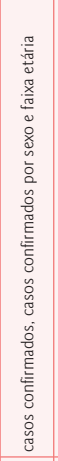 & 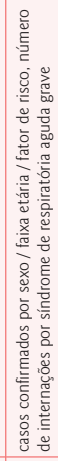 & 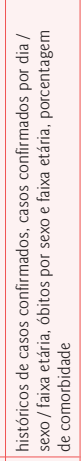 & 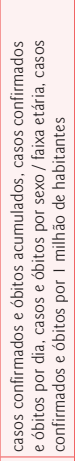 & 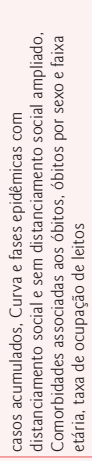 & 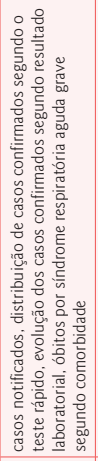 & 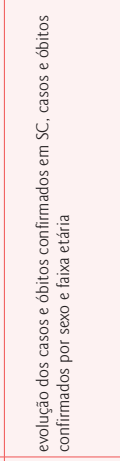 & 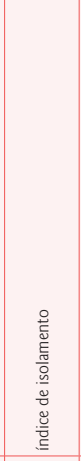 & 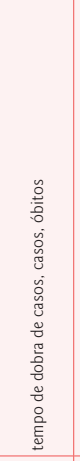 & 兽 \\
\hline 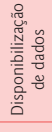 & 혐 & $\stackrel{0}{\dddot{2}}$ & tᄒㅁ & 흠 & $\frac{n}{x}$ & 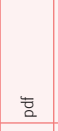 & 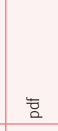 & हे & $\begin{array}{l}\bar{े} \\
\text { o } \\
\bar{y}\end{array}$ & 흠 & tᄒ & ড্ & है & है & 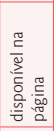 \\
\hline $\begin{array}{l}\frac{0}{\frac{\circ}{g}} \\
\frac{\mathrm{g}}{2}\end{array}$ & $\stackrel{0}{\circ}$ & ֻ & i & 욤 & : 임 & 兽 & 要 & $\begin{array}{l}\frac{\mathrm{g}}{\mathrm{z}} \\
\frac{\mathrm{o}}{2}\end{array}$ & \% & 兽 & 电 & 象 & 兽 & 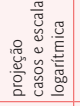 & $\stackrel{\circ}{\circ}$ \\
\hline $\begin{array}{l}\frac{\tilde{m}}{0} \\
\frac{\pi}{2 \pi}\end{array}$ & $\stackrel{0}{\circ}$ & 兽 & 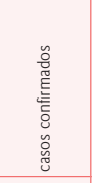 & 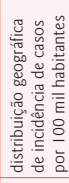 & 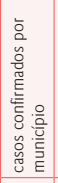 & 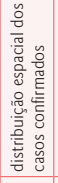 & 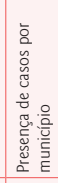 & 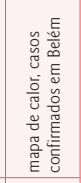 & 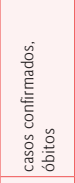 & 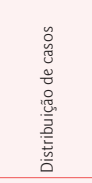 & \% & 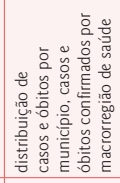 & 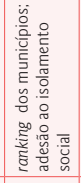 & 总 & 觉 \\
\hline 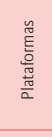 & 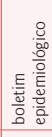 & 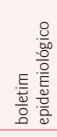 & 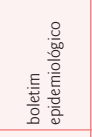 & 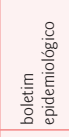 & 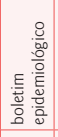 & 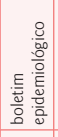 & 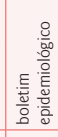 & 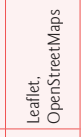 & 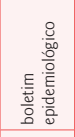 & 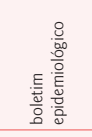 & 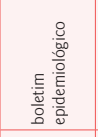 & 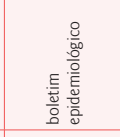 & 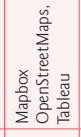 & 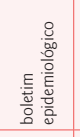 & 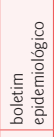 \\
\hline 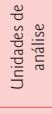 & 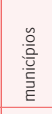 & & 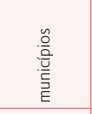 & 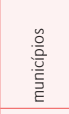 & 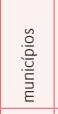 & 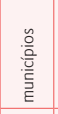 & 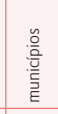 & 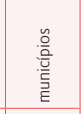 & 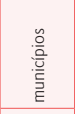 & 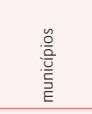 & 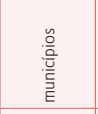 & 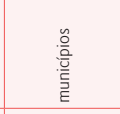 & 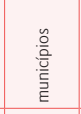 & 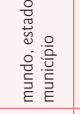 & 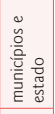 \\
\hline 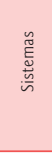 & $\begin{array}{l}\text { 总 } \\
\frac{\pi}{\tilde{\tau}}\end{array}$ & $\begin{array}{l}\text { 营 } \\
\text { 章 }\end{array}$ & 䓵 & 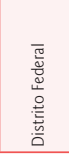 & 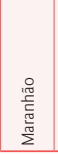 & 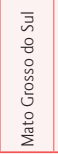 & 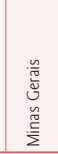 & $\frac{5}{0}$ & 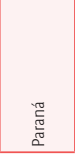 & 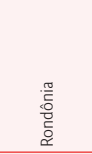 & 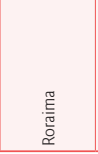 & 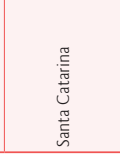 & 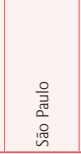 & 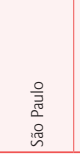 & 产 \\
\hline
\end{tabular}




\begin{tabular}{|c|c|c|c|c|c|c|c|c|c|c|c|c|}
\hline 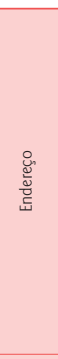 & 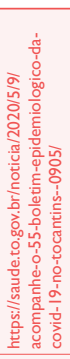 & 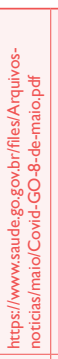 & 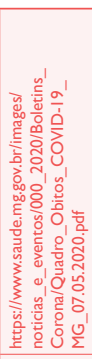 & 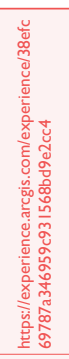 & 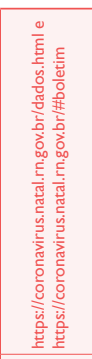 & 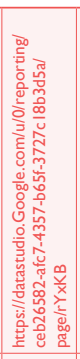 & 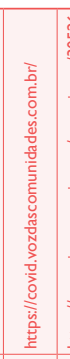 & 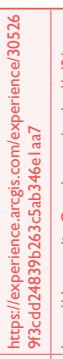 & 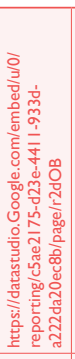 & 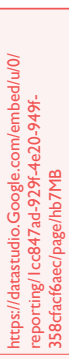 & 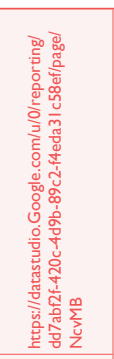 & 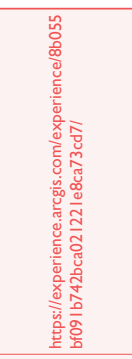 \\
\hline 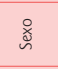 & 틈 & 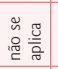 & 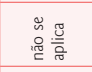 & $\frac{E}{n}$ & 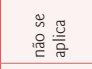 & 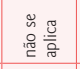 & 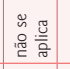 & E & $\frac{E}{n}$ & $\frac{E}{\bar{n}}$ & $\frac{E}{n}$ & $\frac{E}{n}$ \\
\hline 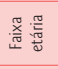 & $\frac{E}{n}$ & 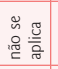 & 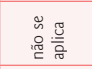 & $\frac{E}{n}$ & 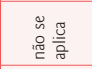 & 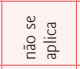 & 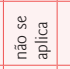 & $\frac{E}{n}$ & $\frac{E}{\bar{n}}$ & $\frac{E}{n}$ & $\frac{E}{n}$ & $\frac{E}{n}$ \\
\hline 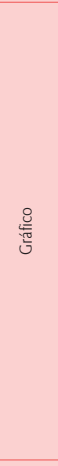 & 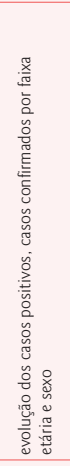 & 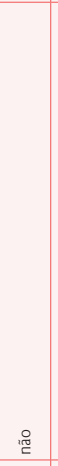 & 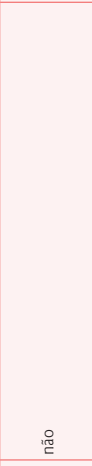 & 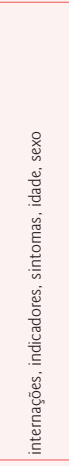 & 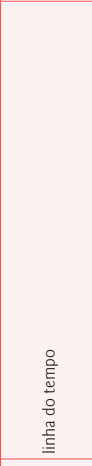 & 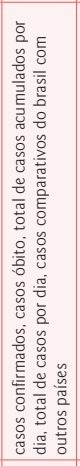 & 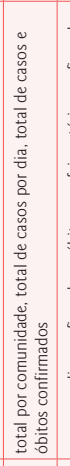 & 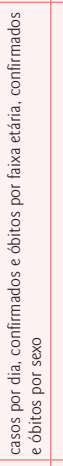 & 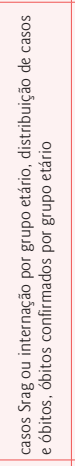 & 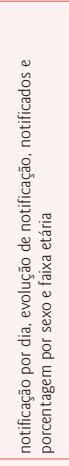 & 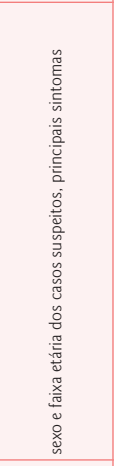 & 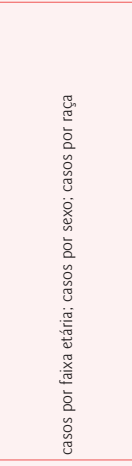 \\
\hline 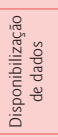 & 흠 & t' & 흠 & ֻٕ & 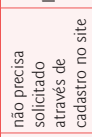 & 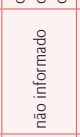 & 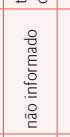 & 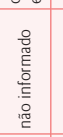 & 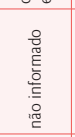 & 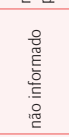 & 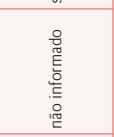 & 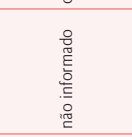 \\
\hline$\frac{\frac{0}{g}}{\frac{g}{g}}$ & \% & 尊 & 电 & : & 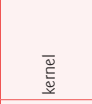 & \% & : & 禺 & 赵 & 禺 & 囟 & \% \\
\hline $\begin{array}{l}\frac{y}{0} \\
\frac{0}{20}\end{array}$ & 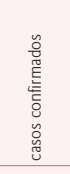 & 兽 & 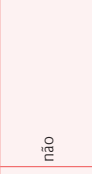 & 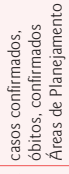 & 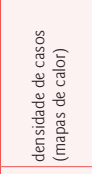 & 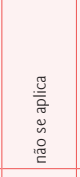 & 电 & 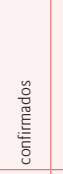 & 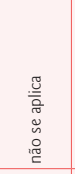 & 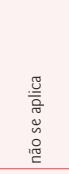 & 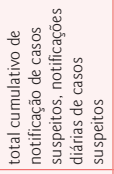 & 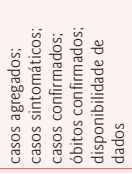 \\
\hline 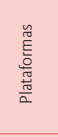 & 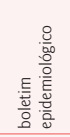 & 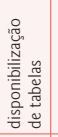 & 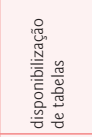 & 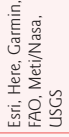 & 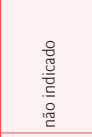 & 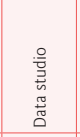 & 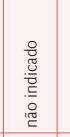 & 5 & 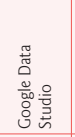 & 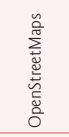 & 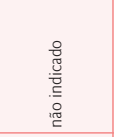 & 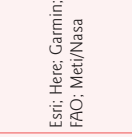 \\
\hline 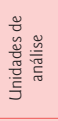 & 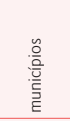 & 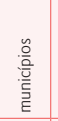 & 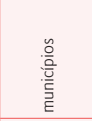 & 莺 & 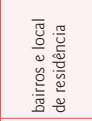 & 嘿 & 响 & 总 & 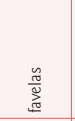 & 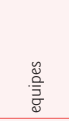 & 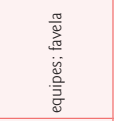 & 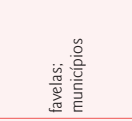 \\
\hline 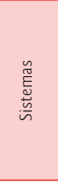 & 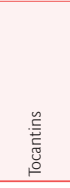 & 戀 & 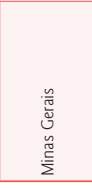 & 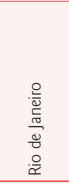 & $\begin{array}{l}\text { 胥 } \\
\text { ziñ }\end{array}$ & 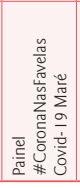 & 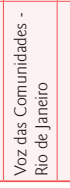 & 鹃 & 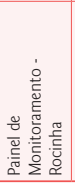 & 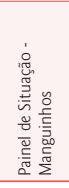 & 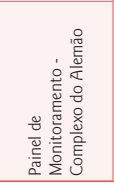 & 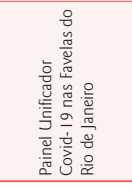 \\
\hline
\end{tabular}




\title{
0 Papel Tripartite na Divulgação de Casos e Óbitos por Covid-19 e a Atuação do Conass
}

\author{
Felipe Ferré, Nereu Henrique Mansano, Marcus Vinícius de Carvalho, \\ Fernando Campos Avendanho, Jurandi Frutuoso Silva e Núbia Cristina da Silva
}

A pandemia da Covid- I 9 explicitou fragilidades dos sistemas de informação de saúde, em especial dos dados abertos de vigilância. Ao mesmo tempo, mostrou a força da conjunção de esforços dos gestores municipais, estaduais e federais para superar obstáculos. Os gestores e a população aprenderam e vivenciaram o quanto é complexo enfrentar uma pandemia, uma vez que a forma como vivemos e nos relacionamos uns com os outros tem impactos no processo saúde-doença. Além disso, existem conflitos relativos às próprias instituições que, ao mesmo tempo, deveriam ofertar continuidade normativa às ações estratégicas, porém são sujeitas a vicissitudes, como a troca de cargos de chefia no meio do caminho, que interferem no inicialmente planejado.

Em meio ao caótico manejo da Covid-19, coube ao Conselho Nacional de Secretários de Saúde (Conass) reiterar o compromisso do Sistema Único de Saúde (SUS) com os princípios previstos na lei 8.080 de 1990 (Brasil, 1990), voltados para a "divulgação de informações quanto ao potencial dos serviços de saúde e a sua utilização pelo usuário"; a "utilização da epidemiologia para o estabelecimento de prioridades, a alocação de recursos e a orientação programática"; a "conjugação dos recursos financeiros, tecnológicos, materiais e humanos da União, dos Estados, do Distrito Federal e dos Municípios na prestação de serviços de assistência à saúde da população" e a "organização dos serviços públicos de modo a evitar duplicidade de meios para fins idênticos”. Nosso objetivo aqui é descrever o ambiente e as ferramentas para a promoção dessas ações que tiveram como esteio um conjunto de painéis, de divulgação aberta e restrita, elaborados durante a pandemia pelo Conass, em parceria com gestores dos três níveis de governo e da sociedade civil, com destaque para o Painel Conass | Covid- 19. 


\section{MÉTODO}

Revisão narrativa dos fatos acerca da notificação de casos e óbitos da Covid-19 com ênfase nas contribuições do Conselho Nacional de Secretários de Saúde (Conass) lastreadas em seu painel informativo e caracterização da capacidade de resposta estratégica à pandemia da Covid-19. A coleta ocorreu de forma não sistemática na base SciELO e em notícias de grande circulação entre fevereiro de 2020 e fevereiro de 2021 .

\section{RESULTADOS E DISCUSSÃO}

Os registros oficiais brasileiros (Brasil, 2021) foram iniciados dia 26 de fevereiro de 2020 com a notificação do primeiro caso de Covid- 19 no estado de São Paulo. No dia 22 de março de 2020, com o primeiro caso em Roraima, o vírus já havia chegado a todos os estados. O primeiro óbito foi registrado dia 17 de março de 2020 no estado de São Paulo, e Tocantins foi o último estado a registar óbito, já no mês seguinte. No dia 26 de abril de 2020, o mundo atingiu 3 milhões de casos e 206 mil óbitos (Souza et al., 2020).

Ainda em maio de 2020, apenas durante a semana epidemiológica (SE) 19, o estado do Amazonas foi o primeiro a registrar a trágica marca de II óbitos por 100 mil habitantes, numa demonstração de crise do sistema de saúde. A doença ainda não era devidamente conhecida e a demanda por equipamentos, em especial ventiladores pulmonares e equipamentos de proteção individual, e por insumos, como medicamentos para intubação, estava em vias de ser identificada e suprida. Ainda em abril de 2020, a imprensa relatou sepultamentos em cova comum devido ao limite diário dos cemitérios (Albuquerque, 2020). Até esse momento, o Brasil havia registrado mais de 230 mil casos em 58\% dos municípios e 15 mil óbitos por Covid- 19 (Cavalcante et al., 2020).

O pico do registro de óbitos por data de notificação, próximo de 10 por 100 mil habitantes em apenas uma semana, foi atingido no Pará em maio de 2020 (SE 22), no Ceará em junho de 2020 (SE 23), em Roraima em julho de 2020 (SE 27) e em agosto de 2020 no Distrito Federal (SE 34). O acompanhamento atento dos gestores e da mídia a esses eventos foi fundamental como argumento para a mobilização de recursos humanos e materiais de modo a evitar que o mesmo cenário se repetisse em todos os demais territórios, ou a mitigar eventuais danos.

A forma de manejo da pandemia durante o primeiro semestre da Covid- I 9 no Brasil foi objeto de divergências entre as casas legislativas, o Supremo Tribunal Federal e as três esferas do Poder Executivo (Cepedisa, 2020). O programa de testagem apresentou dificuldades desde o começo por deficiência de insumos, inicialmente para a própria coleta e posteriormente para outras etapas do processamento laboratorial, especialmente 
para a extração do material genético viral para os exames de RT-PCR, padrão-ouro para o diagnóstico. A despeito da subnotificação, além das questões relacionadas à desigualdade social (Magno et al., 2020), muitos casos podem ter sido registrados com testes sem especificidade adequada, com a disseminação dos chamados "testes rápidos" imunológicos, utilizados muitas vezes de forma inadequada, principalmente no início da pandemia. Consequentemente, os números brasileiros devem ser analisados com o devido cuidado.

Diante da fragilidade e fragmentação dos Sistemas de Informação em Saúde (SIS) nacionais e da falta de uma solução de registro eletrônico em saúde nacionalmente padronizada (Ferré, 202I), novas soluções precisaram ser desenvolvidas de forma emergencial para atender à demanda de monitoramento e avaliação da pandemia. Os papéis institucionais em relação à Covid- 9 não foram normatizados de forma célere em consenso tripartite e entre os três poderes, especialmente quanto ao manejo da contenção do vírus e à tipificação das medidas de restrição e definição de estabelecimentos não essenciais que deveriam fechar as portas durante o processo que se chamou de lockdown (Alves, Ramos \& Delduque, 2020). Cada ente federativo passou a lidar com a pandemia a seu modo, incluindo a relação com a mídia e redes sociais. Os entes federativos não apenas estabeleceram estratégias próprias para lidar com notícias falsas, boatos ou fake news, termo em voga em 2020 (Cantuário, 2020), mas divulgaram painéis próprios de informação da Covid-19, alguns dando ênfase ao número de recuperados. Até a data atual não há um padrão nacional no método de contabilizar casos, óbitos e recuperados; sequer data e hora para encerramento dos números diários pelos estados, restando padrões diferentes de informação para o cidadão ou pesquisador avaliar e comparar dados nacionais e locais.

Em junho de 2020, o país superou 30 mil óbitos de Covid-19, com recorde diário de I.262 mortes, cuja visibilidade pressionou as autoridades (Sandes E Vicentini, 2020). O caso de dissenso relativo aos dados da Covid-19 mais evidente ocorreu no dia 5 de junho de 2020 com a retirada, pelo governo federal, do total de casos e óbitos do sítio oficial (Machado et al., 2020; Covid-19: após..., 2020). O retrocesso nos dados abertos sobre Covid- 19 levou o Brasil a ser removido do ranking internacional de casos e óbitos por país (Coronavírus..., 2020).

Em resposta, no domingo de 7 de junho de 2020 o Conass iniciou a divulgação dos dados oficiais diários de casos e óbitos coletados pelos estados em seus respectivos municípios, com a marca de 680.456 casos e 36.15I óbitos (Rodrigues, 2020). Em menos de 24 horas, a equipe do Conass realizou em paralelo três ações voltadas para a publicação do painel: 1) Ainda na noite do dia 6 de junho de 2020, colaboradores 
especialistas na elaboração de painéis dinâmicos iniciaram o desenvolvimento da estrutura de disposição de informações com a plataforma proprietária de inteligência de negócios mantida pela empresa Tableau (Tableau Software, 2003), inicialmente na sua versão gratuita e, posteriormente, com licença cedida ao Conass em parceria com a Organização Pan-Americana da Saúde (Opas). Em menos de 24 horas, a primeira versão do painel dinâmico já contava com análises geográficas e com a automatização de indicadores de taxas de letalidade, de mortalidade e de incidência. 2) A equipe técnica do Conass iniciou a estruturação de fluxos para recebimento dos dados diários com as secretarias estaduais de Saúde (SES). Na manhã de domingo, 7, todas as SES foram mobilizadas pela Secretaria Executiva do Conass e incluíram os canais de comunicação desta entidade na rotina de envio de dados que vigorava com o Ministério da Saúde. Um banco de dados foi desenvolvido para receber os dados das SES diariamente, até às 16h. Também foi elaborado um fluxo para o acompanhamento e consolidação dos dados recebidos. 3) Ainda no início da tarde do dia do lançamento do Painel Conass | Covid-19, foi iniciada a terceira ação, que consistiu em mobilização da imprensa. Às 18 horas do dia 7 de junho de 2020, o Painel Conass | Covid- 19 foi lançado, com repercussão nas mídias nacionais e internacionais.

O movimento foi seguido pelo consórcio de imprensa que passou a postar dados coletados a partir dos sítios das SES (Veículos..., 2020). Houve relatos de elogios ao movimento, inclusive por congressistas (Zocci, 2020). No dia seguinte, o governo federal retomou a divulgação (Veja, 2020), com ampliação do painel para exploração por dados agregados no nível municipal (Novo..., 2020). Porém, ante a possibilidade de nova retirada de dados, os esforços de consolidação oficiais e extraoficiais estabelecidos foram mantidos, sobretudo para fazer frente à perspectiva negacionista (De Troi $\varepsilon$ Quintilio, 2020) ou à tentativa de minimizar os efeitos da pandemia com boatos ou desinformação (Cantuário, 2020).

A precaução quanto à manutenção da divulgação dos dados de Covid-19, para além do governo federal, contou com novo argumento no enfrentamento dos boatos de que o número de mortes estaria inflado. Entre tantos absurdos, circulou nas redes sociais o rumor de que óbitos por acidente de trânsito estariam sendo contabilizados como decorrentes de Covid- 19 (Facchini, 2020). Em parceria com a Vital Strategies e a Associação Nacional dos Registradores de Pessoas Naturais (Arpen), o Conass lançou, em 3 de agosto de 2020, o painel de excesso de mortalidade, demonstrando que houve $24 \%$ de mortes naturais a mais em relação ao período equivalente do ano anterior (Brasil teve..., 2020). Os dados sobre excesso de mortalidade baseados no registro civil devem ser ponderados (Covid-19..., 2020), especialmente quanto às informações 
relacionadas à causa de óbito. Porém, as informações do registro civil se mostraram as mais oportunas para o monitoramento de óbitos das últimas semanas, pois os dados abertos oficiais registrados no Sistema de Informação de Mortalidade (SIM) são liberados pelo Ministério da Saúde com maior atraso, após cuidadosa codificação e investigação da causa de óbito.

A informação como estratégia de combate à pandemia levou o Conass a aprimorar o sítio Covid-19, conforme solicitado pelos secretários estaduais (Mansano et al., 2020). A apresentação em janeiro de 202 I conta com três seções: "Painel geral", acerca da situação do país quanto aos indicadores taxa de letalidade, taxa de mortalidade e taxa de incidência, além do quantitativo de casos e óbitos do dia; "painel por UF", no qual é possível identificar o detalhamento dos mesmos indicadores por macrorregião de saúde; e "painel por região", onde há os cenários da Covid- 19 relativos a cada uma das cinco grandes regiões do país.

Na página inicial do Painel Conass | Covid- 9 (Figura I) constam os dados oficiais de casos e óbitos por estado e do país atualizados diariamente às 18 horas, bem como os dados consolidados por SE. A consolidação dos casos e óbitos referentes às últimas 24 horas ocorre manualmente, com a transposição de planilhas de cálculo enviadas por e-mail por cada estado. A justificativa para o processo artesanal de coleta é a desigualdade entre as tecnologias da informação em saúde disponíveis nos territórios. Apesar de alguns estados se reportarem à planilha com base em informações recuperadas dos sistemas nacionais de notificação, outros estados a consolidam manualmente junto com os municípios. Dessa forma, não é possível informar diariamente os dados oficiais integralmente de forma automatizada via consulta ao banco de dados mantido pelo sistema de informação. Ainda assim, a consolidação tem se mostrado fidedigna, pois, em processos independentes, Conass e Ministério da Saúde têm invariavelmente divulgado os mesmos números diários. 


\section{Figura I - Página inicial do Painel Conass | Covid-1 9 em 30/0 I/202 I}

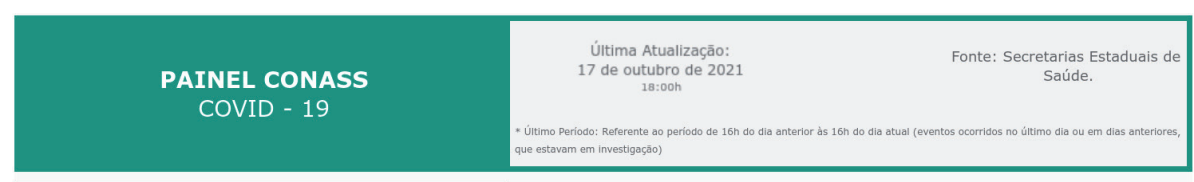

\begin{tabular}{|c|c|c|c|}
\hline $\begin{array}{l}\text { UFS com observação } \\
\text { Selecione a sigla đa UF para maiores } \\
\text { informaçōes }\end{array}$ & MS & MT & To \\
\hline
\end{tabular}

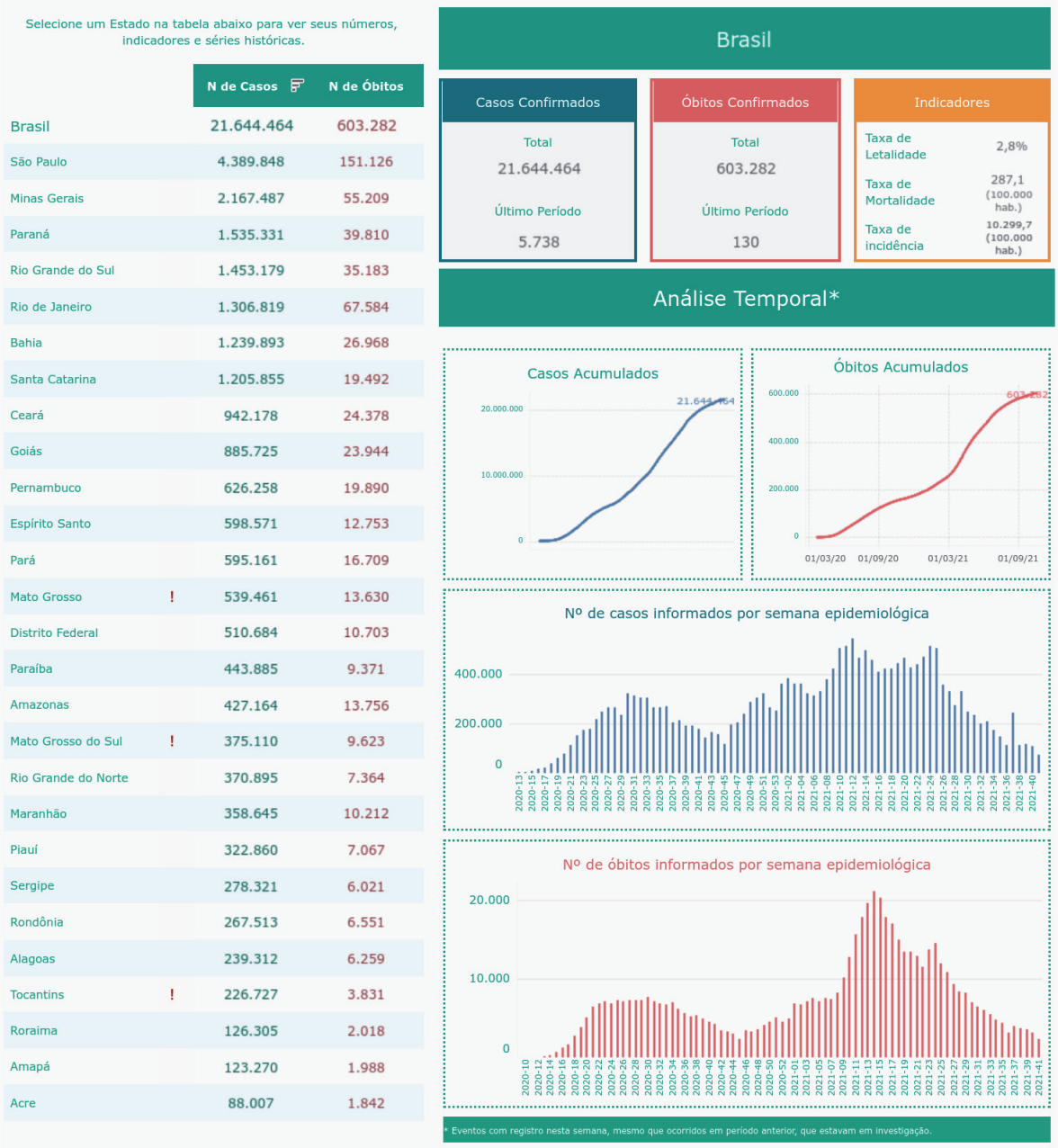

Fonte: <https://www.conass.org.br/painelconasscovid। 9/>. Acesso em: 30 jan. 2021. 
Na Figura 2 é detalhado o cenário nacional quanto aos indicadores elencados. A série temporal mostra que não houve controle da pandemia. Durante o ano de 2020, a média móvel semanal mostrou o mínimo de 18 mil casos e 340 óbitos diários. Em outras palavras, o número de óbitos no país não ficou abaixo de um terço do máximo registrado. Dessa forma, não podemos afirmar que as medidas de contenção da pandemia foram plenamente efetivadas, o que pode estar repercutindo no aumento de casos e óbitos no início de 2021.

Figura 2 - Detalhamento do painel geral quanto aos indicadores relativos a casos e óbitos por Covid- 19 no cenário nacional - Brasil, abril a dezembro de 2020

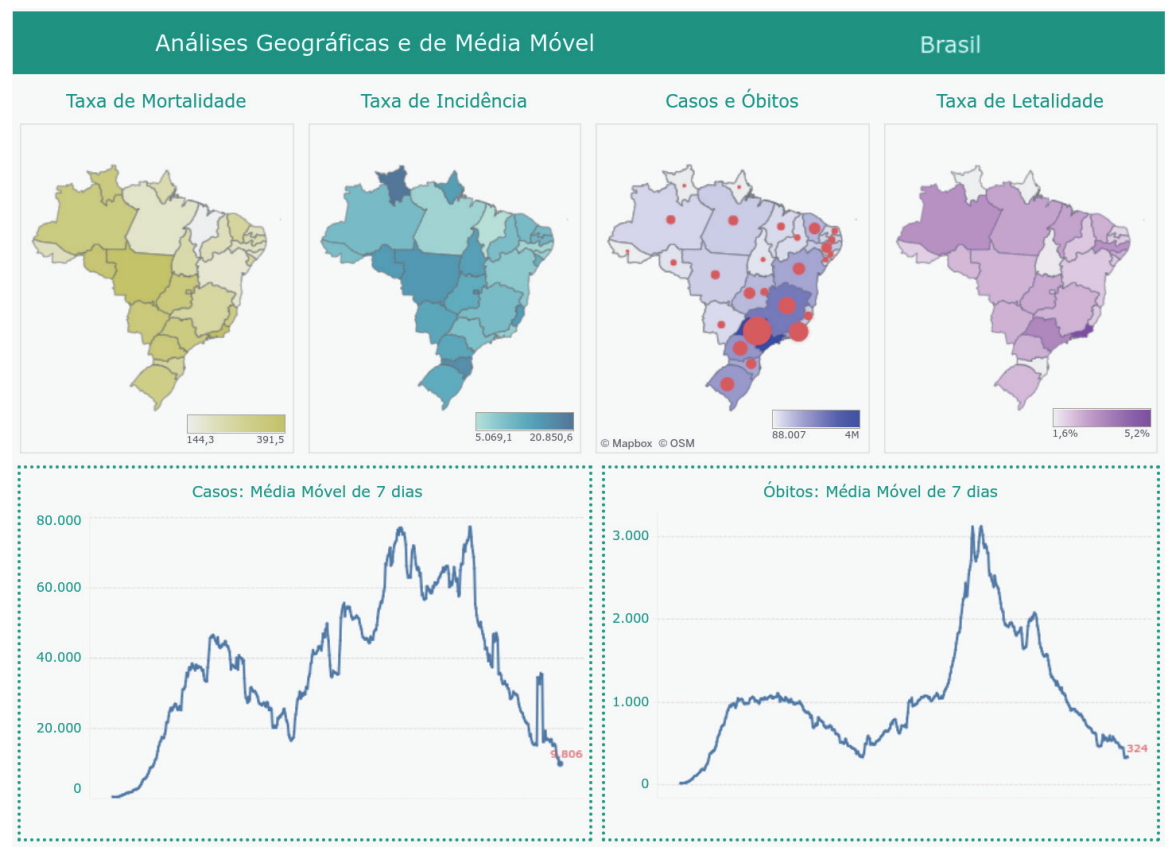

Fonte: <https://www.conass.org.br/painelconasscovid I 9/>. Acesso em: 30 jan. 2021.

Como visto na Figura 3 para Minas Gerais, em cada estado é possível observar, além das curvas epidemiológicas de casos e óbitos, os desfechos distintos para as respectivas macrorregiões de saúde, bem como compará-los com os resultados do estado. De modo geral, a doença se espalhou com maior intensidade em locais com densidade demográfica mais alta. 
Figura 3 - Detalhamento do painel por UF quanto aos indicadores relativos a casos e óbitos por Covid-19 no cenário estadual. (A) Detalhamento das macrorregiões do estado de Minas Gerais. (B) Comparativo da macrorregião Norte em relação ao estado - Brasil, abril a dezembro de 2020

Selecione uma macrorregiấo no mapa
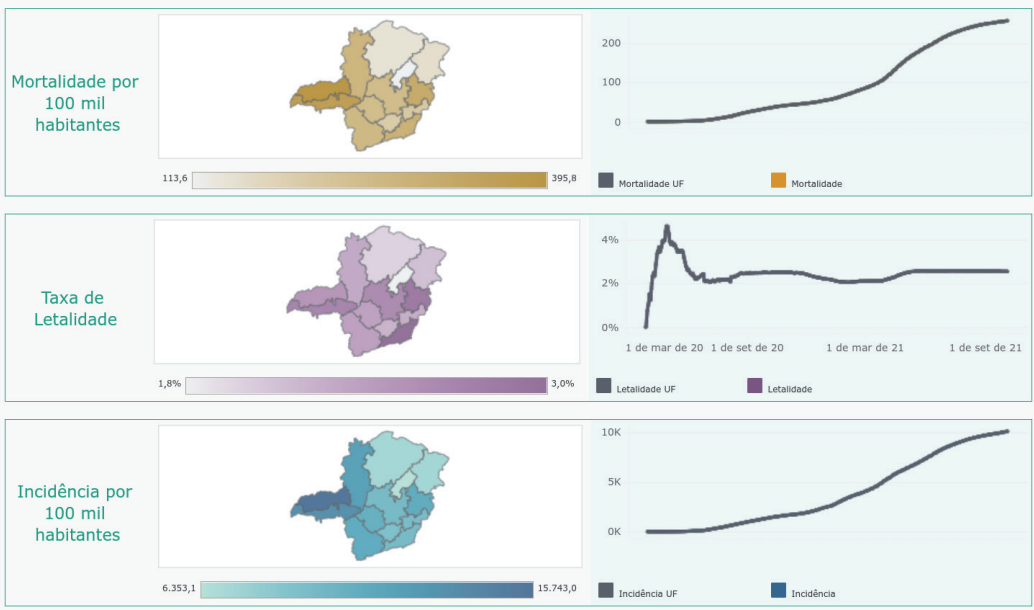

B

Selecione uma macrorregiāo no mapa
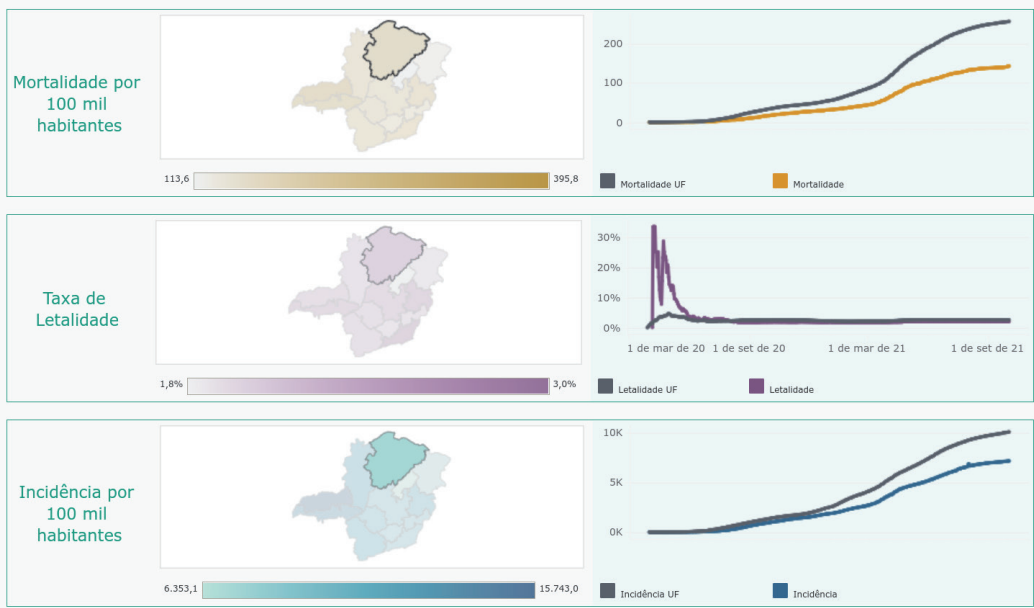

Fonte: <https://www.conass.org.br/painelconasscovid I 9/>. Acesso em: 30 jan. 2021. 
A dispersão da Covid-19 foi diferente em cada região do Brasil, país de dimensões continentais com diferentes culturas e climas. Com o painel por região (Figura 4) é possível visualizar os diferentes momentos da pandemia nas regiões ao longo do ano de 2020. A região Sudeste, com $42 \%$ da população do país, apresentou os maiores números de casos e óbitos ao longo de 2020. Da mesma forma, é notável a posição da região Norte no início da pandemia e seu recrudescimento no início de 2021 em relação ao total nacional. A região, que conta com $8 \%$ da população nacional, chegou a apresentar $23 \%$ dos casos e óbitos do Brasil. Por sua vez, a região Sul foi uma das últimas a registrar elevados índices de Covid- 19.

Figura 4 - Detalhamento do painel por região quanto aos indicadores relativos a casos e óbitos por Covid- 19 no cenário estadual - Brasil, abril a dezembro de 2020

Análise Temporal de Casos e Óbitos
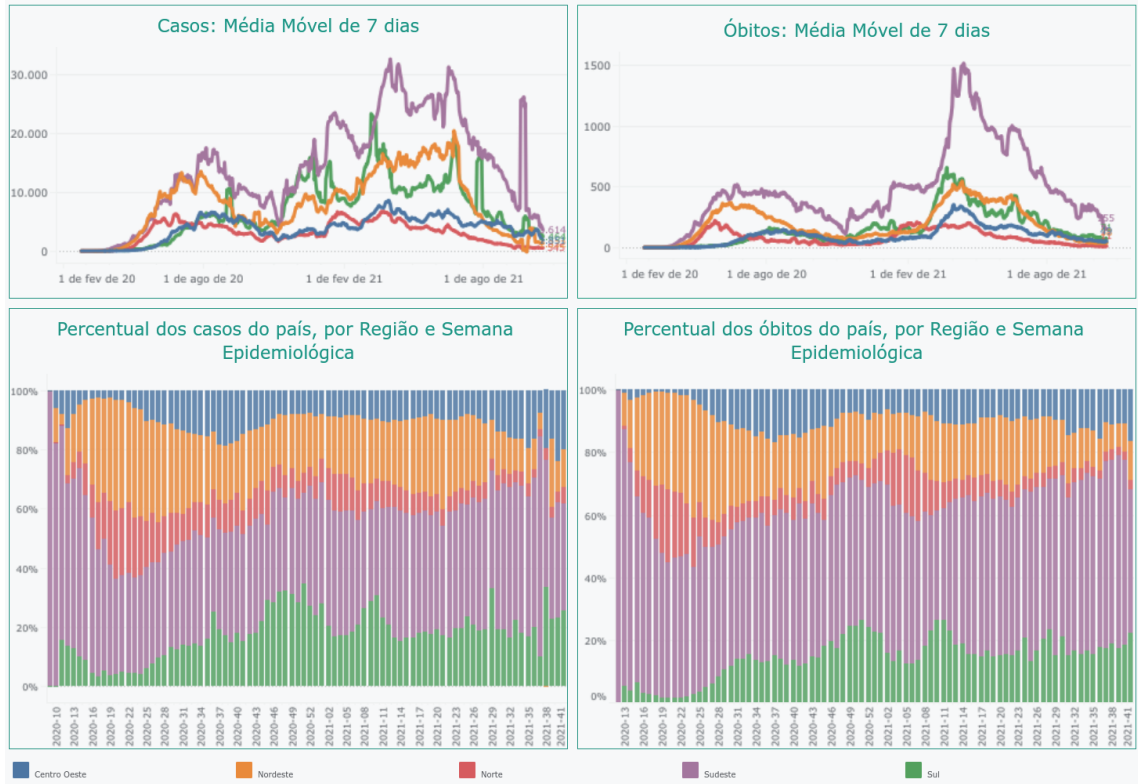

Fonte: <https://www.conass.org.br/painelconasscovid I 9/>. Acesso em: 30 jan. 202 I.

A experiência do Conass na construção do Painel Conass | Covid- 19 em 2020 deixou como legado para a gestão estadual do SUS e o sistema de saúde brasileiro o Centro de Informações Estratégicas para a Gestão Estadual do SUS (Cieges), núcleo de ciência de dados instituído na entidade em conjunto com especialistas da saúde em fevereiro de 2021 para prover respostas rápidas necessárias à tomada de decisão. 
O Cieges tem como objetivo organizar e disponibilizar informações estratégicas de forma automatizada para apoio à decisão estadual do SUS com gestão da saúde informada por evidências. O esforço de ciência de dados com inteligência artificial resultou em painéis dinâmicos que consomem dados organizados num repositório com cerca de II bilhões de registros e já disponibiliza dezenas de painéis acerca de determinantes da saúde, situação de saúde da população, estrutura e produção de serviços de saúde e financiamento do SUS.

O combate à Covid- 19 contou com esforços da assessoria técnica e de comunicação do Conass. O reconhecimento levou o sítio a ser um dos mais acessados para o monitoramento da Covid-19, com 24 milhões de acessos em 2020 (Conass, 202 I).

\section{CONCLUSÃO}

A divulgação de dados abertos é indispensável para a tomada de decisões por parte dos diferentes entes federativos. Contudo, é necessário que mais dados abertos sejam disponibilizados e analisados, visto vez que, a despeito dos esforços, a pandemia ultrapassou em 2021 a pior marca de 2020 sem que tenha sido possível predizer com antecedência o colapso do sistema de saúde, como está ocorrendo novamente no estado do Amazonas, com lotação de hospitais, transferência de usuários do SUS para outros estados e esgotamento de cemitérios (Covid- 19 no..., 2021). No estado, com os dados abertos, é possível observar que o número de óbitos semanais por 100 mil habitantes ultrapassou a marca de 22 nas SEs 3 e 4 de janeiro de 2021, o dobro do auge em 2020. Outra batalha a ser vencida é a fadiga em relação ao alerta (Backman et al., 2017; Covid-19: após..., 2020) que faz com que os altos números observados sensibilizem a sociedade civil. Por exemplo, a relativa estabilidade de óbitos semanais no Rio de Janeiro, entre 2 e 6 por 100 mil habitantes ou em São Paulo entre 2 e 4, desde março de 2020.

Os óbitos brasileiros representam 10\% do total mundial de 2.225.302, num país que não ultrapassa $3 \%$ da população global. Diariamente, inúmeros gestores municipais, estaduais e federais contabilizam casos e óbitos, e devem fazê-lo durante todo o ano de 202I. Entre a SE I e a SE 5 de 202 I, foram cerca de 40 mil casos e mil óbitos ao dia no Brasil. Com a perspectiva de sustentação de casos e óbitos em $202 \mathrm{I}$, os esforços de consolidação de dados podem permitir aos tomadores de decisão e à sociedade civil se situarem quanto à evolução da pandemia em cada território.

A vacinação massiva é a única solução atual para evitar casos graves da doença e óbitos e reduzir a velocidade de sua transmissão. Caso não se consiga expandir com celeridade $\mathrm{o}$ acesso às vacinas, a tendência, com base nos dados informados ao 
Conass até 30 de janeiro de 2021 , aponta para a marca de 400 a 500 mil óbitos até o final deste ano. Os primeiros passos para a vacinação foram dados em 18 de janeiro de 2021. Os painéis de casos e óbitos serão essenciais para acompanhar os efeitos da imunização coletiva na reversão desse quadro.

De 30 mil óbitos em junho de 2020, passamos a 230 mil óbitos acumulados no início de fevereiro de 2021. Não está distante o constrangimento que levou a enfatizar o número de curados e implicou a redundância do controle pelo Conass e consórcio da mídia. Não há pessimismo ou otimismo em dados do mundo real. A interpretação dos fatos deve compor a narrativa centrada, realista, com análise de situação que conduza à gestão pública informada por evidências. As decisões complexas devem ser tomadas com a participação dos diversos atores, em especial pela composição tripartite do SUS (Matus, 1989; Ramos \& Silva, 20 I8).

\section{REFERÊNCIAS}

AlbuQuerque, A. L. Sem espaço para enterrar as vítimas da Covid-19, Manaus empilha caixões. Folha de S.Paulo, São Paulo, 27 abr. 2020. Cotidiano. Disponível em: < https://wwwl .folha.uol.com.br/ cotidiano/2020/04/sem-espaco-para-enterrar-as-vitimas-da-covid- I9-manaus-empilha-caixoes. shtml I>. Acesso em: 31 jan. 2021 .

ALVES, S. M. C.; RAMOS, E. M. B. \& DELDUQUE, M. C. Decretação de lockdown pela via judicial: medida (des)necessária? Cadernos de Saúde Pública, 36: e00II6020, 2020. Disponível em: <www.scielosp. org/article/csp/2020.v36n6/e00II6020/>. Acesso em: 31 jan. 2021.

BACKMAN, R. et al. Clinical reminder alert fatigue in healthcare: a systematic literature review protocol using qualitative evidence. Systematic Reviews, 6(I): 255, 2017. Disponível em: <http://dx.doi. org/I0.1 I86/s13643-017-0627-z>. Acesso em: 31 jan. 2021 .

BRASIL. Lei n. 8.080, de 19 set. 1990. Dispõe sobre as condições para a promoção, proteção e recuperação da saúde, a organização e o funcionamento dos serviços correspondentes e dá outras providências. Casa Civil. Diário Oficial da União, Brasília, 1990. Disponível em: <www.planalto.gov. br/ccivil_03/Leis/L8080.htm>. Acesso em: 31 jan. 2021.

BRASIL. Coronavírus Brasil. Disponível em: <https://covid.saude.gov.br/>. Acesso em: 31 jan. 2021 .

BRASIL teve I 77 mil mortes além do esperado este ano. Estado de Minas, Belo Horizonte, 28 nov. 2020. Disponível em: <www.em.com.br/app/noticia/nacional/2020/1 I/28/interna_nacional,1215319/ brasil-teve-177-mil-mortes-alem-do-esperado-este-ano.shtml>. Acesso em: 31 jan. 2021.

CANTUÁRIO, V. A. P. "Isso é verdade?” A “infodemia” da pandemia: considerações sobre a desinformação no combate à Covid-19. Investigação Filosófica, II(2): I75-I88, 2020. Disponível em: <https:// periodicos.unifap.br/index.php/investigacaofilosofica/article/view/5934>. Acesso em: 31 jan. 202I.

CAVALCANTE, J. R. et al. Covid- I 9 no Brasil: evolução da epidemia até a semana epidemiológica 20 de 2020. Epidemiologia e Serviços de Saúde, 29(4), 2020. Disponível em: < http://dx.doi.org/l 0.5 I 23/ sl 679-497420200004000 I0>. Acesso em: 3 I jan. 202 I. 
CENTRO DE PESQUISAS E ESTUDOS SOBRE DIREITO SANITÁRIO (CEPEDISA). Boletim n. I Direitos na Pandemia: mapeamento e análises das normas jurídicas de resposta à Covid- 19 no Brasil, 8 jul. 2020. Disponível em: <http://cepedisa.org.br/wp-content/uploads/2020/07/0 I boletimcovid_PT_07.pdf>. Acesso em: 31 jan. 2021.

CONSELHO NACIONAL dOS SECRETÁRIOS DE SAúdE (CONASS). Protagonismo dos estados no enfrentamento da pandemia aumenta a procura por informações e dados no portal do Conass. Disponível em: <www.conass.org.br/protagonismo-dos-estados-no-enfrentamento-da-pandemiaaumenta-a-procura-por-informacoes-e-dados-no-portal-do-conass/>. Acesso em: 8 fev. 2021.

CORONAVÍRUS: a polêmica sobre dados de Covid no Brasil que levou universidade a tirar país de ranking. BBC, São Paulo, 6 jun. 2020. Disponível em: <www.bbc.com/portuguese/5295I772>. Acesso em: 31 jan. 2021 .

COVID-19. Excesso de informação ajuda à fadiga pandémica, alerta Graça Freitas. RTP, Lisboa, I3 nov. 2020. Disponível em: <www.rtp.pt/noticias/pais/Covid-19-excesso-de-informacao-ajuda-a-fadigapandemica-alerta-graca-freitas_nI275069>. Acesso em: 31 jan. 2021 .

COVID- I 9 NO Amazonas: novo surto lota hospitais, cemitérios e fecha comércio mais uma vez. GI, Manaus, 6 jan. 2021. Disponível em: <https://gl.globo.com/am/amazonas/noticia/2021/01/06/ covid-no-amazonas-novo-surto-lota-hospitais-cemiterios-e-fecha-comercio-mais-uma-vez. ghtml>. Acesso em: 31 jan. 2021.

COVID-19: APÓS apagão de dados, governo recua e retoma boletins às 18h. Veja, São Paulo, 8 jun. 2020. Disponível em: <https://veja.abril.com.br/saude/Covid-19-apos-apagao-de-dados-governorecua-e-retoma-boletins-as- I8h/>. Acesso em: 31 jan. 2021.

DE TROI, M. \& QUINTILIO, W. Coronavírus: lições anti-negacionistas e o futuro do planeta, 3 I mar. 2020. Disponível em: <https://blog.scielo.org/blog/2020/03/31/coronavirus-licoes-antinegacionistas-e-o-futuro-do-planeta/>. Acesso em: 31 jan. 2021.

FACCHINI, T. "Ninguém morre mais de acidente em Brusque? É tudo Covid-I9!", confira os dados. Disponível em: <https://brusque.portaldacidade.com/noticias/policial/ninguem-morre-mais-deacidente-em-brusque-e-tudo-Covid- I 9-confira-os-dados-46I3>. Acesso em: 31 jan. 202 I.

FERRÉ, F. Infoestrutura para apoio à decisão estratégica no SUS. In: SANTOS, A. O. \& LOPES, L. T. (Org.). Reflexões e Futuro. v. I6. Brasília: Conass, 202 I. (Col. Covid- I9)

MACHADO, R. et al. Governo deixa de informar total de mortes e casos de Covid- I9; Bolsonaro diz que é melhor para o Brasil. Folha de S.Paulo, São Paulo, 6 jun. 2020. Equilíbrio e Saúde. Disponível em: <www I.folha.uol.com.br/equilibrioesaude/2020/06/governo-deixa-de-informar-total-de-mortese-casos-de-Covid- I9-bolsonaro-diz-que-e-melhor-para-o-brasil.shtml>. Acesso em: 3 I jan. 202 I.

MAGNO, L. et al. Challenges and proposals for scaling up Covid- 9 testing and diagnosis in Brazil. Ciência E Saúde Coletiva, 25(9): 3.355-3.364, 2020. Disponível em: < http://dx.doi.org/I 0. I 590/I 4 I 3 81232020259.17812020>. Acesso em: 31 jan. 2021.

MANSANO, N. et al. Painel Covid- 19. Disponível em: <www.conass.org.br/painelconasscovid I 9/>. Acesso em: 31 jan. 2021 .

MATUS, C. Adeus Senhor Presidente: planejamento, antiplanejamento e governo. Recife: Litteris, 1989. 
NOVO painel da Covid- I 9 do Ministério da Saúde entra no ar em versão beta. GI, Rio de Janeiro, I2 jun. 2020. Disponível em: <https://agenciabrasil.ebc.com.br/saude/noticia/2020-06/conselho-desecretarios-estaduais-lanca-painel-com-numeros-da-covid- I9>. Acesso em: 3I jan. 202 Ia.

RAMOS, M. C. \& SILVA, E. N. Como usar a abordagem da Política Informada por Evidência na saúde pública? Saúde em Debate, 42: 296-306, 2018. Disponível em: <www.scielosp.org/article/sdeb/20 I8. v42n I |6/296-306/pt/>. Acesso em: 18 jan. 2020.

RODRIGUES, N. Conselho de Secretários Estaduais lança painel com números da Covid-19. Agência Brasil, Brasília, 7 jun. 2020. Disponível em: <https://agenciabrasil.ebc.com.br/saude/ noticia/2020-06/conselho-de-secretarios-estaduais-lanca-painel-com-numeros-da-covid- I9>. Acesso em: 31 jan. 2021.

SANDES, A. E VICENTINI, R. Brasil passa de 30 mil mortos após aumento recorde em 24 h: 1.262 óbitos. UOL, São Paulo, 2 jun. 2020. Disponível em: <https://noticias.uol.com.br/saude/ultimasnoticias/redacao/2020/06/02/coronavirus-covid I 9-brasil-casos-mortes-2-junho.htm>. Acesso em: 31 jan. 2021.

SOUZA, C. D. F. et al. Spatiotemporal evolution of case fatality rates of Covid- 19 in Brazil, 2020. Jornal Brasileiro de Pneumologia: Publicação Oficial da Sociedade Brasileira de Pneumologia e Tisilogia, 46(4): e20200208, 2020. Disponível em: <http://dx.doi.org/l0.36416/1806-3756/e20200208>. Acesso em: 31 jan. 2021 .

TABLEAU SOFTWARE. Business Intelligence and Analytics Software. Disponível em: <www.tableau. com/>. Acesso em: 31 jan. 2021 .

VEÍCULOS de comunicação formam parceria para dar transparência a dados de Covid- I 9. G I, O Globo, Extra, Estadão, Folha e UOL, 8 jun. 2020. Disponível em: < https://g I.globo.com/politica/noticia/2020/06/08/ veiculos-de-comunicacao-formam-parceria-para-dar-transparencia-a-dados-de-Covid-1 9.ghtml >. Acesso em: 31 jan. $202 \mathrm{lb}$.

ZOCCI, P. Congressistas e entidades elogiam consórcio de imprensa para coletar dados da Covid-19. Folha de S.Paulo, São Paulo, 8 jun. 2020. Equilíbrio e Saúde. Disponível em: <wwwl.folha.uol.com. br/equilibrioesaude/2020/06/congressistas-e-entidades-elogiam-consorcio-de-imprensa-paracoletar-dados-da-Covid-1 9.shtml>. Acesso em: 31 jan. 202 I. 



\title{
MonitoraCovid-19
}

\section{informação e disseminação de indicadores em uma pesquisa multidisciplinar}

\author{
Raphael de Freitas Saldanha, Diego Ricardo Xavier, \\ Mônica de Avelar Figueiredo Mafra Magalhães, \\ Paulo Roberto Borges de Souza Junior, \\ Marcel de Moraes Pedroso e Christovam Barcellos
}

$\mathrm{O}$ MonitoraCovid - I 9 foi construído no Instituto de Comunicação e Informação Científica e Tecnológica da Fundação Oswaldo Cruz (Icict/Fiocruz), que se dedica à criação e manutenção de observatórios e sistemas de informática para doenças e agravos, com recortes para informação científica e tecnológica e também para comunicação em saúde. O processo de sua construção, implementação e manutenção será aqui apresentado com ênfase nas questões institucionais e tecnológicas envolvidas.

Ainda que distantes, em outros continentes, os primeiros casos e óbitos de Covid- 19 naturalmente captavam a atenção de alguns profissionais do Laboratório de Informação em Saúde (LIS/Icict), e discussões sobre a pandemia surgiam nas conversas e e-mails, principalmente sobre estimativas, taxas e outros cálculos importantes para a doença. Em seguida, começamos a nos questionar sobre a situação brasileira. Na época, as questões eram "Quando a pandemia irá chegar aqui?”, "Como o governo está se preparando?”, "O que deve ser feito?”.

Após 26 de fevereiro de 2020, com os primeiros casos autóctones de Covid- 9 no Brasil, alguns cálculos começaram a ser feitos para a realidade brasileira. Acompanhamos pela imprensa os números que timidamente começaram a ser divulgados. Nos meses de fevereiro e março, entrevistas coletivas do Ministério da Saúde (MS) eram diariamente realizadas e transmitidas por praticamente todas as emissoras de televisão. Conforme os números aumentavam, a discussão entre alguns pesquisadores, tecnologistas e bolsistas ficava mais intensa.

Nessa época, o MS não disponibilizava um repositório de dados sobre casos e óbitos aberto para o público. Algumas iniciativas pontuais para registrar os números apresentados nas coletivas começaram a surgir, sendo divulgadas na internet em grupos 
de conversa de jornalistas e cientistas de dados. Podem-se mencionar o dataset publicado na plataforma Kaggle (Fontes, 2020) e os dados publicados no repositório do GitHub (Cota, 2020) como algumas das primeiras fontes de dados estruturados e atualizados regularmente sobre a pandemia de Covid- 19 no Brasil.

Com a disponibilidade de dados internacionais, como os do repositório do European Centre for Disease Prevention and Control (ECDC), e de dados nacionais por unidade da federação (UF), surgiu no Icict a primeira iniciativa formal de acompanhar os dados da pandemia de Covid- 19.

Em todo o mundo, com base em alguns indicadores ou utilizando modelos estatísticos e matemáticos, foram criados diversos painéis de indicadores visando ao monitoramento e previsão de cenários em diversas escalas, da local à global (cf. cap. I 2 desta coletânea). O sistema MonitoraCovid I9, no entanto, adquiriu um caminho próprio, com o envolvimento de grupos de pesquisa e desenvolvedores de tecnologias de informação, caracterizando-se pela multiplicidade de indicadores e fontes de informação utilizadas e por seu uso permanente por gestores e sociedade civil. O desenvolvimento desse sistema, os desafios institucionais e tecnológicos enfrentados e os seus produtos derivados são o objeto deste capítulo.

\section{A CONSTITUIÇÃO DO PROJETO E SEU DESENVOLVIMENTO INICIAL}

Em março de 2020, com o avanço da pandemia de Covid- 9 no Brasil, o trabalho presencial na Fiocruz começou a ser flexibilizado. As salas e laboratórios passaram a ficar gradativamente mais vazias, com eventos, reuniões e encontros postergados. Após algumas semanas de adequação ao novo regime de trabalho, a condução dos projetos e pesquisas em andamento foi reorganizada. Novas datas e prazos foram acordados com instituições parceiras, que invariavelmente também se encontravam na mesma situação. Reuniões virtuais periódicas começaram a ser agendadas, o fluxo de e-mails aumentou e grupos em aplicativos de conversa se multiplicaram enquanto novas diretivas e planos de contingência eram publicados e atualizados pela Fiocruz e pelo lcict.

A missão do Icict se traduz em ações integradas de pesquisa e ensino; comunicação e informação; e gestão e desenvolvimento institucional, alinhadas a quatro eixos temáticos: Desafios do SUS; Ciência e Tecnologia, Saúde e Sociedade; Inovação na Gestão; e Saúde, Ambiente e Sustentabilidade. O objetivo comum desses eixos é fortalecer o SUS e promover melhores condições de vida e saúde da população. O instituto atua no campo da informação e comunicação em saúde, área interdis- 
ciplinar do conhecimento que por sua ampla abrangência gera, ao mesmo tempo, desafios e oportunidades (Icict/Fiocruz, 2020).

O LIS do Icict desenvolve e mantém diversos observatórios e sistemas dedicados a monitorar a saúde da população brasileira e de outros países conveniados, acumulando larga experiência na área. Em colaboração com o MS e com o Instituto Brasileiro de Geografia e Estatística (IBGE), o LIS é responsável pelo aprimoramento do Sistema de Informação sobre Mortalidade, Sistema de Monitoramento da Aids (MonitorAids) e pelo planejamento e desenvolvimento da Pesquisa Nacional de Saúde do IBGE (PNS). O LIS desenvolve sistemas de indicadores que foram criados e são ofertados publicamente com foco no acesso e uso de serviços de saúde pela população brasileira (Proadess), população de idosos (Sisap), qualidade da água e saúde (Água Brasil), monitoramento de clima e saúde (Observatório de Clima e Saúde) e acompanhamento de indicadores de mortalidade infantil (Monitorimi). Esses sistemas dispõem de informações que servem como subsídios para gestores e tomadores de decisão, e também buscam apresentar as informações em linguagem acessível à comunidade acadêmica e ao cidadão usuário do Sistema Único de Saúde (SUS). O LIS abriga o Núcleo de Geoprocessamento, voltado para a produção, adequação e atualização de dados e análises espaciais que relacionam dados socioeconômicos, de saúde e ambiente. Seus pesquisadores, tecnologistas e bolsistas estão rotineiramente envolvidos na construção e/ou manutenção de algum desses sistemas, o que permitiu a acumulação de conhecimentos e técnicas que cobrem diversos aspectos da implementação de observatórios. Nesse contexto surgiu o projeto MonitoraCovid- 19.

\section{DESENVOLVIMENTO TECNOLÓGICO}

Em meados de março de 2020 foi criada uma planilha no software Excel. Com dados do ECDC, foram produzidos alguns gráficos de casos e óbitos e cálculos de fatores de crescimento comparativos entre países.

O projeto nasceu em uma planilha feita para atender à demanda por antevisão de cenários sobre a evolução da pandemia nos países e sua chegada no Brasil. Contudo, a atualização da planilha com dados novos e seu incremento com mais funções se mostrou insustentável. A cada dia entravam novos países na lista, as fontes de dados mudavam seus padrões repentinamente, os dados precisavam ser baixados manualmente, convertidos para outro formato e inseridos na planilha manualmente, e as fórmulas precisavam ser atualizadas para a entrada de novas datas. Em função dessa dinâmica, o editor de planilhas estava em seu limite. 


\section{Figura I - Planilha de cálculos}

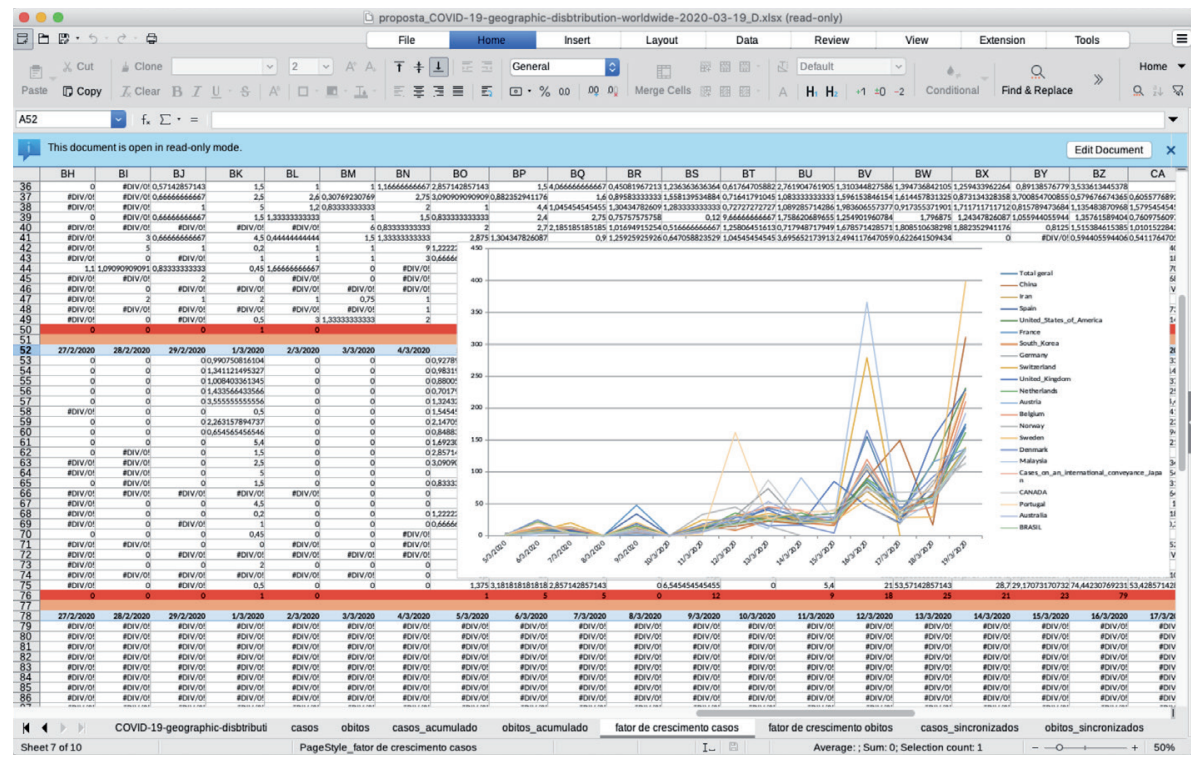

Nesse momento, percebemos que a quantidade de dados aumentava de forma acelerada e que esta seria a tônica da pandemia. O que era só uma curiosidade sobre o processo epidêmico foi se transformando em necessidade de contribuir no enfrentamento do problema de saúde pública. Percebemos nessa época que a pandemia produziria uma grave crise de saúde pública, mas nem nossas piores previsões apontavam para o cenário que se desenharia.

Surgiu a ideia de reproduzir todo esse processo manual de maneira mais automatizada. Um programa que conseguisse baixar os dados da internet, criar uma base única de casos e óbitos por Covid- 19 para países e UFs, produzir gráficos e fazer cálculos de forma automática, conforme novos dados fossem disponibilizados. Nesse momento surge o conceito fundamental do MonitoraCovid-19. Passamos, então, a procurar uma ferramenta mais flexível e escalável para a enxurrada de dados e ideias sobre o que fazer com esses dados. O pacote estatístico R nos possibilitou realizar a importação de diversos tipos de dados com mais facilidade e criar um aplicativo on-line.

Uma das primeiras versões do sistema, ainda sem o nome, apresentava apenas seis abas, conforme a Figura 2, de 23 de março de 2020. 
Figura 2 - Imagem de uma das primeiras versões do MonitoraCovid- 19

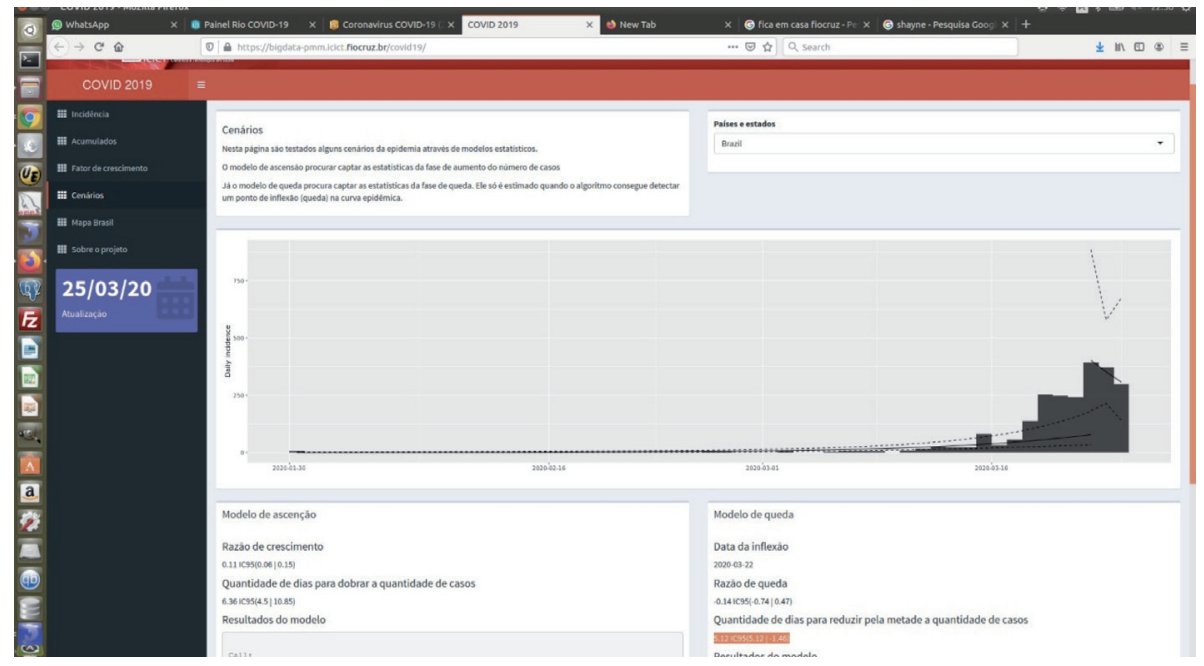

De março ao final de novembro de 2020, as atualizações das bases de dados eram feitas manualmente. Durante 253 dias, os dados foram baixados de suas fontes de forma manual, organizados e padronizados diariamente, e passaram a alimentar a aplicação web.

Não fazíamos ideia do quão pesada seria essa rotina de atualização. Ela surgiu ingênua, da nossa intenção de ver os dados novos nos gráficos que estávamos criando. Conforme mais pessoas se interessavam por nossos gráficos, ainda dentro do LIS, crescia em nós o senso de dever: manter o projeto atualizado e funcionando, todos os dias.

Apenas em dezembro de 2020 uma rotina completamente automática de atualização foi colocada a serviço. Essa etapa será melhor descrita adiante.

\section{DATA DRIVEN ANALYSIS}

Ao escrever sobre o projeto, é tentador afirmar que ele foi o fruto esperado de um extenso e detalhado planejamento, no qual tudo foi pensado e antevisto, e que cada aba e conteúdo foi planejado para ser daquele jeito, desde o começo. Mas seria desonesto. O projeto nasceu sem ser um projeto, ele era um teste, um tubo de ensaio, e hoje, mesmo sendo uma plataforma estável e confiável, continua sendo um laboratório para explorar possibilidades de novas análises e dados. 
O método cartesiano do planejamento, com objetivos, métodos e resultados, tem, obviamente, seu valor. Mas neste caso, invertemos de alguma maneira essa sequência. Não ter uma ideia formalizada do que queríamos nos possibilitou maior liberdade e criatividade para explorar diversas possibilidades de análise data driven (Provost E Fawcett, 2013). Gastamos obscenas quantidades de tempo em gráficos que não publicamos, em reuniões longas sobre temas que não abordamos.

$\mathrm{Na}$ medida em que o projeto avançava, ainda que de forma discreta, precisávamos de um nome para registrar um domínio na internet e podermos nos referir a ele de forma mais precisa. Após algumas sugestões, decidimos por MonitoraCovid- 19.

\section{DIVERSIDADE DE FONTES DE DADOS}

O projeto apoia-se atualmente em mais de dez fontes de dados diferentes, que contemplam desde o número de casos e óbitos de Covid- 19 até variáveis ligadas direta ou indiretamente à doença, como por exemplo mobilidade urbana, população em risco e medidas legislativas.

Atualmente, utilizamos os dados disponibilizados diariamente pelo John Hopkins Coronavirus Resource Center sobre casos e óbitos para os países; dados do MS para casos e óbitos no Brasil, UFs e municípios; InfoGripe para dados de síndrome respiratória aguda grave (Srag); dados do Facebook e da Universidade de Maryland para pesquisa de sintomas; dados de congestionamentos de trânsito da plataforma Waze disponibilizados pelo IDB Coronavirus Impact Dashboard; dados de mobilidade urbana disponibilizados pelo Google; dados de utilização de transporte público disponibilizados pela plataforma Waze (2020); e metadados de legislações municipais, estaduais e federais sobre Covid- 19 disponibilizados pelo site Leis Municipais.

Algumas intercorrências aconteceram, principalmente devido a dificuldades de acesso a dados de casos e óbitos de Covid-19 para as UFs e municípios brasileiros. No início da pandemia (fevereiro e março de 2020), o MS informava a população sobre o número de casos e óbitos exclusivamente por meio de coletivas de imprensa. O MS disponibilizou os dados de casos e óbitos em pelo menos sete sistemas diferentes até o momento, apresentados na Figura 3. 
Figura 3 - Telas de diferentes sistemas de informação de casos e óbitos de Covid- 19 do Ministério da Saúde
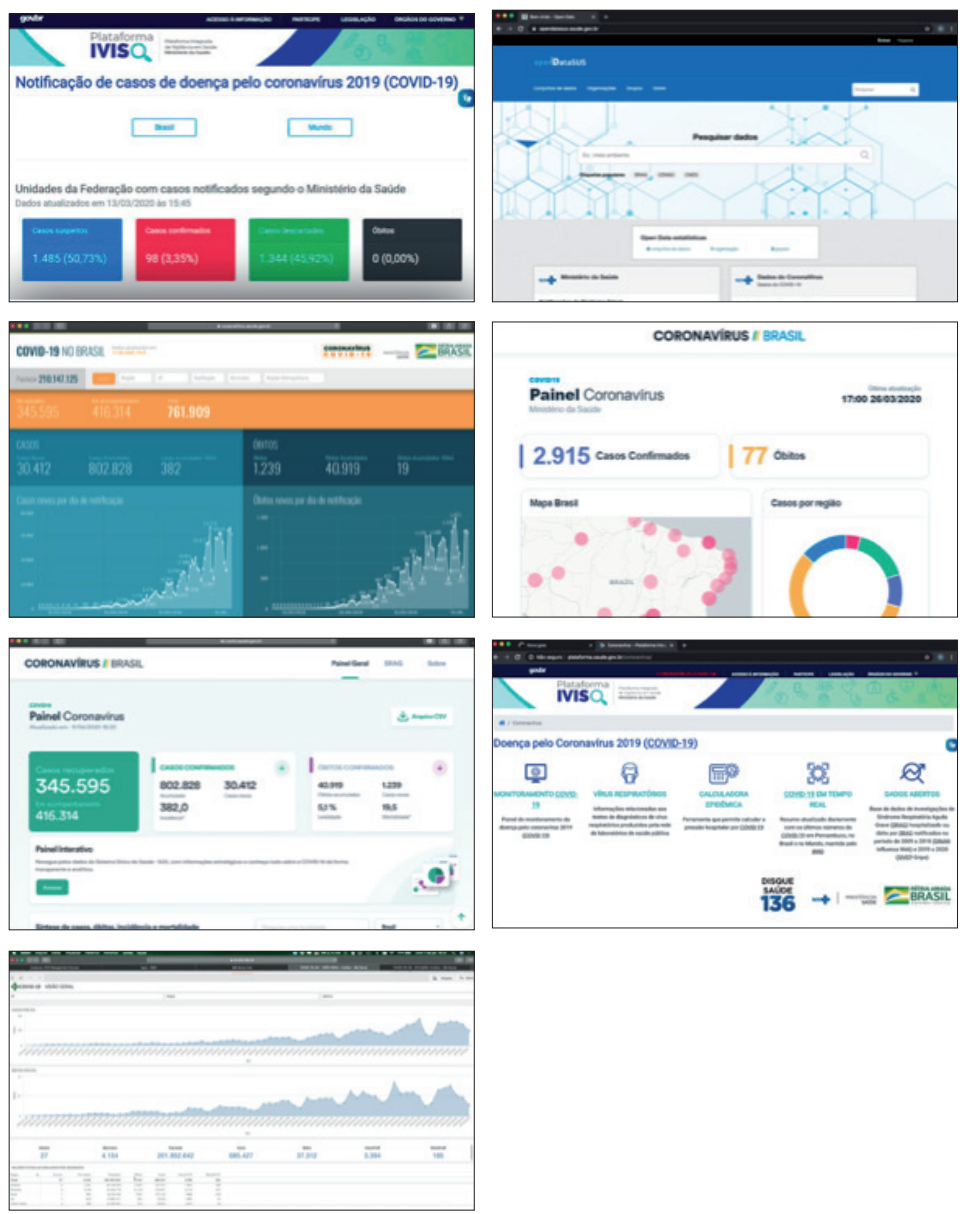

Esses sistemas foram apresentados seguidamente pelo MS, muitas vezes mantendo dois ou três deles em funcionamento e, algumas vezes, com dados divergentes. Embora alguns sistemas ou versões permitissem o download de dados, em vários momentos era oficialmente impossível baixar os dados estruturados oficiais de casos e óbitos por Covid- 19 a partir do MS.

Essas transições entre sistemas e constantes dificuldades em realizar o download diário de dados dificultavam imensamente o processo de atualização da plataforma. Basicamente, a cada dia podia-se esperar algo diferente, fosse na oferta de dados, fosse 
até mesmo variações no formato, extensão, horário de disponibilização dos dados e variáveis constantes nos arquivos. Isso exigia grande esforço da equipe para manter os dados diários atualizados.

Como não havia um repositório oficial de dados históricos da epidemia no Brasil, dependíamos de projetos e iniciativas que os coletavam diariamente, durante as coletivas, e disponibilizavam os dados históricos estruturados de forma on-line.

Em 3 de junho de 2020, data em que o painel Coronavírus Brasil mantido pelo MS foi parcialmente descontinuado, ocorreu o chamado "apagão de dados". Nessa data, regredimos quatro meses em termos de transparência de dados oficiais e passamos a depender diretamente de projetos e iniciativas privadas para manter MonitoraCovid com dados atualizados. Passamos, então, a utilizar diariamente os dados disponibilizados pelo projeto Brasil.IO.

Nos dias seguintes ao apagão, chegamos em um único dia (7 de junho de 2020) a até I 1.565 usuários que procuravam dados atualizados e confiáveis sobre Covid-1 9 no Brasil.

O projeto Brasil.IO é uma iniciativa de código aberto liderada pelo cidadão Álvaro Justen, reconhecido desenvolvedor nas comunidades de software livre e jornalismo de dados brasileiros. Contando com o trabalho voluntário de dezenas de pessoas, o projeto diariamente acessa os painéis, planilhas, postagens em redes sociais e outras mídias disponibilizadas pelas secretarias estaduais de Saúde para reunir os dados de casos e óbitos de Covid- 19 no Brasil, para UFs e municípios.

Como contrapartida institucional e reconhecimento do serviço essencial prestado, o MonitoraCovid- 9 procurou direcionar parte de seu financiamento e recursos para o projeto Brasil.IO por meio de doações.

De 3 de junho até I de dezembro de 2020, utilizamos diariamente os dados sobre Covid-19 disponibilizados pelo Brasil.IO. A partir de dezembro, notada maior estabilidade e qualidade dos dados disponibilizados pelo MS, voltamos a utilizá-los como fonte primária de dados de casos e óbitos por Covid- 19 no Brasil. Essa estabilidade foi interrompida pontualmente no dia 4 de novembro de 2020 por um ataque hacker aos servidores do departamento de informática do Sistema Único de Saúde, o Datasus. A disponibilização de dados de Covid- 19 pelo MS foi parcialmente interrompida nessa data, mas plenamente retomada apenas alguns dias depois. 


\section{GERENCIAMENTO DO PROJETO}

Com o início do trabalho remoto, os pesquisadores, tecnologistas e bolsistas do LIS testaram algumas ferramentas de interação: além do e-mail, passamos a usar plataformas de reuniões on-line e, principalmente, grupos de conversa no aplicativo WhatsApp. Além de um grande grupo para interação de todos no laboratório e outro, mais específico para o Núcleo de Geoprocessamento do LIS, criamos alguns grupos para o gerenciamento específico do MonitoraCovid- 19. A participação nesses grupos seguiu uma premissa básica: será incluído no grupo quem se dispuser a contribuir, direta e ativamente, na evolução do projeto. Naturalmente, diversas pessoas apoiam o projeto e suas iniciativas, mas a inclusão de todos seria contraprodutiva. Seguimos com a lógica de need to know basis.

Por intermédio desses grupos, conseguimos discutir os assuntos e tomar decisões de forma efetiva, diretamente com os envolvidos no projeto. Essa estrutura colaborativa de gestão e atuação no projeto é interinstitucional, contando com a colaboração de vários técnicos e pesquisadores, dentro do Icict e de outros institutos da Fiocruz.

Observamos que, dentro do Icict, com algumas exceções, poucos pesquisadores puderam colaborar diretamente no desenvolvimento contínuo do projeto. Apesar de enviarem sugestões e pedidos de dados em alguns momentos, outras demandas parecem ter limitado a participação de mais profissionais no projeto. Fora do Icict, por sua vez, conseguimos uma colaboração interessante com um pesquisador da Escola Politécnica de Saúde Joaquim Venâncio, que resultou em uma nota técnica publicada e em artigos submetidos a periódicos científicos. Em situações pontuais, no entanto, quando solicitados os pesquisadores com expertise em determinados temas se prontificaram a colaborar. Um exemplo de sucesso foi a parceria entre os pesquisadores para a elaboração da nota técnica sobre a volta às aulas, na qual foi estimada a população com fatores de risco e idosa que convive na mesma habitação com pessoas em idade escolar.

\section{CONSTRUINDO PONTES INTERINSTITUCIONAIS}

Ao longo do desenvolvimento do projeto, procuramos agregar novas fontes de dados e análises e, assim, conseguimos estabelecer algumas parcerias, dentro da própria Fiocruz e com outras instituições e empresas.

Na Fiocruz, estreitamos laços com a equipe do Projeto InfoGripe, responsável pela modelagem e monitoramento de dados de Srag no Brasil. Já conhecíamos parte da equipe de outros projetos e eventos institucionais, mas essa parceria se estabeleceu através de canais bem informais, como mensagens trocadas por meio do Twitter e do WhatsApp. 
Com a rotina de atualização de dados, passamos a conversar mais intensamente, dirimir dúvidas sobre os dados de Srag que divulgamos, indicar dados e eventos e propor colaborações entre os projetos.

Nessa ocasião, vários grupos que estudavam a epidemiologia e padrões da Covid- 19 se reuniram para discutir os dados e possibilidades de análise. Capitaneado pela equipe do InfoGripe, o webinar "O Panorama da Covid-19 no Rio de Janeiro e Brasil: onde estamos e para onde vamos?" possibilitou o intercâmbio de informações e alternativas de análise e estudos compartilhados entre diferentes iniciativas.

Figura 4 - Peça de divulgação do evento "O Panorama da Covid- 9 no Rio de Janeiro e Brasil: onde estamos e para onde vamos?”

\section{WEBINAR}

\section{O Panorama da Covid-19 no Rio de Janeiro e Brasil Onde estamos e para onde vamos?}

\section{Quinta-feira, 10 de setembro, das $19 \mathrm{~h}$ às $20 \mathrm{~h} 30$}

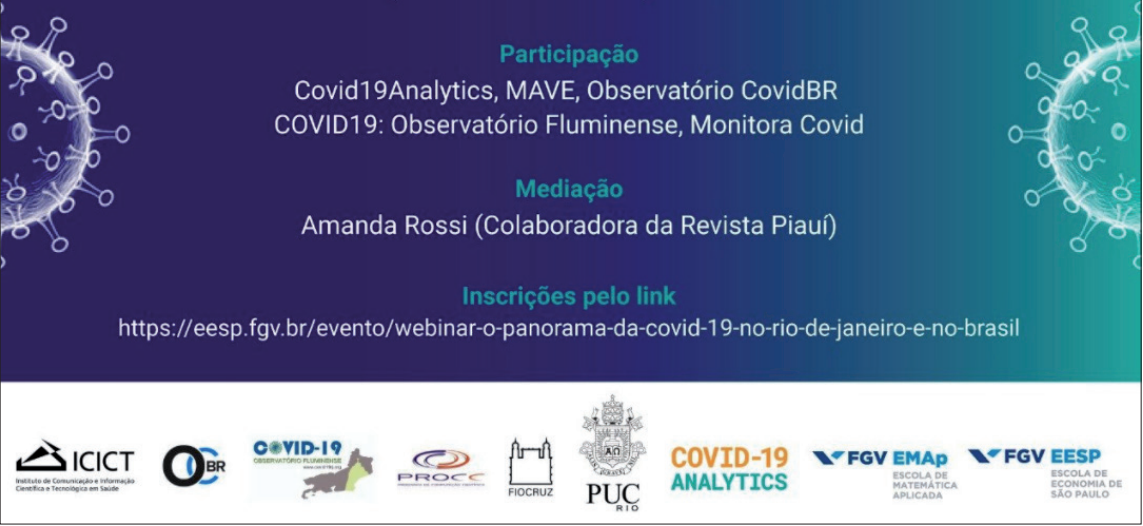

O MonitoraCovid- I 9 também foi apresentado em alguns outros eventos. Podem-se destacar o de 10 de junho, realizado pelo Programa de Pós-Graduação em Informação e Comunicação em Saúde/lcict, intitulado "Acesso Aberto a Dados de Saúde na Perspectiva da Pandemia”, o de 19 de junho de 2020 organizado pelo Centro de Estudos do Icict, intitulado "Informação em Saúde: importância e desafios no enfrentamento da pandemia”, e o de 4 de agosto de 2020, organizado pelo Fórum de Reportagem sobre a Crise Global em Saúde e intitulado "Como usar o MonitoraCovid- 19, Sistema da Fiocruz que Agrupa Dados da Pandemia”. 
Externamente, conseguimos parceria direta com empresas para o fornecimento de dados, como a Moovit, que fornece dados sobre circulação de transporte coletivo nas capitais e regiões metropolitanas. A aplicação avalia tendências globais de transporte público e combina pesquisas de opinião com dados remotos para construir um retrato de como as pessoas transitam por suas cidades. No período epidêmico da Covid-19, a empresa criou o indicador de porcentagem de redução no uso de transporte público em comparação à média anterior ao período da pandemia.

Usamos, também, dados de acesso público do Google que apontam indicadores de mobilidade da população com dados agregados e anônimos usados em produtos como o Google Maps. Os indicadores apontam tendências de deslocamento ao longo do tempo por região e em diferentes categorias de locais, como varejo e lazer, mercados e farmácias, parques, estações de transporte público, locais de trabalho e áreas residenciais.

Também incluímos dados do Waze com informações sobre congestionamento de trânsito que podem ser utilizadas para acompanhamento da mobilidade da população (Waze, 2020). Os dados de variação percentual de quilômetros compartilhados são agregados, anonimizados e foram gerados com base em critérios de privacidade dos usuários. Esses relatórios mostram o aumento ou a redução dos quilômetros rodados como uma variação percentual comparada a dados da linha de base, calculada pela média do dia da semana correspondente ao período de duas semanas antes da decretação de emergência ( I I a 25 de fevereiro de 2020).

Também incluímos no sistema dados do Facebook, que disponibiliza indicadores de Covid- 19 derivados de pesquisas globais de sintomas em sua plataforma. Os dados são mantidos pela Universidade de Maryland, que os compartilha com outros pesquisadores em saúde. Embora seja uma pesquisa que considera informações individuais, esses dados são disponibilizados de forma agregada, o que garante a privacidade do participante. Com base nessas informações, é estimada a porcentagem de pessoas que em determinada região geográfica e em determinado tempo relataram sintomas de Covid- 19.

Ganhamos apoios de empresas como a RStudio e a Digital Ocean, com cupons de gratuidade para utilização de seus serviços por um tempo limitado. Essa oportunidade foi muito importante para manter em funcionamento o projeto, enquanto seguimos amadurecendo a nossa infraestrutura de hospedagem do site, tópico que será abordado a seguir. 


\section{ORGANIZAÇÃO INSTITUCIONAL}

A resposta da Fiocruz à epidemia se iniciou de forma orgânica, originada em grupos preexistentes ou que se formaram espontaneamente congregando profissionais e estudantes. À medida que aumentava o número de casos e óbitos, nos meses de fevereiro e março de 2020, algumas iniciativas foram surgindo nos diferentes institutos e laboratórios da fundação.

Visando a organizar e institucionalizar essas iniciativas, foi criado na Fiocruz o Observatório Covid-19: informação para ação. Após o reconhecimento de cada iniciativa por seu laboratório e instituto, os projetos foram cadastrados no Observatório Covid-19. Em sua página, hospedada no portal Fiocruz, a produção de cada iniciativa é divulgada por meio de notícias, press releases, notas técnicas, links para seminários e outros materiais. Essa foi uma forma acertada de apoiar e organizar as iniciativas existentes na instituição, evitando hierarquizações desnecessárias e sobreposições de trabalhos.

No âmbito do MonitoraCovid-19, a iniciativa foi rapidamente apoiada pelo Núcleo de Ceoprocessamento e pela Plataforma de Ciência de Dados Aplicada à Saúde, ambos vinculados ao Laboratório de Informação em Saúde do Icict. A estratégia de desenvolvimento colaborativo do MonitoraCovid-19, sempre aberto à participação de novas pessoas, de dentro e fora da Fiocruz, inclusive voluntários da sociedade civil, levou a discussões sobre seus objetivos e produtos, problematização sempre necessária ao fazer científico. No início do seu desenvolvimento, a interação do projeto com outros grupos de pesquisa dentro da Fiocruz foi agitada por sugestões vagas, ou mesmo perturbada por declarações de inutilidade do projeto. Com gradativo amadurecimento da iniciativa, a plataforma MonitoraCovid- 19 passou a ser reconhecida com orgulho pela instituição e usada nas apresentações oficiais da Presidência da Fiocruz.

Para a continuidade sustentável do projeto, procuramos alguns editais de financiamento. Além de recursos financeiros pontuais obtidos com a Presidência da Fiocruz, o projeto foi contemplado pelo Edital Inova Fiocruz Ideias e Produtos Inovadores - Covid- 19 - Encomendas Estratégicas, de 2020. Os editais Inova da Fiocruz visam a financiar projetos internos da instituição cujo objetivo geral seja incentivar ambientes favoráveis à pesquisa, desenvolvimento tecnológico e inovação em saúde em todas as áreas de atuação da instituição.

Concorrendo com mais de cem projetos, o MonitoraCovid- 19 foi contemplado e recebeu integralmente o valor planejado na proposta. Esse recurso tem sido destinado principalmente ao pagamento de bolsas e à compra de equipamentos para a manutenção do projeto. 
Além do Edital Inova, o projeto foi agraciado com uma premiação da Escola Nacional de Administração Pública (Enap), na categoria "Desafios Covid- 1 9", em reconhecimento ao seu mérito e qualidade. $\mathrm{O}$ recurso tem sido destinado ao pagamento de bolsas e também ao auxílio financeiro de projetos de parceiros essenciais para a continuidade do MonitoraCovid-19, bem como à melhoria de infraestrutura na unidade.

\section{A RELAÇÃO COM A IMPRENSA}

A publicação de notas técnicas e postagens em redes sociais sobre novos gráficos e análises logo atraiu a atenção de algumas pessoas, e pedidos de entrevistas e solicitações de esclarecimentos sobre a doença e evolução da pandemia começaram a surgir. As demandas da imprensa eram direcionadas à Assessoria de Comunicação (Ascom) do Icict, que nos auxiliava na triagem e atendimento desses pedidos. Em outros momentos, éramos diretamente acionados por órgãos de imprensa para comentar determinado tema em pauta ou produzir indicadores sobre um problema de saúde, sempre usando a plataforma MonitoraCovid- 19.

Sempre tivemos o entendimento de que o papel prioritário do MonitorCovid- 19 era manter a população brasileira informada adequadamente sobre os dados de Covid- I9, e nisso o relacionamento com a imprensa era algo essencial.

Em alguns momentos tivemos dificuldade em atender a todos os pedidos da imprensa, que demandava também dados específicos para certas regiões ou municípios. $\mathrm{O}$ atendimento a esse tipo de demanda era complexo e dividia nossa atenção entre manter o projeto sempre atualizado e atender às solicitações. Procuramos seguir considerando que o conhecimento gerado pelo projeto deveria ser divulgado e propor pautas à imprensa. Até 6 de janeiro de 2021, o portal de notícias do Google apresenta 215 reportagens em que o projeto é citado, em diversos veículos de imprensa, nacionais e internacionais.

\section{OUTRAS FORMAS DE INTERAÇÃO COM A POPULAÇÃO}

Já no início do projeto, quando a primeira versão foi disponibilizada ao público, uma conta de e-mail institucional foi criada para receber dúvidas, sugestões, críticas e pedidos de esclarecimentos dos usuários. Esse canal de comunicação direta com o projeto se mostrou bastante interessante, ainda que exaustivo em alguns momentos. Por ele recebemos demandas de diversos tipos e origens, de cidadãos comunicando imprecisões e pedindo esclarecimentos sobre seus municípios até entes públicos requisitando dados extraoficialmente. Procuramos responder às mensagens enviadas 
com rapidez e precisão, mas sem prejudicar o andamento do projeto como um todo. Em alguns momentos, essas demandas por dados e análises específicas foram enviadas pelo Ministério Público.

O acesso ao projeto foi disponibilizado na internet no dia 23 de março de 2020 . Dessa data até o dia 15 de dezembro de 2020, o site do MonitoraCovid- 19 teve 211 .778 usuários, que abriram as abas do projeto 501.727 vezes (sessões). Atendemos usuários em mais de cem países de todos os continentes, conforme os dados informados pela plataforma Google Analytics (Figura 5b).

Figura 5a - Dados de acesso ao site do projeto

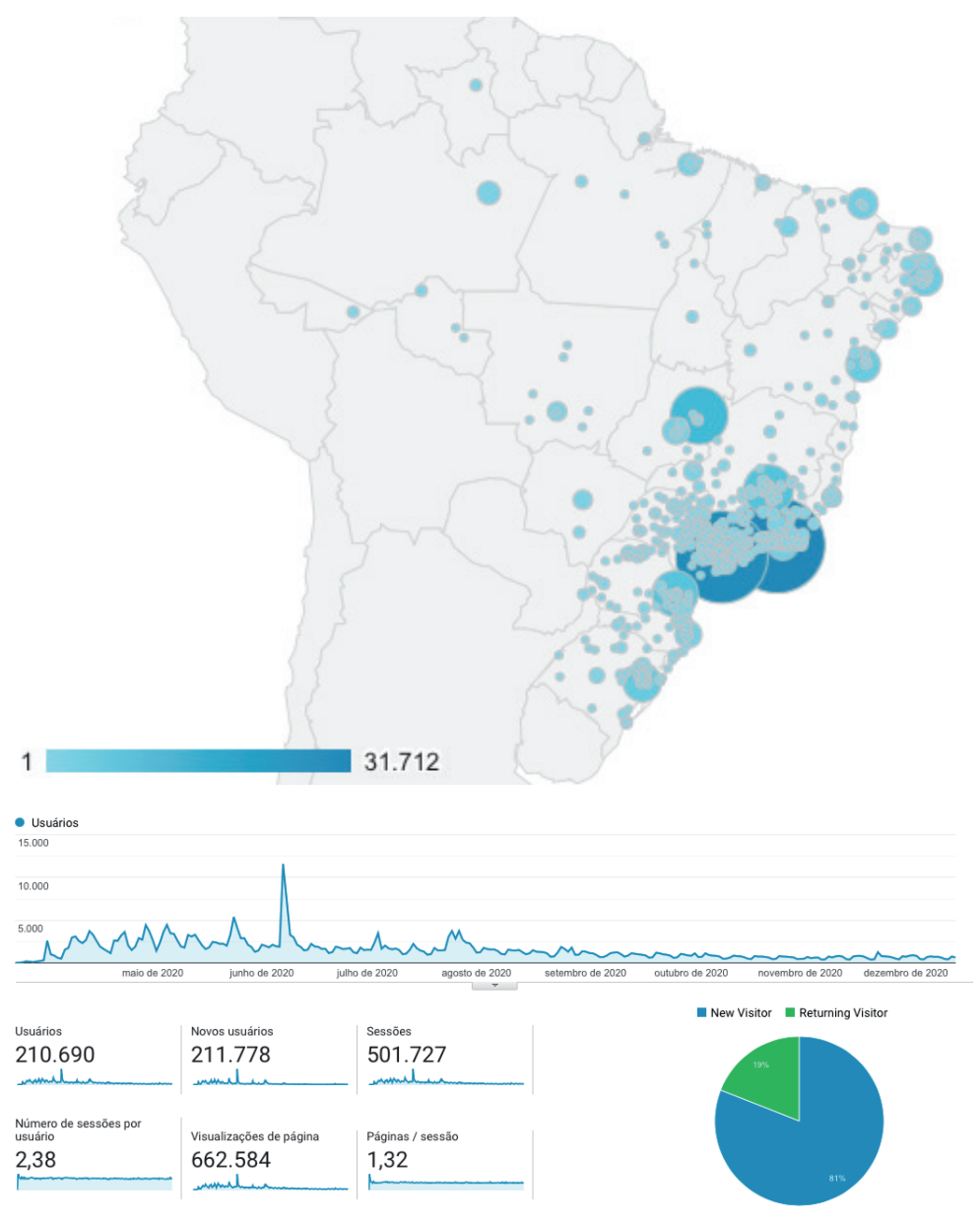




\section{Figura $5 \mathrm{~b}$ - Dados de acesso ao site do projeto}

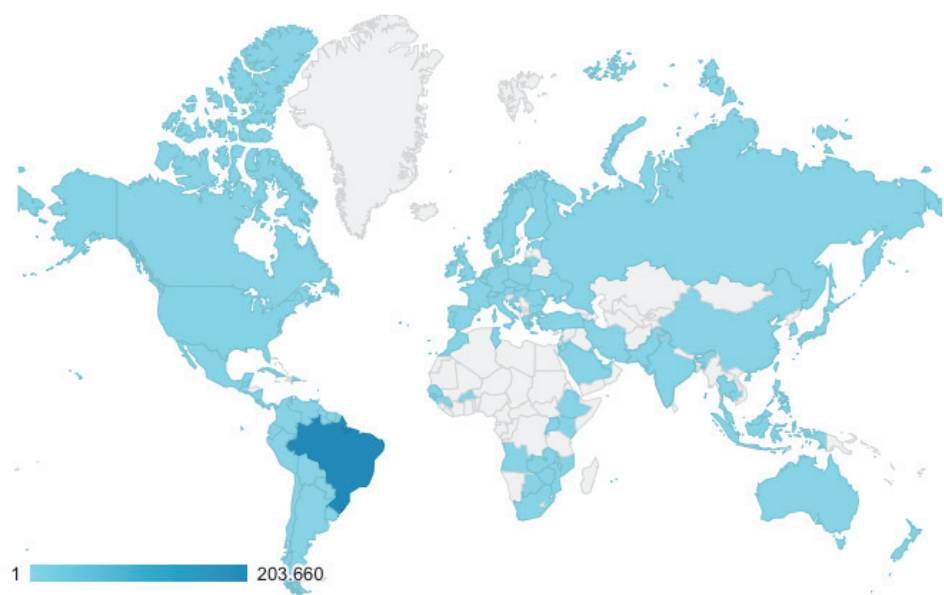

No Brasil, atendemos usuários em todas as 27 UFs, o que se pode creditar, em parte, à divulgação do projeto por meio perfis da Fiocruz nas redes sociais.

\section{Twitter}

Conforme o MonitoraCovid-I9 avançava com novas funções, bases de dados e gráficos, procurávamos uma forma de divulgar estas novidades. Um dos principais canais que utilizamos é o Twitter. Apesar de não termos uma conta exclusiva para o projeto, procuramos divulgar as novidades do projeto em nossas contas pessoais, já conectadas com diversos usuários e grupos. Em geral, essas postagens alcançam certa repercussão, com curtidas e reportagens por centenas de usuários dessa rede social. O Twitter possibilitou também a formação de redes de análise e a troca de informações entre equipes de especialistas de diversas áreas de conhecimento.

Um efeito interessante ocorreu quando o pesquisador e divulgador científico Atila lamarino fez uma postagem em 3 de julho de 2020 sobre o crescimento de casos nas UFs, usando gráficos produzidos no MonitoraCovid-19, incluindo um link para o site do projeto. Essa postagem gerou grande número de usuários acessando o site do projeto em curto tempo, o que levou à instabilidade do sistema. Conforme a postagem repercutia e alcançava mais pessoas, fomos acumulando um número crescente de usuários. No dia seguinte, atingimos um pico de 3.487 usuários em um único dia. 
O projeto também fornece seus dados para outros projetos e instituições. O IBGE tem um link direto de acesso aos nossos dados atualizados para alimentar seu portal sobre a Covid- 19. Outra iniciativa de cessão de dados é destinada ao monitoramento da epidemia na Região Metropolitana de São Paulo.

\section{INFRAESTRUTURA DE COMPUTAÇÃO E HOSPEDAGEM}

O crescimento do projeto em termos do número de dados trabalhados, gráficos disponíveis e número de usuários nos deu melhor dimensão da responsabilidade ativa do projeto em informar a população, diariamente, sem atrasos ou interrupções.

Para isso, foi necessário rever a infraestrutura utilizada para a hospedagem do projeto. Desde o início, a Plataforma de Ciência de Dados aplicada à Saúde (PCDaS) tem apoiado o MonitoraCovid- 19 com sua infraestrutura computacional e revisão técnica do sistema.

Inicialmente, o projeto era hospedado em um servidor da PCDaS localizado fisicamente no Laboratório Nacional de Computação Científica (LNCC), em Petrópolis, RJ. Apesar da alta qualidade ofertada pelo LNCC para computação científica, percebemos que a rede disponível não atendia a pré-requisitos que permitissem atender a grande número de acessos ao site do MonitoraCovid- 19.

Com o crescimento do número de usuários, optamos, então, por hospedar o site do projeto dentro da sala cofre da Fiocruz, contando com a ajuda da equipe da PCDaS e do Centro de Tecnologia da Informação e Comunicação em Saúde (CTIC/Icict) para a migração e manutenção do sistema. Essa sala cofre é uma infraestrutura computacional criada na Fiocruz para prover a instituição de um ambiente computacional seguro, física e virtualmente, oferecendo serviços computacionais como hospedagem de sites, com alta confiabilidade e disponibilidade.

\section{PRODUTOS CIENTÍFICOS DO PROJETO}

Além das abas e gráficos apresentados disponíveis no site, o projeto produziu uma série de notas técnicas cujo teor detalhamos a seguir.

A dinâmica da doença demandou maior celeridade na divulgação das informações para que estas pudessem se tornar política pública. Se antes o caminho habitual passava pela construção de um artigo científico e sua publicação para que houvesse alguma visibilidade, durante a pandemia de Covid- 19 esse caminho moroso não traria muito ganho no sentido de subsidiar decisões e intervenções. Nem mesmo a velocidade dos preprints possibilitava ganho de oportunidade. A decisão foi: precisamos analisar 
os dados do sistema e emitir notas técnicas sobre os cenários da pandemia de forma rápida $e$ independente.

A primeira nota técnica foi divulgada em 2 de abril de 2020 e alertava sobre o processo de interiorização da doença. A doença havia chegado pelas grandes cidades e não havia razão nenhuma para acreditar que não avançasse para as cidades do interior. Foi o que aconteceu. A parceria com o IBGE possibilitou acesso aos dados da pesquisa Regiões de Influência das Cidades (Regic, edição 2018), em especial do componente Saúde, que foi liberado para uso antes mesmo da sua publicação em julho de 2020. Com base nesses dados, estruturamos outras notas e apontamos o caminho esperado da difusão espacial do vírus.

Em maio de 2020, buscamos avaliar a velocidade de disseminação da doença; como já imaginávamos, a chegada da doença no interior do país e a historicamente reduzida disponibilidade de recursos para atendimento de alta complexidade (UTI) trariam um quadro de desassistência à saúde. Levantamos esses dados e estimamos a distância de deslocamento em busca de atendimento e a disponibilidade de recursos dentro das Regiões de Saúde e o fluxo de pacientes que já estava ocorrendo, de um município em busca de outro município que pudesse atendê-los. Os dados permitiram antever uma situação trágica que infelizmente se confirmou. Ainda em maio, em outra nota se avaliavam os dados de Srag do Sistema de Informação da Vigilância Epidemiológica da Gripe (Sivep Gripe) e como esse sistema permitiria avaliar aspectos como sexo, raça, idade, atendimento, entre outros, e se criava um espectro mais amplo para a avaliação da doença.

Em junho de 2020 começou a ocorrer um movimento, originado em setores da economia e da política, em favor da flexibilização das medidas de isolamento e distanciamento social. Esse movimento, junto com outros processos de desgaste de estratégias de proteção da saúde, resultou na demissão do ministro Mandetta em abril e do ministro Teich em maio. Nesse período nos dedicamos a trabalhar com dados de mobilidade urbana apontando os índices de mobilidade disponíveis no sistema. Também buscamos explicar que existiam tempos epidêmicos diferentes em função da chegada da doença. À medida que a doença chegava, os chamados epicentros da doença iam se alterando e uma flexibilização geral defendida pelo governo federal se mostrava uma decisão equivocada.

No mês de julho de 2020, passamos a avaliar os impactos indiretos, sobretudo os óbitos por outras causas e os indiretamente ocorridos pela Covid-19. Outros sistemas estavam disponibilizando os dados de cartórios do registro civil, informações que 
chegamos a implementar no sistema, mas, em razão de inconsistências que observamos à época, bem como de distorções e fake news baseadas em tais informações, foi preciso retirar. Avaliamos então os padrões de mortalidade no município do Rio de Janeiro, que possui seu próprio site de disponibilização de dados, mostrando grande volume de óbitos em domicílios, vias públicas e outras unidades de saúde e sem assistência médica, o que poderia estar se repetindo em outras cidades.

Ainda em julho de 2020, a questão da volta às aulas ganhou força no processo de relaxamento das medidas de isolamento social. Nesse período tal medida se mostrava preocupante diante da alta da taxa de contágio e, principalmente, da exposição da população idosa e da população com fatores de risco que conviviam com pessoas em idade escolar. Fizemos um levantamento com a equipe que detém conhecimento sobre os dados da Pesquisa Nacional de Saúde e apontamos que quase 10 milhões de pessoas idosas ou com fatores de risco conviviam com crianças em idade escolar. Buscamos ser taxativos, mostrando que a retomada das aulas sem testagem, rastreio, medidas de distanciamento físico, de higiene e o uso de máscara seria o fim do isolamento social para essa população.

Os boletins epidemiológicos das secretarias estaduais de Saúde (SES) apresentaram, em alguns momentos, represamento de casos para além do esperado no comportamento cíclico das informações, em função dos fins de semana. Decidimos buscar os sistemas de referência (e-SUS-VE e Sivep Gripe) para comparar a data do evento (óbitos ou data dos primeiros sintomas nos casos) e a data de divulgação dos dados pelas SES. A diferença entre os cenários que a população acompanhava na mídia e aqueles baseados na data em que de fato ocorriam os eventos chegava, para alguns estados, a quase dois meses. Essa nota foi lançada em agosto de 2020. Em setembro, em um evento com outros grupos de análise sobre Covid- 19 do Brasil, elaboramos uma carta aberta que buscava alertar a mídia e a sociedade sobre essa situação. Concordamos que não era um processo simples e que, como já havia o hábito da divulgação dos dados pelos boletins, isso não deveria ser alterado, mas complementado. A divulgação continuou sendo pautada pela mídia com os dados dos boletins das SES e continuamos sujeitos a esse represamento, que se acentuou próximo ao período eleitoral e nos recessos de fim de ano.

Em dezembro de 2020 retomamos a análise sobre o excesso de óbitos no município do Rio de Janeiro, e os números revelaram um cenário trágico de desassistência na cidade, que com certeza se repetiu em muitas outras cidades. O aumento de casos no fim do ano e maior mobilidade das pessoas motivaram a nota técnica que apontava o fim do processo de interiorização e a sincronização da pandemia no espaço. O estudo mostra duas fases na dinâmica espaçotemporal da Covid-19: se em abril e maio havia 
um processo de difusão da doença, das capitais para cidades de menor porte, e aumento de casos à medida que a doença avançava no território, em novembro a doença ocupava todo o território e a movimentação das pessoas entre cidades definiria o aumento de casos de forma sincronizada em vários locais.

\section{MODELOS DE PREVISÃO}

Conforme os casos avançavam no Brasil, em meados de março de 2020, e os primeiros óbitos começavam a ser reportados, diversas propostas nacionais e internacionais surgiram para tentar prever quando ocorreria o auge do número de casos, o chamado pico da curva, e qual seria o número de casos nessa data. Essas informações seriam de grande importância para preparar o sistema de saúde, com a preocupação dominante à época de achatar a curva, para melhor atender a população.

Nessas propostas se utilizaram, em geral, métodos de modelagem epidemiológico compartimentais, como os modelos SIR (Suscetível - Infectado - Recuperado) e algumas variantes.

No âmbito do MonitoraCovid- 19, inicialmente procuramos desenvolver modelos de previsão e chegamos a discutir alguns modelos de previsão a curto prazo considerando o crescimento exponencial da doença. Contudo, no decorrer do processo epidêmico, observamos que a epidemia era muito mais complexa do que se esperava e vários dos modelos propostos inicialmente começaram a ser descartados, pois a incerteza, nos modelos, para efeitos de médio e longo prazos traziam enorme insegurança, devido à falta de conhecimento sobre a doença.

Além disso, enfrentamos - como todos os outros proponentes de modelos grandes dificuldades com a qualidade e as limitações dos dados. Os dados disponíveis sobre a epidemia versavam basicamente sobre o número de casos e óbitos por data de notificação, o que acaba por violar alguns dos pressupostos do modelo. Seria necessário obter a data dos primeiros sintomas dos casos, conhecer precisamente o número de testes aplicados nas populações, detalhes sobre as medidas de prevenção e combate à epidemia e outros fatores que não estavam (e não estão até o momento) disponíveis como dados. Por esses motivos, decidimos não apresentar um modelo publicamente. Priorizamos o trabalho em análises de curto prazo, sobretudo sobre o processo de disseminação espacial da doença e as implicações relacionadas ao atendimento.

De fato, observamos que diversos dos modelos apresentados publicamente foram discretamente retirados, conforme a epidemia avançava. Em geral, eles eram reajustados diariamente com os novos dados, o que acabava por sempre postergar o pico de casos. 
Os valores resultantes desses modelos não pareciam ser compatíveis com a realidade do momento, ou necessitavam de dezenas de parâmetros adicionais, fornecidos pelo usuário para modelar a curva epidêmica, o que virtualmente impedia qualquer previsão. Com efeito, nenhum modelo de previsão alertou para a possibilidade futura de um segundo pico de casos, realidade que começou a se definir em novembro de 2020.

\section{A ESTRUTURA DE CÓDIGO}

A estrutura de código de programação do projeto se divide em duas partes: Extraction, Transform and Load (ETL) e o aplicativo web.

ETL

A estrutura de ETL é responsável pela atualização rotineira dos dados do projeto. Atualmente ela é realizada de forma automática em um servidor e seus passos são notificados via mensagens no Telegram para a equipe técnica do projeto. A execução do script de ETL leva, atualmente, em torno de uma hora para ser executada.

Esta estrutura é composta de uma série de scripts em linguagem R. O primeiro bloco de scripts realiza o download dos dados utilizados no projeto. Outros scripts efetuam transformações e cálculos necessários, enquanto o último bloco de scripts realiza exportações de dados para que projetos parceiros possam consultar nossos dados.

\section{Aplicativo}

O site do projeto é um aplicativo também desenvolvido com a linguagem R, utilizando-se o pacote Shiny para construção de aplicações on-line. Trata-se de um arquivo único contendo em torno de 4.000 linhas, onde são definidas a estrutura visual do site e a execução de códigos dinâmicos para a construção das tabelas, gráficos e mapas apresentados no site.

\section{AVANÇOS E DESAFIOS FUTUROS}

No projeto MonitoraCovid-19 pretende-se continuar cumprindo a missão institucional do Icict, disponibilizando informação de forma aberta e criando interfaces para consultas interativas e aquisição dos dados de forma simples e acessível para a população, os gestores e a sociedade civil.

A curto prazo, o sistema passará por uma remodelagem de layout e usabilidade com a qual se pretende tornar a plataforma ainda mais simples e intuitiva e, portanto, acessível a 
um público mais amplo. Para tanto, esperamos incluir dados sobre Covid- 9 dos demais sistemas de informação de saúde (SIM, SIH, SIA etc.) que devem disponibilizar esses dados seguindo uma defasagem inerente a cada sistema de informação, mas trazem outras possibilidades de análise e entendimento da doença e do processo epidêmico.

As bases de dados do Sivep Gripe e do sistema e-SUS VE serão trabalhadas para criar interfaces de consultas amigáveis e acessíveis a qualquer usuário, sem necessidade de conhecimento especializado sobre modelagem de bancos de dados. Além disso, esperamos incluir os dados sobre vacinação disponíveis tanto no Brasil quanto no mundo.

Esperamos expandir as parcerias e fornecer informação para estudos aprofundados sobre a Covid-19 que nos ajudem a entender a epidemia, para enfrentá-la e criar conhecimento de base para eventuais novos processos endêmicos que venham a ocorrer. Nesse sentido, espera-se maior aproximação das instituições de ensino e das secretarias de Saúde para colaboração na melhoria da informação e na capacitação de pessoal para análise.

\section{REFERÊNCIAS}

COTA, W. Repositório do GitHub-CovidI9Br, 2020. Disponível em: <https://github.com/wcota/ covid I 9br>. Acesso em: dez. 2020.

FONTES, R. Coronavirus - Brazil; Brazil Dataset, 2020. Disponível em: <www.kaggle.com/unanimad/ corona-virus-brazil>. Acesso em: dez. 2020.

INSTITUTO DE COMUNICAÇÃO E INFORMAÇÃO CIENTÍFICA E TECNOLÓGICA EM SAÚdE/ FUNDAÇÃO OSWALDO CRUZ (ICICT/FIOCRUZ). Site. Disponível em: <www.icict.fiocruz.br/ content/sobre-o-icict>. Acesso em: 20 dez. 2020. Acesso em: dez. 2020.

PROVOST, F. \& FAWCETT, T. Data Science and its relationship to big data and data-driven decision making. Big Data, I(I): 5I-59, 20I3. Disponível em: <http://doi.org/l0.I089/big.20I3.I508>. Acesso em: dez. 2020.

WAZE. Mantendo o Waze atualizado durante a pandemia Covid-19, 2020. Disponível em: <www. waze.com/pt-BR/covidI9>. Acesso em: dez. 2020. 



\section{Painel Unificador Covid-19 nas Favelas}

metodologia para dar visibilidade

a territórios periféricos

Renata Gracie, Amanda Scofano de Andrade Silva, Chauncie Bigler, Guilhermo Douglass-Jaimes, Elisa Maria Campos e Theresa Williamson

O primeiro caso confirmado de Covid- 19 no Brasil foi em 26 de fevereiro, no estado de São Paulo. O período inicial da contaminação no país se deu por intermédio de setores da população com melhores condições socioeconômicas. O principal meio de disseminação, nesse primeiro momento, foram viagens e conexões aéreas. Com o passar do tempo, a epidemia foi se interiorizando e, pouco depois, começou-se a identificar a disseminação de casos dentro das áreas mais vulneráveis ao vírus, as áreas informais de favela.

A globalização tem feito aumentar progressivamente a circulação de pessoas, bens, serviços, informações, produtos e dinheiro de forma extremamente acelerada e perversa, o que tem resultado em desigualdades locais (Santos, 2012 ) que repercutem na velocidade da urbanização de muitas cidades pelo mundo e, consequentemente, no aumento do crescimento de favelas (Davis, 2006). No Brasil, o Censo 2010 já apontava para maior crescimento populacional das áreas urbanas nas regiões de favelas do que nas áreas consideradas formais (Pasternak \& D’Ottaviano, 20 I 6). Esses territórios, que já apresentavam déficit de infraestrutura e equipamentos urbanos, trouxeram com ainda mais força a reivindicação do direito à cidade (Harvey, 200 I) no contexto da pandemia.

Aproximadamente $20 \%$ dos lares brasileiros localizados em favelas encontram-se nas duas maiores capitais do país, São Paulo e Rio de Janeiro. De acordo com dados recentes publicados na nota técnica do Instituto Brasileiro de Geografia e Estatística (IBGE), a estimativa de domicílios em favelas, identificadas por esse instituto como aglomerados 
subnormais (AGSNs), é de 5.127.747 num total de I3.15I favelas no Brasil, das quais I.830 no estado e 778 no município do Rio de Janeiro (IBGE, 2020).'

Alguns levantamentos do IBGE (2020) apresentados em nota atestam que aproximadamente dois terços (64,93\%) dos AGSNs do Brasil estão a menos de dois quilômetros de um hospital. E que a maioria (79,53\%) dessas localidades também está próxima - a menos de um quilômetro - de unidades básicas de saúde. Esse fato, porém, não se traduz em acesso à saúde, pois as distâncias em linha reta (euclidianas) não são percorridas pela população. Os obstáculos no caminho entre o indivíduo e a unidade de saúde podem ser bastante grandes, considerando ainda que boa parte dos habitantes de favelas perdeu total ou parcialmente a sua renda durante a pandemia (Maggiola, 2020).

A saúde de determinada população, seja durante uma epidemia ou não, resulta das formas de organização social em diferentes âmbitos, como o comunitário, o econômico, o político e o cultural (Czeresnia E Freitas, 2009). O intencional estado de exceção de políticas públicas nas favelas reverberou em diferentes facetas diante da pandemia da Covid-19. A escassez de testes tem sido um problema no país como um todo, mas nos territórios das favelas a defasagem dos números oficiais de casos e óbitos é ainda maior, intensificando os desafios em relação ao planejamento de ações mitigadoras e de combate à pandemia (Angelo, Leonardo E Perissé, 2020). A própria ONU Habitat (Wilkinson, 2020) reconhece o desafio da falta de dados em favelas e assentamentos informais.

A testagem em massa, recomendada pela Organização Mundial da Saúde (OMS), é um dos métodos de vigilância mais eficazes para controlar a dispersão do vírus, pois com as informações epidemiológicas fornecidas é possível realizar avaliações de risco em diferentes níveis estratégicos, além de auxiliar na orientação de medidas de preparação e resposta. Na ausência da testagem em massa, a OMS recomenda a análise de sintomas e a inclusão de casos prováveis no quadro de pessoas infectadas (OMS, 2020).

O Brasil é o terceiro país do mundo com maior número de casos (6.675.915) e o primeiro da América do Sul. Mesmo diante dessa situação, os dados do Worldometers (2020) demonstram que, até o momento, foram realizados apenas 15 mil testes por milhão de habitantes, o que torna a população extremamente vulnerável à contaminação.

Diante dessa problemática, muitos líderes comunitários, moradores, grupos diversos e agentes comunitários de saúde têm intensificado sua organização coletiva

\footnotetext{
' O número de favelas reconhecidas pelo IBGE difere do número reconhecido pelo Instituto Pereira Passos (IPP), que contabiliza 1.047 favelas na cidade do Rio de Janeiro. Isso se deve a pequenas diferenças nos critérios de demarcação de assentamentos informais. Algumas dessas diferenças são explicadas na seção de métodos.
} 
com diversos tipos de campanhas de prevenção e combate à pandemia, atuando na distribuição de informações, equipamentos de proteção individual, alimentos, água e produtos de higiene. Além disso, as populações dessas comunidades têm objetivado identificar e registrar a situação sanitária da pandemia dentro das favelas. Essa coleta, armazenamento, seleção e distribuição de dados que surge por meio da mobilização popular é chamada vigilância cidadã e desponta como uma possibilidade alternativa ao modelo hegemônico que prioriza investimentos em determinado local em detrimento de outro. A lógica desse modelo consiste em ações gerenciadas continuamente em determinado território para tratar dos agravantes de saúde da população ali residente, combinando práticas coletivas e individuais (Silva E Vieira-da-Silva, 2008).

A informação geográfica voluntária (volunteer geographic information, VIG), uma forma de vigilância cidadã, tem se popularizado cada vez mais na intenção de espacializar diversos fenômenos, produzindo evidências e conhecimento científico. Entramos numa era de esforços que partem dos próprios cidadãos para coletar e compartilhar informações geográficas (Goodchild, Fu E Rich, 2007; Turner, 2006).

Na vigilância cidadã, as atividades empíricas, a vivência local, as relações horizontais e o saber popular são priorizados e entrelaçados aos conhecimentos e métodos científicos, com o objetivo de consolidar os dados técnicos e democratizar as informações produzidas.

Os dados levantados pela sociedade podem contribuir para a efetivação do pacto pela democratização e qualidade da informação e comunicação em saúde estabelecido em 2003 na $12^{\text {a }}$ Conferência Nacional de Saúde, na qual se discutiu e avaliou a necessidade de elaborar e implementar uma política de informação, comunicação e informática para o Sistema Único de Saúde (SUS). Consequentemente, podem contribuir para o controle social, apoiado na garantia das ações e dos recursos que permitam a democratização do acesso à informação, comunicação e informática em saúde (Silva, Cruz E Melo, 2007).

A criação do Painel Unificador Covid- 19 das Favelas teve como impulso a carência de dados, especificamente nas favelas, e a consequente dificuldade no combate à pandemia dentro desses territórios. Utilizando a vigilância cidadã como um poderoso instrumento de transformação social, o Painel Unificador Covid-19 das Favelas, disponível para acesso gratuito desde 7 de julho, tem se construído com base nos dados obtidos por meio do trabalho conjunto de relatores, coletivos e organizações locais.

Nosso objetivo neste texto é apresentar e explicar a metodologia empregada na construção do Painel Unificador Covid-19 nas Favelas, para que todos tenham acesso aos dados nele tabulados ao longo do tempo. Dessa maneira, a sociedade civil, gestores 
e pesquisadores terão acesso a seus dados durante todo o período e, conhecedores da metodologia, poderão interpretar suas informações considerando as limitações inerentes às diferentes fontes de dados.

\section{MATERIAIS E MÉTODOS}

\section{Mapas das favelas em formato digital}

Os mapas criados para visualizar os dados da Covid-19 no Painel Unificador Covid- 19 nas Favelas utilizam uma geodatabase que contém duas camadas espaciais. As camadas contêm apenas geometria, com tipologia vetorial para delinear os limites da favela. A primeira camada contém os limites de 1.047 favelas individuais, obtidos na base de dados gráficos do Instituto Pereira Passos (IPP/Prefeitura do Município do Rio de Janeiro) em 2010. A segunda camada é extraída da mesma origem e contém as favelas agrupadas em 146 complexos reconhecidos pelo IPP. O painel frontal exibe a segunda camada, determinado como mais flexível para os dados Covid- 19 que foram coletados por ampla gama de grupos. O IPP utiliza características espaciais específicas para definir determinada localidade como favela - p. ex., ocupação irregular, lotes pequenos ou indeferidos, vias estreitas, infraestrutura de saneamento precária.

Essas especificidades, entre outros fatores, geram diferenças entre as bases cartográficas de favelas do IPP e do IBCE, mas no último Censo (2010) o percentual de incompatibilidades entre as bases caiu de II\% para 3,5\% (Cavalieri E Vial, 20 I 2). No entanto, algumas diferenças podem ocorrer em razão do fato de o IBGE ter estabelecido um número mínimo de 5 I domicílios para classificar uma favela como AGSN, ao passo que o IPP não lidar com tal limite.

\section{NOMENCLATURA}

$\mathrm{Na}$ camada da favela, os polígonos são nomeados com a seguinte estrutura: [nome da favela] / [nome do bairro]. No entanto, essa estrutura tem dois significados: para favelas que fazem parte de complexos, o nome da favela se reporta à favela principal em que suas áreas são mais comumente conhecidas. Para favelas isoladas são utilizados os seus próprios nomes. Essa denominação serve para distinguir favelas de diferentes áreas do Rio que compartilham o mesmo nome (algumas exceções foram estabelecidas para favelas universalmente reconhecíveis, como Vidigal e Rocinha). 


\section{Alterações nas camadas do mapa}

Todas as alterações nas camadas do mapa são motivadas por percepções e em discussão direta com líderes comunitários e moradores da favela, que comunicam erros no mapa de acordo com a realidade local. As alterações no mapa foram realizadas conforme a necessidade, com prioridade dada às comunidades que não contam com uma fonte de dados de casos/óbitos por Covid- 19 para o Painel Unificador Covid- 19 nas Favelas.

O mapa básico de favelas e complexos usado nesse painel foi publicado pela Prefeitura do Rio em 2010. Nos outros municípios fluminenses as favelas foram delimitadas com base em conversas com as lideranças locais e os polígonos foram delimitados em ambiente de Sistema de Informação Geográfica (SIG). O SIG é uma das técnicas de geoprocessamento que têm por objetivo capturar, armazenar, analisar e divulgar bases de dados geográficas (Pina, 2000). Devido à natureza dinâmica nas favelas, realizar mudanças em nomes, formas e agrupamentos mostrou-se necessário em muitos casos. A metodologia do painel se baseia também nas percepções contínuas dos membros das comunidades, e com ela se busca criar um mapa em formato digital com o qual os moradores se identifiquem e construam, de forma coletiva, um projeto de vigilância participativa.

Três tipos de mudança nas camadas estão sendo feitos: I) mudança do nome de uma favela/complexo, 2) mudança dos agrupamentos de favelas (complexos) e 3) acréscimo de novas favelas.

\section{Mudança na nomenclatura}

26 nomes de favelas e/ou complexos foram alterados para refletir a nomenclatura atual reconhecida pela comunidade desde o início do projeto em julho de 2020.

\section{Alterando 0 agrupamento}

39 favelas em complexos foram ajustadas para refletir agrupamentos reconhecidos pela comunidade. Isso foi feito em discussão direta com membros da comunidade nas favelas do complexo em questão. Muitas vezes, usando o WhatsApp, um membro da comunidade envia à equipe uma lista de favelas reconhecidas dentro do complexo $e$ marca uma captura de tela da configuração do mapa atual. 


\section{Adicionando novas favelas}

Novas comunidades e polígonos correspondentes estão sendo adicionados às camadas do mapa conforme necessário para exibir as fontes de dados Covid-19. Polígonos estão sendo desenhados temporariamente na ausência de trabalho de campo, para correção em data posterior. Os polígonos são desenhados em torno de uma localização de referência fornecida por um residente da comunidade, um endereço e/ou referência cruzada usando o Google Maps.

Foram adicionados 19 polígonos às duas camadas desde julho de 2020, dos quais sete refletem um mapa de polígonos reconhecido pela comunidade, fornecido pela Redes da Maré.

\section{FONTES DE DADOS SOBRE COVID-19}

Os dados do Painel Unificador Covid-19 nas Favelas são capturados a partir de quatro fontes de informação: Autodeclaração, Relatores locais, Informações de outros painéis e Informações por CEPs, conforme descrito a seguir.

\section{Autodeclaração}

O formulário de autodeclaração, cedido pela CovidCheck, pode ser acessado e preenchido pelo público no endereço http://avaliarcovid.favela.info. Ao final do preenchimento é possível classificar o nível de risco no qual a pessoa que respondeu à avaliação se encontra, o que pode auxiliá-la em uma possível tomada de decisão em relação à sua própria saúde. Se o caso em questão resultar em risco médio/alto, ele é automaticamente incorporado aos números de "autodeclarados" do painel.

\section{Relatores locais}

São líderes comunitários e de organizações não governamentais, atuantes há bastante tempo nas favelas, em diversos segmentos sociais. Durante a pandemia estão atuando também na distribuição de cestas básicas e kits de higiene e no fornecimento de orientações para a proteção contra a Covid- 19.

Os registros de casos e óbitos são realizados por apenas um relator em cada favela ou complexo, para que não haja sobreposição de dados. Como cada favela apresenta sua própria dinâmica e complexidade, a identificação dos casos e óbitos é feita pelos relatores de formas distintas: em entrevistas com moradores, levantamentos pelo WhatsApp e utilizando formulários on-line. 


\section{Informações de outros painéis}

Dados divulgados por painéis já existentes, organizados por diversas organizações não governamentais. As informações dessas ONGs, por sua vez, advêm de fontes governamentais, como prefeituras, clínicas da família, centros de saúde, e também de contagens locais de dentro das próprias favelas.

\section{Utilização de CEPS}

Foram empregadas três bases de dados para realizar o mapeamento dos casos e óbitos por código de endereçamento postal (CEP). Em relação aos casos e óbitos por Covid-19, foram utilizadas as informações georreferenciadas da Secretaria Municipal de Saúde do Rio de Janeiro (SMS-RJ). Para as bases cartográficas do município do Rio de Janeiro, foi utilizada a Delimitação das Favelas do Município do Rio de Janeiro mais recente (20 I0), produzida pelo IPP. Foram utilizados também os segmentos de ruas com a informação por CEP.

Para a identificação dos CEPs nas áreas de favelas utilizou-se o ambiente de Sistema de Informação Geográfica (SIG), a ferramenta de seleção por localização. Levando em consideração a distância de até $250 \mathrm{~m}$ da favela selecionada para identificação dos CEPs, foram selecionados os segmentos de ruas dentro dos limites de favela e os segmentos nas áreas do entorno denominados áreas de influência. Posteriormente gerou-se uma camada com esses segmentos de ruas de cada favela escolhida para o levantamento e identificaram-se os CEPs a partir das tabelas dos segmentos de ruas (na Figura I é possível visualizar um exemplo). Esse tratamento foi realizado com o software ArcGIS 10.5.

Com as informações de CEPs localizados nos limites das favelas e nas suas áreas de influência, foi possível contar os casos e os óbitos no sistema de informação Covid por CEP - Rio. Os dados obtidos nessa e nas demais fontes de dados são atualizados quinzenalmente no painel. 
Figura I - Distribuição das favelas com levantamento de casos e óbitos da Covid- 19 por estimativa de CEP e distribuição dos segmentos de ruas da favela Vila Arco Íris, localizada no bairro de Jacarepaguá na Área de Planejamento 4 Exemplo de seleção dos segmentos de ruas de favela e sua área de influência

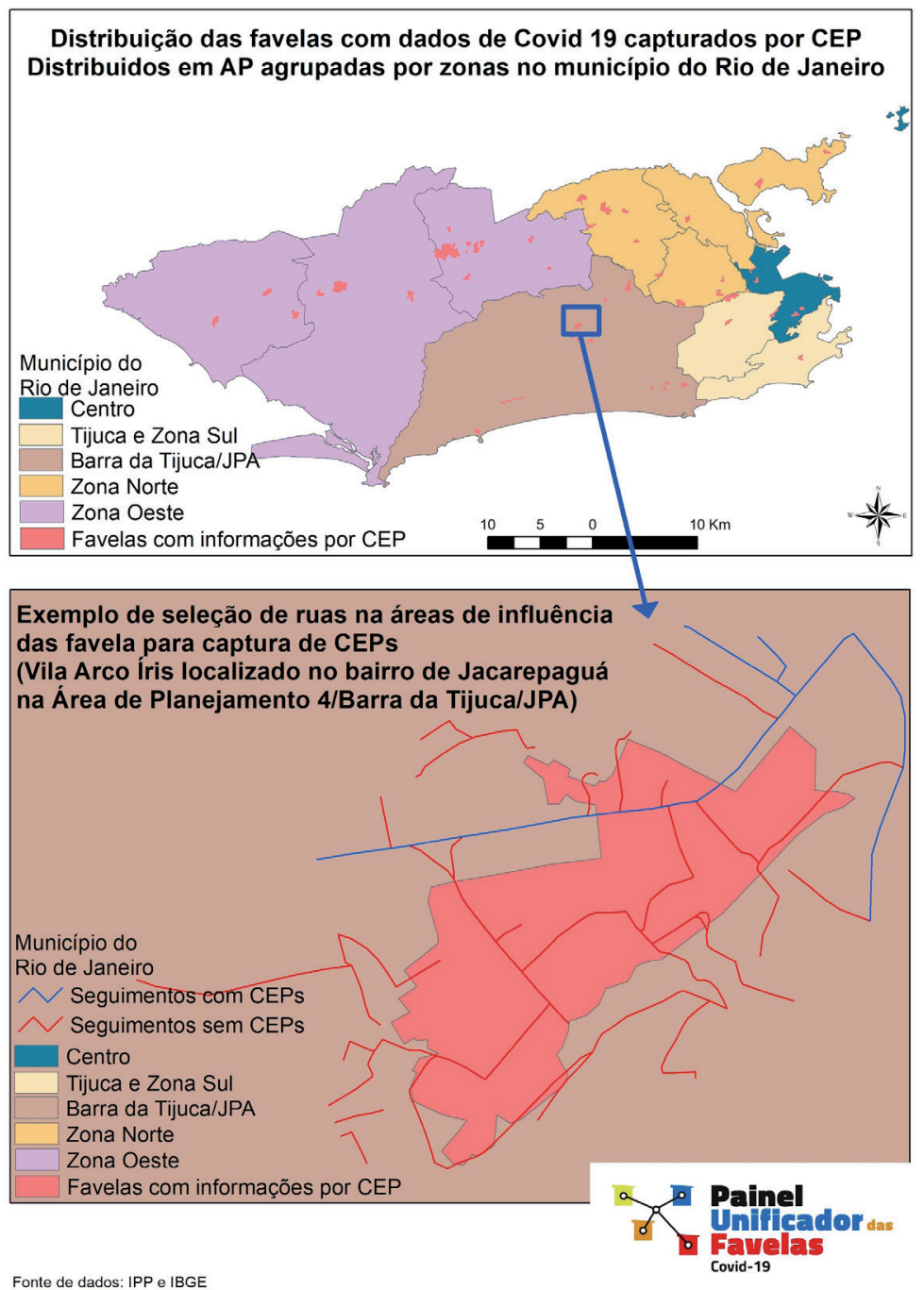




\section{CONSIDERAÇÕES SOBRE A METODOLOGIA DO PAINEL}

O poder público atua nos territórios mediante planejamento e gestão urbana baseados, comumente, em definições e conceitos estabelecidos em estudos e metodologias que ajudam a colocar em prática o controle e o desenvolvimento urbano. A forma como os espaços são organizados deriva de uma lógica contraditoriamente homogeneizadora e heterogeneizadora: ao mesmo tempo que se desconsideram as heterogeneidades locais, criam-se profundas diferenças entre as diversas localidades.

Diferentes conceitos que permeiam o cotidiano urbano, como o de bairro e o de favela, sugerem realidades absolutamente distintas. Segundo o Plano Diretor de Desenvolvimento Sustentável do Município do Rio de Janeiro (201 I), bairros são "porções do território demarcados oficialmente por limites culturalmente reconhecidos pela mesma denominação, sendo unidade territorial de referência na coleta de dados e informações produzidas pelos órgãos do Município e nas ações de planejamento urbano". No mesmo documento, favela é definida como "a área predominantemente habitacional, caracterizada por ocupação clandestina e de baixa renda, precariedade da infraestrutura urbana e de serviços públicos, vias estreitas e alinhamento irregular, ausência de parcelamento formal e vínculos de propriedade e construções não licenciadas, em desacordo com os padrões legais vigentes".

A definição oficial de favela, portanto, está atrelada à ideia de clandestinidade, irregularidade e precariedade, o que, de uma maneira ou de outra, tem impacto direto nas políticas públicas aplicadas nesses territórios. Se um espaço é caracterizado como informal ou ilegal, é dever da Prefeitura formalizá-lo, e essa lógica usualmente indica ações interventoras e amplamente hierarquizadas, que desconsideram os aspectos e peculiaridades locais.

Com a metodologia aplicada no painel, buscou-se sempre checar as informações de domínio público-oficial com os próprios moradores, inquirindo-os, por exemplo, sobre o fato de reconhecerem ou não o nome de determinada favela. Assim, as favelas para as quais havia relatoria local colocadas em forma de complexo no presente estudo foram aquelas reconhecidas desse modo pelos seus habitantes.

Os complexos se desenvolvem a partir do alto crescimento das favelas, que passam a criar, em suas intrincadas relações locais, diferenciações entre si. Surgem, então, favelas com diferentes nomes muito próximas umas das outras, que posteriormente formam um conjunto de favelas, o chamado "complexo". Alguns desses complexos no município do Rio de Janeiro se transformaram em bairros e regiões administrativas, a exemplo do Complexo do Alemão e do Complexo da Maré. 


\section{ANÁLISE DE DADOS}

Quinzenalmente todas essas fontes são consolidadas, tabuladas e inseridas nos mapas em ambiente de Sistema de Informação Geográfica (SIG) (Pina, 2000) e disponibilizadas no painel unificador para que a sociedade civil possa visualizar a si mesma e cobrar dos governantes, e para que os gestores públicos também os acessem de maneira conjunta, para que possam estruturar ações de enfrentamento nos lugares com maior risco para a Covid- 19.

Os levantamentos de dados por todas as fontes foram conferidos e distribuídos em uma planilha onde cada linha representa uma favela ou complexo e as colunas contêm as informações por data de atualização dos casos e dos óbitos adquiridos pelo painel. Esse conjunto de informações se encontra aberto ao público (em Painel Unificador Covid-19 das Favelas, 2020), que poderá fazer análises com outras informações georreferenciadas. Espera-se que dessa forma mais investigações que permitam melhor diagnóstico da situação da Covid- 9 nesses territórios sejam realizadas e que medidas de enfrentamento mais adequadas sejam tomadas.

\section{RESULTADOS}

O Painel Unificador Covid-19 nas Favelas teve seu início no mês de julho de 2020, contemplando 122 favelas nos municípios do Rio de Janeiro e de Mesquita. Desse total, 97 favelas localizam-se na Zona Norte, 19 na Zona Oeste, 4 na Zona Sul, I no Centro e I no município de Mesquita (Figura 2), configurando o total de 140.678 domicílios (de acordo com o IBGE, 2019 e relatores locais) com dados atualizados da pandemia. 
Figura 2 - Favelas contempladas pelo Painel Unificador Covid- 19 nas Favelas e percentual das fontes de dados - Julho de 2020

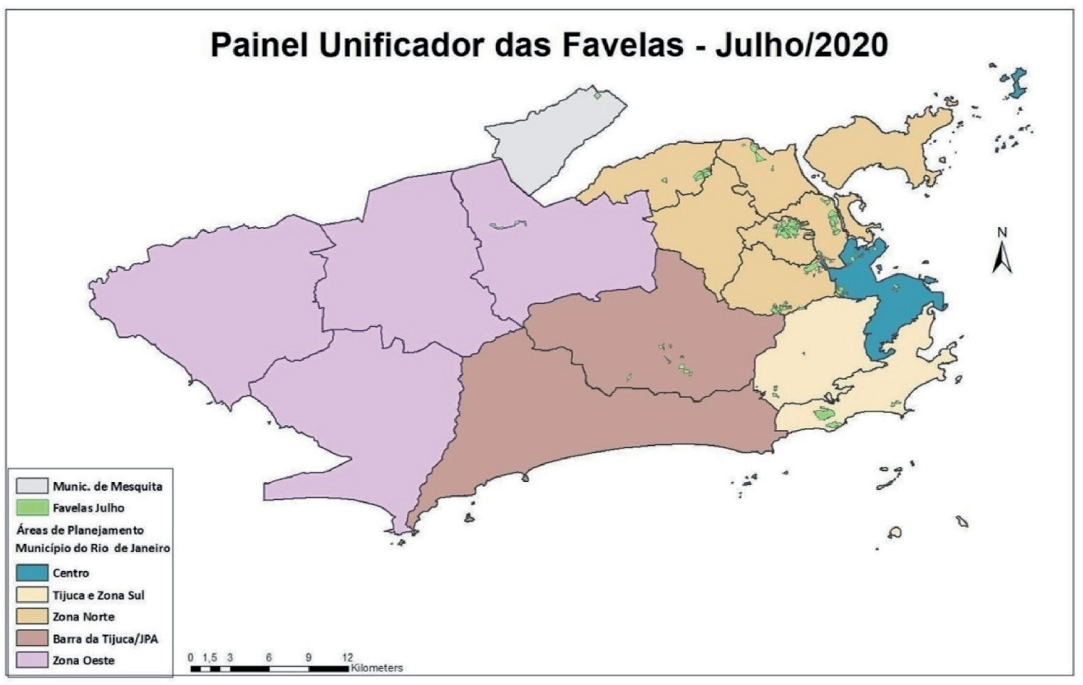

\section{Fontes de dados do Painel Unificador das Favelas - Julho/2020}

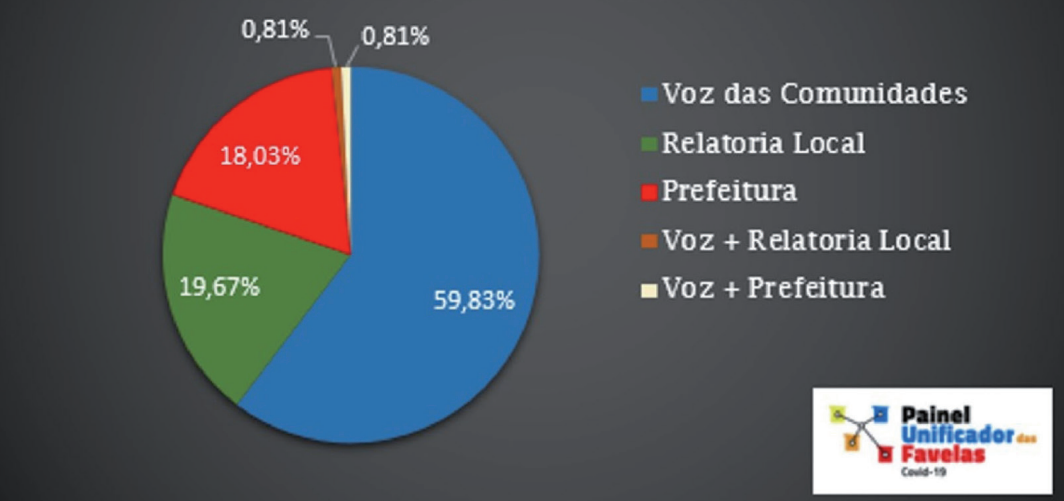

Fonte: Painel Unificador Covid- 19 nas Favelas, 2020.

Do total de 122 favelas, 73 obtiveram dados provenientes do painel do jornal Voz das Comunidades, 24 foram contempladas pela relatoria local, 22 os obtiveram na Prefeitura, I através da união entre Prefeitura e Voz das Comunidades e I da relatoria local em parceria com o Voz das Comunidades (Figura 2). 
Até o mês de dezembro de 2020, a cobertura do Painel Unificador Covid- 19 nas Favelas foi expandida, apresentando dados para 228 favelas nos municípios do Rio de Janeiro, Mesquita e Itaguaí. De acordo com dados do IBGE (2019) acerca dos AGSNs, o município do Rio de Janeiro apresenta 450.438 domićlios em áreas de favelas. $\mathrm{Na}$ contagem de domicílios do IBGE, as 228 favelas incluídas em nossa análise em dezembro possuem cerca de 290.983 domićlios, o que corresponde a 64,6\% dos domicílios dos AGSNs no Rio de Janeiro (Figura 3).

Figura 3 - Favelas contempladas pelo Painel Unificador Covid- 19 nas Favelas e percentual das fontes de dados - Dezembro de 2020
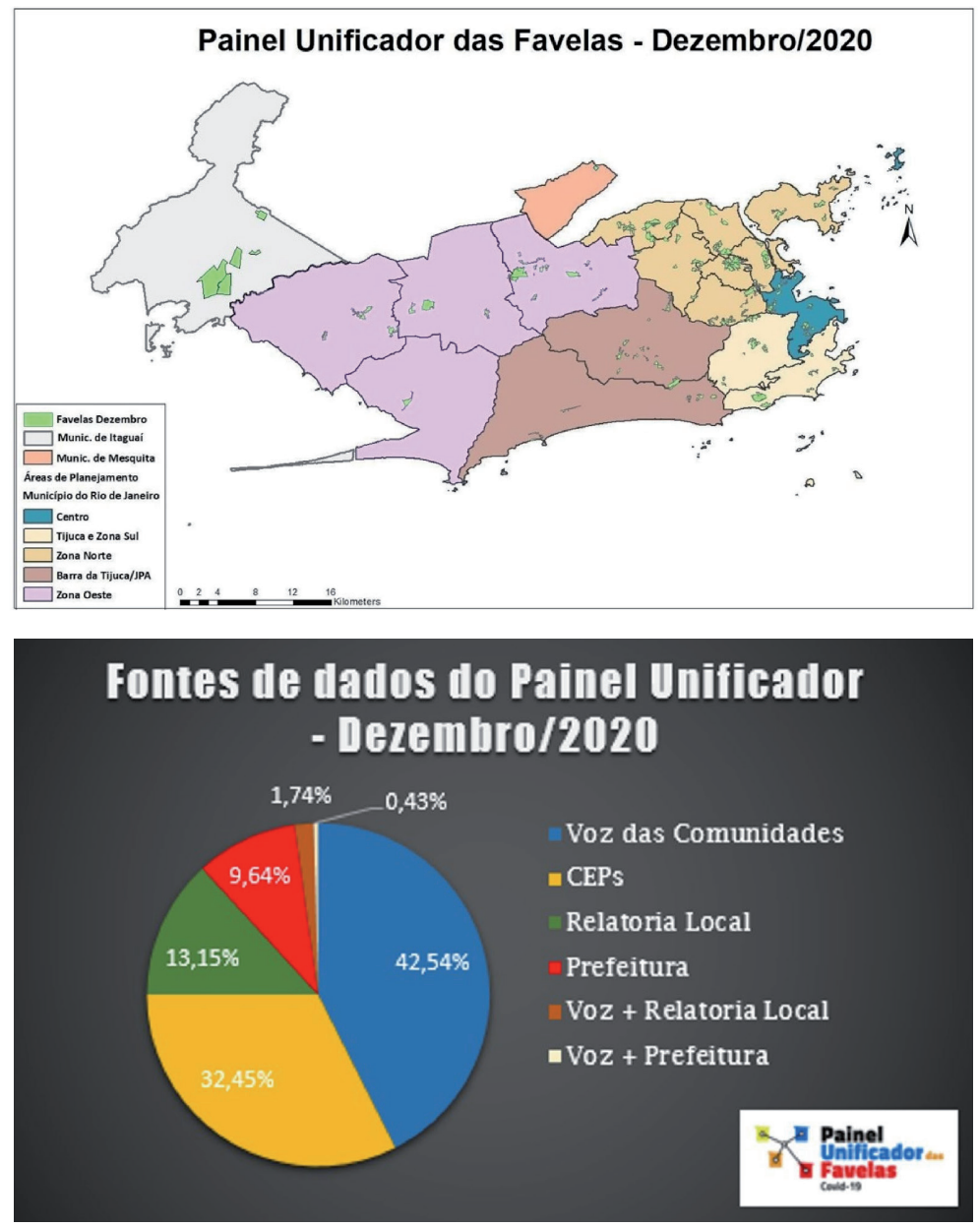

Fonte: Painel Unificador Covid-19 nas Favelas, 2020. 
A observação das figuras 2 e 3 permitiu verificar a expansão da distribuição das favelas com informações no Painel Unificador Covid- 19 nas Favelas do município do Rio de Janeiro e de alguns municípios da Baixada Fluminense.

Do total de 228 favelas, 97 obtiveram dados provenientes do Voz das Comunidades, 74 através do mapeamento por CEPs, 30 pela relatoria local, 22 através de números da Prefeitura, 4 através da combinação entre Voz das Comunidades e relatoria local e I através da união entre Prefeitura e Voz das Comunidades (Figura 3).

A origem diversa das fontes utilizadas no painel gera diferentes respostas numéricas. Para exemplificá-lo, selecionamos quatro comunidades com maior número de casos cujas informações derivam das quatro fontes de dados utilizadas pelo painel, objetivando explicar de forma mais clara as diferenças entre cada uma.

\section{Complexo da Maré e a Redes da Maré}

De acordo com os dados disponíveis no Painel Unificador Covid-19 nas Favelas, o Complexo da Maré, composto por 16 favelas e 24.016 domicílios (IBGE, 2019), apresenta o maior número de casos confirmados: 2.449 até o dia 7 de dezembro de 2020. O Painel da Prefeitura, na mesma data, apresentava 1.063 casos confirmados, o que representa $56,59 \%$ a menos do que o painel unificador registrou. Em relação à quantidade de óbitos, os números apresentam uma diferença menor: I 58 no painel unificador e 137 no painel da Prefeitura.

Esse número, porém, deve ser observado com cautela, visto que o Complexo da Maré é uma comunidade amplamente mapeada e desde o mês de abril realizou o monitoramento de moradores sintomáticos, por meio da campanha "De Olho no Corona!". A partir de julho, com o lançamento do projeto "Conexão Saúde: de olho no corona", os moradores sintomáticos passaram a ser encaminhados para a testagem, por meio do aplicativo do projeto. Com isso, o número de casos suspeitos caiu e o de confirmados aumentou (Angelo, Leonardo e Perissé, 2020).

A Redes da Maré é uma organização social que atua desde 1997 em diversas frentes como educação, cidadania, arte, cultura, desenvolvimento territorial, entre outras. Seu conhecimento prévio e profundo do território do Complexo da Maré foi uma ferramenta indispensável no mapeamento dos casos e óbitos nessa comunidade.

\section{Comunidade do Engenho (Itaguaí) e a relatoria local}

A Comunidade do Engenho, no município fluminense de Itaguaí, possui cerca de 3.000 domicílios e aparece em segundo lugar no número de casos no painel unificador, 
com 1.57 I casos e 212 óbitos, superando inclusive o Complexo da Maré em número de mortos. Isso significa dizer que a Comunidade do Engenho responde por 6, I4\% dos casos e 7,37\% dos óbitos registrados no Painel Unificador Covid- 19 nas Favelas.

O número de casos e óbitos registrados é mais alto do que em favelas de grande porte como a Rocinha. Isso pode ser atribuído às pesquisas em campo realizadas pela relatoria local por intermédio da Associação de Mulheres de Itaguaí - Guerreiras e Articuladoras Sociais (A.M.I.G.A.S.), que efetuaram visitas, entrevistas e anotações nos domicílios locais desde março. Essa espécie de procedimento, realizada regularmente, confere alta confiabilidade aos dados e constitui um belo exemplo de vigilância participativa na saúde.

\section{Rocinha e o Voz das Comunidades}

A Rocinha, localizada na Zona Sul do Rio de Janeiro, é a maior favela do país, com 25.742 domicílios, e mesmo antes da pandemia já apresentava outras questões prévias de saúde pública, como, por exemplo, a alta incidência de tuberculose entre seus moradores (Fiocruz/Ensp, 2020a, 2020b). Atualmente ela aparece em quinto lugar no Painel Unificador Covid- 19 nas Favelas, com 917 casos e 62 óbitos, que correspondem, respectivamente, a $3,58 \%$ e $2,15 \%$ dos casos totais registrados no painel.

A iniciativa do Voz das Comunidades, responsável pela aquisição de dados da Rocinha, foi a primeira a colocar em prática os dados da Covid- 19 nas favelas cariocas, no dia 10 de abril de 2020. Atualmente conta com 25 favelas e complexos listados e compila os dados de diversas fontes como, por exemplo, Clínicas das Família, Prefeitura do Rio, governo estadual do Rio de Janeiro, dentre outros.

\section{Muzema e o mapeamento por CEPs}

A favela da Muzema, no bairro da Zona Oeste do Rio de Janeiro, Itanhangá, tem 2.514 domicílios (IBGE, 2019). Dentre as favelas mapeadas por CEPs, aparece em primeiro lugar, com 56 I casos e 27 óbitos, representando 0,02\% dos casos e 0,97\% dos óbitos registrados no Painel Unificador Covid- 19 nas Favelas até dezembro.

O mapeamento de casos por meio dos CEPs, por áreas de influência, é uma ferramenta indispensável para a obtenção de dados em áreas cujos dados são escassos ou nulos. No caso da Muzema, havia 32 segmentos de ruas contidos na favela; desses, 17 apresentavam CEPs, totalizando $53,12 \%$ das ruas contempladas por CEPs. Foi contabilizado o total de 4 CEPs nessa região, criando-se assim um banco de dados para a favela baseado na proximidade geográfica. 
Conforme os casos supracitados das favelas de Itaguaí e do Complexo da Maré, é possível observar que as localidades cujas ações são mais organizadas por suas lideranças locais estão sendo capazes de informar mais dados a respeito da Covid- 19 (casos e óbitos) e, além disso, estão conseguindo maior apoio para enfrentamento da pandemia, tanto de instituições públicas quanto privadas.

Figura 4 - Delimitação territorial do Complexo da Maré, da Comunidade do Engenho (Itaguaí), da Rocinha e da favela da Muzema
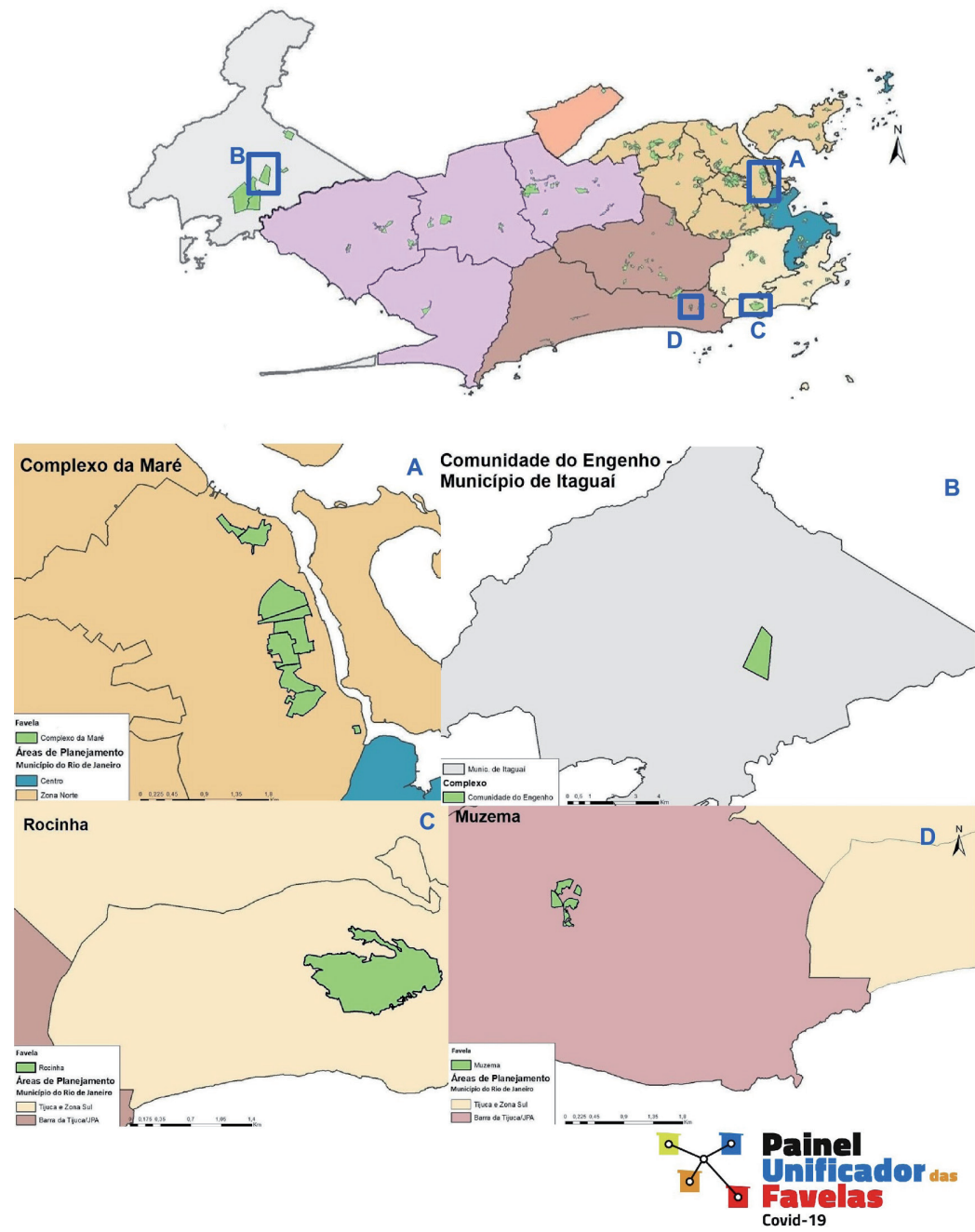

Fonte: Painel Unificador Covid- I 9 nas Favelas, 2020. 


\section{LIMITAÇÕES}

Para entendermos as limitações dos diferentes levantamentos, é importante destacar alguns aspectos dos métodos de aquisição de dados. Por exemplo, a ausência de informação de CEPs para uma média de 58\% dos segmentos de ruas contidas nos limites das favelas e em suas áreas de influência mapeadas até o presente momento pode gerar subnotificação de dados. Além disso, os dados são relativos somente aos casos e óbitos confirmados, e nos territórios de favela a quantidade de testes para Covid- 19 disponibilizada é menor do que no restante da cidade (Angelo, Leonardo E Perissé, 2020). E nas comunidades em que as informações são fornecidas por relatores locais não ocorre levantamento por CEP, pois acredita-se que este método seja mais próximo da realidade do total de casos e óbitos de Covid- 19 do que os levantamentos feitos pela SMS-RJ, que contabilizam os dados confirmados por teste.

Outra limitação diz respeito às relatorias locais, que em algumas favelas eram potencialmente ativas e, no momento atual, não estão conseguindo manter a contagem devido a pressões culturais, políticas ou de poder locais.

No painel existe também a possibilidade do preenchimento do formulário anônimo de autovaliação, porém este não tem gerado um número robusto de preenchimentos.

\section{RELEVÂNCIA DO MÉTODO}

Na pandemia, a questão emergencial ressaltou o abismo que ainda temos entre capacidade tecnológica para mapeamento de dados e a realidade com suas limitações sociais e humanas, sobretudo nos países em desenvolvimento como o Brasil, com alto índice de disparidade social. Assim, ainda que possa parecer implícito, vale ressaltar que o acesso à informação e o mapeamento da situação mais próxima do real da pandemia por meio de ciência de dados cidadã (Silvertown, 2009) nas favelas e comunidades periféricas foram cruciais para informar moradores e o poder público e salvar vidas.

Para garantir a mais alta qualidade metodológica, seguimos algumas orientações já padronizadas pela academia (Silvertown, 2009), como: I) os dados coletados pelo público devem ser validados de alguma forma; 2) os métodos de coleta de dados devem ser bem concebidos e padronizados; 3) o máximo possível de suposições deve ser explicitado; 4) é desejável ter uma hipótese em mente, mesmo que seja apenas uma questão; 5) os voluntários devem receber feedback sobre suas contribuições ou recompensa pela participação.

Os projetos de ciência de dados cidadã, com abordagem multidisciplinar e metodologia colaborativa, têm ganhado grande relevância nos últimos anos por permitirem 
maior proximidade, entendimento e acesso aos dados, em áreas normalmente menos tangíveis pelas metodologias oficiais. O método de ciência de dados cidadã também permitiu viabilizar a construção do conhecimento sobre análise espacial pelas populações locais, respeitando sua cultura e aspectos sociais. Ainda que existam muitos desafios e limitações no método, a relevância e os benefícios alcançados com o acesso à informação são evidentes.

Um fato importante e que pode aumentar o número de análises dos dados do painel é a disponibilização para o público dos dados da série histórica. Assim, mais pesquisadores, gestores e a sociedade civil terão acesso, e quanto mais pessoas analisarem esses dados, maior será a chance de que políticas e ações de enfrentamento à pandemia sejam propostas.

\section{CONCLUSÃO}

O Painel Unificador Covid- 19 nas Favelas incorpora diferentes fontes e formas de aquisição de dados, gerando informações para territórios que antes apresentavam grandes vazios ou defasagem de referências acerca da Covid- 19. Em um futuro próximo, alguns caminhos se apresentam como possibilidades.

A metodologia participativa utilizada pelo Painel Unificador Covid- 19 nas Favelas, baseada em informações das lideranças locais, pode auxiliar na discussão acerca das nomenclaturas das favelas. Desse modo, será possível propor e realizar conversas com instituições como o IPP e o IBGE sobre os nomes com os quais as populações das favelas se reconhecem.

Pretende-se dar continuidade às buscas de dados pelos CEPs visando a atingir cobertura maior que $90 \%$ das áreas de favelas para que seja possível calcular outros indicadores, como letalidade, por exemplo, e comparar os dados dos territórios de favelas com os de outras áreas da cidade. Após o levantamento de dados da maioria das favelas do município do Rio de Janeiro será possível fazer análises com outras informações que auxiliem na identificação da situação de saúde das populações desses territórios em relação à cidade como um todo.

Além disso, no próximo ano assumem prefeitos (novos e reeleitos) e os vereadores, secretários e demais participantes da gestão pública. Pretende-se conversar com os governantes sobre os resultados encontrados pelo painel unificador para cobrar medidas mais eficazes no enfrentamento da pandemia, como, por exemplo, investimentos nas clínicas de Saúde da Família para que atendam esses territórios de maneira mais adequada. 
A segunda onda ou o repique da primeira onda (Castro E Perissé, 2020) torna a continuidade do painel ainda mais importante para os moradores e lideranças locais. O painel vai continuar informando com base nas suas diferentes fontes de dados para evidenciar a importância de mais medidas de enfrentamento da pandemia para proteção dessas populações. Essa iniciativa mostra a importância da vigilância cidadã.

A divulgação realizada pelo Painel Unificador do Covid- 19 nas Favelas ajuda a dialogar com a população, a melhor diagnosticar a situação do Covid- 19 nas favelas e a apontar os territórios de maior risco e com maior necessidade de apoio para o enfrentamento da pandemia, em consonância com o preconizado no pacto pela democratização e qualidade da informação e comunicação em saúde (Silva, Cruz \& Melo, 2007).

A divulgação realizada pelo Painel Unificador do Covid-1 9 nas Favelas é um bom exemplo da ciência cidadã e da democratização da divulgação de informação em saúde utilizadas de maneira conjunta, pois contém informações levantadas pela sociedade civil e também pela SMS manipuladas com técnicas de geoprocessamento para identificação de uma população específica. Mais levantamentos para análises epidemiológicas comparativas com as outras áreas da cidade do Rio de Janeiro ainda são necessários, mas esse painel constitui um avanço para as populações que em geral necessitam de mais atenção do poder público e muitas vezes são tratadas em conjunto com os bairros da cidade. Trata-se de uma ferramenta de diagnóstico mais detalhada, que permite maior proximidade da realidade e soluções mais assertivas também.

\section{REFERÊNCIAS}

ANGELO, J. R.; LEONARDO, B. B. S. E PERISSÉ, A. R. S. Boletim socioepidemiológico da Covid nas favelas. Nota Técnica. Rio de Janeiro: Fiocruz, 2020. Disponível em: <www.arca.fiocruz.br/handle/ icict/44450>. Acesso em: nov. 2020.

CASTRO, H. A. \& PERISSÉ, A. R. S. Documento sobre retorno às atividades no Brasil em vigência da pandemia Covid- 19 - 30/I I/2020: segunda onda, "repique" ou evolução natural dos casos após o relaxamento das medidas não farmacológicas? O que os dados parecem indicar? Nota Técnica. Rio de Janeiro: Ensp/Fiocruz, 2020.

CAVALIERI, F. E VIAL, F. A nova classificação de favelas para o planejamento das políticas públicas. Rio de Janeiro: IPP, 2012. Disponível em: <https://bit.ly/2ZbGDdc>. Acesso em: dez. 2019.

CZERESNIA, D. E FReITAS, C. M. Promoção da Saúde: conceitos, reflexões, tendências. 2. ed. Rio de Janeiro: Editora Fiocruz, 2009.

DAVIS, M. Planeta Favela. Trad. Beatriz Medina. São Paulo: Boitempo, 2006.

FUNDAÇÃO OSWALDO CRUZ. ESCOLA NACIONAL DE SAÚDE PÚBLICA SERGIO AROUCA (FIOCRUZ/ENSP). Caso da Rocinha expõe desigualdades estruturais das populações de favelas no enfrentamento à pandemia. Informe Ensp, 22 abr. 2020a. 2 p. Disponível em: <www.arca.fiocruz.br/ handle/icict/40952 >. Acesso em: nov. 2020. 
ESCOLA NACIONAL DE SAÚDE PÚBLICA/FUNDAÇÃO OSWALDO CRUZ (FIOCRUZ/ENSP). Especialistas falam sobre caso da Rocinha no combate à Covid-19, 27 abr. 2020b. Disponível em: $<$ https://portal.fiocruz.br/noticia/especialistas-falam-sobre-caso-da-rocinha-no-combatecovid-19>. Acesso em: ago. 2020.

GOODCHILD, M. F. ; FU, P. \& RICH, P. Sharing geographic information: an assessment of the Geospatial One-Stop. Annals of the Association of American Geographers, 97(2): 249-265, 2007.

HARVEY, D. 200 I. Condição Pós-Moderna: uma pesquisa sobre as origens da mudança cultural. 10 ed. São Paulo: Loyola, 200 I

INSTITUTO BRASILEIRO DE GEOGRAFIA E ESTATÍSTICA (IBGE). Base de dados tabular, 20 I 9. Disponível em: $<$ www.ibge.gov.br/geociencias/organizacao-do-territorio/tipologias-do-territorio/ 15788 -aglomeradossubnormais.html?edicao $=27720 \varepsilon t=$ acesso-ao-produto $>$. Acesso em: maio 2020.

INSTITUTO BRASILEIRO DE GEOGRAFIA E ESTATÍSTICA (IBGE). Aglomerados subnormais 20I9: classificação preliminar e informações de saúde para o enfrentamento à Covid-19. Notas técnicas. Rio de Janeiro, 2020. Disponível em: < https://biblioteca.ibge.gov.br/index.php/biblioteca-catalogo?view $=$ detalhesEid $=2101717>$. Acesso em: maio 2020 .

MAGGIOLA, T. Nas favelas, $80 \%$ das famílias estão vivendo com menos da metade de sua renda prépandemia. RioOnWatch, 15 jul. 2020. Disponível em: <https://rioonwatch.org.br/?p=48652>. Acesso em: out. 2020.

MESENTIER, T. Covid por CEP - Rio. Disponível em: <https://covidporcep.rio.br/>. Acesso em: set. 2020.

ORGANIZAÇÃO MUNDIAL DA SAÚDE (OMS). Vigilância mundial da Covid-I9 causada por infecção humana pelo vírus Covid-19, 20 mar. 2020. Disponível em: <https://apps.who.int/ iris/bitstream/handle/I0665/33 I 23 I/WHO-20I 9-nCoV-SurveillanceGuidance-2020.4-por. pdf? sequence $=33$ EisAllowed $=y>$. Acesso em: ago. 2020.

PAINEL UNIFICADOR COVID- I 9 NAS FAVELAS. Dados públicos. Disponível em: < https://docs.google. com/spreadsheets/d/I iEVZZG5ZO06zsop6GbeoKGQQrnaL6D_vMnID-q5u0vY/edit\#gid=0>. Acesso em: I set. 2021.

PASTERNAK, S. E D'OTTAVIANO, C. Favelas no Brasil e em São Paulo: avanços nas análises a partir da leitura territorial do Censo de 2010. Cadernos Metrópole, 18(35): 75-100, 2016.

PINA, M. F. Conceitos básicos de cartografia para utilização em Sistemas de Informações Geográficas. In: CARVALHO, M.; PINA, M. F. \& SANTOS, S. (Orgs.). Conceitos Básicos de Sistemas de Informações Geográficas e Cartografia Aplicadas à Saúde. Brasília: Opas, Ripsa, 2000.

RIO DE JANEIRO. Plano Diretor, 20II. Disponível em: <www.rio.rj.gov.br/web/smu/ exibeconteudo?id=2879239> . Acesso em: ago. 2020.

SANTOS, M. Por Uma Outra Globalização: do pensamento único à consciência universal. Rio de Janeiro: Record, 2012

SILVA, A. X.; CRUZ, E. A. \& MELO, V. A importância estratégica da informação em saúde para o exercício do controle social. Ciência E Saúde Coletiva, 12(3): 683-688, 2007.

SILVA, G. A. P. \& VIEIRA-DA-SILVA, L. M. Vigilância em saúde: proposta de ferramenta para avaliação de arranjos tecnológicos nos sistemas locais de saúde. Cadernos de Saúde Pública, 24(I I): 2.463-2.475, 2008. 
SILVERTOWN, J. A new dawn for citizen science. Trends in Ecology E Evolution, 24(9): 467-47I, 2009. Disponível em: < https://doi.org/https://doi.org/I 0.10 I6/j.tree.2009.03.0 I 7>. Acesso em : out. 2020.

TURNER, A. Introduction to Neogeography. Sebastopol: O’Reilly Media, 2006.

VOZ DAS COMUNIDADES. Painel Voz das Comunidades. Disponível em: <https://painel. vozdascomunidades.com.br >. Acesso em dezembro, 2020.

WILKINSON, A. Resposta local em emergências de saúde: principais considerações para abordar a pandemia Covid- 19 em assentamentos urbanos informais. Environment and Urbanization, 5 maio 2020. Disponível em: < https://journals.sagepub.com/doi/full/I 0.1 I 77/0956247820922843>. Acesso em: nov. 2020.

WORLDOMETERS, 2009. Real time world statistics. Disponível em: <www.worldometers.info/ coronavirus/>. Acesso em: 8 out. 2020.

\section{Créditos do Painel Unificador Covid-19 nas Favelas}

Realização: Comunidades Catalisadoras (ComCat)

Parceiros: A.M.I.G.A.S. | Centro Social Fusão | Coletivo Conexões Periféricas-RP | Covid por CEP | Data_Labe | Fala Roça | Favela Vertical | Fiocruz | Fórum Grita Baixada | Frente de Mobilização da Maré | Instituto Educacional Araujo Dutra | Labjaca | Maré de Notícias | Mulheres de Frente | Observatório de Favelas | PerifaConnection | Redes da Maré | SOS Providência | TETO | Voz das Comunidades | WikiFavelas

Desenvolvimento e atualizações: Esri - Environmental Systems Research Institute

Dados demográficos: Prefeitura Rio e IBGE 2010

Tecnologia de integração: Integromat

Vídeo de divulgação: Labjaca (veja video.favela.

DadosSalvamVidas\#DadosSãoPoder\#Covid I 9NasFavelas\# PainelUnificadorDasFavelas 


\section{Tempo dos Dados}

\section{explorando a cobertura e oportunidade dos sistemas de informação Sivep Gripe e e-SUS VE}

Diego Ricardo Xavier, Raphael de Freitas Saldanha, Mônica de Avelar Figueiredo Mafra Magalhães e Christovam Barcellos

\section{SISTEMAS DE INFORMAÇ̃̃O DE SAÚDE}

7 Organização Mundial da Saúde (OMS) define sistema de informação em saúde como - um mecanismo de coleta, processamento, análise e transmissão da informação necessária para planejar, organizar, operar e avaliar os serviços de saúde. Essa definição se traduz na concepção de um sistema de informação que sistematize as questões referentes a demanda e acesso, subsidie o monitoramento e eventual reformulação de políticas e programas, atenda à estrutura organizacional do serviço de saúde e busque responder a objetivos estratégicos em diferentes níveis administrativos e operacionais para tomada de decisão (Souza, 201 I).

As informações coletadas segundo os diferentes sistemas de informação em saúde são disseminadas pelo Departamento de Informática do Sistema único de Saúde, o Datasus. O decreto n. 4.194 de II de abril de 2002 definiu as competências do Datasus (Brasil, 2002), dentre as quais se destaca a coordenação da implementação do sistema nacional de informação em saúde (Brasil, 2002). Além disso, ao longo de sua trajetória o Datasus tem desenvolvido pesquisas que incorporam tecnologias de informática possibilitando a implementação de sistemas e a disseminação de informações necessárias às ações de saúde e mantido o acervo das bases de dados necessárias ao sistema de informações em saúde.

As informações disponibilizadas pelos sistemas de informação em saúde e os indicadores elaborados com base nelas servem de subsídio à vigilância e monitoramento em saúde. Nesse sentido, é importante considerar três campos de conhecimento de natureza interdisciplinar cujas disciplinas básicas são a epidemiologia, as ciências sociais em saúde e o planejamento e gestão (Paim \& Almeida Filho, 1998). A epidemiologia atua 
na produção do conhecimento científico com uma mirada basicamente quantitativa, o campo social reúne análises com base em métodos qualitativos e atua na promoção da saúde, e o planejamento e gestão da saúde atua na formulação, monitoramento e avaliação de políticas e ações (Brasil, 2013).

Entre os principais objetivos da vigilância em saúde estão a identificação de tendências, de grupos especialmente vulneráveis e de fatores de risco com vistas a elaborar estratégias e controles específicos para eventos adversos à saúde; a descrição de padrões de ocorrência de doenças; a pronta detecção de surtos e epidemias; a documentação e a análise de padrões de disseminação de doenças; a estimação da magnitude da morbidade, mortalidade e carga de doenças secundárias a determinados agravos, acompanhada da formulação de recomendações com bases objetivas e científicas a fim de prevenir ou controlar a ocorrência de agravos específicos à saúde; a avaliação do impacto de medidas de intervenção; e a adequação de estratégias de aplicação de medidas de intervenção, com base em seus fundamentos técnicos e em sua factibilidade, aceitabilidade e operacionalização (Waldman, 1998).

Portanto, o objetivo da vigilância não se restringe à coleta e análise das informações; também lhe cabe a responsabilidade de elaborar, com fundamento em conhecimentos científicos, técnicas que oferecerão subsídios aos serviços de saúde no planejamento e implementação dos programas de saúde com a preocupação de contínuo aprimoramento, assim como de identificar agilmente situações cujo controle demande intervenção oportuna.

É importante considerar aspectos dos sistemas de informações para a vigilância em saúde de forma que as informações se prestem ao objetivo final. Dentre os atributos a serem considerados, o sistema deve ser avaliado de acordo com: utilidade (o sistema está alcançando seus objetivos), oportunidade (apresenta agilidade para intervenção), aceitabilidade (disposição favorável dos profissionais que conduzem o sistema possibilitando informações exatas, consistentes e regulares), simplicidade (compreensível e pouco dispendioso), flexibilidade (adapta-se facilmente a novas necessidades), representatividade (quanto a características demográficas, local ou uso de serviços de saúde ou exposição a riscos), sensibilidade (identificar os verdadeiros casos), valor preditivo positivo (observando-se que um baixo valor preditivo positivo exige a investigação de casos que de fato não ocorreram) (Waldman, 1998). Lima e colaboradores (2012) destacam entre as principais dimensões da avaliação nove aspectos: acessibilidade, clareza metodológica, cobertura, completitude, consistência, confiabilidade, não duplicidade, oportunidade e validade. 


\section{A INFORMAÇÃO NA PANDEMIA DE COVID-19}

A pandemia de Covid- 19 trouxe para os sistemas de informação de saúde a necessidade de produzir informação em uma velocidade nunca vista antes. Considerando os sistemas de informação implantados antes do período epidêmico, seria natural que os dados de Covid- 19 fossem distribuídos nos seguintes sistemas: Sinan (Sistema de Informação de Agravos de Notificação) com casos notificados, SIH (Sistema de Informações Hospitalares) com casos de internação e SIM (Sistema de Informação de Mortalidade) com óbitos. Entretanto, a dinâmica da epidemia exigiu maior celeridade da informação para enfrentamento da doença, e esses sistemas apresentam uma defasagem entre a coleta dos dados, sua consolidação e a disseminação das informações que impossibilitaria a tomada de decisão imediata, e por vezes diária, com base na informação.

Com isso, durante a pandemia de Covid- 19 três bases de dados passaram a compor as informações sobre o processo epidêmico, o Sistema de Informação da Vigilância Epidemiológica da Gripe (Sivep Gripe), o e-SUS VE e os boletins das secretarias estaduais de Saúde (SES) que utilizam estes sistemas para sua elaboração. Essa estratégia teve como consequência ganho na velocidade da informação. Contudo, ficou evidente que conhecer a data de ocorrência dos eventos (casos e óbitos) é de extrema relevância para o enfrentamento da pandemia de Covid- 19.

Durante esta pandemia a população tem acompanhado os números baseados na data de divulgação dos dados que são informados pelos boletins estaduais e municipais e posteriormente consolidados e disponibilizados pelo Ministério da Saúde e por outras iniciativas como o Brasil.IO, Consórcio de Imprensa, entre outros. Esses dados são coletados pelo serviço de saúde e registrados em dois principais sistemas de informação: o Sivep Gripe e o e-SUS VE. Os casos hospitalizados de síndrome respiratória aguda grave (Srag) e os óbitos são notificados no Sivep Gripe. Além desses dados, as unidades de vigilância sentinela de síndrome gripal registram casos de síndrome gripal (SG) seguindo fluxos estabelecidos para a vigilância da influenza e outros vírus respiratórios. Todos os hospitais públicos ou privados devem notificar os casos de Srag hospitalizados no Sivep Gripe.

O e-SUS VE registra a notificação de casos suspeitos e confirmados de Covid- 19 e foi desenvolvido pelo Datasus para atender à alta demanda de notificações devida à pandemia. Os casos de SG devem ser notificados pelas unidades públicas ou privadas (unidades de atenção primária, consultórios, clínicas, centros de atendimento, pronto atendimento, entre outros de baixa complexidade) por meio do sistema e-SUS Notifica (Brasil, 202 Ia). 
Cabe ressaltar que, segundo a orientação do Ministério da Saúde, os óbitos por Srag devem, independentemente de hospitalização, ser notificados no Sivep Gripe. Nas situações onde o óbito por Srag ocorra em municípios que não possuem cadastro no Sivep Gripe, por não terem unidade hospitalar, orienta-se que o cadastro no sistema ocorra via Cadastro Nacional de Estabelecimentos de Saúde (CNES) de seus serviços de vigilância epidemiológica para a correta e oportuna notificação (Brasil, 202 l b).

Neste capítulo buscamos, com base nesses dois sistemas de informação e nos dados divulgados nos boletins epidemiológicos das secretarias estaduais de Saúde, avaliar a data de ocorrência dos eventos, considerando a data de início de sintomas preenchida no e-SUS VE para contabilização de casos e data de ocorrência do óbito no Sivep Gripe.

Os casos de Covid- 19 foram selecionados considerando-se o total de registros do e-SUS VE: 10.055.625 até 3 de agosto de 2020. A esses dados foi aplicado o filtro na variável "resultadoTeste $=$ Positivo". Também foram filtrados os casos de Covid- 19 da base de dados do Sivep Gripe considerando a variável "CLASSI_FIN = Covid-19" até a data de 3 de agosto de 2020. Três informações são apresentadas na Tabela I: os dados dos boletins estaduais que compõem a base de dados do Ministério da Saúde, os casos de Covid- 19 filtrados na base do e-SUS VE e a soma de casos filtrados no Sivep Gripe e no e-SUS VE.

Considerando-se a variação percentual entre os bancos de dados, observa-se que no Brasil os dados segundo o e-SUS VE apresentam diferença de 10\% em relação ao observado nos boletins das secretarias estaduais, e somando-se os casos do Sivep Gripe essa variação passa a 4\%. Os estados do Espírito Santo e Paraná apresentam a maior variação percentual na comparação com os dados do Ministério da Saúde. Nesses estados, os números de casos divulgados nos boletins são muito maiores que os casos filtrados nos demais bancos. Situação inversa é observada nos estados de Goiás, Piauí e Rio Grande do Norte, onde o volume de casos registrados nesses sistemas é superior ao observado nos boletins epidemiológicos. 
Tabela I - Casos de Covid- 9 segundo o e-SUS VE, o Sivep Gripe e o Ministério da Saúde até 03/08/2020

\begin{tabular}{|c|c|c|c|c|c|c|}
\hline \multirow{2}{*}{ UF } & \multicolumn{4}{|c|}{ Casos Covid- 19} & \multicolumn{2}{|c|}{ Variação \% } \\
\hline & e-sus & Sivep & e-SUS + Sivep* & MS & e-SUS + Sivep* & e-sus \\
\hline$A C$ & 17.887 & 337 & 18.224 & 20.339 & 10 & 12 \\
\hline$A L$ & 70.160 & 2.085 & 72.245 & 62.778 & -15 & -12 \\
\hline AM & 93.423 & 5.494 & 98.917 & 102.386 & 3 & 9 \\
\hline$A P$ & 28.958 & 393 & 29.351 & 36.804 & 20 & 21 \\
\hline$B A$ & 175.465 & 5.366 & $|80.83|$ & 171.391 & -6 & -2 \\
\hline CE & 163.378 & 9.192 & 172.570 & |76.96| & 2 & 8 \\
\hline DF & 48.881 & 4.423 & 53.304 & 112.044 & 52 & 56 \\
\hline ES & 4.528 & 984 & 5.512 & 85.215 & 94 & 95 \\
\hline $\mathrm{GO}$ & 91.955 & 3.118 & 95.073 & 70.252 & -35 & -31 \\
\hline$M A$ & 116.388 & 2.219 & 118.607 & 122.482 & 3 & 5 \\
\hline MG & 89.865 & 8.572 & 98.437 & 133.743 & 26 & 33 \\
\hline MS & 29.516 & 1.469 & 30.985 & 26.645 & -16 & -11 \\
\hline MT & 28.580 & 11.670 & 40.250 & 54.711 & 26 & 48 \\
\hline $\mathrm{PA}$ & 101.861 & 7.296 & 109.157 & 156.505 & 30 & 35 \\
\hline $\mathrm{PB}$ & 89.956 & 2.502 & 92.458 & 84.211 & -10 & -7 \\
\hline PE & 76.803 & 8.322 & 85.125 & 98.401 & 13 & 22 \\
\hline $\mathrm{PI}$ & 68.206 & 3.382 & 71.588 & 53.224 & -35 & -28 \\
\hline PR & 6.222 & 5.828 & 12.050 & 80.865 & 85 & 92 \\
\hline $\mathrm{RJ}$ & 156.773 & 17.211 & 173.984 & 168.064 & -4 & 7 \\
\hline RN & 60.664 & 2.006 & 62.670 & 52.030 & -20 & -17 \\
\hline RO & 40.782 & 854 & 4.1636 & 40.016 & -4 & -2 \\
\hline RR & 30.738 & 115 & 30.853 & 33.188 & 7 & 7 \\
\hline RS & 87.190 & 6.282 & 93.472 & 71.479 & -31 & -22 \\
\hline SC & 101.388 & 3.437 & 104.825 & 88.889 & -18 & -14 \\
\hline SE & 39.738 & 1.739 & 41.477 & 60.479 & 31 & 34 \\
\hline SP & 618.869 & 66.891 & 685.760 & 560.218 & -22 & -10 \\
\hline TO & 22.726 & 687 & 23.413 & 26.998 & 13 & 16 \\
\hline Brasil & 2.476 .744 & 181.889 & 2.642 .774 & 2.750 .318 & 4 & 10 \\
\hline
\end{tabular}

Fonte: e-SUS VE/Ministério da Saúde.

* Pode apresentar registros duplicados. 
Considerando os dados convergentes em termos absolutos dos estados apresentados nos gráficos da Figura I, é possível verificar a informação de data do primeiro sintoma e a data de divulgação das informações nos boletins epidemiológicos (base de dados do Ministério da Saúde). As linhas em vermelho devem ser analisadas com cautela e a inflexão da curva não reflete uma diminuição de casos segundo data de primeiros sintomas, mas sim uma defasagem na entrada da informação. Entre os estados que apresentam convergência da informação, observa-se no Rio de Janeiro que o pico de casos ocorreu entre o fim do mês de abril e o mês de maio. Na maior parte dos estados observa-se pequena defasagem entre a data da divulgação dos boletins epidemiológicos e a data de primeiros sintomas registrada no e-SUS VE. Esse comportamento sugere que as medidas de intervenção adotadas pelos gestores podem ser mais bem adequadas se for considerada a informação que é apresentada nos boletins epidemiológicos.

Figura I - Análise temporal comparativa entre a data de primeiros sintomas e-SUS VE e a data de divulgação dos dados nos boletins epidemiológicos (dados recentes não consolidados)

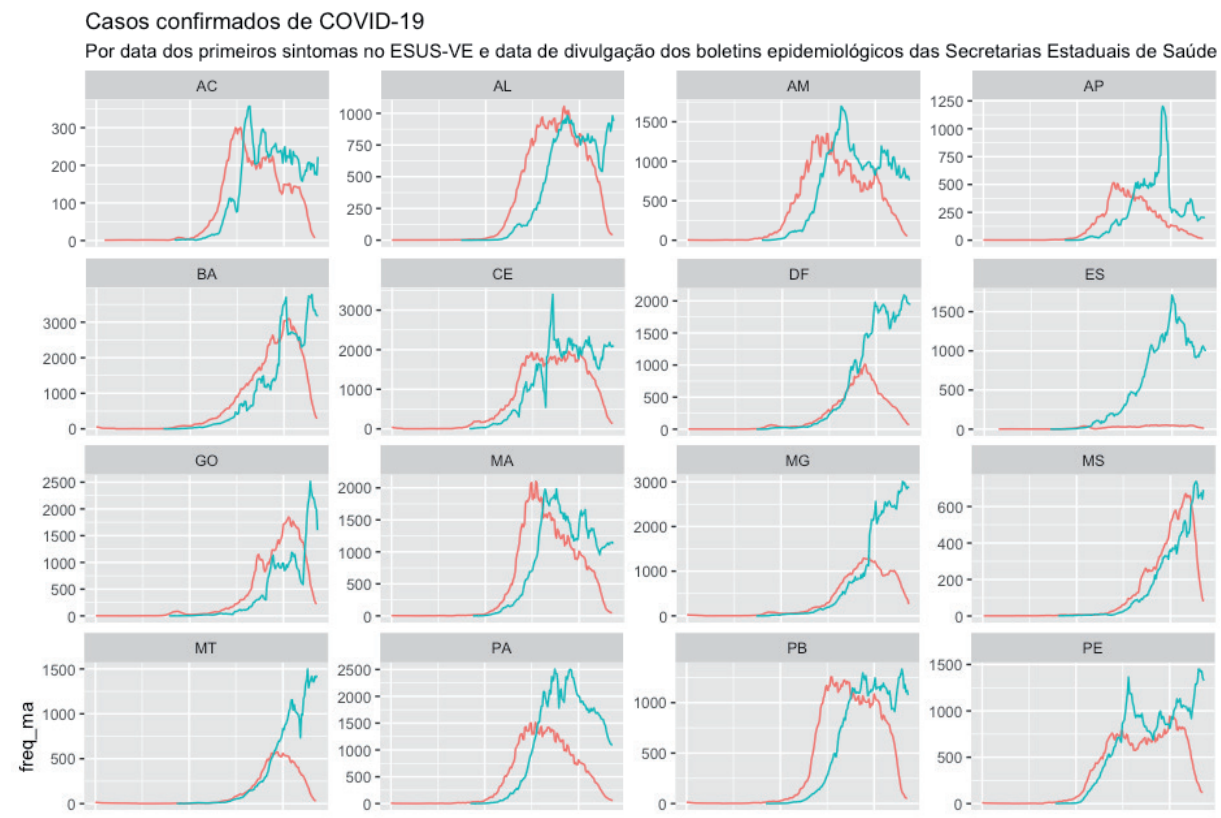


Figura I - Análise temporal comparativa entre a data de primeiros sintomas e-SUS VE e a data de divulgação dos dados nos boletins epidemiológicos (dados recentes não consolidados) (continuação)
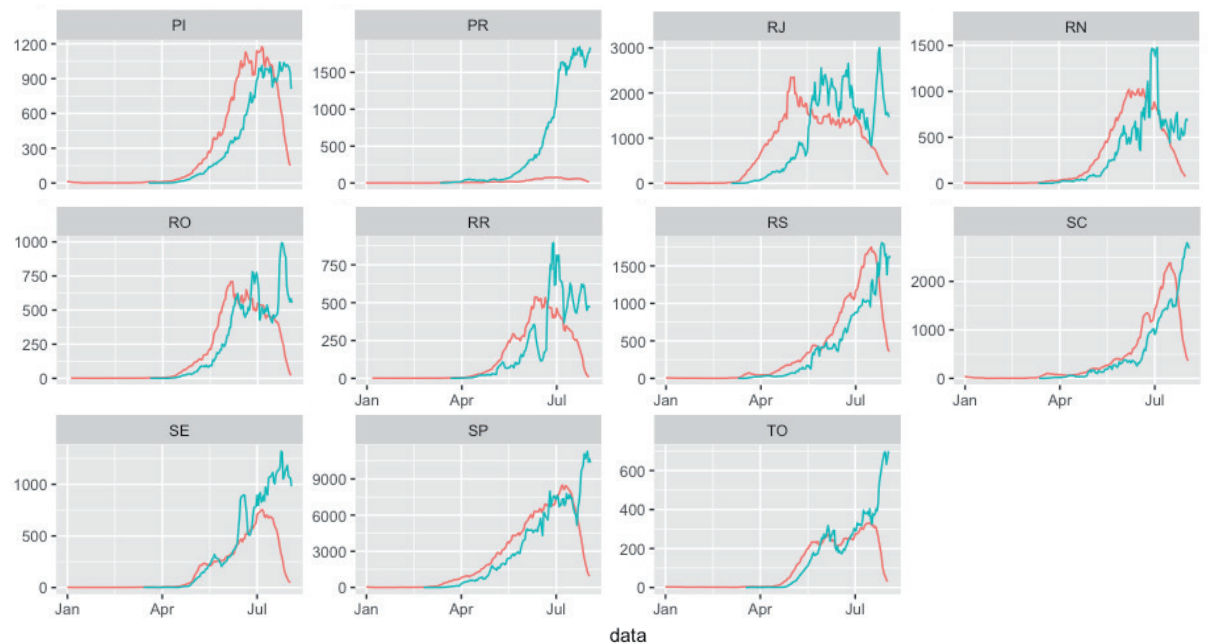

tipo - InicioSintomas - MS

Com base nos gráficos da Figura I, foram selecionados o dia em que ocorreu o maior registro de casos segundo unidade da federação (UF) nos dois sistemas de informação de referência. A Tabela 2 apresenta o dia de máxima e o número de casos segundo o e-SUS VE e os dados do Ministério da Saúde, além da diferença entre as datas em dias e a diferença de casos segundo o dia de máxima. Destacam-se os estados do Rio de Janeiro, Amapá e Maranhão, com uma defasagem de 52 dias quando comparadas a data do evento no sistema e-SUS VE e a registrada no boletim com os dados do Ministério da Saúde. A diferença média entre as datas, considerando-se todos os estados, foi de 17 dias. Nos estados do Ceará e São Paulo observa-se a maior diferença entre o total de casos registrados no dia de máxima até o momento. A diferença média nos registros de casos considerando-se todos os estados foi de 1.740 casos. 
Tabela 2 - Comparativo dos dias de máxima para casos nos estados segundo dados do Ministério da Saúde e-SUS VE, 03/08/2020

\begin{tabular}{|c|c|c|c|c|c|c|c|}
\hline \multirow{2}{*}{ UF } & \multicolumn{2}{|c|}{ Dia de máxima de casos } & \multicolumn{2}{|c|}{ Casos } & \multicolumn{2}{|c|}{ Diferenças $(\Delta)$} & \multirow{2}{*}{$\begin{array}{c}\text { Data não } \\
\text { preenchida } \\
\%\end{array}$} \\
\hline & e-SUS VE & MS & e-SUS VE & MS & Datas & Casos & \\
\hline $\mathrm{RJ}$ & $28 / 04 / 2020$ & $19 / 06 / 2020$ & 5.348 & 6.061 & 52 & 713 & 0.1 \\
\hline AP & $01 / 05 / 2020$ & $22 / 06 / 2020$ & 778 & 3.022 & 52 & 2.244 & 2.2 \\
\hline AM & $10 / 05 / 2020$ & $29 / 05 / 2020$ & 2.589 & 2.763 & 19 & 174 & 0.7 \\
\hline $\mathrm{MA}$ & $10 / 05 / 2020$ & $01 / 07 / 2020$ & 3.347 & 2.805 & 52 & -542 & 0.6 \\
\hline$A C$ & $01 / 06 / 2020$ & $23 / 05 / 2020$ & 388 & 524 & -9 & 136 & 0.1 \\
\hline $\mathrm{CE}$ & $01 / 06 / 2020$ & $30 / 05 / 2020$ & 3.112 & 9.427 & -2 & 6.315 & 1.6 \\
\hline $\mathrm{PA}$ & $01 / 06 / 2020$ & $05 / 06 / 2020$ & 2.732 & 4.387 & 4 & 1.655 & 0.5 \\
\hline$A L$ & $01 / 06 / 2020$ & $14 / 06 / 2020$ & 1.636 & 1.312 & 13 & -324 & 0.3 \\
\hline RN & $01 / 06 / 2020$ & $28 / 06 / 2020$ & 1.554 & 5.483 & 27 & 3.929 & 0.7 \\
\hline $\mathrm{RO}$ & $01 / 06 / 2020$ & $22 / 07 / 2020$ & 1.284 & 2.302 & 51 & 1.018 & 0.1 \\
\hline PB & $01 / 06 / 2020$ & $23 / 07 / 2020$ & 1.943 & 2.132 & 52 & 189 & 0.1 \\
\hline $\mathrm{RR}$ & $10 / 06 / 2020$ & $01 / 07 / 2020$ & 848 & 2.430 & 21 & 1.582 & 0.1 \\
\hline DF & $10 / 06 / 2020$ & $06 / 07 / 2020$ & 1.516 & 2.529 & 26 & 1.013 & 0.4 \\
\hline ES & $10 / 06 / 2020$ & $07 / 07 / 2020$ & 94 & 2.156 & 27 & 2.062 & 12.7 \\
\hline $\mathrm{PE}$ & $01 / 07 / 2020$ & $16 / 05 / 2020$ & 1.532 & 2.279 & -46 & 747 & 0.9 \\
\hline MG & $01 / 07 / 2020$ & $26 / 06 / 2020$ & 1.979 & 6.122 & -5 & 4.143 & 6.0 \\
\hline$B A$ & $01 / 07 / 2020$ & $27 / 06 / 2020$ & 4.461 & 8.822 & -4 & 4.361 & 1.4 \\
\hline $\mathrm{PI}$ & $01 / 07 / 2020$ & $30 / 06 / 2020$ & 1.877 & 1.637 & -1 & -240 & 0.6 \\
\hline SE & $01 / 07 / 2020$ & $19 / 07 / 2020$ & 1.105 & 2.171 & 18 & 1.066 & 0.1 \\
\hline $\mathrm{PR}$ & $01 / 07 / 2020$ & $31 / 07 / 2020$ & 151 & 2.624 & 30 & 2.473 & 16.1 \\
\hline SP & $10 / 07 / 2020$ & $19 / 06 / 2020$ & 10.934 & $19 . .030$ & -21 & 8.096 & 6.7 \\
\hline MT & $10 / 07 / 2020$ & $23 / 07 / 2020$ & 769 & 2085 & 13 & 1.316 & 0.3 \\
\hline SC & $10 / 07 / 2020$ & $30 / 07 / 2020$ & 3.584 & 3.903 & 20 & 319 & 0.0 \\
\hline RS & $10 / 07 / 2020$ & $01 / 08 / 2020$ & 2.559 & 3.764 & 22 & 1.205 & 0.1 \\
\hline GO & $10 / 07 / 2020$ & $04 / 08 / 2020$ & 2.689 & 4.758 & 25 & 2.069 & 0.3 \\
\hline MS & $20 / 07 / 2020$ & $21 / 07 / 2020$ & 916 & 1.503 & 1 & 587 & 0.1 \\
\hline TO & $20 / 07 / 2020$ & $05 / 08 / 2020$ & 545 & 1.227 & 16 & 682 & 0.0 \\
\hline
\end{tabular}

Fonte: e-SUS VE/Ministério da Saúde. 
Os óbitos por Covid- 19 foram selecionados considerando-se o total de casos do Sivep Gripe, que somaram 540.745 registros. Nesses dados foi aplicado o filtro na variável "EVOLUCAO = Óbito" para a consulta da variável "CLASSI_FIN = Covid-19". Também foram filtrados os dados de óbito por Covid- I 9 da base de dados do e-SUS VE considerando-se a variável "resultado Teste = Positivo" e "evolução Caso = Óbito". Três informações são apresentadas na Tabela 3: os dados dos boletins estaduais que compõem a base de dados do Ministério da Saúde, óbitos por Covid- 9 filtrados na base do Sivep Gripe e a soma de casos filtrados do Sivep Gripe e do e-SUS VE.

Considerando-se a variação percentual do total de óbitos entre os bancos de dados, observa-se que no nível nacional os dados segundo o Sivep Gripe apresentam diferença de $6 \%$ em relação ao observado nos boletins das secretarias estaduais. Somando-se os casos do Sivep Gripe, essa variação é - 10\%, ou seja, há mais casos na soma dos sistemas em relação aos dados dos boletins. Os estados do Mato Grosso, Amapá e Rondônia apresentam a maior variação percentual na comparação com os dados do Ministério da Saúde. Em geral, a comparação do filtro apenas no banco do Sivep Gripe apresenta convergência com o observado nos boletins epidemiológicos e na base de dados do Ministério da Saúde.

Tabela 3 - Casos de Covid- 19 segundo o e-SUS VE, o Sivep Gripe e o Ministério da Saúde, até 03/08/2020

\begin{tabular}{c|r|r|r|r|r|r}
\hline \multirow{2}{*}{ UF } & \multicolumn{5}{|c|}{ Óbitos Covid-19 } & \multicolumn{2}{c}{ Variação \% } \\
\cline { 2 - 7 } & e-SUS & Sivep & Sivep + e-SUS* & \multicolumn{1}{c|}{ MS } & Sivep + e-SUS* & Sivep \\
\hline AC & 414 & 366 & 780 & 539 & -45 & 32 \\
\hline AL & 1.180 & 1.506 & 2.686 & 1.607 & -67 & 6 \\
\hline AM & 205 & 3.088 & 3.293 & 3.288 & 0 & 6 \\
\hline AP & 395 & 311 & 706 & 576 & -23 & 46 \\
\hline BA & 2.942 & 3800 & 6.742 & 3.624 & -86 & -5 \\
\hline CE & 2.114 & 7471 & 9.585 & 7.752 & -24 & 4 \\
\hline DF & 100 & 1387 & 1.487 & 1.546 & 4 & 10 \\
\hline ES & 0 & 1.928 & 1.928 & 2.601 & 26 & 26 \\
\hline GO & 285 & 1.745 & 2.030 & 1.716 & -18 & -2 \\
\hline MA & 705 & 2.519 & 3.224 & 3.069 & -5 & 18 \\
\hline MG & 348 & 3.020 & 3.368 & 2.894 & -16 & -4 \\
\hline MS & 4 & 423 & 427 & 421 & -1 & 0 \\
\hline
\end{tabular}


Tabela 3 - Casos de Covid- 19 segundo o e-SUS VE, o Sivep Gripe e o Ministério da Saúde, até 03/08/2020 (continuação)

\begin{tabular}{c|r|r|r|r|r|r}
\hline \multirow{2}{*}{ UF } & \multicolumn{5}{|c|}{ Óbitos Covid-19 } & \multicolumn{2}{c}{ Variação \% } \\
\cline { 2 - 7 } & e-SUS & Sivep & Sivep + e-SUS* & \multicolumn{1}{c}{ MS } & Sivep + e-SUS* & Sivep \\
\hline MT & 177 & 594 & 771 & 1.907 & 60 & 69 \\
\hline PA & 975 & 5.576 & 6.551 & 5.784 & -13 & 4 \\
\hline PB & 385 & 1.831 & 2.216 & 1.870 & -19 & 2 \\
\hline PE & 126 & 6.480 & 6.606 & 6.669 & 1 & 3 \\
\hline PI & 256 & 921 & 1.177 & 1.385 & 15 & 34 \\
\hline PR & 9 & 1.858 & 1.867 & 2.050 & 9 & 9 \\
\hline RJ & 819 & 13.571 & 14.390 & 13.604 & -6 & 0 \\
\hline RN & 530 & 1.367 & 1.897 & 1.894 & 0 & 28 \\
\hline RO & 884 & 545 & 1.429 & 888 & -61 & 39 \\
\hline RR & 52 & 389 & 441 & 513 & 14 & 24 \\
\hline RS & 104 & 2.038 & 2.142 & 2.016 & -6 & -1 \\
\hline SC & 261 & 1.211 & 1.472 & 1.196 & -23 & -1 \\
\hline SE & 1 & 1.203 & 1.204 & 1.489 & 19 & 19 \\
\hline SP & 1.391 & 23.706 & 25.097 & 23.365 & -7 & -1 \\
\hline TO & 243 & 391 & 634 & 402 & -58 & 3 \\
\hline Brasil & 14.905 & 89.245 & 104.150 & 94.665 & -10 & 6 \\
\hline & & & & & & \\
\hline
\end{tabular}

Fonte: Sivep Gripe/Ministério da Saúde.

* Pode apresentar registros duplicados.

Considerando-se os dados convergentes em termos absolutos dos estados apresentados nos gráficos da Figura 2, é possível verificar a informação data de evolução do caso e observar a data do óbito e a data de divulgação das informações nos boletins epidemiológicos (base de dados do Ministério da Saúde). As linhas em vermelho devem ser analisadas com cautela e a inflexão da curva não diz respeito à diminuição do número de óbitos, mas à defasagem na entrada da informação. Dentre os estados que apresentam convergência da informação, observa-se no Rio de Janeiro que o pico de óbitos ocorreu no fim do mês de maio. Na maior parte dos estados observa-se pequena defasagem entre a data de divulgação dos boletins epidemiológicos e a data do óbito. Destacam-se os estados do sul do país nos quais a defasagem é extremamente pequena, o que sugere uma entrada quase em tempo real das informações no sistema de notificação. 
Figura 2 - Análise temporal comparativa entre a data do óbito Sivep Gripe e a data de divulgação dos dados nos boletins epidemiológicos (dados recentes não consolidados)

Óbitos confirmados de COVID-19

Por data da evolução no SIVEP-Gripe (de 21/07/2020) e data de divulgação dos boletins epidemiológicos das Secretarias Estaduais de

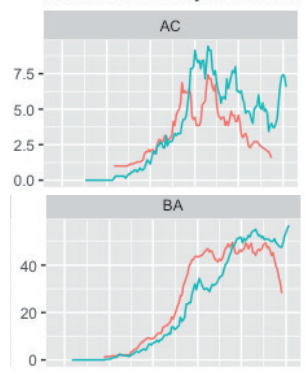

GO
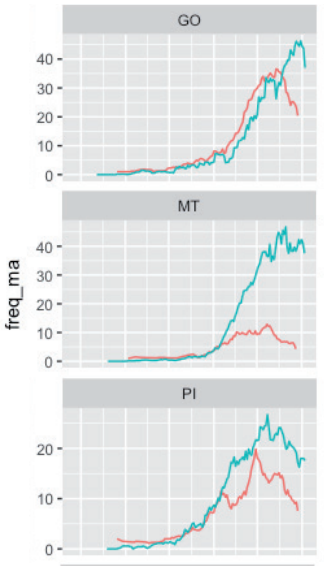

$\mathrm{RO}$
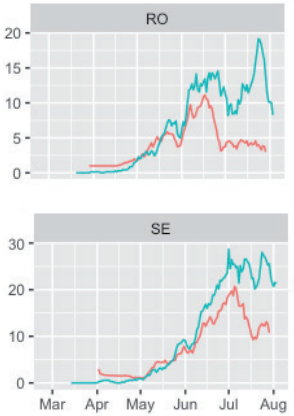

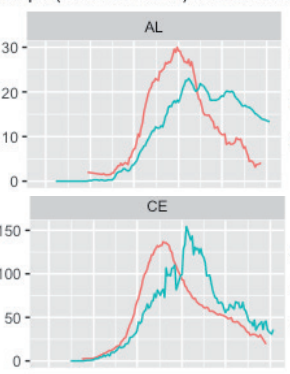

MA
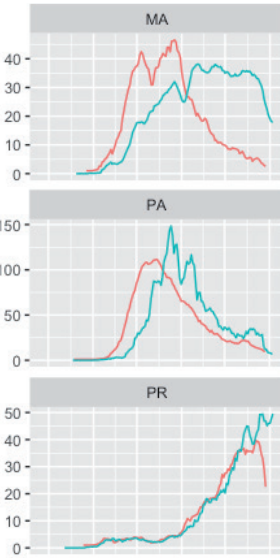

RR
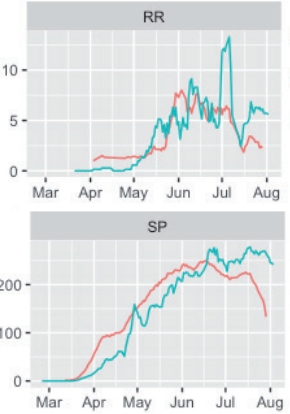

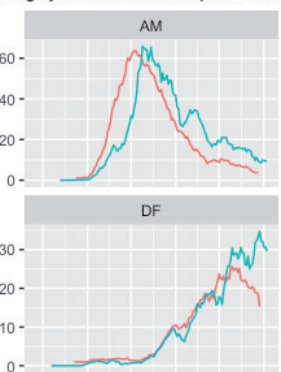

MG

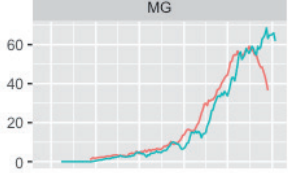

$\mathrm{PB}$
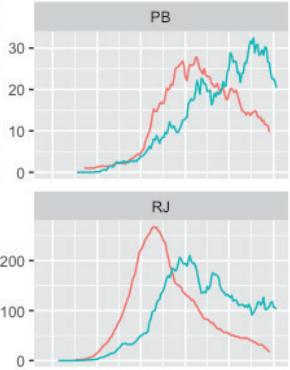

RS
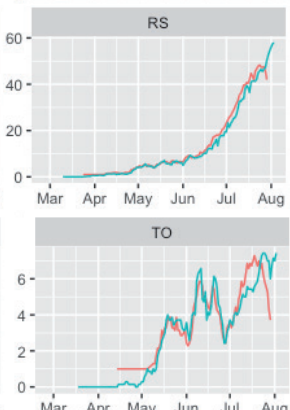

data

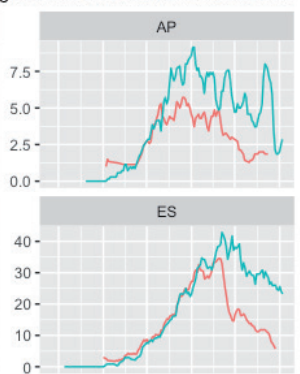

MS
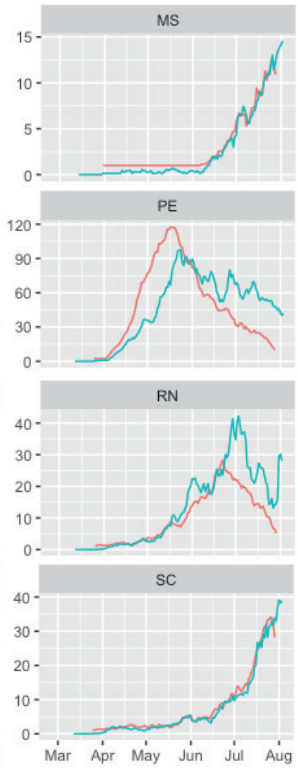

tipo - DT_EVOLUCA - MS 
Foram identificados os dias em que ocorreu o maior registro de óbitos segundo UF nos dois sistemas de informação de referência. A Tabela 4 apresenta o dia de máxima e o número de óbitos segundo Sivep Gripe e os dados do Ministério da Saúde, além da diferença entre as datas em dias e a diferença de casos segundo o dia de máxima. Destacam-se os estados do Amapá, Rio Grande do Norte e Rondônia, com uma defasagem superior a 39 dias quando comparadas a data do evento no sistema Sivep Gripe e aquela registrada no boletim com os dados do Ministério da Saúde. A diferença média entre as datas nos estados foi de 20 dias. Nos estados do Ceará, São Paulo e Pará observa-se a maior diferença entre o total de óbitos registrados no dia de máxima. A diferença média nos registros de óbitos nos estados foi de 38 óbitos.

\section{Tabela 4 - Comparativo dos dias de máxima para óbitos nos estados segundo dados do Ministério da Saúde e do Sivep Gripe, 03/08/2020}

\begin{tabular}{c|c|c|c|c|c|c|c}
\hline \multirow{2}{*}{ UF } & \multicolumn{2}{|c|}{ Dia de máxima de óbitos } & \multicolumn{2}{|c|}{ Óbitos } & \multicolumn{2}{c|}{ Diferenças $(\Delta)$} & $\begin{array}{c}\text { Data não } \\
\text { preenchida }\end{array}$ \\
\cline { 2 - 9 } & Sivep Gripe & MS & $\begin{array}{c}\text { Sivep } \\
\text { Gripe }\end{array}$ & MS & Datas & Óbitos & $\%$ \\
\hline AM & $28 / 04 / 2020$ & $06 / 05 / 2020$ & 72 & 102 & 8 & 30 & 0.3 \\
\hline RJ & $06 / 05 / 2020$ & $03 / 06 / 2020$ & 289 & 324 & 28 & 35 & 0.4 \\
\hline PA & $12 / 05 / 2020$ & $04 / 06 / 2020$ & 127 & 247 & 23 & 120 & 0.5 \\
\hline PE & $14 / 05 / 2020$ & $27 / 05 / 2020$ & 134 & 140 & 13 & 6 & 0.3 \\
\hline CE & $19 / 05 / 2020$ & $02 / 06 / 2020$ & 153 & 316 & 14 & 163 & 1.2 \\
\hline AP & $22 / 05 / 2020$ & $21 / 07 / 2020$ & 9 & 18 & 60 & 9 & 0.0 \\
\hline AC* & $23 / 05 / 2020$ & $23 / 06 / 2020$ & 12 & 16 & 31 & 4 & 0.3 \\
\hline MA* & $25 / 05 / 2020$ & $08 / 06 / 2020$ & 56 & 39 & 14 & -17 & 1.0 \\
\hline PB & $25 / 05 / 2020$ & $30 / 06 / 2020$ & 40 & 46 & 36 & 6 & 0.1 \\
\hline AL & $29 / 05 / 2020$ & $05 / 06 / 2020$ & 37 & 26 & 7 & -11 & 0.2 \\
\hline RR & $30 / 05 / 2020$ & $01 / 07 / 2020$ & 14 & 40 & 32 & 26 & 0.0 \\
\hline SP & $01 / 06 / 2020$ & $23 / 06 / 2020$ & 275 & 434 & 22 & 159 & 0.1 \\
\hline ES* & $03 / 06 / 2020$ & $22 / 06 / 2020$ & 49 & 59 & 19 & 10 & 2.1 \\
\hline TO* & $06 / 06 / 2020$ & $08 / 06 / 2020$ & 10 & 15 & 2 & 5 & 0.0 \\
\hline RO & $13 / 06 / 2020$ & $22 / 07 / 2020$ & 14 & 31 & 39 & 17 & 0.6 \\
\hline MT* & $15 / 06 / 2020$ & $15 / 07 / 2020$ & 15 & 92 & 30 & 77 & 1.3 \\
\hline RN & $21 / 06 / 2020$ & $31 / 07 / 2020$ & 35 & 102 & 40 & 67 & 0.7 \\
\hline BA & $02 / 07 / 2020$ & $31 / 07 / 2020$ & 58 & 72 & 29 & 14 & 1.3 \\
\hline SE & $05 / 07 / 2020$ & $01 / 07 / 2020$ & 33 & 49 & -4 & 16 & 1.0 \\
\hline DF & $09 / 07 / 2020$ & $28 / 07 / 2020$ & 39 & 52 & 19 & 13 & 0.2 \\
\hline
\end{tabular}


Tabela 4 - Comparativo dos dias de máxima para óbitos nos estados segundo dados do Ministério da Saúde e do Sivep Gripe, 03/08/2020 (continuação)

\begin{tabular}{c|c|c|c|c|c|c|c}
\hline \multirow{2}{*}{ UF } & \multicolumn{2}{|c|}{ Dia de máxima de óbitos } & \multicolumn{2}{c|}{ Óbitos } & \multicolumn{2}{c|}{ Diferenças $(\Delta)$} & $\begin{array}{c}\text { Data não } \\
\text { preenchida }\end{array}$ \\
\cline { 2 - 8 } & Sivep Gripe & MS & $\begin{array}{c}\text { Sivep } \\
\text { Gripe }\end{array}$ & MS & Datas & Óbitos & $\%$ \\
\hline MG & $13 / 07 / 2020$ & $05 / 08 / 2020$ & 69 & 152 & 23 & 83 & 0.2 \\
\hline PI & $13 / 07 / 2020$ & $03 / 07 / 2020$ & 25 & 36 & -10 & 11 & 0.0 \\
\hline GO & $14 / 07 / 2020$ & $04 / 08 / 2020$ & 52 & 101 & 21 & 49 & 0.4 \\
\hline PR* $^{*}$ & $21 / 07 / 2020$ & $07 / 08 / 2020$ & 51 & 121 & 17 & 70 & 0.4 \\
\hline RS* $^{*}$ & $21 / 07 / 2020$ & $04 / 08 / 2020$ & 61 & 83 & 14 & 22 & 0.0 \\
\hline SC & $22 / 07 / 2020$ & $05 / 08 / 2020$ & 43 & 71 & 14 & 28 & 0.3 \\
\hline MS & $30 / 07 / 2020$ & $06 / 08 / 2020$ & 20 & 23 & 7 & 3 & 0.0 \\
\hline
\end{tabular}

Fonte: Sivep Gripe/Ministério da Saúde.

* Acre, Espírito Santo, Maranhão, Mato Grosso, Paraná, Rio Grande do Sul e Tocantins apresentaram mais de uma data com máximo de casos em alguns dos sistemas; na tabela está apresentada a data mais antiga.

\section{CONSIDERAÇÕES FINAIS}

A análise apresentada neste capítulo evidencia as realidades diferenciadas dos sistemas de informação dos estados e as diferenças de qualidade entre os bancos de dados. Os dados disponibilizados pelo sistema Sivep Gripe apresentam maior convergência com a informação divulgada nos boletins do que os dados registrados no e-SUS VE, possivelmente porque se trata de um sistema mais consolidado - como foi criado em 2009 após a epidemia de HINI, evoluiu e corrigiu falhas. O processo de evolução do sistema confere aos dados maior convergência entre a informação observada nos boletins e aquela consignada nas bases de dados.

As informações do Sivep Gripe também alimentam o sistema InfoGripe, que apontou ainda na $12^{\circ}$ semana epidemiológica, em meados de março, um comportamento anômalo das Srag, o que já sugeria o processo de transmissão comunitária de Covid- 19 no Brasil (Bastos et al., 2020). A implementação do e-SUS VE se deu de forma gradativa durante a pandemia. Inicialmente o Ministério da Saúde utilizou a plataforma RedCap para captação das informações e alguns estados enviaram arquivos de forma remota até que se estabeleceram os fluxos das informações.

Chama a atenção também o comportamento das curvas de casos e óbitos por Covid- 19 no estado do Rio de Janeiro. Enquanto o pior período epidêmico ocorria, a 
população era informada de que a transmissão ainda era baixa, com pequeno número de casos e óbitos. É provável que, devido ao volume de casos extremamente alto, o próprio sistema epidemiológico de informação tenha colapsado e as informações tenham sido adicionadas aos boletins posteriores.

Em alguns estados é necessária maior investigação sobre o fluxo das informações. É o caso do Mato Grosso e do Amapá, por exemplo, que mesmo no Sivep Gripe não apresentam convergência dos dados, o que suscita questões relativas ao fluxo da informação que esses estados têm adotado.

Com esta análise não buscamos de forma alguma sugerir que os dados sejam alterados para divulgação, pois a população já se habituou a essa lógica e alterar as datas neste momento do processo epidêmico trará mais desinformação que ganho na comunicação. Contudo, esses dados devem ser considerados pelos gestores, sobretudo para tomada de decisão e orientação das intervenções. Outras informações podem ser utilizadas com base nos bancos do e-SUS VE e do Sivep Gripe. No entanto, a análise de convergência dos dados deve ser realizada, e somente para regiões onde esses dados são comparáveis é possível avançar nas análises. Em outras localidades é necessário entender como se dá o fluxo de informação, corrigir desvios e tornar as informações comparáveis para subsidiar a tomada de decisão no processo epidêmico, e fomentar estudos posteriores que auxiliem em outros processos epidêmicos no futuro.

Nenhum sistema de saúde estava preparado para enfrentar problemas com as dimensões que a pandemia de Covid-19 trouxe, principalmente no desencontro entre a capacidade de suprir as demandas e os recursos disponíveis. Muitos dados disponibilizados nos diferentes sistemas de informações de saúde já eram utilizados para tomadas de decisão, mas a velocidade da pandemia trouxe urgência e aumento na frequência com que esses dados precisam ser consolidados.

A capilaridade do Sistema Único de Saúde (SUS), que está presente em grande número de estabelecimentos de saúde em todo o país, e o volume de informações disponibilizadas pelo Datasus tornam o compartilhamento de dados confiáveis e a transparência do processo de coleta e disponibilização cruciais para o enfrentamento da pandemia. Os sistemas de informação citados permitem que esses estabelecimentos sejam conectados a secretarias e ao Ministério da Saúde, no entanto produzindo dados com qualidade e cobertura desiguais. $\mathrm{O}$ aperfeiçoamento desses sistemas pode auxiliar as tomadas de decisão e a governança mais assertiva, bem como permitir a migração de recursos de uma região para outra, auxiliando na construção de uma sociedade mais equânime. 


\section{REFERÊNCIAS}

BASTOS, L. S. et al. Covid- 19 e hospitalizações por Srag no Brasil: uma comparação até a $12^{\text {a }}$ semana epidemiológica de 2020. Cadernos de Saúde Pública, 36: e00070I20, 2020.

BRASIL. Decreto n. 4.194, de II abr. 2002. Aprova a Estrutura Regimental e o Quadro Demonstrativo dos Cargos em Comissão e das Funções Gratificadas do Ministério da Saúde, e dá outras providências. Diário Oficial da União, Brasília, 2002.

BRASIL. Ministério da Saúde. Secretaria de Vigilância em Saúde. Análise de Situação de Saúde: liuro-texto. v. I. Brasília: Ministério da Saúde, Universidade Federal de Goiás, 2013.

BRASIL. Ministério da Saúde. E-SUS notifica, 27 jul. 202 Ia. Disponível em: <www.gov.br/saude/ pt-br/composicao/vigilancia-em-saude-svs/sistemas-de-informacao/e-sus-notifica >. Acesso em: 17 set. 2021 .

BRASIL. Ministério da Saúde. Orientações sobre notificação e registros de casos de Covid- 19 no Brasil. Disponível em: <www.gov.br/saude/pt-br/coronavirus/artigos/notificacao-e-registro>. Acesso em: 17 set. 202 Ib.

LIMA, L. D. et al. Regionalização e acesso à saúde nos estados brasileiros: condicionantes históricos e político-institucionais. Ciência E Saúde Coletiva, I 7(I I): 2.88I-2.892, 2012.

PAIM, J. S. \& ALMEIDA FILHO, N. Saúde coletiva: uma "nova saúde pública" ou campo aberto a novos paradigmas? Revista de Saúde Pública, 32(4): 299-316, 1998.

SOUZA, M. Sistema de información de salud: conceptos básicos e implicaciones para las políticas de salud. New York: International Standards for Civil Registration and Vital Statistics Systems, 201 I.

WALDMAN, E. A. Usos da vigilância e da monitorização em saúde pública. Informe Epidemiológico do SUS, 7(3): 7-26, 1998. 

PARTE III

\section{ESTRATÉGIAS DE ENFRENTAMENTO E VIGILÂNCIA}

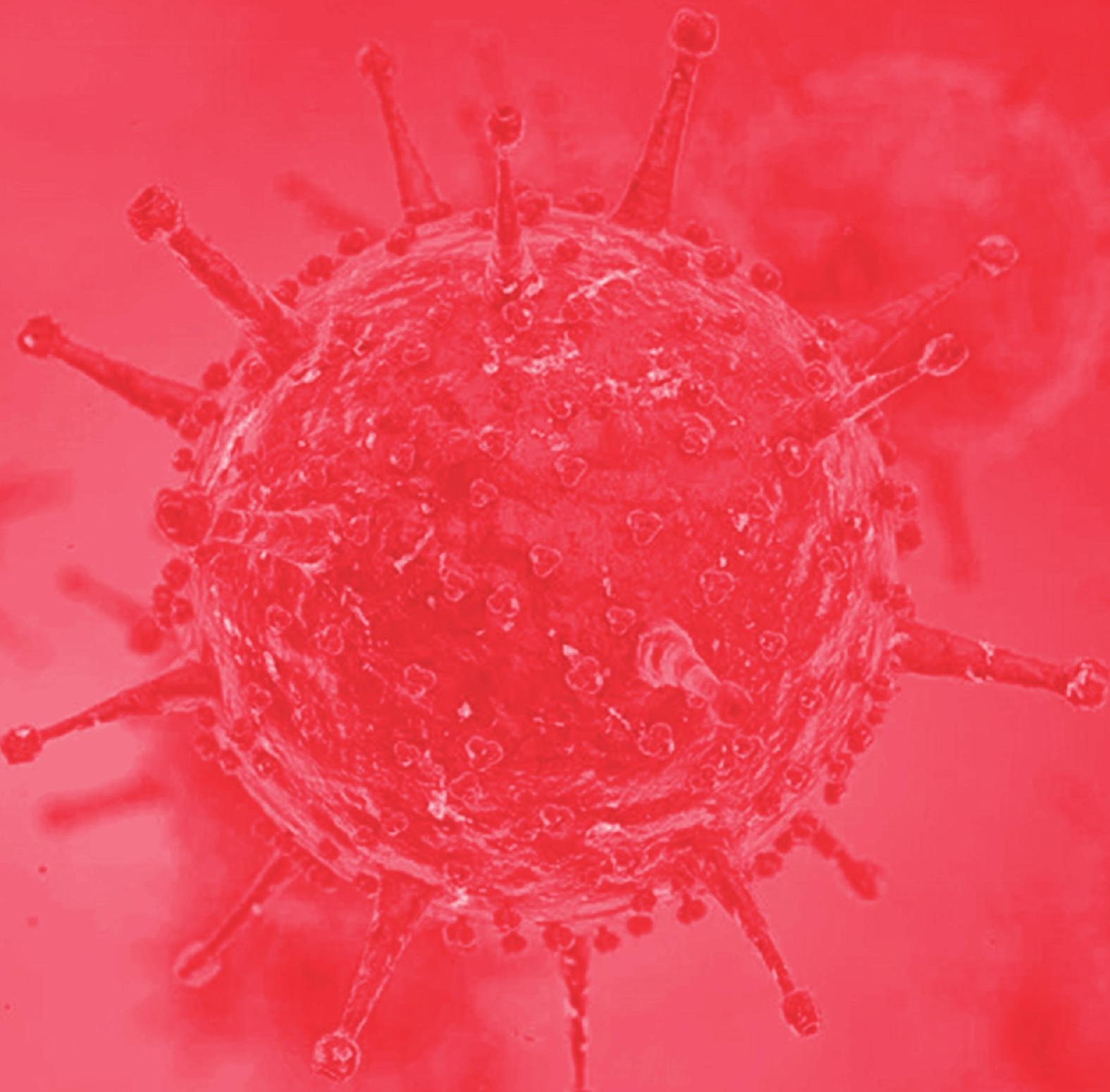



Vigilância em Saúde

preparação, resposta às emergências de saúde pública e o enfrentamento da Covid-19 no Brasil

Eduardo Hage Carmo e Maria Gloria Teixeira

7 pandemia de Covid-19 tem implicado uma série de consequências na saúde da população mundial, configurando-se como um dos maiores problemas de saúde pública do presente século. Tendo iniciado no final de 2019, presumidamente em Wuhan, na província de Wubei, China (Mallapaty, 2020), até o mês de setembro de 2021 já eram registrados aproximadamente 225 milhões de casos e 4,6 milhões de mortes em 196 países ou territórios. Até o mês de setembro do presente ano, o Brasil era o terceiro país com maior número de casos e o segundo em número de mortes (Jonhs Hopkins University \& Medicine, 202 I).

No Brasil, esta pandemia tem implicado muitos desafios para o Sistema Único de Saúde (SUS), tendo em vista a necessidade de oferecer à população atendimento adequado, recomendações e adoção de medidas de prevenção e controle, com o fim de reduzir mortes e hospitalizações e de limitar a disseminação da doença. Por se tratar de uma doença nova, muitos aspectos necessários ao desenvolvimento de medidas terapêuticas, diagnósticas e preventivas eram, em parte ou totalmente, desconhecidos. Apesar de algumas lacunas no conhecimento dessa doença ainda persistirem (algumas incertezas foram surgindo durante a própria evolução da pandemia), muito se avançou no desenvolvimento e na adoção daquelas medidas.

É importante levarmos em conta que esses avanços somente foram alcançados porque o país já contava com um sistema de saúde estruturado para o enfrentamento dos principais problemas de saúde, especialmente no manejo de emergências de saúde pública anteriores, como a pandemia de influenza HINI e de zika/síndrome congênita de zika, as recorrentes epidemias de febre amarela, sarampo, dengue e outras doenças, além do desenvolvimento das capacidades para gestão de risco de desastres (Brasil, 2012; Oliveira et al., 2017; Teixeira et al., 2018a). 
Em que pese uma série de insuficiências na coordenação nacional do SUS, especialmente no segundo semestre de 2020, com sucessivos erros estratégicos na condução do enfrentamento da pandemia pela gestão federal (como a produção e disseminação de protocolos de tratamento precoce sem eficácia comprovada, o desestímulo a medidas de contenção, a falta de coordenação nacional para aquisição de insumos para diagnóstico e tratamento, entre outros), nas esferas estadual e municipal muitas iniciativas alcançaram êxito, contribuindo para a reduzir o impacto da pandemia, se considerarmos as previsões iniciais.

Tratamos aqui das iniciativas de aperfeiçoamento das capacidades do país para a preparação e resposta às emergências de saúde pública, a partir de um breve histórico na área de vigilância em saúde, e da contribuição das estratégias utilizadas neste campo da saúde pública no enfrentamento da Covid- 19 no Brasil.

\section{A VIGILÂNCIA EM SAÚDE: PREPARAÇÃO E RESPOSTA ÀS EMERGÊNCIAS DE SAÚDE PÚBLICA}

É tarefa difícil identificar em que período podem ser situadas as primeiras ações estruturadas de vigilância em saúde no enfrentamento das epidemias no Brasil, até mesmo porque o conceito desta prática de saúde pública surge na década de 90 do século passado. Desde o século XVII foram realizadas campanhas sanitárias contra doenças infecciosas específicas, embora de etiologias desconhecidas na época, como as ações de controle de epidemias de febre amarela empreendidas pelo marquês de Montebelo em Recife, assim como as medidas adotadas para controle de epidemias de cólera, peste bubônica, varíola (incluindo o início da vacinação), além de novas epidemias de febre amarela no século XIX em grandes cidades brasileiras. Entretanto, essas ações eram descontinuadas ou localizadas, seja porque o conhecimento científico sobre essas doenças e o desenvolvimento tecnológico para seu controle eram ainda incipientes, seja porque não contavam com respaldo institucional mais duradouro ou as instituições de saúde pública eram inexistentes (Romero, 2019).

Somente a partir de algumas ações específicas de vigilância sanitária e epidemiológica no controle de doenças epidêmicas no início do século XX é possível identificar as primeiras ações sistemáticas dessas práticas de saúde pública que viriam a constituir a vigilância em saúde, agregando-se posteriormente as ações nas áreas que viriam a ser denominadas de vigilância ambiental em saúde e vigilância em saúde do trabalhador (Franco-Netto et al., 2017).

As ações de vacinação contra varíola, as campanhas contra febre amarela (que foram adotadas tendo como modelo as de Emilio Ribas em São Paulo), as medidas para o 
controle da peste bubônica, associadas às intervenções de saneamento na então capital do país, o Rio de Janeiro, todas promovidas por Oswaldo Cruz, figuram entre as primeiras medidas de saúde pública e viriam a ser ampliadas para prevenção e controle dessas e de outras doenças nas grandes cidades brasileiras (Benchimol, 2020).

Posteriormente, Carlos Chagas, contando com maior apoio institucional em meio à pandemia de influenza (1918-1919), intensificou as ações de controle dessas epidemias, incluindo ações no campo da vigilância sanitária de alimentos e de medicamentos e a vigilância das condições de trabalho de mulheres e crianças (Romero, 2019).

Entretanto, até o último quarto do século XX as ações de controle dessas epidemias eram a realizadas de forma centralizada, sob coordenação e execução exclusiva ou predominantemente da esfera federal. O país já contava com um sistema nacional de vigilância epidemiológica e com o Programa Nacional de Imunizações (PNI), instituídos em 1975 (Brasil, 1975) como tentativa de resposta do governo ditatorial às epidemias de meningite (Barradas, 1988), além de um órgão federal responsável pela organização das ações de vigilância sanitária, a Secretaria Nacional de Vigilância Sanitária (Brasil, 1976). Ainda assim não dispunha de capacidade para responder de forma oportuna às epidemias, desastres e outras situações inusitadas e complexas, nem contava com processos e instrumentos padronizados para detectar e monitorar essas situações (Teixeira et al., 2018b).

Na esfera estadual, as equipes de vigilância epidemiológica e sanitária, que já contavam com técnicos responsáveis por programas específicos nessas áreas, aliadas às estruturas laboratoriais das secretarias estaduais de Saúde (SES) situadas nas capitais, os laboratórios centrais de Saúde Pública (Lacens) e em algumas regionais, gradativamente assumiam ações de investigação e resposta oportuna às epidemias. Em situações de maior complexidade era necessária a coordenação pelo Ministério da Saúde (MS), como na epidemia de cólera em 199I iniciada em Tabatinga, no Amazonas, à qual era preciso acrescentar a mobilização de profissionais de várias SES e de outros órgãos de saúde e instituições de ensino e pesquisa (Teixeira et al., 2018b).

$\mathrm{Na}$ esfera municipal, a maioria dos municípios não tinha essa capacidade e dependia do apoio das demais esferas para o enfrentamento das epidemias, pois não contava com recursos financeiros, tecnológicos e humanos.

Com a criação do SUS em 1990, o país passa a ampliar sua capacidade de prevenção e controle de fatores de risco, doenças e agravos, inclusive para o enfrentamento das epidemias e outras situações de risco imediato para a saúde da população. Ainda no último quarto do século XX algumas mudanças importantes foram implementadas: 
reorganização do Ministério da Saúde, especialmente com a criação do Centro Nacional de Epidemiologia (Cenepi) (Brasil, I 99I); a instituição do Sistema Nacional de Vigilância Sanitária (SNVS) junto com a criação da Agência Nacional de Vigilância Sanitária (Anvisa) (Brasil, 1999a); a definição das competências das esferas de gestão, com a instituição de novos mecanismos para repasse financeiro para estados e municípios (Brasil, I 999b), possibilitando maior autonomia desses entes para desenvolvimento de suas ações; e a descentralização das ações de prevenção e controle de doenças, muitas delas de caráter epidêmico, que antes eram de responsabilidade da esfera federal.

Apesar dessas iniciativas no SUS, até então não existiam estruturas para a gestão de surtos, epidemias e outras situações que exigissem resposta rápida e coordenada, que ocorriam com grande frequência no território nacional, como as epidemias de dengue, cólera e febre amarela.

Para resposta a cada epidemia de maior complexidade eram constituídas equipes temporárias com pessoal das três esferas de gestão, recrutando-se profissionais de outros estados, além do território afetado, o que dispendia um tempo precioso, recursos financeiros vultosos e implicava uma logística muito complexa (Teixeira et al., 20 I 8b). Os processos e instrumentos para investigação eram, muitas vezes, elaborados durante 0 curso da própria epidemia, em uma época em que os recursos tecnológicos (informação, comunicação, análise de dados) eram escassos.

A necessidade de contar com estruturas e processos mais adequados de resposta desde a esfera federal ficou mais evidente ainda durante a ocorrência de um surto de nefrite epidêmica em Nova Serrana, MG (Balter et al., 2000), entre 1997 e 1998 , quando foi necessária a vinda de uma equipe de investigação dos Centros de Prevenção e Controle de Doenças dos Estados Unidos (CDC), para cooperação com o Cenepi. No campo da vigilância sanitária, pelo menos três eventos inusitados ocorridos entre 1996 e 1997 (óbitos de idosos na Clínica Santa Genoveva no Rio de Janeiro, contaminação em clínicas de hemodiálise com 71 mortes, em Caruaru, PE e acidentes tromboembólicos pela contaminação de soro do laboratório Endomed) que resultaram na criação do SNVS e da Anvisa também revelavam fragilidades na coordenação entre os órgãos responsáveis pelas ações nesta área (Silva, Costa E Lucchese, 2018).

No ano de 2000 foi criado, no âmbito do Cenepi, o Núcleo de Respostas Rápidas em Emergências Epidemiológicas (Nurep), que passou a organizar a gestão de surtos, epidemias e outros eventos urgentes, em coordenação com as SES. No mesmo ano teve início o Programa de Treinamento em Epidemiologia Aplicada aos Serviços do SUS (Episus), voltado para a formação de profissionais da saúde pública, em um período de 
dois anos, contando nos primeiros anos de implementação com a colaboração dos CDC (Teixeira et al., 20 I 8b). Desde seu início, esse treinamento vem sendo realizado por meio de ensino-aprendizagem em serviços de saúde, dentro da estrutura do MS, atuando na investigação e proposição de medidas de controle de eventos mais complexos que necessitam do apoio da instância federal.

Inicialmente o Episus era voltado para a formação de técnicos que iriam compor as equipes das áreas de vigilância em saúde do MS, e posteriormente muitos profissionais formados passaram a compor as equipes de outros órgãos do SUS, como a Anvisa, e secretarias estaduais e municipais de Saúde (Carmo, Oliveira \& Penna, 2008).

Em 2003, com a criação da Secretaria de Vigilância em Saúde (SVS), órgão do MS que viria a substituir o Cenepi, ampliou-se o escopo de atuação da esfera federal e fortaleceuse a coordenação das ações neste campo com os estados e municípios (Brasil, 2003). Na Vigilância em Saúde, foi incorporada a área de vigilância em saúde do trabalhador e a área de vigilância em saúde ambiental passou a ser melhor estruturada, assumindo novas atribuições.

No campo de diagnóstico laboratorial, em 2004 o SUS estruturou uma rede de laboratórios de saúde pública ampla, complexa e constituída por unidades de referência nacional (incluindo os laboratórios da Fiocruz, o Instituto Adolfo Lutz e o Instituto Evandro Chagas), referências regionais, os laboratórios centrais dos estados (Lacens) e os laboratórios municipais (Brasil, 2004). Essa extensa rede, coordenada pela SVS, tem executado os principais métodos diagnósticos, incluindo os mais complexos, para identificação de agentes biológicos, além das demais tecnologias para abordagem diagnóstica das emergências, não restritas àquelas de natureza biológica. Atuando em conjunto com outras unidades públicas (em especial das instituições de ensino e pesquisa) e privadas, tem possibilitado autonomia e mesmo protagonismo do país no manejo de epidemias e outros eventos inusitados.

Com a aprovação pela Assembleia Mundial da Saúde de 2005 do Regulamento Sanitário Internacional (RSI 2005), um novo conceito passou a ser difundido e aplicado pelos serviços nacionais de saúde pública, o de emergências de saúde pública de importância internacional (Espii). Esse conceito, que inclui não somente as epidemias de doenças transmissíveis, mas também desastres e situações de risco de natureza química ou radionuclear, é utilizado para qualquer evento de saúde pública que implique risco de disseminação internacional, conforme análise realizada por meio de um instrumento de decisão padronizado (WHO, 20I6). Com a aprovação do RSI 2005, os países se comprometeram a desenvolver e aperfeiçoar seus sistemas de saúde para melhorar a 
capacidade de detecção, análise e resposta às potenciais emergências em seus territórios, evitando ou reduzindo o risco de disseminação para outros países.

No mesmo ano da aprovação do RSI 2005, foi criado na estrutura da SVS o Centro de Informações Estratégicas de Vigilância em Saúde (Cievs) (Brasil, 2007). À semelhança de unidades existentes, até então, nos Estados Unidos, no Canadá e na sede da Organização Mundial da Saúde (OMS), o Cievs realiza monitoramento ativo e oportuno de eventos de saúde pública (com uso de ferramentas de vigilância ativa e captura eletrônica de rumores), procedendo à análise desses eventos com o objetivo de apoiar a definição e adoção de medidas necessárias, atendendo assim aos preceitos do referido regulamento. O Cievs representa a SVS como ponto focal do RSI 2005, perante a OMS, sendo responsável pela comunicação com esse órgão sobre potenciais emergências de saúde pública (ESPs), assim como sobre a própria aplicação do RSI pelo país.

Em 2006 começou a ser estruturada a Rede Nacional de Alerta e Resposta em Emergências de Saúde Pública, coordenada pelo Cievs nacional e composta por unidades em todas as SES e municípios das capitais (Brasil, 2007). De acordo com a natureza de cada evento a ser monitorado, essa rede se articula com outras áreas do SUS e outros setores governamentais.

Para melhor coordenação de todas essas instâncias, sempre que necessário se estabelece um Centro de Operações de Emergências em Saúde (COE) específico para cada evento. Esse novo processo de gestão de emergências surgiu a partir de cooperação com outros organismos, incluindo a Organização Pan-Americana da Saúde (Opas), quando da elaboração do Plano Multirrisco, além dos planos de contingência específico para cada tipo de emergência, incluindo os desastres. As mudanças no processo de gestão das emergências, utilizando-se de experiências na gestão de riscos de desastres, envolvem não somente as atividades dirigidas à preparação e resposta, muito utilizadas no manejo de epidemias de doenças infecciosas, mas também uma série de estratégias que incluem a avaliação e o monitoramento do risco, a identificação de ameaças e vulnerabilidades, além de ações dirigidas à recuperação, reconstrução, reabilitação (Opas \& Brasil, 20 I 5).

Visando à detecção precoce de doenças graves com potencial de disseminação, que são identificadas pela rede hospitalar, bem como à promoção de maior integração com esta fonte de notificação para a vigilância epidemiológica e sanitária, o país conta também com uma rede de núcleos de vigilância epidemiológica hospitalar. Composta por unidades existentes em hospitais públicos e privados, essa rede se integra à rede Cievs, aos núcleos de gestão de risco hospitalar e de segurança do paciente, ampliando a ca- 
pacidade de detecção oportuna de emergências epidemiológicas e de vigilância sanitária (Carmo, Oliveira \& Penna, 2008).

Em 20 I I, foram regulamentados critérios para a declaração de uma Emergência de Saúde Pública de Importância Nacional (Espin), que pode ser caracterizada nas seguintes situações: I) epidemiológicas (surtos e epidemias; 2) desastres; 3) desassistência, as quais podem contar com participação da Força Nacional do SUS, envolvendo as três esferas deste sistema (Brasil, 20 I I).

Nos anos de 2017 e 2018 duas importantes iniciativas foram implementadas no SUS: a Política Nacional de Atenção Básica (Brasil, 2017) e a Política Nacional de Vigilância em Saúde (CNS, 2018). A instituição de ambas as políticas consolidou um movimento de integração entre a vigilância e a atenção primária à saúde (APS), por meio da qual, no âmbito da gestão das emergências de saúde pública, o SUS ampliou sua capacidade de detecção precoce desses eventos, que sempre se originam em territórios da Atenção Básica. Como consequência, as equipes de vigilância e atenção podem contar com melhor caracterização dos fatores envolvidos na sua produção e disseminação, com a participação dos recursos humanos locais (especialmente em áreas com cobertura adequada das equipes de Saúde da Família) e com os recursos tecnológicos existentes no próprio território, apoiados pelas ações compartilhadas com as demais instâncias de gestão, o que favorece uma resposta mais oportuna e efetiva.

Esses avanços aqui identificados na capacidade do país para o enfrentamento das emergências de saúde pública não teriam sido alcançados se não se tivessem contado também com uma rede de instituições de ensino e de pesquisa e desenvolvimento tecnológico (PED), composta por unidades distribuídas em todo o país. Já foram mencionadas algumas dessas instituições que compõem a rede de laboratórios, cabendo ainda destacar a participação da rede de PED na produção de insumos (incluindo vacinas e outros imunobiológicos, medicamentos, diagnóstico laboratorial), no desenvolvimento e aplicação de métodos para análise e monitoramento dos eventos, incluindo novas ferramentas de tecnologia de informação e comunicação, e na identificação de medidas de controle mais apropriadas (Morel, 2020).

\section{A VIGILÂNCIA EM SAÚDE (VS) E 0 ENFRENTAMENTO DA COVID-19}

Como visto, a Vigilância em Saúde (VS), bem como outras áreas do SUS, já contava com uma série de iniciativas que aprimoraram suas capacidades de detectar, monitorar e responder às emergências de saúde pública quando se iniciou a pandemia de Covid- I9. Essas capacidades estavam presentes em todas as três esferas do SUS, embora com 
grande heterogeneidade entre as unidades federadas e no interior de cada uma delas, o que contribuiu para que a resposta à pandemia venha apresentando diferentes impactos nas populações de cada território.

Em que pese o grande número de casos e óbitos decorrentes da pandemia no país, o que a coloca como um dos principais flagelos da saúde pública brasileira, assim como a sua longa duração, é possível - e necessário - apontar alguns resultados positivos das ações promovidas ou apoiadas pela VS, certamente em conjunto com outras áreas da saúde pública e de outras instâncias de decisão governamentais.

A adoção de medidas de distanciamento social e outras não farmacológicas em muitos estados e municípios, especialmente durante os primeiros meses da pandemia, contribuiu para que o impacto deste evento fosse menor do que o previsto (Kerr et al., 2020), o que tornou possível a ampliação e qualificação na rede de atenção, com consequente redução no número de casos graves e óbitos em relação às estimativas iniciais. Para a definição e implementação dessas medidas foi necessário contar com bases de dados e informações, para a qual a VS contribuiu significativamente, bem como com a cooperação entre as instituições de ensino e pesquisa e as instâncias do SUS.

No país como um todo, a VS acionou e vem adotando todas as estratégias de prevenção e controle desenvolvidas ao longo do tempo, adaptando-as para a nova pandemia e as contínuas mudanças ocorridas no conhecimento durante o seu curso (Croda et al., 2020).

Desde o início foram criados e aperfeiçoados instrumentos específicos e elaborados protocolos para detecção, notificação e monitoramento de casos e seguimento dos contatos, o que tem permitido o acompanhamento da pandemia em tempo real, na ocorrência de casos leves, graves e de óbitos, além das indicações para adoção de isolamento domiciliar. Muitos dos procedimentos adotados durante a pandemia foram desenvolvidos a partir da experiência de enfrentamento da pandemia de influenza $A$ (HINI) em 2009 e da reestruturação da vigilância de influenza e síndrome respiratória aguda grave desde então.

O desenvolvimento de estratégias de monitoramento, estimativas e projeções mais precisas do comportamento epidemiológico da pandemia, e sua apropriação pelos serviços de saúde, para o que tem sido fundamental a parceria com instituições de ensino e pesquisa e da Opas, têm possibilitado o redimensionamento e ampliação, pela rede, da sua capacidade de atenção.

Com base nas informações produzidas a partir dos dados consolidados em plataformas dos órgãos de saúde nas três esferas do SUS, a comunicação à população 
e aos profissionais da saúde e a construção e atualização diária dos painéis de monitoramento têm se revelado instrumentos importantes não somente para assegurar a transparência (e confiança) necessária em momentos de crise sanitária, mas também para apoiar a adoção de medidas de contenção da pandemia (Oliveira et al., 2020)

A articulação entre a vigilância epidemiológica e a APS, otimizando a potencialidade deste campo de prática do SUS já evidenciado no enfrentamento da Covid-I 9 (Sousa et al., 2020), tem se mostrado importante estratégia de atuação no território. O compartilhamento e análise conjunta dos dados, a investigação dos casos e o monitoramento dos contatos de forma integrada ampliam a capacidade de detecção de novos casos e a análise de risco de agravamento e permitem a identificação de grupos mais vulneráveis.

Também merece destaque a articulação com a rede privada de atenção, especialmente a rede hospitalar, inserida nos procedimentos de notificação e monitoramento dos casos, ampliando mais ainda o conhecimento sobre a pandemia em cada território.

O rápido desenvolvimento de métodos diagnósticos e a sua ampla utilização pela rede de laboratórios, incluindo Lacens, laboratórios de referência nacional, instituições de ensino e pesquisa e os laboratórios privados, têm permitido a detecção mais precoce de casos e o monitoramento da pandemia com maior precisão, por meio da inserção dos dados laboratoriais no fluxo de notificação, embora com importante variação dessas capacidades no curso da pandemia e entre os diferentes estados.

As ações de fiscalização de estabelecimentos públicos e privados, que são objeto da VS (bares, restaurantes, farmácias e drogarias, unidades de saúde, entre outros), em conjunto com outros órgãos, tem contribuído para o cumprimento das medidas que visam a reduzir o risco de transmissão, bem como a assegurar a oferta de produtos médicos conforme padrões de qualidade exigidos.

Importante ressaltar a participação de todos os setores da VS, incluindo a vigilância em saúde do trabalhador, na elaboração de protocolos de funcionamento e de biossegurança dos estabelecimentos públicos e privados, emitidos pelas autoridades governamentais. O estabelecimento de normas, a observação do cumprimento da distribuição e a utilização de equipamentos de proteção individual pelas vigilâncias sanitária e da saúde do trabalhador também se registram como atividade importante no controle desta pandemia.

Por fim, sem querer esgotar todo o escopo de atuação da VS no enfrentamento da pandemia, a recente disponibilidade de vacinas, que inclui a participação na produção pela Fundação Oswaldo Cruz (Fiocruz) e pelo Instituto Butantan, traz para o SuS 
uma ferramenta importante para o controle desta pandemia. A VS tem atuado desde as etapas de autorização para produção, importação e utilização das vacinas no país, que apresentam dados suficientes de eficácia e segurança, por intermédio da Anvisa, até a sua utilização em toda a rede do PNI, que envolve a participação ativa nas três esferas de gestão.

São muitos os desafios que a VS tem enfrentado para a utilização de toda a sua potência construída ao longo dos anos, mas aqui relacionamos apenas alguns deles:

I. Embora a VS seja reconhecida como um conjunto de atividades centrais para apoiar a tomada de decisões com base no conhecimento científico, em muitas situações esse processo não levou em conta, parcial ou totalmente, as recomendações emanadas da área. Essa deficiência, embora seja mais visível na esfera federal, também pode ser identificada nas demais instâncias.

2. Os procedimentos e os instrumentos de notificação de casos adotados pelo SUS, assim como em epidemias anteriores (zika, HINI), têm se mostrado insuficientes para monitorar uma pandemia desta magnitude e complexidade, gerando atrasos e incertezas no seu conhecimento.

3. Ainda que esteja estabelecido que a realização de testes diagnósticos é estratégia importante para a detecção de casos e monitoramento da pandemia, uma série de problemas tem se revelado neste aspecto, entre os quais a insuficiência de testes em quantidade para atender à grande demanda internacional, a qualidade desses testes e as diferentes metodologias utilizadas, o que tem gerado dificuldades para o próprio monitoramento da pandemia.

4. A sobrecarga de atividades de responsabilidade para a VS - bem como na rede de atenção - tem gerado exaustão de seus profissionais, especialmente em um cenário no qual esse campo de prática não tem sido devidamente reconhecido pelos próprios gestores, o que contribui para a manutenção de reduzido número de profissionais em períodos interepidêmicos.

\section{VIGILÂNCIA EM SAÚDE E AS PANDEMIAS: TAREFA AINDA INCONCLUSA}

Ainda não é possível fazer uma avaliação mais completa da resposta oferecida pela VS no enfrentamento da pandemia da Covid- 19 no Brasil, especialmente porque este evento ainda está em curso, com frequentes alterações no seu comportamento e uma evolução futura indefinida, embora com perspectivas favoráveis dada a disponibilidade recente de vacinas, caso se apresente em quantidade suficiente e em tempo oportuno 
para os grupos prioritários. Tal avaliação não pode ser feita sem que se considere o papel dos diferentes campos de prática do SUS, que também contribuem para um resultado mais eficaz no controle da pandemia.

Vários fatores têm dificultado o desempenho da VS na resposta à pandemia, em especial a insuficiente coordenação nacional, que muitas vezes emite sinais trocados sobre as estratégias que o SUS deve adotar - exemplos mais recentes são as erráticas informações quanto à estratégia de vacinação e às recomendações sobre uso de medicamentos sem nenhuma evidência científica de eficácia. Some-se a esse tipo de problema a crônica limitação de recursos para o SUS, que incide - e muito - sobre a VS.

Mas a história de organização do SUS, aqui brevemente relatada, bem como das iniciativas governamentais que o precederam, na gestão das emergências de saúde pública evidencia a existência de uma base sólida na saúde pública nacional e na vigilância em saúde em particular. O conhecimento que foi acumulado ao longo dos anos não se perderá pelos problemas conjunturais, por mais agudos que sejam. A força de trabalho atuante na saúde pública, mesmo antes do SUS, sempre soube encontrar formas de expressar toda a potência deste sistema, embora com algumas flutuações e frustações. Esta pandemia irá passar, infelizmente com enorme saldo de vidas perdidas e sofrimento. Mas esperamos que as lições apreendidas neste longo período sirvam para que estejamos ainda mais preparados para esta e futuras pandemias.

\section{REFERÊNCIAS}

BALTER, S. et al. Epidemic nephritis in Nova Serrana, Brazil. The Lancet, 355(9.2 I 7): I.776- I.780, 2000. BARRADAS, R. C. B. Meningite: uma doença sob censura? São Paulo: Cortez, 1988.

BENCHIMOL, J. L. (Coord.). Manguinhos do Sonho à Vida: a ciência na Belle Époque. Reimpr. atual. Rio de Janeiro: Editora Fiocruz, 2020.

BRASIL. Presidência da República. Casa Civil. Subchefia para Assuntos Jurídicos. Lei n. 6.259, de 30 out. 1975. Dispõe sobre a organização das ações de Vigilância Epidemiológica, sobre o Programa Nacional de Imunizações, estabelece normas relativas à notificação compulsória de doenças, e dá outras providências. Diário Oficial da União, Brasília, 1975. Disponível em: <http://www.planalto.gov.br/ ccivil_03/leis/l6259.htm>. Acesso em: 13 set. 2021.

BRASIL. Presidência da República. Casa Civil. Subchefia para Assuntos Jurídicos. Decreto n. 79.056, de 30 dez. 1976. Dispõe sobre a organização do Ministério da Saúde e dá outras providências. Diário Oficial da União, Brasília, 1976. Disponível em: <www2.camara.leg.br/legin/fed/decret/1970-1979/decreto79056-30-dezembro- 1976-428077-publicacaooriginal- I-pe.html >. Acesso em: 13 set. 202 I.

BRASIL. Presidência da República. Casa Civil. Subchefia para Assuntos Jurídicos. Decreto n. I00, de 16 abril I99I. Institui a Fundação Nacional de Saúde e dá outras providências. Diário Oficial da União, Brasília, I99I. Disponível em: <www.planalto.gov.br/ccivil_03/decreto/I990-I994/d0 I00.htm>. Acesso em: 13 set. 2021. 
BRASIL. Presidência da República. Casa Civil. Subchefia para Assuntos Jurídicos. Lei n. 9.782, de 26 jan. 1999. Define o Sistema Nacional de Vigilância Sanitária, cria a Agência Nacional de Vigilância Sanitária, e dá outras providências. Diário Oficial da União, Brasília, 1999a. Disponível em: <www.planalto.gov. br/ccivil_03/leis/19782.htm>. Acesso em: I3 set. 2021.

BRASIL. Ministério da Saúde. Gabinete do Ministro. Portaria n. 1.399, de 15 dez. 1999. Regulamenta a NOB SUS 0I/96 no que se refere às competências da União, estados, municípios e Distrito Federal, na área de epidemiologia e controle de doenças, define a sistemática de financiamento e dá outras providências. Diário Oficial da União, Brasília, 1999b. Disponível em: <www.funasa.gov.br/site/wpcontent/files_mf/Pm_1399_1999.pdf>. Acesso em: 13 set. 2021.

BRASIL. Presidência da República. Casa Civil. Subchefia para Assuntos Jurídicos. Decreto n. 4.726, de 9 jun. 2003. Aprova a Estrutura Regimental e o Quadro Demonstrativo dos Cargos em Comissão e das Funções Gratificadas do Ministério da Saúde, e dá outras providências. Diário Oficial da União, Brasília, 2003. Disponível em: <www.planalto.gov.br/ccivil_03/decreto/2003/D4726.htm>. Acesso em: 13 set. 2021.

BRASIL. Ministério da Saúde. Gabinete do Ministro. Portaria n. 2031, de 23 set. 2004. Dispõe sobre a organização do Sistema Nacional de Laboratórios de Saúde Pública. Diário Oficial da União, Brasília, 2004. Disponível em: <http://bvsms.saude.gov.br/bvs/saudelegis/gm/2004/prt203 I_23_09_2004. html>. Acesso em: 13 set. 2021 .

BRASIL. Ministério da Saúde. Centro de Informações Estratégicas em Vigilância em Saúde (Cievs). Brasília: Ministério da Saúde, 2007. Disponível em: < http://bvsms.saude.gov.br/bvs/publicacoes/ centro_informacoes_estrategicas_vigilancia_saude.pdf >. Acesso em: 13 set. 2021 .

BRASIL. Presidência da República. Casa Civil. Subchefia para Assuntos Jurídicos. Decreto n. 7.6I6, de 17 nov. 20II. Dispõe sobre a declaração de Emergência em Saúde Pública de Importância Nacional - ESPIN e institui a Força Nacional do Sistema Único de Saúde - FN-SUS. Diário Oficial da União, Brasília, 20II. Disponível em: <www.planalto.gov.br/ccivil_03/_Ato20l I-2014/20 I I/Decreto/ D76I6.htm>. Acesso em: 13 set. 2021.

BRASIL. MinistériodaSaúde.SecretariadeVigilânciaemSaúde. Informetécnicodelnfluenza, 20I 2. Disponívelem: $<$ https://antigo.saude.gov.br/images/pdf/20 I 4/maio/22/informe-influenza-2009-20 I 0-20 I I-2205 I4. pdf > . Acesso em: 13 set. 2021.

BRASIL. Ministério da Saúde. Gabinete do Ministro. Portaria n. 2.436, de 21 set. 2017 . Aprova a Política Nacional de Atenção Básica, estabelecendo a revisão de diretrizes para a organização da Atenção Básica, no âmbito do Sistema Único de Saúde (SUS). Diário Oficial da União, Brasília, 20 I 7. Disponível em: $<$ https://bvsms.saude.gov.br/bvs/saudelegis/gm/2017/prt2436_22_09_2017.html>. Acesso em: 13 set. 2021 .

CARMO, E. H.; OLIVEIRA, W. K. E PENNA, G. Emergências de saúde pública: conceito, caracterização, preparação e resposta. Estudos Avançados, 22(64): I9-3I, 2008.

CONSELHO NACIONAL DE SAÚDE (CNS). Resolução 588, de 12 jul. 2018. Disponível em: <www. conasems.org.br/wp-content/uploads/20 I 9/02/Reso588.pdf>. Acesso em: I3 set. 2021.

CRODA, J. et al. Covid- 9 in Brazil: advantages of a socialized unified health system and preparation to contain cases. Revista da Sociedade Brasileira de Medicina Tropical, 53, 2020. 
FRANCO-NETTO, G. et al. Vigilância em saúde brasileira: reflexões e contribuição ao debate da Ia Conferência Nacional de Vigilância em Saúde. Ciência E Saúde Coletiva, 22(I0), 20 I 7. Disponível em: <https://doi.org/I0.1590/I4I3-8I2320172210.18092017>. Acesso em: 13 set. 2021.

JONHS HOPKINS UNIVERSITY \& MEDICINE. Covid- 19 Dashboard by Center for System Science and Engineering (CSSE), 202I. Disponível em: <https://coronavirus.jhu.edu/map.html>. Acesso em: I3 set. 2021 .

KERR, L. et al. Covid- 19 in northeast Brazil: achievements and limitations in the responses of the state governments. Ciência E Saúde Coletiva, 25, supl. 2: 4.099-4.I20, 2020.

MALLAPATY, S. The scientistis investigating the pandemic's origins. Nature, 588: 208, 2020. Disponível em: <www.nature.com/articles/d41586-020-03402-I >. Acesso em: I3 set. 2021.

MOREL, C. M. Régua e compasso na turbulência da pandemia. Folha de S.Paulo, São Paulo, 8 nov. 2020. Opinião. Disponível em: <wwwl.folha.uol.com.br/opiniao/2020/I I/regua-e-compasso-naturbulencia-da-pandemia.shtml>. Acesso em: 13 set. 2021.

OLIVEIRA, W. K. et al. Infection-related microcephaly after the 2015 and 2016 Zika virus outbreaks in Brazil: a surveillance-based analysis. The Lancet, 390(10.097): 86I-870, 2017.

OLIVEIRA, W. K. et al. Como o Brasil pode deter a Covid-19. Epidemiologia e Serviços de Saúde, 29(2), 2020. Disponível em: <www.scielosp.org/article/ress/2020.v29n2/e2020044>. Acesso em: 13 set. 2021 .

ORGANIZAÇÃO PAN-AMERICANA DA SAÚDE (OPAS) \& BRASIL. Ministério da Saúde. Desastres Naturais e Saúde no Brasil. Brasília: Opas, Ministério da Saúde, 20 I 5. (Série Desenvolvimento Sustentável e Saúde, 2).

ROMERO, L. C. P. Saúde e Política: a doença como protagonista da história. Brasília: Outubro Edições, 2019.

SILVA, J. A. A.; COSTA, E. A. E LUCCHESE, G. SUS 30 anos: vigilância sanitária. Ciência E Saúde Coletiva, 23(6): 1.953-1.96I, 2018.

SOUSA, A. J. M. et al. Atenção primária à saúde e Covid- 19: uma revisão integrativa. Cadernos ESP . Revista Científica da Escola de Saúde Pública do Ceará, I4(I), 2020. (Edição Especial - Enfrentamento da Covid-19)

TEIXEIRA, M. G. et al. Conquistas do SUS no enfrentamento das doenças transmissíveis. Ciência $\mathcal{G}$ Saúde Coletiva, 23(6): 1.819-1.828, 2018a.

TEIXEIRA, M. G. et al. Vigilância em Saúde no SUS: construção, efeitos e perspectivas. Ciência E Saúde Coletiva, 23(6): 1.811-1.818, 2018b.

WORLD HEALTH ORGANIZATION (WHO). International Health Regulations. 3. ed. Geneva: WHO, 2016. 



\title{
Gestão de Riscos no Primeiro Mês de Enfrentamento da Pandemia de Covid-19 no Brasil
}

\author{
Isadora Vida de Mefano e Silva, Carlos Machado de Freitas, \\ Natália da Cunha Cidade, Mariano Andrade da Silva e \\ Maria Cristina Mitsuko Peres
}

A presentamos aqui um desdobramento do relatório técnico "Gestão de Riscos e no primeiro mês" (Freitas et al., 2020), que teve sua elaboração iniciada exatamente no contexto em que foi declarada pela Organização Mundial da Saúde (OMS) a pandemia global, em I I de março de 2020, e aprovado pelo Congresso Nacional o reconhecimento do estado de calamidade pública em 18 de março. O referido relatório foi publicado no dia 12 de maio.

No intervalo de oito semanas, entre o início da produção do relatório (semana epidemiológica 13) e sua conclusão (semana epidemiológica 20), os números de casos e de óbitos passaram de 2.775 e 96, para 77.203 e 5.006, respectivamente. Ou seja, houve um crescimento de cerca de 28 vezes no número de casos e de 52 vezes no de óbitos. Nesse período também assistimos a um grande crescimento dos números na pandemia em países da Europa, nas situações dramáticas vivenciadas na Itália, na Espanha e no Reino Unido, seguidas de debates e da implementação de medidas para contenção e organização dos serviços de saúde.

No Brasil, os primeiros decretos estaduais relativos ao enfrentamento da Covid- 19 começaram a ser publicados em 13 de março de 2020. Aqui, sistematizamos e analisamos os decretos e diretrizes publicados nas 27 unidades da federação (UFs) no primeiro mês de enfrentamento da pandemia, com o objetivo de contribuir para uma gestão de riscos ativa e prospectiva em relação às respostas aos desastres e emergências em saúde no âmbito do Sistema Único de Saúde (SUS). 


\section{A PANDEMIA COMO DESASTRE E ENFRENTAMENTO NA PERSPECTIVA DA GESTÃO DE RISCO DE DESASTRES}

Desde a década de 90 do século XX tem havido importantes movimentos no âmbito da comunidade científica e dos organismos internacionais para a redução de desastres e de emergências em saúde. Esses movimentos foram resultando na convergência cada vez maior entre os temas relacionados aos desastres com origens em ameaças/perigos de origem natural e/ou tecnológica e aqueles atinentes às emergências em saúde pública (ESPs) com origens em ameaças/perigos de origem biológica.

Foi neste contexto que a OMS publicou, no final de 2019, o documento "Estrutura de gestão de risco de desastres e emergências em saúde" (WHO, 201 9). Esse documento tem como referência importante o Marco de Sendai para Redução de Risco de Desastres (UNDRR, 2015), que junto com os Objetivos do Desenvolvimento Sustentável e o Acordo de Paris constituem os marcos de referência do pós-2015 e têm como foco políticas, medidas e ações para reduzir as situações de crises, sejam elas de origem climática, humanitária, de desastres ou ESPs.

Particularmente o Marco de Sendai, em 2015, e o documento da OMS, em 2019, refletem uma mudança de perspectiva, procurando priorizar uma gestão de riscos mais ativa, preventiva e prospectiva e menos reativa e focada na redução dos impactos e dos danos com estratégias que priorizam a resposta. A convergência das agendas relacionadas aos desastres e às ESPs combina a multiplicidade de processos, desde a prevenção de riscos de desastres e ESPs até os que envolvem a preparação, o alerta precoce, as respostas e os processos de reabilitação, recuperação e reconstrução das condições de vida e saúde (Freitas et al., 2019).

É na convergência dessas agendas que procuramos abordar a pandemia por Covid-19 no marco conceitual dos desastres, mediante a compreensão de algumas características fundamentais. Primeiro, esta pandemia combina quatro elementos importantes: I) um novo vírus, Sars-Cov-2, como uma ameaça; 2) a exposição da população em diferentes situações de vida e trabalho a um novo vírus; 3) as condições de vulnerabilidade de determinados grupos sociais por idade (idosos), por comorbidades (diabéticos, hipertensos, com insuficiência cardíaca, renal ou doença respiratória crônica) ou por precariedade das condições de vida e proteção social (trabalho, renda, saúde e educação, habitação e saneamento, entre outros) afetando principalmente os mais pobres; 4) capacidades para respostas e redução dos riscos e danos à saúde da população, o que envolve, entre outros aspectos, a infraestrutura de saúde. Em segundo lugar, combina impactos sociais, econômicos, sanitários e políticos 
que alteram a rotina de uma sociedade ou mesmo crises, como também sobrepujam as capacidades de resposta, incluindo as dos sistemas de saúde, dos municípios, estados ou países afetados (Freitas, Silva E Cidade, 2020).

A gestão de riscos de desastres abrange um conjunto de etapas e processos interligados, como prevenção e mitigação, preparação e resposta, reabilitação, recuperação e reconstrução, com medidas combinadas para cada um dos elementos que compõem o desastre. Isso significa que, além de focalizar a gestão reativa, que caracteriza a fase de manejo da resposta, a gestão de riscos deve se combinar com uma gestão corretiva dos problemas conjunturais e estruturais e prospectiva dos riscos, o que envolve o conjunto de medidas e ações que antecipem e previnam a construção de novos fatores de risco para o enfrentamento de ESPs futuras (Freitas et al., 2019).

Assim, na impossibilidade de eliminar uma ameaça como o vírus Sars-Cov-2 e até que se tenha a imunidade coletiva por meio de uma vacina, devem ser combinadas medidas: I) para reduzir a exposição (medidas de distanciamento físico e social) para todos, principalmente os grupos populacionais vulneráveis por idade ou doenças crônicas; 2) para reduzir as condições de vulnerabilidade social das populações com condições de vida e trabalho mais precárias e sem acesso à proteção social; 3) para fortalecer as capacidades de respostas e de redução dos riscos dentro do setor Saúde - desde a Atenção Primária à Saúde (APS) até a atenção hospitalar -, assim como das capacidades de detecção e vigilância em saúde, e fora do setor Saúde (ver Quadro I). Essas combinações envolvem as medidas relacionadas com a gestão corretiva (redução dos riscos já existentes), as de gestão prospectiva dos riscos (redução dos riscos futuros) e as de promoção, proteção e recuperação da saúde.

Assim, um dos grandes desafios da gestão de riscos é fazer com que um conjunto de ações de enfrentamento da emergência seja implementado de forma coordenada e articulada, intersetorial e considerando as etapas e processos fundamentais, rompendo a lógica setorizada de atuação e promovendo uma articulação horizontal entre os diferentes setores e atores sociais envolvidos. Isso significa que as medidas adotadas no manejo da resposta a uma pandemia ou desastre devem implicar não só ações para cessar a exposição ao vírus e, por conseguinte, reduzir os riscos imediatos, mas também a capacidade de reduzir os riscos de futuras pandemias e desastres, que se encontram relacionados aos processos de reabilitação, recuperação e reconstrução das condições de vida e saúde no pós-pandemia. Nessa perspectiva, compreender as primeiras medidas adotadas é fundamental para compreender o alcance e os limites da forma de enfrentamento adotada. 


\section{MÉTODO}

Realizamos um levantamento de medidas legais, em nível estadual, que foram publicadas em decretos entre o dia 26 de fevereiro de 2020, quando foi confirmado o primeiro caso da Covid- 19 no Brasil, no estado de São Paulo, e o dia 26 de março de 2020.

O levantamento foi realizado na plataforma Legisweb, tendo como palavra-chave de busca "Covid-19". Para análise e sistematização das medidas legais foi elaborada uma ficha que continha o código referente ao instrumento específico (decreto); o objeto do instrumento; a temporalidade da vigência do instrumento; as medidas gerais identificadas (envolvendo diversos setores) e as adotadas para o setor Saúde.

Após a leitura e fichamento dos decretos, elaboramos um quadro para sistematização de todas as medidas identificadas utilizando duas categorias analíticas: "medidas gerais" e "medidas do setor saúde". No Quadro I apresentamos subcategorias utilizadas visando a maior detalhamento na análise. Estas categorias serviram de referência para organizar, sistematizar e analisar as medidas legais nas UFs e apresentar os resultados.

\section{Quadro I - Categorias e descrição das medidas}

\begin{tabular}{|l|l|}
\hline \multicolumn{1}{|c|}{ Categoria de medida } & \multicolumn{1}{c|}{ Mescrição das medidas } \\
\hline Coordenação & $\begin{array}{l}\text { Medidas multissetoriais, envolvendo setores governamentais (níveis federal, } \\
\text { estadual e municipal) e não governamentais, além de setores privados. } \\
\text { Implicam atores que atuem na gestão da emergência, tendo como base o } \\
\text { monitoramento e o planejamento das ações necessárias a uma resposta efetiva } \\
\text { e oportuna. }\end{array}$ \\
\hline Distanciamento social & $\begin{array}{l}\text { Medidas tomadas para reduzir o risco de contágio, particularmente para } \\
\text { os grupos de alto risco, a fim de reduzir a transmissão e, assim, diminuir a } \\
\text { pressão sobre o sistema de saúde. }\end{array}$ \\
\hline $\begin{array}{l}\text { Informação e } \\
\text { comunicação }\end{array}$ & $\begin{array}{l}\text { Medidas que garantam o direito à informação e à comunicação das populações } \\
\text { expostas. Englobam medidas que garantam o intercâmbio necessário de } \\
\text { informações para tomada de decisão e gestão da emergência. }\end{array}$ \\
\hline $\begin{array}{l}\text { Controle e limite de } \\
\text { fronteiras }\end{array}$ & $\begin{array}{l}\text { Medidas visando a reduzir a transmissão fronteiriça de um município, } \\
\text { estado ou país, por meio da restrição da entrada por vias aéreas, terrestres e } \\
\text { marítimas. }\end{array}$ \\
\hline Higiene coletiva & $\begin{array}{l}\text { Medidas de cunho coletivo e individual que propiciem a higiene individual e } \\
\text { coletiva de pessoas, transportes e ambientes. }\end{array}$ \\
\hline $\begin{array}{l}\text { Controle de produtos } \\
\text { no mercado }\end{array}$ & Medidas para controle de preços e de venda de produtos no mercado. \\
\hline Segurança pública & \begin{tabular}{l} 
Medidas de garantia da ordem pública durante o período da pandemia. \\
\hline
\end{tabular} \\
\hline
\end{tabular}




\section{Quadro I - Categorias e descrição das medidas (continuação)}

\begin{tabular}{|l|l|}
\hline \multicolumn{1}{|c|}{ Categoria de medida } & \multicolumn{1}{c|}{ MEDIDAS DO SETOR SAÚDE } \\
\hline Coordenação & $\begin{array}{l}\text { Medidas que envolvem atores do setor Saúde que atuem na gestão da } \\
\text { emergência, tendo como base o monitoramento e o planejamento das ações } \\
\text { necessárias a uma resposta efetiva e oportuna. }\end{array}$ \\
\hline $\begin{array}{l}\text { Atenção Primária à } \\
\text { Saúde (APS) }\end{array}$ & $\begin{array}{l}\text { Medidas relacionadas aos fluxos de atendimento da APS para garantia de } \\
\text { manutenção da assistência de saúde nas unidades básicas de Saúde de maneira } \\
\text { a assegurar acompanhamento, monitoramento e vigilância da população } \\
\text { coberta pela rede de atenção. }\end{array}$ \\
\hline $\begin{array}{l}\text { Atenção hospitalar, } \\
\text { urgência e emergência }\end{array}$ & $\begin{array}{l}\text { Medidas relacionadas à organização da assistência em saúde, garantindo a } \\
\text { realização de procedimentos essenciais e manutenção dos fluxos na rede de } \\
\text { serviços hospitalar e diretrizes específicas para redução dos riscos relacionados } \\
\text { à infecção nas instituições hospitalares. }\end{array}$ \\
\hline Vigilância em saúde & $\begin{array}{l}\text { Medidas e ações de monitoramento e vigilância, prevenção e controle da } \\
\text { Covid-19 relacionadas ao manejo da resposta. }\end{array}$ \\
\hline $\begin{array}{l}\text { Informação e } \\
\text { comunicação }\end{array}$ & $\begin{array}{l}\text { Medidas e estratégias de produção e divulgação regular de informações } \\
\text { sobre evolução e quadro atual da emergência em saúde pública, bem como } \\
\text { desenvolvimento de estratégias de comunicação para a população e com os } \\
\text { demais setores da sociedade. }\end{array}$ \\
\hline Manejo de cadáver & $\begin{array}{l}\text { Medidas específicas para atender à demanda e restringir o risco de transmissão } \\
\text { da doença após o óbito. }\end{array}$ \\
\hline
\end{tabular}

\section{ANÁLISE DAS MEDIDAS IDENTIFICADAS NOS DECRETOS}

Os decretos analisados têm o objetivo de estabelecer normas para o funcionamento das atividades cotidianas e institucionais da sociedade no nível de gestão estadual, no contexto específico do enfrentamento da pandemia por Covid-19. Entre o dia 26 de fevereiro, quando houve o primeiro caso confirmado no Brasil, e o dia 13 de março, nenhum decreto ou lei foi publicado. Entre os dias 13 e 26 de março foram publicados III decretos (ver Gráfico I). 
Gráfico I - Evolução temporal dos decretos: número de decretos relacionados ao enfrentamento da Covid- 19 por unidades da federação, por dia - 26 fev. a 26 mar. 2020

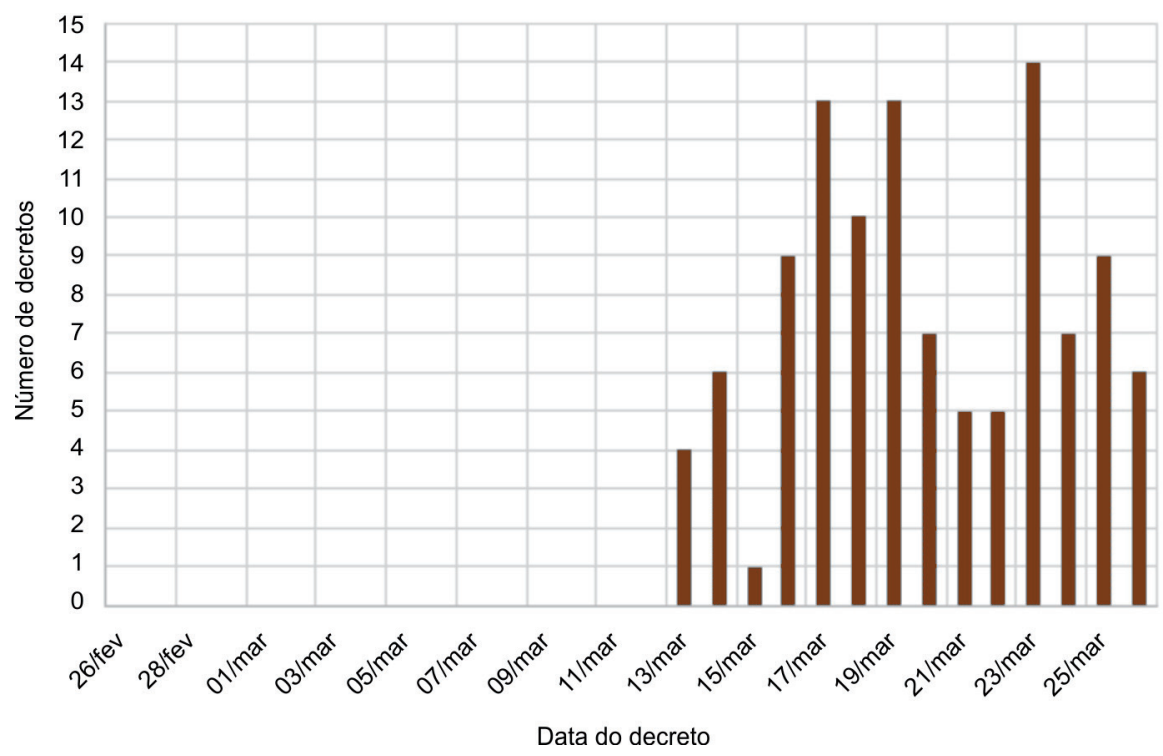

O Gráfico 2 demonstra o número total dessas medidas adotadas por UF. Na categoria "Medidas do setor Saúde", destacamos os estados de Alagoas e Ceará e o Distrito Federal no tocante ao número de medidas adotadas, ao passo que os estados do Amazonas, Minas Gerais, Piauí e São Paulo destacam-se pela reduzida publicação de medida específicas desta categoria. Na categoria "Medidas gerais", de competência de outros setores de igual importância para a gestão do evento, como Segurança Pública, Educação, Água e Saneamento, destacamos os estados de Sergipe, Santa Catarina, Rio de Janeiro, Rio Grande do Sul e Paraná, embora tenha havido publicações em todas as UFs. 
Gráfico 2 - Distribuição geográfica dos decretos e seleção por grupo de medidas (setor Saúde e medidas gerais): total de medidas adotadas por unidade da federação - 26 fev. a 26 mar. 2020

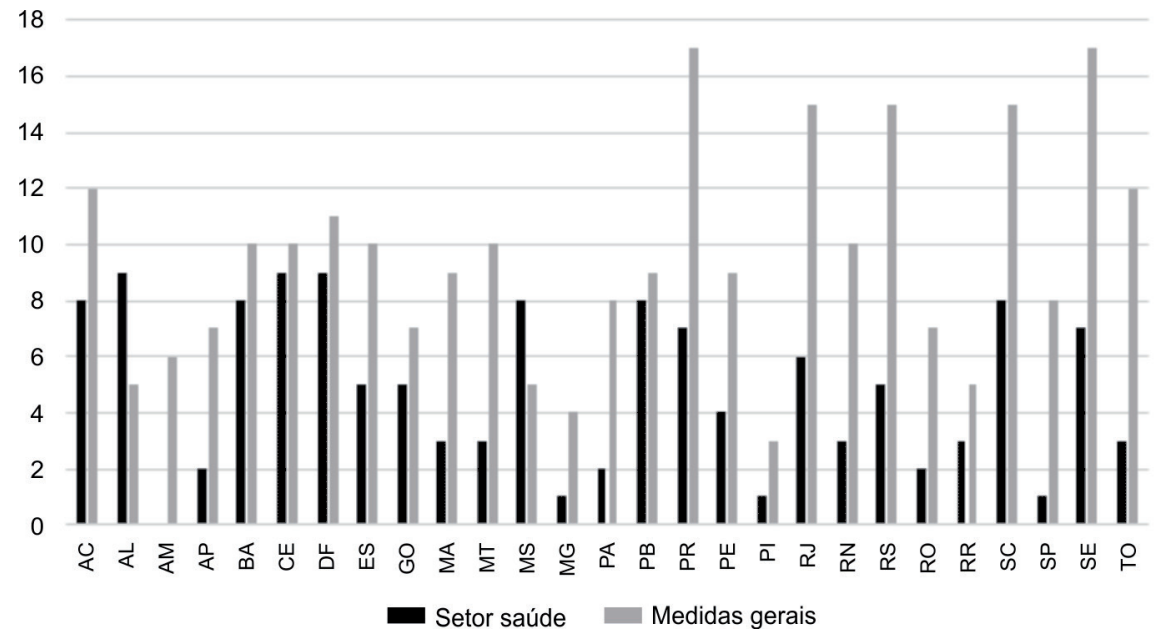

No Gráfico 3, apresentamos o conjunto de medidas levantadas.

Gráfico 3 - Distribuição percentual das medidas de enfrentamento da emergência sanitária adotadas pelos estados - 26 fev. a 26 mar. 2020

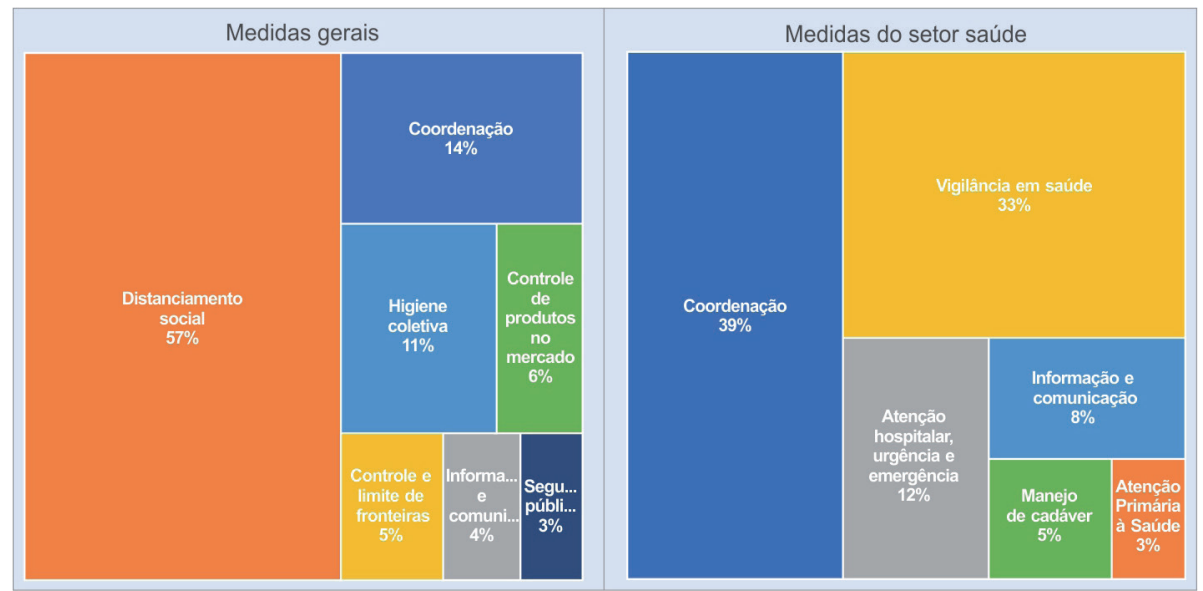


Na categoria "Medidas gerais", destacamos a subcategoria "Distanciamento social", que apresenta notória proporção majoritária (57\%) entre as medidas desta categoria adotadas. Medidas de distanciamento social são parte do conjunto de medidas não farmacológicas para reduzir situações que favoreçam a ampliação da cadeia de transmissão. Nessa categoria foram identificadas medidas de proibição de eventos públicos; proibição da permanência de pessoas em espaços públicos de uso coletivo e ambientes educacionais; fechamento ou modificação da rotina de empreendimentos públicos e privados de caráter não essencial; proibição ou modificações da rotina do transporte coletivo urbano municipal, intermunicipal e interestadual de passageiros; suspensão ou reorganização de atividades da administração pública; continuidade de prestação de serviços públicos e privados essenciais; restrição no sistema carcerário; e suspensão do recadastramento e prova de vida para aposentados, pensionistas e militares inativos.

As medidas de "Coordenação" (14\%) apresentaram-se como a segunda subcategoria mais expressiva dentre as estratégias adotadas. Essa categoria se destinou a reduzir a complexidade da gestão e aprimorar a necessária estrutura de ação e comando envolvendo gestores, empregadores e/ou líderes comunitários para proteger a população. Tais ações asseguram que as medidas implementadas sejam geridas de forma que haja coordenação das ações necessárias e que seja assegurada a participação da sociedade civil e de outros setores governamentais relevantes no processo.

Nessa categoria "Medidas gerais" também destacamos aquelas de "Informação e comunicação", "Controle de fronteiras", "Higiene coletiva" e "Controle de produtos e mercado", que somadas representaram $29 \%$ das estratégias de gestão e enfrentamento da pandemia. Tais medidas, de alcance individual, ambiental e comunitário, visam a reduzir o risco de interiorização da doença, evitando que a cadeia de transmissão se espalhe para locais com pouca capacidade de resposta e reduzida infraestrutura hospitalar instalada, os quais se encontram, em sua maioria, concentrados nas regiões metropolitanas.

O controle fronteiriço nos diversos modais de transporte, medidas para garantia da higiene individual em espaços públicos, garantia da higiene e controle de circulação em ambientes públicos, medidas que garantam a higiene pessoal e controle dos preços de produtos e serviços compõem o conjunto de medidas não farmacológicas adotadas para mitigar as fragilidades da estrutura social, que não se restringem à dimensão biomédica.

No Gráfico 3, no conjunto das medidas do setor Saúde, as categorias "Coordenação" e "Vigilância em saúde", quando somadas, respondem por $72 \%$ das medidas. Guiado por princípios finalísticos e estratégicos presentes no SUS, o processo de coordenação 
na gestão do enfrentamento da pandemia deve fazer parte de políticas que conectem a ampliação do quadro de profissionais da saúde, gestores e serviços complementares capacitados; medidas financeiras e contratuais para melhor equipar o sistema de saúde; medidas para criação/atualização de comitês especiais e medidas para garantir tratamento universal, integral e equânime durante esse o enfrentamento.

Na categoria "Vigilância em saúde" destacamos medidas específicas de contenção e supressão da cadeia de transmissão do vírus; algumas medidas voltadas para o ideal da imunização em massa; medidas que assegurem a ampliação, capacitação e habilitação de laboratórios da rede e expansão da cobertura de monitoramento e vigilância; definição de fluxo de informação ao enfrentamento da pandemia; e normas de regulação do emprego da força policial sanitária, quando necessário. O restante das medidas do setor Saúde, que respondem por $28 \%$ do total, é representado pelas subcategorias "Atenção hospitalar, urgência e emergência" (I 2\%), "Informação e comunicação" (8\%), "Manejo de cadáver" (5\%), e "Atenção primária” (3\%). Apesar de se apresentarem de modo pouco expressivo na gestão das UFs, tais categorias se traduzem em ações complementares de estratégias fundamentais já inseridas nos territórios de saúde.

\section{DISCUTINDO AS MEDIDAS ADOTADAS NUM PAÍS DESIGUAL COMO 0 BRASIL}

Propomos, aqui, que a pandemia de Covid- 19 seja compreendida como um desastre - por envolver uma ameaça, população exposta e condições de vulnerabilidade que modificam os níveis de exposição de cada grupo populacional - e que são necessárias capacidades de resposta que alcancem o nível de complexidade e a magnitude dos desafios postos por esta emergência sanitária. Se assim considerada, cabe pensar a gestão do seu enfrentamento com o arcabouço da gestão de risco de desastres e, portanto, direcionar medidas e estratégias específicas para cada um dos elementos que a compõem como desastre, em um processo de etapas interligadas que combinem correção dos problemas conjunturais e estruturais e prospecção dos riscos.

Em relação à ameaça, que neste caso está associada ao vírus Sars-CoV-2, apesar dos extraordinários esforços da comunidade científica em todo o mundo, nenhum tratamento específico além das vacinas foi aprovado. O desenvolvimento de novos medicamentos é um processo complexo e seus resultados levam tempo para aparecer. Um longo caminho foi percorrido na busca do reposicionamento de fármacos para a Covid-19. Após meses de testes em meio a muitas controvérsias, a realidade mostrou que a chance de se encontrar algum antiviral específico no espaço químico ocupado pelos fármacos aprovados é baixa ou nula (Ferreira E Andricopulo, 2020). Dessa forma, na impossibilidade de eliminar uma ameaça como o vírus Sars-Cov-2 e até que se tenha 
a imunidade coletiva por meio de uma vacina, medidas não farmacológicas devem ser implementadas na tentativa de reduzir a exposição e a vulnerabilidade, além de aprimorar e fortalecer a capacidade de resposta no enfrentamento da pandemia.

Uma das estratégias que se fez presente de forma mais expressiva no conjunto de "Medidas gerais" apresentado nos resultados, o grupo das medidas de "Distanciamento social", pode ser compreendida nesse processo como uma medida com o objetivo de reduzir a exposição de pessoas, buscando diminuir ou interromper a cadeia de transmissão da doença pelo distanciamento físico entre indivíduos que possam estar infectados e os saudáveis, além de proteger aqueles indivíduos em risco de desenvolver a doença de forma mais grave. Entretanto, para além do setor Saúde, é importante considerar os inevitáveis impactos sociais e econômicos que a implementação dessas medidas irá necessariamente causar. Por esse motivo, é importante que haja uma avaliação cuidadosa do momento epidemiológico mais adequado para a aplicação dessas medidas, assim como da sua vigência, com o objetivo de maximizar os efeitos desejáveis na saúde enquanto se minimizam os danos sociais e econômicos (Silva et al., 2020).

No Brasil, a efetiva adoção dessas medidas esbarra também em profundos problemas estruturais ligados às desigualdades e iniquidades sociais. Segundo o primeiro Boletim Socioepidemiológico da Covid-I 9 nas Favelas do Rio de Janeiro (Fiocruz, 2020), o índice de letalidade pela doença cresce de acordo com o nível de concentração de aglomerados subnormais (favelas) por bairro. Nos bairros de concentração alta e altíssima de favelas, as taxas chegam a quase 16,5\% e 19,5\% respectivamente, ao passo que a média do município fica em aproximadamente $11,8 \%$. As condições de vida nas favelas se apresentam como enormes desafios no que se refere a cumprir tanto as medidas de higiene coletiva (também implementadas pelos estados) quanto as medidas de distanciamento social, e refletem os limites e desafios para sua adoção nesses territórios.

Esses territórios se caracterizam pela alta densidade de habitações e arruamentos e por acesso insuficiente ao saneamento básico, o que faz com que algumas medidas sejam inexequíveis para uma parte dessa população. Em muitos casos as moradias têm grande número de moradores e contam com poucas divisões internas, grande proximidade entre residências, pouca ventilação, muita umidade no interior das casas, constituindo cenários muito propícios para a sobrevivência do vírus e sua disseminação e, portanto, para a intensificação de sua propagação.

Além da alta concentração de pessoas por casa nas favelas, segundo o mesmo boletim a restrição da mobilidade e a interrupção de atividades de serviços, comércio e indústria têm produzido graves impactos econômicos e sociais, "porque um grande 
contingente populacional de moradores de favelas são trabalhadores informais. Muitos destes perderam suas fontes de renda e outros são impossibilitados de realizar o isolamento, acentuando a já acelerada velocidade de contágio na direção de territórios populares" (Fiocruz, 2020).

No âmbito do trabalho e renda, as limitações impostas pela necessidade do distanciamento social esbarram no risco do desemprego, no cenário de uma crise de empregos gerada pela pandemia e de obstáculos no acesso ao auxílio emergencial, tanto por dificuldade no entendimento do cadastro quanto por atraso e confusão por parte do governo, como relata o jornal Maré Online (2020). Ainda segundo o boletim, outro fator que contribui para a dificuldade de realização das medidas de distanciamento social nos territórios de favelas é o fato de que grande parte de sua população é trabalhadora de serviços essenciais, que foram mantidos de forma presencial. Além da exposição no ambiente de trabalho, a dinâmica social do seu cotidiano inclui também locomoção em transportes públicos, o que aumentando o nível de sua exposição.

A tudo isso se soma o fato de que no Brasil o presidente da República não só vinha sinalizando com ameaças de editar um decreto para impedir a autonomia dos estados e municípios para determinar medidas de distanciamento social (Teixeira, 2020), como também as vinha boicotando por meio de decretos presidenciais que ampliam o que é considerado atividade essencial, incluindo templos religiosos e academias de esporte, salões de beleza e barbearias.

O auxílio emergencial aqui mencionado foi a principal medida implementada no nível federal de gestão para minimizar os efeitos socioeconômicos das medidas restritivas e do distanciamento social. No arcabouço da gestão de risco de desastres, essa pode ser interpretada como uma medida que busca reduzir a vulnerabilidade posta pelas desigualdades e iniquidades no acesso à renda. Também se reforçam as medidas de distanciamento social, que ampliam as possibilidades de grupos populacionais permanecerem em suas casas nos momentos de quarentena, tendo influência, desta forma, na redução da exposição. Essa medida, entretanto, como já mencionado, encontrou obstáculos e levou algum tempo para ser implementada de forma efetiva para a população. No entanto, houve drástica redução do auxílio emergencial, de quase $100 \%$ do valor, a partir do final de 2020, assim como redução no universo de beneficiários. Estima-se que a crise gerada pela pandemia, somada às restrições impostas por essa medida, levem a um aumento da vulnerabilidade: cerca de 61 milhões de pessoas em situação de pobreza e 19,3 milhões em situação extrema pobreza em 2021 (Nassif-Pires, Cardoso E Oliveira, 202I). 
Outra estratégia fundamental para a redução da exposição está conectada com as medidas de vigilância em saúde. A OMS preconiza o uso de alguns indicadores-chave no monitoramento da situação epidemiológica e da capacidade de resposta nos estados e regiões. Esses indicadores estão relacionados à incidência e mortalidade por Covid-19, à incidência de síndrome respiratória aguda grave (Srag) e à disponibilidade de leitos, e servem para balizar as tomadas de decisão relacionadas à flexibilização ou manutenção das medidas de distanciamento social nos estados. Evidências sugerem que a adoção precoce das medidas de distanciamento social em conjunto com a estratégia de controle baseado na aplicação de teste em larga escala seria fundamental para frear a transmissão da doença e, consequentemente, reduzir a demanda aos serviços de saúde.

Embora a testagem em escala tenha sido sugerida como um dos principais instrumentos para a vigilância e monitoramento da epidemia, no Brasil houve priorização de estratégias equivocadas, com reflexos no atual cenário epidemiológico (Icict/Fiocruz, 2021). Em uma emergência sanitária como a pandemia por Covid-19, há necessidade de orientação oportuna para definição do tipo de teste mais apropriado para os casos suspeitos, prováveis e confirmados (Sharfstein, Becker \& Mello, 2020), o que possibilita a avaliação da situação do passado e no presente, e projetar os passos futuros. Isso porque, além da identificação e isolamento de pacientes sintomáticos, o controle eficaz da disseminação exigiria a redução do risco de transmissão de pessoas assintomáticas ou oligossintomáticas, população que representa aproximadamente $60 \%$ dos casos de Covid- 9 (Qiu, 2020).

Entretanto, o que pudemos observar é que durante o período analisado e posterior, ocorreu a disseminação do uso de teste do tipo rápido (tipologia analítica capaz de gerar resultados de prevalência populacional), em detrimento da aquisição de testes do tipo RT-PCR (método ideal para o controle da incidência da infecção), capazes de identificar transmissões potenciais (sintomáticos e assintomáticos), apresentando real ganho estratégico de rastreamento populacional (Icict/Fiocruz, 202I). Testar todos os suspeitos de infecção ainda se apresenta como um desafio no Brasil. Os testes usados na triagem, no diagnóstico e no acompanhamento de Covid-1 9 devem ser elencados considerando-se os diferentes cenários clínicos e de saúde pública (ArevaloRodriguez, Seron \& Buitrago-García, 202 I), pois se aplicados de forma oportuna são potencialmente capazes de identificar populações e regiões prioritárias na contenção da disseminação do vírus (lcict/Fiocruz, 2021).

Essas medidas de vigilância, por sua vez, não devem ocorrer de forma isolada e independente, nem no âmbito intersetorial nem no intrassetorial. Por esse motivo, medidas de coordenação específicas do setor Saúde, que representaram número 
expressivo (39\%), embora ainda insuficientes são fundamentais para a gestão da pandemia. A articulação da vigilância com a APS, por exemplo, apresenta diversas potencialidades não só para o aprimoramento da capacidade de resposta como também para a redução da exposição e de vulnerabilidades no contexto da pandemia. Uma delas, capaz de contribuir para o aumento da sensibilidade da Vigilância Epidemiológica (VE), consiste no rastreamento de todos os contatos. Tal iniciativa possibilitará a ampliação das medidas de proteção e controle da Covid-19, com participação ativa da APS (Teixeira et al., 2020).

Teixeira e colaboradores (2020) sistematizaram algumas intervenções na APS que articulam medidas de VE no contexto da pandemia por Covid-19, que trazemos para complementar a demonstração de como podem estar associadas à gestão para a redução da exposição e da vulnerabilidade e para a ampliação da capacidade de resposta. Infelizmente, entretanto, tais medidas de APS representaram quantitativo inexpressivo (3\%), quase inexistente, entre as estratégias adotadas pelos estados:

I. Medidas voltadas para redução do risco de expansão da epidemia, como: a) divulgação dos cuidados de higiene, b) participação ativa na notificação dos casos, c) indicação e monitoramento do isolamento domiciliar e quarentena dos contatos e d) incentivo à adesão ao distanciamento social;

2. Atenção aos usuários portadores de Covid-1 9 com quadros leves, que devem ser acompanhados adequadamente pelas equipes de APS, com a adoção de alternativas - a depender da realidade local - por gestores e profissionais, prontamente divulgadas entre a população, como, por exemplo: a) a separação de indivíduos suspeitos de Covid- 19 dos demais usuários (espaços físicos ou fluxos/horários distintos; tendas externas) e b) as transferência para atendimento hospitalar (transporte sanitário apropriado); e

3. Suporte social a grupos mais frágeis e vulneráveis (idosos, portadores de comorbidades, etc.) que: a) se encontram isolados, sem rede de apoio social e/ou com autonomia de limitada para circular e obter produtos essenciais à sua vida cotidiana, e b) necessitam de apoio, proteção e segurança.

Portanto, é fundamental que as equipes de APS ampliem as articulações e parcerias com organizações governamentais, não governamentais e movimentos sociais, para minimizar os problemas decorrentes dessas vulnerabilidades.

Com a pandemia em curso, cirurgias de média complexidade foram suspensas ou canceladas, consultas de acompanhamento foram reorganizadas e a demanda atendida 
pelos profissionais foi afetada pela sobrecarga resultante das mudanças nos protocolos de acolhimento, pelo ônus causado pelas políticas de financiamento e pelo excesso laboral. É urgente, portanto, uma organização em Rede de Atenção à Saúde (RAS) que integre os diversos pontos de atenção, além de capacitação para os profissionais da saúde que atuam na linha de frente (Teixeira et al., 2020).

No escopo do conceito de desastres é possível identificar a importância da articulação em rede entre os mais diversos atores, como por exemplo a APS, a atenção secundária $e$ as ações relacionadas à atenção terciária, dentro das quais se encaixam as medidas relacionadas à internação hospitalar e à provisão de leitos de UTI. Nesse sentido, compreender a RAS como uma estrutura complexa que precisa de articulação para o bom desenvolvimento de estratégias de prevenção, atenção, vigilância, acompanhamento, encaminhamento e internação, quando necessário, é essencial.

Outro fator relevante a ser evidenciado nas orientações técnicas e ações de âmbito estadual é a forte verticalização operacional sem que tenha havido necessariamente coordenação e coesão no enfrentamento, que pressuporia discussão com o Conselho Nacional de Secretários de Saúde (Conass) e o Conselho Nacional de Secretarias Municipais de Saúde (Conasems), pactuação com Comissões Intergestores Tripartites e Comissões Intergestores Bipartites, respeitando-se as particularidades de cada local. Boa coordenação é fundamental para que a gestão da pandemia se traduza, entre outras, no fortalecimento da capacidade de resposta dos estados diante da crise sanitária. No Brasil, desde o primeiro caso registrado, poucas foram as medidas implementadas em nível federal; delegou-se ao Distrito Federal, estados e municípios a implementação de estratégias farmacológicas e não farmacológicas para o controle da Covid-19, de acordo com a situação epidemiológica experimentada (Silva et al., 2020).

Em diferentes países, a pandemia por Covid- 19 também tem revelado tensões entre governos centrais e governos estaduais e locais. Na Itália, por exemplo, decretos dos governadores de Marche e Lombardia foram anulados pelo governo central sob a argumentação de que ações descentralizadas produziriam caos (Polato $\varepsilon$ Muraro, 2020). Na Espanha, o País Basco declarou emergência em saúde pública antes de qualquer outra região. A Catalunha adotou o fechamento de toda a região, incluindo fronteiras, além de medidas de distanciamento social (Legido-Quigley et al., 2020). Nos EUA, Cornwall e colaboradores (2020) destacaram que a ausência de uma forte coordenação nacional fez com que governos estaduais seguissem seu próprio caminho e acentuou a divisão do poder legal entre esses diferentes níveis. Para os autores, à medida que a pandemia foi se intensificando e ampliando no Brasil, os governadores foram seguindo 
seus próprios caminhos, com alguns adotando medidas rigorosas e outros ignorando a necessidade de ação imediata.

O enfrentamento da Covid- 19 foi marcado pela insegurança, pela falta de insumos básicos e de estrutura física compatível com as necessidades conjunturais, bem como por um contexto de desinformação e iniquidades sociais. Compreender a importância de medidas que garantam não apenas o direcionamento das ações em saúde, mas de todos os setores, numa perspectiva inter e intrassetorial, se faz essencial para que a proteção à saúde da população aconteça de maneira eficaz, em consonância com as necessidades impostas pelo desastre. Medidas preventivas individuais não são suficientes, o que torna essencial adotar medidas de alcance comunitário (Oliveira et al., 2020). O conjunto de medidas iniciais conforma uma estratégia de gestão de riscos da pandemia que irá definir o alcance e os limites do enfrentamento desse desastre no Brasil.

\section{CONSIDERAÇÕES EM BUSCA DE UMA GESTÃO PROSPECTIVA E LIÇÕES APRENDIDAS}

O processo de gestão da pandemia, quando bem-sucedido, tem poupado vidas e proporcionado tempo para adequação do sistema de saúde e ampliação da capacidade de detecção, capacitação de equipes especializadas e oferta de suprimentos de forma a assegurar as intervenções médicas necessárias. Esse processo é composto por medidas do setor Saúde e de outros setores, uma vez que os impactos da pandemia vão muito além dos impactos imediatos sobre a saúde, envolvendo também os econômicos, sociais, educacionais e culturais na sociedade. Além disso, as medidas do setor Saúde devem ocorrer de forma articulada com as de outros setores, de forma que as segundas propiciem e sejam implementadas também em prol das primeiras.

Na discussão sobre as medidas adotadas pelas 27 UFs brasileiras no primeiro mês de enfrentamento da pandemia não se pode perder de vista três perguntas fundamentais: l) se foram efetivas em reduzir a exposição para todos, principalmente os grupos populacionais vulneráveis por idade ou doenças crônicas; 2) se foram efetivas em reduzir as condições de vulnerabilidade social das populações em situação de vida e trabalho mais precária e sem acesso à proteção social; 3) se foram efetivas em fortalecer as capacidades de resposta e de redução dos riscos dentro do setor Saúde (fortalecimento e ampliação desde a APS até a atenção hospitalar, assim como das capacidades de detecção e vigilância em saúde) e fora do setor Saúde. No escopo das medidas de extrema relevância, o primeiro mês constitui o momento de assentamento das bases para uma gestão corretiva e prospectiva. 
Para uma coordenação efetiva na resposta à pandemia, as ações necessárias devem mobilizar de forma plena e articulada o SUS, patrimônio nacional e política de Estado que garante o acesso às ações e serviços de saúde aos mais de 210 milhões de habitantes do Brasil. O que torna necessário contar com a participação dos municípios, dos estados e da União, além do envolvimento de todos os governos, nos três níveis de gestão, do Congresso Nacional, do Poder Judiciário e da sociedade brasileira (Oliveira et al., 2020).

\section{REFERÊNCIAS}

AREVALO-RODRIGUEZ, I.; SERON, P. \& BUITRAGO-GARCÍA, D. Recommendations for Sars-CoV-2/ Covid-19 testing: a scoping review of current guidance. BMJ, II: e043004, 2021. Disponível em: $<$ https://bmjopen.bmj.com/content/I I/I/e043004>. Acesso em: 16 fev. 2021.

CORNWALL et al. The United States leads in coronavirus cases, but not pandemic response. Science News Staff, I abr. 2020. Disponível em: <www.science.org/news/2020/04/united-states-leadscoronavirus-cases-not-pandemic-response>. Acesso em I5 nov. 2020.

FERREIRA, L. L. G. \& ANDRICOPULO, A. D. Medicamentos e tratamentos para a Covid- 19. Estudos Avançados, 34(100), 2020. Disponível em: <www.scielo.br/scielo.php?script=sci_arttextEpid =S0 I 03-40 I 42020000300007>. Acesso em: I 6 fev. 202I.

FREITAS, C. M.; SILVA, I. V. M. \& CIDADE, N. C. Covid- I 9 as a global disaster: challenges to risk governance and social vulnerability in Brazil. Ambiente E Sociedade, 23, 2020. Disponível em: <www.scielo.br/scielo. php?pid =S I 4 I 4-753X2020000 I00906Escript =sci_abstract $>$. Acesso em: 23 mar. 2021 .

FREITAS, C. M. et al. Mudanças climáticas, redução de riscos de desastres e emergências em saúde pública nos níveis global e nacional. Relatório final. Rio de Janeiro: Fiocruz, 2019. Disponível em: <https:// saudeamanha.fiocruz.br/wp-content/uploads/2020/02/FREITAS-CARLOS-et-al-Mudan\%C3\%A7asclim\%C3\%A I ticas-redu\%C3\%A7\%C3\%A3o-de-riscos-de-desastres-e-emerg\%C3\%AAncias-emsa\%C3\%BAde-p\%C3\%BAblica.pdf>. Acesso em: I nov. 2020.

FREITAS, C. M. et al. A Gestão de Riscos e Governança na Pandemia por Covid- 9 no Brasil: análise dos decretos estaduais no primeiro mês. Relatório técnico e sumário executivo. Rio de Janeiro: Cepedes, Ensp/ Fiocruz, 2020. Disponível em: <www.arca.fiocruz.br/bitstream/icict/41452/2/relatorio_cepedes_ gestao_riscos_covid I9_final.pdf>. Acesso em: 16 fev. 2021.

FUNDAÇÃO OSWALDO CRUZ (FIOCRUZ). Sala de Situação Covid-I 9 nas Favelas. Observatório Covid- 19 Fiocruz. Boletim Socioepidemiológico da Covid- 19 nas Favelas: análise da frequência, incidência, mortalidade e letalidade por Covid-19 em favelas cariocas, I, 2020. Portal Fiocruz, Rio de Janeiro, 2020. Disponível em: <https://portal.fiocruz.br/documento/boletim-socioepidemiologico-da-covid-19nas-favelas-ed-1>. Acesso em: 14 mar. 2021.

INSTITUTO DE COMUNICAÇÃO E INFORMAÇÃO CIENTÍFICA E TECNOLÓGICA EM SAÚDE/ FUNDAÇÃO OSWALDO CRUZ (ICICT/FIOCRUZ). MonitoraCovid- 19. Rio de Janeiro. Disponível em: $<$ https://bigdata-covid I 9.icict.fiocruz.br/>. Acesso em: 23 mar. 2021.

LEGIDO-QUIGLEY, H. et al. The resilience of the Spanish health system against the Covid- I 9 pandemic. The Lancet Public Health, 5(5): e25I-e252, 2020. Disponível em: <www.ncbi.nlm.nih.gov/pmc/ articles/PMC7 I04264/>. Acesso em: 16 fev. 2021. 
MARÉ ONLINE. Vírus atinge famílias mais vulneráveis na maré. Maré Online, Rio de Janeiro, 18 jun. 2020. Disponível em: <https://mareonline.com.br/virus-atinge-familias-mais-vulneraveis-namare/>. Acesso em: 25 jan. 2021 .

NASSIF-PIRES, L.; CARDOSO, L. \& OLIVEIRA, A. L. M. Gênero e raça em evidência durante a pandemia no Brasil: o impacto do Auxílio Emergencial na pobreza e extrema pobreza. MADE, USP. São Paulo, 202I. Disponível em: <https://madeusp.com.br/wp-content/uploads/202 I/04/NPE-0 I 0-VF.pdf>. Acesso em: 20 fev. 2021 .

OLIVEIRA, W. K. et al. Como o Brasil pode deter a Covid- I 9. Epidemiologia e Serviços de Saúde, 29(2), 2020. Disponível em: <www.scielo.br/scielo.php?pid=S2237-96222020000200200Escript=sci_ arttext>. Acesso em: 13 jan. 2021.

POLATO, A. E MURARO, C. I mês de coronavírus no Brasil: compare a situação do país com China, Itália, EUA e Coreia do Sul no mesmo período da epidemia. GI, Rio de Janeiro, 23 mar. 2020. Disponível em: <https://gl.globo.com/bemestar/coronavirus/noticia/2020/03/26/I-mesde-coronavirus-no-brasil-compare-a-situacao-do-pais-com-china-italia-eua-e-coreia-do-sulno-mesmo-periodo-da-epidemia.ghtml>. Acesso em: 16 fev. 2021.

QIU, J. Covert coronavirus infections could be seeding new outbreaks. Nature, 2020. Disponível em: <www.nature.com/articles/d41 586-020-00822-x>. Acesso em: 20 fev. 2021.

SHARFSTEIN, J. M.; BECKER, S. J. \& MELLO, M. M. Diagnostic testing for the novel coronavirus. Jama, 323: I.437-I.438, 2020. Disponível em: <https://jamanetwork.com/journals/jama/fullarticle/276295 I >. Acesso em: 15 jan. 2021.

SILVA, L. L. S. et al. Medidas de distanciamento social para o enfrentamento da Covid- I 9 no Brasil: caracterização e análise epidemiológica por estado. Cadernos deSaúdePública, 36(9), 2020. Disponível em: $<$ www.scielo.br/scielo.php?script=sci_arttextEpid=S0 I 02-3 I I X2020000905003Etlng =pt > . Acesso em: 23 mar. 2021.

TEIXEIRA, M. Em derrota a Bolsonaro, Moraes decide que estados têm autonomia para impor isolamento social. Presidente vinha ameaçando editar medida para romper com decisão de estados e municípios. Folha de S.Paulo, São Paulo, 8 abr. 2020. Disponível em: <wwwl.folha.uol.com.br/poder/2020/04/ em-derrota-a-bolsonaro-moraes-decide-que-estados-tem-autonomia-para-impor-isolamento-social. shtml>. Acesso em: 16 fev. 2021.

UNDRR, M. G. et al. Reorganização da atenção primária à saúde para vigilância universal e contenção da Covid-19. Epidemiologia e Serviços de Saúde, 29(4), 2020. Disponível em: <www.scielo.br/scielo. php?pid=\$2237-96222020000400900Escript $=$ sci_arttext $>$. Acesso em: 16 fev. 2021 .

UNITED NATIONS OFFICE FOR DISASTER RISK REDUCTION (UNDRR). Sendai Framework for Disaster Risk Reduction 2015-2030. UNDRR, 2015. Disponível em: <www.undrr.org/publication/sendaiframework-disaster-risk-reduction-2015-2030>. Acesso em: I 5 nov. 202I.

WORLD HEALTH ORGANIZATION (WHO). Health Emergency and Disaster Risk Management Framework. Geneva: World Health Organization, 2019. Disponível em: <www.who.int/hac/techguidance/ preparedness/health-emergency-and-disaster-risk-management-framework-eng.pdf $>$. Acesso em: 15 nov. 2021. 



\section{O Panorama da Pandemia Covid-19 no Brasil diferentes graus de mitigação nos estados e processo de recrudescimento}

Daniel Antunes Maciel Villela

o longo dos meses de pandemia, os cenários epidemiológicos foram acompanhados
mediante a utilização de indicadores importantes para monitorar a situação de modo a se obter respostas rápidas de auxílio à vigilância e a se dispor de um sistema de saúde preparado com número adequado de leitos em enfermaria e leitos de UTI. Esses cenários foram descritos em apresentações em seminários virtuais para informar a situação com base em dados como número de casos confirmados de Covid- 19 divulgados pelas secretarias de Saúde e número de casos de síndrome respiratória aguda grave (Srag), que são casos graves de doenças respiratórias, incluindo casos de Covid-19, que demandam hospitalização ou foram a óbito. Esses registros são mantidos no Sistema de Informação da Vigilância Epidemiológica da Gripe (Sivep Gripe).

Apresentarei aqui as observações, resultados e conclusões que divulguei nesses seminários, baseados no conhecimento atual da pandemia (Villela, 2020a, 2020b).

\section{CENÁRIO DO BRASIL E DE OUTROS PAÍSES}

Após meses de declarada a pandemia de Covid-19 pela Organização Mundial da Saúde (OMS), o Brasil apresentava um número de casos muito grande comparado aos de vários outros países.

A Figura I apresenta o número de casos acumulado no período total a partir do momento em que esses países registraram 50 casos até o dia 8 de dezembro de 2020. A utilização desse critério é importante para alinhar as séries temporais pelo momento em que se iniciou a transmissão comunitária. Os Estados Unidos da América registraram aproximadamente 15 milhões de casos. A Índia havia notificado mais de 9 milhões de ca- 
sos, seguida do Brasil, que havia excedido 6 milhões de casos. Esses números dependem também da disponibilidade de exames diagnósticos para confirmação de casos. Portanto, pode haver uma subnotificação que varia entre os países. No entanto, os números de casos em milhões e óbitos em centenas de milhares de casos evidenciam a gravidade da crise instalada e o desafio imposto na mitigação de seus efeitos. O número de óbitos confirmados excedia, naquele momento, 172 mil óbitos.

Figura I - Número de casos confirmados por países a partir do $50^{\circ}$ caso confirmado

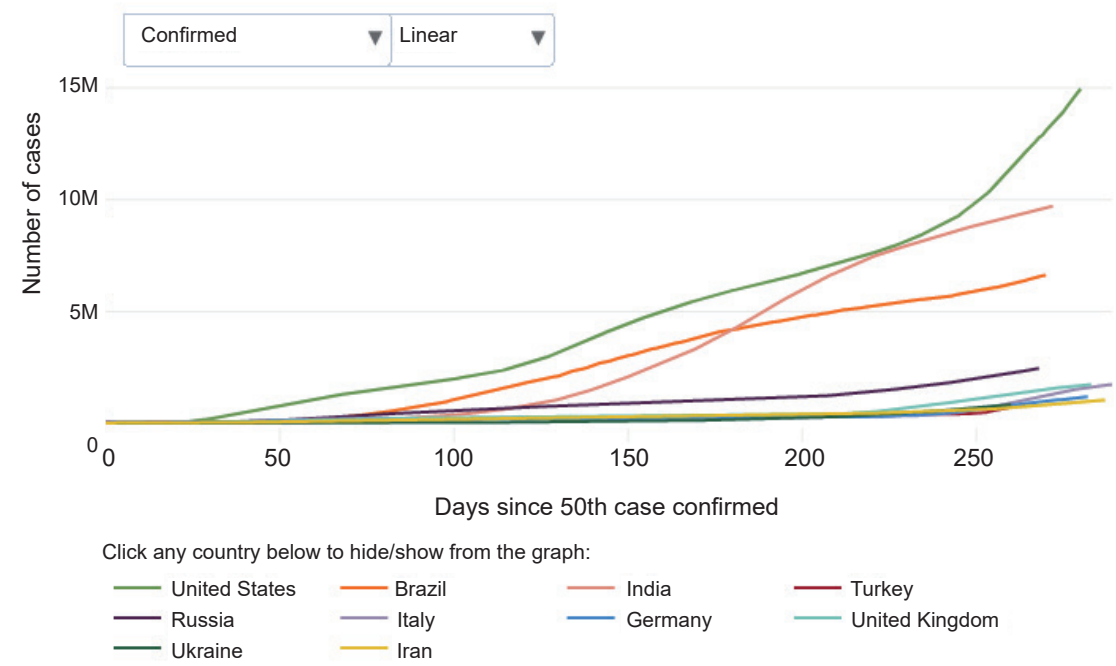

Fonte: Johns Hopkins University \& Medicine, 2020.

\section{EMERGÊNCIA DO VIIRUS SARS-COV-2 NO BRASIL: VIGILÂNCIA SINDRÔMICA}

Para avaliar a pressão sobre um sistema de saúde, como o sistema hospitalar, o ideal é analisar os casos que requerem internação, como casos mais severos. De fato, existe uma vigilância sindrômica de doenças respiratórias a partir de sintomas, mantidas no Sistema de Vigilância Epidemiológica (Sivep Gripe). Nesse caso, a contagem do número de casos de síndromes respiratórias agudas graves (Srag) se mostra importante, porque se trata registros de internações ou óbitos que apresentaram sintomas como febre, tosse ou dor de garganta, dispneia ou saturação baixa de $\mathrm{O}_{2}$. Durante a pandemia, com alta proporção de casos em idosos, para uma vigilância mais sensível os registros de Srag podem ser considerados mesmo sem o sintoma de febre. 
Os casos de síndrome gripal com exame diagnóstico positivo para Sars-CoV-2 são registrados no sistema e-SUS Notifica.

Com os registros no Sivep Gripe, o protocolo normal é o encaminhamento para exame diagnóstico de detecção de vírus respiratório. Observa-se que, atualmente, pouco mais da metade $(\sim 54 \%)$ apresenta algum resultado positivo para vírus respiratório. No entanto, uma parcela muito significativa, da ordem de $97 \%$ dos registros com detecção, teve confirmação positiva para Sars-CoV-2, o que mostra que a análise de incidência de Srag é um bom indicador para Covid-19. Mesmo sem testagem, dada a predominância de casos com Sars-CoV-2, avalia-se que os indicadores baseados em Srag apontam tendências da pandemia no país. Portanto, a partir do início da pandemia, por exemplo, as curvas epidêmicas apresentam o padrão epidêmico observado para a incidência do novo coronavírus para os casos mais graves.

O sistema InfoGripe (Fiocruz, 2020), desenvolvido no Programa de Computação Científica da Fundação Oswaldo Cruz, no grupo de Métodos Analíticos em Vigilância Epidemiológica (Mave), com parceiros de outras instituições do Rio de Janeiro, produz semanalmente avaliações da incidência de Srag. O InfoGripe realiza análises dos casos de Srag para vigilância de casos de influenza e outros vírus respiratórios com dados de registro iniciados em 2009.

Essa vigilância pode ser utilizada como sentinela para eventos importantes. De fato, a vigilância de Srag até a Semana Epidemiológica (SE) 12 apontou mudança no perfil etário nos registros de Srag. O estudo de Bastos e colaboradores analisou hospitalizações por Srag em várias faixas etárias (Bastos et al., 2020). O padrão dos anos anteriores mostrava uma concentração nos mais jovens, principalmente em faixa etária de crianças. Em 2020, a partir da entrada do vírus Sars-CoV-2, os casos nas faixas etárias dos mais idosos tornam-se predominantes.

\section{MEDIDAS DE MITIGAÇÃO: INTERVENÇÕES NÃO FARMACOLÓGICAS}

Após identificada a transmissão comunitária, com a ausência de tratamento específico como antivirais e também a ausência de uma vacina, muitos esforços se voltaram para mitigar a transmissão (Wilder-Smith E Freedman, 2020). Dessa forma, muitas iniciativas promoveram redução da taxa de contágio por meio de distanciamento físico, uso de máscaras e recomendações de higienização. Houve também restrições de viagens, suspensão de aulas e outras atividades. Uma vez iniciada a epidemia em um local, esses esforços se voltaram para reduzir a intensidade de transmissão e, por consequência, o pico da epidemia, em um conjunto de esforços para o que ficou 
conhecido como "achatar a curva". Um dos objetivos foi evitar sobrecarga no sistema de saúde, porque, com o sistema de saúde com operação próxima de saturação, com taxa de ocupação de leitos em hospitais em 100\% ou próximo de 100\%, muitas mortes aconteceriam por falta de cuidados básicos, e porque era necessário alongar o processo de forma a permitir que o sistema se preparasse melhor (Villela, 2020a).

O Observatório Fiocruz Covid-19 gerou um importante documento no qual, tomando como referência a resolução OMS (WHO, 2020), estabeleceu um conjunto de indicadores baseados na avaliação de tendência de número de casos, ocupação hospitalar e testagem. Esse documento contém importantes diretrizes quando se trata de avaliar condições que demandem manutenção daquelas medidas ou permitam eventual flexibilização (Fiocruz, 2020a).

A possibilidade de pressão intensa e a falta de capacidade no sistema de saúde eram, efetivamente, reais. Nos primeiros meses, o número de casos em Manaus e cidades do Amazonas excediam à capacidade de atendimento, com reflexo no número de óbitos (Orellana et al., 2020). Na Figura 2 é possível observar que, mesmo em julho, a ocupação dos leitos de UTI destinados à Covid- 19 aparecia bem alta em vários estados, em particular em Goiás, com 87\%. Uma taxa de ocupação acima de $80 \%$ significa reduzida margem para atendimento prioritário em caso de aumento no número de casos. Portanto, taxas de ocupação muito altas demonstram sinal inequívoco de alerta, juntamente com os demais indicadores de incidência e de exposição da população. 
Figura 2 - Taxa (\%) de ocupação dos leitos em UTI destinados à Covid- 19 nos estados brasileiros. Níveis acima de $80 \%$ estão assinalados em vermelho, níveis entre $60 \%$ e $80 \%$ em amarelo e taxas de ocupação abaixo de $60 \%$ apresentam-se na cor verde

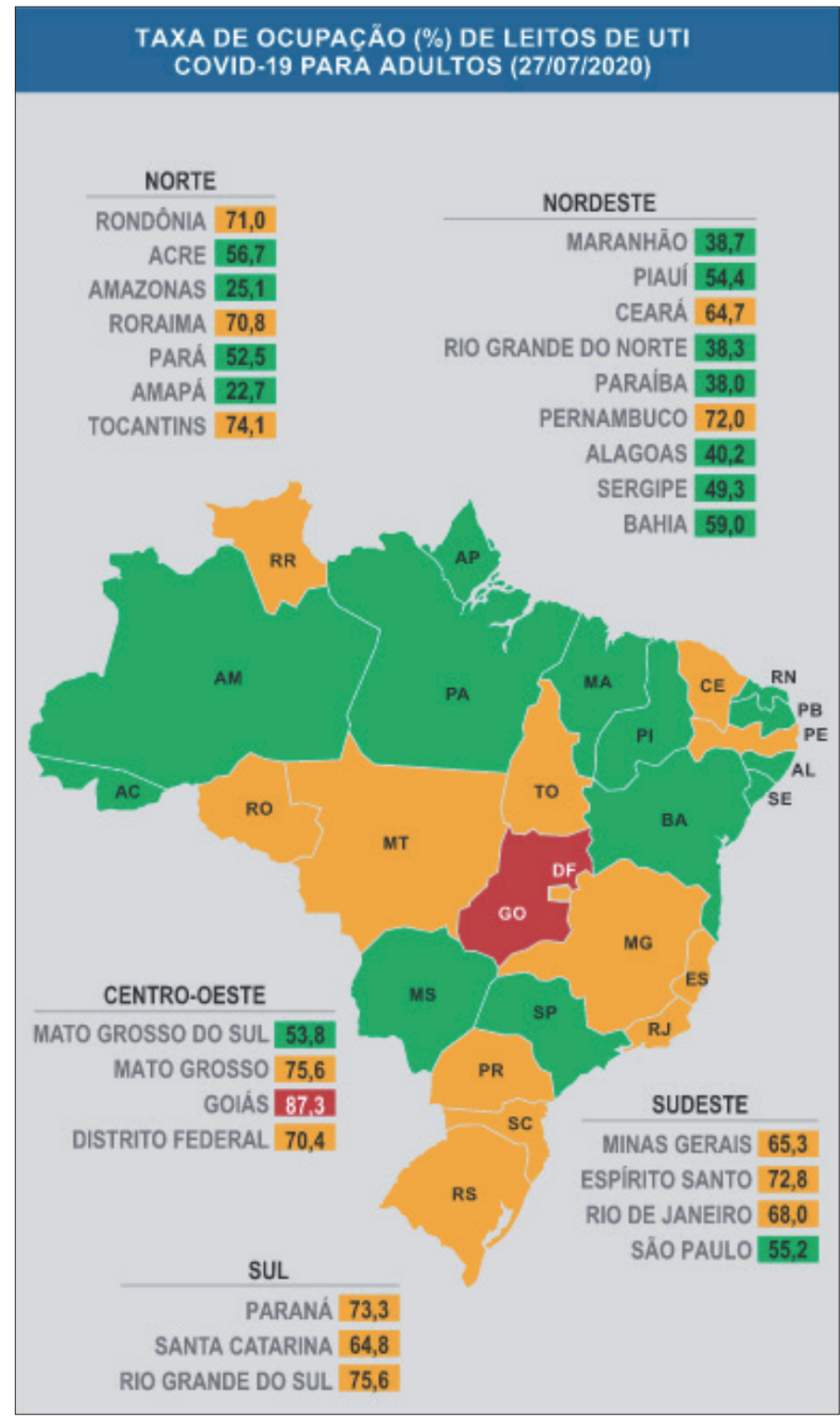

Fonte: Boletim Observatório Fiocruz Covid-19, semanas 31-32. Fiocruz, 2020c. 


\section{VIGILÂNCIA SINDRÔMICA: EVIDÊNCIAS DA MITIGAÇÃO}

A partir da SE 12, em meados de março, há um crescimento expressivo do número de casos, mas em vários estados e municípios decidiu-se restringira mobilidade intramunicipal e interurbana, assim como viagens aéreas, e foram recomendadas várias medidas não farmacológicas para reduzir a intensidade de transmissão do vírus SarsCoV-2 e, assim, mitigar os efeitos da pandemia. Essas medidas não farmacológicas envolveram distanciamento físico, com grande ênfase em evitar aglomerações, suspensão de aulas, recomendações de higiene de mãos e superfícies e uso de equipamento de proteção individual como máscaras de proteção.

Os boletins InfoGripe permitem observar esses padrões ao longo das semanas. Nas regiões Norte e Nordeste, houve um crescimento de casos de Srag muito intenso no início da pandemia, em particular no estado do Amazonas e no Ceará. Mas houve mudança bem clara de padrão, mais pronunciada em particular nas regiões Centro-Oeste e Sul, mas também em alguns estados da região Sudeste, como Minas Gerais. Nesses estados e regiões, a intensidade do crescimento do número de casos se reduziu, muito provavelmente como efeito das várias ações de mitigação dos efeitos da pandemia.

A Figura 3 apresenta o número de casos registrados de Srag ao longo das semanas epidemiológicas. Para as semanas mais recentes o número de casos é estimado por meio de modelo estatístico que avalia o tempo de oportunidade para a digitação dos casos a partir da notificação (Bastos et al., 20I9).

Figura 3 - Número de casos de síndrome respiratória aguda grave por semana epidemiológica no Brasil. A curva azul apresenta a média móvel do número de casos. A curva em cor preta apresenta o número total registrado até a SE 48. As curvas em tracejado representam o intervalo de confiança a partir de processo de nowcasting

SRAG

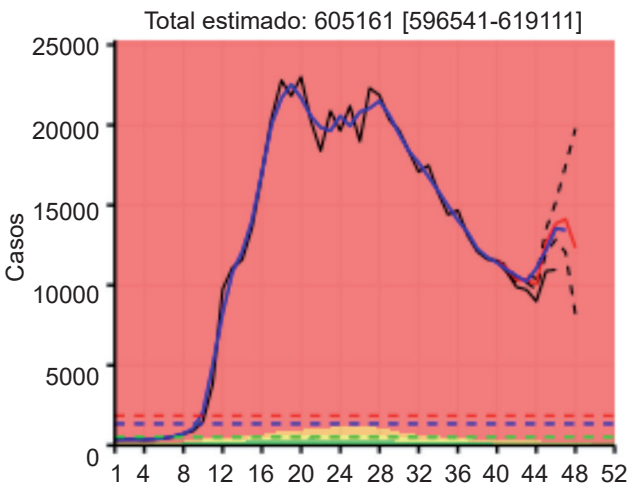

Fonte: website InfoGripe (Fiocruz, 2020b). 


\section{PROCESSO DE RECRUDESCIMENTO}

A partir da SE 42, acontece um processo de reversão: o número de casos não apenas deixa de diminuir, mas, ao contrário, passa a aumentar. A incidência crescente surge ao mesmo tempo que se observa fenômeno de uma "segunda onda" em vários países da Europa, como Itália, Espanha, Reino Unido e França.

Na Europa houve número bem grande de casos de Covid- 9 no início do ano, e no momento do fim do verão europeu aparece um novo ciclo de crescimento intenso do número de casos em vários de seus países. De forma geral, a caracterização de uma segunda onda se daria em razão de um novo e significativo aumento de casos após um período de redução. Isso aparece de forma bem marcada nesses países porque houve controle efetivo no primeiro momento, com medidas fortes que permitiram redução bastante acentuada no número de casos.

$\mathrm{Na}$ Europa, surgem algumas questões ligadas à mudança de estação, ao término do verão, e à sazonalidade habitualmente bem definida de doenças respiratórias. Não podemos afirmar que o vírus atua de forma sazonal, mas o fim do verão e início de temporada fria leva indivíduos a menor distanciamento e à formação de grupos em locais fechados como ambientes de trabalho.

Cabe destacar que na segunda onda da Europa, apareceu a princípio grande parcela de casos em pessoas mais jovens, o que corrobora a explicação de que pessoas nessas faixas etárias voltaram a circular mais e a ficar mais expostas ao risco de infecção. Além disso, a mortalidade foi bem menor que a registrada nos primeiros meses do ano. Não houve evidência de que o vírus tenha reduzido ou aumentado sua letalidade. Para o cálculo de letalidade são necessários os dois indicadores em uma razão, número de óbitos (numerador) e número de casos confirmados (denominador). Portanto, o número de casos entra como denominador, de forma que uma possível melhora na avaliação do número de casos possibilitada por maior quantidade de testes, melhor qualidade dos testes, com consequente melhor diagnóstico e confirmação de casos impacta no cálculo de letalidade. Quanto à mortalidade, a concentração de casos em faixas etárias mais jovens e a melhoria no atendimento dos casos também contribuíram para reduzi-la após o verão europeu.

No Brasil observa-se, passados meses da pandemia:

- Primeiro, o número de casos se reduziu lentamente a partir da SE 28 (Figura 2), quando idealmente se esperaria, com controle efetivo, redução mais acentuada.

- Posteriormente, a incidência permaneceu alta, mesmo com padrões heterogêneos na dinâmica observada ao longo do país e nos estados e nos municípios. 
- A partir da SE 44, já há um processo de reversão, com vários estados e municípios apresentando ou estabilidade ou mesmo aumento do número de casos.

A razão mais provável para um novo aumento de casos e um recrudescimento seria a volta de circulação das pessoas, muitas das quais ainda suscetíveis, por terem se protegido no início da pandemia e, portanto, estarem passíveis de infecção, principalmente se houver flexibilização de alguns cuidados importantes na convivência com a pandemia. Todas essas observações levaram à recomendação de que tais cuidados, como uso de máscaras e evitar aglomerações, continuem.

Ainda na comparação com outros países, é importante ter em mente que o Brasil é um país de dimensões grandes, bem maiores que as dos países da Europa, quando observados de forma isolada, e que aqui a epidemia de Covid- 9 não ocorreu de forma síncrona ao longo do território. O crescimento da incidência se deu em ritmo muito acelerado nos centros urbanos de Rio de Janeiro e São Paulo, e também de forma intensa em estados da região Norte, como Amazonas, e da região Nordeste, como Ceará. Mais tarde, o número de casos começou a aumentar também em estados do Centro-Oeste e da região Sul. A curva de incidência nacional reflete o somatório de todas essas múltiplas epidemias nos vários estados e regiões.

O risco de uma segunda onda, ou seja, de novo aumento de casos, deve ser observado de modo focalizado, por exemplo nos estados ou mesmo nas capitais. No entanto, independentemente de na cidade ou no estado haver aumento de casos, o próprio recrudescimento em várias localidades impõe a permanência de medidas importantes para evitar ou mitigar o aumento de transmissão.

\section{CASO DO ESTADO DO RIO DE JANEIRO: EVIDÊNCIA DE MÚLTIPLAS EPIDEMIAS}

Como evidência de que a epidemia começou sem sincronismo entre os municípios e requer ações focais e coordenadas, pode-se observar o exemplo do estado do Rio de Janeiro e seus municípios, onde o número de reprodução de Sars-CoV-2 ficou estimado em $R_{0}=2,34(95 \% \mathrm{Crl}=1,89-2,82)$ (Villela, 2020b). 
Figura 4 - Taxa de incidência (por 100 mil hab.) diária nos 92 municípios do estado do RJ, Brasil. A curva em azul mostra a taxa de incidência (média móvel) para a capital Rio de Janeiro e as curvas em cinza a mostram para os demais municípios

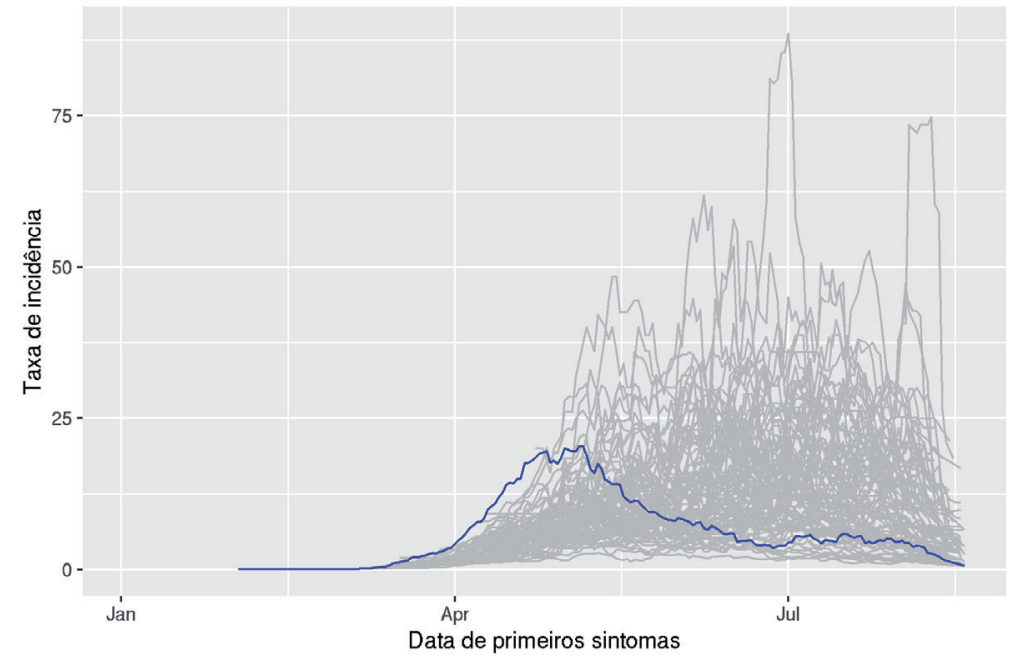

Fonte de dados: Rio de Janeiro, 2020.

A Figura 4 mostra a epidemia em vários municípios do estado do Rio de Janeiro por meio da média móvel da incidência para estes municípios. A curva em azul é dada pela média móvel para o município do Rio de Janeiro onde acontece inicialmente a transmissão sustentada, bem antes dos outros municípios. Esse gráfico mostra como a epidemia não acontece necessariamente com sincronia entre municípios ainda que em um mesmo estado. Nos dados mais recentes parece haver redução do número diário de casos, mas na verdade isso se deve ao tempo decorrido até o momento da digitação, haja vista que muitos dados recentes não foram digitados no sistema.

\section{IMPACTOS EPIDEMIOLÓGICOS E SOCIAIS}

No início da pandemia, inquéritos sorológicos foram iniciados em vários países. No Brasil, o estudo EpiCovid teve abrangência nacional com amostragem em 132 municípios, até então o maior inquérito sorológico de Sars-CoV-2 do Brasil (Hallal et al., 2020). O objetivo dos inquéritos sorológicos mediantes testes para verificação da presença de anticorpos IgG seria verificar a proporção da população que já havia sido exposta. Assumindo-se uma resposta imunológica duradoura, seria possível saber o quão longe se estaria de uma teórica imunidade de rebanho. 
No entanto, os resultados dos inquéritos revelaram proporções menores em levantamentos subsequentes para várias cidades. O teste rápido WONDFO Sars-CoV-2 Antibody Test (Wondfo Biotech, Guangzhou, China) utilizado no estudo mede infecções recentes e relativamente severas, por isso a alta proporção de sintomáticos. No entanto, o teste não informa sobre imunidade celular. Portanto, não deve ser interpretado como proporção para imunidade de rebanho.

Mas o estudo EpiCovid foi muito importante para o conhecimento de informações sobre desigualdades. No primeiro levantamento foi possível observar, por exemplo, uma prevalência acima de 10\% na região Norte, ao longo do rio Amazonas. Em relação a etnias, foi possível observar prevalência mais alta em indígenas e pretos (Hallal et al., 2020).

De fato, o estudo de Baqui e colaboradores (2020) mostrou maior risco de mortalidade em pacientes internados em hospital para indivíduos das etnias preta e parda (HR=1.45, Int. Conf. 95\% 1.33-1.58 para pardos e HR=1.32, Int. Conf. 95\% 1.15-1.52 para pretos) (Baqui et al., 2020).

\section{SOBRE A POSSIBILIDADE DE IMUNIDADE DE REBANHO (HERD IMMUNITY)}

A imunidade de rebanho acontece quando o número de suscetíveis fica abaixo do inverso do número de reprodução. Quando tal situação acontece, o número de novos infectados tende a ser menor do que o número de novos recuperados. Trata-se de um conceito que explica a teoria do fenômeno epidemiológico. Houve pessoas que, por considerarem que esse fenômeno seria inevitável, defenderam a imunidade de rebanho como uma estratégia, por exemplo na Great Barrington Declaration (Burki, 2020). No entanto, a adoção desse modelo envolve sérias limitações, pois: I) implica número muito grande de infectados (recuperados/infectados/mortos); 2) pressupõe homogeneidade na população; e 3) assume como premissa que a imunidade assim obtida será permanente ou duradoura.

Para estimar o número de infectados/recuperados/óbitos, pode-se usar o valor estimado para o número de reprodução de Sars-CoV-2 em $R_{0}=2,34(95 \% \mathrm{Crl}=1,89-2,82)$ no estado do Rio de Janeiro (Villela, 2020b). Em outros estudos para outros países foram avaliados valores até superiores (Kucharski et al., 2020). A consequência, portanto, seria um número de infectados/recuperados/óbitos > 57\% da população.

Quanto ao pressuposto de homogeneidade populacional, modelos desse tipo consideram que a taxa de transmissão seria a mesma em toda a população; no entanto, pode haver variações. Além de que, conforme já descrito, a epidemia aconteceu de forma assíncrona. 
Em relação aos indivíduos recuperados após infecção, havia uma expectativa de que estes indivíduos obteriam imunidade permanente ou duradoura. Vários inquéritos sorológicos foram realizados em cidades de diferentes países com o objetivo de acompanhar a evolução da proporção de soroprevalentes na população local, ou seja, proporção de indivíduos que já teriam desenvolvido anticorpos e mostraram baixas proporções mesmo após várias semanas.

É importante também observar que estudos iniciais apontavam que grande parcela de casos não seria notificada, o que parecia sugerir pequena probabilidade de casos sintomáticos. No entanto, avaliações mais recentes de metanálise revelam uma probabilidade da ordem de 20\% (intervalo de confiança 95\% = 17-25\%) (BuitragoGarcia et al., 2020).

Mesmo sem a possibilidade de que inquéritos sorológicos gerassem uma avaliação para responder sobre o alcance de uma eventual imunidade de rebanho, o processo de reversão em curso em vários municípios e estados e o esforço de mitigação da pandemia sugere que a imunidade de rebanho não está próxima de ser atingida nos vários estados e municípios. Portanto, mesmo após vários meses, ao final de 2020 permanece a recomendação de manutenção das principais medidas de distanciamento, uso de máscaras e reforço dos protocolos de mitigação no sentido de evitar aglomerações nas esferas municipal, estadual e federal.

\section{INCERTEZAS, VACINAS E A NECESSIDADE DE MANTER AÇÕES DE CONTROLE}

Em recente editorial, George Davis Messi escreveu: "Quanto mais certo alguém estiver sobre a Covid-19, menos se deve confiar nessa pessoa” (tradução livre) (Davey Smith, Blastland \& Munafò, 2020). Ainda persistem muitas incógnitas, como a duração da imunidade quando a pessoa é infectada. Os estudos sobre a probabilidade de desenvolvimento de sintomas apresentam resultados bastante variados (BuitragoGarcia et al., 2020). Os indicadores são bastante sensíveis à qualidade dos dados, por isso são importantes a testagem, a identificação de casos e a disponibilização dos dados sobre casos confirmados, casos testados e casos suspeitos.

Mesmo que a imunidade de rebanho não esteja próxima, a iminência de disponibilidade de vacina permite vislumbrar uma aceleração no processo de alcançá-la. Contudo, várias perguntas ainda pairam, inclusive sobre as vacinas em desenvolvimento e fase de liberação, como o tempo de imunidade, o efeito na morbidade e na infecção; enfim, sobre a eficácia da vacina. Mesmo com a proximidade de uma vacina, permanece muito importante manter todas as ações, até porque, mesmo que seja eficaz, a vacina será 
aplicada em fases, e os indivíduos precisarão tomar duas doses espaçadas. Portanto, esse processo tende a levar tempo e, nesse ínterim, todos os esforços para reduzir a taxa de transmissão devem ser mantidos, tais como o de fortalecimento da vigilância em saúde, por exemplo exercendo o rastreamento de contatos a partir da identificação de casos.

Por fim, a pandemia no Brasil passou por várias fases, mas a necessidade de cuidados permanece. As importantes lições aprendidas mostram o tempo de permanência em hospitais, a qualidade do atendimento, a atenção primária em saúde para tratar casos de forma a impedir que evoluam para casos graves e a vulnerabilidade social aos efeitos da doença, com consequente necessidade de assistência a populações e grupos vulneráveis.

\section{REFERÊNCIAS}

BAQUI, P. et al. Ethnic and regional variations in hospital mortality from Covid- 19 in Brazil: a crosssectional observational study. The Lancet Global Health, 8(8): el.018-1.026, 2020. Disponível em: $<$ www.thelancet.com/journals/langlo/article/PIIS22 I4-I09X(20)30285-0/fulltext>. Acesso em: I set. 2021 .

BASTOS, L. S. et al. A modelling approach for correcting reporting delays in disease surveillance data. Statistics in Medicine, 38(22): 4.363-4.377, 2019. Disponível em: <https://onlinelibrary.wiley.com/ doi/full/I0.1002/sim.8303 >. Acesso em: 25 out. 2019.

BASTOS, L. S. et al. Covid- 19 and hospitalizations for SARI in Brazil: a comparison up to the 12th epidemiological week of 2020. Disponível em: <www.scielo.br/j/csp/a/KQxzHZdFHcPx5CftPXZKwg s/?lang = ptEformat $=p d f>$. Cadernos de Saúde Pública, 36(4): e00070I20, 2020. Acesso em: I ago. 2020.

BUITRAGO-GARCIA, D. et al. Occurrence and transmission potential of asymptomatic and presymptomatic Sars-CoV-2 infections: a living systematic review and meta-analysis. Plos Medicine, I 7(9): el 003346, 2020. Disponível em: <https://journals.plos.org/plosmedicine/article?id= I0.137 I/ journal.pmed. I003346>. Acesso em: I fev. 2021 .

BURKI, T. K. Herd immunity for Covid-19. The Lancet Respiratory Medicine, 9(2): 135-136, 2020. Disponível em: <www.thelancet.com/journals/lanres/article/PIIS22 I 3-2600(20)30555-5/fulltext>. Acesso em: 10 dez. 2020.

DAVEY SMITH, G.; BLASTLAND, M. \& MUNAFÒ, M. Covid- I 9's known unknowns. BMJ, 37I: m3979, 2020. Disponível em: <www.bmj.com/content/37 I/bmj.m3979>. Acesso em: 14 nov. 2020.

FUNDAÇÃO OSWALDO CRUZ (FIOCRUZ). Observatório Fiocruz Covid-19. Nota técnica sobre a importância das medidas de distanciamento social no contexto atual da Covid- 19 no Rio de Janeiro. Portal Fiocruz, Rio de Janeiro, 2020a. Disponível em: < https://agencia.fiocruz.br/sites/agencia. fiocruz.br/files/u9I/nota_tecnica_sobre_criterios_e_medidas_de_distanciamento_social_ covid-19_28_05_2020.pdf>. Acesso em: 10 dez. 2020.

FUNDAÇÃO OSWALDO CRUZ (FIOCRUZ). InfoGripe. Monitoramento de casos de síndrome respiratória aguda grave (Srag) notificados no Sivep Gripe. Disponível em: <http://info.gripe.fiocruz.br $>$. Acesso em: 17 dez. 2020b. 
FUNDAÇÃO OSWALDO CRUZ (FIOCRUZ). Bolem Observatório Fiocruz Covid-19. Semanas epidemiológicas 3 I e 32. Portal Fiocruz, Rio de Janeiro, 2020c. Disponível em: < https://portal.fiocruz. $\mathrm{br} / \mathrm{sites} /$ portal.fiocruz.br/files/documentos/boletim_covid_semana_3I-32_2020-08-I4_.pdf >. Acesso em: 30 jun. 2020.

HALLAL, P. C. et al. Sars-CoV-2 antibody prevalence in Brazil: results from two successive nationwide serological household surveys. The Lancet Global Health, 8(I I): el.390-el.398, 2020. Disponível em: <www.thelancet.com/journals/langlo/article/PIIS22 I4-I09X(20)30387-9/fulltext>. Acesso em: 14 out. 2020.

JOHNS HOPKINS UNIVERSITY \& MEDICINE. Coronavirus Resource Center. Cumulative cases by days since 50th confirmed case. Disponível em: <https://coronavirus.jhu.edu/data/cumulative-cases $>$. Acesso em: 8 dez. 2020.

KUCHARSKI, A. J. et al. Early dynamics of transmission and control of Covid-19: a mathematical modelling study. The Lancet Infectous Diseases, 20(5): 553-558, 2020. Disponível em: <www.thelancet. com/journals/laninf/article/PIIS I 473-3099(20)30 I44-4/abstract>. Acesso em: 15 mar. 2020.

ORELLANA, J. D. Y. et al. Explosão da mortalidade no epicentro amazônico da epidemia de Covid- 19. Cadernos de Saúde Pública, 36(7): e00 I 20020, 2020. Disponível em: <http://cadernos.ensp.fiocruz. br/static/arquivo/I 678-4464-csp-36-07-e00 I 20020.pdf>. Acesso em: 6 set. 2020.

RIO DE JANEIRO. Secretaria de Estado de Saúde do Rio de Janeiro (SES-RJ). Painel Coronavírus Covid-19. Disponível em: <https://painel.saude.rj.gov.br/monitoramento/covidI9.html\#>. Acesso em: 31 jul. 2020.

VILLELA, D. A. M. The value of mitigating epidemic peaks of Covid- 9 for more effective public health responses. Revista da Sociedade Brasileira de Medicina Tropical, 53, 2020a. Disponível em: <www. scielo.br/j/rsbmt/a/Y9Gg4hDvX4BpYJJ3GPMfxXB/?lang=en>. Acesso em: 20 mar. 2020.

VILLELA, D. A. M. How limitations in data of health surveillance impact decision making in the Covid- I 9 Pandemic. Revista Saúde em Debate, 12(24): 190-202, 2020b. Disponível em: <www.scielo. $\mathrm{br} / \mathrm{j} / \mathrm{sdeb} / \mathrm{a} / \mathrm{bRLLBqVfxGbhcfmTnTRhLHG/?lang=en \varepsilon format=pdf>.} \mathrm{Acesso} \mathrm{em:} 2$ ago. 2020.

WILDER-SMITH, A. \& FREEDMAN, D. O. Isolation, quarantine, social distancing and community containment: pivotal role for old-style public health measures in the novel coronavirus (20 I $9-\mathrm{nCoV})$ outbreak. Journal of Travel Medicine, 27(2): taaa020, 2020. Disponível em: <https://academic.oup. com/jtm/article/27/2/taaa020/5735321 >. Acesso em: 2 maio 2020.

WORLD HEALTH ORGANIZATION (WHO). Public health criteria to adjust public health and social measures in the context of Covid-19. Annex to Considerations in adjusting public health and social measures in the context of Covid-19. Report n. WHO/20/9-nCoV/Adjusting_PH measures/ Criteria/2020. I. Geneva: World Health Organization, 2020. Disponível em: < https://apps.who.int/iris/ handle/I0665/332073 >. Acesso em: I dez. 2020. 



\section{A Produção de Informação para Ação no Contexto da Pandemia na Interface com 0 Ministério Público e a Defensoria Pública}

Carlos Machado de Freitas, Christovam Barcellos, Daniel Antunes Maciel Villela, Margareth Crisóstomo Portela e Valcler Rangel Fernandes

\footnotetext{
O
} Observatório Covid-19 foi proposto em março de 2020, por demanda da Presidência da Fiocruz, para o monitoramento da situação de saúde e do sistema de saúde durante a pandemia de Covid-19, e iniciou as suas atividades no dia $1^{\circ}$ de abril, disponibilizando seu site na web. Entre seus objetivos estava o de articular os diferentes grupos, laboratórios, setores e unidades da Fiocruz para produzir informações para ações, no âmbito do enfrentamento da pandemia, com base em análises integradas, combinadas à formulação de políticas e proposição de estratégias.

O Observatório Covid- 9 Fiocruz é estruturado em torno de quatro eixos: Cenários Epidemiológicos; Medidas de Controle e Organização dos Serviços e Sistemas de Saúde; Qualidade do Cuidado, Segurança do Paciente e Saúde do Trabalhador; Impactos Sociais da Pandemia.

Neste capítulo abordaremos um tipo de produção específico do eixo Cenários Epidemiológicos, na sua interface com o eixo Medidas de Controle e Organização dos Serviços e Sistemas de Saúde. Tomaremos como casos exemplares duas demandas que foram muito importantes no processo de aprendizado da equipe de coordenação do observatório, pois contribuíram para conformar a estrutura dos boletins publicados quinzenalmente a partir de julho de 2020 e semanalmente a partir de março de 2021 .

\section{CONTEXTO E DEMANDAS}

No final de maio de 2020, considerando o contexto de aumento exponencial no número de casos de Covid- 9 no município do Rio de Janeiro e as iniciativas do poder público municipal de flexibilizar as medidas não farmacológicas de controle e 
prevenção, o Ministério Público do Estado do Rio de Janeiro (MPRJ) demandou ao Observatório Covid- 19 Fiocruz um "posicionamento atualizado sobre a importância das medidas de isolamento social no contexto atual” (Observatório Covid- 9 Fiocruz, 2020a). Dois meses depois, no final de julho de 2020, considerando ainda os cenários de transmissão e infecções no município, a Defensoria Pública do Estado do Rio de Janeiro (DPRJ) demandou também ao Observatório Covid-19 Fiocruz um parecer sobre "a preocupante situação envolvendo a desativação de grande número de leitos hospitalares no atual momento da pandemia por Covid- 19 em curso" (Observatório Covid- 19 Fiocruz, 2020b).

No momento em que essas duas demandas foram apresentadas, o grupo de pesquisadores do Observatório Covid- 19 Fiocruz entendia que mesmo com medidas de distanciamento social, o Sars-Cov-2 continuaria circulando, o que resultaria no risco de aumento do número de casos e óbitos por muito tempo e, a depender do cenário, poderia perdurar por entre dois ou quatro anos mais, com riscos de novos ressurgimentos e demandando medidas de distanciamento social intermitentes (Kissler, 2020). Ao mesmo tempo, era evidente a necessidade de que fossem mantidas medidas de controle e prevenção que preservassem as taxas de infecções baixas o suficiente para que os hospitais, em particular os leitos de UTI Covid-19, não fossem sobrecarregados (Anderson et al., 2020).

Foi nesse contexto de demandas e de entendimento da pandemia que o observatório produziu duas notas técnicas para subsidiar as ações do Ministério Público e da Defensoria Pública em defesa dos direitos dos cidadãos e dos interesses da sociedade, bem como da redução das desigualdades no acesso aos serviços de saúde durante a pandemia. Para tanto, considerou-se que, além da literatura científica disponível naquele momento, o enfrentamento da pandemia por Covid- 19 devia se pautar no mesmo conjunto de critérios que vinha orientando as políticas públicas de outros países que já tinham enfrentado graves situações durante a pandemia.

\section{CRITÉRIOS PARA MONITORAR A PANDEMIA E ORIENTAR POLÍTICAS PÚBLICAS}

A Organização Mundial da Saúde (OMS) sistematizou de modo objetivo o conjunto de parâmetros que orientam o processo de monitoramento da pandemia no documento "Critérios de saúde pública para ajustar medidas de saúde pública e social no contexto do Covid-19” (WHO, 2020), o qual serviu como principal referência para as notas técnicas que foram demandadas, bem como para a produção dos boletins a partir de julho de 2020. 
Os critérios estão agrupados em três dimensões, que devem ser avaliadas quando se trata de responder a três perguntas centrais: I) A pandemia está ou não controlada? 2) O sistema de saúde tem ou não capacidades para enfrentar um eventual surto de casos Covid-19? e 3) O sistema de vigilância em saúde tem ou não capacidade para detectar casos (incluindo assintomáticos) e membros da comunidade não infectados, e realizar o manejo por meio das medidas de distanciamento social e quarentena, assim como prevenir novos surtos de casos? Essas três dimensões de avaliação sistematizadas pela OMS e as três perguntas centrais estão apresentadas a seguir.

\section{Existem indícios de que a pandemia está controlada?}

Indicador-chave: número efetivo de reprodução (Rt) inferior a I por pelo menos duas semanas epidemiológicas (SES).

Em teoria, um Rt (número efetivo de casos secundários por caso de infecção em uma população) menor que I é a melhor indicação de que a pandemia está controlada e diminuindo. Em países, estados e municípios com grande contingente populacional, o Rt pode variar entre diferentes segmentos da população e deve ser estimado para estes diferentes segmentos (municípios e bairros, por exemplo).

Devido às incertezas envolvidas no cálculo do Rt, este indicador foi sendo gradualmente substituído ou complementado por parâmetros obtidos de diversas fontes de informação, conforme o quadro a seguir.

\begin{tabular}{|l|l|}
\hline \multicolumn{1}{|c|}{ Critério epidemiológico } & \multicolumn{1}{c|}{ Justificativa } \\
\hline $\begin{array}{l}\text { Diminuição do número de casos em pelo menos } \\
\begin{array}{l}50 \% \text { durante um período de } 3 \text { SEs, a partir do } \\
\text { último valor máximo, e diminuição constante } \\
\text { na incidência observada de casos confirmados e } \\
\text { prováveis. }\end{array}\end{array}$ & $\begin{array}{l}\text { Isso indica uma redução na transmissão pela } \\
\text { metade durante um período de 3 SEs ou menos, } \\
\text { a partir do último valor máximo, desde que a } \\
\text { estratégia de teste seja mantida ou reforçada para } \\
\text { testar uma porcentagem maior de casos suspeitos. }\end{array}$ \\
\hline $\begin{array}{l}\text { Menos de } 5 \% \text { dos testes diagnóstico positivos } \\
\text { para Covid- } 19 \text { pelo menos nas últimas 2 SEs, } \\
\text { desde que a vigilância de casos suspeitos seja } \\
\text { abrangente. }\end{array}$ & $\begin{array}{l}\text { A porcentagem de testes positivos só pode ser } \\
\text { interpretada com vigilância e análise abrangentes } \\
\text { de amostras de casos suspeitos, na ordem de } \\
\text { I/I.000 da população/SE. }\end{array}$ \\
\hline $\begin{array}{l}\text { Durante as } 2 \text { últimas SEs, pelo menos, menos de } \\
5 \% \text { das amostras obtidas de casos com síndrome } \\
\text { de influenza e analisadas em centros de vigilância } \\
\text { sentinela apresentaram resultado positivo para } \\
\text { Covid- } 19 .\end{array}$ & $\begin{array}{l}\text { No contexto da vigilância sentinela da síndrome } \\
\text { da influenza, baixa porcentagem de amostras } \\
\text { positivas indica baixa transmissão comunitária. }\end{array}$ \\
\hline
\end{tabular}




\begin{tabular}{|l|l|}
\hline \multicolumn{1}{|c|}{ Critério epidemiológico } & \multicolumn{1}{|c|}{ Justificativa } \\
\hline $\begin{array}{l}\text { Pelo menos } 80 \% \text { dos casos pertencem a listas } \\
\text { de contatos e podem ser vinculados a clusters } \\
\text { identificados. }\end{array}$ & $\begin{array}{l}\text { Indica que a maioria das cadeias de transmissão } \\
\text { foi identificada, o que permite o monitoramento. } \\
\text { Pode ser limitado pelo fato de que as informações } \\
\text { certamente não serão coletadas no auge da } \\
\text { epidemia. }\end{array}$ \\
\hline $\begin{array}{l}\text { Diminuição do número de mortes entre casos } \\
\text { confirmados e prováveis pelo menos nas últimas } \\
\text { 3 SEs. }\end{array}$ & $\begin{array}{l}\text { Indica, com um intervalo de aproximadamente } 3 \\
\text { SEs, que o número total de casos está diminuindo. } \\
\text { Se o número de testes realizados diminuiu, o } \\
\text { número de mortes entre os casos prováveis será } \\
\text { mais preciso. }\end{array}$ \\
\hline $\begin{array}{l}\text { Diminuição permanente do número de } \\
\text { hospitalizações e internações em UTI de casos } \\
\text { confirmados e prováveis pelo menos nas últimas } \\
2 \text { SEs. }\end{array}$ & $\begin{array}{l}\text { Indica diminuição no número de casos, com } \\
\text { um lapso de aproximadamente I SE, desde que } \\
\text { os critérios de hospitalização não tenham sido } \\
\text { alterados. }\end{array}$ \\
\hline $\begin{array}{l}\text { Diminuição do excesso de mortalidade, com } \\
\text { estratificação por idade, devido a pneumonia. }\end{array}$ & $\begin{array}{l}\text { Quando a triagem de pneumonia não pode } \\
\text { ser realizada rotineiramente, a diminuição na } \\
\text { mortalidade por pneumonia indica, indiretamente, } \\
\text { redução no excesso de mortalidade por Covid- I9. }\end{array}$ \\
\hline
\end{tabular}

Observações: 1) A avaliação da tendência requer que não tenham ocorrido alterações na estratégia de teste ou medição; 2) O período de 2 SEs corresponde ao período máximo de incubação e é o período mínimo para avaliar mudanças nas tendências.

\section{0 sistema de saúde tem capacidade de enfrentar o crescimento do número de casos de Covid-19 ou eventual ressurgimento de casos após adaptar algumas medidas?}

Indicador-chave: o número de casos que requerem hospitalização é menor do que a capacidade máxima de leitos hospitalares e de UTIs do sistema de saúde (ou seja, o sistema de saúde pode enfrentar novas hospitalizações sem ficar sobrecarregado e manter, ao mesmo tempo, a prestação de serviços essenciais).

$\mathrm{Na}$ ausência dessa informação, pode-se levar em conta uma avaliação qualitativa baseada em alguns ou em todos os critérios detalhados no quadro a seguir. 


\begin{tabular}{|c|c|}
\hline Critério relacionado ao sistema de saúde & Justificativa \\
\hline $\begin{array}{l}\text { Tem capacidades para tratar todos os pacientes de } \\
\text { Covid-19, de acordo com as diretrizes nacionais. }\end{array}$ & \multirow{3}{*}{$\begin{array}{l}\text { Indica que o sistema de saúde está novamente } \\
\text { em uma situação em que todas as condições } \\
\text { necessárias (pessoal, leitos, medicamentos, } \\
\text { equipamentos etc.) estão com capacidade para } \\
\text { fornecer o mesmo nível de atendimento que havia } \\
\text { antes da pandemia. }\end{array}$} \\
\hline $\begin{array}{l}\text { Tem capacidades para tratar o restante dos } \\
\text { pacientes com doenças graves, que não sejam } \\
\text { Covid- } 19 \text {, em conformidade com as diretrizes } \\
\text { nacionais. }\end{array}$ & \\
\hline $\begin{array}{l}\text { A mortalidade hospitalar por doenças diferentes } \\
\text { de Covid- } 19 \text { não aumentou. }\end{array}$ & \\
\hline $\begin{array}{l}\text { O sistema de saúde pode absorver um aumento } \\
\text { de, pelo menos, } 20 \% \text { dos casos de Covid- } 19 \text { ou } \\
\text { os serviços podem ser expandidos para lidar com } \\
\text { isso. }\end{array}$ & $\begin{array}{l}\text { Indica que o sistema de saúde está adequado para } \\
\text { absorver um possível ressurgimento de casos } \\
\text { como consequência do relaxamento das medidas } \\
\text { de saúde pública e social. Para isso, é necessário } \\
\text { um nível suficiente de pessoal, equipamento, } \\
\text { leitos etc. }\end{array}$ \\
\hline $\begin{array}{l}\text { Existe um coordenador para a prevenção e controle } \\
\text { de infecções em todos os estabelecimentos } \\
\text { de saúde ( I coordenador para a prevenção e } \\
\text { o controle de infecções treinado e em período } \\
\text { integral a cada } 250 \text { leitos) e no nível distrital. }\end{array}$ & $\begin{array}{l}\text { Indica grande capacidade de coordenação, } \\
\text { supervisão e treinamento em prevenção e controle } \\
\text { de infecções, inclusive nos estabelecimentos de } \\
\text { atenção primária à saúde. }\end{array}$ \\
\hline $\begin{array}{l}\text { Todos os estabelecimentos de atenção em saúde } \\
\text { contam com testes para detecção de Covid- } 19 .\end{array}$ & $\begin{array}{l}\text { Garante que todos os pacientes que são assistidos } \\
\text { pelos centros de Saúde são submetidos a testes de } \\
\text { detecção de Covid- } 19 \text {, a fim de prevenir infecções } \\
\text { relacionadas à atenção em saúde. }\end{array}$ \\
\hline $\begin{array}{l}\text { Todos os estabelecimentos de atenção em saúde } \\
\text { possuem meios para isolar casos suspeitos de } \\
\text { Covid- } 19 \text {. }\end{array}$ & $\begin{array}{l}\text { O sistema de saúde tem capacidade suficiente } \\
\text { para isolar todos os pacientes com Covid- } 19 .\end{array}$ \\
\hline
\end{tabular}

\section{0 sistema de vigilância em saúde pode identificar a maioria dos casos e os seus contatos?}

É fundamental ter capacidade de realizar testes laboratoriais suficiente e uma estratégia para identificar a cadeia de contágio de maneira rápida e precisa.

Uma avaliação qualitativa pode ser realizada com base em alguns ou em todos os critérios apresentados no quadro a seguir. 


\begin{tabular}{|c|c|}
\hline Critério relacionado à vigilância em saúde & Definição \\
\hline \multicolumn{2}{|c|}{ Sistema de vigilância } \\
\hline $\begin{array}{l}\text { É possível identificar e registrar novos casos e ter seus } \\
\text { dados incluídos na análise epidemiológica dentro de } 24 \\
\text { horas. }\end{array}$ & $\begin{array}{l}\text { Existe um sistema de vigilância Covid-19 com cobertura } \\
\text { geográfica completa que inclui todos os indivíduos e } \\
\text { comunidades em risco. A vigilância em saúde abrangente } \\
\text { inclui vigilância a nível comunitário, em centros de } \\
\text { atenção primária à saúde e em hospitais, bem como } \\
\text { através de centros de vigilância sentinela para gripe e } \\
\text { outras doenças respiratórias, onde existam. }\end{array}$ \\
\hline $\begin{array}{l}\text { É exigida a declaração imediata de casos prováveis } \\
\text { e confirmados de Covid- } 19 \text { como uma doença de } \\
\text { notificação compulsória. }\end{array}$ & $\begin{array}{l}\text { Indica que políticas apropriadas de saúde pública estão } \\
\text { em vigor para notificação imediata dos casos de Covid- } 19 \\
\text { por todos os centros de saúde. }\end{array}$ \\
\hline $\begin{array}{l}\text { A vigilância em saúde em ambientes residenciais fechados } \\
\text { e entre grupos vulneráveis foi melhorada. }\end{array}$ & $\begin{array}{l}\text { Indica que as autoridades de saúde pública identificaram } \\
\text { populações que vivem em ambientes residenciais } \\
\text { fechados ou são vulneráveis e que a vigilância em relação } \\
\text { a essas populações tem sido melhorada. }\end{array}$ \\
\hline $\begin{array}{l}\text { A vigilância da mortalidade por Covid- } 19 \text { é realizada em } \\
\text { hospitais e nas comunidades. }\end{array}$ & $\begin{array}{l}\text { Indica a capacidade de rastrear de maneira rápida } \\
\text { e confiável o número de mortes por Covid-19. Se } \\
\text { possível, um atestado de óbito médico deve ser emitido } \\
\text { para mortes por Covid-19. Outras abordagens para o } \\
\text { monitoramento da mortalidade podem ser consideradas, } \\
\text { como registros de cartórios, centros religiosos ou } \\
\text { funerários. }\end{array}$ \\
\hline $\begin{array}{l}\text { O número total de testes laboratoriais realizado para } \\
\text { detecção do vírus Covid- I } 9 \text { é comunicado diariamente. }\end{array}$ & $\begin{array}{l}\text { O conhecimento do denominador dos testes pode } \\
\text { indicar o grau de atividade de vigilância em saúde, e a } \\
\text { proporção de testes positivos pode indicar a intensidade } \\
\text { da transmissão entre os indivíduos sintomáticos. }\end{array}$ \\
\hline \multicolumn{2}{|c|}{ Investigação de casos } \\
\hline $\begin{array}{l}\text { As equipes de saúde pública de resposta rápida estão } \\
\text { operacionais em todos os níveis administrativos } \\
\text { relevantes. }\end{array}$ & $\begin{array}{l}\text { Mede a capacidade de investigação de casos e } \\
\text { conglomerados de Covid-19. }\end{array}$ \\
\hline $\begin{array}{l}90 \% \text { dos casos suspeitos são isolados e confirmados ou } \\
\text { liberados dentro de } 48 \text { horas após o início dos sintomas. }\end{array}$ & $\begin{array}{l}\text { Indica que a investigação e o isolamento de novos casos } \\
\text { são suficientemente rápidos para minimizar a ocorrência } \\
\text { de casos secundários. }\end{array}$ \\
\hline \multicolumn{2}{|c|}{ Rastreio de contato } \\
\hline $\begin{array}{l}\text { Pelo menos } 80 \% \text { dos casos novos são rastreados e } \\
\text { colocados em quarentena em até } 72 \text { horas após a } \\
\text { confirmação. }\end{array}$ & $\begin{array}{l}\text { Indica que a capacidade de rastreamento de contatos é } \\
\text { suficiente para o número de casos e contatos. }\end{array}$ \\
\hline $\begin{array}{l}\text { Pelo menos } 80 \% \text { dos contatos são acompanhados } \\
\text { durante } 14 \text { dias. }\end{array}$ & $\begin{array}{l}\text { O monitoramento diário com os contatos deve ser } \\
\text { mantido durante o período de } 14 \text { dias e, idealmente, não } \\
\text { mais que dois dias devem passar sem informações de } \\
\text { contato. }\end{array}$ \\
\hline $\begin{array}{l}\text { Sistemas de gerenciamento de informações e dados estão } \\
\text { em funcionamento para rastreamento de contatos e } \\
\text { outros dados relacionados. }\end{array}$ & $\begin{array}{l}\text { Ao passo que os dados de rastreamento de contatos em } \\
\text { pequena escala podem ser gerenciados por formulários } \\
\text { em papel, para rastreamento de contatos em larga escala } \\
\text { podem ser usadas ferramentas digitais de rastreamento } \\
\text { de contatos. }\end{array}$ \\
\hline
\end{tabular}


Tendo como base esse conjunto de critérios e as perguntas centrais, procuramos responder a pelo menos duas delas, que consideramos fundamentais diante das demandas colocadas acerca das medidas de distanciamento social, dos impactos de sua flexibilização e da situação envolvendo a desativação de grande número de leitos hospitalares com a pandemia por Covid-19 em curso.

\section{O CRITÉRIO DO CONTROLE DA PANDEMIA}

Dois conjuntos de indicadores foram utilizados para responder à pergunta relacionada a este critério: a situação da síndrome respiratória aguda grave (Srag) e de casos e óbitos Covid-19. Descrevemos, a seguir, brevemente os resultados das análises em ambas as notas técnicas, em que se demonstrava que a alta incidência de Srag e de casos Covid- 19 resultaria em uma demanda muito elevada ao sistema de saúde.

\section{Síndrome respiratória aguda grave (Srag)}

Para Srag, na nota técnica publicada em maio registrou-se que o estado do Rio de Janeiro vivenciava um aumento acentuado a partir da $10^{\text {a }}$ SE de 2020. Tendo como referência os níveis históricos de Srag nesse período do ano em anos anteriores, os dados indicavam um patamar de incidência muito alto no estado do Rio de Janeiro, com uma estimativa de incidência de 15,85 ( I $8^{\mathrm{a}} \mathrm{SE}$ ), 13,9 ( $\left.9^{\mathrm{a}} \mathrm{SE}\right), 14,2$ (20 $\mathrm{SE}$ ) casos/100 mil habitantes. Na nota técnica se destacava que, considerados os níveis históricos, os níveis se encontravam muito acima do esperado, não havendo indicação de redução de casos novos.

Na nota técnica publicada em agosto fazia-se um retrospecto das SEs anteriores e se demonstrava que o número semanal de casos foi se reduzindo, mas a partir da SE 24 (início de junho) começou a ficar estável em um nível alto quando comparado com a incidência de Srag no mesmo período nos anos anteriores, não havendo indicação de redução de casos novos.

\section{Covid-19}

Para os casos Covid- I 9, na nota técnica publicada em maio apontava-se a tendência de crescimento do número de casos novos, tanto no estado do Rio de Janeiro quanto no Brasil. Para o estado do Rio de Janeiro, destacava-se a tendência de redução da velocidade de aumento do número de casos, o que podia indicar a redução da transmissão nas últimas SEs. 
Na nota técnica publicada em agosto, demonstrava-se que o estado do Rio de Janeiro vinha apresentando uma fase de oscilação, tanto no número de casos quanto no número de óbitos nos três últimos meses, em particular depois de uma fase de ascensão que evoluiu até o fim de maio.

\section{O CRITÉRIO DA CAPACIDADE DO SISTEMA DE SAÚDE DE ENFRENTAR 0 CRESCIMENTO DO NÚMERO DE CASOS DE COVID-19}

Na nota técnica de maio, destacava-se que, para além dos leitos que constavam do plano de contingência e ainda não haviam sido implementados (42,9\% dos leitos clínicos e 47,9\% dos leitos de UTI), havia naquele momento sérios problemas na disponibilização efetiva dos leitos implementados. Ao mesmo tempo, atestava-se que era baixa a capacidade de programação e reordenamento de ações, incluindo diferentes alternativas como, por exemplo, a inclusão de leitos do Sistema Único de Saúde (SUS) não considerados e, especialmente, leitos do setor privado - que dispunha de 2-3 vezes mais leitos de UTI do que o SUS em fevereiro de 2020 - mediante negociações voltadas para a resposta oportuna à demanda colocada. Por fim, chamava-se a atenção para problemas que merecem destaque e incluíam a baixa capacidade de coordenação da rede de serviços como um todo, por intermédio de uma central de regulação; o bloqueio de leitos por falta de pessoal e outros recursos; a provisão inadequada de condições de trabalho para os profissionais da saúde.

A conclusão da nota técnica era que, segundo os dados disponíveis, as condições de oferta de recursos hospitalares na capital e em alguns municípios do estado do Rio de Janeiro não atendiam aos critérios para o afrouxamento das medidas de distanciamento social naquele momento. A fila para acesso ainda era muito grande e se observava incapacidade de atendimento hospitalar de todos os pacientes com Covid-19 que o demandavam. A mortalidade estava elevada como resultado da dificuldade no acesso aos cuidados de saúde necessários, e a isso se somavam dificuldades no atendimento de pacientes com outras condições de saúde.

$\mathrm{Na}$ nota técnica de agosto destacou-se que, considerando-se o panorama das internações e leitos UTI, a questão da desativação de leitos para a Covid - 19 no estado deveria ser abordada com base em duas constatações. A primeira: o cenário epidemiológico ainda se encontrava no nível de alerta, mesmo considerando-se que as taxas de ocupação de leitos por Covid - 19 não apresentavam mais níveis de alerta críticos, como em meses anteriores. A segunda: o estado do Rio de Janeiro era, naquele momento, o único do Brasil que não tornava pública sistematicamente a sua taxa de ocupação de leitos de UTI Covid-19. Os números divulgados esporadicamente 
expressavam taxa de ocupação geral em torno de $50 \%$. Para a cidade do Rio de Janeiro, a taxa de ocupação de leitos de UTI Covid- 19 encontrava-se acima de 60\%, mas abaixo de $70 \%$. Nesse contexto, na nota se afirmava ser razoável considerar a retração de recursos direcionados à Covid- 19 e natural que, diante de uma pandemia como a da Covid-19, se levassem em conta momentos de necessidade de ampliação, com possibilidades de novas ondas, seguidos pela retração de serviços, que também devem atender a outras necessidades da população.

Por fim, se mostrava, em retrospecto, que algumas escolhas feitas no Rio de Janeiro se mostravam mais problemáticas. Sem dúvida, a perda da oportunidade de investir em estruturas já existentes foi um dos grandes problemas, que talvez pudesse ser mitigado mediante a realocação de recursos comprados para os hospitais de campanha em hospitais públicos com estruturas permanentes, o que fortaleceria o SUS, ponto fundamental para a possibilidade de enfrentamento consistente de novas ondas da Covid- 19 ou outras crises.

\section{A INFORMAÇÃO PARA AÇÃO NO CONTEXTO DA PANDEMIA}

Ainda que produzidas em momentos distintos, ambas as notas técnicas procuraram responder a duas diferentes demandas, a do MPRJ e a da DPRJ, considerando sempre e em perspectiva os cenários epidemiológicos (com foco nos registros de Srag e Covid-19) e de capacidades do sistema de saúde (com foco nos leitos UTI Covid-19), uma vez que o conjunto de indicadores propostos no documento da OMS "Critérios de saúde pública para ajustar medidas de saúde pública e social no contexto do Covid- I9” (WHO, 2020) não se encontravam publicamente disponíveis e com acesso facilitado para diferentes tipos de análise.

De qualquer modo, para os cenários epidemiológicos, nas notas técnicas registrouse que no período de maio a pandemia estava em patamares muito altos e que mesmo em agosto não se poderia considerar que a pandemia estava controlada no estado do Rio de Janeiro, com a taxa de incidência de Srag ainda em níveis muito altos comparada com a sua incidência no mesmo período nos anos anteriores. No mês de agosto, para os casos e óbitos Covid-19, a situação, ainda que estável, não permitia afirmar que estava ocorrendo queda sustentada da pandemia no estado.

Para as capacidades do sistema de saúde, com foco nos leitos UTI Covid-19, demonstrou-se em maio que a oferta de recursos hospitalares na capital e em alguns municípios do estado do Rio de Janeiro não era suficiente, o que era atestado pelas filas para acesso e pela incapacidade de atendimento hospitalar de todos os pacientes com 
Covid- 19 que o demandavam. Assim, em agosto, mesmo com a redução dos registros de Srag e Covid-19, não foi possível assegurar que o sistema de saúde do estado tinha capacidades para enfrentar um crescimento rápido do número de casos de Covid-19, considerando suas tendências e instabilidade.

Para atender às demandas do MPRJ e da DPRJ, foi preciso não só realizar análises de dados, mas produzir informações que subsidiassem essas instituições com um posicionamento sobre a situação epidemiológica da pandemia, avaliando se era o momento ou não de flexibilizar as medidas de distanciamento físico e social, sobre a capacidade do sistema de saúde para atender às necessidades dos pacientes Covid- 19 e sobre a falta de segurança para considerar a desativação de leitos em um contexto de variações na própria dinâmica da pandemia. De qualquer modo, as análises realizadas e presentes nas duas notas técnicas constituíram as bases dos boletins do Observatório Covid- I 9 Fiocruz que passaram a ser publicados em julho de 2020.

\section{REFERENNCIAS}

ANDERSON, R. M. et al. How will country-based mitigation measures influence the course of the Covid-I 9 epidemic? The Lancet, 395(1 0.228): 931-934, Mars 2020. Disponível em: <www.thelancet. com/journals/lancet/article/PIISO I40-6736(20)30567-5/fulltext>. Acesso em: I8 abr. 2020.

KISSLER, S. M. Projecting the transmission dynamics of Sars-CoV-2 through the post pandemic period. Science, 368: 860-868, May 2020. Disponível em: <https://science.sciencemag.org/ content/368/6493/860 >. Acesso em: 30 maio 2020.

OBSERVATÓRIO COVID - I 9 FIOCRUZ. Nota Técnica sobre a importância das medidas de distanciamento social no contexto atual da Covid- 19 no Rio de Janeiro. Rio de Janeiro. Observatório Covid- 19 Fiocruz. Maio de 2020a. Disponível em: <https://agencia.fiocruz.br/sites/agencia.fiocruz.br/files/u9l/ nota_tecnica_sobre_criterios_e_medidas_de_distanciamento_social_covid-19_28_05_2020.pdf >. Acesso em: set. 2020.

OBSERVATÓRIO COVID- I 9 FIOCRUZ. Nota Técnica: tendências das Srag e Covid- I 9 nas semanas epidemiológicas 33 e 34 e situação dos leitos hospitalares no contexto da pandemia no estado do Rio de Janeiro. Agosto de 2020b. Disponível em: < https://portal.fiocruz.br/sites/portal.fiocruz.br/ files/documentos/nota_tecnica_sobre_desativacao_de_leitos_hospitalares_covid-19_no_rj_3 I_ agosto_2020.pdf>. Acesso em: set. 2020.

WORLD HEALTH ORGANIZATION (WHO). Public health criteria to adjust public health and social measures in the context of Covid-19, 2020. Disponível em: <https://iris.paho.org/ handle/10665.2/521 78 >. Acesso em: 30 maio 2020. 


\section{Vigilância em Saúde do Trabalhador na Pandemia}

René Mendes

$\mathrm{Ne}_{\mathrm{e}}^{\mathrm{e}}$ este capítulo procuro sintetizar a breve apresentação feita no webinar Desafios e Perspectivas da Atuação da Vigilância da Saúde do Trabalhador na Pandemia e Pós-Pandemia, realizado em 3 de setembro de 2020, com o propósito de ampliar o entendimento sobre a importância do trabalho na determinação social da pandemia da Covid- I 9 no Brasil (e em países de estrutura social similar), tendo como corolários vinculados: I) o entendimento da importância da Vigilância em Saúde no mundo do trabalho, com destaque para a Vigilância em Saúde do Trabalhador; 2) o reconhecimento sanitário e médico-previdenciário da Covid-19 relacionada ao trabalho como direito. Direito que implica deveres e obrigações.

A priori e partindo da admissibilidade dos pressupostos teóricos e empíricos da "determinação social do processo saúde/doença” (Laurell, I982; Breilh, 2013), tomo aqui o trabalho como uma categoria central do processo saúde-doença "por se encontrar na base das relações sociais de produção, por onde a vida (e, portanto, a humanidade) corre". (Souza E Vasconcellos, 2018). Entre nós, a "determinação social da Covid-19" foi pioneiramente analisada por Souza (2020), em texto que pavimenta o caminho para a questão da centralidade do trabalho nesta pandemia, que ainda carece de análises mais bem elaboradas.

Contudo, nesta síntese de algumas reflexões iniciais, sem o compromisso de filiação prévia a escolas de pensamento mais rigorosas e ortodoxas, prefiro ampliar o alcance da categoria trabalho para o da categoria mundo do trabalho (que poderia incluir a anterior), por vê-la mais rica nas interfaces com o objeto de análise: a epidemiologia da pandemia da Covid- 9 no Brasil, e, por extensão, a abrangência e alcance da Vigilância em Saúde, nela incluídas a Vigilância Epidemiológica, a Vigilância em Saúde do Trabalhador e a Vigilância Sanitária. 
Assim (e sem compromissos de ortodoxia), como âncora de referência para o termo mundo do trabalho adoto aqui o que propõe a profa. Roseli Figaro:

... o conjunto de fatores que engloba e coloca em relação a atividade humana de trabalho, o meio ambiente em que se dá a atividade, as prescrições e as normas que regulam tais relações, os produtos delas advindos, os discursos que são intercambiados nesse processo, as técnicas e as tecnologias que facilitam e dão base para que a atividade humana de trabalho se desenvolva, as culturas, as identidades, as subjetividades e as relações de comunicação constituídas nesse processo dialético e dinâmico de atividade. Ou seja, é um mundo que passa a existir a partir das relações que nascem motivadas pela atividade humana de trabalho, e simultaneamente conformam e regulam tais atividades. É um microcosmo da sociedade, que embora tenha especificidade, é capaz de revelá-la. (Figaro, 2008: 92, destaque do original)

Como bem explica Figaro, mundo do trabalho é uma categoria ampla, difusa e complexa, característica e fundamento da sociedade, pois é um lugar privilegiado que abriga grande parte da atividade humana. Prossegue a autora:

[o mundo do trabalho] é uma categorização ampla, porque possibilita congregar conceitos como trabalho, relações de trabalho, vínculos empregatícios, mercado de trabalho, salário, tecnologia, troca, lucro, capital, organizações, controle, poder, sociabilidades, cultura, relações de comunicação. (Figaro, 2008: 93)

Citando Marx, a autora afirma que "no mundo do trabalho encontram-se os conflitos centrais que estruturam e regulam o sistema socioeconômico e político" (Figaro, 2008: 93).

Pois bem, como reflexão inicial proponho a tese de que, de um lado, o acelerado processo de precarização do trabalho e vulnerabilização das pessoas inseridas nesse mundo do trabalho (e, também, as excluídas pelas políticas neoliberais) favoreceu a entrada e a rápida disseminação do novo coronavírus Sars-CoV-2 e da Covid- 19 em nosso país. De outro lado, a pandemia impactou e tem impactado severamente o mundo do trabalho, posto que, pela ausência do Estado, ou até por ele intencionalmente induzida - como uma das expressões de sua necropolítica deliberada -, a pandemia gera (ou enganosamente justifica) desemprego, subemprego e agravamento dos processos de precarização. Assim, o mundo do trabalho pode e deveria ser visto no epicentro do pensamento epidemiológico crítico, ancorado no macrocontexto das profundas desigualdades sociais, desveladas e acentuadas pela pandemia.

Essa é uma forma de ver o cenário onde se insere a vigilância da saúde na pandemia e na pós-pandemia, a qual não se limita a "vigilar" (vigiar) e lutar contra o "novo coronavírus”, mas combate também a invasão e a crescente hegemonia de velhos e novos 
vírus e viroses, altamente letais, tão ou mais danosos, que não serão neutralizados pelas vacinas contra a Covid- I9, de qualquer procedência.

\section{TRABALHO E EMPREGO NO CENTRO DA DETERMINAÇÃO SOCIAL DA PANDEMIA NO BRASIL}

A ocorrência e a gravidade da pandemia da Covid-19, globalmente, e muito especialmente no Brasil, não podem ser corretamente analisadas e entendidas apenas com o instrumental das ciências biológicas, da infectologia, da virologia e de outras disciplinas que desconsiderem a importância das ciências sociais e não valorizem a lógica do modelo de determinação social do processo saúde-doença, cujo epicentro é o trabalho na vida das pessoas e da sociedade. O mundo do trabalho de hoje é um mundo favorecedor e acelerador do poder destrutivo do vírus Sars-CoV-2.

Assim, e com as limitações próprias de um texto breve em que busco recuperar uma fala informal e mais operacional, defendo aqui a tese de que a centralidade do mundo do trabalho - com destaque para a categoria trabalho - deveria ser mais bem analisada e valorizada no processo de disseminação da pandemia - de Wuhan, na China, até todos os confins da Terra - e que a classe dos que vivem do seu trabalho deveria ser considerada como essencial e prioritária para o entendimento da epidemiologia da Covid-19, bem como nas políticas públicas de prevenção, controle e recuperação da crise sanitária e da crise econômica no Brasil.

Como já mencionado, as trágicas dimensões da pandemia da Covid- 9 no Brasil (e em outros países de estrutura social similar) podem ser atribuídas à profunda desigualdade social, a qual foi e está sendo ainda mais agravada pela forma desigual como atinge trabalhadores e trabalhadoras "essenciais" (porém precarizados) e grandes segmentos populacionais socialmente invisíveis e vulnerabilizados pela adoção do receituário neoliberal e ultraneoliberal em nosso país.

\section{CONTEXTUALIZAÇÃO}

A pandemia da Covid-19, no Brasil aparentemente detectada em março de 2020, encontrou e tomou conta de um país marcado pela perda de direitos sociais, pela precarização do trabalho, por políticas de austeridade e Estado mínimo, e por medidas que visavam (e continuam a visar) à fragilização e desmanche do nosso Sistema único de Saúde (SUS).

Com efeito, listo alguns exemplos, como expressão formal e resumida desse contexto de entrada e sucesso destrutivo da pandemia: 
Emenda constitucional n. 95/2016: congelou por vinte anos os gastos sociais públicos, neles incluídas as rubricas da Educação e da Seguridade Social, entre outras.

- Lei n. 13.429/2017: permitiu a terceirização irrestrita, porta principal para a precarização do trabalho.

- Lei n. 13.467/20 I 7: institucionalizou o desmanche da legislação trabalhista, com legalização da precarização do trabalho e destruição dos princípios do trabalho decente ou digno.

- Lei n. 13.846/2019: instituiu ataques aos direitos sociais previdenciários, aos segurados è̀s seguradas, sempre sob o pretexto de combate a fraudes e a supostos privilégios. Seus efeitos devastadores sobre a vida e saúde dos injustamente excluídos ainda não foram adequadamente avaliados, pois eles pertencem às franjas mais vulneráveis de todos os sistemas nacionais e, consequentemente, são de pouco interesse para as estatísticas econômicas.

- Emenda constitucional n. 103/2019 (PEC 06.2019): a denominada Reforma Previdenciária, com os seus impactos nefastos sobre a vida de trabalhadores e trabalhadoras, como amplamente debatido no meio acadêmico e sindical.

Portanto, vê-se que na realidade brasileira (e na de países em estágio socioeconômico similar) aquilo que vem sendo denominado como "transmissão comunitária" na pandemia da Covid-19 não é inseparável do mundo do trabalho, o qual, por sua vez, tende a ser o mundo real. Não apenas nas viagens e deslocamentos a serviço (que trouxeram o vírus para o Brasil), mas também nos deslocamentos do dia a dia, por razões de sobrevivência. Esse mundo real contrasta, por certo, com o mundo do "fique em casa”, do isolamento e distanciamento sociais, vistos como as mais eficientes medidas de prevenção da transmissão do vírus e do consequente adoecimento. Ficar em casa pode ser ficar no trabalho, até porque casa, trabalho, trabalhador e trabalhadora são conceitos e circunstâncias indissociáveis, para os mais vulneráveis, muitos dos quais nem casa têm. E nas condições em que vivem - sobrevivem - as medidas apregoadas pelos combatentes teóricos da pandemia não os protegerão de nada. Por conseguinte, para não ser hipócrita e descolada do contexto do mundo real, a visão de "transmissão comunitária” deve ter essa abertura para o mundo do trabalho.

Com efeito, muito embora não se disponha de estudos mais robustos sobre a distribuição da variável ocupação na epidemiologia da pandemia da Covid- 9 no Brasil, até por negligência dos sistemas de notificação da doença no Ministério da Saúde, é do senso comum o conhecimento de que trabalhadores verdadeiramente essenciais à vida e à saúde, tais como médicos, enfermeiros e técnicos de enfermagem e outros, trabalhadores da segurança pública, motoristas de transporte público, agentes 
funerários e trabalhadores de cemitérios, entre outras profissões ou tipos de vínculo, adoeceram mais do que pessoas de outras profissões, ou mais do que a população geral de referência.

Diante da fragilidade do conceito, da inadequação dos critérios de inclusão e da questionável eticidade do significado de essencialidade de determinadas atividades ou profissões, com graves impactos epidemiológicos negativos sobre o curso e a gravidade da pandemia nas condições brasileiras, talvez melhor fosse considerar todos os trabalhadores e trabalhadoras como essenciais, como, aliás, recomenda um grupo de especialistas em direitos humanos da Organização das Nações Unidas (ONU):

todos os trabalhadores são essenciais, independentemente da categoria que the apliquem os Estados ou as empresas. Nenhum trabalhador é prescindível. Todos os trabalhadores têm o direito de estar protegidos dos perigos nos locais de trabalho, incluindo o coronavírus (ONU, 2020, tradução minha)

Essa reflexão está associada ao uso oportunista do termo essenciais para passar a designar muitas categorias de trabalhadores e trabalhadoras que, portanto, não podem parar de trabalhar, sendo obrigados e obrigadas a quebrar a ordem do confinamento e isolamento social. Sem eles e elas, nós não poderíamos usufruir do privilégio de nos homiziarmos em nossas casas. Sem eles e elas, nós não teríamos onde receber atenção de saúde, quando adoecermos, ou atenção funerária, quando morrermos. E muitas são as categorias - de fato - que foram obrigadas a trabalhar. Trabalhar por nós. Trabalho vicário, que acabo de assim denominar. Porém, muito se abusou sob um conceito flexível e sem-vergonha, por exemplo, em relação às trabalhadoras domésticas e aos trabalhadores em frigoríficos (voltados para a exportação), entre outras categorias.

Muitas atividades de trabalho não regulamentadas, tais como o serviço de entrega por plataformas digitais (iFood, Rappi, Uber Eats e Loggi, entre outros) foram, nesta pandemia, guindados à categoria de essenciais para que não parassem de servir àqueles e àquelas que se quedam em casa, em isolamento social, única medida recomendada para os que não gostariam de se enfermar e morrer antes da hora... Contudo, esses trabalhadores e trabalhadoras não o podem fazer, e estão a rodar em suas bicicletas, em média, $10 \mathrm{~km}$ ao dia, e alguns até $50 \mathrm{~km}$ por dia, trabalhando em jornadas cada vez mais longas e ganhando cada vez menos.

Além disso, é preciso lembrar dos milhões de trabalhadores e trabalhadoras que não podem realizar trabalho remoto ou teletrabalho de suas casas (quando as têm), como são os "informais", os trabalhadores e trabalhadoras "por conta própria" (mais de 24 milhões), os desempregados e muitos outros, com a vida piorada pela insuficiência ou 
inadequação do auxílio emergencial, regido pela lógica do Estado mínimo. Com efeito, a Pesquisa Nacional por Amostra de Domicílios: Pnad Covid 9 vem mostrando que dos cerca de 8 milhões de trabalhadores e trabalhadoras que aderiram ao trabalho remoto, $30 \%$ têm curso superior e até pós-graduação; no outro extremo da escala, apenas 0,3\% dos que aderiram ou puderam trabalhar a distância (de casa) não têm instrução ou têm o primário incompleto. Portanto trabalho remoto, apesar de desagradável e patogênico, não deixa de ser uma alternativa elitista. É preciso ter casa para ficar, espaço e local para isolamento, espaço e instalações para trabalhar, e trabalho compatível com esta modalidade, que, segundo as más línguas, "veio para ficar".

Assim, num país abissalmente desigual e socialmente injusto, obrigar a ficar em casa pode ser uma provocação, uma ironia; ou talvez, uma afronta! E com isso, ruem por terra os principais pilares da prevenção da Covid- 19 e da proteção individual e coletiva.

Enfatizar a centralidade do trabalho como expressão da determinação social do processo saúde-doença no caso da Covid-19, considerando suas dimensões pandêmicas, não exclui que outras categorias sejam também valorizadas nos estudos epidemiológicos, demográficos e sociais. A identificação de distribuições geográficas e sociais da pandemia, claramente não aleatórias, requer abordagens interseccionais que, além da questão do trabalho/emprego/ocupação, levem em conta dimensões e categorias como nível de renda, local de moradia (periferia, favelas etc.) gênero, cor/raça, que, obviamente se entrecruzam. Por sua vez, local de moradia (bairro, periferia) tem a ver com a necessidade de transporte coletivo, variável que leva, novamente, para a questão do local de trabalho. Onde e por que as pessoas precisam trabalhar? E transporte coletivo implica - quase sempre - não poder cumprir diretrizes de distanciamento social.

Saliente-se, ainda, que a obrigação de trabalhar (e trabalhar fora de casa) tem a ver com a insuficiência ou ausência do auxílio emergencial.

Portanto, minha conclusão parcial, neste momento, é que na pandemia, na póspandemia e sempre, a vigilância da saúde (e principalmente Vigilância em Saúde do Trabalhador) deve incluir a vigilância dos determinantes do processo saúde-doença, e não apenas a saúde-doença, por seus indicadores habitualmente valorizados. Tal abrangência está alinhada com a conceituação de Vigilância em Saúde' nos termos da

\footnotetext{
I "Entende-se por Vigilância em Saúde o processo contínuo e sistemático de coleta, consolidação, análise de dados e disseminação de informações sobre eventos relacionados à saúde, visando o planejamento e a implementação de medidas de saúde pública, incluindo a regulação, intervenção e atuação em condicionantes e determinantes da saúde, para a proteção e promoção da saúde da população, prevenção e controle de riscos, agravos e doenças" (parágrafo $1^{\circ}$ do artigo $2^{\circ}$, destaque meu).
} 
resolução MS/CNS n. 588, de 12 de julho de 2018, que instituiu a Política Nacional de Vigilância em Saúde - PNVS (Brasil, 20 I8).

\section{CONCEITO DE “COVID-19 RELACIONADA AO TRABALHO" E SUA IMPORTÂNCIA}

É preciso abrir espaço para o entendimento do conceito de "Covid- 19 relacionada ao trabalho" e sua decorrente operacionalização, considerando sua dimensão mais abrangente e inclusiva, tal como foi proposta pela Frente Ampla em Defesa da Saúde dos Trabalhadores, segundo a qual esse conceito

... refere-se aos casos da doença contraída por trabalhadores(as) que precisam exercer suas atividades de trabalho fora de seus domicílios, assim como por aqueles(as) que, em decorrência de atividades econômicas desenvolvidas em seu domicílio, têm contato com pessoas de fora de seu convívio domiciliar. Serão considerados casos, atuais ou pregressos, aqueles com diagnóstico ou suspeita diagnóstica firmada por médico e os assintomáticos com teste positivo. Seu devido reconhecimento e notificação são fundamentais para que trabalhadores(as) adoecido(as) tenham acesso a direitos sociais, bem como para contribuir com a Vigilância em Saúde do Trabalhador. (Frente Ampla em Defesa da Saúde dos Trabalhadores, 2020, destaques meus)

O mesmo grupo de trabalho da frente ampla que propôs esse conceito ampliado de Covid- 19 relacionada ao trabalho desenvolveu outras importantes ferramentas de trabalho, entre as quais destacam-se o "Fluxograma de reconhecimento e notificação da Covid- 19 relacionada ao trabalho" e o "Roteiro de investigação para o reconhecimento e notificação da Covid- 19 relacionada ao trabalho". O fluxograma pode também ser encontrado na plataforma Renast Online (2020). Recomendo seu conhecimento e adoção.

O referido fluxograma preconiza os passos decorrentes do reconhecimento do nexo causal entre Covid- 19 e atividades de trabalho, pois a caracterização como "doença relacionada ao trabalho" ("doença do trabalho" ou "acidente do trabalho") implica direitos previdenciários diferenciados. Isto é, além da notificação para o Sistema de Informação de Agravos de Notificação (Sinan), requerida pelas autoridades sanitárias, a Comunicação de Acidente do Trabalho (CAT), requerida pelo art. 22 da lei $n$. 8.213/91 (Brasil, 1991). Outros regimes previdenciários preconizam obrigações de comunicação equivalentes.

\section{A IMPORTÂNCIA DA VIGILÂNCIA EM SAÚDE DO TRABALHADOR NA PANDEMIA}

Apesar de a Covid-19 não ser formalmente reconhecida como doença relacionada ao trabalho (a despeito dos esforços para que fosse formalmente reconhecida pelo Ministério da Saúde), reitero, neste breve texto, a importância da Vigilância em Saúde do 
Trabalhador na pandemia, recomendando aos leitores que atentem para o documento oficial "Orientações de vigilância epidemiológica da Covid- 19 relacionada ao trabalho", elaborado pelo Ministério da Saúde e divulgado em agosto de 2020 (Brasil, 2020), e dele façam uso máximo.

O referido documento tem como objetivo

orientar os profissionais da Rede Nacional de Atenção Integral à Saúde do Trabalhador (Renast), principalmente as equipes de vigilância em saúde dos municípios, Centros de Referência em Saúde do Trabalhador (Cerest) estaduais, regionais e municipais, demais serviços de vigilância em saúde do trabalhador, bem como equipes das redes de atenção primária e especializada, para o desenvolvimento de ações de vigilância epidemiológica em saúde do trabalhador relacionadas à Covid-19. (Brasil, 2020: 4)

As orientações do documento referem-se, principalmente, à investigação epidemiológica complementar de casos de Covid-19, com o objetivo de estabelecer se houve ou não relação da doença com o trabalho, para que sejam implementadas oportunamente medidas de intervenção, controle e interrupção da cadeia de transmissão da doença nos ambientes laborais. Nele também são descritos os procedimentos para notificação dos casos confirmados de Covid- 19 relacionada ao trabalho no Sistema de Informações de Agravos de Notificação (Sinan) e o processo de investigação de óbito e verificação dos dados constantes na Declaração de Óbito (DO), de modo a garantir que informações de interesse para a saúde do trabalhador estejam corretamente registradas no Sistema de Informações sobre Mortalidade (SIM) (Brasil, 2020).

Prossegue o documento do Ministério da Saúde recomendando que essas ações sejam realizadas mediante articulação da Vigilância em Saúde com os comitês de crise ou de emergência em saúde nos municípios e nas regiões de Saúde, sempre que necessário acionando a rede de apoio técnico e institucional da Renast, as representações dos trabalhadores, as instâncias do controle social do SUS e as instituições parceiras (Brasil, 2020).

Segundo o documento orientador do Ministério da Saúde, são objetivos da Vigilância Epidemiológica em Saúde do Trabalhador considerando a Covid- I9:

- Orientar as equipes de Vigilância em Saúde da Renast e demais instâncias da rede de atenção à saúde do SUS quanto à investigação epidemiológica e aos critérios para estabelecimento da relação entre a Covid- 19 e o trabalho.

- Indicar medidas de proteção e promoção da saúde dos trabalhadores contra a Covid-19, principalmente na execução de atividades com maior risco de exposição. 
- Contribuir para análise de situação de saúde dos trabalhadores no contexto da Covid- 19.

- Orientar quanto à notificação dos casos de Covid- 19 registrados no e-SUS/VE e Sivep Gripe e que tiveram a relação com o trabalho investigada e confirmada, na Ficha de Acidente de Trabalho do Sinan. (Brasil, 2020: 5)

Destaco, por último, o elenco de atividades de vigilância epidemiológica de casos de Covid-I 9 relacionados ao trabalho, preconizadas no documento orientador do Ministério da Saúde, a saber:

- Coleta e monitoramento dos registros de casos e óbitos por Covid-19, suspeitos e confirmados, potencialmente relacionados ao trabalho.

- Investigação epidemiológica da relação entre o trabalho e os casos e óbitos registrados por Covid- 19.

- Notificação dos casos de Covid- 9 relacionados ao trabalho na Ficha de Acidente de Trabalho do Sinan.

- Recomendação e promoção de medidas de controle apropriadas da Covid- 19 nos ambientes e processos de trabalho.

- Elaboração de relatório final, contendo: investigações, medidas de controle adotadas, impacto obtido com as medidas de controle, medidas de prevenção, dentre outras informações relevantes.

- Divulgação das informações. (Brasil, 2020: 6)

Corretamente, o Ministério da Saúde enfatiza que todos os profissionais da saúde (das redes pública, privada e conveniada), bem como as diversas esferas do sistema (municipal, estadual, federal), têm entre as suas atribuições a realização de ações de Vigilância Epidemiológica. Dependendo da inserção profissional e da capacidade executiva, técnica e gerencial de cada área, essas funções vão desde a notificação de casos suspeitos ou confirmados da Covid-19, que compõem o sistema de vigilância, até a investigação epidemiológica da relação com o trabalho e a adoção de medidas de controle, coleta, análise e interpretação de dados (Brasil, 2020).

\section{CONCLUSÕES}

Apesar das evidências epidemiológicas e sociodemográficas das relações entre Covid- 19 e trabalho, persiste, no Brasil, lamentável assincronia entre o entendimento sobre a importância do trabalho na determinação social da pandemia da Covid- 19 no Brasil e o seu devido reconhecimento formal, legal e normativo, o que prejudica pessoas 
e coletividades no tocante a aspectos que vão desde as medidas de prevenção até os direitos de reparação.

Por conseguinte, ações de vigilância em saúde, acordes com as dimensões preconizadas pela Política Nacional de Vigilância em Saúde (Brasil, 20 I 8), e aderentes às "Orientações de vigilância epidemiológica da Covid-19 relacionada ao trabalho" (Brasil, 2020) poderiam contribuir para ampliar compreensão da importância e a visibilidade da categoria trabalho como uma expressão central da determinação social da pandemia da Covid- 9 no Brasil. Postas a serviço de uma política de enfrentamento desta pandemia, ações de vigilância em saúde poderiam melhorar o desempenho desta luta, abrindo a possibilidade de que seja mais bem-sucedida.

\section{REFERENNCIAS}

BRASIL. Lei n. 8.213, de 24 jul. I991. Dispõe sobre os Planos de Benefícios da Previdência Social e dá outras providências. Diário Oficial da União, Brasília, I99I. Disponível em: <www.planalto.gov.br/ ccivil_03/leis/l82 I3compilado.htm>. Acesso em: 20 set. 2020.

BRASIL. Ministério da Saúde. Conselho Nacional de Saúde. Resolução MS/CNS n. 588, de 12 jul. 2018. Fica instituída a Política Nacional de Vigilância em Saúde (PNVS), aprovada por meio desta resolução. Diário Oficial da União, Brasília, 2018. Disponível em: <https://conselho.saude.gov.br/ resolucoes/2018/Reso588_publicada.pdf>. Acesso em: 20 set. 2020.

BRASIL. Ministério da Saúde. Secretaria de Vigilância em Saúde. Coordenação-Geral de Saúde do Trabalhador. Orientações de vigilância epidemiológica da Covid- 19 relacionada ao trabalho. Brasília: Ministério da Saúde, 2020. Disponível em: < https://docs.bvsalud.org/biblioref/2020/08/I I I6664/ covid-orienta-es-trabalho.pdf>. Acesso em: 20 set. 2020.

BREILH, J. La determinación social de la salud como herramienta de transformación hacia una nueva salud pública (salud colectiva). Revista de la Facultad Nacional de Salud Pública, 31, supl. I: 8SI3-S27, 2013. Disponível em: <www.scielo.org.co/pdf/rfnsp/v3 I s I/v3 I s I a02.pdf>. Acesso em: 20 set. 2020.

FIGARO, R. O mundo do trabalho e as organizações: abordagens discursivas de diferentes significados. Organocom, 5(9): 90-100, 2008. Disponível em: <https://www.revistas.usp.br/organicom/article/ view/I 38986/I34334>. Acesso em: 20 set. 2020.

FRENTE AMPLA EM DEFESA DA SAÚDE DOS TRABALHADORES. Ampliação do conceito de Covid- 19 relacionada ao trabalho: ações necessárias e recomendadas para avançar. Disponível em: www. frenteamplast.com/post/gt-2-amplia\%C3\%A7\%C3\%A3o-do-conceito-de-covid- I 9-relacionada-aotrabalho-a\%C3\%A7\%C3\%B5es-necess\%C3\%A I rias-e-recomendadas-p>. Acesso em: 20 set. 2020.

LAURELL, A. C. La salud-enfermedad como proceso social. Revista Latinoamericana de Salud, 2: $7-25,1982$

ORGANIZAÇÃO DAS NAÇÕES UNIDAS (ONU). Ningún trabajador es prescindible, empresas y Gobiernos deben protegerlos del coronavirus u otro peligro, I8 Mayo 2020. Disponível em: <https:// news.un.org/es/story/2020/05/I474542>. Acesso em: 20 set. 2020. 
PLATAFORMA RENAST ONLINE. Fluxograma de reconhecimento e notificação da Covid-19 relacionada ao trabalho. Disponível em: <https://renastonline.ensp.fiocruz.br/recursos/fluxogramareconhecimento-notificacao-covid- I 9-relacionada-trabalho>. Acesso em: 20 set. 2020.

SOUZA, D. O. A pandemia de Covid-19 para além das Ciências da Saúde: reflexões sobre sua determinação social. Ciência E Saúde Coletiva, 25, supl. I: 2.469-2.477, 2020. Disponível em: <www. scielo.br/pdf/csc/v25s I/I4I3-8I 23-csc-25-s I-2469.pdf>. Acesso em: 20 set. 2020.

SOUZA, D. O. E VASCONCELLOS, L. C. F. Trabalho. In: MENDES, R. (Org.). Dicionário de Saúde e Segurança do Trabalhador: conceitos - definições - história - cultura. Novo Hamburgo: Proteção Publicações, 2018. 

Covid-19

\section{situação de saúde entre trabalhadores da Fiocruz}

Sônia Regina da Cunha Barreto Gertner, Andréa da Luz Carvalho, Flavia Soares Lessa, Márcia Vieira Pacheco, Cecília de Aquino Barbosa,

Caroline Marcelino Sixel Amorim da Silva, Fabiola Naomi Eto, Marcelo Moreno dos Reis, Marília Santini de Oliveira, Rosane Harter Griep, Lúcia Rotenberg, Marcelo Silva Santos e Marisa Augusta de Oliveira

A crise sanitária deflagrada pela pandemia de Covid-19 potencializou as demais crises vivenciadas pela população mundial, principalmente políticas, financeiras, econômicas (Santos, 2020). No Brasil, a pandemia afetou a classe trabalhadora de formas diferenciadas: para alguns trabalhadores foi possível a adoção das recomendações de distanciamento social para evitar o contágio pelo novo coronavírus, mas para aqueles em atividades e serviços essenciais e os informais, tal medida não se configurou em realidade.

Na Fundação Oswaldo Cruz (Fiocruz) não foi diferente. Desde março de 2020, seguindo as recomendações do Plano de Contingência da Fiocruz diante da pandemia da doença pelo Sars-CoV-2 (Covid-19) (Fiocruz, 2020a), parte da comunidade passou a desenvolver suas atividades laborais remotamente, enquanto a parcela vinculada aos serviços essenciais manteve atividades presenciais. Assim, no contexto da pandemia o fortalecimento e a reorganização das ações de investigação e intervenção na relação do processo de trabalho com a saúde se fizeram indispensáveis e urgentes. Para responder a essa demanda e visando à proteção da saúde da sua comunidade, a Fiocruz desenvolveu diversas ações cujos aspectos essenciais serão descritos aqui. 


\section{A VIGILÂNCIA EM SAÚDE DO TRABALHADOR NA FIOCRUZ NA PANDEMIA DO NOVO CORONAVÍRUS}

A vigilância em saúde do trabalhador (VST) é compreendida como uma atuação contínua e sistemática, ao longo do tempo, no sentido de detectar, conhecer, pesquisar e analisar os fatores determinantes e condicionantes dos agravos à saúde relacionados aos processos e ambientes de trabalho, em seus aspectos tecnológico, social, organizacional e epidemiológico, com a finalidade de planejar, executar e avaliar intervenções sobre esses aspectos, de forma a eliminá-los ou controlá-los (Brasil, 20 I7a). Em contexto de pandemia, inclui todos os procedimentos indicados na vigilância epidemiológica (VE) da população em geral, como atender à demanda, registrar os casos, testar, orientar e rastrear os contactantes (Brasil, 2020b).

Na experiência da Fiocruz, destacamos a realização de ações com foco nos locais e processos de trabalho e no controle do vírus internamente. Nesta instituição, parte da VST se efetivou por meio de:

- Ações de comunicação para informar os trabalhadores sobre a Covid-19;

- Atendimento presencial de trabalhadores sintomáticos e orientação para autonotificação no sistema nustcovid I 9' (Fiocruz, 202 la);

- Confirmação diagnóstica pelo teste RT-PCR em secreção respiratória;

- Análise dos dados epidemiológicos para tomada de decisões e disseminação de informações em boletins epidemiológicos;

- Avaliação das condições de trabalho dos serviços considerados essenciais.

\footnotetext{
' O sistema nustcovid I 9 (Fiocruz, 202 I a) é uma plataforma digital criada para registro das situações de sinais e sintomas pela comunidade da Fiocruz e uma das fontes de dados para a elaboração de boletins epidemiológicos. É desenvolvido em parceria com o Instituto de Comunicação e Informação Científica e Tecnológica em Saúde (Icict) e a Coordenação de Saúde do Trabalhador da Coordenação Geral de Gestão de Pessoas (CST/Cogepe).
} 


\section{TESTAGEM DOS TRABALHADORES E DAS TRABALHADORAS DA FIOCRUZ}

Apesar de o diagnóstico clínico de sinais e sintomas característicos da Covid- 19 ser suficiente para $\mathrm{O}$ afastamento do trabalhador do trabalho, ${ }^{2}$ a adoção do teste padrão ouro RT-PCR (reverse-transcriptase polymerase chain reaction) em tempo real para a confirmação diagnóstica tem sido internacionalmente recomendada por sua precisão diagnóstica. A testagem de trabalhadores e trabalhadoras ajuda a orientar as demais ações de vigilância, como o rastreamento dos contactantes e a geração de dados para a elaboração de boletins epidemiológicos.

Desde março de 2020, a Fiocruz realiza testagem de seus trabalhadores com o RTPCR em secreções respiratórias, iniciando por profissionais da assistência do Instituto Nacional de Infectologia (INI) e do Instituto Fernandes Figueiras (IFF) e estendido em abril para todos os trabalhadores da fundação. A Coordenação de Vigilância em Saúde e Laboratório de Referência (CVSLR) e a Coordenação Geral de Gestão de Pessoas (Cogepe) organizaram, em conjunto com o Laboratório de Vírus Respiratórios e Sarampo do Instituto Oswaldo Cruz (LVRS/IOC), ${ }^{3}$ uma rede interna de postos de coleta. Cabe ao LVRS realizar os exames e fazer os laudos com os resultados, que podem ser acessados pelo Gerenciador de Ambiente Laboratorial, sistema de gerenciamento de amostras e resultados da Coordenação Geral de Laboratórios de Saúde Pública do Ministério da Saúde (CGLAB/SVS/MS). Compõem a rede, além do INI e do IFF, a Escola Nacional de Saúde Pública Sergio Arouca (Ensp), o Instituto de Tecnologia em Fármacos (Farmanguinhos), o Instituto de Tecnologia em Imunobiológicos (Bio-Manguinhos) e o Núcleo de Saúde do Trabalhador a Coordenação de Saúde do Trabalhador do (Nust/CST/ Cogepe), responsáveis por coletar amostras de material biológico, encaminhá-las ao LVRS, comunicar resultados e realizar as demais ações de VST. As unidades localizadas fora do Rio de Janeiro também participam dessa ação mediante articulações locais com laboratórios próprios ou das secretarias estaduais/municipais de Saúde.

Para a organização dos postos de coleta, investiu-se na compra de equipamentos de proteção individual, na contratação/treinamento para a testagem e na adaptação de locais ao ar livre para garantir segurança na testagem.

\footnotetext{
${ }^{2}$ Várias legislações no âmbito do governo federal e no âmbito do Ministério Público do Trabalho indicaram o afastamento de trabalhadores de organizações privados e de servidores públicos a partir de autodeclarações de sinais e sintomas da Covid-19. Destacamos como exemplos desses instrumentos legais a recomendação n. I - PGT/GT Covid-19, publicada pelo Ministério Público do Trabalho (Brasil, 2020c), e as instruções normativas 19 e 27 (Brasil, 2020d, 2020e) no caso dos servidores públicos federais.

${ }^{3}$ O Laboratório de Vírus Respiratórios e Sarampo do IOC é referência nacional para o diagnóstico da Covid- 19 junto ao Ministério da Saúde e referência nas Américas para a Organização Mundial da Saúde (OMS).
} 
Para o monitoramento dos casos, foi criado um questionário usando-se o software REDCap (Harris et al., 2009, 2019), espelhando a ficha de notificação dos casos de Covid- 19 do Ministério da Saúde, que permite preenchimento on-line no local de coleta das amostras biológicas. As informações consolidadas em gráficos e tabelas podem ser acompanhadas em tempo real no painel Dashboard Suspeitos Covid I 9, feito em parceria com o Laboratório de Pesquisa Clínica em DST e Aids (LapClinAids/INI). Esses dados são publicados nos boletins epidemiológicos da Coordenação de Saúde do Trabalhador (Fiocruz, 2020c) e serão apresentados adiante. O Nust alimenta o sistema de doenças de notificação compulsória (e-SUS/VE) do Ministério da Saúde.

\section{ACOMPANHANDO OS TRABALHADORES NA PANDEMIA: UMA EXPERIÊNCIA DE CUIDADO EM SAÚDE}

A complexidade envolvida na totalidade de cuidados expressa a forma como está estruturado o acompanhamento. Desde as primeiras semanas de vigência do Plano de Contingência da Fiocruz (Fiocruz, 2020a), ressoavam as vozes dos trabalhadores que em seus telefonemas e mensagens traziam inquietações sobre sintomas e preocupação com familiares, testes, dúvidas sobre o enquadramento em grupo de risco, entre outras questões. Faziam-se necessárias respostas coordenadas, sob pena de se tornarem ineficazes.

O cenário evidenciava a importância de outra finalidade, além da notificação de sintomas e adoecimentos: o estabelecimento de um canal sistemático de diálogo com os trabalhadores, ou seja, um canal não somente para aqueles que manifestavam sintomas típicos da Covid-19, mas para todos que desejassem falar sobre suas dúvidas e diferentes formas como a pandemia os afetava no cotidiano.

Uma equipe inicial foi direcionada para retornar os contatos, dialogar com os trabalhadores sobre sintomas, dúvidas e demandas diversas. Com a instalação, em abril de 2020, da plataforma eletrônica nustcovid I 9, o volume de acessos ao sistema gerou a ampliação da equipe, que passou a contar com cinco residentes de saúde do trabalhador (ST), duas técnicas de enfermagem, uma enfermeira, uma médica e uma profissional responsável pela articulação intrainstitucional.

Definiu-se que o contato seria, preferencialmente, por meio de ligações telefônicas, para escuta, identificação e encaminhamentos das demandas dos trabalhadores. Após o primeiro contato - realizado pelas residentes -, de acordo com a situação apresentada e com critérios de alerta construídos pela equipe, o acompanhamento era feito mediante contato pela equipe de enfermagem e, em casos de maior gravidade, pela médica. 
Nas unidades que dispunham de serviços de ST, os trabalhadores eram acompanhados pelas equipes de tais serviços, com vistas ao fortalecimento da atuação local de cada serviço.

Os encaminhamentos foram feitos para distintas equipes profissionais dependendo da situação, a saber: I) equipe médica, que prestava orientações sobre dificuldade de acesso aos serviços de saúde, situações familiares, questões relacionadas ao trabalho; 2) equipe de psicologia (Fiocruz, $202 \mathrm{Ib}$ ), que dava suporte às pessoas em sofrimento psíquico em decorrência da pandemia; 3) equipe de serviço social, que acompanhava os casos de internação hospitalar; 4) equipe de testagem, que encaminhava a realização do teste RT-PCR.

$\mathrm{Na}$ articulação com o Serviço Social, a equipe se depara com a complexidade do campo de forças que tecem as relações trabalho-saúde no contexto da pandemia. No acompanhamento dos trabalhadores, foram ouvidos relatos de pessoas que não se afastaram da atividade presencial, a despeito das orientações institucionais. O que ocorre nesses casos? Desconhecimento das orientações oficiais tão divulgadas pela Comunicação Social em diferentes canais? Pressão de chefias sobre a equipe, na contramão das orientações institucionais? Vinculação do trabalhador à atividade, ou medo do questionamento sobre tal vinculação? Naturalização da doença, com redução da sensação de risco para si e para o coletivo?

A compreensão do fenômeno requer escuta livre de julgamentos sobre o trabalhador e, de acordo com a situação, intervenções que garantam o afastamento imediato do trabalhador sintomático e a sustentação, perante as hierarquias institucionais ou empresas de terceirização de mão de obra, da solicitação de que esta medida seja cumprida. A atuação do Serviço Social em suas visitas aos ambientes laborais e no diálogo in loco sobre as condições de trabalho amplia a compreensão e as possibilidades de intervenção da equipe no acompanhamento aos trabalhadores.

Uma breve retrospectiva sobre a construção do acompanhamento dos trabalhadores que notificam sintomas e diagnóstico de infecção por Covid- 19 evidencia uma diretriz central do trabalho: o cuidado. Desde a constituição desse acompanhamento, o método estabelecido baseia-se na possibilidade de escuta. O cuidado como diretriz é evidenciado, por exemplo, nas situações em que os acessos não informam nenhum sintoma, contato com pessoa adoecida por Covid-19, grupo de risco ou outro sinal de alerta. Ainda assim, segundo o método acordado, a equipe deve realizar as ligações oferecendo a possibilidade ao trabalhador de dizer algo que via sistema não quis ou conseguiu falar. 
Nesse contexto, pode-se destacar outra diretriz deste trabalho de acompanhamento: a integralidade, numa perspectiva que coincide com a ideia de "imagem-objetivo" apresentada por Mattos (2006), ou seja, a integralidade a ser construída continuamente a partir da crítica ao que existe. Assume-se, então, a busca da integralidade como um valor no acompanhamento aos trabalhadores que fazem notificações na plataforma nustcovid19. Assim, há na atuação da equipe uma atitude de "recusa em reduzir o paciente ao aparelho ou sistema biológico que supostamente produz o sofrimento e, portanto, à queixa desse paciente" (Mattos, 2006: 50).

Paciente está sendo entendido aqui como o trabalhador com quem a equipe de saúde dialoga. Alinhando-se aos diferentes aspectos abordados por Mattos (2006), a integralidade pode ser apreendida como valor que atravessa a atitude individual do profissional da saúde, o processo de trabalho, que estamos denominando de acompanhamento, e a própria organização do trabalho, na medida em que busca manter viva e permeável a interface entre diferentes equipes.

As condições de trabalho da própria equipe de acompanhamento são fundamentais para que a ação possa se desenvolver. Portanto, quando entende que o cuidado em saúde não pode "se restringir apenas às competências e tarefas técnicas, pois o acolhimento, os vínculos de intersubjetividade e a escuta dos sujeitos compõem os elementos inerentes à sua constituição" (Pinheiro, 2008: I 13), a instituição entende, também, a importância de que os critérios de retorno não estejam vinculados exclusivamente a condições clínicas, como resultado de RT-PCR positivo ou sintomas frequentes, como febre e tosse.

Finalmente, a participação ativa do trabalhador e seu poder de estabelecer suas necessidades de saúde são aspectos cruciais na construção do trabalho de acompanhamento. A despeito das articulações e encaminhamentos possíveis, colocam-se questões como: nesta modalidade de cuidado, de forma remota, quais os limites éticos da atuação da equipe na relação com o trabalhador que relata sintomas, diagnóstico, risco, sofrimento e outras dificuldades? Como lidar com as situações em que não ocorre a usual receptividade ao contato da equipe? Como identificar problemas nos ambientes laborais quando o trabalhador receia falar com um profissional com o qual ainda não teve tempo de estabelecer vínculo? Lida-se com tais limites, orienta-se cuidadosamente sobre sinais de alerta para que busquem um serviço de saúde presencial. Outros limites continuam sendo reconhecidos, testados, discutidos ou superados no diálogo contínuo entre a equipe e os trabalhadores, com os quais se dá a construção viva desta ação de cuidado em saúde.

O leitor interessado poderá obter informações sobre as iniciativas e materiais produzidos que complementam as ações de cuidado e promoção da ST (Fiocruz, 202 I c) 
aqui brevemente citadas, assim como o relatório de avaliação sobre os hábitos de saúde dos trabalhadores durante a pandemia (Fiocruz, 202 Id) e o plano de convivência com orientação aos trabalhadores e trabalhadoras sobre as novas condições e configurações do trabalho (Fiocruz, 202 le).

Com a construção do Centro Hospitalar Covid- 19 (INI/Fiocruz), uma equipe de ST foi constituída com o objetivo de promover acolhimento, cuidado e assistência aos trabalhadores envolvidos no atendimento direto e indireto à população internada, conforme o Plano de Ação (Fiocruz, 202lf) desenhado em consonância com os princípios do SUS e da Política Nacional de Saúde do Trabalhador e da Trabalhadora, de forma pactuada e coordenada com as instâncias institucionais

\section{COVID-19 COMO DOENÇA RELACIONADA AO TRABALHO, HISTÓRICO E ESTADO DA ARTE}

A gravidade sanitária e social instaurada pela pandemia da Covid-19 fomentou no Brasil numerosas discussões e debates promovidos pelos aparelhos de Estado, por movimentos sociais organizados e pela comunidade acadêmica sobre o reconhecimento de nexo causal e sobre a notificação da Covid- 19 como doença relacionada ao trabalho e suas diretas relações com o modelo socioprodutivo vigente.

É importante relembrar que o campo da ST compreende "um conjunto de atividades que se destina, por meio das ações de vigilância epidemiológica e vigilância sanitária, à promoção e proteção da saúde do trabalhador, assim como visa à recuperação e à reabilitação dos trabalhadores submetidos aos riscos e agravos advindos das condições de trabalho" (parágrafo $3^{\circ}$ do artigo $6^{\circ}$ da Lei Orgânica da Saúde). A atual Política Nacional de Saúde do Trabalhador e da Trabalhadora (Portaria GM/MS n. I.823/I2) enfatiza a assistência integral ao trabalhador, a capacitação voltada para a aplicação de medidas básicas de promoção, prevenção e educação em saúde e para as orientações quanto aos direitos dos trabalhadores, bem como a participação em estudos, pesquisas, avaliação e controle dos riscos e agravos existentes no processo de trabalho (Brasil, 20I2). Na Fiocruz, as ações de ST são atravessadas por políticas específicas - Política de Atenção à Saúde e Segurança do Trabalho do Servidor Público Federal/ Subsistema Integrado de Atenção à Saúde do Servidor (Pass/Siass), Política Nacional de Segurança e Saúde no Trabalho (PNSST), Política Nacional de Saúde do Trabalhador e da Trabalhadora (PNSTT) -, o que confere especificidades em intervenções, em especial quanto às notificações, e a CST/Cogepe elaborou um manual orientador sobre a questão (Fiocruz, 2020b). 
Segundo Maeno e Carmo (2020: I), "todos os casos de Covid- 19 contraída por trabalhadores que foram obrigados a exercer suas atividades de trabalho fora de seus domicílios devem ser considerados como relacionados ao trabalho". A tese se ancora principalmente na compulsoriedade da exposição ao contato inter-humano e de superfícies, em especial nos transportes públicos, a despeito de todos os métodos de prevenção, bem como nas desencontradas e insuficientes medidas de proteção coletiva adotadas pelos governos.

$\mathrm{Na}$ ocorrência do acidente de trabalho por contaminação, independentemente de afastamento, é obrigatória a emissão da Comunicação de Acidente de Trabalho (CAT) por parte do empregador, importante para a caracterização do nexo técnico previdenciário (NTeP) e para o controle estatístico e epidemiológico. O fato de o afastamento durar menos de 15 dias não impede a empresa de cumprir a legislação trabalhista e previdenciária, além de preservar a saúde dos trabalhadores.

Para os servidores/trabalhadores vinculados ao Regimento Jurídico único (lei $\mathrm{n}$. 8. 1 12/90), acidente de trabalho é aquele ocorrido com o servidor no exercício do cargo, que se relacione direta ou indiretamente com as atribuições a ele inerentes, provocando lesão corporal ou perturbação funcional ou que possa causar a perda ou redução, permanente ou temporária, da capacidade para o trabalho.

A doença em que a atividade laboral é fator de risco desencadeante, contributivo ou agravante de um distúrbio latente ou de uma doença preestabelecida estará caracterizada quando diagnosticado o agravo e for possível estabelecer uma relação epidemiológica com a atividade laboral. As doenças endêmicas contraídas no exercício do trabalho também serão caracterizadas como doenças relacionadas ao trabalho (Brasil, 20 I 7b).

Ao revogar, em sua plena manifestação, o art. 29 da MP 927 e a MP 905/I9, da extinção de acidente de percurso, o Supremo Tribunal Federal apontava para um justo reconhecimento do risco aumentado, podendo gerar presunção de nexo causal entre o processo de trabalho e fontes de infecção, adoecimento e morte. Contudo, em sua tramitação a MP 927 não foi votada no Senado dentro do prazo necessário (julho de 202I), tendo por isso se tornado sem eficácia (Brasil, 202I).

O Ministério Público do Trabalho ratificou a emissão de CAT em casos suspeitos e confirmados de Covid-19, além de ações básicas de VE (Brasil, 2020a). Quanto à VE e ao Sistema Nacional de Agravos de Notificação (Sinan), somente em agosto de 2020 foi incluído o campo Ocupação segundo a Classificação Brasileira de Ocupações (CBO) na plataforma e-SUS, bem como foi emitida orientação de investigação para notificação em Ficha de Acidente de Trabalho de 2019. A CST tem procedido a investigações epidemiológicas e à emissão de CAT, entendida como ferramenta fundamental da VST 
para conhecimento dinâmico e atualizado do perfil epidemiológico, contribuindo para o combate a este agravo, para a garantia de direito dos trabalhadores e para reflexões sobre o modelo produtivo e suas relações com a saúde e a doença.

\section{INICIATIVAS DE ACESSIBILIDADE E INCLUSÃO DOS TRABALHADORES NA PANDEMIA}

Preocupada com a comunicação e o cuidado com os trabalhadores com deficiência, considerados do grupo de maior risco, a Fiocruz implementou recursos de acessibilidade em seus vídeos sobre a Covid-19, mediante uma articulação entre o Comitê Fiocruz pela Acessibilidade e Inclusão das Pessoas com Deficiência, o Projeto Empregabilidade da Pessoa Surda, da Cooperação Social da Fiocruz, o Programa Fiocruz Saudável (CST) e a Coordenação Geral de Gestão de Pessoas (Cogepe/Fiocruz).

Já são mais de 160 vídeos traduzidos para a língua brasileira de sinais (Libras), disponíveis na área especial sobre o novo coronavírus do Portal Fiocruz e na Biblioteca Virtual de Saúde (Fiocruz, 202 lg) da instituição (BVS Fiocruz). Os vídeos semanais estão disponíveis no canal da Fiocruz no YouTube (Fiocruz, 2020e) e nas redes sociais da instituição no Facebook (Fiocruz, 202 I h), no Instagram (Fiocruz, 202 I i) e no Twitter (Fiocruz, 202 lj).

Uma importante contribuição foi a publicação Diálogos sobre Acessibilidade, Inclusão e Distanciamento Social: territórios existenciais na pandemia (Mendes et al., 2020), com reflexões sobre as vulnerabilidades das pessoas com deficiência em meio à pandemia. Trata-se de iniciativa da plataforma IdeiaSUS/Fiocruz, em parceria com o Comitê Fiocruz pela Acessibilidade e Inclusão das Pessoas com Deficiência, o Departamento de Direitos Humanos, Saúde e Diversidade Cultural da Ensp e a Universidade Federal de Goiás.

\section{SITUAÇÃO DE SAÚDE DOS TRABALHADORES}

Desde março de 2020, quando a Fiocruz iniciou a testagem RT-PCR para Covid- 19 em seus trabalhadores, o número de testes realizados aumentou substancialmente. Em dezembro de 2020, a fundação contava com um total de 12 centros de coleta, distribuídos em suas diferentes unidades nos estados brasileiros.

Entre as semanas epidemiológicas 10 e 50, foram realizados 10.568 testes RT-PRC para Covid-19, tendo o número de resultados negativos obtidos sido maior do que o de positivos na maioria das semanas. Ao longo do período de testagem, dois momentos se destacam em relação ao número de testes e de resultados positivos: entre as semanas epidemiológicas 17 e 26 e entre as semanas 46 e 50 (Gráfico I). 


\section{Gráfico I - Resultado dos testes para Covid- 19 realizados nos centros de coleta da Fiocruz ao longo das semanas epidemiológicas - Março a dezembro de 2020}

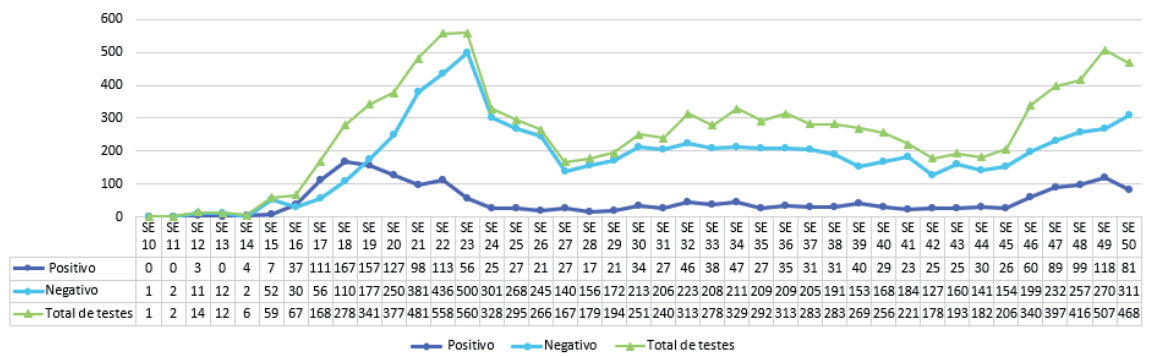

Legenda das Semanas Epidemiológicas (SE) Semana 10 - 01/03 a 07/03 Semana 11 - 08/03 a 14/03 Semana 15 - 05/04 a 11/04 Semana $16-12 / 04$ a $18 / 04$ Semana 20 - 10/05 a 16/05 Semana $21-17 / 05$ a 23/05 Semana 25 - 14/06 a 20/06 Semana 26 - 21/06 a 27/06 Semana 30 - 19/07 a 25/07 Semana 31 - 26/07 a 01/08 Semana 35 - 23/08 a 29/08 Semana 36 - 30/08 a 05/09 Semana 40 - 27/09 a 03/10 Semana 41 - 04/10 a 10/10 Semana 45 - 01/11 a 07/11 Semana 46 - 08/11 a 14/11 Semana 50 - 06/12 a $12 / 12$

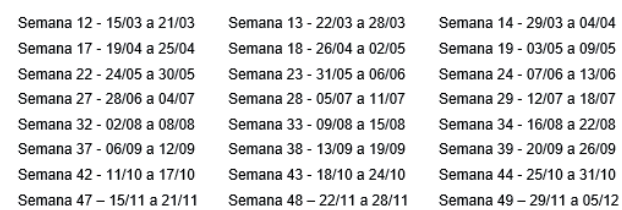

Fonte: RedCap Fiocruz, jan. 202 I c.

\section{Características dos trabalhadores que testaram positivo e dos que testaram negativo para Covid-19}

Em aproximadamente dez meses (de março a dezembro de 2020), 4.047 trabalhadores foram acompanhados diretamente pelo Nust e/ou por meio da plataforma eletrônica para fins de monitoramento de seu estado de saúde e possíveis desfechos relacionados com a infecção pelo Sars-CoV-2. Em relação ao monitoramento dos trabalhadores que responderam às perguntas na plataforma eletrônica, sabe-se apenas o resultado obtido, mas não o tipo de teste realizado ou se este foi realizado ou não fora da Fiocruz.

Por meio dos dados da base cadastral da Fiocruz, obteve-se a proporção de trabalhadores que relataram ter realizado o teste para Covid-19 e a proporção de resultados positivos segundo a unidade de trabalho. Aproximadamente a metade dos trabalhadores do Instituto de Tecnologia em Fármacos Farmanguinhos $(50 \%, n=473)$ e do hospital Instituto Nacional de Saúde da Mulher, da Criança e do Adolescente Fernandes Figueira ( $48 \%, n=550$ ) realizou o teste, possivelmente devido ao fato de essas unidades terem mantido a maior parte do trabalho em regime presencial na maioria dos setores. Essas duas unidades concentraram a maior proporção de resultados positivos ( $19 \%, n=18 \mid$ e $17 \%, n=197$, respectivamente) (Gráfico 2). 
Gráfico 2 - Proporção de respondentes testados e que receberam resultado do teste positivo segundo unidade da Fiocruz (testados $=2.199$, positivos $=898$ )

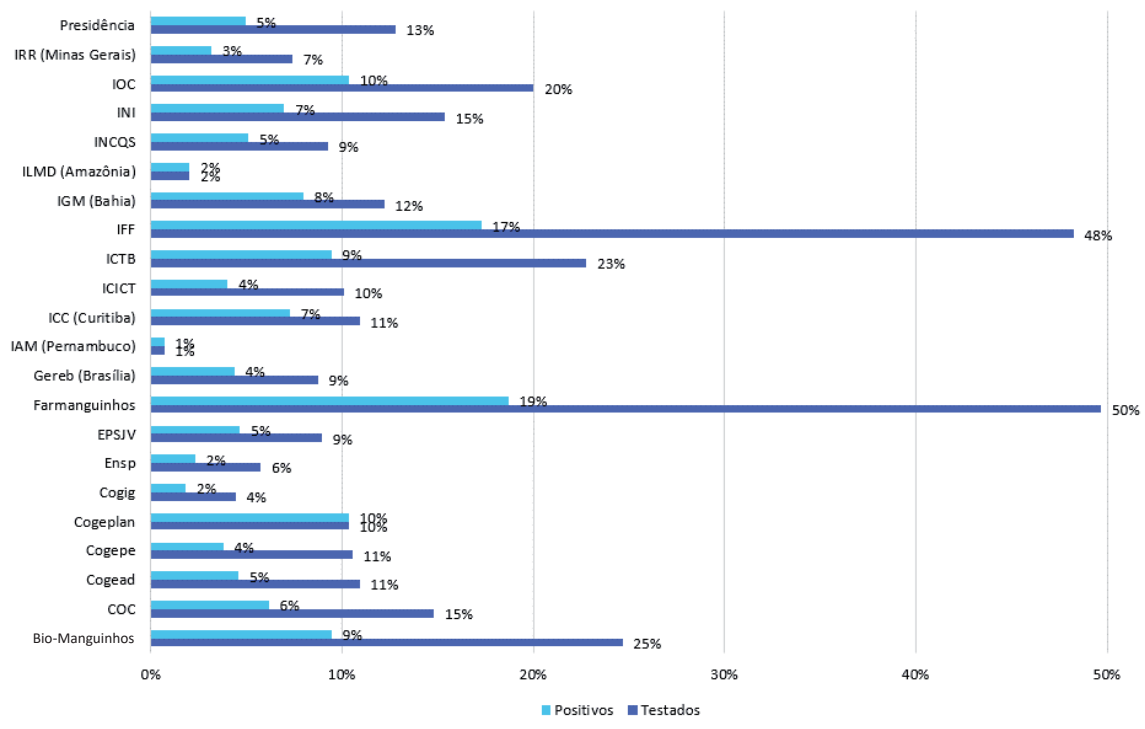

Fonte de dados: Nust Covid- 19 (Fiocruz, 202 I a).

Entre os trabalhadores que testaram positivo para Covid-19, os sintomas mais frequentemente relatados foram tosse seca, dor no corpo, perda do olfato e paladar e coriza. Quando comparados com os que testaram negativo, os que testaram positivo referiram mais frequentemente dor no corpo, perda do olfato e do paladar e febre (Gráfico 3).

Os testes foram realizados mais frequentemente entre as mulheres, comparadas aos homens ( 1.188 e 889, respectivamente). A maioria dos resultados foi negativo para a Covid- 19 tanto entre as mulheres (59\%) quanto entre os homens $(53,7 \%)$, com maior proporção de negativos entre elas (Gráfico 4).

Em todas as faixas etárias, a proporção de resultados negativos superou a de positivos. O maior número de testes realizados se concentrou na faixa 30-59 anos. A proporção de testes positivos cresceu segundo o aumento da faixa etária (Gráfico 5).

Em relação ao tipo de vínculo com a Fiocruz, há maior proporção de resultado positivo entre os alunos, estagiários e aposentados, ao passo que a maior parte dos trabalhadores terceirizados, servidores, bolsistas e residentes recebeu resultado do teste negativo (Gráfico 6). 
Gráficos 3 - Frequência dos principais sintomas entre os trabalhadores que testaram negativo us positivo

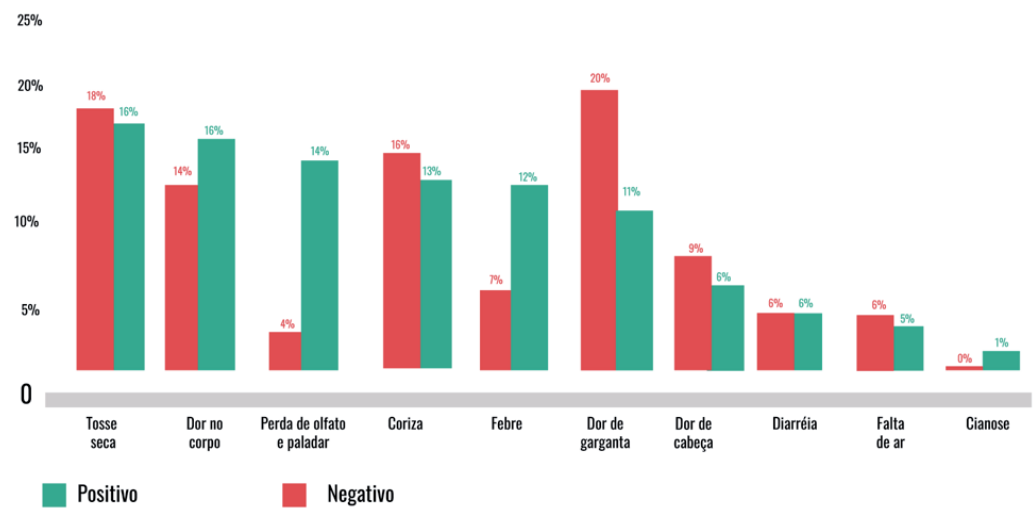

Fonte de dados: Nust Covid-I 9 (Fiocruz, 202 Ia).

Gráfico 4 - Proporção de homens e mulheres segundo resultado do teste para Covid 19 (homens $=889$, mulheres $=1.188$ )

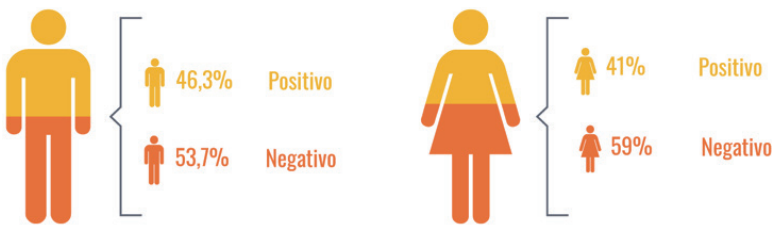

Fonte de dados: Nust Covid-I 9 (Fiocruz, 202 Ia).

Gráfico 5 - Resultado positivo do teste para Covid- 19 segundo a faixa etária (até 29 anos $=356$, de 30 a 44 anos $=1.041$, de 45 a 49 anos $=592$, mais de 60 anos $=86$ )

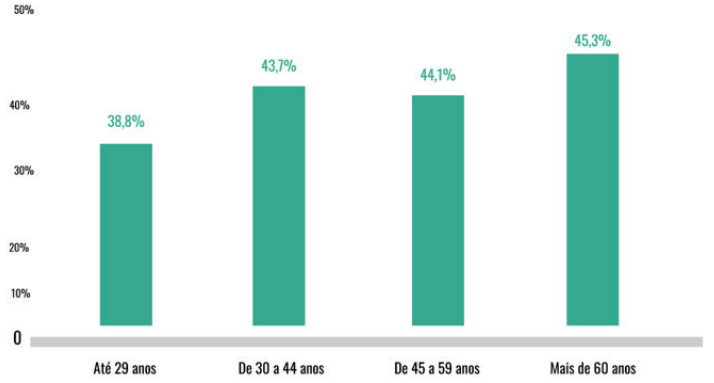

Fonte de dados: Nust Covid- 19 (Fiocruz, 202 I a). 
Gráfico 6 - Proporção de trabalhadores que testaram positivo para Covid- 19 segundo o tipo de vínculo com a Fiocruz (aposentado $=5$, estagiário $=9$, aluno $=36$, residente $=73$, bolsista $=125$, servidor $=537$, terceirizado $=1.296$ )

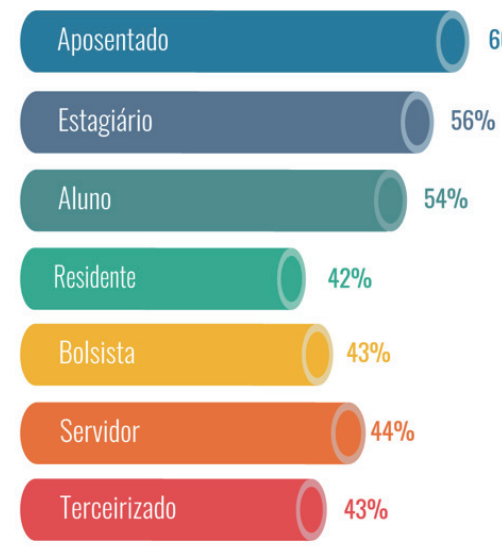

Fonte de dados: Nust Covid- 19 (Fiocruz, 202 la).

\section{Perfil dos trabalhadores hospitalizados e óbitos relacionados com a Covid-19}

Entre março e dezembro de 2020, 48 trabalhadores foram hospitalizados em decorrência da ou suspeita de infecção pela Covid-19. Desses, 56\% eram homens $(n=27)$ e $44 \%$ mulheres $(n=21)$. A maior parte dos hospitalizados $(68 \%)$ tinha entre 40 e 59 anos. Os 3 hospitalizados com idade maior que 69 anos eram homens; o único hospitalizado com idade entre 20 e 29 anos era mulher (Gráfico 7).

A maioria dos hospitalizados eram servidores e trabalhadores terceirizados (Gráfico 8). Dezesseis trabalhadores foram a óbito com suspeita $(n=3)$ ou casos confirmados $(n=13)$ de Covid- 19. Desses, II eram homens e 5 mulheres, sendo 8 deles com idades de 50 a 59 anos (Gráfico 9). Treze trabalhadores que foram a óbito eram servidores ou terceirizados, 2 eram aposentados e I era bolsista (Gráfico I0). 
Gráfico 7 - Hospitalizações relacionadas com casos suspeitos ou confirmados de Covid- 19 segundo faixa etária e sexo (homens $=27$, mulheres $=21$ )

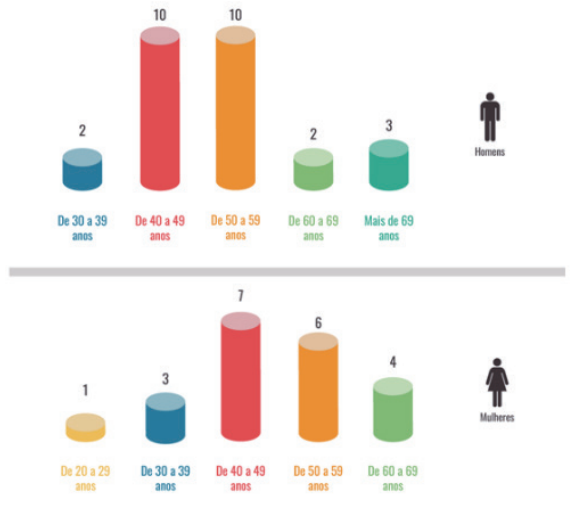

Fonte de dados: Nust Covid- I 9 (Fiocruz, 202 Ia).

Gráfico 8 - Distribuição dos trabalhadores que foram hospitalizados segundo tipo de vínculo com a Fiocruz $(n=48)$

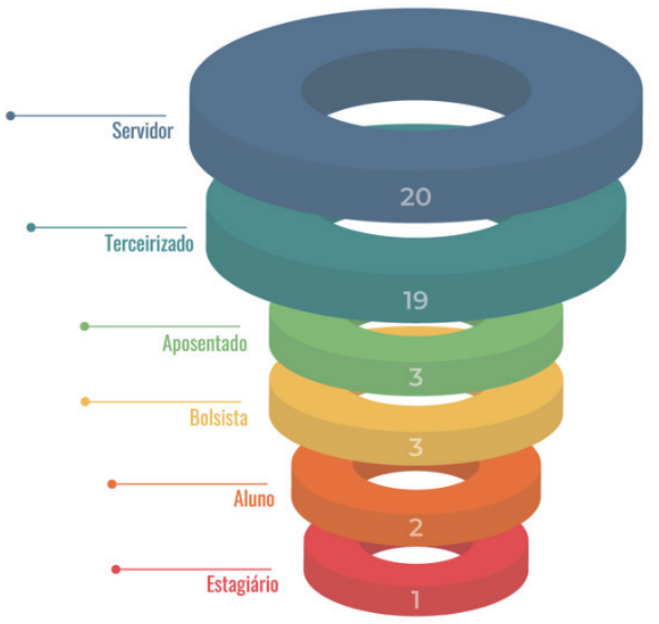

Fonte de dados: Nust Covid- 19 (Fiocruz, 202 Ia). 
Gráfico 9 - Óbitos relacionados a casos suspeitos ou confirmados de Covid- 19 segundo faixa etária e sexo (homens $=11$, mulheres $=5$ )

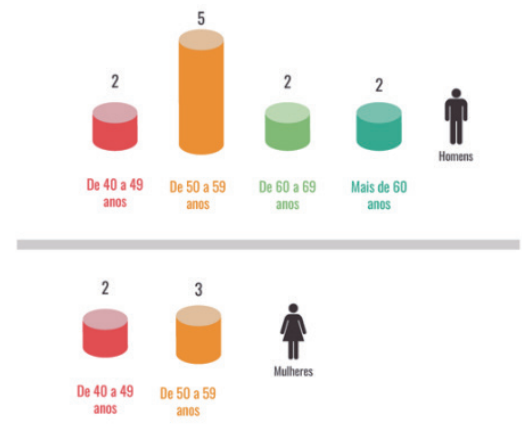

Fonte de dados: Nust Covid-19 (Fiocruz, 202 I a).

Gráfico 10 - Distribuição dos trabalhadores que foram a óbito segundo tipo de vínculo com a Fiocruz $(n=16)$

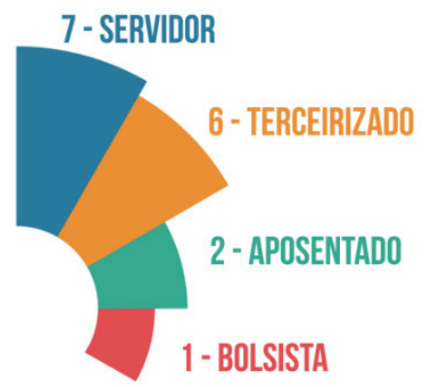

Fonte de dados: Nust Covid- 19 (Fiocruz, 202 I a).

\section{REINVENTAR O CAMINHO JUNTO COM O TRABALHADOR}

A Figura I sintetiza as ações desenvolvidas na Fiocruz que foram descritas no presente capítulo, as quais só foram possíveis com a participação ativa do trabalhador, pressuposto essencial da vigilância em saúde do trabalhador, numa busca coletiva e solidária por reinventar as formas de continuar vivendo e trabalhando, mesmo diante do inesperado de uma pandemia. 
Figura I - Vigilância em saúde do trabalhador no contexto da pandemia da Covid- 19 - Fiocruz, 2020

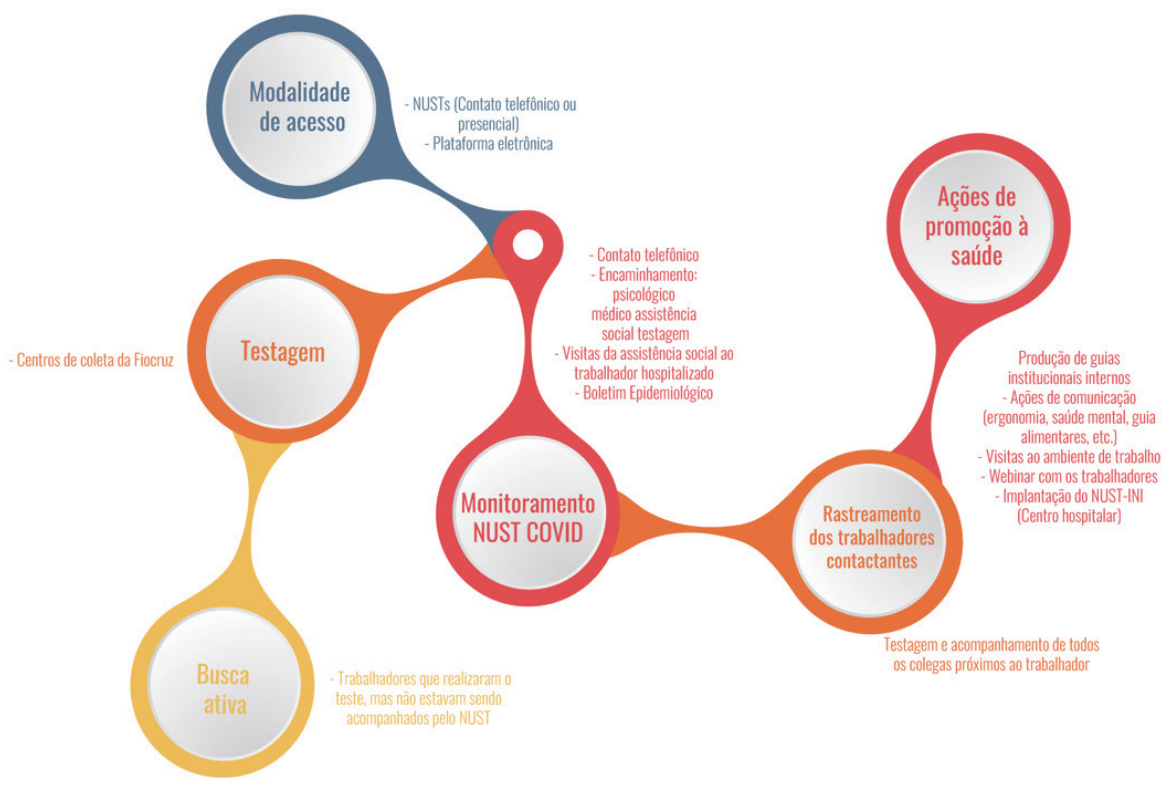

A experiência de testagem de trabalhadores na Fiocruz constituiu uma ferramenta fundamental no conjunto de ações de vigilância da Covid- 19 no trabalho, cujo principal resultado foi garantir a proteção do trabalhador e a manutenção das atividades essenciais na Fiocruz. Há poucos documentos técnicos que levam em consideração as ações de VE no trabalho; um deles, o do Ministério da Saúde (Brasil, 2020f), atribui pouca ênfase à testagem como estratégia de controle da circulação de vírus no trabalho, e somente em dezembro de 2020 o Ministério Público do Trabalho reuniu em uma nota técnica uma série de recomendações sobre medidas de VE nas relações de trabalho. A Fiocruz, no entanto, desde o início da pandemia assumiu a responsabilidade de investir nas condições de trabalho para o funcionamento das suas atividades.

Registrar esse percurso é também o exercício de identificar o que foi eficaz, sem deixar de reconhecer o quanto ainda precisará ser inventado, atualizado ou modificado. Esperamos igualmente contribuir com essas experiências para que outras instituições/ organizações, públicas ou privadas, tenham, no enfrentamento da pandemia da Covid-19, como valor primordial o cuidado com sua força de trabalho. 
Assim, é possível elencar, resumidamente, algumas recomendações para a construção de um plano de contingência em ST:

- Garantia de segurança para a saúde dos trabalhadores nos postos de trabalho;

- Apoio à saúde mental dos trabalhadores que retornam ao trabalho presencial e daqueles que trabalharão remotamente;

- Desenvolvimento de iniciativas voltadas para a sustentabilidade dos serviços;

- Manutenção de regras de distanciamento social adequadas;

- Execução de plano de vigilância em saúde com acesso suficiente aos testes e à atenção à saúde dos doentes e contactantes;

- Fortalecimento de ações de comunicação interna para transparência na gestão das constantes mudanças (Fiocruz, 2020d).

Em cada uma dessas iniciativas voltadas para a VST houve o esforço por se reinventar e buscar o menor impacto possível no enfrentamento da nova realidade imposta pela pandemia. Em todas as ações, há o compromisso de fazer o melhor possível. Há conquistas, como as já citadas neste capítulo, mas também frustrações. A pandemia evidencia a imensa desigualdade social do sistema econômico perverso que produz enorme sobrecarga de iniquidades sociais, refletidas em doenças e mortes precoces, em especial de trabalhadores. Um vírus colocou em evidência que algo ia muito mal em nossa casa planetária, essencial à sobrevivência da humanidade. Expôs o sistema excludente, perverso e insustentável, no caso do Brasil, com o agravante do desgoverno que prevalece. Resta saber se seremos capazes de interpretar as mutações em curso, diante do desafio de reinventar a política, a democracia e a cidadania.

Agradecemos a importante colaboração da equipe da ST da Cogepe/Fiocruz e de todos os parceiros que viabilizaram a realização do trabalho aqui relatado.

\section{REFERÊNCIAS}

BRASIL. Ministério da Saúde. Portaria n. 1.823, de 23 ago. 2012. Institui a Política Nacional de Saúde do Trabalhador e da Trabalhadora. Diário Oficial da União, Brasília, 20 I2, Ano CXLIX, n. I65. Seção I, p. 46-5I.

BRASIL. Ministério da Saúde/GM. Portaria n. 5, de 28 set. 201 7. Consolidação das normas sobre as ações e os serviços de saúde do Sistema Único de Saúde. Anexo LXXIX, Instrução Normativa de Vigilância em Saúde do Trabalhador no SUS (Origem: PRT MS/GM 3120/I998, Anexo I). Diário Oficial da União, Brasília, 20I7a. (Suplemento ao n. 190, de 03 out. 20I7, p. 498-50I). Disponível em: < http://bvsms. saude.gov.br/bvs/saudelegis/gm/20 I7/prc0005_03_I0_20I7.html>. Acesso em: 4 jan. 202 I. 
BRASIL. Ministério do Planejamento, Desenvolvimento e Gestão. Subsistema Integrado de Atenção à Saúde do Servidor. Manual de Perícia Oficial em Saúde do Servidor Público Federal. 3. ed. Brasília: Ministério do Planejamento, Desenvolvimento e Gestão, 2017b.

BRASIL. Ministério Público do Trabalho. Nota técnica GT Covid-I9 n. 20/2020, dez. 2020a. Disponível em: <www.conjur.com.br/dl/mpt-emite-nota-tecnica-considera-covid.pdf>. Acesso em: 3 jan. 202 I.

BRASIL. Ministério da Saúde. Orientações de Vigilância Epidemiológica da Covid-19 Relacionada ao Trabalho. Brasília: Ministério da Saúde, 2020b. Disponível em: <https://docs.bvsalud.org/ biblioref/2020/08/I I I6664/covid-orienta-es-trabalho.pdf>. Acesso em: 3 jan. 202 I.

BRASIL. Ministério Público do Trabalho. Recomendação n. I - PGT/GT Covid- I9, 21 mar. 2020c. Disponível em: < https://mpt.mp.br/pgt/noticias/recomendacao_atestados-3.pdf>. Acesso em: 5 mar. 2020.

BRASIL. Ministério da Economia. Secretaria Especial de Desbucrotização, Gestão e Governo Digital. Secretaria de Gestão e Desempenho de Pessoal. Instrução normativa n. 19, de 12 mar. 2020d. Diário Oficial da União, Brasília, I 3 mar. 2020, edição 50. Seção I, p. 13.

BRASIL. Ministério da Economia. Secretaria Especial de Desbucrotização, Gestão e Governo Digital. Secretaria de Gestão e Desempenho de Pessoal. Instrução normativa n. 27, de 25 mar. 2020e. Diário Oficial da União, Brasília, 26 mar. 2020, edição 59, seção I, p. 43.

BRASIL. Biblioteca Virtual em Saúde do Ministério da Saúde - BVS MS. Orientações de vigilância epidemiológica da covid- 19 relacionada ao trabalho. Brasília, 2020f. Disponível em: <covid-orientaes-trabalho.pdf (bvsalud.org) >. Acesso em: 2 set. 2020.

BRASIL. Congresso Nacional. Medida provisória n. 927. Brasília, 2021. Disponível em: https://www. congressonacional.leg.br/materias/medidas-provisorias/-/mpv/I4I I 45 Acesso em: 2 I jul. 202 I.

FUNDAÇÃO OSWALDO CRUZ (FIOCRUZ). Plano de Contingência da Fiocruz diante da pandemia da doença pelo Sars-CoV-2 (Covid-19), mar. 2020a. Disponível em: <https://portal.fiocruz.br/sites/ portal.fiocruz.br/files/documentos/plano_de_contigencia_covid I 9_fiocruzvl.4.pdf >. Acesso em: 4 jan. 2021.

FUNDAÇÃO OSWALDO CRUZ (FIOCRUZ). CST: Emissão de Comunicação de Acidente de Trabalho para Trabalhadores que contraíram o Coronavírus (Covid-19) em decorrência de suas atividades laborais, jul. 2020b. Disponível em: <https://portal.fiocruz.br/sites/portal.fiocruz.br/files/ documentos/documento_st_._cat._covid- 19._julho.2020_final.pdf>. Acesso em: 10 jul. 2020.

FUNDAÇÃO OSWALDO CRUZ (FIOCRUZ). Coordenação de Saúde do Trabalhador. Boletim Epidemiológico, n. 13, 17 nov. 2020c. Disponível em: <https://portal.fiocruz.br/noticia/fiocruzdivulga-o-volume-13-do-boletim-epidemiologico-da-covid-19>. Acesso em: 2 jan. 2021.

FUNDAÇÃO OSWALDO CRUZ (FIOCRUZ). As operações da Fiocruz no contexto da pandemia e a gestão das medidas de restrição. Documento do Conselho Deliberativo da Fiocruz. Versão junho 2020d.

FUNDAÇÃO OSWALDO CRUZ (FIOCRUZ). Agência Oficial de Notícias - Covid- I9. (Semana 20 a 24/04), 30 abr. 2020e. Disponível em: <www.youtube.com/watch?v=8NR7eJ-xG5w>. Acesso em: 4 jan. 2021.

FUNDAÇÃO OSWALDO CRUZ (FIOCRUZ). Coordenação de Saúde do Trabalhador. Plataforma eletrônica para notificação. Disponível em: < https://nustcovid I 9.fiocruz.br/user/login > . Acesso em: 3 jan. 202 Ia. 
FUNDAÇÃO OSWALDO CRUZ (FIOCRUZ). Coordenação de Saúde do Trabalhador. Orientações para o cuidado e autocuidado em saúde mental dos trabalhadores da Fiocruz. Disponível em: < https://portal. fiocruz.br/sites/portal.fiocruz.br/files/documentos/cartilha_cogepe_saude-mental_2020-05-I4. pdf >. Acesso em: 4 jan. 202 lb.

FUNDAÇÃO OSWALDO CRUZ (FIOCRUZ). Ações de cuidado e promoção à saúde do trabalhador. Disponível em: <https://portal.fiocruz.br/documentos-para-comunidade-fiocruz>. Acesso em: 4 jan. 202 IC.

FUNDAÇÃO OSWALDO CRUZ (FIOCRUZ). Relatório do questionário de avaliação sobre os hábitos de saúde dos trabalhadores durante a pandemia. Disponível em: < https://portal.fiocruz.br/sites/portal. fiocruz.br/files/documentos/relatorio_final_questionario_nasa.pdf>. Acesso em: 4 jan. $202 \mathrm{ld}$.

FUNDAÇÃO OSWALDO CRUZ (FIOCRUZ). Guia de Orientações da Saúde do Trabalhador/Cogepe: plano de convivência com orientação dos trabalhadores e trabalhadoras sobre as novas condições e configurações do trabalho. Disponível em: <https://portal.fiocruz.br/sites/portal.fiocruz.br/files/documentos/guia de_orientacoes_da_saude_do_trabalhador_cogepe.pdf > . Acesso em: 4 jan. 202 le.

FUNDAÇÃO OSWALDO CRUZ (FIOCRUZ). Plano de Ação de Saúde do Trabalhador do Centro Hospitalar INI/Fiocruz. Disponível em: <https://portal.fiocruz.br/sites/portal.fiocruz.br/files/documentos/ plano_de_acao_covid I9_28.04_final_capa_I_I.pdf > . Acesso em: 4 jan. 202 If.

FUNDAÇÃO OSWALDO CRUZ (FIOCRUZ). Biblioteca Virtual de Saúde (BVS). Disponível em: < https:// bvsfiocruz.fiocruz.br/fi-multimedia >. Acesso em: 4 jan. $202 \mathrm{lg}$.

FUNDAÇÃO OSWALDO CRUZ (FIOCRUZ). Página oficial da Fiocruz no Facebook. Disponível em: $<w w w . f a c e b o o k . c o m / o f i c i a l f i o c r u z />$. Acesso em: 4 jan. $202 \mathrm{lh}$.

FUNDAÇÃO OSWALDO CRUZ (FIOCRUZ). Página oficial da Fiocruz no Instagram. Disponível em: <www.instagram.com/oficialfiocruz/?hl=pt-br>. Acesso em: 4 jan. $202 \mathrm{li}$.

FUNDAÇÃO OSWALDO CRUZ (FIOCRUZ). Perfil oficial da Fundação Oswaldo Cruz (Ministério da Saúde) no Twitter. Disponível em: <https://twitter.com/fiocruz>. Acesso em: 4 jan. $202 \mathrm{lj}$.

HARRIS, P. A. et al. Research Electronic Data Capture (REDCap): a metadata-driven methodology and workflow process for providing translation al research informatics support. Journal of Biomedical Information, 42(2): 377-38I, 2009. Disponível em: <www.sciencedirect.com/science/article/pii/ SI532046408001226>. Acesso em: 13 dez. 2020.

HARRIS, P. A. et al. REDCap Consortium, The REDCap Consortium: building an international community of software partners. Journal of Biomedical Information, 95, 20 I 9. Disponível em: <www.sciencedirect. com/science/article/pii/S I 53204641930 I 26I ?via\%3Dihub>. Acesso em: 13 dez. 2020.

MAENO, M. \& CARMO, J. C. A Covid- I 9 é uma doença relacionada ao trabalho. Disponível em: <www. ensp.fiocruz.br/portal-ensp/informe/site/arquivos/ckeditor/files/A\%20COVID\%20\%C3\%89\%20 DOEN\%C3\%87A\%20OCUPACIONAL\%20I50520\%20(I).pdf>. Acesso em: I3 dez. 2020.

MATTOS, R. A. Os sentidos da integralidade: algumas reflexões acerca de valores que merecem ser defendidos. In: PINHEIRO, R. \& MATTOS, R. A. (Orgs.). Os Sentidos da Integralidade na Atenção e no Cuidado à Saúde. Rio de Janeiro: IMS/Uerj, Abrasco, 2006. 
MENDES, A. et al. (Orgs.). Diálogos sobre Acessibilidade, Inclusão e Distanciamento Social: territórios existenciais na pandemia. Rio de Janeiro: Ensp/Fiocruz, IdeiaSUS, UFG, 2020. Disponível em: <www. arca.fiocruz.br/handle/icict/42296>. Acesso em: jan. 2021.

PINHEIRO, R. Cuidado em saúde. In: PEREIRA, I. B. E LIMA, J. C. F. Dicionário da Educação Profissional em Saúde. 2. ed. rev. ampl. Rio de Janeiro: EPSJV/Fiocruz, 2008.

SANTOS, B. S. A Cruel Pedagogia do Vírus. Coimbra: Edições Almedina, 2020. 


\title{
Retorno às Atividades Escolares no Brasil em Vigência da Pandemia Covid-19
}

\author{
André Reynaldo Santos Périssé, Patricia Canto Ribeiro e \\ Hermano Albuquerque de Castro
}

D ados das Nações Unidas de agosto de 2020 indicavam que a pandemia de SarsCoV-2, iniciada no final de 2019, afetava no meio de abril de 2020 cerca de 1,6 bilhão de estudantes em mais de 190 países e todos os continentes, chegando a $99 \%$ de impacto em países de baixa e média rendas (UN, 2020). No mesmo documento se afirma, ainda, que o impacto pode ser geracional a longo prazo, anulando décadas de progresso educacional, e resultar em abandono ou falta de acesso à escola adicional de quase 24 milhões de crianças e jovens em 2021, ampliando ainda mais a disparidade entre os países ricos e aqueles periféricos.

Segundo o Fundo das Nações Unidas para a Infância (Unicef), as crianças podem se tornar vítimas invisíveis da pandemia (Unicef, 2020a). Aspectos como disparidades no acesso à internet, na disponibilidade de computador pessoal e no acesso à água corrente, insegurança alimentar e violência doméstica são fatores importantes que ampliam a vulnerabilidade infantil na pandemia. Dados do Unicef para o Brasil indicam que $48 \%$ dos lares no país possuem acesso à internet e que 52\% têm computador. $61 \%$ das escolas no país possuem serviços básicos de higiene instalados, em 35\% delas o acesso a esses serviços é classificado como limitado e 4\% não possuem nenhum serviço de higiene. Os dados indicam ainda que, ao passo que $96 \%$ das crianças em idade para a escola primária estão matriculadas, esses números caem para $87 \%$ nas faixas etárias iniciais e para 70\% nas idades finais da escola secundária. Tais informações representam um claro desafio ao já deficitário e desigual quadro educacional brasileiro.

O debate sobre o retorno às atividades escolares é fundamental e deve ser priorizado nas discussões públicas. Sabe-se que não é uma discussão simples, dado que vários fatores relacionados ao impacto das crianças e adolescentes na disseminação do vírus 
ainda não estão completamente elucidados (Couzin-Frankel, Vogel $\&$ Weiland, 2020). Qual a real probabilidade de uma criança adquirir ou transmitir o Sars-CoV-2 dentro e fora do ambiente escolar? Há alguma diferença no papel das crianças de acordo com as faixas etárias? As escolas são responsáveis pelo espalhamento do vírus nos territórios onde estão inseridas? As evidências científicas relacionadas a esses e a outros fatores ainda são poucas e conflitantes (Heald-Sargent et al., 2020; Leeb et al., 2020; PanovskaGriffiths et al., 2020; Stage et al., 2020). Entretanto, sabe-se que, no mundo, o controle comunitário da infecção e medidas como higiene pessoal, distanciamento físico e uso de máscaras no ambiente escolar foram fundamentais e indispensáveis para todas as experiências de sucesso de retorno seguro às aulas (Vozes da Educação, 2020).

\section{PANORAMA EPIDEMIOLÓGICO}

No fim de semana de 12-13 de dezembro de 2020, o mundo chegará à marca de 70 milhões de casos da infecção pelo Sars-CoV-2 e mais de 1,6 milhão de mortes (WHO, 2020a). Mais de 50 milhões de casos e 1,3 milhão de óbitos estão concentrados em apenas duas das seis regiões que fazem parte da Organização Mundial da Saúde (OMS): Américas (43\% e 49\%, respectivamente) e Europa (32\% e 30\%, respectivamente). Estados Unidos da América do Norte, EUA (15.404.889 casos e 290.133 óbitos), Índia (9.826.775 casos e 142.628 óbitos) e Brasil (6.781.799 casos e 179.765 óbitos) representavam, juntos, $46 \%$ dos casos e $38 \%$ dos óbitos registrados no mundo. No Brasil, São Paulo é o estado com o maior número de casos $(n=1.333 .763 / 20 \%)$ e óbitos $(n=43.971 / 25 \%)$, seguido por Minas Gerais $(n=464.545 / 6,9 \%)$, Bahia ( $n=443.465 / 6,5 \%)$ e Santa Catarina $(426.095 / 6,3 \%)$ em número de casos e pelo Rio de Janeiro ( $n=23.7$ I8/13,1\%) em número de óbitos (Conass, 2020).

Vários dados coletados ao redor do mundo têm demonstrado que tanto a infecção quanto a evolução com gravidade de óbito são distribuídos de forma desigual conforme algumas variáveis. Assim, pessoas do sexo masculino, da raça negra e grupos vulneráveis como moradores de favelas e indígenas têm maior risco de adquirir a doença, ao passo que idosos e pessoas com comorbidades têm maior risco de evoluir com gravidade e óbito (Angelo et al., 2020a; Angelo et al., 2020b; Cobre et al., 2020; Peckham et al., 2020; Williamson et al., 2020). Por outro lado, por uma razão ainda pouco compreendida, os percentuais de contágio e óbito entre as crianças têm se mantido baixos quando comparados com os de outras faixas etárias. A Academia Americana de Pediatria dos EUA compilou dados e resumiu as informações públicas de 49 estados e quatro cidades e indicou que as crianças representavam I $2 \%(n=1.460 .905)$ dos casos notificados no boletim de 03/12/2020 e que tal número representava um aumento de 
$23 \%$ ao longo de duas semanas, observando que a definiç̧ão de criança varia entre os estados, podendo indicar desde indivíduos de 0-14 até pessoas de 0-20 anos (AAP, 2020). Em relação aos dados de internação, por sua vez, as crianças representavam entre 1 , I \% e 3\% do total de hospitalizações no país, sendo que até $5 \%$ das crianças com Covid- 19 necessitaram de internação, com menos de 0,23\% de mortes. Dados da França para a semana epidemiológica (SE) 49 indicavam uma taxa de incidência de 52 por 100 mil para crianças entre 0 e 14 anos, dado que representava redução de $12 \%$ em relação à SE 48 (France, 2020). No continente sul-americano, a Argentina voltou a reduzir o número total de casos notificados, e em I 2/12/2020 contava com 1.489.328 casos da Covid- 19 confirmados, sendo apenas 2,7\% entre crianças com 0-9 anos, 5,8\% para indivíduos com idades entre 10 e 19 anos, sendo que apenas 0,3\% dos 40.606 óbitos notificados ocorreram na faixa etária de 0-19 anos (Argentina, 2020).

A baixa ocorrência de casos e óbitos parece ser também a regra em estados e municípios do Brasil. No estado de São Paulo $(n=1.333 .763), 2,5 \%$ dos casos notificados ocorreram em crianças com até 9 anos e 5\% entre aquelas com 10-19 anos. Dos 43.97 I óbitos, apenas 0,1\% ocorreu em crianças com até 9 anos e 0,2\% entre aquelas com 10-19 anos. A cidade de São Paulo apresentou, para o mesmo período, informações similares para seus 371.468 casos e 14.944 óbitos (São Paulo, 2020). Para a cidade do Rio de Janeiro, há dados disponíveis apenas para o número de casos e, entre os 151.210 casos notificados até 12/12/2020, 1,2\% ocorreu em crianças até 9 anos e 2,4\% em crianças de 10 - 19 anos (Rio de Janeiro, 2020). Outros dois estados brasileiros bastante impactados pela Covid-19. Amazonas e Ceará, apresentam dados semelhantes. O Amazonas apresenta, entre seus 185.932 casos notificados, 3,6\% de casos entre meninos com até 5 anos e 2,6\% entre meninas; 2,3\% entre meninos e 2\% (meninas) para a faixa etária de 5-9 anos; e 6,7\% (meninos) e 7,9\% (meninas) para aqueles entre 10-19 anos, sendo os óbitos menores que 1\% nas três faixas etárias em meninos e meninas (FVS, 2020). O estado do Ceará apresentou 2,2\% dos seus 315.328 casos confirmados entre crianças de 0-4 anos, I,8\% entre 5 e 9 anos e 2,3\% para pessoas entre 10 e 14 anos, tendo os óbitos para as três faixas etárias indicadas ficado abaixo de 0,5\% (Ceará, 2020). O último dado nacional de soroprevalência disponível coletado pela Universidade de Pelotas indicou a prevalência de 2,2\% para crianças entre 0 e 4 anos, de 1,9\% para aquelas entre 5 e 9 anos e de 0,9\% para a faixa etária de 10 a 19 anos (UFPel, 2020). 


\section{INFORMAÇÕES SOBRE ISOLAMENTO E CONTÁGIO}

\section{Índice de isolamento no Brasil}

O índice de isolamento tem sido utilizado para avaliar as políticas públicas não farmacológicas definidas para manter as pessoas em casa, com orientação sobre quais atividades são essenciais para reduzir casos e morte por Covid-19. Durante a primeira onda na Europa e em outros países que adotaram a política de bloqueio parcial ou total, conhecido como lockdown, estes mantiveram esse índice acima de 70\%, por período suficiente capaz de diminuir os impactos da pandemia. No Brasil, nunca atingimos esse índice; tivemos nosso pico de isolamento social em 22/03/2020, com índice de 62,2\%, e ficamos a maior parte do tempo abaixo de $50 \%$, na média, o que significa funcionamento de atividades consideradas não essenciais contribuindo para aumento de casos e óbitos. A Figura I contém os índices de isolamento social no Brasil, ao longo da pandemia (Inloco, 2020).

Figura I - Índice de isolamento social no Brasil até 22 fev. 2021

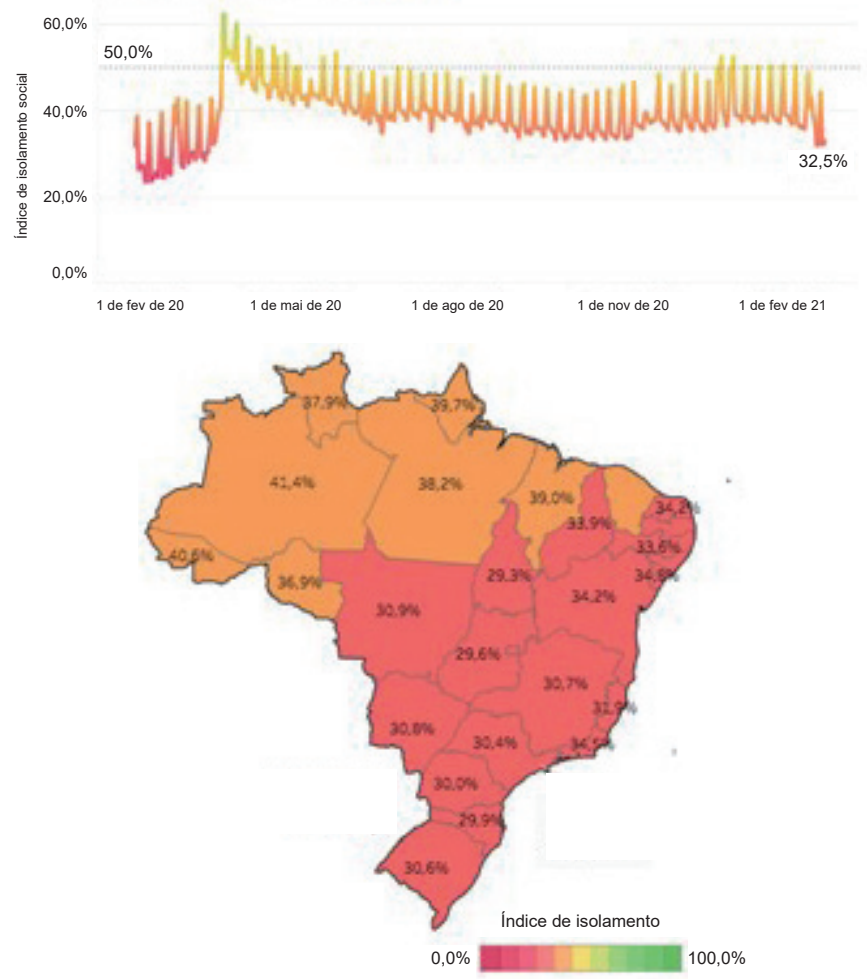

Fonte: Inloco, 2020. 


\section{TAXA DE CONTÁGIO NO BRASIL}

Um indicador utilizado para avaliar a taxa de contágio pelo vírus SarsCoV-2 da Covid-19 é o $R_{0}$ ( $R$ zero) ou número básico de reprodução. O $R_{0}$ mede a transmissibilidade do agente infeccioso e seu valor informa quantas pessoas podem ser contaminadas a partir de uma ou mais pessoas infectadas; de acordo com os especialistas da OMS, I pessoa é capaz de infectar entre 2 e 3 outras. As políticas de distanciamento social servem para reduzir essa taxa de contágio. Estudos mostram que medidas de distanciamento suficientemente fortes e robustas podem controlar com mais eficácia a transmissão e o contágio da Covid- 19 (Anderson et al., 2020). O cálculo do $\mathrm{R}_{0}$ leva em consideração o fato de a população não estar vacinada, o número de infectados e casos em dado momento. Uma das suas limitações metodológicas está na presença de subnotificação e na baixa testagem no país.

$\mathrm{O}$ valor de $\mathrm{R}_{\mathrm{t}}$ indica taxa de contágio em uma região; o ideal é que esteja abaixo de 0,5 . Quanto maior o valor, maior será a chance de contágio. Valores acima de I mostram que a região está com contágio ascendente e abaixo de I, que a curva de contágio está descendente. A Figura 2 mostra a comparação do valor de $\mathrm{R}_{\mathrm{t}}$ entre os estados, do melhor para o pior (Loft, 202I).

Figura 2 - Valor de $\mathrm{R}_{\mathrm{t}}$ entre os estados brasileiros, dados de 22 fev. 2021

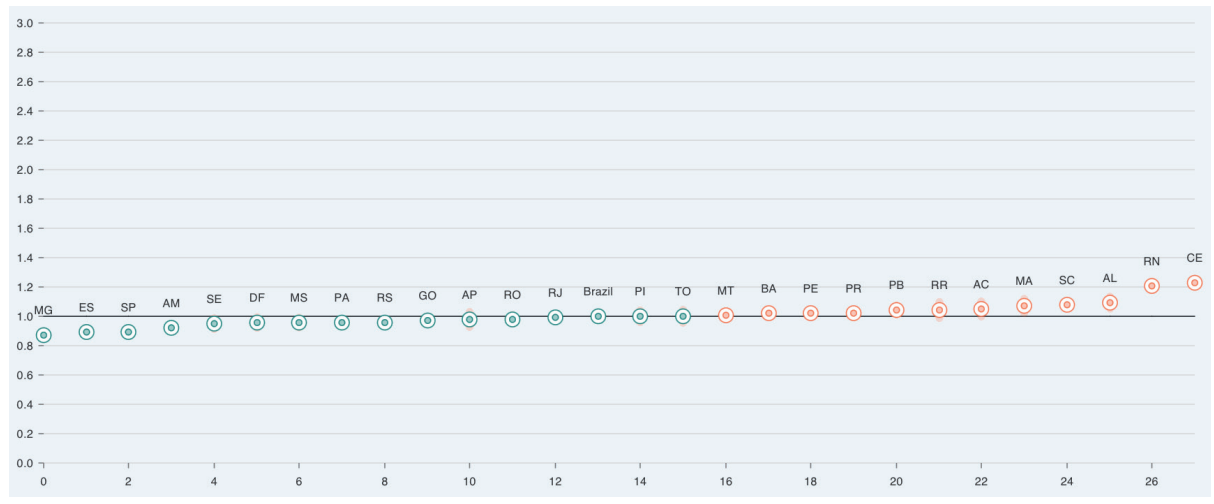

Fonte: Loft, 2021.

Nos dez meses de pandemia no Brasil, poucos foram os períodos em que estivemos com $\mathrm{R}_{\mathrm{t}}$ abaixo de $\mathrm{I}$, e não conseguimos atingir valores abaixo de 0,5 , o que revela a manutenção da pandemia em níveis longe do aceitável, como aconteceu em vários países, após a primeira onda. 


\section{INDICADORES DE RETORNO ÀS ATIVIDADES ESCOLARES}

No momento de recrudescimento da pandemia é necessário reavaliar cada indicador e tomá-los como orientadores para restringir flexibilizações autorizadas anteriormente. A OMS e a Organização das Nações Unidas para a Educação, a Ciência e a Cultura (Unesco) recomendam a adoção de alguns critérios no planejamento da retomada das atividades escolares e alertam que a diminuição de casos e mortes pela Covid- 19 não é o único indicador para retorno das atividades em geral nos países. Por isso, é necessária a construção de um conjunto de indicadores para orientar o retorno dessas atividades. No Brasil, utilizamos os indicadores construídos e orientados pelo Conselho Nacional de Secretários de Saúde (Conass) e o Conselho Nacional de Secretarias Municipais de Saúde (Conasems), sobre taxa de ocupação de leitos, taxa de positividade de RT-PCR na população e outros (Conasems, 2020).

\section{INDICADORES DE SAÚDE PARA CONTROLE DA PANDEMIA COVID-19 E RETORNO ÀS AULAS}

I. Redução da transmissão comunitária: número de casos novos por dia por 100 mil habitantes, nos últimos 7 dias (Quadro I).

2. Indicadores de medidas sanitárias a serem implementadas nas escolas (Quadro 2).

3. Taxa de contágio - valor de $\mathrm{R}<\mathrm{I}$ (ideal 0,5) por um período de pelo menos 7 dias.

4. Disponibilidade de leitos clínicos e leitos de UTI, na faixa de 25\% livres (Faixa verde - Conass/Conasems).

5. Redução de $20 \%$ ou mais em número de óbitos e casos de síndrome respiratória aguda grave (Srag) na última SE finalizada em relação à antepenúltima SE (Faixa verde - Conass Conasems).

6. Taxa de positividade para Covid- 19 menor que 5\% - número de positivos/número de amostras para Sars-CoV-2 realizadas em determinado período.

7. Porcentagem de testes positivos de RT-PCR na comunidade durante os últimos 7 dias.

8. Capacidade para detectar, testar (RT-PCR), isolar e monitorar pacientes/contactantes. Diagnosticar pelo menos 80\% dos casos no município ou território. Este indicador se relaciona diretamente com a rede do Sistema Único de Saúde (SUS) e com o investimento necessário na Atenção Primária à Saúde (APS) e no nível de atenção especializada e hospitalar para atender com qualidade a população. 
Quadro I - Indicadores de casos, positividade de RT-PCR

\begin{tabular}{|l|c|c|c|c|}
\hline \multicolumn{1}{|c|}{ Indicadores } & $\begin{array}{c}\text { Baixo risco } \\
\text { de transmissão } \\
\text { nas escolas }\end{array}$ & $\begin{array}{c}\text { Risco moderado } \\
\text { de transmissão } \\
\text { nas escolas }\end{array}$ & $\begin{array}{c}\text { Elevado risco } \\
\text { de transmissão } \\
\text { nas escolas }\end{array}$ & $\begin{array}{c}\text { Elevadíssimo risco } \\
\text { de transmissão } \\
\text { nas escolas }\end{array}$ \\
\hline $\begin{array}{l}\text { Número de novos } \\
\text { casos por 100 mil } \\
\text { habitantes nos } \\
\text { últimos 7 dias* }\end{array}$ & $0-9$ & $10-49$ & $50-99$ & $>100$ \\
\hline $\begin{array}{l}\text { Porcentagem de } \\
\text { testes RT-PCR } \\
\text { positivos nos } \\
\text { últimos 7 dias** }\end{array}$ & $<5 \%$ & $5 \%$ a $7,9 \%$ & $8 \%$ a $9,9 \%$ & $\geq 10 \%$ \\
\hline
\end{tabular}

Fonte: CDC, 2020a.

* O número total de novos casos por 100 mil pessoas nos últimos 7 dias é calculado adicionando-se o número de novos casos nos últimos 7 dias dividido pela população e o multiplicando por 100 mil.

** A porcentagem de RT-PCR de diagnóstico e triagem positivos durante os últimos 7 dias é calculada dividindo-se o número de testes positivos durante os últimos 7 dias pelo número total de testes resultantes nos últimos 7 dias.

\section{Quadro 2 - Indicadores de medidas sanitárias para as escolas}

\begin{tabular}{|c|c|c|c|c|c|}
\hline Indicadores & $\begin{array}{c}\text { Baixíssimo risco } \\
\text { de transmissão } \\
\text { nas escolas }\end{array}$ & $\begin{array}{c}\text { Baixo risco } \\
\text { de transmissão } \\
\text { nas escolas }\end{array}$ & $\begin{array}{c}\text { Risco moderado } \\
\text { de transmissão } \\
\text { nas escolas }\end{array}$ & $\begin{array}{c}\text { Elevado risco } \\
\text { de transmissão } \\
\text { nas escolas }\end{array}$ & $\begin{array}{l}\text { Elevadíssimo } \\
\text { risco de } \\
\text { transmissão } \\
\text { nas escolas }\end{array}$ \\
\hline $\begin{array}{l}\text { Capacidade da escola } \\
\text { para implementar } 5 \\
\text { estratégias principais } \\
\text { de mitigação: } \\
\text { - Uso correto e } \\
\text { constante de } \\
\text { máscaras } \\
\text { - Distanciamento } \\
\text { social o máximo } \\
\text { possível } \\
\text { - Higiene respiratória e } \\
\text { - das mãos } \\
\text { - Limpeza e } \\
\text { desinfecção } \\
\text { - Rastreamento } \\
\text { - de contato em } \\
\text { colaboração com } \\
\text { departamentos de } \\
\text { saúde locais }\end{array}$ & $\begin{array}{c}5 \\
\text { estratégias } \\
\text { implementadas } \\
\text { de forma correta } \\
\text { e constante }\end{array}$ & $\begin{array}{c}5 \\
\text { estratégias foram } \\
\text { implementadas } \\
\text { corretamente, } \\
\text { mas de forma } \\
\text { inconsistente }\end{array}$ & $\begin{array}{c}3-4 \\
\text { estratégias foram } \\
\text { implementadas } \\
\text { de forma correta } \\
\text { e consistente }\end{array}$ & $\begin{array}{l}\text { 1-2 } \\
\text { estratégias foram } \\
\text { implementadas } \\
\text { de forma correta } \\
\text { e consistente }\end{array}$ & $\begin{array}{l}\text { As estratégias } \\
\text { não foram } \\
\text { implementadas }\end{array}$ \\
\hline
\end{tabular}

Fonte: CDC, 2020a. 


\section{PLANEJAMENTO DE RETORNO ÀS ATIVIDADES PRESENCIAIS NAS ESCOLAS}

Diante da enorme diversidade de cenários epidemiológicos nos estados, municípios e Distrito Federal, o retorno às atividades escolares presenciais requer um planejamento territorializado e que, necessariamente, contemple as participações da saúde, da educação e de toda comunidade escolar. O diálogo com a APS garante a vigilância e a promoção da saúde mais adequadas ao território e pode dar suporte às ações de assistência e, fundamentalmente, compor a participação no plano de retorno às atividades presenciais.

Para manter a comunidade escolar o mais segura possível, as medidas não farmacológicas permanecem como a melhor opção para redução da transmissão da doença.

Na reabertura, a prioridade deve ser a saúde de alunos, dos profissionais da educação e dos familiares de todos (Unicef, 2020b). A avaliação da situação de cada uma das escolas deve incluir a infraestrutura e a condição sanitária, com garantia de fornecimento de água, materiais de higiene e mesmo reformas e adequações com cronogramas definidos. A realidade de muitas de nossas escolas já mostrava nossos desafios nesses quesitos, antes mesmo do início da pandemia, quando até o fornecimento de água era precário em vários territórios.

Segundo as recomendações do Centers for Diseases Control and Prevention (CDC) EUA) apresentadas no Quadro 2 (CDC, 2020a), as escolas devem ser capazes de garantir alguns quesitos, detalhados a seguir.

\section{Estratégias que garantam o correto uso das máscaras por toda a comunidade escolar}

As medidas ditas não farmacológicas, aí incluídas o uso de máscaras, distanciamento social e a adequada higiene das mãos, são, até o momento, a maior arma no combate à infecção pelo Sars-CoV-2, uma vez que sua transmissão ocorre prioritariamente através de gotículas respiratórias e do contato próximo. A infecção por aerossóis ainda está sendo melhor estudada.

O uso de máscaras por toda a comunidade é uma medida de proteção tanto individual quanto coletiva. Para a população em geral, recomenda-se o uso de máscaras de pano, de camada tripla (Jotz \& Bittencout, 2020). É importante que as máscaras sejam utilizadas seguindo-se as recomendações de uso adequado (Mayo Clinic, 2020).

O CDC/EUA não recomenda o uso de máscaras por crianças menores de 2 anos de idade ou por pessoas com algum grau de deficiência ou alteração da consciência que possa prejudicar a capacidade de retirar a máscara sem auxílio. No Reino Unido, crianças 
com menos de I I anos não são obrigadas a usá-las. No Brasil, a lei n. I4.0 I 9/20 prevê que crianças com menos de 3 anos estão dispensadas do uso obrigatório de máscaras (Brasil, 2020).

Segundo a OMS, a orientação para a confecção das máscaras de pano é que tenham pelo menos três camadas de materiais diferentes: uma interna com material absorvente como algodão, uma camada intermediária de materiais não tecidos como polipropileno (filtro) e uma camada externa de material não absorvente, como poliéster ou uma mistura (Opas, 2020).

Pessoas com sintomas gripais não devem frequentar o ambiente escolar e devem comunicar-se imediatamente com o serviço de saúde mais próximo para o devido acompanhamento e o controle dos contatos. As escolas, dentro de seu plano de retorno, devem contemplar o afastamento de casos e suspeitos com o devido processo de vigilância, já organizado na APS.

\section{Distanciamento social}

Distanciamento social ou distanciamento físico significa manutenção de um espaço seguro entre você e outras pessoas que não são de sua casa. Para praticar o distanciamento social ou físico, deve-se manter uma distância de pelo menos 1,5 a $2 \mathrm{~m}$ (cerca de 2 braços de comprimento) de outras pessoas que não sejam de sua casa em espaços internos e externos. $O$ distanciamento social deve ser praticado em combinação com outras ações preventivas cotidianas para reduzir a propagação de Covid-19, incluindo o uso de máscaras, evitando tocar o rosto com as mãos não lavadas e lavando frequentemente as mãos com água e sabão por pelo menos 20 segundos.

Manter a distância mínima de 1,5 a 2 m entre os alunos e entre estes e demais profissionais é considerado ideal para redução dos riscos de infecção. Além disso, é importante garantir a adequada ventilação das salas, evitando o uso do ar-condicionado e privilegiando atividades ao ar livre ou em ambientes abertos. A redução do número de alunos por turmas é necessária, o que implica a necessidade de manutenção de opções de ensino remoto.

Sempre que possível, as refeições devem ser feitas ao ar livre ou nas salas de aula, em vez de em um refeitório comunitário, mantendo-se a distância social (pelo menos I,5 a 2 m de distância) tanto quanto possível (CDC, 2020a). 


\section{Higiene das mãos}

O estímulo à higiene frequente das mãos deve ser adotado. As escolas devem oferecer locais com disponibilização de álcool em gel a $70 \%$ e, fundamentalmente, o fornecimento regular de água e sabão. Crianças pequenas e alunos com deficiência devem receber ajuda para realizar a adequada higiene das mãos (United Kingdom, 2020). A facilidade de acesso aos locais com água e sabão para a lavagem das mãos ou a pontos com álcool em gel é fundamental para o estímulo da higienização regular.

Uma observação importante é a limpeza de cisternas e caixas d'água se as escolas estiverem fechadas por longos períodos, para a prevenção de doenças transmitidas pela água ou da contaminação ambiental por potenciais patógenos após a reabertura da escola (WHO, 2020b).

\section{Limpeza e desinfecção}

No tocante à limpeza e desinfecção, o primordial é contarmos com o fornecimento regular de água para todas as escolas. O uso de sabão e água sanitária é o recomendado para esse processo; o uso de álcool a 70\% também pode ser uma opção para superfícies.

A limpeza reduz germes, sujeiras e impurezas de superfícies ou objetos e funciona com o uso de sabão (ou detergente) e água para a remoção física dos germes de superfícies. Após a limpeza, deve-se proceder à desinfecção, ou seja, à utilização de produtos químicos que matem ou inativem os germes (CDC, 2020b).

Atenção especial deve ser dispensada a locais e objetos de uso comum ou possivelmente compartilhado, como maçanetas e interruptores de luz. Todas as superfícies devem ser limpas pelo menos uma vez ao dia e entre o uso por alunos diferentes ou entre os turnos, antes da chegada à sala dos alunos, antes e após as refeições, antes do retorno dos intervalos (recreio) e ao final do dia.

\section{Rastreamento de contatos em parceria com a equipe de saúde local}

Conforme indicamos no documento Contribuições para o Retorno às Atividades Escolares Presenciais no Contexto da Pandemia Covid-19, o rastreamento por sintomas de casos confirmados ou suspeitos e também de seus contatos é a estratégia recomendada em um contexto onde a realização de testes pode ser um dificultador, ou mesmo impedimento para a vigilância (Fiocruz, 2020). 
Os sintomas mais comuns de Covid-19, até o momento, são: febre, tosse, falta de ar, cefaleia, calafrios, dor de garganta, diarreia, anosmia (perda do olfato) ou hiposmia, ageusia (perda do paladar), mialgia e astenia, de acordo com nota técnica da Anvisa (Anvisa, 2020).

Diante de qualquer um desses sintomas, é importante considerar a possibilidade de Covid-19 e manter as medidas de isolamento, conforme Quadro 2. O contato com o serviço de saúde do território para as medidas de vigilância adequadas e o acompanhamento do caso é fundamental, como também o informe à comunidade escolar para a tomada de decisão conforme o plano elaborado.

No Quadro 3 estão as condutas a serem adotadas em cada uma das situações passíveis de serem consideradas casos suspeitos ou confirmados (Fiocruz, 2020).

\section{Quadro 3 - Vigilância de casos e contatos nas escolas}

\begin{tabular}{|c|c|c|c|}
\hline & \multicolumn{2}{|c|}{$\begin{array}{l}\text { Isolamento de caso de Covid-19 } \\
\text { (suspeito ou confirmado) }\end{array}$} & \multirow{2}{*}{$\begin{array}{l}\text { Isolamento de contato próximo } \\
\text { Isolamento de contato próximo } \\
\text { de caso de Covid- I } 9 \text { (suspeito } \\
\text { ou confirmado) }\end{array}$} \\
\hline & $\begin{array}{l}\text { Isolamento de pessoas } \\
\text { SINTOMÁTICAS }\end{array}$ & $\begin{array}{l}\text { Isolamento de pessoas } \\
\text { ASSINTOMÁTICAS }\end{array}$ & \\
\hline Situação & $\begin{array}{l}\text { Pessoa da comunidade escolar } \\
\text { com sintomas sugestivos de } \\
\text { Covid-19 }\end{array}$ & $\begin{array}{l}\text { Pessoa da comunidade } \\
\text { escolar com teste RTPCR com } \\
\text { Sars-CoV-2 detectado, sem } \\
\text { sintomas e que permanecerem } \\
\text { sem sintomas }\end{array}$ & $\begin{array}{l}\text { Pessoa da comunidade escolar } \\
\text { que teve contato próximo } \\
\text { com alguém com infecção } \\
\text { por Covid- } 19 \text { (suspeita ou } \\
\text { confirmada) nos } 2 \text { dias antes } \\
\text { a } 10 \text { dias depois da data do } \\
\text { início dos sintomas (nos } \\
\text { assintomáticos, da data de } \\
\text { coleta do teste RT-PCR com } \\
\text { Sars-CoV-2 detectado) }\end{array}$ \\
\hline Conduta & $\begin{array}{l}\text { Afastamento das atividades } \\
\text { presenciais da escola; } \\
\text { encaminhamento para } \\
\text { realização de teste RT-PCR e } \\
\text { avaliação de contatos próximos }\end{array}$ & $\begin{array}{l}\text { Afastamento das atividades } \\
\text { presenciais da escola; } \\
\text { encaminhamento para } \\
\text { realização de teste RT-PCR e } \\
\text { avaliação de contatos próximos }\end{array}$ & $\begin{array}{l}\text { Afastamento das atividades } \\
\text { presenciais da escola; } \\
\text { encaminhamento para } \\
\text { realização de teste RT-PCR e } \\
\text { avaliação de contatos próximos }\end{array}$ \\
\hline $\begin{array}{l}\text { Critérios e tempo } \\
\text { para retorno } \\
\text { à atividades } \\
\text { presenciais na escola } \\
\text { após isolamento } \\
\text { (independentemente } \\
\text { da realização do } \\
\text { RT-PCR) }\end{array}$ & $\begin{array}{l}\text { - I0 dias após o aparecimento } \\
\text { dos primeiros sintomas (ou } \\
20 \text { dias quando doença grave } \\
\text { por Covid-19) e } \\
\text { - } 24 \text { horas sem febre, sem o } \\
\text { uso de medicamentos para } \\
\text { baixar a febre e } \\
\text { - Melhora dos sintomas de } \\
\text { Covid-19). }\end{array}$ & $\begin{array}{l}\text { Retorno à escola após I0 dias } \\
\text { desde o dia da coleta do teste } \\
\text { viral para Covid-19 positivo. } \\
\text { Se a pessoa da comunidade } \\
\text { escolar desenvolver sintomas } \\
\text { após o teste RT-PCR com } \\
\text { Sars-CoV-2 detectado, } \\
\text { deverá seguir os critérios } \\
\text { de isolamento descritos no } \\
\text { campo "Isolamento de pessoas } \\
\text { sintomáticas" }\end{array}$ & $\begin{array}{l}\text { Retorno à escola após I } 4 \\
\text { dias desde o último dia } \\
\text { que teve contato próximo } \\
\text { com alguém com infecção } \\
\text { por Covid- I } 9 \text { (suspeita ou } \\
\text { confirmada). Em caso de } \\
\text { sintomas, seguir os critérios } \\
\text { de isolamento descritos no } \\
\text { campo "Isolamento de pessoas } \\
\text { sintomáticas" }\end{array}$ \\
\hline
\end{tabular}

Fonte: Fiocruz, 2020. 


\section{DESAFIOS PARA UM RETORNO PRESENCIAL SEGURO}

Um ponto central para o retorno seguro é a necessidade de um plano estratégico nacional de enfrentamento da pandemia da Covid-19, com políticas públicas bem articuladas entre os entes federativos, nas áreas de saúde, educação, assistência social e trabalho, com participação da sociedade civil organizada na busca de soluções e enfrentamento da desigualdade social.

Como visto aqui, o conhecimento das características locais da circulação do SarsCoV-2 e controle efetivo da pandemia, a implementação de medidas preventivas não farmacológicas como distanciamento físico, uso de máscaras e hábitos de higiene pessoal e a vigilância em saúde são medidas fundamentais para que possamos pensar em um retorno seguro às atividades escolares presenciais. Mesmo com a implementação de tais medidas, não há garantia de um retorno que não venha a gerar casos entre os diferentes atores que fazem parte da comunidade escolar, e por isso uma vigilância bem planejada, integrada com as escolas e atuante é fundamental para o acompanhamento da reabertura e para a rápida tomada de decisões na eventualidade da ocorrência de casos em unidades escolares.

Durante a segunda onda da pandemia no hemisfério Norte, vários países optaram por adotar medidas restritivas, mantendo, entretanto, as escolas abertas, mas em nenhum país tal abertura foi possível sem que as medidas preventivas estivessem implementadas (Frente pela Vida, 2020). Ou seja, para que a reabertura seja possível, é preciso investimento e planejamento em um ambiente escolar distinto do que existia antes da pandemia, onde medidas de redução das turmas, implementação de "coortes" de alunos e maior fixação de professores, uso obrigatório de máscaras e distanciamento físico entre as diversas pessoas que integram a comunidade escolar têm que fazer parte da rotina. A experiência prévia de outros países é essencial para que possamos organizar a volta às aulas presenciais de forma segura, mas não podemos esquecer as peculiaridades e diferenças regionais de um país continental como o Brasil, que sofre com grande desigualdade no acesso à educação e com grande número de escolas com deficiências estruturais que impedem a implementação de medidas para evitar a disseminação do Sars-CoV2. Por isso, é fundamental que comecemos a gerar informações próprias sobre a reabertura das escolas nas diferentes partes do país.

O planejamento para um retorno seguro às atividades escolares não pode ser tarefa apenas da área da saúde e tem que envolver, necessariamente, amplo debate entre todas as áreas evolvidas, seja da esfera pública ou da sociedade civil. Diversos setores das três esferas da gestão pública devem ser envolvidos, como a própria saúde, a educação, a 
assistência social, a área de transportes e a área econômica, entre outros. Sindicatos patronais e dos trabalhadores, representações dos estudantes e dos pais e organizações da sociedade civil que atuem na área da educação têm que participar ativamente das discussões e da implementação dos planos de retorno seguro das atividades escolares.

Embora seja necessária a elaboração de protocolos e planos abrangentes, é importante que sejam feitas adequações respeitando as peculiaridades dos territórios onde as unidades escolares estão inseridas. Isso só será possível se garantida ampla participação dos atores sociais locais, maiores conhecedores das características e desafios que podem assegurar ou impedir a implementação de medidas para um retorno seguro das atividades escolares nos territórios. A implementação de comitês locais que possam, juntamente com setores da educação e da saúde, auxiliar no diagnóstico inicial do território no que diz respeito à estrutura física das unidades escolares, à necessidade de equipamentos de proteção individual, a características da força de trabalho disponível para o retorno, às necessidades pedagógicas das crianças e adolescentes das unidades escolares e ao nível de integração da unidade escolar com a unidade de saúde de referência é fundamental para o sucesso de qualquer plano de retorno às atividades escolares presenciais.

O desafio é muito grande. Planejamentos e discussões já deveriam estar em curso desde o momento em que as escolas foram fechadas no início de 2020, principalmente em razão da conhecida burocracia e lentidão da gestão pública na liberação de financiamento para execução de obras públicas e contratação de pessoal, fundamentais para um retorno seguro. No município do Rio de Janeiro, por exemplo, dados de janeiro de 2021 indicavam a existência de 1.543 unidades escolares em funcionamento, com 644.138 alunos, 39. 178 professores e 13.721 funcionários de apoio administrativo (Rio de Janeiro, 202 la). Ou seja, são cerca de 700 mil pessoas que deverão conviver nas unidades escolares e circular pela cidade ao longo de 202I, isso sem levar em conta as escolas estaduais, prioritariamente de ensino médio, e as escolas privadas. Devemos acrescentar a esses números, ainda, os responsáveis pelas crianças e jovens que deverão circular pela cidade em transportes coletivos.

Dados do Tribunal de Contas do Município do Rio de Janeiro indicavam que, em 2019 , cerca de $70 \%$ das unidades escolares em funcionamento eram consideradas precárias, ou seja, "funcionavam de maneira não satisfatória para o conforto dos alunos e professores, servindo de sinalização para que medidas mais densas por parte da Secretaria Municipal de Educação pudessem ser tomadas" (Rio de Janeiro, 202 l b). Tal percentual passou de $14,4 \%$ em 2008 para $57,9 \%$ em 2017, ao passo que as escolas com condições estruturais consideradas boas passaram de 48,5\% em 2008 para 3,6\% em 2017, variação que indica "uma diminuição drástica que vem ocorrendo ao longo 
dos anos dos recursos destinados às unidades escolares, principalmente, aquele que tem como objetivo dotar a escolas de verbas para uso em sua manutenção" (Rio de Janeiro, $202 \mathrm{Ic}$ ). Esses dados permitem afirmar que há grande número de alunos e profissionais da educação atuando em escolas sem condições ideias de utilização, situação anterior à pandemia que já indicava grande desigualdade no acesso à educação na cidade. A não ser que haja uma opção política clara pelo investimento em educação em 2021, dificilmente conseguiremos solucionar, ou pelo menos minimizar, os problemas estruturais das unidades escolares para que estas tenham condições de implementar medidas de prevenção da disseminação do Sars-CoV-2, como redução da circulação escolar, distanciamento físico e higiene pessoal.

Para que uma vigilância epidemiológica seja efetiva, os sistemas de saúde e educação devem estar perfeitamente integrados, dentro de uma vigilância que pode ser chamada de "vigilância da Covid- 19 nas unidades escolares". Cabe lembrar que a vigilância em saúde é uma tarefa do poder público que está inserida entre as atribuições da APS dentro do SUS brasileiro. A vigilância sanitária deverá ser capaz de orientar e aprovar os protocolos locais das unidades escolares, públicas e privadas, e deverá, juntamente com a vigilância epidemiológica, atuar na prevenção da disseminação do vírus no ambiente escolar e no território em seu entorno, em atividades como detecção precoce dos casos, orientações preventivas e rastreamento de contatos. As coordenadorias regionais de educação e as unidades escolares deverão atuar em estreita cooperação com as coordenadorias de saúde e unidades de APS responsáveis pelos territórios onde estão inseridas as unidades escolares para que o impacto de eventuais casos de Covid- 19 na comunidade escolar seja minimizado.

\section{Desafio para manutenção das aulas presenciais diante da persistência da pandemia}

Desde o início da pandemia os especialistas da Fiocruz se somaram ao conjunto dos cientistas para enfrentar a maior crise sanitária vivida em 2020. O fechamento das atividades econômicas e sociais incluíram, de imediato, o fechamento das escolas em todo o mundo e o início do ensino remoto em larga escala, com enormes consequências e impactos sobre a educação. À medida que o conhecimento sobre a pandemia avançava, os desafios para retorno às aulas presenciais para milhares de alunos foram se desenhando e, nesse contexto, a Presidência da Fiocruz elaborou uma portaria para que um grupo de trabalho (GT) pudesse se dedicar ao tema de retorno às aulas.

De acordo com estudo desenvolvido por Vozes da Educação (2020), os principais pontos comuns aos países que tiveram retorno às aulas de forma satisfatória foram a curva de contágio estável ou decrescente, medidas sanitárias e distanciamento social 
implementados com bons resultados, monitoramento e contenção dos casos isolados, reaberturas faseadas, adoção de políticas específicas para profissionais pertencentes aos grupos de risco e boa comunicação, com transparência, das políticas governamentais. Entre os países com reabertura satisfatória, a maioria reabriu as escolas antes ou no mesmo momento da reabertura das atividades econômicas, mas sempre com controle da pandemia.

Possivelmente, 2022 ainda será um ano de grandes desafios para a educação. A vacinação não pode ser encarada como condição para o retorno das atividades presenciais plenas e o contexto epidemiológico deve ser o norteador para a reabertura.

Deve-se considerar o retorno às aulas como atividade essencial e, para isso, é necessário um planejamento entre a saúde e a educação. Esse planejamento deve ser interdisciplinar e participativo, incluindo toda a comunidade escolar. Para que a abertura das escolas no ano de 2021 possa ocorrer, todo esforço e planejamento deve ser envidado imediatamente.

As atitudes assumidas neste momento mostrarão às futuras gerações como enfrentamos uma das maiores crises sanitárias da humanidade e o que foi considerado por nós como essencial para reduzirmos as inúmeras perdas a que fomos submetidos ao longo de 2020. Reduzir o contágio por meio das medidas de controle como uso de máscaras, lavagem das mãos e distanciamento social, vigilância epidemiológica e políticas públicas territorializadas está em nossas mãos, só nos resta agir e reagir.

Nosso agradecimento especial aos membros do GT instituído pela portaria n. 5.608 de I de setembro de 2020, que elaborou o documento Contribuições para o Retorno às Atividades Escolares Presenciais no Contexto da Pandemia de Covid-19: Adriana Coser Gutiérrez (Vice-Presidência de Educação, Informação e Comunicação), Ana Cristina Garcia Ferreira (Gerência Regional de Brasília), Ingrid D’Avilla Freire Pereira (Escola Politécnica de Saúde Joaquim Venâncio) e, do Instituto Nacional de Saúde da Mulher, da Criança e do Adolescente Fernandes Figueira, Lívia Almeida de Menezes, Márcio Fernandes Nehab e Maria Martha Duque de Moura. 


\section{REFERÊNCIAS}

AGÊNCIA NACIONAL DE VIGILÂNCIA SANITÁRIA (ANVISA). Nota técnica n. 04-2020 GVIMS-GGTESAnvisa atualizada. Disponível em: <www.gov.br/anvisa/pt-br/centraisdeconteudo/publicacoes/ servicosdesaude/notas-tecnicas/nota-tecnica-gvims_ggtes_anvisa-04_2020-25-02-para-o-site. pdf/@@download/file/NOTA\%20TECNICA\%20GVIMS_GGTES_ANVISA\%2004_2020\%20-\%20 25.02.pdf>. Acesso em: 20 set. 2021.

AMERICAN ACADEMY OF PEDIATRICS (AAP). Children and Covid-19: state-level data report (Critical updates on Covid- 19). Disponível em: <https://services.aap.org/en/pages/2019-novel-coronavirusCovid-19-infections/children-and-Covid-19-state-level-data-report/>. Acesso em: 12 dez. 2020.

ANDERSON, S. C. et al. Quantifying the impact of Covid-19 control measures using a Bayesian model of physical distancing. PLoS Computational Biology, I6(I2): el 008274, 2020. Disponível em: <https:// journals.plos.org/ploscompbiol/article?id=10.137 I/journal.pcbi. I008274 >. Acesso em: 20 set. 2021 .

ANGELO, J. R. et al. 2. Boletim Socioepidemiológico da Covid-19 nas Favelas: análise da frequência, incidência, mortalidade e letalidade por Covid-19 em favelas cariocas, n. 2, 2020a. Disponível em: $<w w w . a r c a . f i o c r u z . b r / h a n d l e / i c i c t / 44450>$. Acesso em: 13 dez. 2020.

ANGELO, J. R. et al. Boletim Socioepidemiológico da Covid-I9 nas Favelas: análise da frequência, incidência, mortalidade e letalidade por Covid-19 em favelas cariocas, n. 01, 2020b. Disponível em: <www.arca.fiocruz.br/handle/icict/42662>. Acesso em: I3 dez. 2020.

ARGENTINA. Ministerio de Salud. Nuevo coronavírus Covid- 19: información epidemiológica. Disponível em: <www.argentina.gob.ar/salud/coronavirus-Covid- 19/sala-situacion>. Acesso em: 12 dez. 2020.

BRASIL. Presidência da República. Secretaria Geral. Combate ao coronavírus: lei sobre uso de máscaras é sancionada. Disponível em: <www.gov.br/secretariageral/pt-br/noticias/2020/julho/lei-sobre-usode-mascaras-e-sancionada >. Acesso em: 20 dez. 2020.

CEARÁ. Secretaria Estadual de Saúde. Boletim Epidemiológico Novo Coronavírus (Covid-19). Disponível em: $<$ https://indicadores.integrasus.saude.ce.gov.br/indicadores/indicadores-coronavirus/coronavirusceara >. Acesso em: 12 dez. 2020.

CENTERS FOR DISEASE CONTROL AND PREVENTION (CDC). Operational strategy for K-12 schools through phased prevention. Disponível em: <www.cdc.gov/coronavirus/20 I9-ncov/community/ schools-childcare/indicators.html\#thresholds>. Acesso em: 20 dez. 2020a.

CENTERS FOR DISEASES CONTROL AND PREVENTION (CDC). Cleaning and disinfecting in school classrooms. Disponível em: <www.cdc.gov/coronavirus/20 I 9-ncov/downloads/community/schoolschildcare/cleaning-disinfecting-school-classrooms.pdf>. Acesso em: 20 dez. 2020b.

COBRE, A. F. et al. Risk factors associated with delay in diagnosis and mortality in patients with Covid- 19 in the city of Rio de Janeiro, Brazil. Ciência E Saúde Coletiva, 25, supl. 2: 4.131-4.140, 2020. Disponível em: <www.scielo.br/j/csc/a/8ZkCwsPy9Wdjy9P5Jkyr46v/?format=pdfElang= en>. Acesso em: 20 set. 2021 .

CONSELHO NACIONAL DE SECRETARIAS MUNICIPAIS DE SAÚDE (CONASEMS). Covid-19, Estratégia de Gestão. Instrumento para apoio à tomada de decisão na resposta à pandemia da Covid- 9 na estratégia local. Brasília: Conasems, 2020. Disponível em: <www.conass.org.br/wp-content/uploads/2020/I0/ Estrategia-de-Gestaao-Covid-19-2-1.pdf>. Acesso em: 22 fev. 2021. 
CONSElho nacional de SeCretários de SAúde (C). Painel Conass Covid-19. Disponível em: <www.conass.org.br/painelconassCovid-19/>. Acesso em: 12 dez. 2020.

COUZIN-FRANKEL, J.; VOGEL, G. \& WEILAND, M. School openings across globe suggest ways to keep coronavirus at bay, despite outbreaks. Science, 369(6.50I): 24I-245, 2020. Disponível em: <www. sciencemag.org/news/2020/07/school-openings-across-globe-suggest-ways-keep-coronavirusbay-despite-outbreaks>. Acesso em: 13 dez. 2020.

FRANCE. Santé Publique. Covid-19: point épidémiologique du 10 décembre 2020. Disponível em: $<w w w$.santepubliquefrance.fr/maladies-et-traumatismes/maladies-et-infections-respiratoires/ infection-a-coronavirus/documents/bulletin-national/covid- I 9-point-epidemiologique-du- I 0decembre-2020>. Acesso em: 12 dez. 2020.

FRENTE PELA VIDA. Manifesto: Ocupar escolas, proteger pessoas, valorizar a educação, nov. 2020. Disponível em: <http://cebes.org.br/2020/I I/manifesto-ocupar-escolas-proteger-pessoas-valorizara-educacao-e-atualizado/>. Acesso em: 16 fev. 2021.

FUNDAÇÃO DE VIGILÂNCIA EM SAÚDE DO AMAZONAS (FVS). Painel Covid-I9 Amazonas. Disponível em: <http://saude.am.gov.br/painel/corona/>. Acesso em: 12 dez. 2020.

FUNDAÇÃO OSWALDO CRUZ (FIOCRUZ). Contribuições para o Retorno às Atividades Escolares Presenciais no Contexto da Pandemia Covid-19. Disponível em: <https://portal.fiocruz.br/sites/portal. fiocruz.br/files/documentos/contribuicoes_para_o_retorno_escolar_-_08.09_4_I.pdf>. Acesso em: 20 dez. 2020.

FUNDO DAS NAÇÕES UNIDAS PARA A INFÂNCIA (UNICEF). Data to inform the Covid- 19 response, Apr. 2020a. Disponível em: <https://data.unicef.org/resources/data-to-inform-the-covid-19response/>. Acesso em: 13 dez. 2020.

FUNDO DAS NAÇÕES UNIDAS PARA A INFÂNCIA (UNICEF). Reabrir as escolas com segurança: recomendações para a construção de um processo adequado de retorno às aulas para prevenir e combater a violência contra as crianças nas escolas e fora delas, jul. 2020b. Disponível em: <www. unicef.org/brazil/reabertura-segura-das-escolas\#wash>. Acesso em: 20 dez. 2020.

HEALD-SARGENT, T. et al. Age-related differences in nasopharyngeal severe acute Respiratory Syndrome Coronavirus 2 (Sars-CoV-2) levels in patients with mild to moderate Coronavirus disease 2019 (Covid- 19). Jama Pediatrics, I 74(9): 902-903, 2020. Disponível em: < https://jamanetwork.com/ journals/jamapediatrics/fullarticle/2768952>. Acesso em: 20 set. 2021.

INLOCO. Mapa brasileiro da Covid- 19. Disponível em: < https://mapabrasileirodacovid.inloco.com.br/ pt/>. Acesso em: 20 dez. 2020.

JOTZ, G. P. \& BITTENCOURT, A. G. Why we need to use and which mask types are effective against the Novel Coronavirus (Covid- 19)? International Archives of Otorhinolaryngology, 24(3), 2020.

LEEB, R. T. et al. Covid-1 9 trends among school-aged children: United States, March I-September 19 , 2020. Morbidity and Mortality Weekly Report, 69(39): I.4 10-1.415, 2020. Disponível em: <www.cdc. gov/mmwr/volumes/69/wr/mm6939e2.htm>. Acesso em: 13 dez. 2020.

LOFT. $R_{t}$ do Covid- 19 por estado no Brasil. Disponível em: <https://loft.science/>. Acesso em: 22 fev. 2021 . 
MAYO CLINIC. How well do face masks protect against coronavirus? Disponível em: <www mayoclinic. org/diseases-conditions/coronavirus/in-depth/coronavirus-mask/art-20485449>. Acesso em: 20 dez. 2020.

ORGANIZAÇÃO PAN-AMERICANA DA SAÚDE (OPAS). Iris - Repositório Institucional para Troca de Informações. Orientação sobre o uso de máscaras no contexto da Covid-19. Orientação provisória. Junho, 2020. Disponível em: <https://iris.paho.org/handle/l0665.2/52254>. Acesso em: 20 dez. 2020.

PANOVSKA-GRIFFITHS, J. et al. Determining the optimal strategy for reopening schools, the impact of test and trace interventions, and the risk of occurrence of a second Covid- 19 epidemic wave in the UK: a modelling study. The Lancet Child E Adolescent Health, 4(I I): 817-827, 2020. Disponível em: $<$ www.thelancet.com/journals/lanchi/article/PIIS2352-4642(20)30250-9/fulltext > . Acesso em: 20 set. 2021 .

PECKHAM, H. et al. Male sex identified by global Covid- I 9 meta-analysis as a risk factor for death and ITU admission. Nature Communications, I I: 6.3 I 7, 2020. Disponível em: <www.nature.com/articles/ s41467-020-19741-6>. Acesso em: 20 set. 2021.

RIO DE JANEIRO. Prefeitura do Rio de Janeiro. Painel Rio Covid- 19. Disponível em: < https://experience. arcgis.com/experience/38efc69787a346959c93 I568bd9e2cc4>. Acesso em: I2 dez. 2020.

RIO DE JANEIRO. Secretaria Municipal de Educação. Educação em números. Disponível em: <www.rio. rj.gov.br/web/sme/educacao-em-numeros>. Acesso em: 16 fev. 202 la.

RIO DE JANEIRO. Câmara Municipal do Rio de Janeiro. Ofício conjunto n. 0I/2020. Junho de 2020. Disponível em: <www.cnte.org.br/images/stories/2020/2020_06_22_pedido_nao_retorno_aulas_ rj.pdf>. Acesso em: 20 set. $202 \mathrm{lb}$.

RIO DE JANEIRO. Tribunal de Contas do Município do Rio de Janeiro. Programa de visitas às escolas. Disponível em: <https://app.tcm.rj.gov.br/VisitaEscolas/Noticia?NoticialD=13817>. Acesso em: 16 fev. 202 Ic.

SÃO PAULO. Governo do Estado de São Paulo. SP Contra o Novo Coronavírus: boletim completo. Disponível em: <www.seade.gov.br/coronavirus/\#>. Acesso em: 12 dez. 2020.

STAGE H. B. et al. Shut and re-open: the role of schools in the spread of Covid- 19 in Europe. medRxiv, 2020. Disponível em: <www.medrxiv.org/content/I 0. I I 0 I/2020.06.24.20 I39634v2>. Acesso em: 20 set. 2021.

UNITED KINGDOM. Guidance: Actions for schools during the coronavirus outbreak. Disponível em: $<$ www.gov.uk/government/publications/actions-for-schools-during-the-coronavirus-outbreak/ guidance-for-full-opening-schools>. Acesso em: $20 \mathrm{dez} .2020$.

UNITED NATIONS (UN). Policy Brief: education during Covid-19 and beyond, Aug. 2020. Disponível em: $<$ https://unsdg.un.org/resources/policy-brief-education-during-covid-19-and-beyond>. Acesso em: 13 dez. 2020.

UNIVERISDADE FEDERAL DE PELOTAS (UFPEL). $4^{\text {a }}$ fase do EPICovid-19 mostra desaceleração do coronavírus no Brasil, 15 set. 2020. Disponível: <www.epidemio-ufpel.org.br/site/content/ sala_imprensa/4-fase-do-epiCovid-I 9-mostra-desaceleracao-do-coronavirus-no-brasil. php? noticia=3149>. Acesso em: 5 dez. 2020. 
VOZES DA EDUCAÇÃO. Levantamento Internacional de Retomada das Aulas Presenciais, ago. 2020. Disponível em: <http://vozesdaeducacao.com.br/>. Acesso em: 13 dez. 2020.

WILLIAMSON, E. J. et al. Factors associated with Covid-19-related death using OpenSAFELY. Nature, 584: 430-436, 2020. Disponível em: <www.nature.com/articles/s41586-020-2521-4>. Acesso em: 20 set. 2021 .

WORLD HEALTH ORGANIZATION (WHO). Coronavirus Diseases (Covid- 19) Dashboard. Disponível em: <https://Covid- 19. who.int/>. Acesso em: 12 dez. 2020a.

WORLD HEALTH ORGANIZATION (WHO). Checklist to support schools re-opening and preparation for Covid- 9 resurgences or similar public health crises, I I Dec. 2020b. Disponível em: <www.who. int/publications/i/item/97892400 I 7467 >. Acesso em: 20 dez. 2020. 



\section{Vigilância Popular em Saúde em Tempos de Pandemia} proposta de um caminho

Jorge Mesquita Huet Machado, Fatima Pivetta, Jacinta de Fátima Sena da Silva e Osvaldo Peralta Bonetti

A s ações de vigilância popular em saúde (VPS) desenvolvidas no enfrentamento da pandemia configuram uma prática sanitária participativa e integrada às ações de vigilância em saúde (VS), às redes, aos serviços assistenciais e às ações comunitárias de cuidado, de prevenção e de apoio social. Essas ações se organizam em um processo contínuo de aperfeiçoamento, a partir da identificação e consideração das dinâmicas socioambientais em relação às necessidades de saúde vivenciadas nos territórios. Dessa forma, a VPS é uma estratégia de ação e de promoção da saúde em busca de respostas aos desafios colocados no enfrentamento da Covid-19. Trata-se de uma atividade permanente de informação para orientar a ação institucional e popular, apta a captar as dinâmicas dos temas, dos problemas, das necessidades, assim como potencialidades e instrumentais disponíveis nos territórios, visando à redução da transmissibilidade, ao manejo clínico epidemiológico da propagação da doença e à redução dos múltiplos impactos da Covid-19, em especial em contextos de vulnerabilidades e resiliências.

Essa perspectiva de vigilância se alicerça em, ou tem como referência, um projeto emancipatório de sociedade, comprometido com a democratização do Sistema Único de Saúde (SUS) e com o aprofundamento e ressignificação da participação popular. Essa proposição, por sua vez, orienta a VS no sentido da promoção da saúde, com base nas necessidades da população.

O território-lugar tem centralidade em nossas reflexões e propostas de políticas públicas e de ação. Como afirma Maria Adélia de Souza, o mundo é globalizado apenas para alguns setores - para o dinheiro, para as mercadorias, para a informação -, mas não igualmente para todos. Ecoando o pensamento de Milton Santos, a autora diz que o mundo é, de fato, fragmentado, e que o fragmento é o lugar (Souza, 2004). 
Os lugares, por meio da informação, se conectam fazendo com que o global e o local interajam e tornem o território usado e o lugar dimensões centrais da vida social. Dessa maneira, "democratizar, hoje, é democratizar a informação sobre os lugares e sua qualidade", e a vigilância popular é uma estratégia fundamental nesse processo (Souza, 2004: 72).

Os territórios da Atenção Primária à Saúde (APS) em nosso país são lugares historicamente sujeitos a processos de vulnerabilização, em razão da precariedade das políticas públicas, como as de habitação, saneamento, educação, mobilidade, saúde, justiça e segurança pública, entre outras. Mas são também lugares de potencialidades, em razão da capacidade das pessoas e de seus modos de produzir o território e nele viver, enfim, de criar cultura. Segundo Monken e Barcellos (2007: 18I),

... se a doença é uma manifestação do indivíduo, a situação de saúde é uma manifestação
do lugar. Os lugares e seus diversos contextos sociais, dentro de uma cidade ou região,
são resultados de uma acumulação de situações históricas, ambientais, sociais, que
promovem condições particulares para a produção de doenças.

No mesmo sentido, Luiz Jacintho da Silva (2003) destaca que "Olhar o território e buscar entendê-lo é mais que dominar um conjunto de técnicas; é assumir uma forma de raciocínio, adotar uma lógica diferente para a compreensão do processo saúde-doença”.

Olhar o território na perspectiva da promoção da saúde e apreender a complexidade do processo saúde-doença significam assumir seus dois pilares estruturantes - a intersetorialidade e a participação comunitária, numa visão integrada de saúde abordando a saúde do território, e não a visão setorizada e fragmentadora do território da saúde. Assim, vemos como responsabilidade do setor Saúde promover essa reflexão no âmbito das disputas políticas na formulação de políticas públicas.

Consideramos, de certa forma, dramático o fato de a elevação do reconhecimento do SUS pela sociedade ter decorrido da tragédia social em nosso país devida à pandemia da Covid-19, o que nos leva a aprofundar as críticas ao processo de implementação da Reforma Sanitária, que privilegiou a institucionalização do SUS, relegando ao quase esquecimento o diálogo com a sociedade, salvo pela implementação dos conselhos e conferências de Saúde. Segundo Alcides Miranda, esse processo relegou a um plano muito secundário a aposta em estratégias de horizonte da Reforma Sanitária como movimento instituinte que jamais poderia ter se descolado dos movimentos sociais e dos princípios do SUS, principalmente o da participação social (Miranda, 20I7). Mesmo os conselhos de Saúde ficaram reféns do clientelismo e dos interesses privados. Foram esquecidos os próprios movimentos que levaram à organização da $8^{a}$ Conferência Nacional de Saúde e à inscrição do capítulo da Saúde na Constituição Federal de 1988. 


\section{MUDANDO 0 FOCO}

Com essa perspectiva, propomos mover o foco para a pesquisa e a intervenção do "ponto de vista popular" e suas potencialidades instituintes no debate da vigilância popular em saúde (VPS). Pensamos VPS como um movimento que para nós não se confunde com o Estado, apresenta autonomia em relação às instituições governamentais e contribui, sim, com a dimensão instituinte da Reforma Sanitária. Isso que dizer que as ações de VPS buscam a potencialização dos processos autônomos desenvolvidos nos territórios, no sentido de fortalecer a resposta sanitária à pandemia. Contudo, esses processos instituintes devem interferir nas ações e políticas públicas e contaminá-las, e não ser capturados ou institucionalizados em sua integralidade, aprisionando suas potencialidades em dimensões nem sempre alcançadas pela ação institucional.

Reproduzimos aqui a fala de Alan Brum Pinheiro, da coordenação do Instituto Raízes em Movimento, do Complexo do Alemão, em um debate sobre a pandemia com moradores de favelas do Rio de Janeiro organizado no âmbito da disciplina Educação Popular e Construção Compartilhada do Conhecimento do Programa de Pós-Graduação da Escola Nacional de Saúde Pública Sergio Arouca/Fiocruz em 8 de maio de 2020:

Os governantes trabalham numa burocracia instalada, sem saber agir em situações de emergência; não conseguem agir. O engessamento da estrutura pública é mesmo para não agir. E nessa situação emergencial da pandemia, as coisas foram desnudadas, como a covardia e a falta de proatividade dos governantes.

Somando-nos à fala do Alan, afirmamos que a pandemia deixou clara para a sociedade a importância da organização local da população e de suas redes de informação. Essa organização e ação dos coletivos locais é que tem dado sustentação às ações de combate à Covid- 19 nas favelas e periferias, e evitado uma tragédia maior nesses espaços da cidade em que muitas vezes o Estado está parcialmente presente, representado apenas pelas forças policiais repressivas. Nesses contextos, são os coletivos locais que têm alimentado a sociedade e os profissionais da saúde com as informações sobre a realidade da pandemia.

Não se trata, portanto, de propor uma VPS autônoma, pois ela já existe, mas pensar em como estabelecer um diálogo entre essas redes populares de produção de conhecimento e de informação e as instituições de Estado. Para tanto, vemos como necessidade o reconhecimento dos saberes e das informações produzidos nos territórios e sua incorporação aos sistemas de informação em saúde oficiais (ou institucionais), à rede local de informação ou ao sistema informativo popular. 
O reconhecimento do papel dos moradores como sujeitos implica integrar o conhecimento sobre o território produzido por aqueles que são especialistas do lugar, os analistas práticos, que conhecem mais do que ninguém sua realidade (Pivetta, 2021 ; Pivetta, Porto $E$ Cunha, 2020). Esses atores sociais apreendem e compreendem a realidade em suas múltiplas dimensões e integram, em seus mapas mentais, a complexidade expressa nas situações particulares da vida cotidiana. Não são meros informantes, mas aqueles que produzem um conhecimento primário e trazem os dados pré-interpretados (Martins, 2014). Desvelam processos de produção da saúde-doença invisibilizados para pesquisadores e profissionais, mesmo para aqueles que atuam nesses territórios. Voltando à fala de Maria Adélia, "democratizar hoje é democratizar a informação sobre os lugares e sua qualidade", qualidade que é dada quando produzida no e com o território.

O conhecimento produzido no cotidiano do território e sua circulação nas redes locais é o que possibilita aos sistemas de saúde e de outras áreas da gestão acompanhar a dinamicidade local e dar respostas mais adequadas. Esse conhecimento é essencial para compreender as necessidades reais do território e construir uma linguagem comum e habilidade em lidar com os diferentes tempos, os institucionais e os do território, que são centrais e definem a possibilidade de comunicação e de resposta aos problemas.

Uma questão se coloca: por que a VPS deve ser autônoma e ao mesmo tempo manter a rede do território como espaço instituinte? A autonomia e o diálogo com as estruturas de gestão do território são questões que colocamos para nós, pesquisadores e gestores.

A VPS é dinâmica, aponta diretamente para as necessidades imediatas e urgentes; é espontânea e horizontal, e desafia a vigilância institucional, centralizada, hierarquizada, verticalizada, com processos de trabalho protocolizados que engessam iniciativas mais autônomas dos profissionais da saúde diante das urgências, o que prejudica a formulação de respostas mais efetivas para a população. Em outras palavras, a VPS deve acompanhar, com seu trabalho, a dinamicidade do território. Manter a rede do território como espaço instituinte, no nosso ponto de vista, é fundamental para definir agendas de gestão do território que de fato deem respostas às necessidades mais prementes da população. Ao mesmo tempo, a VPS fortalece e ressignifica a participação no SUS.

O desafio, portanto, está em estabelecer uma relação entre os dois sistemas de vigilância, o popular e o institucional, sem perder o caráter instituinte da vigilância popular, enclausurando-a nas amarras burocráticas ou na tutela institucional.

Está sendo um desafio muito grande, para todos nós do campo da saúde coletiva, manter o diálogo com os territórios no contexto da pandemia de Covid-19. Mas é 
também uma oportunidade de exercermos nossa capacidade imaginativa e, num trabalho artesanal cotidiano, experimentarmos possibilidades novas e emancipatórias de diálogo e participação popular na reflexão e compreensão dos processos de vulnerabilização.

Torna-se fundamental um trabalho emergencial e necessário que integre olhares e modos de fazer as ações de cuidado, proteção e prevenção sanitária e social pactuadas em distintos territórios por dispositivos mobilizadores de contato de ideias, insumos e informações em processos de gestão compartilhados no tempo da crise e na convivência com a Covid- 19.

Como ação prática de fortalecimento das ações nos territórios, a VPS deve considerar o contexto dos desafios socioambientais e suas repercussões na sustentabilidade do desenvolvimento territorial, e simultaneamente integrar políticas públicas na prática da vigilância em saúde, das vigilâncias em saúde ambiental, epidemiológica, sanitária e do trabalhador, da APS e do saneamento ambiental. Essa práxis é mediada por temáticas mobilizadoras, que produzam estratégias de promoção da saúde em diferentes escalas, em que a dimensão local comunitária tenha uma expressão determinante e determinada pela sua interação com processos de territorialização.

\section{AS AÇÕES DE VIGILÂNCIA EM SAÚDE DE BASE TERRITORIAL PARTICIPATIVA E INTEGRADA}

Vigilância é uma ação de intervenção comunicativa em duplo sentido, da informação para ação e da ação para informação. A conexão entre as políticas intersetoriais e os serviços de saúde é orientada por dispositivos conceituais e por estruturas de gestão e operação de interface/contato popular e institucional. A intervenção sanitária comunitária e intersetorial é organizada e desencadeia um deslocamento conceitual e operativo por estruturas de conexão (local/comunitária, microrregional, municipal, estadual, regional/macrorregional, nacional) em uma ação participativa em rede.

A chave estruturante da VPS é a conexão entre a comunidade e os profissionais da saúde, para a produção conjunta de informações dos problemas do território, de forma a orientar as estratégias de intervenção e de comunicação. A informação é o insumo da problematização, análise e difusão que fundamenta as ações de intervenção.

Assim, podemos discutir as ações de VS de base territorial participativa e integrada em três âmbitos: I) Características gerais da ação; 2) Características operacionais; 3) Capacidade técnica e modelo de operação. 


\section{Características gerais da ação}

- A organização da integração das informações territoriais, quali-quantitativas, a partir de fluxos de consolidação regional e de observações comunitárias, de modo a possibilitar a conformação de um painel de indicadores que ressaltam os resultados das ações, tanto positivos quanto negativos, para a promoção da saúde e redução da transmissibilidade, buscando estabelecer um acompanhamento das dinâmicas da saúde e de sua determinação nos territórios.

- A operação por comitês populares em conexão com núcleos de integração, compostos por profissionais da vigilância epidemiológica e da APS e representantes/interlocutores das comunidade: das temáticas relacionadas aos impactos da Covid-19; do apoio ao distanciamento social; da proteção aos deslocamentos decorrentes da mobilidade urbana; das situações de trabalho e das situações de contatos interpessoais; da intervenção sanitária, de isolamento dos casos e contatos, de acompanhamento clínico e epidemiológico; do acompanhamento, organização e discussão das medidas de proteção coletivas, domiciliares e individuais, e de apoio social e econômico.

- Eixos de observação do trabalho segundo características da rotina diária, momentos em espaços fechados com ou sem contatos interpessoais, o período de cada atividade e a possibilidade de proteção em diferentes momentos do cotidiano, destacando os tempos comunitários e domiciliares e de intervenção segundo as necessidades de:

- Realização de trabalho/atividades essenciais de amplo reconhecimento para a reprodução social da população. O exemplo dos trabalhadores da saúde é o mais evidente, devendo ter um tratamento especial devido à intensidade de exposição.

- As atividades econômicas de produção e distribuição de alimentos, medicamentos e transporte.

- Os deslocamentos decorrentes de demandas sociais e apoio comunitário de organização estrutural logística, econômica e financeira, especialmente de assistência social para aplicação estratégias de suporte social.

- Realização de trabalho/atividades por grupos econômica e socialmente vulneráveis. Trabalhadores/atividades informais. Geração de renda precária, dependente da venda diária de serviços e mercadorias. 
- Deslocamentos decorrentes de situações psicossociais, políticas, físicas e emocionais, associados fundamentalmente à saúde mental.

- Realização de outras atividades de produção e reprodução social na dinâmica de maior ou menor isolamento sanitário/social, em decorrência da dinâmica de abertura e fechamento de atividades.

- Atividades de segurança, de serviços domésticos, de limpeza e de manutenção de instalações prediais e veículos.

\section{Características operacionais}

A operacionalização do modelo está associada a:

- Condições estruturais - espaço físico e institucional, equipamentos de comunicação e informática, integração a redes de vigilância e atenção e a serviços de referência - que compõem a rede acadêmica, institucional e comunitária.

- Capacidade instalada de equipes direta e indiretamente envolvidas com interação externa de organizações populares e interinstitucionais integradas segundo as funçães de gestão da informação, de intervenção e de difusão/comunicação em temáticas mobilizadoras e estruturantes.

- Organização de processos de trabalho, produção, discussão e análise de protocolos e procedimentos de prevenção, bem como sua aplicação, acompanhamento e difusão.

\section{Capacidade técnica e modelo de operação.}

Devem ser desenvolvidos componentes de um mosaico de alternativas integradas de:

- Procedimentos de intervenção estabelecidos por temáticas geradoras e mobilizadoras da ação.

- Estruturação de uma ação sistêmica de VPS articulada pela temática do distanciamento social em escala comunitária, microrregional e municipal;

- Definição e implementação de um modelo comunicação popular a partir de informações territorializadas e comunitárias, com acompanhamento de indicadores epidemiológicos, sociais e de atividades preventivas com conexões interinstitucionais e populares de monitoramento epidemiológico, da organização do trabaIho dos distintos grupos de atividades e das necessidades e demandas sociais e de assistência à saúde. 
Em síntese, o objetivo é produzir no território ações integradas e transetoriais de proteção, acolhimento, encaminhamento e tratamento.

Esta proposta está referenciada nas possibilidades reais de sua execução pelas instâncias e serviços, tendo como objetivo estratégico a articulação territorial da vigilância epidemiológica e da APS segmentadas pelas unidades de Saúde da Família e com organização e gestão da VS e da atenção primária à Covid- 19.

A estruturação de instâncias de conexão participativas e de compartilhamento de informações internas aos serviços de saúde e a organização de núcleos e comitês populares é uma dessas possibilidades. Essas instâncias se diferenciam e ao mesmo tempo se constituem como referências para respostas à pandemia nos territórios, se organizando de acordo com as necessidades de reprodução social e a situação de saúde, assumindo responsabilidades e sua legitimidade social.

Para tanto, é necessário estabelecer pontos de VS de base territorial, em unidades territoriais, definidas pela rede de APS em conexão e apoio às ações de VPS comunitárias, assim como definir atividades, equipe e processos de gestão da informação para ação nesses locais. O compartilhamento dos dados de serviços e de morbimortalidade, de informações comunitárias de alerta, de situações de vulnerabilidade e risco permite a vigilância em saúde ambiental e do trabalhador com olhar diferenciado: de um lado para os casos, e de outro para as estratégias de acompanhamento e apoio sanitário e social.

Fazem-se necessárias ações estruturantes de deslocamento do modelo assistencial para um modelo de atenção integral, com interação popular-institucional. Apresentamos a seguir algumas sugestões voltadas para a implementação de um plano de ação.

\section{Quanto à estrutura}

- Organizar força-tarefa com todos os profissionais da saúde, da assistência social e da educação que atuam no território, para equacionamento dos problemas e definição de responsabilidades e tarefas; acionar imediatamente a prefeitura para disponibilização dos profissionais; incluir os membros da comunidade que participam da rede de vigilância popular; definir o comando e os parceiros.

- Organizar uma estrutura por áreas: atendimento social e psicossocial e de comunicação; geração de informação e acesso à informação; epidemiologia; saúde ambiental; assistência; acompanhamento de situações críticas e direitos.

- Montar uma estrutura de atenção aos casos suspeitos e doentes no posto da saúde de família estabelecendo uma referência de encaminhamento para os agentes comunitários de saúde (ACS), convocando e treinando profissionais. 


\section{Quanto às estratégias}

- Fornecer as condições materiais para atendimento (fornecimento de equipamentos de proteção para os profissionais, insumos, medicamentos etc.) e para o encaminhamento de pacientes graves, caso exijam vagas nas UTIs.

- Dar apoio às pessoas para o isolamento social, especialmente aos idosos e doentes crônicos em articulação com a Estratégia Saúde da Família, mediante mapeamento e visitação com registro de inconformidades, queixas e demandas de acesso e de dificuldades e sugestões de redes de solidariedade e produção de conexão com responsáveis por unidade territorial.

- Fortalecer a segurança alimentar.

\section{Quanto à estratégia e à estrutura}

- Criar uma central de informações com a organização de boletim periódico com as ocorrências de casos, as observações relativas aos problemas de atendimento e de controle - por exemplo, acesso à água e necessidade de trabalho em condições de aglomeração - e sugestões de ações solidariedade e redução de problemas sociais.

- Centrar os informes nas necessidades dos vulneráveis, estabelecer uma tipologia de vulnerabilidades a serem monitoradas.

Essa central de conexão de informações deve ser operada por profissional da VS, ACS e agentes de saúde ambiental, em um espaço de captação de informações a partir do qual são disparadas respostas aos organizadores de núcleos territoriais de VS de base territorial integrada e participativa, em que se insere a VPS. Podem-se visualizar dois serviços interligados: um de assistência social e outro de vigilância ambiental e epidemiológica. À organização e monitoramento desses serviços se somam as observações do grupo de assistência social. Devem ser definidos espaços de coordenação da ação de VPS para instalação de equipes e equipamentos em conexão com os comitês por comunidade/território de dupla via: por fluxos de informações e por orientações para as distintas ações.

A informação para ação, como definida na VS, realiza no âmbito do SUS as ações de promoção da saúde em um território em suas várias dimensões, que correspondem a atividades múltiplas e de uso intensivo de força de trabalho. Como ação inovadora e variada, há sempre necessidade de novos operadores e de interconexão entre eles, em um processo de formação-ação contínua. 
Todos somos agentes populares de saúde, especialmente durante uma pandemia. São inúmeros os papéis na realização das interconexões em que as atividades dos agentes populares de saúde se organizam, em contato e como resultado de reflexões entre as pessoas.

\section{Síntese}

Promover uma ação de VPS pressupõe diálogo contínuo, uma política pública popular organizada e produzida a partir da fala e da escuta, incorporando saberes e práticas a uma ação forjada no território de referência, que pode ser construída a partir de necessidades locais, de temas transversais e mesmo decorrente de questões abstrato-conceituais.

Essas ações de VPS devem estar organizadas e divididas em várias dimensões dos territórios - a família, a casa, o lote, a roça, a comunidade, o assentamento, a favela, o bairro, o município, a região, o estado - e dos movimentos e agregações entre essas dimensões. As conexões abstratas/ou simbólicas e estruturais da cultura, das temáticas mobilizadoras e das necessidades das pessoas e dos lugares poderão ser identificadas nas relações entre os vários agentes de VPS, em um processo de participação e de construção de narrativas no território, de promoção da saúde em múltiplas formas, espaços sociais e dimensões.

A VPS deve produzir e inserir ações nos planos e projetos de conexão entre redes, temas, lugares e pessoas, em uma epidemiologia situada nos territórios concretos e abstratos, nos quais a temática transversal será a promoção da saúde, o cuidado integral, individual e coletivo e, também, a prevenção. No caso, o "pulo do gato" (deslocamento estruturante) que transforma o saber acumulado em ação está no deslocamento de o que fazer (prescrições, protocolos de Covid-19, recomendações de integração) para como fazer. Ao conectar os saberes populares com os grupos institucionais ao redor das necessidades de saúde, constrói-se uma comunicação e uma narrativa comum que, compartilhada e problematizada, produz ação.

\section{Diretrizes de vigilância popular em saúde}

Teoria

I. Interação da epidemiologia situada com a educação popular em saúde.

2. Mediação da formação para a ação.

3. Deslocamento conceitual interseccional associando abordagens sanitárias e culturais. 


\section{Estratégia}

4. Participação com produção de narrativas populares.

5. Promoção de saúde intersetorial em múltiplas escalas.

6. Territórios saudáveis e sustentáveis (conceito integrador/mobilizador).

7. Conexão (entre redes, temas, lugares, pessoas).

\section{Operação}

8. Comunicação da pedagogia do cuidado.

9. Integração do cuidado com a pedagogia dos lugares.

10. Ação preventiva com atividades de proteção, o fazer compartilhado.

A integração das diretrizes como princípios aglutinados por blocos de operação (8, 9 e 10) estratégias (4, 5, 6 e 7) e conceitos ( 1,2 e 3 ) possibilita olhar para as pessoas que estão em situação de risco e produz a pedagogia do cuidado, necessária no contexto da pandemia. Além disso, permite participar da organização de fluxos de atendimento, especialmente em situações de emergência; planejar os caminhos dos territórios, integrados às linhas de cuidado; e produzir um olhar voltado para a prevenção e promoção de saúde no âmbito da VPS.

O trabalho de estabelecer barreiras sanitárias e o cuidado com as conexões interpessoais aproximam as atividades dos agentes populares de saúde da ideia de convivência e solidariedade. A VPS é, portanto, constituída de múltiplas funções de agentes públicos e sociais que produzem políticas intersetoriais, conexões interseccionais de desenvolvimento regional e gestão urbana, com destaque para a produção e distribuição de alimentos, a segurança alimentar e o saneamento em suas relações com as políticas de saúde.

\section{CAMINHOS PERCORRIDOS}

As práticas decorrentes do inédito viável se conectam com potencialidades presentes e constituídas do autocuidado nos territórios das favelas, das periferias, dos povos do campo, da floresta e das águas, suas organizações, conexões culturais e institucionais em que, além de secretarias municipais e estaduais de Saúde, de Agricultura Familiar e Desenvolvimento Social, se destaca a ação social. São exemplos desses esforços a ação mobilizadora da Articulação do Semiárido Brasileiro (ASA), a Rede Nacional de Médicas e Médicos Populares, movimentos nacionais dos trabalhadores rurais, o Movimento do Trabalhadores Sem Terra (MST) e a Confederação dos Trabalhadores Rurais (Contag), que 
com suas federações e sindicatos produziram a pedagogia do exemplo e da solidariedade em redes sociais. Por sua vez, as organizações de pesquisadores e profissionais formaram uma episteme informacional, acadêmica, institucional e popular de resiliência diante do descontrole da pandemia, produzindo pressões por controle e vigilância nesta crise sanitária e humanitária. Essas ações têm sido voltadas para:

- As necessidades de um cuidado entre as pessoas, com conexões entre as instâncias envolvidas no ciclo da atenção integral à saúde - em abordagem intersetorial e interseccional, com recortes de classe, gênero e raça-etnia - e as instâncias de coordenação de políticas econômicas e sociais;

- A organização de estratégias de VS como ação motivada e mobilizada por interações, de intensidades e formas distintas, entre os movimentos sociais comunitários e de trabalhadores e trabalhadoras e as instâncias institucionais.

A experiência do Radar das Favelas do Rio de Janeiro visa à superação da invisibilidade da cultura e da diversidade das populações e espaços da periferia urbana e à valorização das potencialidades de ações solidárias de assistência social e de combate à fome. A pandemia de Covid- 19 nos coloca a necessidade de analisar a tessitura histórica das respostas produzidas pelos coletivos das favelas, a fim de ampliar os conhecimentos sobre aspectos pouco evidenciados nos processos de determinação social da saúde - a memória coletiva, a experiência e a cultura local -, e sobre as formas de participação social. Isso significa

Dialogar com a experiência dos moradores, significa também ir além dos determinantes sociais tangíveis, que se referem aos indicadores econômicos, sociais, ambientais e epidemiológicos e que dão base aos sistemas de informação clássicos que alimentam a APS, mas que são insuficientes quando se trata de compreender as formas de adoecimento e morte da população. Para avançar, consideramos importante acessar os determinantes intangíveis, expressos nos depoimentos e narrativas das experiências e saberes dos moradores (Cunha et al., 20 I 8: 88)

O Radar de Territórios no Distrito Federal busca aproximar a vigilância epidemiológica e a APS, com atividades comunitárias de economia solidária e a construção de uma informação territorializada que evidencie as potencialidades e vulnerabilidades dos lugares. Propõe-se a operar a integração de epidemiologia comunitária, educação popular, ações comunitárias sociais e de gestão participativa de desenvolvimento regional e promoção de territórios saudáveis e sustentáveis.

No Caminho das Águas, Alimentos e Pessoas no Semiárido, a VPS tem feito a articulação entre os projetos de tecnologias sociais desenvolvidos pela ASA e os movimentos 
sociais do campo, colocando em conexão agricultores familiares, técnicos assessores dos movimentos e os ACS dos municípios.

Os povos quilombolas e indígenas estreitaram suas redes de comunicação e apoio com a circulação de informações, inclusive epidemiológicas; a organização de observatórios; a distribuição de boletins de acompanhamento de notícias; informes de encontros virtuais e relatos populares de casos, apoiados por grupos institucionais e acadêmicos.

As tragédias aqui apenas esboçadas não têm sido ignoradas por organizações da sociedade civil, o que pode estar apontando para a configuração de um campo de práticas de uma vigilância popular da saúde e do ambiente. Gabinetes de crise em favelas [...], comitês populares [...], articulações solidárias, plataformas [...], observatórios acadêmico-populares [...], barreiras sanitárias populares [...] e portais de monitoramento participativo da doença na internet, como o "Quarentena Indígena” [...] e o "Quilombos Sem Covid-19" [...], são algumas das formas que, espontaneamente, têm surgido nas favelas e nos territórios de povos tradicionais para dar conta de enfrentar a Covid- 9 num ambiente em que várias injustiças se combinam. (Carneiro \& Pessoa, 2020: 4)

A campanha nacional Periferia Viva tem formado brigadas populares de barreiras e ações sanitárias múltiplas nas comunidades, em um processo de formação-ação para o cuidado e vigilância que se espalhou por várias regiões do Brasil, envolvendo desde as periferias do Nordeste e do Sudeste até os povos do campo, das florestas e das águas, no rastilho das redes de movimentos sociais, associações de bairros e sindicatos com ações solidárias de promoção da saúde, informação e prevenção, das quais se destacam o combate à fome e a assistência social comunitária. Acionando a rede de educação popular em saúde, tem amplificado a formação de agentes populares de saúde para a VPS.

A formação de agentes populares promovida pela Fiocruz Brasília é fundada na articulação entre os princípios da Reforma Sanitária, da educação popular freiriana e da VPS. Essa formação tem se realizado em parceria com um conjunto de movimentos, em especial a campanha de solidariedade Nós por Nós Contra o Coronavírus (NPN), realizada no Distrito Federal como uma vertente da campanha nacional Periferia Viva, tendo em vista ampliar a capacidade de resposta à pandemia, que vem se alastrando de forma acelerada, em especial em contextos de alta densidade demográfica e altos índices de vulnerabilidade.

Participam da iniciativa, construindo essa estratégia de solidariedade, as seguintes entidades e organizações: Levante Popular da Juventude, Consulta Popular, Família Hip Hop, Movimento de Trabalhadoras e Trabalhadores por Direitos (MTD), Movimento de 
Trabalhadoras e Trabalhadores Sem Terra (MST), Rede Nacional de Médicas e Médicos Populares, Evangélicos por Justiça (EPJ), Movimento Popular de Moradia do DF (Amora), Diretório Central dos Estudantes da Universidade de Brasília (DCE UnB), Grupo de Educação Popular em Saúde da Associação Brasileira de Saúde Coletiva (EPS/Abrasco) e Associação Brasileira de Enfermagem (ABEn).

Esse processo de formação tem como método e concepção de trabalho a construção compartilhada, a problematização e a leitura da realidade, a gestão participativa e a articulação entre os saberes técnico-científicos e os populares no desenvolvimento de ações de VS. Assim, promove trocas e a sensibilização sobre as condutas necessárias para implementar o distanciamento social. Contudo, mesmo sem desconsiderar o importante apoio das tecnologias digitais que podem facilitar a interação à distância e a promoção dos processos de conscientização, nesse processo identifica-se a necessidade de estar junto dos territórios e das pessoas, construindo a práxis educativa com, e não para, aqueles que mais sofrem os impactos da pandemia, pois são estes que conhecem as realidades, as situações-limite vivenciadas nos cotidianos e as dificuldades em seguir as condutas recomendadas e garantir suas formas de subsistência.

Esse processo em curso tem reorientado a VPS, as ações comunitárias de VS de base territorial e interinstitucional, a APS e as vigilâncias epidemiológica, sanitária em saúde ambiental e em saúde do trabalhador.

\section{INTERSECCIONALIDADES E PERSPECTIVAS}

Como compartilhamento de uma multiplicidade de experiências, conhecimentos e visões de mundo, a ação da VPS tem como objetivo garantir a qualidade da informação para os processos de tomada de decisão. Isso se dá pela ação dialógica aproximando a realidade da "verdade" e pelo encontro solidário de saberes não como um ideal utópico paralisante, mas como elaboração de um "inédito viável" e no âmbito do "viável histórico", como nos ensina Paulo Freire. A legitimação do conhecimento é dada pela qualidade da reflexão que propicia, eticamente produzida no e com o território, e, pela própria natureza do processo, se desdobra em ações.

Enfim, o que propomos como projeto emancipatório de vigilância popular se contrapõe à VS de um Estado capitalista, patriarcal e colonizado em que vigiar e punir é a regra e se expõe o espetáculo do racismo ambiental, policial e cibernético digital. No lugar de instituições totais, é necessário construir políticas de saúde populares, em que a VS de base territorial integrada e participativa se insere. 


\section{REFERÊNCIAS}

CARNEIRO, F. F. \& PESSOA, V. M. Iniciativas de organização comunitária e Covid-19: esboços para uma vigilância popular da saúde e do ambiente. Trabalho, Educação e Saúde, I8(3): e00298I30, 2020. Disponível em: <www.scielo.br/j/tes/a/QL8wS8krxQ8p8qgjxqrP87D/?format=pdfElang=pt>. Acesso em: 18 set. 2021 .

CUNHA, M. B. et al. Vigilância popular em saúde: contribuições para repensar a participação no SUS. In: BOTELHO, B. O. et al (Org.). Educação Popular no Sistema Único de Saúde. São Paulo: Hucitec, 2018. Disponível em: <www.ccm.ufpb.br/vepopsus/wp-content/uploads/2018/02/ Livro-Educa\%C3\%A7\%C3\%A3o-Popular-no-Sistema-\%C3\%9Anico-de-Sa\%C3\%BAde-HucitecEditora-2018.pdf>. Acesso em: 17 mar. 2021.

FIOCRUZ BRASÍLIA. Caderno de Orientações para Agentes Populares de Saúde. Brasília: Fiocruz, 202 I .

MARTINS, J. S. Uma Sociologia da Vida Cotidiana: ensaios na perspectiva de Florestan Fernandes, de Wright Mills e de Henri Lefebure. São Paulo: Contexto, 2014.

MIRANDA, A. S. A Reforma Sanitária encurralada? Apontamentos contextuais. Saúde Debate, 4 I ( I I 3): 385-400, 2017.

MONKEN, M. \& BARCELLOS, C. O território na promoção e vigilância em saúde. In: FONSECA, A. F. E CORBO, A. (Orgs.). Território e o Processo Saúde-Doença. Rio de Janeiro: EPSJV/Fiocruz, 2007. (Col. Educação Profissional e Docência em Saúde: a formação e o trabalho do agente comunitário de saúde)

PIVETTA, F. Comunidade Ampliada de Pesquisa-Ação: uma contribuição metodológica para a promoção emancipatória da saúde nos espaços urbanos, 2021. Tese de Doutorado, Rio de Janeiro: Programa de PósGraduação em Saúde Pública, Escola Nacional de Saúde Pública Sergio Arouca, Fundação Oswaldo Cruz. Disponível em: <www.arca.fiocruz.br/handle/icict/48469>. Acesso em: 9 jul. 2021.

PIVETTA, F. R.; PORTO, M. F. S. E CUNHA, M. B. Comunidade ampliada de pesquisa-ação do laboratório territorial de Manguinhos: um caminho de interação com o território. In: ODDONE, I. et al. (Orgs.). Ambiente de Trabalho: a luta dos trabalhadores pela saúde. 2. ed. São Paulo: Hucitec, 2020.

SILVA, L. J. Prefácio. In: ROJAS, L. I. \& BARCELLOS, C. (Orgs.). O Território e a Vigilância em Saúde. Rio de Janeiro: Fundação Oswaldo Cruz, Escola Politécnica de Saúde Joaquim Venâncio, 2003. (Programa de Formação de Agentes Locais em Saúde, módulo 3)

SOUZA, M. A. A. Uso do território e saúde: refletindo sobre "municípios saudáveis". In: SPERANDIO, A. M.G. (Org.). O Processo de Construção da Rede de Municípios Potencialmente Saudáveis. v. 2. Campinas: Ipes Editorial, 2004. 



\title{
Considerações sobre a Possibilidade de Transmissão Fecal-Oral da Covid-19'
}

\author{
Leo Heller, Cesar Rossas Mota Filho e Dirceu Bartolomeu Greco
}

O vírus Sars-CoV-2, causador da pandemia Covid-19, é transmitido principalmente através de gotículas respiratórias e superfícies de contato, ou fômites (WHO, 2020). Esse vírus usa a enzima de conversão da angiotensina ACE2 como receptor para entrar nas células humanas (Xu et al., 2020) e o RNA mensageiro da ACE2 é fortemente expresso no sistema gastrointestinal (Harmer et al., 2002). Os pacientes com Covid- 9 podem liberar o vírus nas fezes durante dias após o desaparecimento de todos os sintomas respiratórios (Wu et al., 2020). O RNA do vírus tem sido encontrado em amostras de esgoto (Ahmed et al., 2020; Chernicharo et al., 2020; Fongaro et al., 2020; La Rosa et al., 2021 ; Medema et al., 2020; Mota, Bressani-Ribeiro E Araújo, 202 I), lodo de esgoto (Peccia et al., 2020) e água superficial (Guerrero-Latorre et al., 2020). Além disso, Sars-CoV-2 viável foi isolado de fezes (Wang et al., 2020; Zhang et al., 2020, Xiao et al., 2020) e de urina de pacientes (Sun et al., 2020), o que sugere a possibilidade de transmissão fecal-oral para a Covid- 19.

Oliveira e colaboradores (2021), em estudo recente sobre a persistência do SarsCoV-2 em amostras de água e esgoto, demonstram o decaimento de $99 \%$ do Sars-CoV-2 em água de rio no período de 6,4 dias em temperatura ambiente (aproximadamente $23^{\circ} \mathrm{C}$ ) e 18,7 dias a $4^{\circ} \mathrm{C}$. No esgoto, o tempo para atingir decaimento de $99 \%$ foi de 4 dias em temperatura ambiente e 17,5 dias a $4^{\circ} \mathrm{C}$. A persistência de coronavírus humanos em superfícies é altamente variável (de 2 horas a 9 dias), dependendo da temperatura, umidade, tipo de superfície e cepa do vírus (Kampf et al., 2020). Além disso, vários coronavírus humanos mostraram ser particularmente sensíveis à cloração da água.

\footnotetext{
1 Baseado no artigo dos mesmos autores: Covid-19 faecal-oral transmission: are we asking the right questions? Science of the Total Environmental, 729: I389 | 9, 2020. Disponível em: < https://doi.org/I 0. I 0 I 6/j. scitotenv.2020.1389|9>.
} 
Se confirmada, a "hipótese fecal-oral" para Covid- 19 pode resultar em consequências de longo alcance para a saúde pública e para as estratégias de controle da pandemia. No entanto, análise abrangente e mais matizada é necessária para testar essa hipótese, levando em consideração a dinâmica ambiental e a persistência viral no ambiente.

\section{VIAS FECAIS-ORAIS DE TRANSMISSÃO DE DOENÇAS INFECCIOSAS}

As classificações ambientais de doenças infecciosas remontam à década de 1970 e baseiam-se em suas rotas de transmissão ambiental e no ciclo de vida dos agentes infecciosos. Essas classificações diferem da classificação biológica tradicional de doenças, com foco no agente etiológico.

Em um estudo seminal, White, Bradley e White (1972) avaliaram as rotas de transmissão de doenças para perigos relacionados à água e as classificaram em quatro categorias. Duas podem ser de especial relevância para Covid-19: ÁGUA I - transmissão pela água, em que esta ocorre pela ingestão de um patógeno presente na água, e a água atua como um veículo passivo para o agente infeccioso; e ÁGUA2 - associada à água para limpeza, em que a infecção pode ser prevenida com o fornecimento de água suficiente para a higiene doméstica e pessoal.

As doenças relacionadas com excretas são classificadas em seis categorias (Feachem et al., 1983). Duas delas podem ser relevantes para a pandemia atual. SANEAMENTO I inclui infecções fecais-orais (não bacterianas), caracterizadas por agentes capazes de ser transmitidos mesmo com baixas doses do patógeno, incluindo agentes como enterovírus (poliovírus, ecovírus e coxsackievírus), vírus da hepatite $A$ e rotavírus, que podem se disseminar facilmente quando a higiene doméstica ou pessoal é inadequada. Para essa rota, o descarte de excretas tem efeito limitado sobre a incidência de infecções, quando esse descarte não estiver associado a mudanças significativas na limpeza pessoal, o que requer grandes melhorias no abastecimento de água, na habitação e na educação sanitária. Outra rota preocupante é a transmissão por insetos vetores relacionados a excretas (categoria SANEAMENTO6). Vetores como moscas e baratas circulam em ambientes onde há fezes e podem transportar vírus em seu corpo e no trato intestinal, contaminando superfícies (Dehghani E Kassiri, 2020).

O papel da água na transmissão de doenças infecciosas respiratórias foi sugerido décadas após a classificação original das doenças relacionadas à água. No entanto, o foco estava principalmente no efeito protetor da lavagem das mãos (Cairncross, 2003; Fung $\&$ Cairncross, 2006). Recentemente, uma quinta categoria de doenças relacionadas à água foi proposta (Bartram E Hunter, 2015): ÁGUA5 - transmissão associada aos 
sistemas de abastecimento de água e esgotamento sanitário, incluindo a inalação de gotículas ou aerossóis gerados em encanamentos (por exemplo, Legionella). Esta categoria pode ser de interesse para uma possível rota de inalação fecal do Sars-CoV-2, uma vez que as pesquisas têm indicado a possibilidade de propagação do vírus através de sistemas de escoamento de águas residuais, tais como a disseminação relatada de coronavírus Sars em aerossóis de esgoto em um edifício residencial de 50 andares em Hong Kong (WHO, 2003) e, posteriormente, em experimentos controlados utilizando plataforma com tubulações em escala real (Gormley et al., 2020). Kang e colaboradores (2020) relataram recentemente evidências circunstanciais da transmissão de Sars-CoV-2 por águas residuais, aerossolizadas em um edifício residencial em Guangzhou, China. No entanto, esses desenvolvimentos mais recentes, sobre a associação entre água a doenças respiratórias, não foram capazes de caracterizar ou esclarecer totalmente as rotas complexas possivelmente envolvidas na transmissão do Sars-CoV-2 das fezes para a boca de uma pessoa suscetível.

\section{UMA PROPOSTA DE ARCABOUÇO CONCEITUAL PARA AVALIAÇÃO DAS POSSÍVEIS ROTAS DE TRANSMISSÃO FECAL-ORAL DA COVID-19}

Com base nas rotas ambientais das doenças excretadas e no estado atual do conhecimento da persistência e infecciosidade do Sars-CoV-2, desenvolveu-se uma proposta de arcabouço conceitual para o teste da hipótese de transmissão fecal-oral da Covid-19, revelando as possíveis rotas ambientais a partir das fezes até a boca (Figura 1). Esta estrutura não deve ser vista como confirmação dessa hipótese, mas sim como uma visão ampliada de suas complexidades, o que poderia ajudar a moldar uma agenda de pesquisa para uma série de questões que permanecem sem resposta.

A partir das fezes, existiriam três rotas principais para o vírus: para a água, para as superfícies ou para locais onde vetores podem estar presentes. A partir desses ambientes, por diferentes vias, os vírus podem chegar à boca e infectar tanto o trato intestinal quanto o respiratório de um hospedeiro susceptível. Cada uma das quatro categorias ambientais de doenças relacionadas à água e excretas (ÁGUAI, ÁGUA2, SANEAMENTOI e SANEAMENTO6) desempenha um papel nessa estrutura. Além disso, surge uma quinta categoria: a categoria "limpeza com água", em que a água contaminada usada para limpar superfícies pode, pelo contato com as mãos, levar o vírus à boca.

A validação desse modelo exigirá esforços significativos de pesquisas para melhor elucidação da persistência e da infecciosidade do Sars-CoV-2 em fezes, esgoto e água não tratada e do papel dos vetores no transporte do vírus, bem como a investigação apropriada da rota de "limpeza com água". 
Figura I - Arcabouço conceitual das possíveis rotas de transmissão fecal-oral da Covid- 19

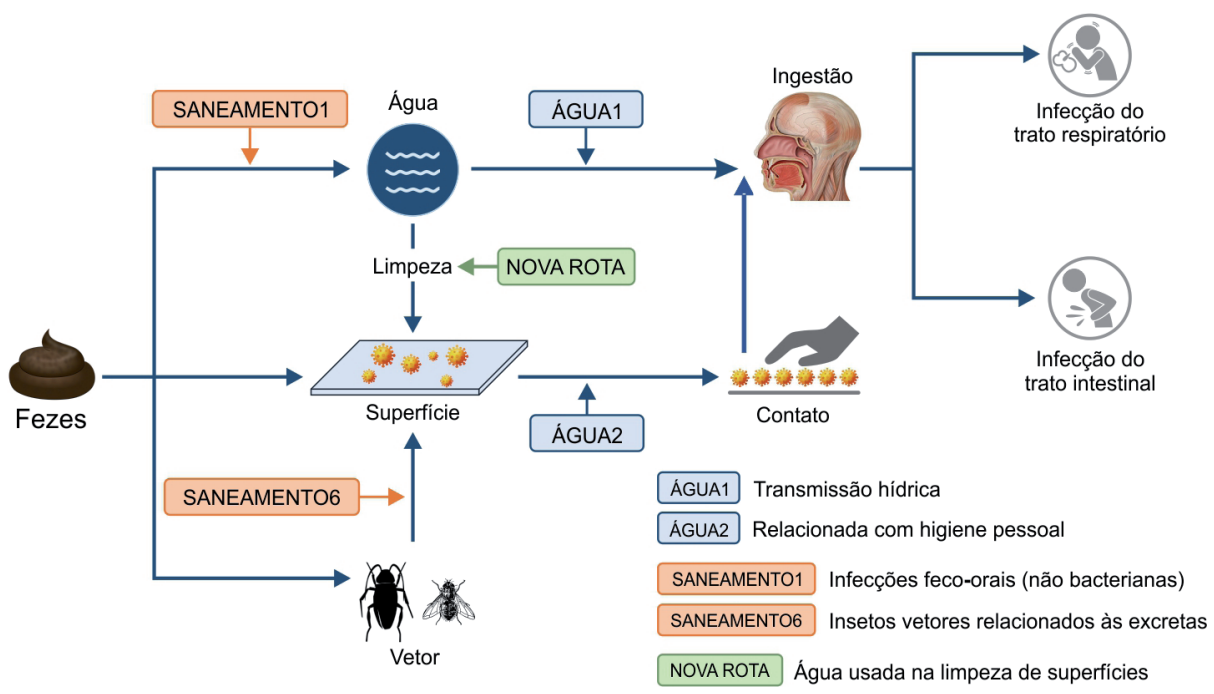

\section{IMPLICAÇÕES PARA A CIÊNCIA E PARA A SOCIEDADE}

Devido à atual compreensão das evidências científicas sobre a relevância da transmissão fecal-oral do Sars-CoV-2, afirmamos aqui a necessidade de pesquisas mais aprofundadas para determinar o papel real das intervenções de água e saneamento na prevenção dessa via de transmissão. Se a relevância da hipótese fecal-oral for confirmada, as intervenções relacionadas ao fornecimento de água potável e saneamento adequado devem ser imediatamente adicionadas às estratégias para o controle da pandemia Covid-19, bem como de outros vírus que infectam o trato respiratório, além do já reconhecido papel fundamental da água para adequada higienização das mãos. Ainda assim, considerando que 2,2 bilhões de pessoas no mundo não têm acesso a água potável com gestão segura e 4,2 bilhões não têm acesso a solução adequada de esgotamento sanitário, a possível contenção da Covid- 19 por meio do acesso a esses serviços é por si só uma justificativa para que se estabeleçam medidas imediatas para mitigar a exposição de pessoas que vivem em situações de maior vulnerabilidade às infecções transmitidas pela via fecal-oral. Ao mesmo tempo, isso atenderá ao apelo da Agenda 2030 das Nações Unidas e reforçará a necessidade urgente de concretizar os direitos humanos à água potável e ao saneamento. 


\section{REFERÊNCIAS}

AHMED, W. et al. First confirmed detection of Sars-CoV-2 in untreated wastewater in Australia: a proof of concept for the wastewater surveillance of Covid-19 in the community. Science of the Total Environment, 728, 2020. Disponível em: <https://doi.org/I0.1016/j.scitotenv.2020.138764> Acesso em: 06jan2021.

BARTRAM, J. E HUNTER, P. Bradley Classification of disease transmission routes for water-related hazards. In: BARTRAM, J. et al. (Eds.). Routledge Handbook of Water and Health. London and New York: Routledge, 2015.

CAIRNCROSS, S. Editorial: handwashing with soap - a new way to prevent ARIs? Tropical Medicine and International Health, 8: 677-679, 2003.

CHERNICHARO, C. A. L. et al. Monitoramento do esgoto como ferramenta de vigilância epidemiológica para controle da covid- 19: estudo de caso na cidade de Belo Horizonte. Engenharia Sanitária e Ambiental, 2020. Disponível em: <http://abes-dn.org.br/?page_id=3568I >. Acesso em: 6 jan. 2021 .

DEHGHANI, R. \& KASSIRI, H. A brief review on the possible role of houseflies and cockroaches in the mechanical transmission of coronavirus disease 2019 (Covid-19). Archives of Clinical Infectious Diseases, I 5: el 02863, 2020. Disponível em: < https://sites.kowsarpub.com/archcid/articles/I 02863. html>. Acesso em: 6 jan. 2021.

FEACHEM, R. G. et al. Sanitation and Disease: health aspects of excreta and wastewater management. New York: John Wiley E Sons, 1983. (World Bank Studies in Water Supply and Sanitation, n. 3). Disponível em: <http://documents.worldbank.org/curated/en/70404l468740420 I I8/Sanitationand-disease-health-aspects-of-excreta-and-wastewater-management>. Acesso em: 06jan202I. FONGARO, G. et al. Sars-CoV-2 in human sewage in Santa Catalina, Brazil, November 20 I 9. medRxiu, 2020. Acesso em: 6 jan. 2021 .

FUNG, I., C.-H. \& CAIRNCROSS, S. Effectiveness of handwashing in preventing Sars: a review. Tropical Medicine and International Health, I I: I.749-1.758, 2006.

GORMLEY, M. et al. 2020. COVID-19: mitigating transmission via wastewater plumbing systems. Lancet Global Health, 2020. Disponível em: <https://doi.org/10.1016/S2214-109X(20)30112-1>. Acesso em: 6 jan. 2021.

GUERRERO-LATORRE, L. et al. Sars-CoV-2 in river water: implications in low sanitation countries. Science of Total Environmental, 743: 140832, 2020. Disponível em: <https://doi.org/10.1016/j. scitotenv.2020.140832>. Acesso em: 6 jan. 2021.

HARMER, D. et al. Quantitative mRNA expression profiling of ACE 2, a novel homologue of angiotensin converting enzyme. FEBS Letters, 532: 107-1 10, 2002.

KAMPF, G. et al. Persistence of coronaviruses on inanimate surfaces and their inactivation with biocidal agents. The Journal of Hospital Infectious, 104(3): 246-25I, 2020. Disponível em: <www. journalofhospitalinfection.com/article/SO I 95-670 I (20)30046-3/fulltext>. Acesso em: 6 jan. 202 I.

KANG, M. et al. Probable evidence of fecal aerosol transmission of Sars-CoV-2 in a high-rise building. Annals of internal medicine, I73(I2): 974-980, 2020.

LA ROSA, G. et al. Coronavirus in water environments: occurrence, persistence and concentration methods - a scoping review. Water Research, 179: II5899, 2020. Disponível em: <https://doi. org/I 0.1016/j.watres.2020.II 5899 >. Acesso em: 6 jan. 2021. 
MEDEMA, G. et al. Presence of Sars-Coronavirus-2 in sewage. medRxiv, 2020. Disponível em: <https:// doi.org/l 0.1 I 0 I/2020.03.29.20045880 >. Acesso em: 6 jan. 2021 .

MOTA, C. R.; BRESSANI-RIBEIRO, T. \& ARAúJO, J. C. Assessing spatial distribution of Covid-19 prevalence in Brazil using decentralised sewage monitoring. Water Research, 2021.

OLIVEIRA, L. C. et al. Viability of Sars-CoV-2 in river water and wastewater at different temperatures solids content. Water Research, 195, 2021. Disponível em: <www.sciencedirect.com/science/article/ pii/S0043 I 3542 I 00200 I >. Acesso em: I 0 maio 202 I.

PECCIA, J. et al. Measurement of Sars-CoV-2 RNA in wastewater tracks community infection dynamics. Nature Biotechnology, 38: I. I64- I.I 67, 2020. Disponível em: <https://doi.org/I 0. I038/s4 I 587-0200684-z>. Acesso em: 6 jan. 2021.

SUN, J. et al. Isolation of infectious Sars-CoV-2 from urine of a Covid- 9 patient. Emerging Microbes and Infectious, 9: 991-993, 2020. Disponível em: <https://doi.org/I0.1080/22221751.2020.1760 144>. Acesso em: 6 jan. 2021.

WANG, W. et al. Detection of Sars-CoV-2 in different types of clinical specimens. JAMA, 323(I8), 2020. Disponível em: <https://doi.org/10.1001/jama.2020.3786>. Acesso em: 6 jan. 2021.

WHITE, G.; BRADLEY, D. \& WHITE, A. Drawers of Water. Chicago: University of Chicago Press, 1972.

WORLD HEALTH ORGANIZATION (WHO). Consensus document on the epidemiology of severe acute respiratory síndrome (Sars), 2003. Disponível em < https://apps.who.int/iris/handle/I0665/70863>. Acesso em: 6 jan. 2021 .

WORLD HEALTH ORGANIZATION (WHO). Modes of transmission of virus causing Covid-I9: implications for IPC precaution recommendations, 2020. Disponível em: <www.who.int/news-room/ commentaries/detail/modes-of-transmission-of-virus-causing-covid- I 9-implications-for-ipcprecaution-recommendations >. Acesso em: 10 abr. 2020.

WU, Y. et al. Prolonged presence of Sars-CoV-2 viral RNA in faecal samples. The Lancet Gastroenterology E Hepatology, 5: 434-435, 2020. Disponível em: < https://doi.org/I 0. I 01 6/S2468-I253(20)300832>. Acesso em: 6 jan. 2021.

$\mathrm{XIAO}$, F. et al. Evidence for gastrointestinal infection of Sars-CoV-2. Gastroenterology, 158(6): I83 I1833.e3, 2020. Disponível em: <www.gastrojournal.org/article/S00 I 6-5085(20)30282- I/fulltext>. Acesso em: 6 jan. 2021.

$\mathrm{XU}, \mathrm{H}$. et al. High expression of ACE2 receptor of 2019-nCoV on the epithelial cells of oral mucosa. International Journal of Oral Science, 12, 8, 2020. Disponível em: < https://doi.org/10.1038/ s41368-020-0074-x>. Acesso em: 6 jan. 2021.

ZHANG, Y. et al. Isolation of 20I9-nCoV from a stool specimen of a laboratory-confirmed case of the Coronavirus disease 2019 (Covid- 19). China CDC Weekly, 2(8): I23-124, 2020. 


\section{OUTROS TÍTULOS DA SÉRIE \\ Informação para Ação na Covid- 19}

Diplomacia da Saúde e Covid- 19: reflexões a meio caminho

Paulo Marchiori Buss e Luiz Eduardo Fonseca (orgs.)

http://books.scielo.org/id/hdyfg

Os Impactos Sociais da Covid- I 9 no Brasil:

populações vulnerabilizadas e respostas à pandemia

Gustavo Corrêa Matta, Sergio Rego, Ester Paiva Souto e Jean Segata (orgs.)

http://books.scielo.org/id/r3hc2 
Formato: $16 \times 23 \mathrm{~cm}$

Tipologia: GoudySnas Lt BT, GoudySans Md BT e Interstate-LightCondensed Rio de Janeiro, outubro de 2021

Os livros da Editora Fiocruz podem ser encontrados nas boas livrarias e em www.livrariaeditorafiocruz.com.br ou books.scielo.org/fiocruz

Av. Brasil, 4036, térreo, sala II 12 - Manguinhos

2 1040-36 I - Rio de Janeiro, RJ

Tel.: (2 I) 3882-9039 e 3882-9007

Telefax: (2I) 3882-9006

editora@fiocruz.br

www.fiocruz.br/editora 
Passados os primeiros meses da pandemia do novo coronavírus no Brasil, o Observatório Covid- 9 Fiocruz, em parceria com a Editora Fiocruz e com o apoio da Rede SciELO Livros, traz para o público leitor um conjunto de livros instantâneos sobre as análises nele realizadas desde que foi criado para subsidiar o seu combate.

Nesta série Informação para Ação na Covid- 19 será apresentado um balanço do conjunto de documentos (notas e relatórios técnicos, boletins, informes, recomendações, ensaios, artigos, entre outros) produzidos em resposta à pandemia. Cada volume da série se estrutura em torno de um tema: aspectos globais da pandemia e da diplomacia em saúde; cenários epidemiológicos e vigilância em saúde; as políticas e a gestão dos serviços e sistemas de saúde; orientações para os cuidados e a saúde dos trabalhadores da saúde; impactos sociais e desigualdades sociais na pandemia.

Com a publicação destes estudos em livros de acesso aberto colocamos à disposição do público o conjunto de informações e conhecimentos gerados no âmbito do Observatório Covid- 19 Fiocruz, realizamos um balanço e uma reflexão sobre como chegamos ao cenário atual e apontamos caminhos para um futuro próximo. E, ao mesmo tempo, mantemos o registro histórico desse conhecimento produzido a quente, no calor da hora.
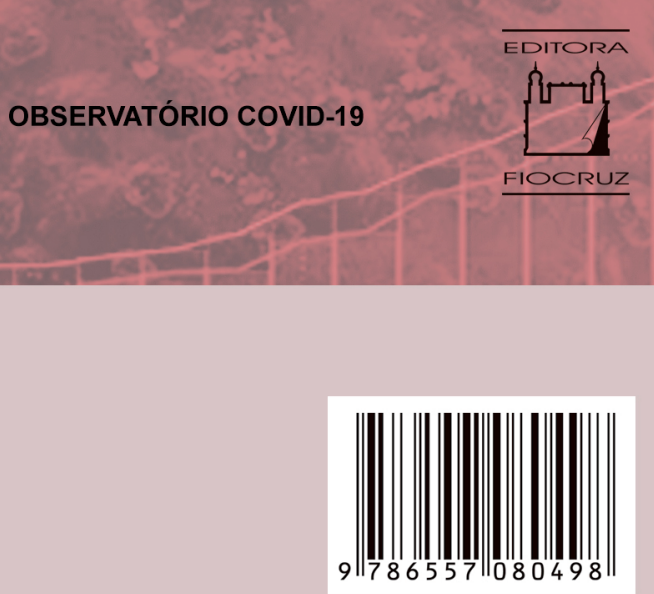